Universidade de São Paulo

Faculdade de Filosofia, Ciências e Letras de Ribeirão Preto

Departamento de Química

Programa de Pós-Graduação em Química

\title{
"Estudos Sintéticos e Teóricos Sobre Anulenos e Baquenolidas"
}

Kleber Thiago de Oliveira

Tese apresentada à Faculdade de Filosofia, Ciências e Letras de Ribeirão Preto da Universidade de São Paulo, como parte das exigências para a obtenção do título de Doutor em Ciências, Área: Química

RIBEIRÃO PRETO-SP 

Universidade de São Paulo

Faculdade de Filosofia, Ciências e Letras de Ribeirão Preto

Departamento de Química

Programa de Pós-Graduação em Química

\section{"Estudos Sintéticos e Teóricos Sobre Anulenos e Baquenolidas”}

Kleber Thiago de Oliveira

Tese de Doutorado

Orientador: Prof. Dr. Mauricio Gomes Constantino

RIBEIRÃO PRETO-SP 


\section{FICHA CATALOGRÁFICA}

Oliveira, Kleber Thiago

Estudos Sintéticos e Teóricos Sobre Anulenos e Baquenolidas. Ribeirão Preto, 2006.

380 p. : il. ; $30 \mathrm{~cm}$

Tese de Doutorado, apresentada à Faculdade de Filosofia Ciências e

Letras Ribeirão Preto/USP - Área de concentração: Química.

Orientador: Constantino, Mauricio Gomes.

1. Reação de Diels-Alder. 2. Anulenos. 3. Baquenolidas.

4. Pentacloreto de Nióbio. 
"De tudo ficaram três coisas:

a certeza de que estamos sempre começando ... a certeza de que é preciso continuar ... A certeza de que seremos interrompidos antes de terminar... Portanto, devemos: fazer da interrupção um caminho novo ... da queda um passo de dança ... do medo, uma escada ... do sonho, uma ponte... da procura um encontro."

Fernando Pessoa. 


\section{Precisa-se}

De pessoas que tenham os pés na terra e a cabeça nas estrelas.

Capazes de sonhar, sem medo dos sonhos.

Tão idealistas que transformem seus sonhos em metas.

Pessoas tão práticas que sejam capazes de transformar suas metas em realidade.

Pessoas determinadas que nunca abram mão de construir seus destinos e arquitetar suas vidas.

Que não temam mudanças e saibam tirar proveito delas. Que tornem seu trabalho objeto de prazer e uma porção substancial de realização pessoal. Que percebam, na visão e na

missão de suas vidas profissionais, de suas dedicações humanistas em prol da humanidade, um forte impulso para sua própria motivação.

Pessoas com dignidade, que se conduzam com coerência em seus discursos, seus atos, suas crenças e seus valores.

Precisa-se de pessoas que questionem, não pela simples contestação, mas pela necessidade íntima de só aplicar as melhores idéias.

Pessoas que mostrem sua face serena, de parceiros legais, sem se mostrarem superiores nem inferiores; mas...iguais.

Precisa-se de pessoas ávidas por aprender e que se orgulhem por absorver o novo, pessoas de coragem para abrir caminhos, enfrentar desafios, criar soluções, correr riscos calculados. Sem medo de errar.

Precisa-se de pessoas que construam suas equipes e se integrem nelas. Que não tomem para si o poder, mas saibam compartilhá-lo. Pessoas que não se empolguem com o seu próprio brilho, mas com o brilho do resultado alcançado em conjunto.

Precisa-se de pessoas que enxerguem as árvores, mas também prestem atenção na magia da floresta, que tenham percepção do todo e da parte. Seres humanos justos, que inspirem confiança e demonstrem confiança nos parceiros.

Precisa-se de pessoas que criem em torno de si um ambiente de entusiasmo, de liberdade, de responsabilidade, de determinação, de respeito e de amizade.

Precisa-se de seres tão racionais, que compreendam que sua realização pessoal está atrelada à vazão de suas emoções. É na emoção que encontramos a razão de viver.

Precisa-se de gente que saiba administrar coisas e liderar pessoas.

Precisa-se urgentemente de um novo ser.

ISAC LIBERMAN 


\section{Dedico esta Tese}

À minha esposa Josiane, pessoa a quem amo incondicionalmente, e que com muita perseverança me acompanhou desde o principio deste trabalho sempre me compreendendo e me apoiando nos momentos de dificuldade. Ela, mulher forte, soube estar comigo nas horas de alegria e de queda.

Aos meus amados Pais, Sebastião e Leonice, que a mim concederam pela vontade de Deus o dom da vida, e me ensinaram os principais valores do ser humano; o amor e a honestidade. Eles, na sua imensa simplicidade, aprenderam a me apoiar, valorizar e incentivar durante a minha caminhada. 



\section{Agradecimentos}

Primeiramente agradeço a Deus, ator da vida e da inteligência humana. Aquele que a mim permitiu cultivar e aprender com o dom da ciência.

Ao Prof. Dr. Mauricio Gomes Constantino, por todos esses anos de convivência; pela orientação, pela dedicação, amizade, paciência e principalmente por tudo que aprendi ao seu lado.

Ao Prof. Dr. Sérgio Emanuel Galembeck, pela colaboração, amizade e pelo espaço cedido em seu laboratório para a realização de alguns dos estudos teóricos.

Ao Prof. Dr. Gil Valdo José da Silva e ao Prof. Dr. Paulo Marcos Donate, pela amizade e colaboração.

Ao Prof. Dr. Adilson Beatriz, Prof. Dr. Valdemar Lacerda Júnior e Dr. Daniel Frederico, pela amizade, pelos ensinamentos, pela boa convivência e participação neste trabalho.

Ao Prof. Dr. Cláudio Francisco Tormena pela amizade, pelas discussões e sugestões em alguns dos estudos teóricos.

Ao Dr. Renato Haddad pelas análises de massa (ESI) de alta resolução.

Ao Prof. Dr. Norberto Pepoline Lopes pelas análises de massa.

Ao Prof. Dr. Osvaldo Antônio Serra pela amizade e pelo apoio oferecido para que eu continuasse a minha formação.

Ao Dr. Cláudio Néri pela amizade e apoio durante os anos que estive nesta unidade.

A todos os demais docentes do departamento de química que de alguma maneira contribuíram para a minha formação e para com este trabalho.

Às Irmãs da Ordem de Santa Ângela, e a todos os professores e amigos do Instituto Santa Úrsula de Ribeirão Preto, pelo carinho com que me acolheram durante meus estudos de ensino médio.

Ao meu grande amigo Giovanni Caramori pela convivência, amizade e grande contribuição neste trabalho.

Às minhas grandes amigas Érika e Mirela pelo carinho, sinceridade e companheirismo durante todos estes anos.

Aos meus amigos Arthur, Nazareth, Juliana, José Mário e Iraci, pessoas queridas que sempre me incentivaram ao longo desta caminhada.

À Virginia, pela amizade, dedicação e pela exímia competência na obtenção dos espectros de RMN. 
Aos alunos de Iniciação Científica que trabalharam comigo e muito contribuíram durante estes anos: Vinícius Silveira Garcia, Daiane Cristina Sass, Ellen Christine Polo e Roberta Cerasi Urban.

A todos os amigos do Laboratório, Dr. Felipe, Dr. Luiz Carlos, Ricardo Gimenez, Paulo, Álvaro, Valquíria, Dra. Susimaire, Dra. Lílian, Miro, Francisco, Luiz Felipe, Marco, Rodrigo, Shirlei, Emílio, Giovana, Fausto, André, Viviane e todos os quais pude conviver, muito obrigado pela amizade e apoio.

Aos funcionários do Departamento de Química: Lâmia, Bel, Sônia, Emerson, André, Mércia, Djalma, Vera e Olímpia pela amizade e atenção durante todos esses anos.

Às funcionárias da Seção de Pós-Graduação: Denise, Inês, Sônia, pela amizade, atenção e competência.

A todos que de alguma forma contribuíram para a realização deste trabalho.

À FAPESP pelo apoio financeiro e pela constante atenção com que assiste nossa pesquisa. 


\section{Abreviações}

AIBN - Azo-bis-isobutironitrila

ASE - Aromatic Stabilization Energy

AcOH - Ácido Acético

$\mathrm{Ac}_{2} \mathrm{O}$ - Anidrido Acético

B3LYP - Terceira revisão do método de Beeck incluindo os parâmetros de correlação de Lee, Yang e Parr.

B3PW91 - Terceira revisão do método de Beeck incluindo os parâmetros de correlação de Perdew-Wang 1991.

Bn - Benzil

BnBr - Brometo de Benzila

BnOH - Álcool Benzílico

BHT - Butylated Hydroxytoluene

$\mathrm{Bz}$ - Benzoil

${ }^{13} \mathrm{C}\{\mathrm{H}\}$ - Carbono Totalmente Desacoplado de Hidrogênio

cc-pVDZ - correlation-consistent polarized Valence Duble Zeta

$\mathrm{Cp}$ - Ciclopentadienil

CTAB - Brometo de cetiltrimetilamônio

DBN - 1,5-Diazabiciclo[4.3.0]non-5-eno

DBU - 1,8-Diazabiciclo[5.4.0]undec-7-eno

DDQ - 2,3-Dicloro-5,6-diciano-1,4-benzoquinona

DHP - Di-hidropirano

DIBALH - Hidreto de di-isobutilalumínio

DMAP - Dimetilaminopiridina

DMF - Dimetilformamida

DMSO - Dimetilsulfóxido

DEPT-135 - Distortionless Enhancement by Polarization Transfer - angle $135^{\circ}$

ESI-Q-TOF - Electron Spray Ionization-Quadrupole-Time of Flight

ESI-TOF - Electron Spray Ionization - Time of Flight

FMO - Frontier Molecular Orbital

GCE - Grupo Captor de Elétrons

GDE - Grupo Doador de Elétrons

gCOSY - Correlation Spectroscopy

gHMBC - Heteronuclear Multiple-Bond Correlation

gHMQC - Heteronuclear Multiple-Quantum Correlation

gJres - J resolved

HMDS - Hexametildisilazano

HMPA - Hexametilfosforamida, $\left(\mathrm{Me}_{2} \mathrm{~N}\right)_{2} \mathrm{P}=\mathrm{O}$

HMPT - Hexametilfósforotriamida, $\left(\mathrm{Me}_{2} \mathrm{~N}\right)_{3} \mathrm{P}$

HOMA - Harmonic Oscilator Model of Aromaticity

HOMO - Highest Occupied Molecular Orbital

LDA - Di-isopropilamideto de Lítio

LiHMDS -Hexametildisilazida de Lítio

LUMO - Lowest Unoccupied Molecular Orbital

$\mathrm{Me}_{3} \mathrm{O}^{+} \mathrm{BF}_{4}^{-}-$Tetrafluorborato de trimetiloxônio

$\mathrm{Me}_{3} \mathrm{SiI}$ - Iodotrimetilsilano

MCPA - Ácido m-cloroperoxibenzóico 
$\mathrm{MsCl}$ - Cloreto de metanossulfonila (cloreto de mesila)

NBO - Natural Bond Orbital

NBS - N-bromosuccinimida

NICS - Nucleus Independent Chemical Shift

$\mathrm{NOCl}$ - Cloreto de Nitrosilo

NOE - Nuclear Overhauser Effect

NRT - Natural Resonance Theory

-OAc - Acetato

-OMs - Mesilato

-OPP - Pirofosfato

PCC - Clorocromato de piridínio

PTSA - Ácido p-toluenosulfônico

Py - Piridina

RE - Resonance Energy

SE(HD) - Homodesmotic Steric Energy

$\mathrm{SE}(\mathrm{ba})$ - Steric Energy of bent anulene

SE(br) - Steric Energy of the bridge

TBDMS - $t$-butildimetilsilil

t-BuOK - t-butóxido de potássio

THF - Tetra-hidrofurano

$\mathrm{Ts}=p-T s=p-$ Toluenosulfonil $-($ Tosil $)$

$\mathrm{TsCl}=$ Cloreto de $p$-Toluenosulfonila

ZPE - Zero Point Energy 


\section{Índice}

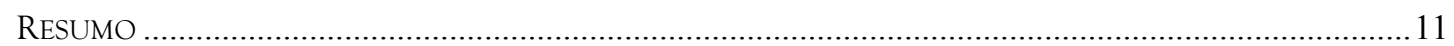

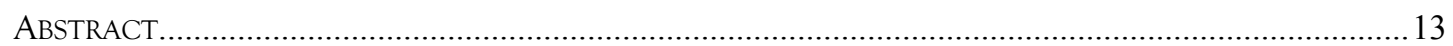

“PARTE A: ESTUDOS SINTÉTICOS E TEÓRICOS SOBRE O 1,4-METANO[1O]ANULENO”.......15

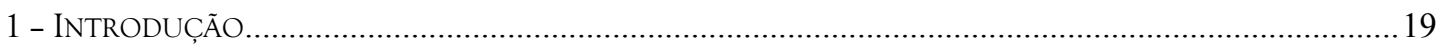

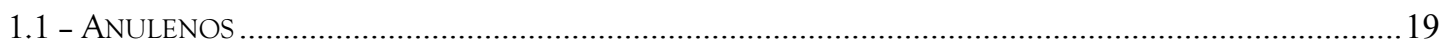

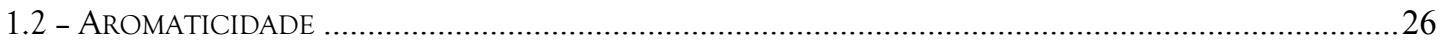

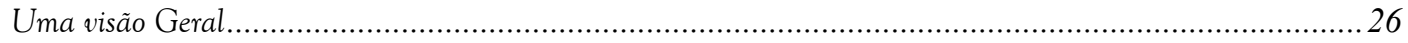

Desenvolvimento Histórico do Conceito. ${ }^{2,12}$.........................................................................................26

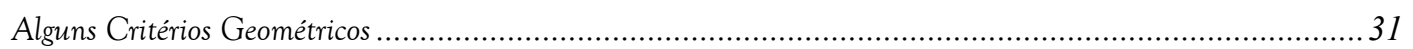

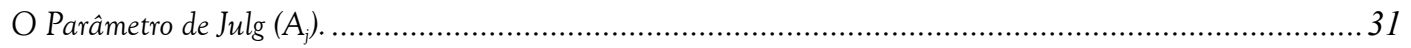

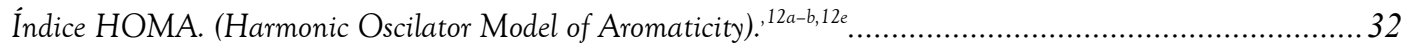

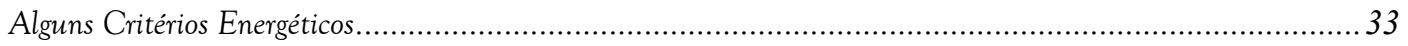

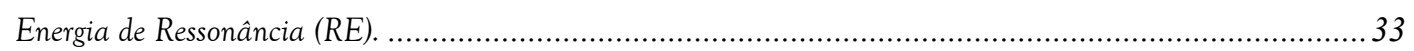

Reações Isodésmicas e Homodesmóticas: Cálculo das Energias de Estabilização Aromática (ASE)...................34

Análises de NBO (Natural Bond Orbital) e NRT (Natural Resonance Theory). ......................................... 35

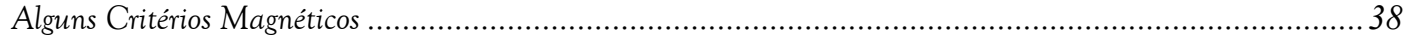

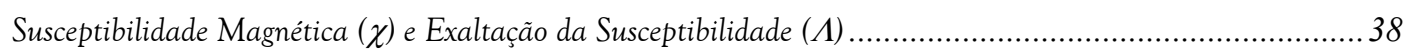

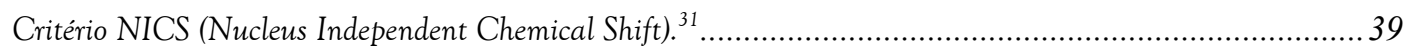

Métodos Computacionais e Conjunto de Funções de Base - Os Modelos Quânticos......................................40

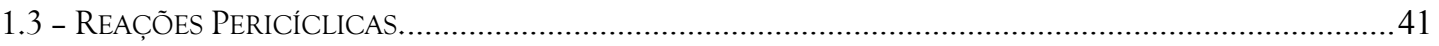

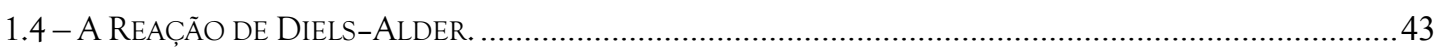

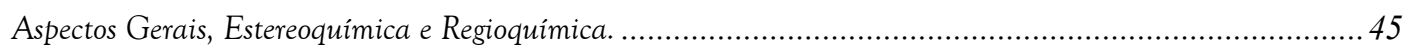

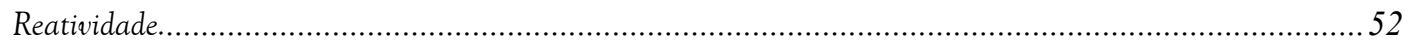

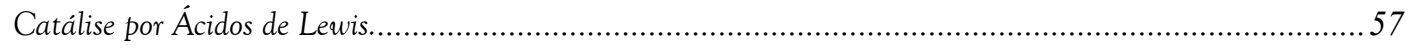

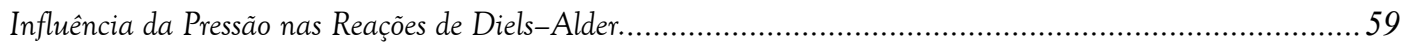

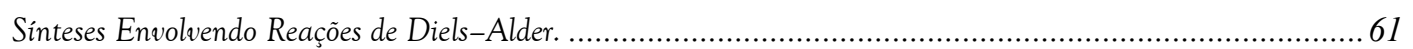

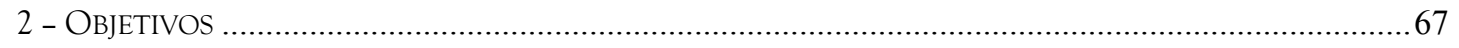

3 - PLANO DE PESQUISA..............................................................................................................

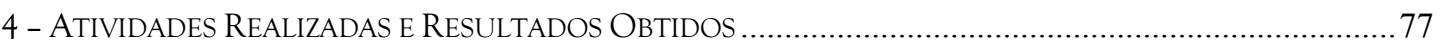

Abordagem Sintética Baseada na Reação de Diels-Alder. ...................................................................... 77

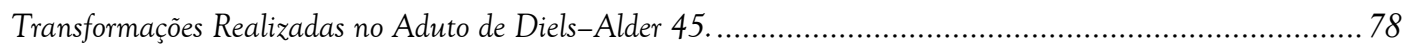

Abordagens Sintéticas Utilizando Quinonas Substituidas nas Reações de Diels-Alder....................................85

Cicloadição do tipo [6+4] - Uma Nova Abordagem Para a Sintese do Anuleno 41 …................................... 90

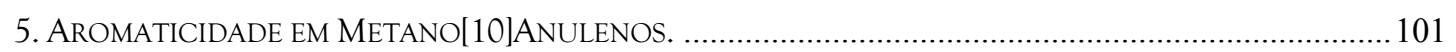

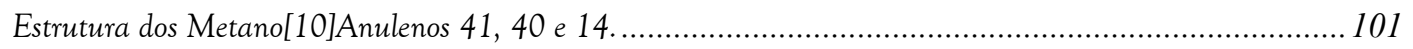

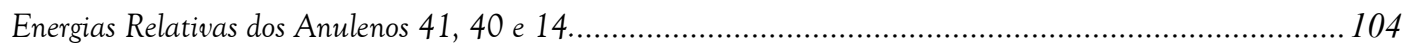




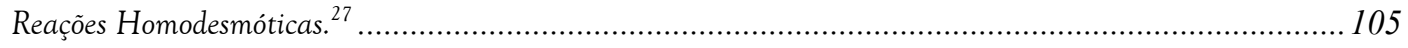

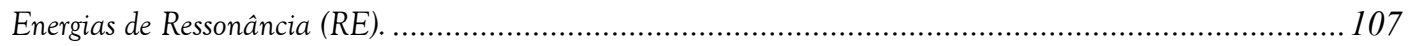

Análises dos NBO (Natural Bond Orbital)........................................................................................ 108

Análise NRT (Natural Resonance Theory)................................................................................... 110

Índice HOMA (Harmonic Oscilator Model of Aromaticity). ${ }^{23,12 a-b, 12 e}$.................................................. 112

Critério NICS (Nucleus Independent Chemical Shift). ${ }^{31}$............................................................... 113

Conclusões Sobre os Estudos Teóricos com os Metano[10]Anulenos......................................................... 115

PARTE B: ESTUDOS SINTÉTICOS E TEÓRICOS SOBRE A (土)-BAQUENOLIDA A...................117

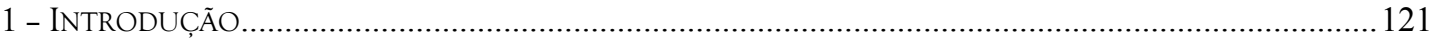

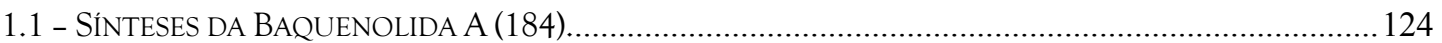

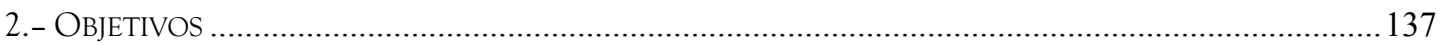

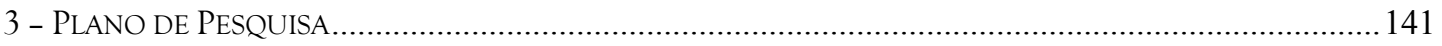

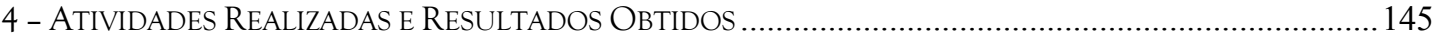

Preparação dos Ácidos $\beta$-vinilacrílico (281) e Tíglico (282). .................................................................. 145

Preparação do Composto 285 e Testes da Reação de Diels-Alder Intramolecular....................................... 145

Reação de Diels-Alder entre o Dieno 298 e o Tiglaldeído (299)........................................................... 148

Transformações Realizadas no Aduto 300 - Síntese da ( \pm )-Baquenolida A (184). .................................. 149

Estudos sobre a Variação das Proporções dos Epimeros 306 e 307............................................................. 155

5 - CinÉTICA dAs REAC̣Ões de FormaC̣Ão dos Compostos 287, 288, 306 E 307: UM EstUdO TEÓRICO 157

6 - CONCLUSÕES E CONSIDERAÇÕES FinAIS - PARTE A E B................................................................... 163

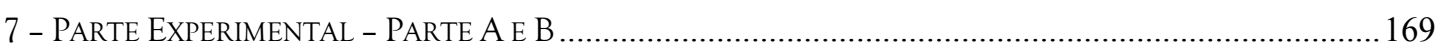

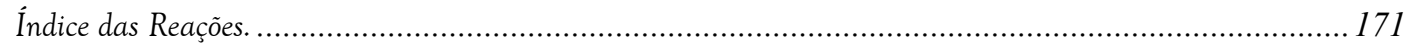

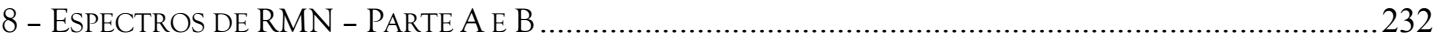

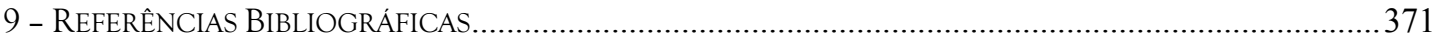




\section{Resumo}

Neste trabalho foram desenvolvidos alguns estudos que tiveram como objetivo principal a utilização de reações de cicloadição como a Reação de Diels-Alder e a Cicloadição do tipo [6+4] na síntese de anulenos e baquenolidas. Na primeira parte (Parte A) são apresentadas algumas abordagens com o objetivo de produzir sistemas do tipo biciclo[6.2.1] undecano (42), similares a sistemas existentes em produtos naturais e que são precursores diretos do 1,4-metano[10]anuleno (41), uma estrutura hipotética, cuja síntese ainda não foi descrita.

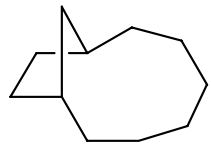

42

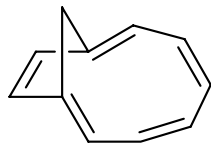

41

Os melhores resultados foram obtidos através de uma cicloadição [6+4] entre o ciclopentadieno 43 e a tropona 139 o que forneceu 140. Este produto guarda grande semelhança estrutural com o anuleno 41.

Para efetuar o rompimento da ponte carbonílica, o melhor método que encontramos consistiu em transformar a cetona 140 em oxima, depois em lactama através de um rearranjo de Beckmann, transformação na forma tosilada e redução com $\mathrm{LiAlH}_{4}$. O álcool primário de 171 pôde ser eliminado com relativa facilidade, mas o grupo NHTs mostrou-se extremamente resistente à alquilação exaustiva/eliminação; apenas quando utilizamos sal de oxônio tivemos evidências de formação de carbocátion.
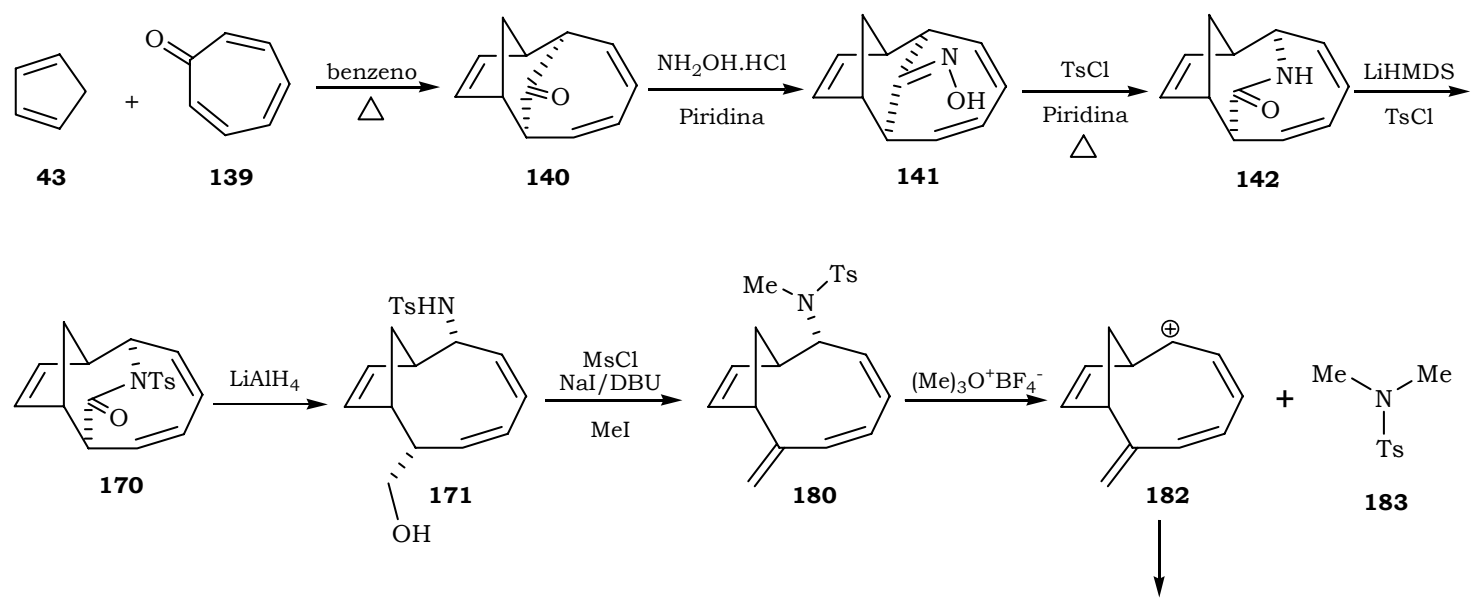

Polimeros

No entanto, os resultados experimentais indicaram fortemente que o anuleno 41 não deve possuir estabilização aromática, pois não encontramos nada deste material no produto da eliminação que, além de $\mathrm{Me}_{2} \mathrm{NT}$ s, continha apenas polímeros. Alguns cálculos teóricos levaram também à conclusão de que 41 não deve ser aromático.

$\mathrm{Na}$ segunda parte deste trabalho (Parte $B$ ) foram realizados alguns estudos sobre a síntese do produto natural $( \pm)$-baquenolida A (184). A etapa principal da síntese realizada foi uma reação de Diels-Alder entre o dieno 298 e o dienófilo 299 sob catálise de $\mathrm{NbCl}_{5}$. O aduto obtido (300) encontra-se devidamente funcionalizado e com a estereoquímica 
relativa apropriada para a síntese de vários produtos naturais da classe dos eremofilanos e dos bacanos, incluindo as baquenolidas.

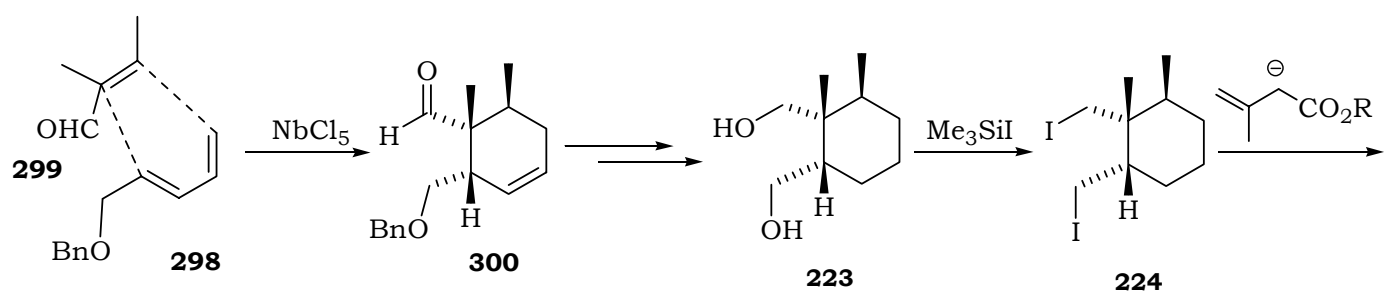

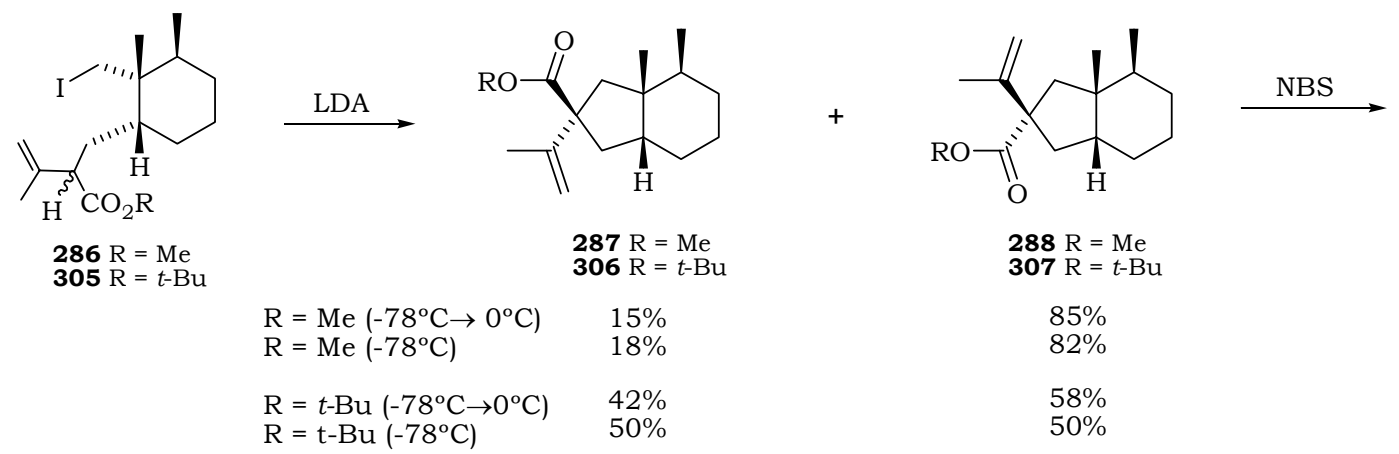<smiles>C=C(CBr)[C@]1(C(=O)O[13CH3])C[C@H]2[C@@H](C)CC[C@H](C)[C@@]2(C)C1</smiles>

308

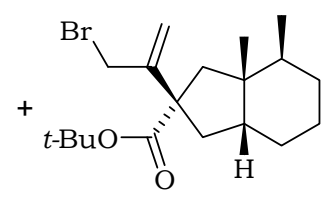

309

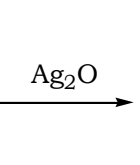

(1)<smiles>C=C1COC(=O)[C@]12C[C@H]1CC[C@H](C)[C@](C)(C1)[C@@H]2C</smiles>

184<smiles>C=C1COC(=O)C12CC1CCCC(C)C1(C)C2</smiles>

226

(士)-Baquenolida A (士)-7-epi-Baquenolida A

A síntese do produto natural 184 foi concluída em 8 etapas e com rendimento global de 13,3\%. Finalmente foram realizados alguns estudos teóricos dos estados de transição envolvidos nas ciclizações dos enolatos dos compostos 286 e 305 obtendo-se proporções teóricas entre os epímeros 287/288 e 306/307 razoavelmente de acordo com os resultados experimentais. 


\section{Abstract}

In this work are described some studies of cycloaddition reactions, such as [4+2] (Diels-Alder reaction) and [6+4] cycloadditions, for the purpose of synthesizing annulenes and bakkenolides. In the first part (Part A) are presented some approaches for the synthesis of the bicyclo[6.2.1]undecane system (42), which is not only similar to systems that occur in some natural products, but also can be considered as a direct precursor of 1,4-metano[10]annulene (41) (a hypothetical structure, which has not yet been synthesized).

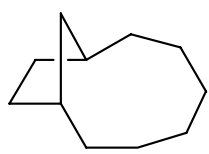

42

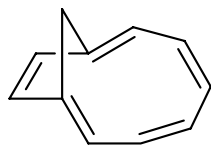

41

The best results were obtained through the [6+4] cycloaddition between cyclopentadiene (43) and tropone (139), which furnished 140. This product is already very similar to the annulene 41 .

To perform the rupture of the carbonyl bridge, the best method that we found consists in transforming the ketone 140 in to the oxime, which was converted to the lactam 142 through a Beckmann rearrangement. This compound was tosilated and subsequently reduced with $\mathrm{LiAlH}_{4}$. The primary alcohol of 171 was easily eliminated but the NHTs group did not react under exhaustive alkylation/elimination conditions; we have obtained evidence of carbocation formation only when the alkylation was performed with oxonium salt.
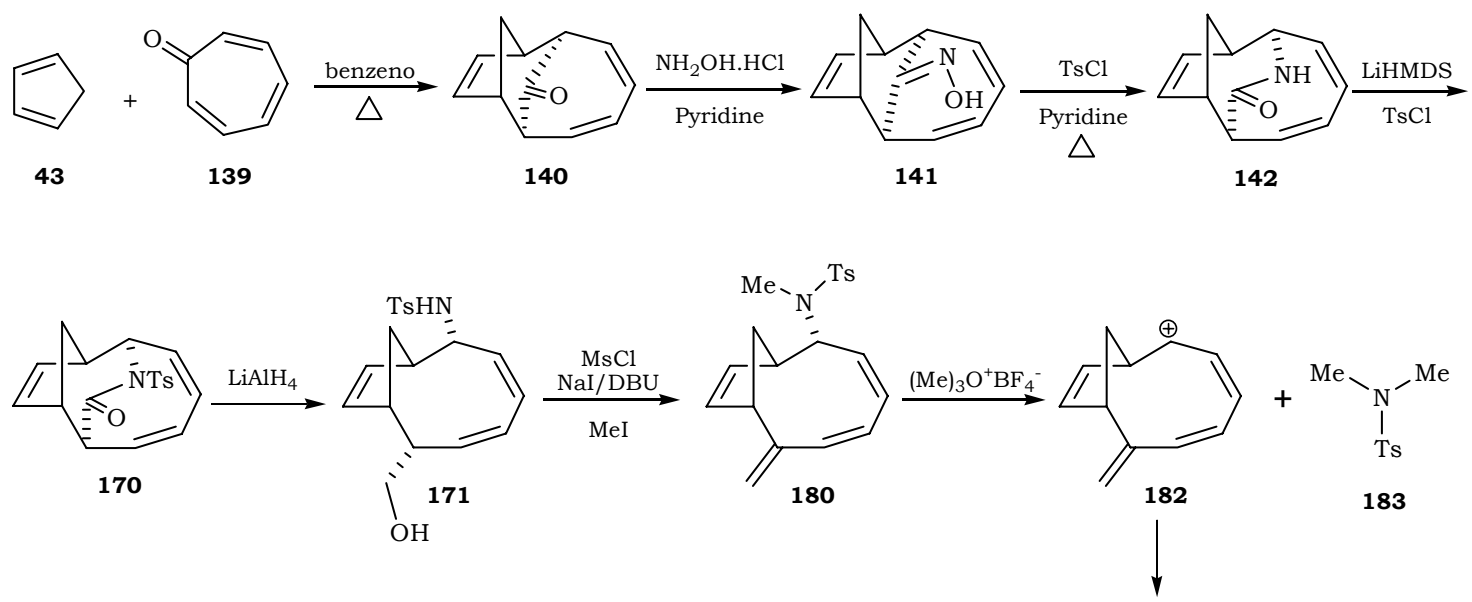

Polymers

However, the experimental results could indicated that the hypothetical annulene 41 is not aromatic, because we not find this material in the elimination product, which contained only $\mathrm{Me}_{2} \mathrm{NT}$ s and polymers. Some theoretical calculations also confirmed that 41 should not be aromatic.

In the second part of this work (Part $B$ ) are described some studies about the synthesis of the natural product $( \pm)$-bakkenolide A (184). The main step of the synthesis 
was a Diels-Alder reaction between diene 298 and dienophyle 299 under catalysis by $\mathrm{NbCl}_{5}$. The obtained adduct (300) is suitably functionalized and exhibit the appropriate relative stereochemistry for the synthesis of some natural products belonging to the class of eremophilanes and bakkanes, including the bakkenolides.

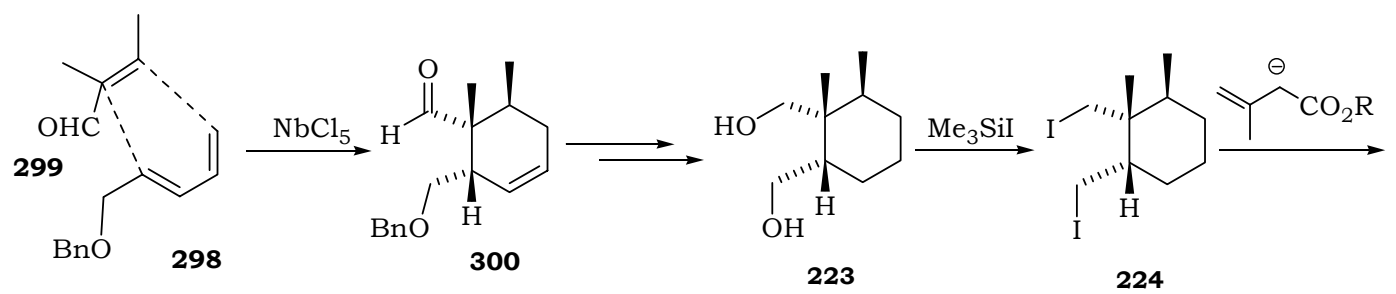

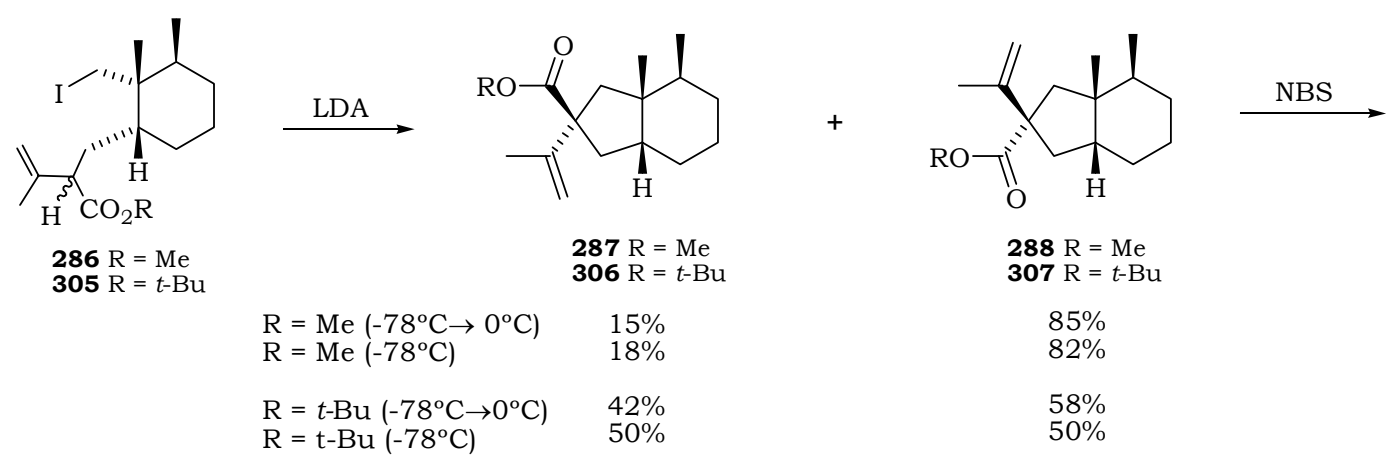<smiles>C=C(CBr)[C@]1(C(=O)OC(C)(C)C)C[C@H]2CCC[C@@H](C)[C@]2(C)C1</smiles>

308

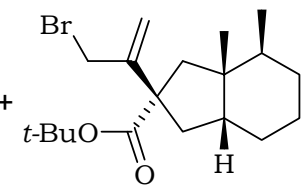

309

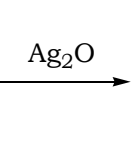

(1)<smiles>C=C1COC(=O)C12CC1CC3(C)C(C)CC[C@@H](C2)C13</smiles>

184

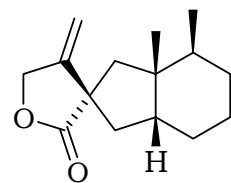

226

(士)-Bakkenolide A $\quad( \pm)$-7-epi-Bakkenolide A

The synthesis of 184 was realized in 8 steps, with a global yield of $13.3 \%$. Finally, some theoretical studies, involving the transition states in cyclizations of the enolates of compounds 286 and 305, were carried out. These studies furnished the theoretical ratios between the epimers $287 / 288$ and 306/307 in good agreement with the experimental results. 
"Parte A: Estudos Sintéticos e Teóricos sobre o 1,4-metano[10]anuleno" 

Introdução - Parte $A$ 



\section{1 - Introdução}

A descoberta e a avaliação das propriedades de novos compostos têm sido há séculos o objetivo de muitos químicos. Novas substâncias podem ser obtidas fundamentalmente de duas maneiras. A primeira delas é através do isolamento de produtos naturais: neste caso a própria natureza atua como laboratório vivo de síntese de substâncias que estão fora do conhecimento humano. A outra maneira consiste na realização da síntese de novos compostos: neste caso o químico sintético é o personagem que propõe, executa e identifica suas substâncias. Esta é uma tarefa árdua, artesanal e que requer inteligência, criatividade, e acima de tudo, perseverança durante a realização de seu trabalho.

Das ferramentas disponíveis ao químico sintético, destaca-se hoje a evolução dos métodos e teorias químico-quânticas, que se utilizados de maneira adequada, podem se tornar grandes aliados no desenvolvimento de uma síntese. Muitos químicos orgânicos aprenderam a se basear apenas em dados empíricos e de raciocínio simples, o que resolve de certa forma uma grande parte dos problemas encontrados durante a prática da síntese orgânica. No entanto, há um aumento acentuado da complexidade dos sistemas a serem sintetizados o que tem dificultado e muitas vezes inviabilizado um raciocínio simplista, e exigido algo mais. Algumas pessoas acreditam que os métodos de análise teórica de compostos evoluíram apenas em função dos problemas surgidos durante $\mathrm{O}$ reconhecimento das propriedades de novas substâncias, e isto não é verdade. Esta evolução é um processo complexo onde as diversas áreas da ciência têm trabalhado lado a lado, cada uma a seu tempo e com sua parcela de contribuição. Durante muitas décadas, houve uma constante luta dos cientistas para descreverem as ligações químicas e os átomos como um todo. Os métodos de análise das estruturas eletrônicas dos compostos químicos foram melhor desenvolvidos fundamentalmente depois da consolidação do modelo atômico e da descrição do elétron como onda por Schrödinger. É evidente que Schrödinger não pretendia avaliar as conformações de um determinado composto orgânico, mas foi graças às suas descrições realizadas para o elétron, que a química quântica e junto com ela os métodos computacionais se ascenderam, e hoje chegaram a níveis tão refinados capazes de descrever com precisão várias estruturas orgânicas e até inorgânicas.

Desta maneira, é possível hoje fazer da síntese orgânica e da química teórica áreas da química que colaborem entre si e juntas possam tornar este universo atômico um pouco mais compreensível e manipulável. Da mesma forma que na síntese orgânica, a química teórica não deve ser vista como um conjunto de modelos prontos, verdadeiras "caixas pretas" que resolvem os problemas indiscriminadamente; é preciso conhecer ou colaborar com as pessoas certas para que o trabalho tenha acima do sucesso e do objetivo cumprido, aquilo que conhecemos como credibilidade.

\section{1 - Anulenos}

O termo "anuleno" se refere, segundo a IUPAC, ${ }^{1}$ a estruturas poliênicas, monocíclicas e não substituídas, contendo um número máximo de ligações duplas não acumuladas e com fórmula geral $\mathrm{C}_{n} \mathrm{H}_{n}$ ou $\mathrm{C}_{n} \mathrm{H}_{n+1}$ (com $n$ superior a 6). Nestes casos as 
estruturas são denominadas como [n]anulenos, onde $n$ é o número de carbonos do sistema cíclico (figura 1).<smiles>C1=CC=CC=CC=C1</smiles>

[10]anuleno 1<smiles>C1=C\C/C=C\C\C=C/1</smiles>

$1 H$-[9] anuleno

2<smiles>C1=C\C=C/C=C\C=C/C=C\C=C/1</smiles>

[12]anuleno

3<smiles>C1=C\C=C/C=C\C=C/C=C\C=C/C=C\C=C/1</smiles>

[18]anuleno

4

Figura 1: Exemplos de Alguns [n]anulenos.

Uma característica interessante de alguns anulenos é a presença da aromaticidade. ${ }^{2}$ Muitos destes sistemas possuem as condições adequadas para que um composto possa apresentar estabilização aromática, como o número adequado de elétrons $\pi([4 n+2]$; regra de Hückel), planaridade adequada para o alinhamento dos orbitais $\pi$ e estabilização extra de energia.

Os [10]anulenos, por exemplo, possuem quase todas as características estruturais para que seja verificada uma estabilização aromática, no entanto, um dos principais motivos que impede a existência desta estabilizaçaõ é a falta de planaridade. Na figura 2 são mostrados os possíveis isômeros configuracionais do [10]anuleno, sendo que os isômeros 5, 6 e 7 já foram preparados em condições bastante peculiares e tiveram suas estruturas determinadas por análise de raios-X e RMN de ${ }^{1} \mathrm{H}^{2 a} \mathrm{O}$ isômero 8 é apenas uma estrutura hipotética, pois ainda não foi sintetizado.

Pode-se atribuir esta ausência de planaridade nestes [10]anulenos a dois fatores principais - a repulsão entre os hidrogênios internos dos anéis e a exigência de ângulos de ligação entre as duplas do anel bem diferentes dos esperados para carbonos do tipo $\mathrm{sp}^{2}$. Com isso, o alinhamento ideal dos orbitais $\pi$ é dificultado e faz com que a conjugação e a estabilização sejam bem menores que a conferida pela aromaticidade. Aliás, o tema aromaticidade é um assunto bastante amplo e seguramente merecerá uma discussão mais aprofundada neste texto.
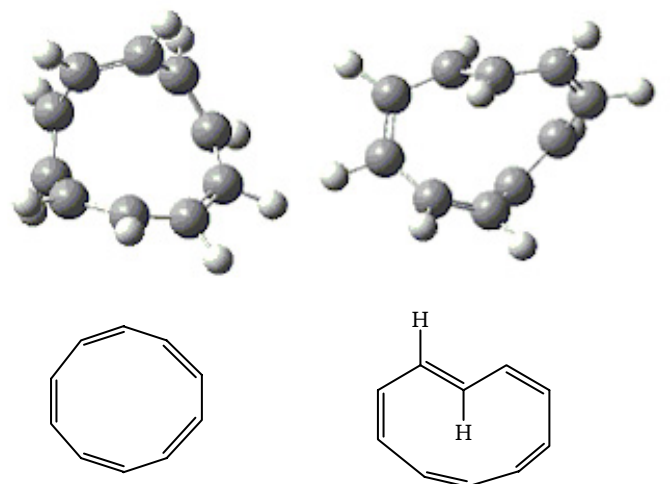

cis-[10]anuleno

5

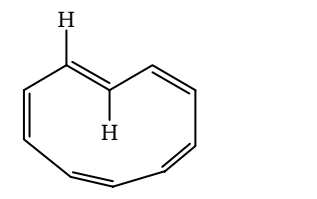

mono-trans-[10]anuleno

6
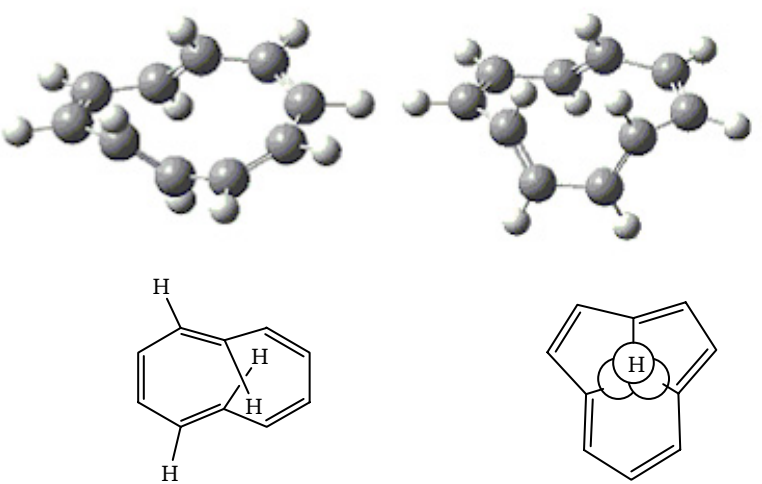

di-trans-[10]anuleno

7

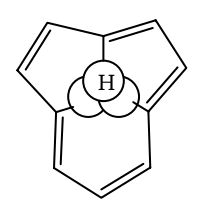

tri-trans-[10]anuleno

8 
Figura 2: Isômeros Configuracionais do [10]anuleno - Otimizados com o Modelo B3LYP/6-311+G(d,p).

Uma das maneiras de remover as interações dos hidrogênios internos em alguns anulenos consiste em introduzir mais algumas insaturações nos anéis formando ligações triplas. ${ }^{2 a}$ Esta estratégia, no entanto, não se aplica aos [10]anulenos pois provocaria tensões anelares bem maiores. Uma outra estratégia é realizar a inserção de pontes metilênicas ou de outros heteroátomos, o que remove ao mesmo tempo os dois principais fatores que impedem estruturas como 7 de ter uma planaridade suficiente para o alinhamento do sistema $\pi$.

Esta última estratégia foi utilizada com sucesso por Vogel e colaboradores que prepararam em 1964 o primeiro anuleno com ponte ("bridged annulene"), o 1,6metano[10]anuleno (14), ${ }^{3}$ e produziram a partir desta síntese inúmeros trabalhos.

$\mathrm{Na}$ síntese de Vogel foram utilizados intermediários bastante simples e um número reduzido de etapas (esquema 1).

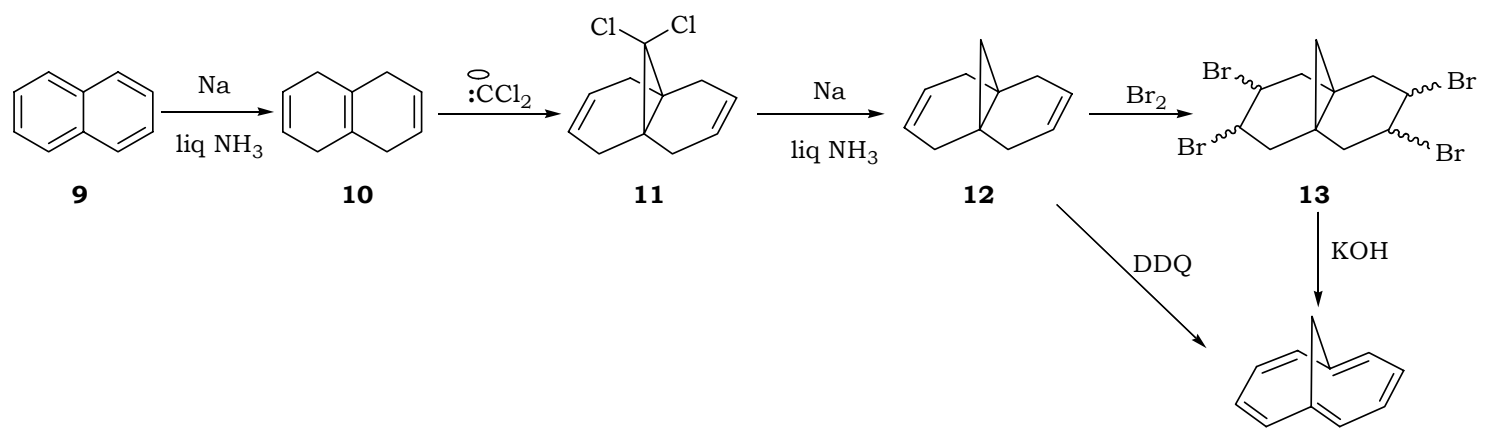

14

Esquema 1: Sintese de Vogel do 1,6-metano[10]anuleno (14).

O anuleno 14, apesar de não ser totalmente planar (figura 3), possui todos os indicativos de aromaticidade, desde propriedades como anisotropia diamagnética (evidenciada pela $\mathrm{RMN}$ de ${ }^{1} \mathrm{H}$ ) até reatividade típica de sistemas aromáticos como sofrer reações de substituição eletrofílica e apresentar resistência a hidrogenações catalíticas. ${ }^{2 a, 4}$
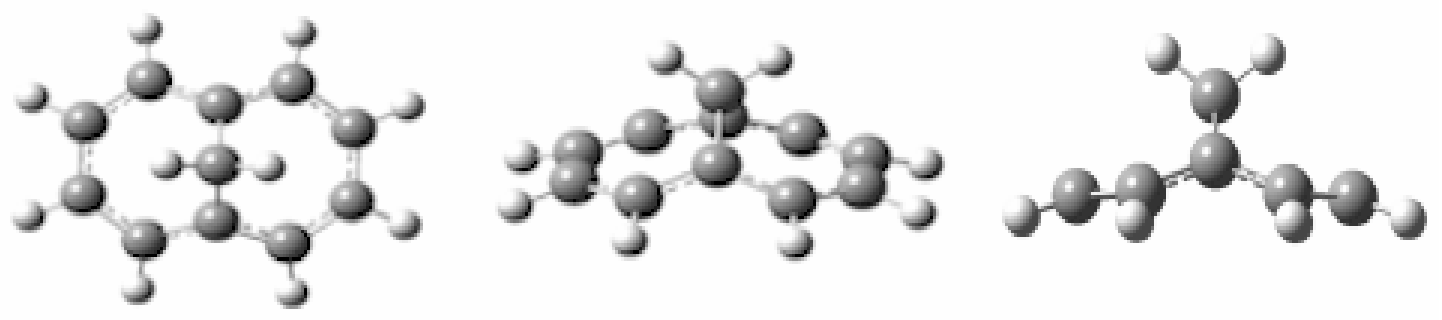

Figura 3 - Estrutura do Anuleno 14 - Otimizado com Modelo B3LYP/6-311+G(d,p).

Dentre os trabalhos desenvolvidos após a preparação do anuleno 14 podem-se destacar as sínteses dos compostos $15-17,{ }^{4 a, 5}$ que foram posteriormente estudados tanto em termos de teoria quanto de aplicações em sistemas biológicos. Alguns destes anulenos apresentaram uma boa atividade virulicida, além da permeabilidade em membranas biológicas. ${ }^{6}$ 


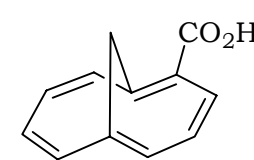

15

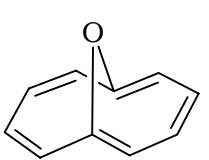

16<smiles></smiles>

17

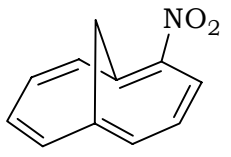

18

Figura 4: Anulenos com Ponte.

Estes anulenos foram preparados a partir do próprio anuleno 14 ou através de intermediários envolvidos na primeira síntese de Vogel (esquema 1). O composto 15 foi obtido de duas maneiras diferentes conforme mostrado no esquema $2 .^{4 a}$

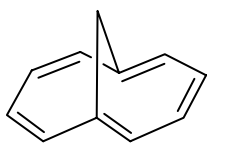

14

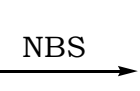<smiles>Brc1cccc2ccccc12</smiles>

20

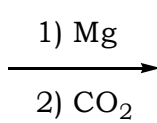

2) $\mathrm{CO}_{2}$

1) $\mathrm{Mg}$

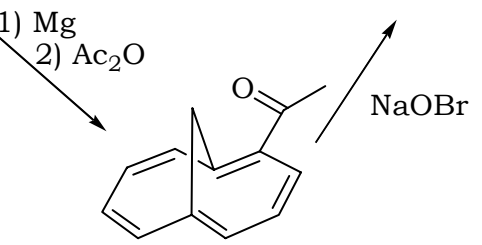

21

Esquema 2: Sintese do derivado 15.

De maneira semelhante, os derivados 18 e 19 foram sintetizados a partir de $14 .^{4 a}$

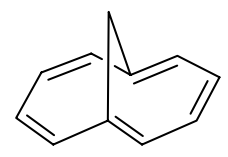

14

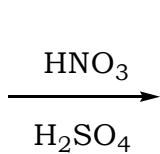<smiles>O=[N+]([O-])c1cccc2ccccc12</smiles>

18<smiles>O=C(O)c1cccc2ccccc12</smiles>

15

$\mathrm{OBr}$

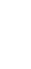




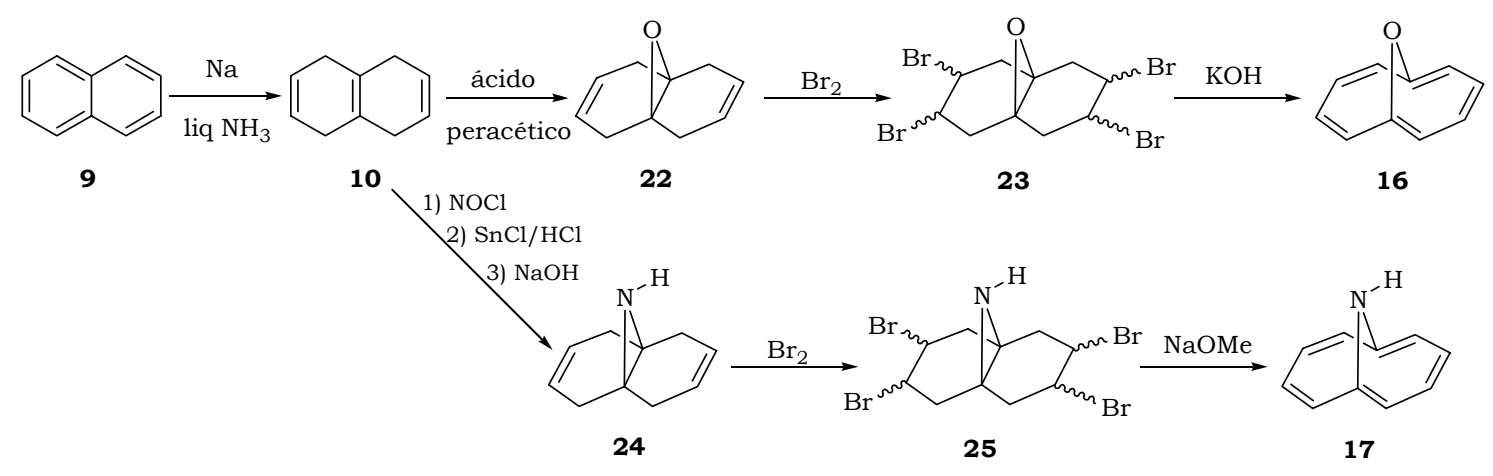

Esquema 4: Sintese dos anulenos 16 e 17.

Um segundo tipo de anuleno, agora com as pontes nas posições 1,5 foi preparado alguns anos depois por Masamune e colaboradores. ${ }^{7}$ Novamente foram observadas propriedades típicas de compostos aromáticos no anuleno 40.
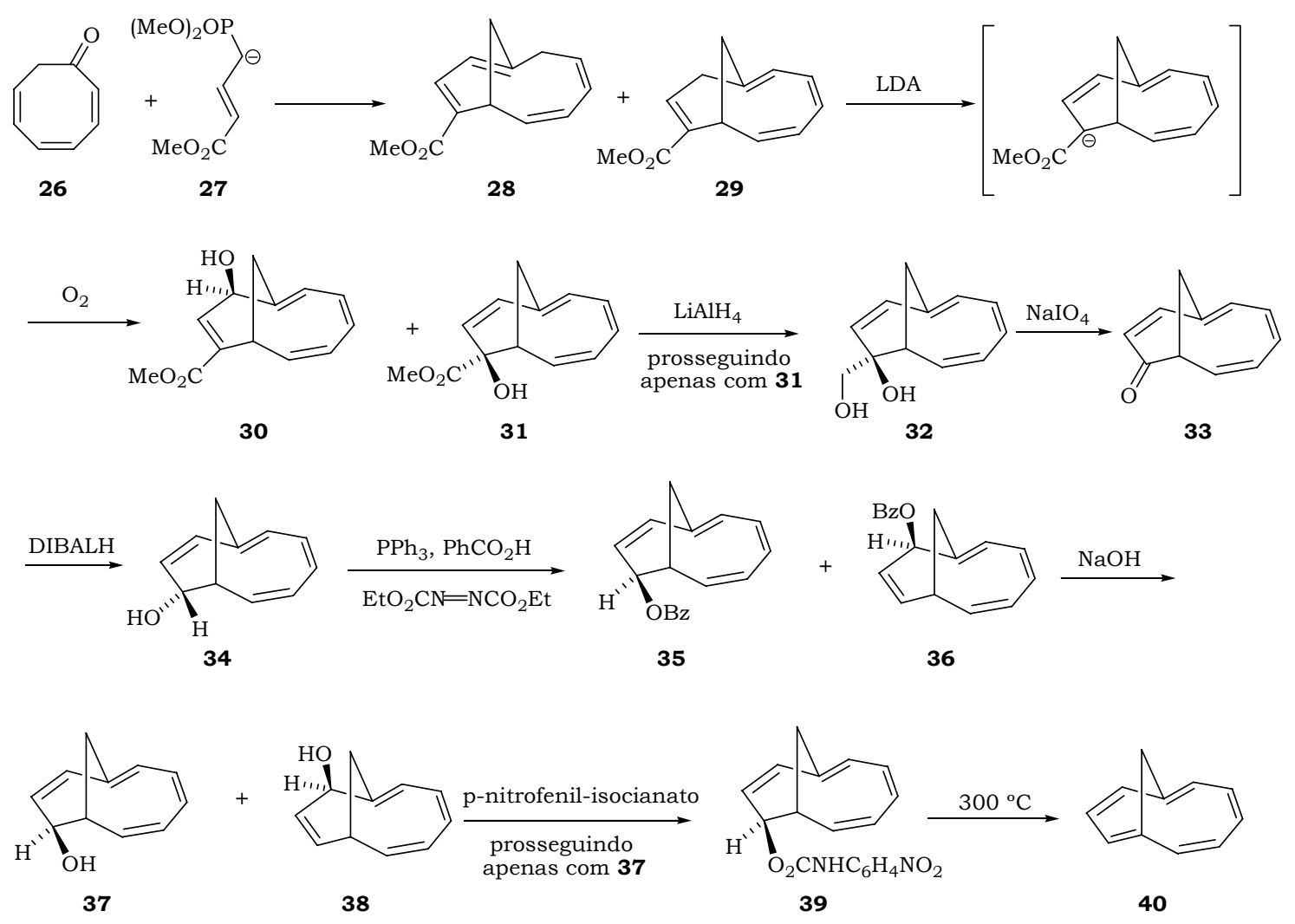

Esquema 5: Sintese do 1,5-metano[10]anuleno (40).

Como já mencionado, a síntese destes anulenos com ponte despertou um grande interesse da comunidade científica, que na época, desenvolvia e aprimorava os métodos computacionais capazes de descrever os sistemas moleculares e suas propriedades.

$\mathrm{Na}$ década de 70 foram surgindo os primeiros trabalhos teóricos sobre metano[10]anulenos, ${ }^{8}$ com o intuito de descrever a aromaticidade destes compostos. Espinosa-Muller e colaboradores ${ }^{9}$ realizaram alguns estudos interessantes envolvendo os anulenos 14 e 40 utilizando mecânica molecular. Pelos dados de geometria obtidos e pela 
equalização dos comprimentos de ligação os autores inferiram algo sobre as propriedades aromáticas e mostraram que o 1,6-metano[10]anuleno (14) era mais estável que o 1,5metano[10]anuleno (40) por um diferença de $20,88 \mathrm{kcal} / \mathrm{mol}$.

Um dos primeiros trabalhos sobre metano[10]anulenos envolvendo métodos quânticos foi realizado por Grunewald e colaboradores em $1975 .{ }^{10}$ Neste trabalho os autores realizam alguns estudos sobre reatividade e aromaticidade comparando o 1,6metano[10]anuleno (14) com naftaleno, através de cálculos com método semi-empírico.

Desta época em diante muitos outros trabalhos foram surgindo especialmente com a evolução dos modelos químico-quânticos e dos recursos computacionais. ${ }^{11}$

Uma opinião aparentemente comum entre as diversas áreas da química é que o estudo de anulenos com ponte parece ser um alvo muito fecundo de trabalhos do ponto de vista sintético, teórico e de aplicações em sistemas biológicos. Desta maneira, a busca de novas estruturas passa a ser imprescindível.

Uma estrutura cuja síntese ainda não é conhecida é a do 1,4-metano[10]anuleno (41). Do ponto de vista sintético, o composto 41 é um sistema do tipo biciclo[6.2.1] undecano (42), contendo várias insaturações. Parece mais ou menos claro que no composto 41 deve haver uma forte tensão anelar provocada pelas ligações duplas nas posições "cabeça de ponte". No entanto, estas tensões poderiam ser superadas pela alta estabilidade conferida pela aromaticidade.

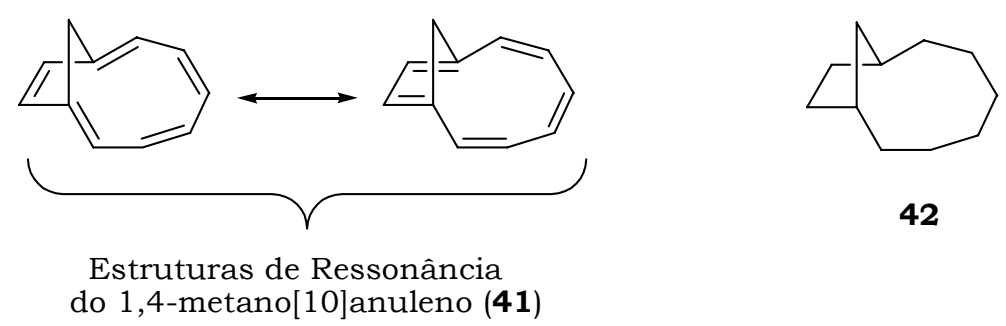

Figura 5: Sistemas de Interesse Sintético.

Há, portanto, vários pontos para serem avaliados com relação ao anuleno 41.

- Primeiramente há de se destacar o desafio sintético que representa esta estrutura. A síntese do próprio sistema carbônico do tipo biciclo[6.2.1]undecano (42) por si só já representa uma grande dificuldade.

- Um outro ponto a ser elucidado é se as tensões de anel imprimidas pela presença de várias insaturações nas posições requeridas, seriam suficientemente altas a ponto de inviabilizar sua preparação. Neste caso a estabilização aromática poderia superar estes efeitos.

- Um outro fator importante a ser avaliado é com relação à planaridade do anuleno 41. A dúvida é se ela seria suficiente para permitir o alinhamento ideal dos orbitais $\pi$.

Estes são os principais desafios que impulsionaram os estudos relacionados a esta parte do trabalho e fizeram com que um número considerável de abordagens sintéticas e teóricas fossem realizadas, buscando avaliar as propriedades do anuleno 41. É preciso destacar que ainda não há na literatura nenhum estudo sintético com o objetivo de preparar o anuleno 41 e nem mesmo nenhum trabalho de caráter teórico que avalie as propriedades desta estrutura. 
Antes de dar continuidade com os estudos efetivamente propostos e realizados, serão feitas algumas considerações sobre a aromaticidade, incluindo definições e métodos de análise teórica e experimental do efeito. Será dada uma atenção especial para os métodos de análise computacionais atualmente disponíveis, e que foram utilizados durante os estudos teóricos realizados para o anuleno 41.

Com relação aos estudos sintéticos realizados neste trabalho, pode-se dizer que todas as propostas aqui apresentadas terão como etapa principal reações de Diels-Alder ou cicloadição do tipo [6+4] (casos particulares de reações pericíclicas) e por isso serão feitas algumas considerações sobre estas reações incluindo aspectos como tipos de reações, estereoquímica envolvida, orbitais de fronteira, dentre outros. 


\section{2 - Aromaticidade}

\section{Uma visão Geral}

O termo aromaticidade/aromático tem se consolidado como um dos termos de maior destaque na química. ${ }^{12}$ Basta realizar uma simples busca na literatura que será constatada uma utilização massiva do termo e dos conceitos associados a esta propriedade.

O que parece realmente difícil é uma definição única e ampla que agrade a todos os estudiosos da química. Entre os químicos orgânicos tem-se a idéia fixa de estado de energia e de algumas regras provenientes dos estudos de Hückel. Já os físico-químicos defendem idéias de que parâmetros físicos, como a susceptibilidade magnética, é que melhor descrevem os compostos aromáticos. Pelo jeito está longe a idéia de conceito único, até porque a aromaticidade de fato é um conceito difuso e pode ser avaliada de diversas maneiras. Talvez a melhor definição de compostos aromáticos seja aquela que os classifique como substâncias com múltiplas propriedades e características, tanto físicas quanto químicas, o que faz com que sejam estruturas bem distintas dentro da química orgânica.

Nesta parte do trabalho, será realizada uma breve descrição dos aspectos históricos e atuais sobre a aromaticidade. Serão apresentados alguns dos principais métodos atualmente disponíveis para classificar os compostos dos pontos de vista qualitativo e quantitativo. Nesta apresentação será dada ênfase à qualidade e à quantidade de informações que poderão ser retiradas dos métodos de análise, poupando o leitor das complicadas deduções matemáticas inerentes aos métodos teóricos. A compreensão destes métodos é de grande importância, pois neste trabalho foram utilizados vários dos métodos que aqui serão discutidos.

\section{Desenvolvimento Histórico do Conceito. $^{2,12}$}

Alguns registros históricos revelam que o termo "aromático" começou a ser utilizado por volta de 1800 para classificar as substâncias e os óleos essenciais provenientes de algumas plantas de utilidade popular. ${ }^{\mathrm{i}}$ Muitas destas substâncias como a vanilina, o anetol, dentre outras, de fato possuem estrutura aromática (isto porque suas estruturas, hoje, são muito bem conhecidas), mas na época não se tinha uma idéia bem definida de estrutura química. Alguns anos depois (1825) Michael Faraday isolou pela primeira vez o benzeno. Na sua preparação, Faraday realizou a pirólise de óleo de baleia, que na época produzia "gás de iluminação", e que após ser submetido a forte compressão originava benzeno (esquema 6).

\footnotetext{
i Os primeiros registros indicam que o odor das substâncias era utilizado como critério para classificar uma substância como aromática, ou seja, a classificação como aromática ou não aromática era associada à sensação de odor provocada por determinadas substâncias.
} 


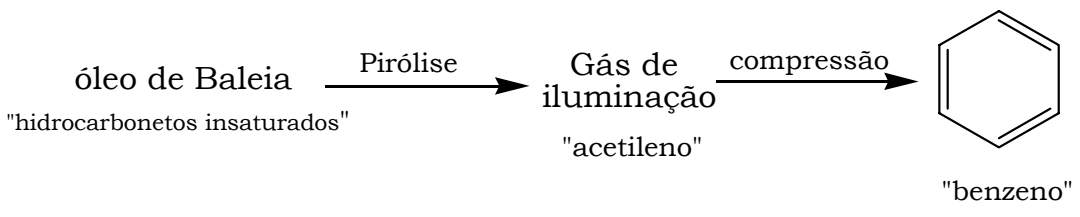

Esquema 6: Primeira sintese do Benzeno

Pouco tempo depois Eilhard Mitscherlich também realizou uma síntese do benzeno partindo do ácido benzóico.

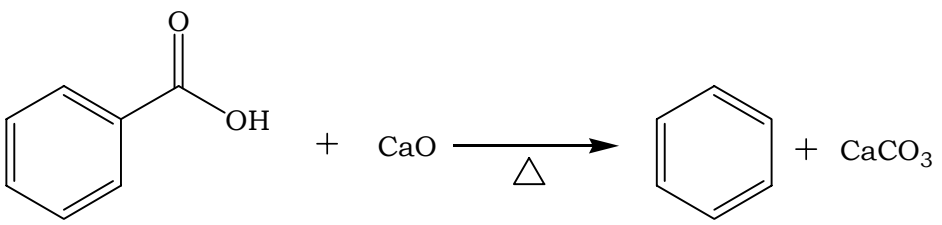

Esquema 7: Sintese de Mitscherlich

O benzeno, além de ser um marco histórico, é até hoje referência em se tratando do conceito aromaticidade.

Ainda no século XIX surgiram alguns estudos sobre as características do benzeno classificando-o como um composto que continha carbono e uma pequena quantidade de hidrogênio (com muitas insaturações). Logo vieram as propostas de Kekulé ${ }^{13}$ (1865) e de vários outros cientistas para uma provável estrutura cíclica do benzeno. Quanto à estrutura de Kekulé, há muita "história" sobre as suas bases científicas. Outras estruturas como a de Ladenburg, Claus, Armstrong-Bayer, Thiele e Dewar foram sugeridas.

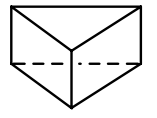

Ladenburg

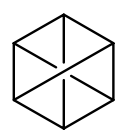

Claus

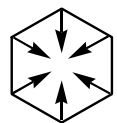

ArmstrongBayer<smiles></smiles>

Thiele<smiles>C1=CC2C=CC1C2</smiles>

Dewar

Figura 6: Estruturas Inicialmente Propostas para o Benzeno.

Alguns cientistas da época contestavam a estrutura defendida por Kekulé, mas foi a partir do surgimento da teoria quântica, que Hückel sugeriu a estrutura real do benzeno como um híbrido de ressonância.

No fim do século XIX começaram a surgir algumas definições de compostos aromáticos. A primeira delas, realizada por Erlenmeyer (1866), dizia que compostos aromáticos seriam aqueles que realizavam reações semelhantes às do benzeno. ${ }^{14}$

No começo do século XX surgiram as primeiras idéias de parâmetros físicos que descrevessem o fenômeno da aromaticidade em compostos orgânicos. O primeiro deles foi o da susceptibilidade magnética. Pascal ${ }^{15}$ descreveu bem este conceito e constatou que esta era uma propriedade aditiva dos átomos e das ligações que constituíam as moléculas. Mais tarde, alguns autores ${ }^{16}$ mostraram que os compostos aromáticos possuíam um aumento desta susceptibilidade se comparados aos compostos livres do efeito da aromaticidade. Criou-se então a idéia que os compostos aromáticos são diamagnéticos e 
possuem uma "exaltação da susceptibilidade magnética", idéia que é defendida e ampliada até hoje por grandes nomes da química teórica como Schleyer. ${ }^{17}$

Denominam-se diamagnéticas as substâncias que, não possuindo magnetização a campo zero, apresentam uma magnetização contrária a um campo aplicado, ou seja, uma susceptibilidade magnética negativa. Por outro lado, substâncias que não apresentam magnetização espontânea (a campo nulo), mas magnetizam-se no mesmo sentido de um campo aplicado, têm uma susceptibilidade magnética positiva, são chamadas paramagnéticas.

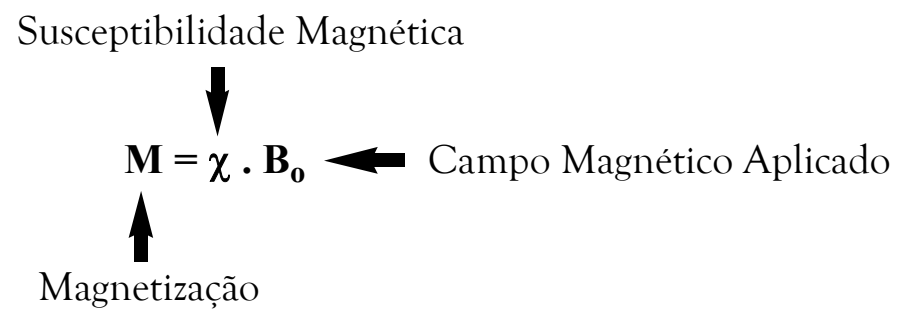

(Equação 1)

A molécula de benzeno é invariavelmente um bom exemplo para evidenciar algumas das idéias mencionadas.

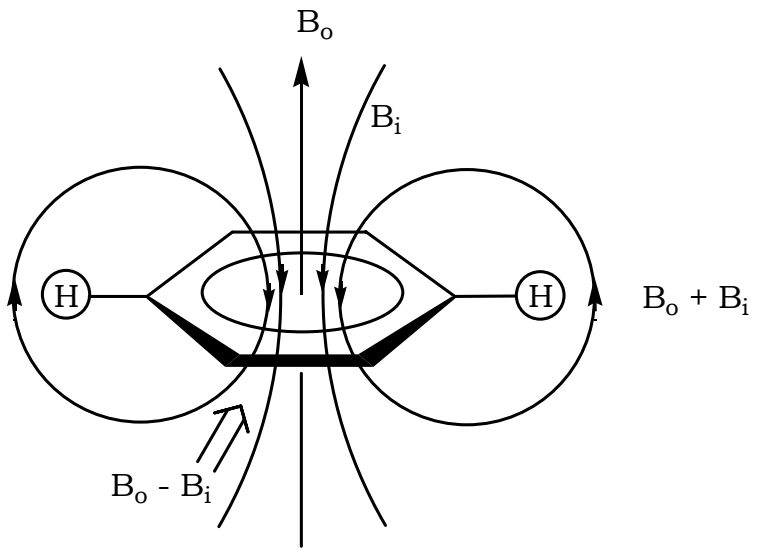

Figura 7: Correntes de Anel e Linhas de Força Induzidas no Benzeno.

Desta maneira, a susceptibilidade magnética pode ser considerada como uma medida do quanto os elétrons da substância são capazes de induzir um campo magnético a favor ou contra o campo aplicado. Por isso compostos aromáticos possuem uma alta susceptibilidade, pois são capazes de induzir campos magnéticos significativos a ponto de interferir nas freqüências de ressonância de átomos ligados ao anel aromático. Neste caso, são conhecidos os efeitos de proteção e desproteção de núcleos provocados pelas correntes de anel.

Os compostos aromáticos possuem núcleos externos ao anel, como os hidrogênios, bastante desprotegidos $(\approx 7 \mathrm{ppm})$, pois as linhas de força do campo induzido $B_{i}$, afetam os hidrogênios somando-se ao campo $B_{o}$ naquele ponto (figura 7). Já hidrogênios localizados "próximos" ao centro de um anel aromático, por exemplo, aqueles de anulenos com ponte $\mathrm{CH}_{2}$, são bastante protegidos $(\approx$ -1ppm), pois as linhas de força de $B_{i}$ afetam estes núcleos de modo que o campo sentido por eles naquele ponto, seja menor $\left(B_{o}-B_{i}\right)$. 


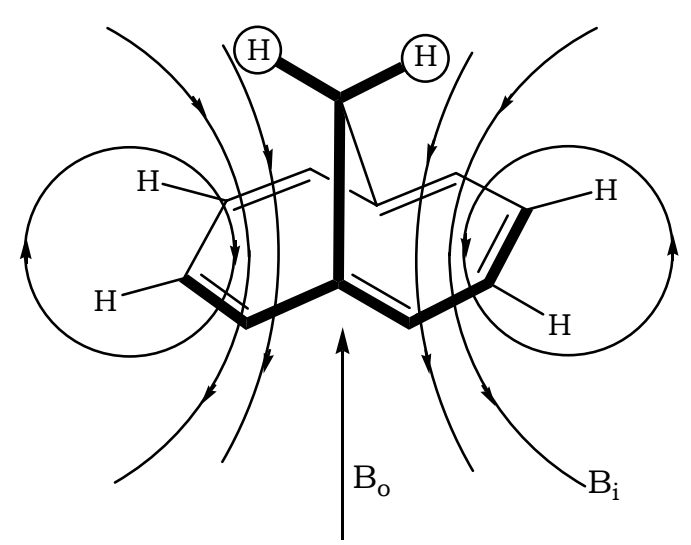

Figura 8: Linhas de Força Induzidas no 1,6-metano[10]anuleno (14).

Dando seqüência aos relatos históricos, foram sendo introduzidos muitos conceitos, mas foram as idéias de $\mathrm{Hückel}^{18}$ (teoria de orbitais moleculares) que realmente esclareceram muitos pontos sobre as estruturas eletrônicas dos compostos orgânicos e de aspectos como a aromaticidade.

Hückel mostrou que hidrocarbonetos cíclicos com $(4 n+2)$ elétrons $\pi$ (sendo $n$ um número inteiro) possuiriam uma estabilidade extra de energia, isto porque seriam compostos de camada de valência fechada - aromáticos (figura 9).

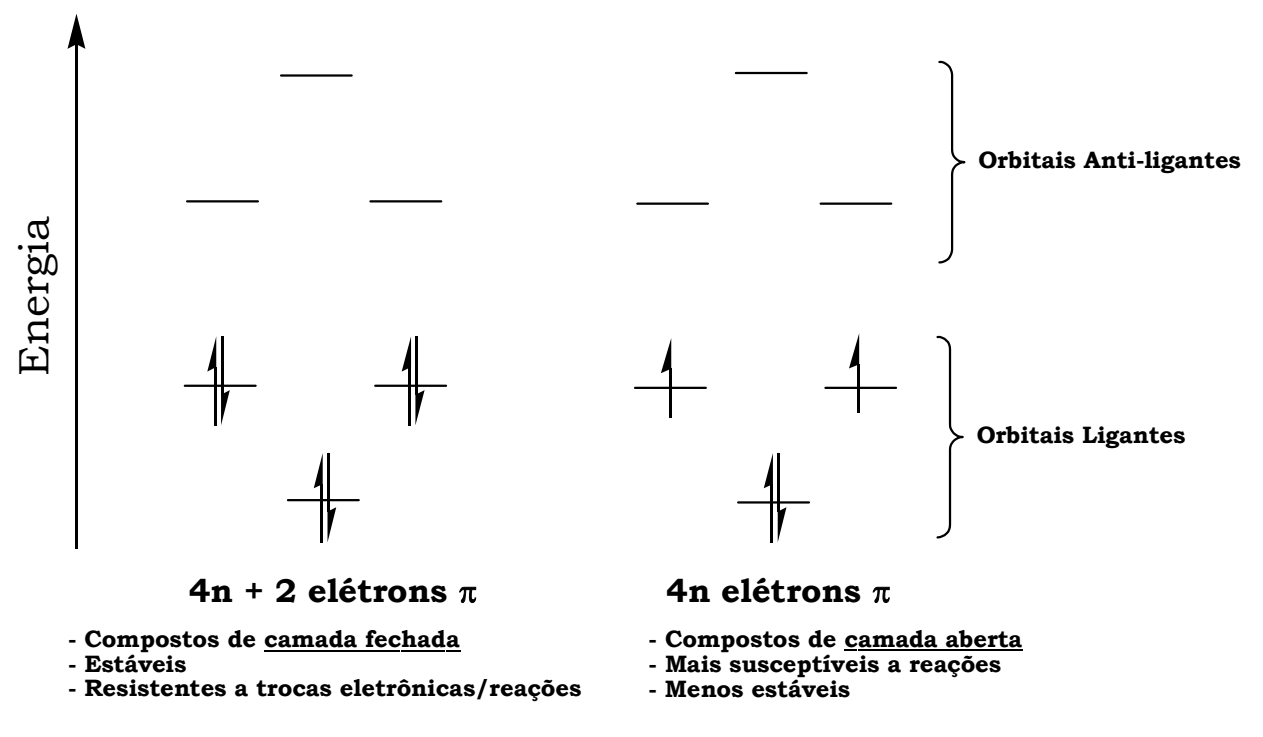

Figura 9: Diagrama de Orbitais para Compostos de Camada de Valência Aberta e Fechada.

A teoria de Hückel passou a explicar e predizer um grande número de estruturas aromáticas. No entanto, toda regra acaba esbarrando-se em uma exceção. Foi verificado que alguns compostos como os [10]anulenos, possuíam o número adequado de elétrons $\pi$, mas não as demais propriedades de um composto aromático (estabilidade, reatividade, propriedades magnéticas típicas e planaridade da molécula).

As explicações foram baseadas na falta de planaridade destes sistemas, provocadas pelas repulsões dos hidrogênios internos destas estruturas (ver figura 2). Esta falta de planaridade impedia uma boa conjugação do sistema $\pi$, justificando o caráter não aromático dos [10]anulenos. 
$\mathrm{Na}$ mesma época, surgiram algumas medidas experimentais das "energias de ressonância” ou do ganho de estabilidade conferido aos compostos aromáticos.

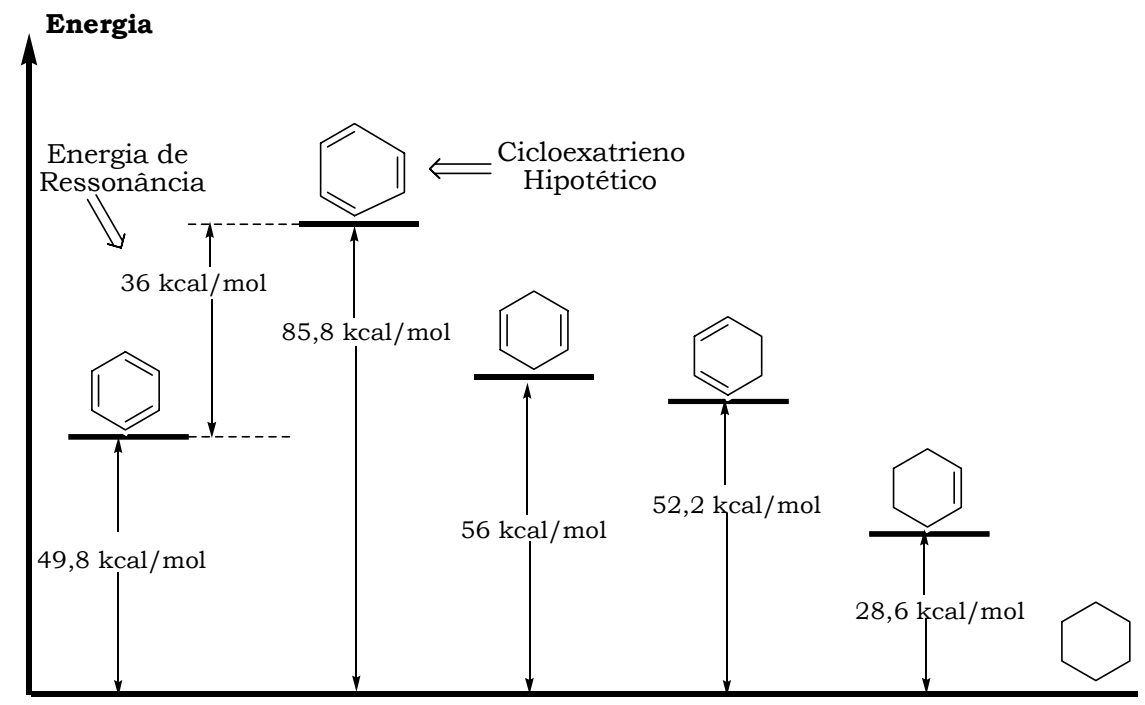

Figura 10: Diagrama de Energia - Energia de Ressonância do Benzeno.

Pauling $(1933)^{19}$ e Kistiakowsky $(1936)^{20}$ calcularam a energia de ressonância do benzeno através dos calores de hidrogenação de algumas reações. Em seus experimentos foram encontrados valores em torno de $36 \mathrm{kcal} / \mathrm{mol}$.

Estas medidas de calores de formação serviram também para classificar alguns compostos como não aromáticos ou como anti-aromáticos. A exemplo dos compostos aromáticos, a não aromaticidade e a anti-aromaticidade representam estados de energia, ou seja, há compostos com uma estabilização extra de energia conferida pelo sistema $\pi$ de elétrons (aromáticos), outros compostos sem estabilização extra de energia (não aromáticos) e, finalmente, há também compostos desestabilizados em função de problemas geométricos, torcionais, ou mesmo do sistema $\pi$ eletrônico (anti-aromáticos). Na figura 11 são mostrados exemplos destes compostos e seus estados de energia relativos.

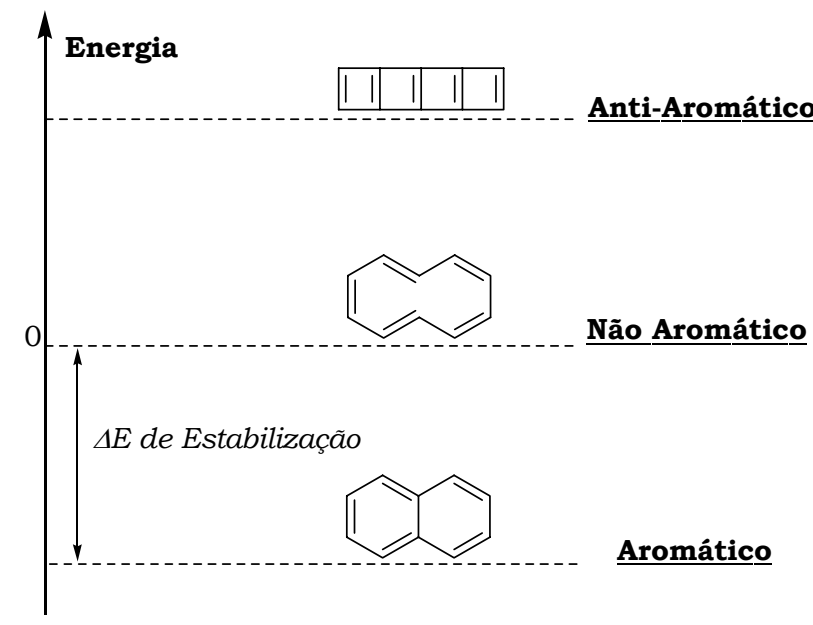

Figura 11: Energias Relativas de Compostos Aromáticos, Não Aromáticos e Anti-Aromáticos.

Pode-se dizer que a segunda metade do século XX foi marcada por inúmeros avanços da química quântica e, com isso, dos métodos de análise teórica dos sistemas 
atômicos. No entanto, estes avanços estiveram sempre atrelados aos avanços dos recursos computacionais. No final dos anos 60 foram surgindo muitos métodos ou critérios teóricos para avaliar a aromaticidade nos compostos orgânicos. A seguir, serão apresentados alguns dos critérios que mais se destacaram.

\section{Alguns Critérios Geométricos}

Do ponto de vista da equalização dos comprimentos de ligação, geralmente comum a anéis aromáticos, pode-se dizer que um simples tratamento estatístico dos comprimentos de ligação poderia oferecer informações valiosas sobre a aromaticidade em compostos orgânicos. Parâmetros como o desvio médio, variância, dentre outros, dariam uma idéia do quanto um composto possui características aromáticas. No entanto, estes tratamentos certamente excluiriam propriedades moleculares e das ligações químicas e com isto trariam informações que não estariam de acordo com a realidade. Por exemplo, em um tratamento estatístico não seria levado em conta o fato de que a ligação química entre átomos de carbono tem comprimento diferente da ligação química $\mathrm{C}-\mathrm{N}$, isto por motivos orbitalares. $\mathrm{O}$ resultado seria uma variação razoável nos comprimentos de ligação mesmo que o composto seja aromático.

Alguns dos critérios desenvolvidos ignoraram estes detalhes e por isso ficaram um pouco esquecidos. Adiante serão destacados dois critérios por questão de história e relevância.

\section{O Parâmetro de Julg $\left(\mathrm{A}_{\mathrm{i}}\right)^{21}$}

O primeiro parâmetro teórico de medida da aromaticidade em compostos orgânicos foi criado em 1967 por Julg e François. ${ }^{21} \mathrm{O}$ termo $\mathrm{A}_{\mathrm{j}}$ é calculado com base na geometria molecular (comprimentos de ligação). Este índice é uma função normalizada da variação de comprimentos de ligação. A partir dele são tiradas informações sobre uma diminuição na aromaticidade de acordo com a variação dos comprimentos. A variável $n$ é o número de ligações do anel sendo cada uma delas de comprimentos $R$ r. O valor $R$ é obtido através da média dos comprimentos de ligação e o valor 225 vem da condição ideal com $A_{j}$ igual a zero e dos comprimentos de ligação do benzeno. Como resultado tem-se que, quanto menor o valor de $A_{j}\left(A_{j}<1\right)$ menor a aromaticidade do composto avaliado.

$$
\mathrm{A}_{J}=1-\left(\frac{225}{n}\right) \sum_{r}^{n}\left(1-\frac{R_{r}}{R}\right)^{2}
$$

Infelizmente este parâmetro não pôde ser aplicado para compostos heteroaromáticos devido a variações pronunciadas nos comprimentos de ligação nestes heterociclos (por exemplo, $\mathrm{C}=\mathrm{C}$ e $\mathrm{C}=\mathrm{N}$ ). No entanto, o parâmetro de Julg teve o seu devido valor e inclusive foi aplicado a sistemas onde mais tarde outros índices de aromaticidade descreveram os mesmos aspectos. 
Outros parâmetros geométricos foram criados (Parâmetros de Bird) ${ }^{22}$ buscando resolver estes problemas, mas todos se esbarravam em algumas limitações como o tamanho dos anéis (5 e 6 membros apenas).

\section{Índice HOMA. (Harmonic Oscilator Model of Aromaticity). ${ }^{23,12 a-b, 12 e}$}

Este é um dos índices teóricos mais recentes e de grande reconhecimento dentro da comunidade científica. Apesar de ser baseado em parâmetros geométricos, o índice HOMA possui um tratamento matemático e conceitual bem diferenciado. A exemplo de outros parâmetros (ou índices) de aromaticidade, o índice HOMA mede os decréscimos da aromaticidade do sistema, ou seja, quanto menor for o valor do índice menor será a aromaticidade do composto; o valor máximo (ideal) do índice HOMA é 1.

No cálculo de HOMA são introduzidos dois conceitos: o de elongação das ligações (EN) e o de alternância (GEO).

$$
H O M A=1-\left[\alpha\left(R_{o p t}-R_{a v}\right)^{2}+\frac{\alpha}{n} \sum\left(R_{a v}-R_{i}\right)^{2}\right]=1-E N-G E O \quad(\text { Equação 3) }
$$

O termo EN é calculado a partir de uma constante empírica $\alpha$ (obtida quando HOMA é igual à zero), com o $\mathrm{R}_{\text {opt }}$ (raio ótimo) e $\mathrm{R}_{\mathrm{av}}$ (média dos comprimentos de ligação). $\mathrm{O}$ valor do $\mathrm{R}_{\mathrm{opt}}$ é tirado de uma média de comprimentos de ligação de um hidrocarboneto acíclico como o butadieno, podendo ser outro se o sistema onde a aromaticidade será avaliada for heterocíclico. $\mathrm{O}$ valor de $\mathrm{R}_{\mathrm{av}}$ é tirado do composto onde está sendo avaliada a aromaticidade.

O termo GEO é calculado utilizando-se, além de $\alpha$, a variável $n$ que é o número de ligações do anel (neste caso os autores falam em perímetro do anel, por exemplo, para o benzeno $n=6$ ). Também são utilizados os valores de $R_{a v}$ e $R_{i}$ (comprimentos de ligação individuais no anel analisado).

Desta maneira, quanto maiores os termos de elongação (EN) e de alternância $(\mathrm{GEO})$ menor será o índice HOMA $(\mathrm{HOMA}<1)$ e menos aromático será o sistema. $\mathrm{Na}$ tabela 1 estão relacionados alguns exemplos de valores para o índice HOMA.

Tabela 1: Índices HOMA para Alguns Compostos. ${ }^{12 \mathrm{~b}}$

\begin{tabular}{cccc}
\hline Compostos & HOMA & EN & GEO \\
\hline benzeno & 0,996 & 0,004 & 0,000 \\
naftaleno & 0,824 & 0,038 & 0,138 \\
indol & 0,909 & 0,006 & 0,086 \\
quinolina & 0,710 & 0,004 & 0,286 \\
[18]anuleno & 0,899 & 0,010 & 0,091 \\
ciclobutadieno & $-2,570$ & 1,317 & 2,253 \\
Ciclo-octatetraeno & $-0,295$ & 0,103 & 1,192 \\
\hline
\end{tabular}

Uma das grandes vantagens deste índice é a possibilidade de se medir a aromaticidade local, ou seja, em policiclos aromáticos é possível medir a aromaticidade de cada um dos anéis. Aliás, segundo os autores o índice HOMA tem por objetivo e definição medir a aromaticidade local. 


\section{$\underline{\text { Alguns Critérios Energéticos }}$}

Ao contrário dos critérios geométricos, os critérios energéticos descrevem apenas a aromaticidade do composto por inteiro. Pode-se dizer que o primeiro critério energético de medida da aromaticidade foi a medida experimental das Energias de Ressonância (RE) realizada por Pauling ${ }^{19}$ e Kistiakowsky (calores de hidrogenação). ${ }^{20}$ Atualmente é possível realizar alguns cálculos teóricos de (RE) baseadas na diferença de energia dos orbitais de fronteira. ${ }^{12 c}$

Além do cálculo de RE, alguns cálculos envolvendo reações isodésmicas e homodesmóticas têm sido realizados. ${ }^{27}$ Nestes cálculos são propostas algumas reações não necessariamente executáveis (podem ser hipotéticas), capazes de avaliar os efeitos da estabilização aromática, dentre outros.

Há ainda outros critérios e cálculos que foram desenvolvidos como as análises de NBO (Natural Bond Orbital) ${ }^{24}$ e NRT (Natural Resonance Theory). ${ }^{25}$ Nas análises de NBO podem ser avaliadas as energias de estabilização ao longo das ligações químicas, podendo-se inferir algo sobre a aromaticidade. Nas análises de NRT podem ser avaliadas as estruturas de ressonância e as ordens de ligação entre os átomos do anel.

\section{Energia de Ressonância (RE).}

Haddon e Fukunaga ${ }^{26}$ demonstraram a relação entre as energias de ressonância e as diferenças de energia entre os orbitais moleculares de fronteira. Foi mostrado que quanto maior a diferença de energia entre os orbitais HOMO e LUMO maior era a estabilização aromática de um determinado composto aromático. Estes autores desenvolveram a expressão abaixo, cuja dedução é complexa, mas as informações tiradas da mesma são de grande valor.

$$
R E=-\frac{\left(\pi \rho_{r s}\right)^{2}}{24}\left(\varepsilon_{L U M O}-\varepsilon_{\text {HOMO }}\right)
$$

$\left(\varepsilon_{\mathrm{LUMO}}-\varepsilon_{\mathrm{HOMO}}\right)$ é a diferença de energia entre os orbitais HOMO e LUMO do composto. $\left(\pi \rho_{\mathrm{rs}}\right)$ é uma média das ordens de ligação do sistema, e são valores calculados. Assim, quanto maiores os valores de RE, maior será a aromaticidade do sistema.

É preciso não confundir os valores de energia de ressonância calculados experimentalmente com estes valores teóricos. Estes valores de RE, obtidos pela equação 4, devem ser encarados como um índice de aromaticidade e não como um cálculo que reproduz os valores obtidos experimentalmente. Na tabela a seguir são mostrados alguns valores de RE calculados pela equação 4. 
Tabela 2: Energias de Ressonância. ${ }^{12 c}$

\begin{tabular}{cc}
\hline Compostos & Energias de Ressonância (RE) kcal/mol \\
\hline benzeno & 45,8 \\
piridina & 43,3 \\
tiofeno & 43,0 \\
imidazol & 40,0 \\
pirrol & 34,8 \\
furano & 27,2 \\
naftaleno & 80,3 \\
antraceno & 111,5 \\
bifenil & 94,7 \\
\hline
\end{tabular}

\section{Reações Isodésmicas e Homodesmóticas: Cálculo das Energias de Estabilização Aromática (ASE). ${ }^{27}$}

Uma reação isodésmica é uma reação hipotética que não necessariamente é executável no laboratório. Com este modelo reacional é possível avaliar alguns efeitos da estrutura eletrônica como a aromaticidade e as tensões anelares nos compostos orgânicos. Na prática o que se faz é otimizar os compostos envolvidos nos cálculos (com métodos e funções de base que os descrevam) e então fazer um cálculo termoquímico da energia da reação $\left(\sum E_{\text {produtos }}-\sum E_{\text {reagentes }}\right)$, sendo $E=E_{0}+Z P E$. ii

A diferença básica entre as reações isodésmicas e homodesmóticas ${ }^{27}$ é que nas reações isodésmicas devem ser mantidos nos reagentes e produtos o mesmo número de ligações e o número de átomos. Nas reações homodesmóticas além de mantidas as condições anteriores, deve ser mantido o número de átomos com suas respectivas hibridizações. No esquema 8 são exemplificadas algumas destas reações juntamente com os valores experimentais.

\footnotetext{
ii "E" é a energia eletrônica total do sistema e é obtida através dos cálculos quânticos. Esta energia às vezes é chamada de "energia corrigida" pois envolve $E_{o}$ (energia eletrônica) mais a correção vibracional "ZPE" que quer dizer "zero point energy”. A ZPE é obtida durante o cálculo das freqüências vibracionais do composto.
} 


\section{Isodésmica}

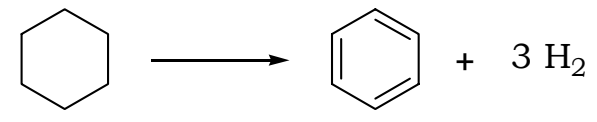

$\Delta \mathrm{E}=49,8 \mathrm{kcal} / \mathrm{mol}$ - Experimental (Calores de Formação)

$\Delta \mathrm{E}=50,0 \mathrm{kcal} / \mathrm{mol}$ - Reação Isodésmica Calculada com HF $/ 6-311+\mathrm{G}(\mathrm{d}, \mathrm{p})$

\section{Homodesmótica}

3

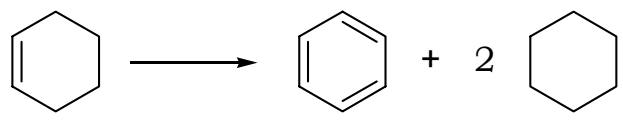

$\Delta \mathrm{E}=36,0 \mathrm{kcal} / \mathrm{mol}$ - Experimental (Calores de Formação)

$\Delta \mathrm{E}=35,6 \mathrm{kcal} / \mathrm{mol}$ - Reação Homodesmótica Calculada com B3LYP $/ 6-311+\mathrm{G}(\mathrm{d}, \mathrm{p})$

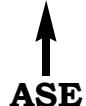

Esquema 8: Reações Isodésmica e Homodesmótica. ${ }^{27 c}$

Com este modelo teórico de reação é possível prever a variação da entalpia $(\Delta \mathrm{H})$ de muitas reações e compará-los com valores experimentais.

\section{Análises de NBO (Natural Bond Orbital) e NRT (Natural Resonance Theory). ${ }^{24,25}$}

$\mathrm{Na}$ sua essência os NBOs podem ser descritos como orbitais moleculares localizados nas ligações químicas. Este conceito de orbitais naturais é usado para distribuir elétrons dentro de orbitais atômicos e moleculares de modo a descrever cargas atômicas e ligações moleculares a partir da densidade eletrônica entre átomos.

O NBO para uma ligação química $(\sigma$ ou $\pi$ ) localizada entre dois átomos $\mathrm{A}$ e $\mathrm{B}$, é formado a partir dos orbitais naturais híbridos $(h)$, os quais são compostos de um conjunto de orbitais atômicos de valência.

$$
\pi_{A B}=c_{A} h_{A}+c_{B} h_{B}
$$

Da mesma forma que qualquer combinação linear de orbitais, a formação de um NBO ligante $(\sigma$ ou $\pi)$ também leva à formação de um NBO antiligante $\left(\sigma^{*}\right.$ ou $\left.\pi^{*}\right)$, que são orbitais desocupados na estrutura de Lewis e que podem ser utilizados para descrever efeitos como: aromaticidade, efeitos hiperconjugativos, ligações de hidrogênio, e várias outras interações de caráter não covalente. Em resumo a interação entre um NBO ligante de uma ligação A-B e um orbital antiligante de outra ligação C-D pode ser entendida com uma interação estabilizadora de um sistema doador-aceitador eletrônico. $\quad \mathrm{Na}$ figura 12 são mostradas interações entre um orbital ocupado $\pi$ de energia $\varepsilon_{\mathrm{i}}$ e um desocupado $\pi^{*}$ de energia $\varepsilon_{j}$. Na mesma figura estão ilustradas as energias do sistema após as interações $\left(\mathrm{E}_{1}\right.$ e $\left.\mathrm{E}_{2}\right)$ e a energia de estabilização de segunda ordem $\Delta \mathrm{E}_{i, j}^{(2)}$. 


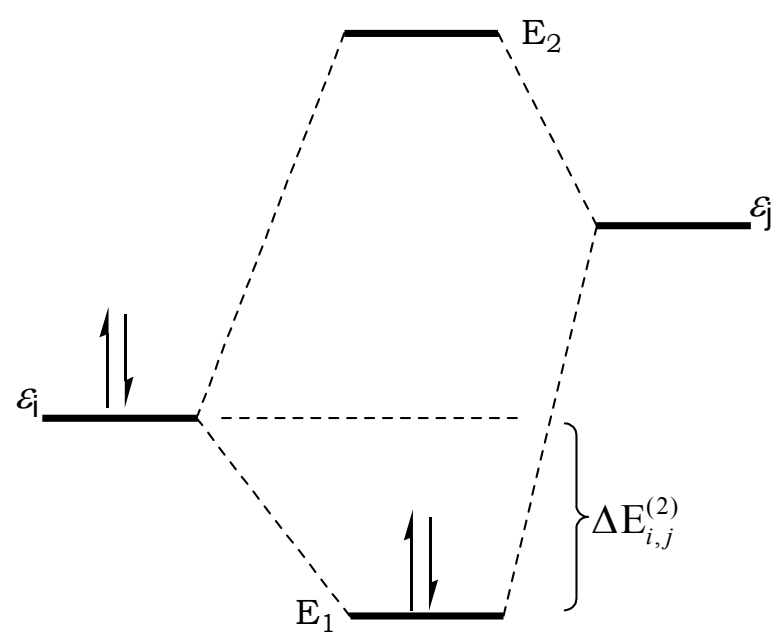

Figura 12 - Interação Envolvendo NBOs $\pi$ e $\pi^{*}$.

Pode-se concluir que quanto maior $\Delta \mathrm{E}_{i, j}^{(2)}$, maior será a "interação estabilizadora”, e melhor caracterizados serão os efeitos de conjugação, hiperconjugação, ligações de hidrogênio, e aromaticidade. No caso da avaliação da aromaticidade, pode-se concluir que quanto maior forem as energias de estabilização $\left(\Delta \mathrm{E}_{i, j}^{(2)}\right)$ ao longo das ligações do anel aromático, e quanto mais abundantes forem estas interações, maior será a aromaticidade no sistema.

A análise de NRT também é uma importante ferramenta para avaliar a aromaticidade dos compostos orgânicos. Esta análise fornece as possíveis formas canônicas de ressonância, incluindo os pesos de cada uma, e as ordens de ligação interatômicas. Para uma dada estrutura, sabe-se que quanto maior o número de estruturas canônicas, maior será a distribuição eletrônica no híbrido de ressonância, e mais aromático será o composto. A presença de poucas estruturas de ressonância ou de estruturas com pesos porcentuais muito elevados indica uma má distribuição eletrônica e menor estabilização aromática. Com relação às ordens de ligação entre átomos de um composto aromático, é considerado como um valor ideal uma média entre 1 (ligação simples) e 2 (ligação dupla). Na tabela 3 são mostrados alguns valores das energias de estabilização provenientes das interações de NBOs e alguns valores de ordens de ligação. 
Tabela 3: Interações, Ordens de Ligação e Energias de Estabilização Calculados com B3LYP/6-31+G(d,p). ${ }^{28}$

\begin{tabular}{|c|c|c|c|c|c|c|}
\hline \multirow[t]{2}{*}{ Compostos } & \multicolumn{2}{|c|}{$\overline{\text { Ligações }}$} & \multicolumn{2}{|c|}{ Ordens de Ligação (NRT) } & \multicolumn{2}{|c|}{$\Delta \mathrm{E}_{i, j}^{(2)}(\mathrm{kcal} / \mathrm{mol})$} \\
\hline & $\mathrm{a}$ & $\mathrm{b}$ & $\mathrm{a}$ & $\mathrm{b}$ & $\Delta \mathrm{E}_{\pi \mathrm{a} \rightarrow \pi \mathrm{b}^{*}}$ & $\Delta \mathrm{E}_{\pi \mathrm{b} \rightarrow \pi \mathrm{a}^{*}}$ \\
\hline & $\mathrm{C}_{1}-\mathrm{C}_{2}$ & $\mathrm{C}_{3}-\mathrm{C}_{4}$ & 1,498 & 1,498 & $-20,4$ & $-20,4$ \\
\hline & $\mathrm{C}_{1}-\mathrm{C}_{2}$ & $\mathrm{C}_{3}-\mathrm{C}_{7}$ & 1,891 & 1,943 & $-17,8$ & $-6,6$ \\
\hline & $\mathrm{C}_{2}-\mathrm{C}_{3}$ & $\mathrm{C}_{4}-\mathrm{C}_{5}$ & 1,365 & 1,365 & $-17,8$ & $-17,8$ \\
\hline & $\mathrm{C}_{2}-\mathrm{C}_{3}$ & $\mathrm{C}_{4}-\mathrm{C}_{5}$ & 1,886 & 1,886 & $-7,2$ & $-7,2$ \\
\hline$\square_{3}^{2}$ & $\mathrm{C}_{1}-\mathrm{C}_{2}$ & $\mathrm{C}_{3}-\mathrm{C}_{4}$ & 1,998 & 1,998 & $\approx 0$ & $\approx 0$ \\
\hline
\end{tabular}

Pode-se observar que as interações entre $\underline{\operatorname{NBOs}}\left(\Delta \mathrm{E}_{i, j}^{(2)}\right)$ são da ordem de -20 $\mathrm{kcal} / \mathrm{mol}$ para compostos ou íons aromáticos e as ordens de ligação possuem valores iguais ao longo do anel e próximos de 1,5, indicando uma boa deslocalização eletrônica. $\mathrm{Na}$ figura 13 há um exemplo de interação entre NBOs; no caso, foi selecionada a interação $\pi \mathrm{C}_{1}-\mathrm{C}_{2} \rightarrow \pi * \mathrm{C}_{3}-\mathrm{C}_{4}$ do benzeno mostrada em duas projeções diferentes.
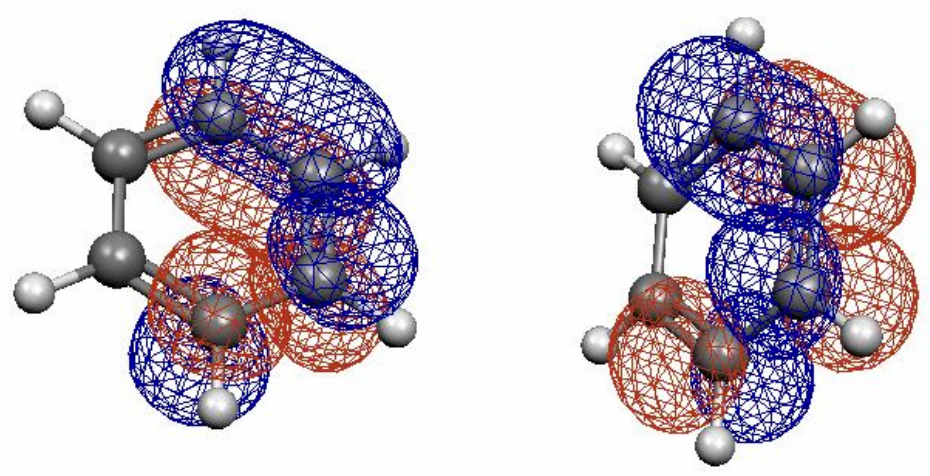

Figura 13: Interação entre NBOs $\pi \mathrm{C}_{1}-\mathrm{C}_{2} \rightarrow \pi^{*} \mathrm{C}_{3}-\mathrm{C}_{4}$ no Benzeno (B3LYP/6-31+G(d,p). ${ }^{29}$ 


\section{Alguns Critérios Magnéticos}

Neste texto já foi abordado o critério da susceptibilidade e foi mencionado que os compostos aromáticos possuem "valores elevados" desta grandeza (muito negativos, indicando forte diamagnetismo). Esta grandeza física pode ser medida tanto experimentalmente (por exemplo, através de ressonância magnética nuclear) ${ }^{30}$ quanto pode ser calculada por métodos quânticos. No entanto, a grandeza que geralmente é adotada para quantificar a aromaticidade de um composto é a "exaltação da susceptibilidade magnética" $(\Lambda)$ que pode ser calculada pela diferença entre a susceptibilidade medida experimentalmente e a estimada pelo método de Pascal. ${ }^{15}$

Um outro critério magnético bastante atual é o índice NICS (Nucleus Independent Chemical Shift). ${ }^{31}$ Este índice pode ser obtido pelo cálculo das blindagens magnéticas absolutas em pontos no espaço molecular. A partir dos valores obtidos é possível inferir algo sobre a aromaticidade dos compostos.

\section{Susceptibilidade Magnética $(\chi)$ e Exaltação da Susceptibilidade $(\Lambda) .{ }^{16,32}$}

Para se referir a algumas substâncias aromáticas muitos autores costumam utilizar o termo susceptibilidade diamagnética devido à predominância dos efeitos diamagnéticos nestes compostos. Os valores absolutos de $\chi$ podem ser utilizados como parâmetro de medida da aromaticidade (ppm), no entanto, a grandeza mais utilizada é $\Lambda$.

$$
\Lambda=\chi_{m}-\chi_{a}
$$

(Equação 6)

$\chi_{\mathrm{m}}$ é o valor da medida experimental e $\chi_{\mathrm{a}}$ o valor estimado pelo método de Pascal (sem considerar a aromaticidade). Na tabela 4 estão relacionados alguns valores de referência das susceptibilidades atômicas e na tabela 5 alguns valores de $\Lambda$.

Tabela 4: Valores de Referência de $\chi_{\mathrm{a}}{ }^{16 b}$

\begin{tabular}{cccc}
\hline Átomo & $\chi_{\mathrm{a}}(\mathrm{ppm})$ & Correções de Ligação & $\chi_{\mathrm{a}}(\mathrm{ppm})$ \\
\hline $\mathrm{H}$ & $-2,9$ & $\mathrm{C}=\mathrm{C}$ & 5,5 \\
$\mathrm{C}$ & $-6,0$ & $\mathrm{C}=\mathrm{N}$ & 8,2 \\
$\mathrm{~N}$ & $-5,6$ & $\mathrm{C}=\mathrm{O}$ & 6,3 \\
$\mathrm{O}$ & $-4,6$ & & \\
$\mathrm{~S}$ & $-15,0$ & & \\
\hline
\end{tabular}

Tabela 5: Valores das Grandezas Magnéticas de Alguns Compostos Orgânicos. ${ }^{16 a}$

\begin{tabular}{cccc}
\hline Composto & $\chi_{\mathrm{m}}(\mathrm{ppm})($ Experimental) & $\chi_{\mathrm{a}}(\mathrm{ppm})$ (Soma de Pascal) & $\Lambda(\mathrm{ppm})$ \\
\hline Benzeno & $-55,6$ & $-36,9$ & $-18,7$ \\
Naftaleno & $-91,9$ & $-55,7$ & $-36,2$ \\
Tropona & $-54,0$ & $-41,2$ & $-12,8$ \\
Azuleno & $-91,0$ & $-55,7$ & $-35,3$ \\
Ciclo-octatetraeno & $-51,9$ & $-49,2$ & $-2,7$ \\
\hline
\end{tabular}


Por exemplo, para o cálculo de $\chi_{a}$ para o benzeno, basta somar 6 vezes a contribuição do carbono, o mesmo para os hidrogênios e 3 vezes a contribuição das ligações $\mathrm{C}=\mathrm{C}$. Será encontrado o valor de $-36,9$ ppm.

Quanto ao cálculo teórico de $\Lambda$ (via métodos quânticos), há alguns autores que o consideram trabalhoso, pois requer alguns parâmetros de referência. Na tabela 6 são mostrados alguns valores de $\Lambda$, obtidos através de cálculos computacionais.

Tabela 6: Exaltação da Susceptibilidade Magnética - Valores Teóricos. ${ }^{12 \mathrm{~b}}$

\begin{tabular}{cccc}
\hline Composto & $\Lambda(\mathrm{ppm})(\mathrm{HF} / 6-31+\mathrm{G}(\mathrm{d})$ & Composto & $\Lambda(\mathrm{ppm})(\mathrm{HF} / 6-31+\mathrm{G}(\mathrm{d})$ \\
\hline benzeno & $-13,4$ & azuleno & $-42,9$ \\
naftaleno & $-28,2$ & pirrol & $-12,1$ \\
furano & $-9,1$ & tiofeno & $-10,0$ \\
ciclopentadieno & $-2,4$ & antraceno & $-49,8$ \\
ciclobutadieno & 18,0 & ciclopentadienil & $-17,2$ \\
\hline
\end{tabular}

\section{Critério NICS (Nucleus Independent Chemical Shift).}

O critério NICS é um dos mais novos métodos, baseados em critérios magnéticos, para a medida da aromaticidade. No entanto, este critério tem sofrido muitas críticas, inclusive de seus autores, e tem sido aplicado com bastante cuidado. Para os compostos mais simples, como sistemas benzenóides, a aplicabilidade é boa, mas para compostos com ponte (por exemplo, anulenos com ponte) a análise pode ser falha. De uma maneira geral, tanto o critério quanto os cálculos a serem efetuados são relativamente simples. Os compostos são otimizados e então são calculados os deslocamentos químicos absolutos (chamados de tensores de blindagem absolutos) sem considerar o padrão interno para referência. Os valores que interessam são aqueles calculados no centro dos anéis aromáticos (um ponto no espaço), os que estão $1 \AA$ acima e $1 \AA$ abaixo. Para o benzeno veja na figura 14.

Os pontos destacados em lilás são os pontos onde foram calculados os tensores ("índices NICS"). Os pontos no centro do anel são chamados de NICS(0), os localizados acima do plano do anel de NICS(1) e abaixo de NICS(-1).

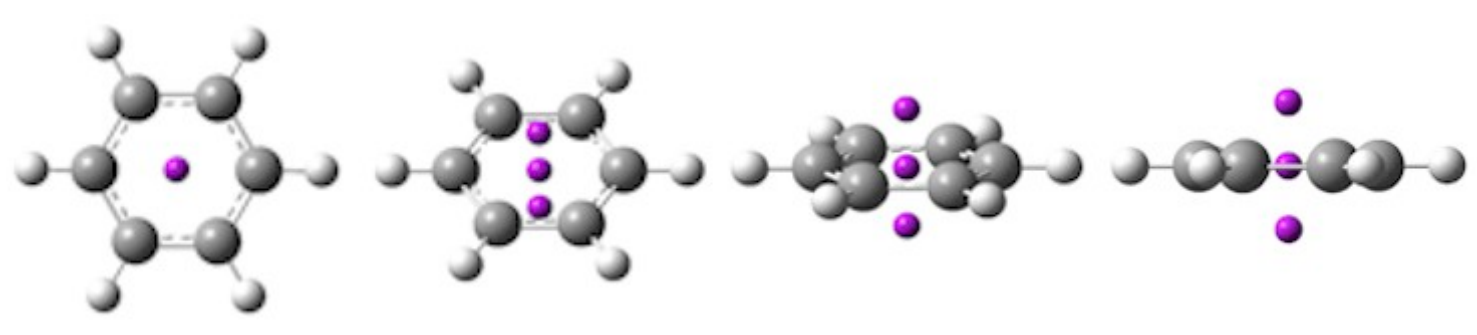

Figura 14: NICS do Benzeno.

Os resultados assumidos são os valores negativos destes tensores e, desta maneira, quanto mais negativos forem os valores de NICS maior a aromaticidade no anel avaliado. Atualmente, alguns autores têm recomendado a utilização dos índices localizados acima e 
abaixo do plano do anel, visto que nestes pontos os efeitos paramagnéticos das ligações $\sigma$ são menores. Na tabela 7 estão listados alguns valores de NICS.

Tabela 7: Valores de NICS para Alguns Compostos Orgânicos. ${ }^{33,12 d}$

\begin{tabular}{cccc}
\hline Compostos & NICS(-1) & NICS(0) & NICS(1) \\
\hline benzeno & $-10,60$ & $-8,80$ & $-10,60$ \\
furano & $-9,36$ & $-12,31$ & $-9,36$ \\
pirrol & $-10,60$ & $-14,86$ & $-10,60$ \\
1,3-ciclo-hexadieno & $+1,90$ & $+4,60$ & $+1,90$ \\
ciclobutadieno & $+12,70$ & $+20,80$ & $+12,70$ \\
\hline
\end{tabular}

É importante salientar que o critério NICS, apesar das críticas que tem recebido, é um critério bastante útil e de fácil computação. Ao contrário de muitos outros métodos que requerem cálculos adicionais, equações termoquímicas, dentre outras, o método NICS é direto. Talvez a maior dificuldade seja adequar o modelo quântico que descreva corretamente o sistema, principalmente para o cálculo de tensores.

\section{Métodos Computacionais e Conjunto de Funções de Base - Os Modelos Quânticos.}

Até agora foram mencionados em vários pontos do texto os termos métodos computacionais e conjunto de funções de base, geralmente representados por simbologias como B3LYP/6-31+G(d,p). Os químicos teóricos costumam chamar de "modelos quânticos" a associação dos métodos mais o conjunto de funções de base. Na notação acima os métodos quânticos vêm localizados à esquerda e antes da barra (por exemplo, HF/....; $\mathrm{B} 3 \mathrm{LYP} / . . .$. .). Os conjuntos de funções de bases ficam localizados à direita (por exemplo, ....../6-31+G(d,p); ....../cc-pVDZ).

Pode-se definir um método quântico com sendo a maneira pela qual será resolvida a equação de onda para todo o sistema eletrônico (composto químico).

Há métodos que resolvem a equação de onda sem inclusão de valores empíricos e com aproximações de caráter matemático; estes são chamados de Ab Initio, ou seja, resolvem a função do início. O método mais conhecido é o "HF", Hartree-Fock. Este método, no entanto, tem suas limitações de cálculo, pois não inclui correlações eletrônicas.

Outros métodos são capazes de realizar estas correlações eletrônicas tais como os vários híbridos DFT (Density Functional Theory) que são métodos de cálculo provenientes da Teoria Funcional de Densidade, ${ }^{34}$ (por exemplo B3LYP, B3PW91). Há também os métodos pertubacionais (MP2, MP3...), cujo nível das correlações eletrônicas é bem mais aprimorado.

O conjunto de funções de base é a parte do cálculo que define o conjunto de orbitais que serão considerados. Basicamente pode-se dizer que são um conjunto de funções matemáticas que vão descrever os orbitais. Estas funções podem descrever orbitais s, p, d, $\mathrm{f}, \mathrm{g}, \ldots$ com gaussianas $(\mathrm{G})$ e incluindo polarizações $(\mathrm{d}, \mathrm{p})$ e difusas $(+)$. 


\section{3 - Reações Pericíclicas.}

De acordo com a IUPAC, ${ }^{1}$ uma reação pericíclica é uma reação química em que ocorre uma reorganização concertada de ligações através de um arranjo cíclico de átomos continuamente interligados. Neste processo, a reação ocorre através de um estado de transição cíclico completamente conjugado e o número de átomos no arranjo cíclico é usualmente seis, podendo conter também outro número.

Os principais tipos de reações pericíclicas são: Reações Eletrocíclicas, Reações de Cicloadição, Reações de Rearranjo Sigmatrópico, Reações Queletrópicas e as Reações do tipo "Ene".

Nas figuras a seguir serão mostrados alguns exemplos destas reações. ${ }^{35}$

\section{$\underline{\text { Reações Eletrocíclicas }}$}

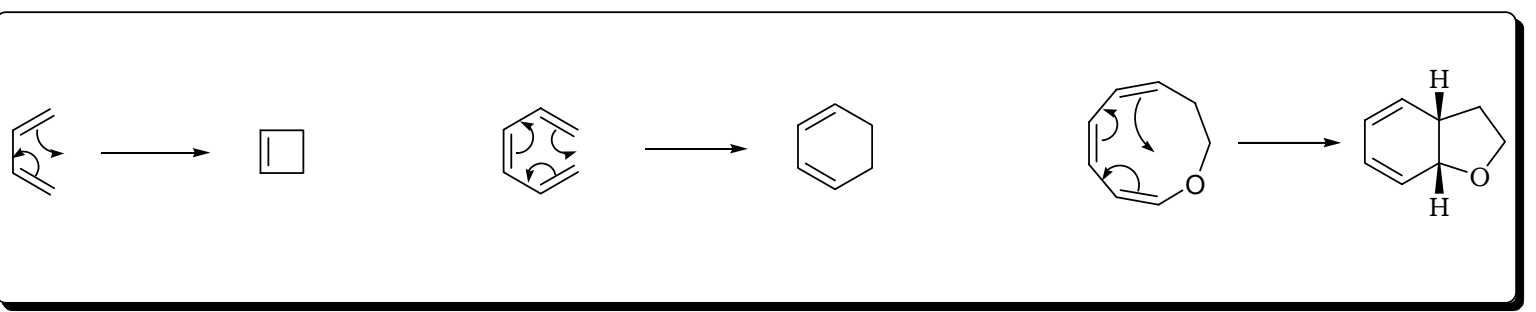

Figura 15: Exemplos de Reações Eletrocíclicas.

\section{Reações de Cicloadicão}

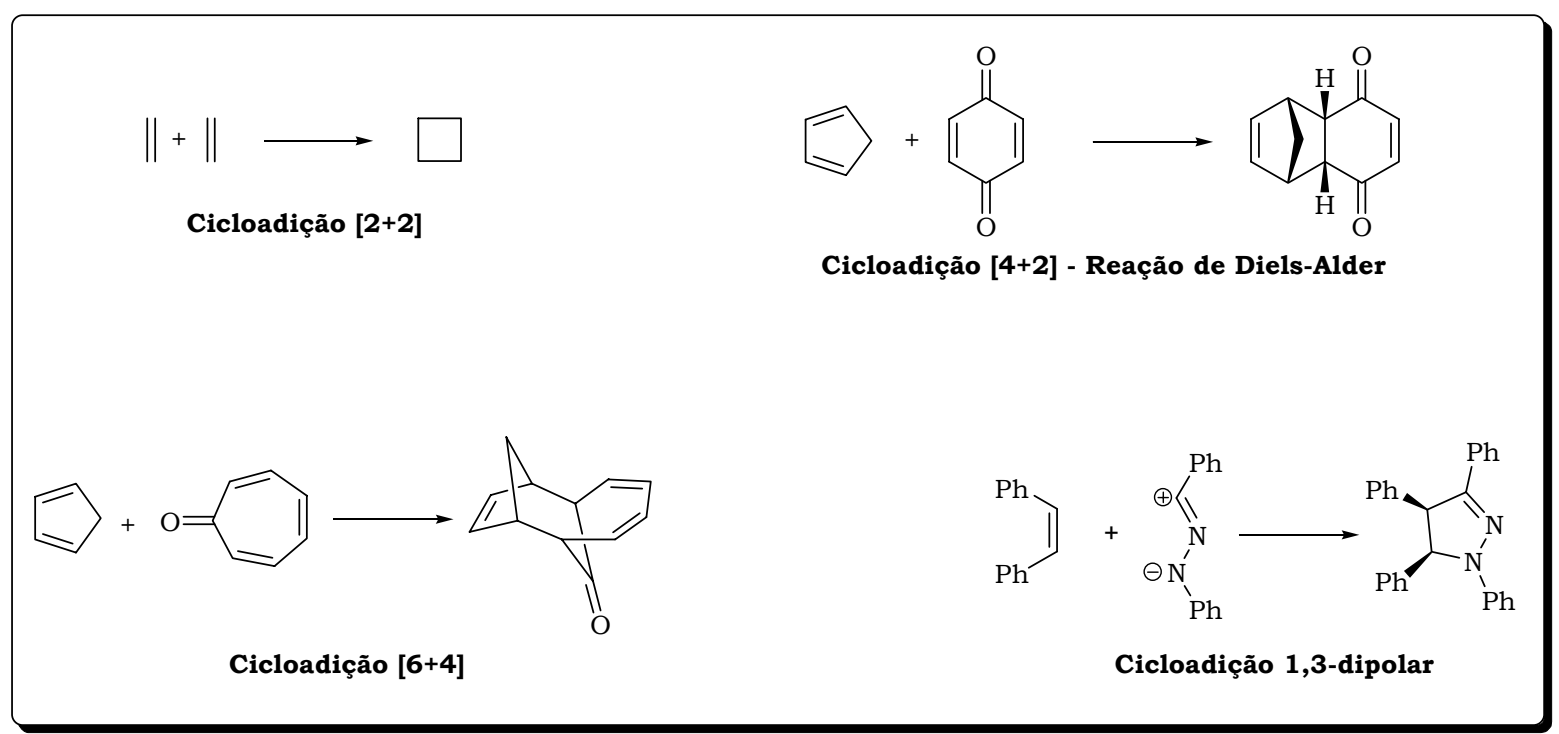

Figura 16: Exemplos de Reações de Cicloadição. 
<smiles>[R]CC=CCCCC</smiles>

Rearranjo [1,3] Sigmatrópico<smiles>[R]c1ccco1</smiles>

Rearranjo [3,3] Sigmatrópico

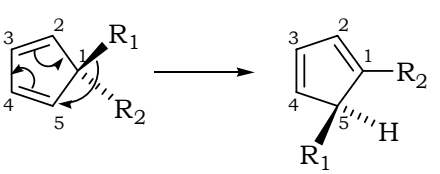

Rearranjo [1,5] Sigmatrópico

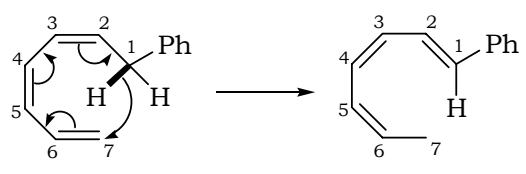

Rearranjo [1,7] Sigmatrópico

Figura 17: Exemplos de Rearranjos Sigmatrópicos.

\section{Reações Queletrópicas}

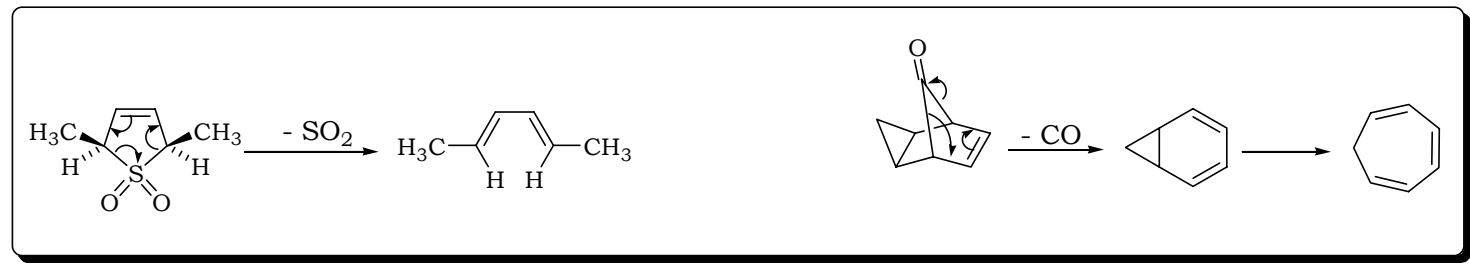

Figura 18: Exemplos de Reações Queletrópicas.

\section{Reações do Tipo "Ene"}

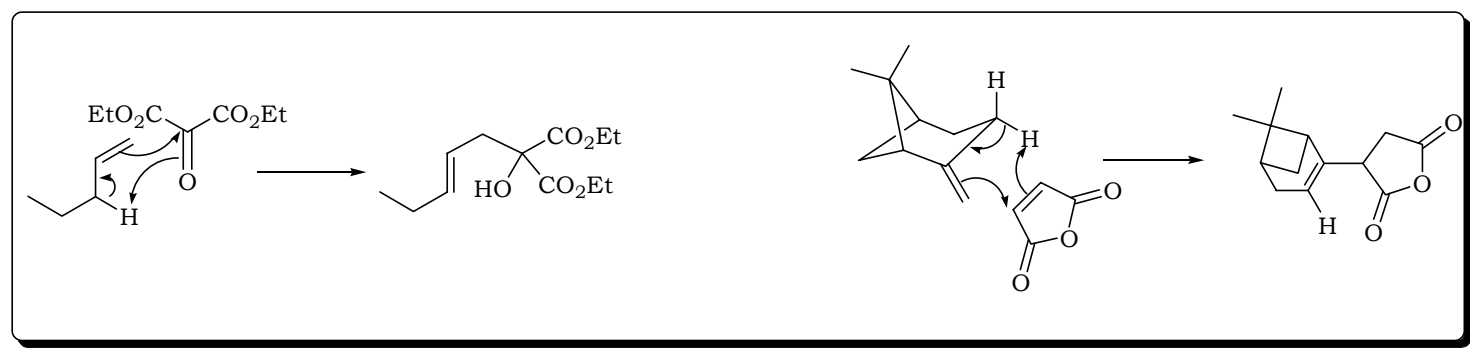

Figura 19: Exemplos de Reações do tipo "Ene".

Evidentemente que neste texto será dada uma atenção especial às reações de cicloadição, particularmente a de Diels-Alder. Serão abordados alguns aspectos como: reatividade das espécies envolvidas, efeito de catalisadores (ácidos de Lewis), estereoquímica, regioquímica e alguns aspectos teóricos. 


\section{4- A Reação de Diels-Alder. ${ }^{36}$}

Desde sua descoberta em $1928^{37}$ por Otto Diels e seu estudante Kurt Alder, a reação de Diels-Alder vem se destacando como uma das reações mais empregadas na síntese orgânica. ${ }^{i}$ Esta reação reúne características de grande valor para química sintética, como o fato de ser essencialmente estereoseletiva e de possibilitar, nas suas versões intermolecular e intra-molecular, a síntese de estruturas de grande complexidade. Um outro aspecto marcante da reação de Diels-Alder é a questão da "economia de átomos", ou seja, durante o processo reacional, independente da natureza da reação (inter ou intramolecular), não há perda de átomos ou de grupos funcionais. Em sua publicação original, ${ }^{37}$ os autores Diels e Alder pareciam prever a revolução que seus estudos trariam para a química sintética, tanto que afirmaram com propriedade: ${ }^{38}$ “... Our results will play a role only in the discussion of theoretically interesting questions, for example, the relationships of strain in policiclic systems, but probably also will yield greater significance in a practical sense. Thus it appears to us that the possibility of synthesis of complex compounds related to or identical with natural products such as terpenes, sesquiterpenes, perhaps even alkaloids, has been moved to the near prospect..."

A primeira reação publicada pelos seus descobridores envolvia dois compostos relativamente simples, o ciclopentadieno (43) e a benzoquinona (44). Segundo os autores, foram isolados dois produtos: o aduto 45 e o bis-aduto 46 .

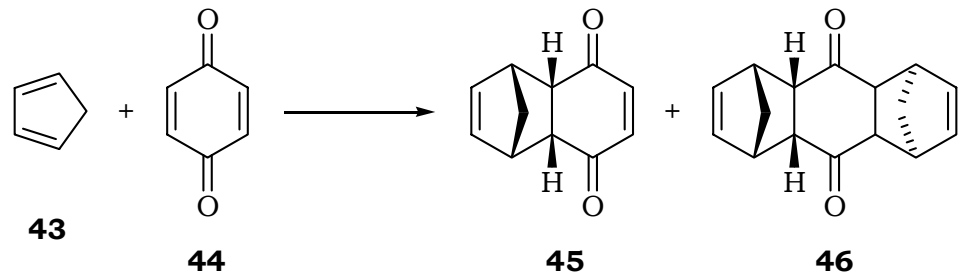

Esquema 9: Os primeiros Adutos isolados por Diels e Alder.

Os compostos que participam da reação de Diels-Alder, normalmente são chamados de dieno e dienófilo; a espécie que contribui com dois pares de elétrons $\pi$ durante a reação é o dieno e a que participa com apenas um par de elétrons $\pi$ o dienófilo.

Um ponto contraditório e até surpreendente é o grande intervalo entre o comunicado da existência da reação de Diels-Alder ${ }^{\text {ii }}$ e a primeira síntese total envolvendo uma reação deste tipo (1951)..$^{39}$ Alguns autores modernos atribuem este intervalo de tempo ao caráter da própria pesquisa realizada por Diels e por Alder e ao empenho destes autores em estudar a reação mais a fundo para então dominar suas características e particularidades. Isto fica bastante evidente quando alguns anos depois da publicação original, Alder publica uma seqüência de trabalhos experimentais que fundamentavam o que hoje conhecemos como "Regra de Alder" ou Regra de Adição "endo". ${ }^{40}$ Um outro motivo a ser destacado é o contexto político e científico vivido na Alemanha nas décadas

\footnotetext{
'Desde sua descoberta foram publicados mais de 28.700 trabalhos envolvendo o termo "Diels-Alder". Somente nos últimos dois anos (2004-2005) foram publicados 2.281trabalhos, o que equivale a mais de 3 trabalhos por dia! Fonte: SciFinder Scholar 2006.

ii A reação de Diels-Alder também era conhecida como "diene synthesis" principalmente antes dos autores ganharem o Prêmio Nobel em 1950.
} 
de 1930 e 1940. Seguramente esta "lacuna" tem origens no atraso imposto pelo regime político da época. Há uma frase dita pelos próprios autores Diels e Alder que mostra bem $\mathrm{o}$ interesse em não perderem a autoridade com relação à reação que descobriram. ${ }^{38}$... "We explicit reserve for ourselves the application of the reaction developed by us to the solution of such problems"...

Um momento inevitável de divulgação e reconhecimento dos trabalhos de Diels e Alder foi a indicação e a conquista do Prêmio Nobel em 1950. A partir deste ano começaram a aparecer muitos trabalhos envolvendo não somente a reação de DielsAlder, mas reações pericíclicas em geral.

A primeira síntese de um produto natural envolvendo a reação de Diels-Alder foi a síntese da cantaridina (55) publicada em 1951 por Stork e colaboradores (esquema 10). ${ }^{39}$

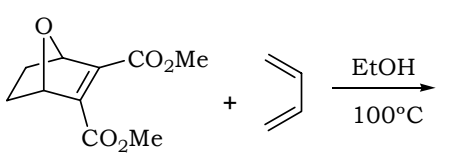

47

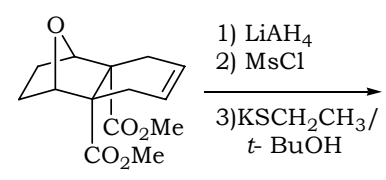

49

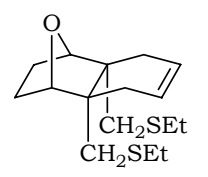

50

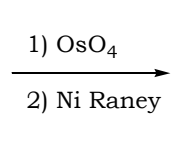<smiles>OC1CC2CCC(C1)C(O)C2</smiles>

51

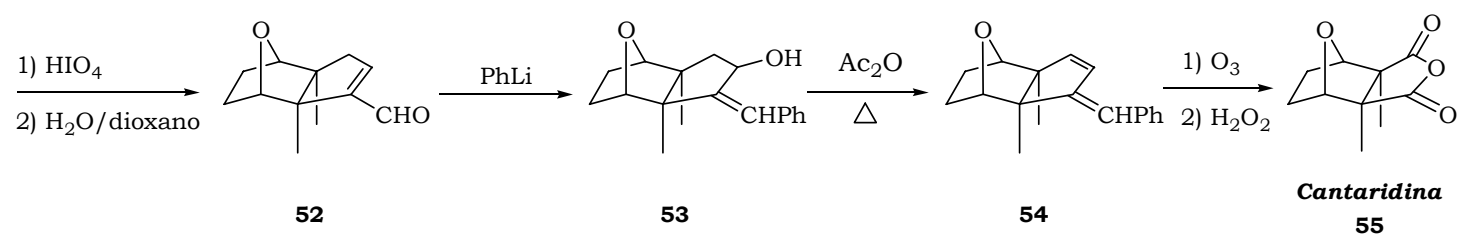

Esquema 10: Primeira Sintese da Cantaridina.

No ano seguinte a esta publicação, Gates e Tschudi publicaram a síntese da morfina (60) onde em uma das etapas sintéticas foi empregada a reação de Diels-Alder ou a "diene synthesis", como se referem os autores na literatura original. ${ }^{41}$

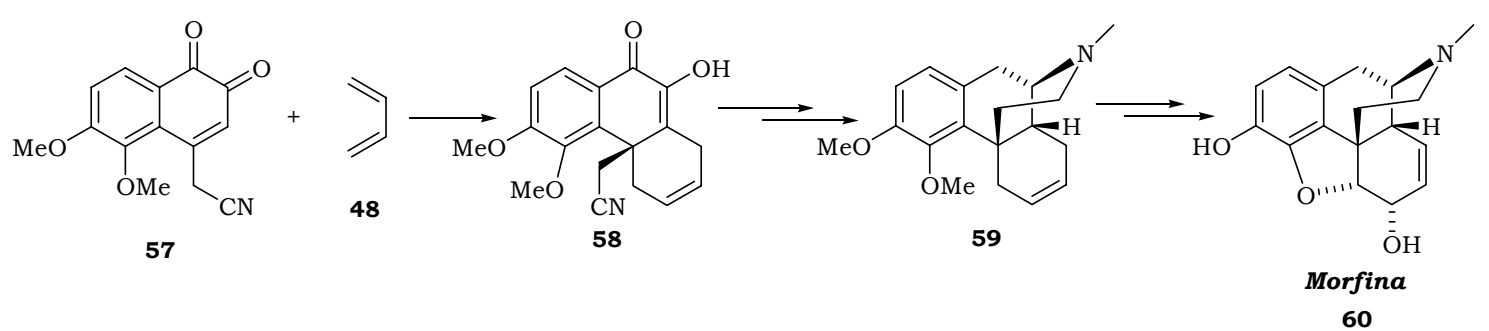

Esquema 11: Sintese da Morfina Utilizando a Reação de Diels-Alder.

No entanto, a síntese mais importante da época, e que envolvia a reação de DielsAlder, foi a síntese dos esteróides cortisona (65) e colesterol (66), realizada por Woodward e colaboradores. ${ }^{42}$ Nesta síntese foram abandonados alguns procedimentos e rotas sintéticas históricas de preparação destes esteróides, e empregada logo na "primeira etapa”, uma reação de Diels-Alder com uma quinona (esquema 12). 


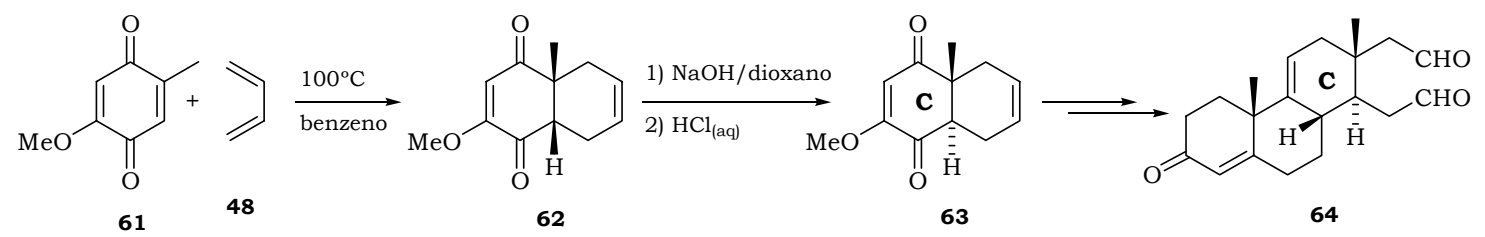

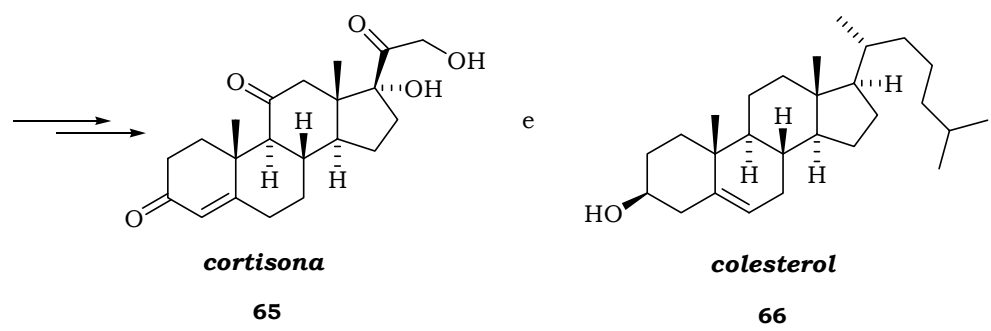

Esquema 12: Sintese da Cortisona e do Colesterol Utilizando a Reação de Diels-Alder.

A partir deste momento a reação de Diels-Alder ganhava não somente mais notoriedade, mas se firmava como uma das ferramentas sintéticas mais promissoras da química orgânica. Lamentavelmente foi durante o auge da aplicação desta reação e de algumas outras descobertas, que ocorreu a morte de seus descobridores (Otto Diels em 1952 e Kurt Alder em 1958).

A seguir serão descritos os principais aspectos da Reação de Diels-Alder dando ênfase a temas como estereoquímica, regioquímica, ativação dos dienos e dienófilos, catálise por ácidos de Lewis, dos aspectos teóricos envolvidos, e de outros detalhes. É preciso ressaltar que não se pretende realizar uma revisão completa sobre o assunto, mas abordar alguns aspectos às vezes esquecidos em alguns textos, e dar uma visão geral sobre cada ponto.

\section{Aspectos Gerais, Estereoquímica e Regioquímica.}

Como já mencionado, as duas espécies químicas envolvidas na reação de DielsAlder são os dienos e dienófilos. Classicamente poderíamos representar uma reação de Diels-Alder pela reação entre o butadieno (48) e o eteno (67). No processo reacional são desfeitas três ligações do tipo $\pi$ e formadas duas ligações do tipo $\sigma$ e uma nova ligação $\pi$.

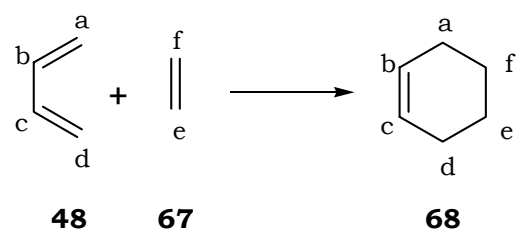

Esquema 13: Reação de Diels-Alder

Do ponto de vista energético, a reação de Diels-Alder ocorre com uma variação não muito alta de energia. Se considerarmos apenas a variação de entalpia $(\Delta H)$, proveniente da quebra e formação das ligações, será obtido um valor em torno de 30-40 $\mathrm{kcal} / \mathrm{mol}$, sendo que, geralmente, os produtos possuem um conteúdo menor de energia que os reagentes. ${ }^{43}$ Há, no entanto, situações onde a presença de determinados substituintes pode reverter esta situação. 
Com relação à variação de entropia, pode-se dizer que, pelo próprio aspecto da reação de Diels-Alder, ela deve a exercer uma importância significativa nos valores absolutos das grandezas cinéticas e termodinâmicas destas reações $(\Delta \mathrm{G}=\Delta \mathrm{H}-\mathrm{T} . \Delta \mathrm{S})$. No caso das entropias molares de ativação $\left(\Delta S^{\ddagger}\right)$ são registrados na literatura, ${ }^{43}$ valores que oscilam pouco de uma reação para outra (entre -29 e $\left.-38 \mathrm{cal} \cdot \mathrm{K}^{-1} \cdot \mathrm{mol}^{-1}\right)$. Note que estes valores estão em calorias.

Porém, pelo fato dos valores $\left(\Delta S^{\ddagger}\right)$ não variarem substancialmente de uma reação para outra, e de que em uma mesma reação, são esperados valores muito próximos para os estados transição de um isômero e outro (endo e exo), pode-se, em princípio, não considerar este termo na previsão da reatividade (cálculo das energias de ativação das reações de Diels-Alder). Evidentemente que estas são aproximações às vezes perigosas, e podem levar a erros quando o assunto é comparar pequenas diferenças de reatividade $\left(\Delta \mathrm{G}^{\ddagger}\right)$ entre dienos e dienófilos. No que diz respeito ao cálculo destas grandezas cinéticas e também das termodinâmicas, grande parte dos trabalhos da literatura considera apenas as variações de entalpia (tanto de ativação quanto de reação) e parece ou se esquecer ou não dar tanta importância à entropia. Em outros trabalhos, são consideradas apenas as energias eletrônicas dos compostos ignorando efeitos como temperatura e solvatação.

De uma maneira geral, a diferença de energia entre os reagentes e produtos (calor da reação), não é muito alta nas reações de Diels-Alder e as energias de ativação $\left(\Delta \mathrm{E}^{\ddagger}\right)$ também não costumam ser elevadas (oscilam em torno de $20 \mathrm{kcal} / \mathrm{mol}$ ). ${ }^{43}$ Isto permite que haja em várias circunstâncias, o acúmulo do produto termodinâmico da reação (processo reversível). Na reação de Diels-Alder são esperados dois tipos de produtos: o produto endo (geralmente o cinético) e o produto exo (geralmente o termodinâmico).

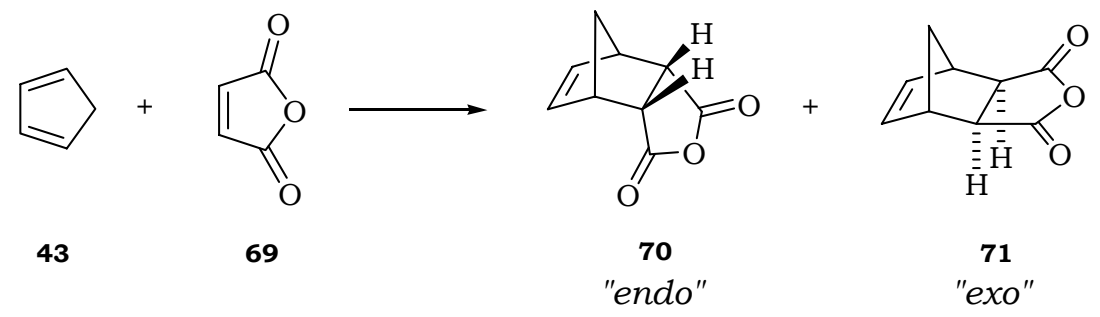

Esquema 14: Adutos de Diels-Alder Endo e Exo.

Em algumas situações é possível obter uma seletividade bem acentuada ou até a formação de um único produto. Este aspecto interessante da reação de Diels-Alder é explicado pela Regra de Adição Endo, mais conhecida como Regra de Alder.

Nos seus estudos, Alder $^{40}$ mostrou que quando alguns grupos presentes no dienófilo interagem com os elétrons $\pi$ do dieno, o estado de transição para a formação do produto endo, fica mais estabilizado, favorecendo a sua formação (produto cinético). Portanto, a Regra de Alder diz que o produto endo deve predominar, mas só quando a reação é controlada cinéticamente.

A estabilização que favorece o produto endo é proveniente da superposição de orbitais $\pi$ do dieno e do dienófilo. Consideram-se não apenas os orbitais $\pi$ diretamente envolvidos na reação, mas também aqueles dos grupos ligados ao dienófilo. Esta estabilização "extra" de energia é conferida pela superposição de orbitais $\pi$ dos grupos ligados ao dienófilo com os orbitais $\pi$ do dieno, e atualmente é denominada como Estabilização Orbitalar Secundária (figura 20). ${ }^{44,46}$ 


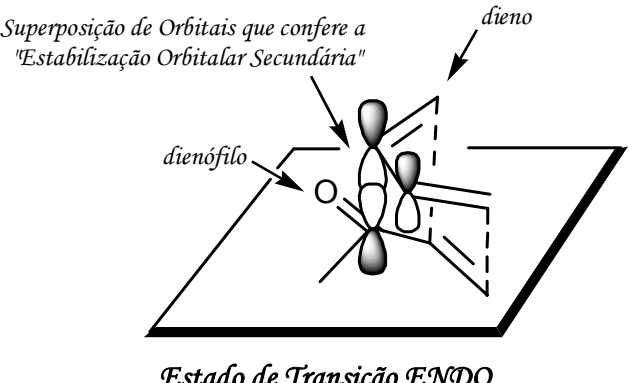

Estado de Transição ENDO

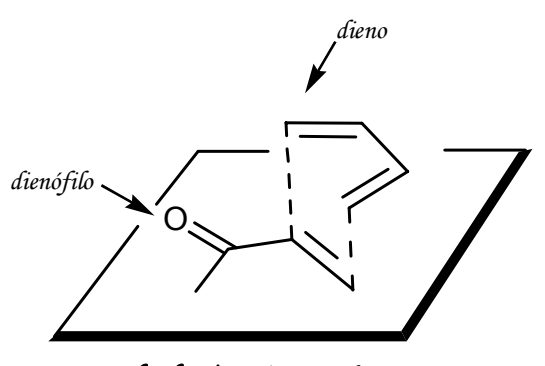

Estado de Transição EXO

Figura 20: Estados de Transição Endo e Exo nas Reações de Diels-Alder.

Pela observação dos estados de transição das reações de Diels-Alder é possível deduzir outro aspecto importante desta reação; o Princípio da Adição Cis.

Este princípio refere-se à configuração relativa dos grupos que pertenciam originalmente ao dienófilo, ou dos grupos que faziam parte do dieno. Pode-se dizer que, durante a ocorrência da reação, as duas ligações são formadas do mesmo lado do plano das duplas ligações, tanto do dieno quanto do dienófilo (figura 21).

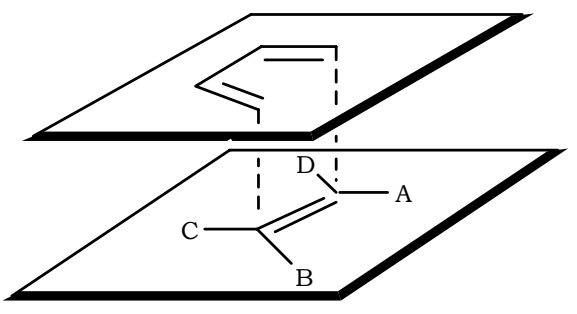

Figura 21: Adição Cis entre um Dieno e um Dienófilo.

Sendo assim, os substituintes que se encontrem em relação cis no dienófilo (A e B, figura 22) vão guardar essa mesma relação cis no produto. Aqueles que estiverem em relação trans (A e C, por exemplo) também estarão em relação trans no produto.
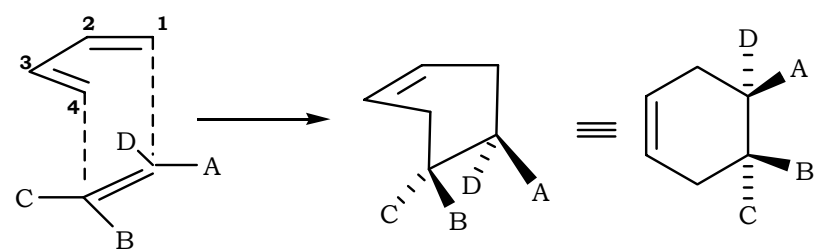

Figura 22: Estereoquímica dos Substituintes do Dienófilo. 
Considerando agora os substituintes nas posições 1 e 4 de um dieno na forma cisóide (figura 23), pode-se observar que quando ambos se encontram em cis (sempre comparando o substituinte de uma dupla com a outra dupla ligação) eles estarão em relação cis no produto (por exemplo, os substituintes $\mathrm{X}$ e $\mathrm{Y}$ da figura 23). Para os substituintes que estiverem em trans ( $\mathrm{Z}$ e W), a relação entre eles no produto final também será cis.

Se um dos substituintes estiver em cis (D) e outro em trans (E) a relação entre eles no produto será trans (figura 23).
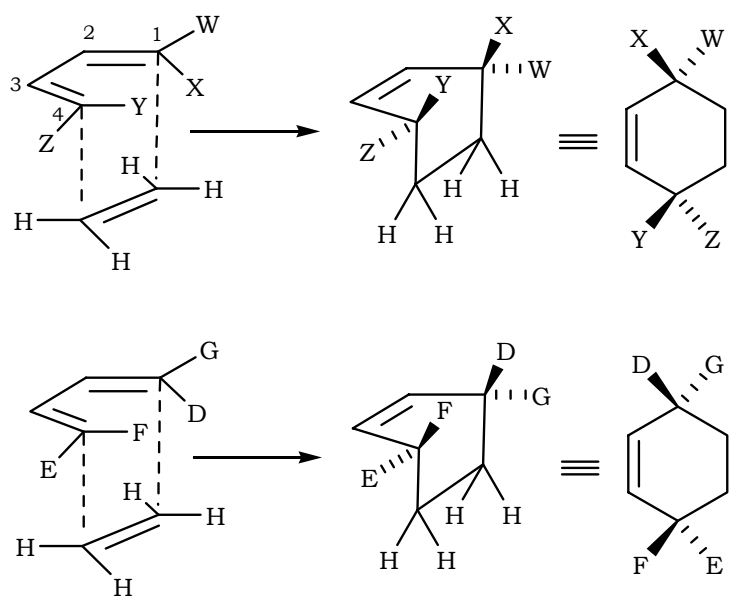

Figura 23: Estereoquimica dos Substituintes do Dieno.

De uma maneira geral, a reação de Diels-Alder além de ser considerada altamente estereoseletiva, é também estereoespecífica, pelo fato de que a cicloadição sempre ocorre em cis (Princípio da Adição Cis).

Um outro aspecto interessante é quando uma reação de Diels-Alder já estereoseletiva, também apresenta regioseletividade. Na figura 24 contém um exemplo onde são possíveis quatro isômeros 74-77, sendo que dois são obtidos preferencialmente (endo-orto e exo-orto). 


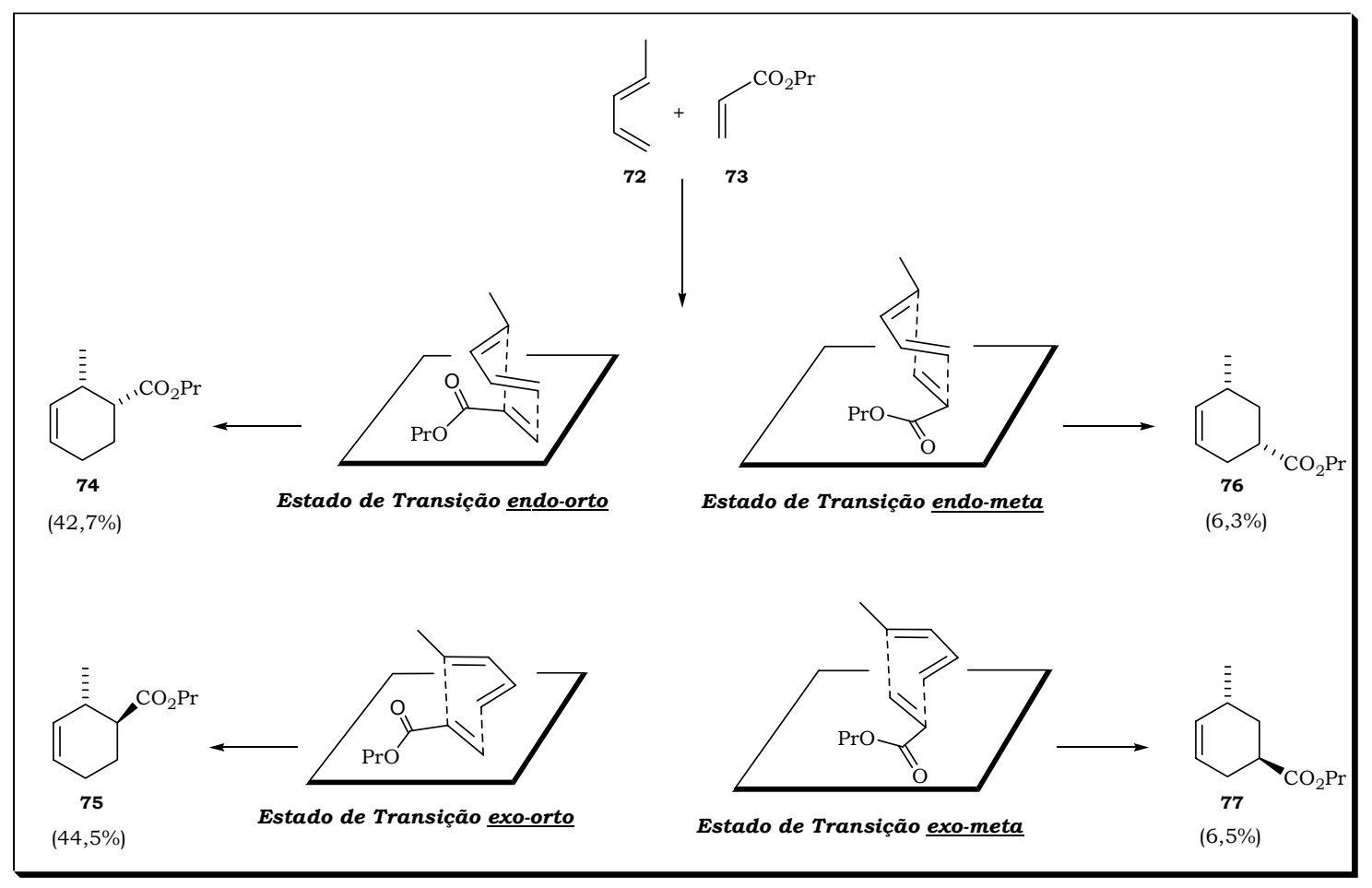

Figura 24: Estados de Transição Envolvendo Estereoseletividade e Regioseletividade.

A estereoseletividade é altamente influenciada pelos efeitos estéricos (Impedimento Estérico) e eletrônicos (Estabilização Orbitalar Secundária) já a regioseletividade é influenciada principalmente pela Simetria dos Orbitais de Fronteira. ${ }^{45}$

Segundo as Teorias Quânticas, uma ligação química entre átomos será mais facilmente formada quando os orbitais envolvidos estiverem em fase e quanto maior for a superposição entre eles. Desta maneira, pode-se dizer que a regioquímica das reações de Diels-Alder pode ser controlada com a variação dos tipos de substituintes dos dienos e dienófilos, e com a posição destes substituintes. Na figura 25 é mostrado em que circunstância um determinado regioisômero é favorecido. Estes dados podem ser confirmados tanto experimentalmente quanto pelos coeficientes dos Orbitais de Fronteira HOMO e LUMO (HOMO-Highest Occupied Molecular Orbital; LUMO-Lowest Unoccupied Molecular Orbital) das espécies envolvidas.

Nota-se nos casos I e II (figura 25), que independentemente da natureza dos grupos substituintes (doadores ou captores de elétrons), o produto favorecido é o de Orientação "orto". Para os casos III e IV são favorecidos os produtos de Orientação "para". No entanto, a natureza destes substituintes pode variar a proporção dos produtos, e em "casos extremos" (de grande impedimento estérico), pode predominar o isômero geralmente menos favorecido. Há também uma variação significativa nestas seletividades se forem variadas a temperatura do sistema reacional, a pressão (condições de alta pressão), ou se as reações forem realizadas sob catálise ácida (ácidos de Lewis). descritos. ${ }^{46,47}$

$\mathrm{Na}$ figura 26 constam alguns exemplos dos aspectos de regioseletividade aqui 


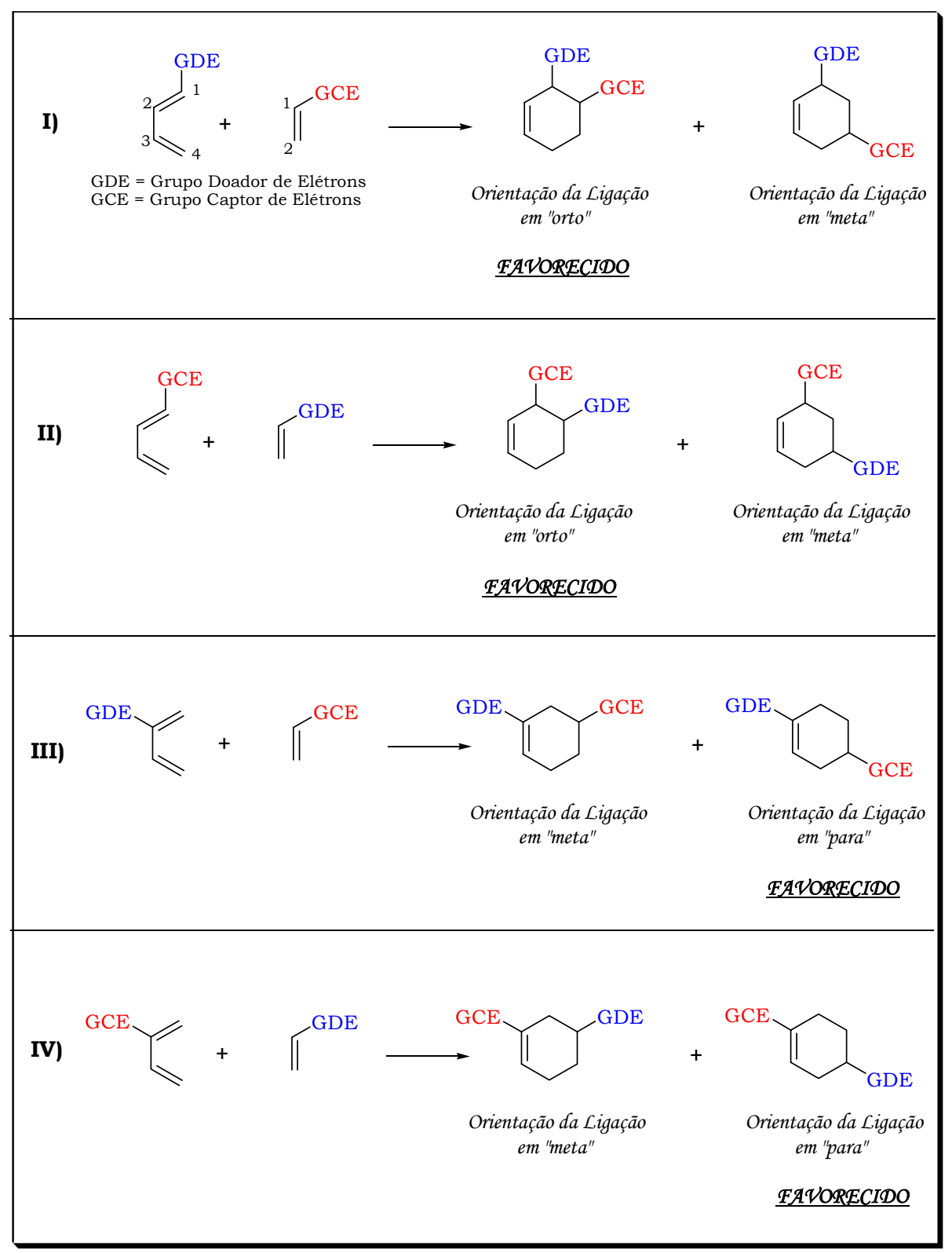

Figura 25: Regioquimica na Reação de Diels-Alder. 


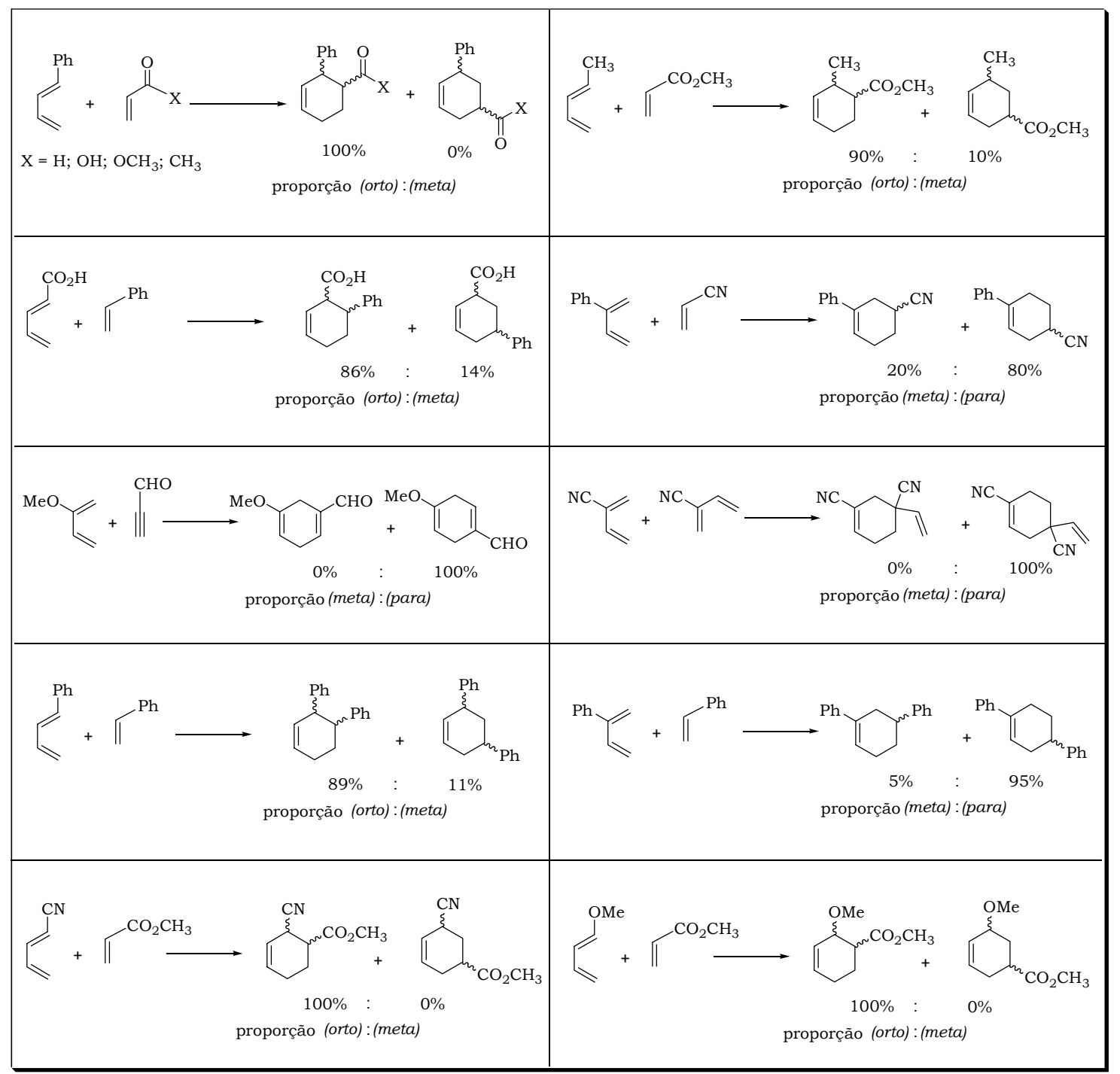

Figura 26: Exemplos de Reações de Diels-Alder Regioseletivas. ${ }^{46,47}$

Um exemplo dos valores dos coeficientes de orbitais $\mathrm{HOMO}_{\text {dieno }}-\mathrm{LUMO}_{\text {dienófilo, }}$, pode ser visto na figura 27. Também são mostradas as superfícies dos orbitais de fronteira indicando a regioquímica favorável.

De uma maneira geral dienos com grupos doadores de elétrons em $\mathrm{C}_{1}$ (caso I figura 25) torna o coeficiente em $\mathrm{C}_{4}$ maior o que faz com que a regioquímica favorecida seja a de junção "orto", já que o coeficiente maior no LUMO do dienófilo (substituído com grupos captores de elétrons) se localiza em $\mathrm{C}_{2}$. A presença de grupos captores de elétrons em $\mathrm{C}_{1}$ do dieno modifica significativamente a energia dos orbitais de fronteira, mas não faz variar significativamente os valores dos coeficientes de orbitais, de modo a não alterar as tendências de regioquímica.

Quando os grupos doadores de elétrons (GDE) se encontram em $\mathrm{C}_{2}$ no dieno o maior coeficiente de $\mathrm{HOMO}$ deste dieno está localizado em $\mathrm{C}_{1}$, favorecendo a junção em "para".

Algumas reações menos típicas também são relatadas onde ambos (dieno e dienófilo) estão substituídos por grupos apenas doadores ou apenas captores de elétrons. 
Mesmo assim as tendências de regioseletividade (orientação orto-meta e meta-para) continuam valendo, variando apenas as velocidades com que as reações se processam.

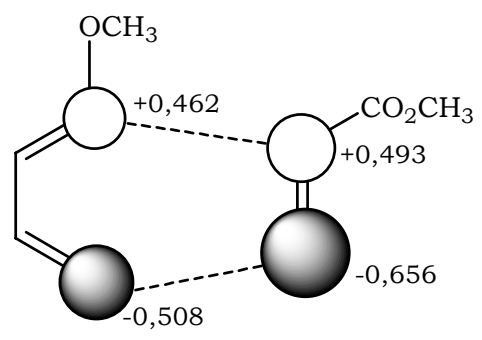

HOMO - LUMO

"Orto" (Favorecida)

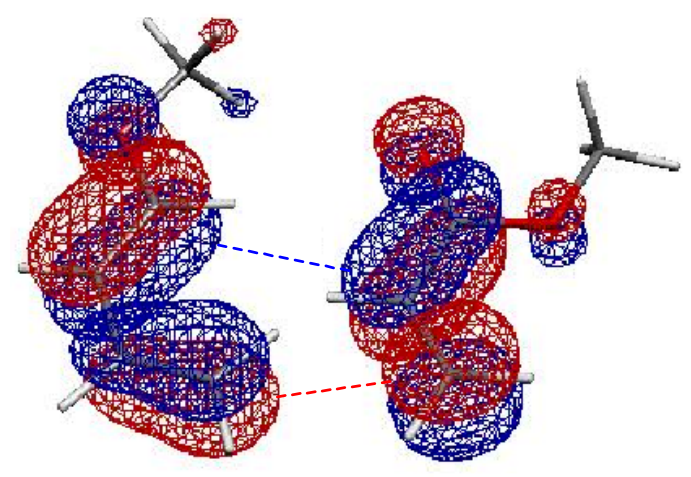

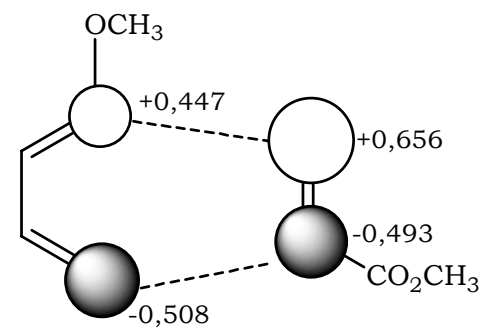

HOMO - LUMO

"Meta" (Menos Favorecida)

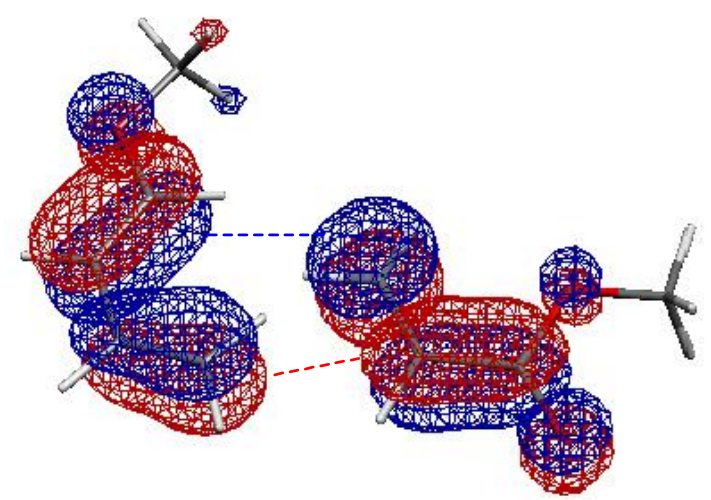

Figura 27: Coeficientes de Orbitais de Fronteira e Superfícies Moleculares destes Orbitais (método PM3).

\section{$\underline{\text { Reatividade. }}$}

A reação de Diels-Alder pode ser favorecida quando dienos e dienófilos se encontram devidamente ativados. Esta ativação pode ocorrer quando substituintes com caráter doador de elétrons (GDE) estão ligados ao dieno e substituintes com caráter captor de elétrons (GCE) estão ligados ao dienófilo. Nesta circunstancia diz-se que a reação ocorre com "Demanda Normal de Elétrons" e segundo a teoria de orbitais moleculares, as energias dos Orbitais de Fronteira (HOMO e LUMO) são alteradas; há um aumento da energia de HOMO do dieno e uma diminuição da energia de LUMO do dienófilo, diminuindo assim o "gap" de energia entre os orbitais das espécies envolvidas. Uma conseqüência direta disto é que as energias dos Estados de Transição também são diminuídas, favorecendo a ocorrência da reação.

Outras reações de Diels-Alder podem ser favorecidas e ocorrer com "Demanda Inversa de Elétrons". Nesta circunstância o dieno encontra-se substituído com grupos captores de elétrons (GCE) e o dienófilo com grupos doadores de elétrons (GDE); neste caso o "gap" de energia entre o $\mathrm{LUMO}_{\text {dieno }}-\mathrm{HOMO}_{\text {dienófilo }}$ é menor.

Do ponto de vista das energias dos Orbitais de Fronteira, é possível classificar facilmente se uma reação de Diels-Alder ocorre com demanda direta ou inversa de elétrons. Basta calcular as energias dos FMO das estruturas em questão e então efetuar a 
diferença entre as energias do $\left(\mathrm{HOMO}_{\text {dieno }}-\mathrm{LUMO}_{\text {dienófilo }}\right)$ e do $\left(\mathrm{LUMO}_{\text {dieno }}\right.$ $\mathrm{HOMO}_{\text {dienófilo }}$ ). A combinação de menor "gap" de energia será a mais favorecida. Será considerada com Demanda Normal de Elétrons aquela cujo "gap" é menor em $\left(\mathrm{HOMO}_{\text {dieno }}\right.$

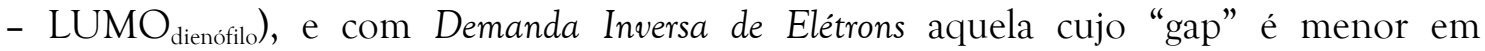
$\left(\mathrm{LUMO}_{\text {dieno }}-\mathrm{HOMO}_{\text {dienófilo }}\right)$. Na situação onde os grupos substituintes do dieno e dienófilo são apenas doadores de elétrons ou apenas captores de elétrons, a reação pode ocorrer com Demanda Normal ou Inversa de Elétrons. ${ }^{46}$

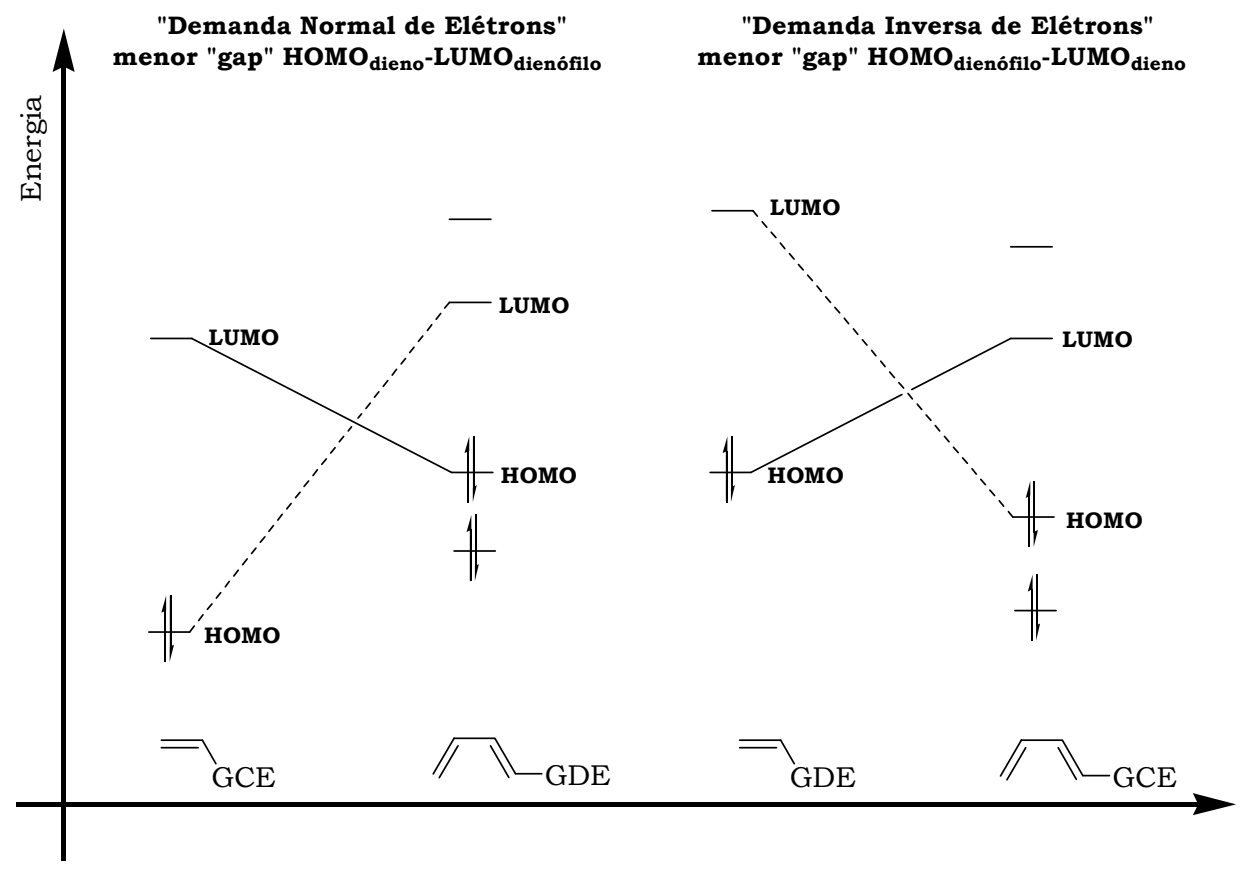

Figura 28: Demanda Eletrônica em Algumas Reações de Diels-Alder.

As energias dos Orbitais de Fronteira são extremamente úteis na previsão da reatividade nas reações de Diels-Alder. Porém, atualmente, têm sido utilizados alguns parâmetros de reatividade derivados da Teoria Funcional de Densidade (DFT), ${ }^{34}$ que segundo alguns autores como Contreras e colaboradores, ${ }^{48}$ descrevem melhor as propriedades eletrônicas dos compostos.

Estes autores utilizam como índice de reatividade as propriedades globais como o potencial químico eletrônico $\left(\mu \approx\left(\mathrm{E}_{\mathrm{HOMO}}+\mathrm{E}_{\mathrm{LUMO}}\right) / 2\right)$, a dureza química $\left(\eta \approx \mathrm{E}_{\mathrm{LUMO}}-\right.$ $\left.E_{\text {Hомо }}\right)$ e a eletrofilicidade global $\left(\omega=\mu^{2} / 2 \eta\right)$. A eletrofilicidade global $(\omega)$ pode ser entendida como sendo uma medida do quanto um dienófilo está propenso a adquirir uma carga adicional (aproximação do sistema doador $\pi$ ), durante a formação do estado de transição. Um bom dienófilo é então caracterizado por um alto valor de $\omega$, e consequentemente um alto valor de $\mu$ (em módulo) e baixo valor de $\eta$. Na tabela 8 são mostrados alguns exemplos destes valores. 
Tabela 8: Propriedades Globais de Alguns Compostos que realizam Reação de Diels-Alder

\begin{tabular}{|c|c|c|c|c|c|}
\hline Compostos & HOMO(a.u) & $\operatorname{LUMO}(\mathbf{a} \cdot \mathbf{u})$ & $\mu(\mathrm{a} . \mathrm{u})$ & $\eta(\mathbf{a} . \mathbf{u})$ & $\omega(\mathrm{eV})$ \\
\hline & $-0,2667$ & $-0,0188$ & $-0,1239$ & 0,2885 & 0,73 \\
\hline & $-0,2115$ & $-0,0099$ & $-0,1107$ & 0,2016 & 0,83 \\
\hline & $-0,2892$ & $-0,0563$ & $-0,1728$ & 0,2329 & 1,74 \\
\hline & $-0,3112$ & $-0,1037$ & $-0,2074$ & 0,2075 & 2,82 \\
\hline & $-0,3056$ & $-0,1101$ & $-0,2078$ & 0,1956 & 3,01 \\
\hline & $-0,3068$ & $-0,1126$ & $-0,2097$ & 0,1942 & 3,08 \\
\hline $\mathrm{CN}$ & $-0,3231$ & $-0,1497$ & $-0,2364$ & 0,1734 & 4,38 \\
\hline $\mathrm{NC}^{\prime}$ & $-0,3351$ & $-0,1823$ & $-0,2587$ & 0,1528 & 5,96 \\
\hline
\end{tabular}

Estes parâmetros, apesar de deduzidos de uma teoria baseada na densidade eletrônica, ainda consideram apenas os efeitos eletrônicos locais, e não são "capazes” de levar em conta os efeitos espaciais, muito importantes em se tratando das reações de Diels-Alder. Uma maneira de contornar estas "falhas" obtidas nas previsões de reatividade (tanto pelo "gap" de energia (HOMO-LUMO) quanto pelos parâmetros $\omega, \mu$ e ๆ), é localizar e calcular as energias dos Estados de Transição dos compostos envolvidos. Neste sentido, a reação de Diels-Alder é um excelente modelo de cálculo, dado o caráter geralmente concertado da reação.

Atualmente, inúmeros trabalhos vêm sendo publicados na literatura ${ }^{49}$ descrevendo bem a reatividade relativa entre espécies envolvidas nas reações de Diels-Alder, além de aspectos como regioseletividade e estereoseletividade. Os exemplos a seguir foram extraídos do trabalho Cayzer e colaboradores. ${ }^{50}$ Neste caso, foram escolhidas duas reações de Diels-Alder Intramoleculares, cujas proporções endo:exo dos adutos formados variam drasticamente e foram descritas pelos cálculos teóricos realizados. Os exemplos aqui destacados fazem parte de um conjunto de muitos outros, conforme pode ser verificado na literatura citada..$^{50}$

Neste trabalho foram realizados vários cálculos de localização dos estados de transição (TS) e de otimização dos respectivos materiais de partida. Juntamente com os cálculos foram realizados os experimentos reacionais com o objetivo de confrontar os resultados. Foram calculadas as energias de ativação para cada isômero (endo e exo) e os seus valores foram comparados (distribuição de Boltzmann) para que se determinasse a proporção teórica entre os produtos.

No esquema 15, são apresentadas duas das reações estudadas ${ }^{50}$ (compostos 78 e 80) onde foram obtidos os adutos $79 \mathrm{a} / 79 \mathrm{~b}$ e $81 \mathrm{a} / 81 \mathrm{~b}$. 
<smiles>C/C=C\C=C\COC(=O)/C=C/Cl</smiles>

78<smiles>C/C=C\C=C\COC(=O)/C=C/Cl</smiles>

80<smiles>C[C@H]1C=C[C@H]2COC(=O)[C@@H]2[C@H](Cl)[C@H]1[13CH3]</smiles>

endo<smiles>C[C@H]1C=C[C@H]2COC(=O)[C@H]2[C@H]1Cl</smiles>

81a exo<smiles>C[C@H]1C=C[C@H]2COC(=O)[C@@H]2[C@H]1Cl</smiles>

81b

Esquema 15: Reações de Diels-Alder Intramoleculares.

$\mathrm{Na}$ tabela 9 estão resumidos os resultados teóricos e experimentais e na figura 29 são apresentadas as estruturas dos estados de transição que foram localizados.

Tabela 9: Resultados Experimentais e Teóricos Obtidos para as Reações do Esquema 15.

\begin{tabular}{cccccc}
\hline $\begin{array}{c}\text { Material } \\
\text { de Partida }\end{array}$ & $\mathrm{T}^{\circ} \mathrm{C}$ & Tempo (h) & $\begin{array}{c}\text { Produtos Endo:Exo } \\
\text { (experimental) }\end{array}$ & $\begin{array}{c}\text { Produtos Endo:Exo } \\
\text { (teórica) }\end{array}$ & $\begin{array}{c}\mathrm{E}_{\text {cinética Endo:Exo }} \\
\text { (kcal/mol)(teórica) }\end{array}$ \\
\hline 78 & 180 & 40 & $18: 82$ & $10: 90$ & $38,38: 36,35$ \\
80 & 180 & 187 & $72: 28$ & $85: 15$ & $39,67: 41,25$ \\
\hline
\end{tabular}
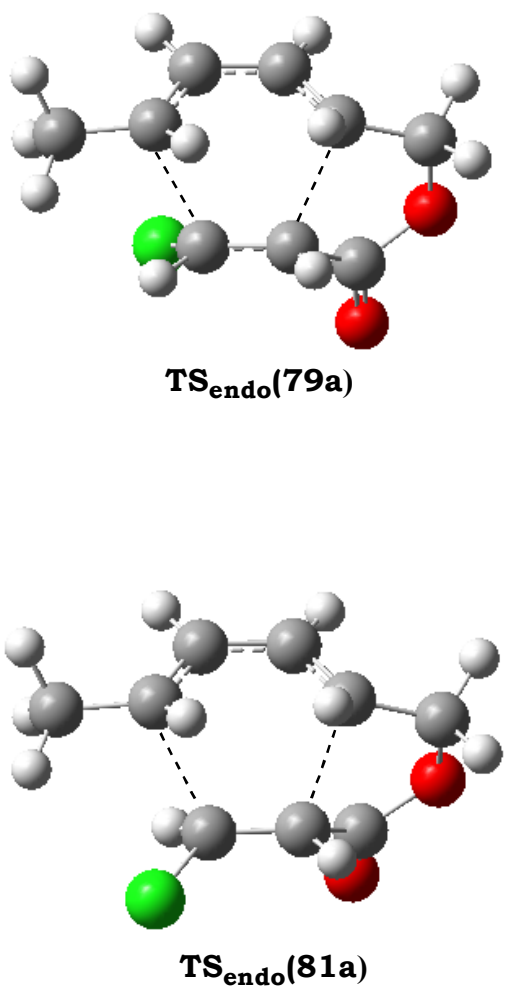
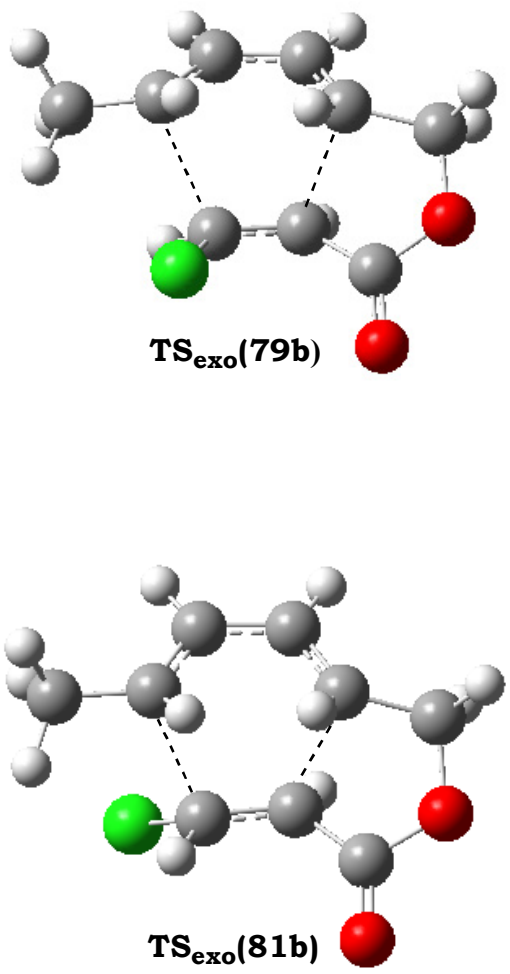

Figura 29: Estados de Transição Localizados com o Modelo B3LYP/6-31+G(d). 
Nas figuras 30 e 31 podem ser visualizadas as curvas de reação para os compostos 78 e 80 , contendo um esboço de cada espécie envolvida no processo reacional, bem como as energias relativas entre os materiais de partida e os estados de transição.

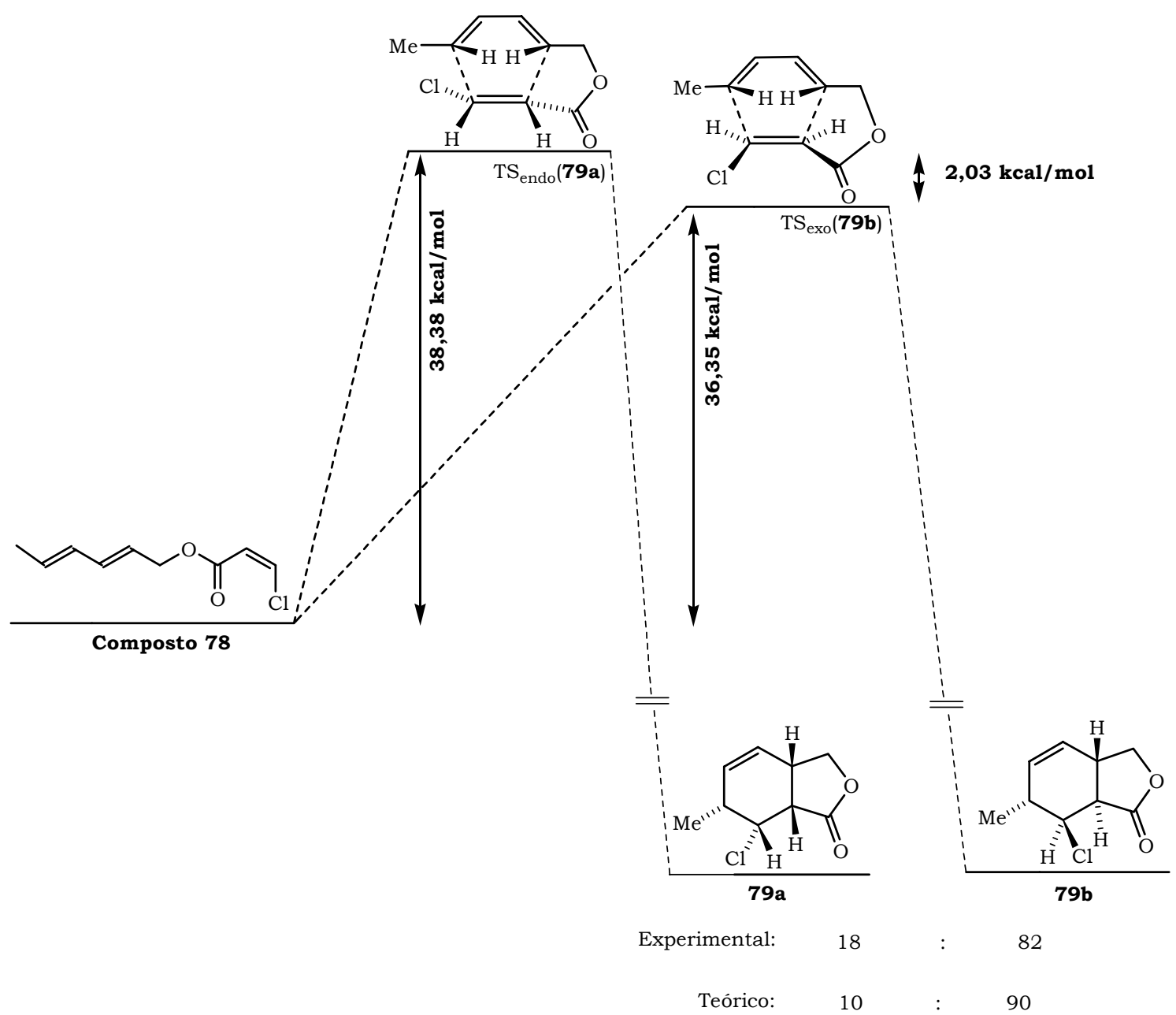

Figura 30: Curvas de Reação para o Composto 78. 


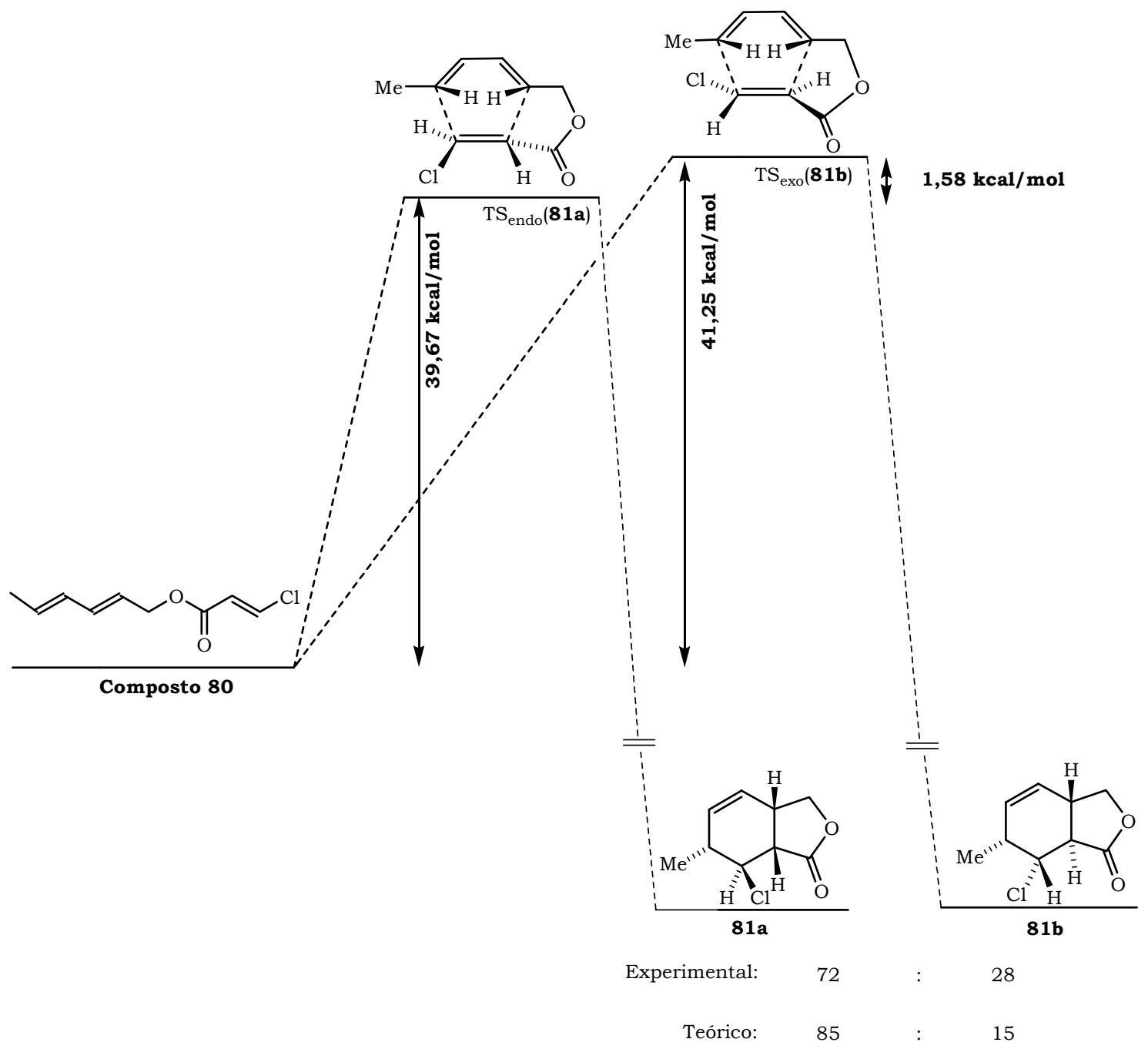

Figura 31: Curvas de Reação Para o Composto 80.

Fundamentalmente pode-se destacar o fato de que os cálculos descreveram com eficiência as proporções entre os produtos obtidos. Cabe reforçar a inversão das proporções dos adutos endo:exo pela simples mudança da estereoquímica do $\mathrm{Cl}$ nos materiais de partida, que foi descrita pelos cálculos teóricos.

\section{Catálise por Ácidos de Lewis.}

Até o início dos anos 60 (1960) acreditava-se que alguns catalisadores (como ácidos de Lewis) poderiam influenciar muito pouco a velocidade da reação de DielsAlder. Porém, com a publicação dos trabalhos de Yates e Eaton, ${ }^{51}$ vários outros pesquisadores passaram a utilizar ácidos de Lewis em reações de Diels-Alder. Atualmente, é bastante reconhecido o papel de catalisadores em reações de Diels-Alder.

Basicamente o ácido de Lewis se complexa mais fortemente com grupos como carbonila $(\mathrm{CO})$, nitrila $(\mathrm{CN})$, dentre outros, geralmente ligados ao dienófilo. Nesta circunstância, o dienófilo se torna extremamente reativo, pois é diminuída significativamente a energia do orbital LUMO. A reação entre o ciclopentadieno (43) e a ciclo-hexenona (82) constitui um exemplo interessante da ação de ácidos de Lewis. Esta reação quando realizada em condições térmicas (apenas com aquecimento) não evolui 
para a formação de nenhum dos adutos (endo e exo) esperados. Quando realizada sob catálise, a reação pode até ser $100 \%$ estereoseletiva (esquema 16). ${ }^{52}$<smiles>C1=C[CH+]C=C1</smiles>

43<smiles>CC1CCCCC1</smiles>

82<smiles>C[C@]12CCCC(=O)[C@H]1C1C=CC2C1</smiles>

83

$0 \%$

$89 \%$

$80 \%$

$100 \%$

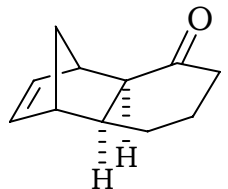

84

$0 \%$

$11 \%$

$20 \%$

$0 \%$

Esquema 16: Ação de Ácidos de Lewis em Reações de Diels-Alder. ${ }^{52,53}$

Na figura 32 é apresentado um exemplo de Orbitais de Fronteira e de suas energias relativas com e sem $\mathrm{AlCl}_{3}$. Nota-se uma redução significativa do "gap" de energia $\mathrm{HOMO}_{\text {dieno }}-\mathrm{LUMO}_{\text {dienófilo }}$ quando a reação está sob a ação deste ácido de Lewis. ${ }^{54}$

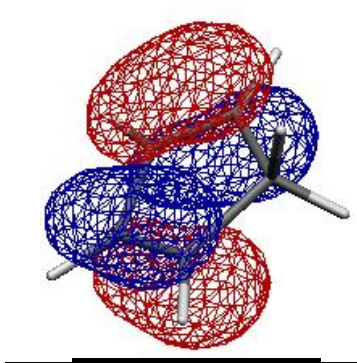

Hомо

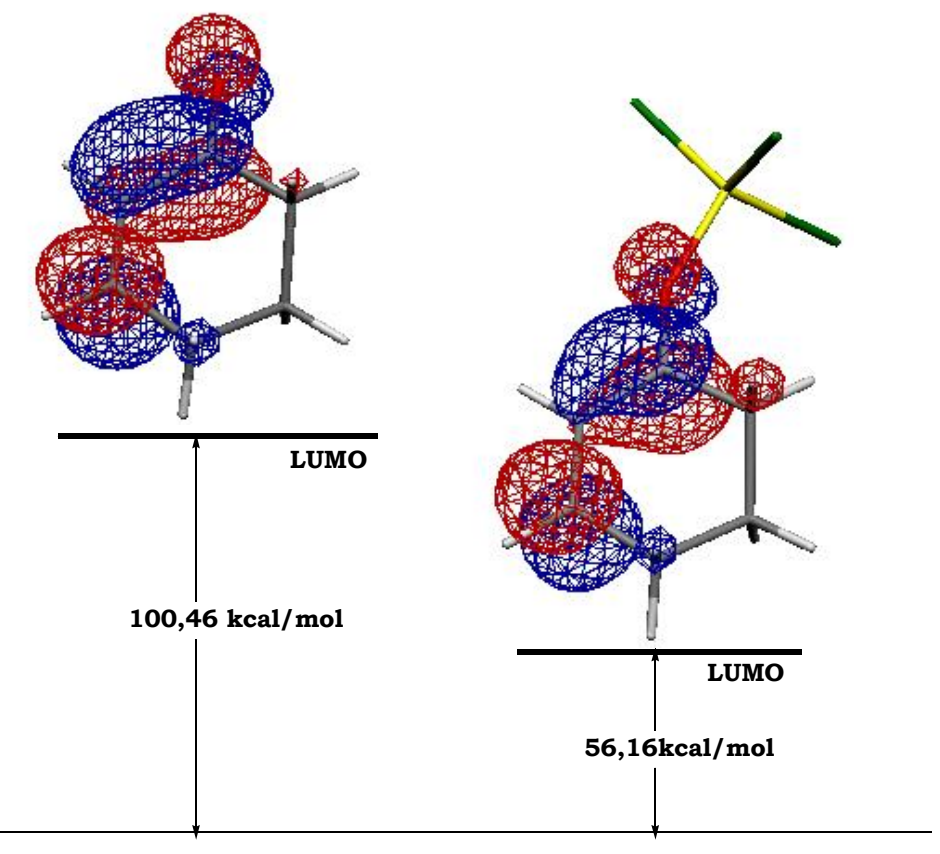

Figura 32: "Gap" de Energia entre HOMO de 43 e LUMO de 76 (com e sem catálise) - B3LYP/6-311++G(d,p).

Além de favorecer as reações e induzir estereoseletividade, os ácidos de Lewis $\left(\mathrm{AlCl}_{3}, \mathrm{BF}_{3}, \mathrm{TiCl}_{4}, \mathrm{NbCl}_{5} \ldots\right)$ podem induzir também a regioseletividade nas reações de Diels-Alder. Um dos trabalhos pioneiros sobre regioseletividade induzida por ácidos de Lewis foi realizado por Inukai e Kojima ${ }^{55}$ e serve como um bom exemplo. A reação entre o isopreno (85) e o acrilato de metila (86) fornece os dois regioisômeros 87 e 88 . Sem a ação de $\mathrm{AlCl}_{3}$, a reação além de lenta (41 dias), são obtidas proporções relativamente próximas entre os regioisômeros, e um rendimento de $32 \%$. Na presença do $\mathrm{AlCl}_{3}$, a reação se processa em 3 horas dando uma regioseletividade superior e um rendimento melhor (50\%). 


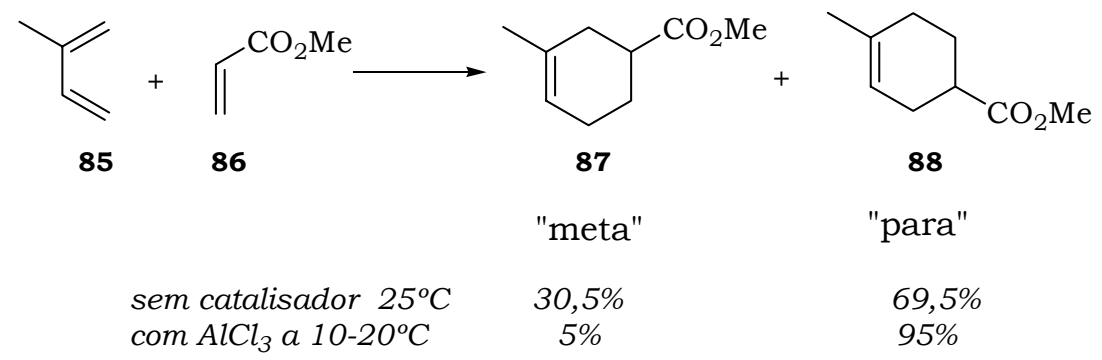

Esquema 17: Efeitos dos Ácidos de Lewis na Regioseletividade.

Alguns outros catalisadores (complexos metálicos e compostos de boro) podem induzir até enantioseletividade nas reações de Diels-Alder, porém este é um assunto que não será detalhado neste texto, e que poderá ser bem visto em alguns trabalhos da literatura. ${ }^{56}$

Para concluir esta discussão sobre a reação de Diels-Alder serão apresentadas algumas idéias sobre a "Influência da Pressão nas Reações de Diels-Alder" (geralmente ausente nos principais textos que falam sobre a reação de Diels-Alder), e por fim, serão apresentadas algumas sínteses notáveis.

\section{Influência da Pressão nas Reações de Diels-Alder.}

As reações de Diels-Alder realizadas sob altas pressões são a primeira vista um pouco inviáveis, dada a necessidade de pressões relativamente altas (1-20kbar). ${ }^{ }$No entanto, é possível atingir estes valores utilizando reatores específicos (cilindros com pistões) que atualmente nem são de tão difícil acesso. ${ }^{36 \mathrm{e}}$

As vantagens em se utilizar altas pressões para promover as reações de Diels-Alder são muitas. Frequentemente são encontrados vários problemas de caráter experimental ao se realizar uma reação desta natureza, e talvez, o principal deles seja a degradação dos materiais de partida por serem termo-sensíveis, ou sensíveis a ácidos de Lewis.

Neste sentido, as reações realizadas sob alta pressão, oferecem uma grande vantagem pois tendem a favorecer um número bem menor de reações laterais e a favorecer bastante as cicloadições. A razão pela qual a reação de Diels-Alder é favorecida por altas pressões é relativamente simples, porém quase nunca citada nos textos de química orgânica.

A reação de Diels-Alder apresenta um volume molar de ativação $\left(\Delta V^{\ddagger}\right)$ negativo, o que quer dizer que as moléculas no estado de transição ocupam um volume menor que nos reagentes. ${ }^{57}$ Nas reações intermoleculares esta "contração de volume" é bem mais pronunciada que nas intramoleculares e pode oscilar de -10 à $-45 \mathrm{~cm}^{3} \cdot \mathrm{mol}^{-1}$.

A dependência da constante de velocidades (k) destas reações com a pressão é dada pela equação 6 .

$$
\left(\frac{\partial \ln k}{\partial P}\right)_{T}=-\frac{\Delta V^{\ddagger}}{R T}
$$

\footnotetext{
${ }^{v}$ Estes valores em uma unidade mais familiar (atm) parecem ainda mais assustadores. A pressão de $1 \mathrm{kbar}$ equivale a $986,9 \mathrm{~atm}$, o que quer dizer que estas reações são realizadas sob pressões entre mais ou menos 1.000 e $20.000 \mathrm{~atm}$.
} 
Logo, se $\Delta V^{\ddagger}$ é negativo, a velocidade da reação tende a aumentar quanto maior for a pressão aplicada. As conseqüências disso é que não somente a velocidade de formação dos produtos é aumentada, mas também podem ser modificadas as razões entre alguns isômeros (regioseletividade e estereoseletividade). Uma outra vantagem é que o equilíbrio destas reações geralmente é deslocado, visto que o volume molar de reação também é negativo $(\Delta V)$. Desta maneira, o aumento da pressão provoca o aumento da constante de equilíbrio favorecendo a formação dos produtos (equação 7).

$$
\left(\frac{\partial \ln K}{\partial P}\right)_{T}=-\frac{\Delta V}{R T}
$$

Há muitos exemplos interessantes, onde algumas reações de Diels-Alder que não ocorrem em condições térmicas, ocorrem sob pressão. Também de algumas reações que ocorrem em condições térmicas muito drásticas, e que acabam ocorrendo em temperaturas relativamente baixas sob pressão. De uma maneira geral, as reações sob altas pressões também podem ser associadas com as condições em que estas reações são comumente realizadas (uso de temperaturas superiores à ambiente e também de ácidos de Lewis), porém, com a vantagem de serem bem mais favorecidas e de requererem condições bem mais suaves.

As reações relatadas por Dauben e Baker ${ }^{58}$ servem como exemplos interessantes onde o dienos como 89, que são pouco reativos a temperatura ambiente e que polimerizam em altas temperaturas, reagem bem formando adutos como 90 , quando a reação é realizada sob pressão de 15 kbar.<smiles>O=C1C=CC(=O)C=C1</smiles>

44

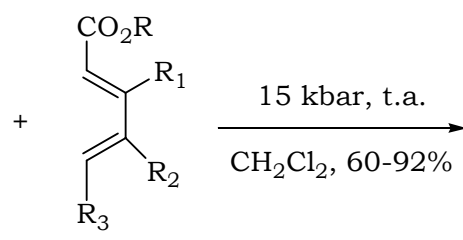

89<smiles>[R]C1=C([R])C([R])C2C(=O)C=CC(=O)C2C1[R]</smiles>

90

$\mathrm{R}=\mathrm{H}, \mathrm{CH}_{3}, \mathrm{CH}_{2} \mathrm{CH}_{3}$, mentil ; $\mathrm{R}_{1}=\mathrm{H}, \mathrm{CH}_{2} \mathrm{CH}_{3}$;

$\mathrm{R}_{2}=\mathrm{H} ; \mathrm{R}_{3}=\mathrm{H}, \mathrm{CH}_{3}, \mathrm{CH}\left(\mathrm{OCH}_{3}\right)_{2}, \mathrm{CH}_{2} \mathrm{OTBDMS}$

Esquema 18: Exemplo de Reação de Diels-Alder sob Alta Pressão.

Um outro exemplo de grande expressão é a reação entre dienos do tipo 91 e a 3metil-ciclo-hexenona (92), que não ocorre em nenhuma das condições usuais (sob catálise de ácidos de Lewis e em temperaturas acima da ambiente), mas sob pressão e catálise de $\mathrm{EtAlCl}_{2}$, ela ocorre fornecendo adutos como 93 e 94, que são intermediários de alguns produtos naturais. ${ }^{59}$ 


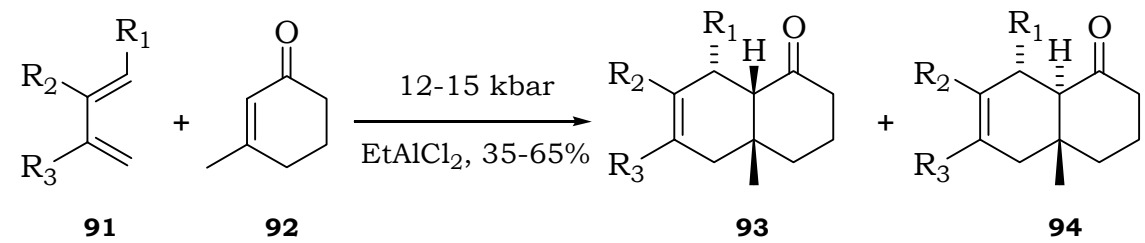

$\mathrm{R}_{1}, \mathrm{R}_{2}, \mathrm{R}_{3}=\mathrm{H} ; \mathrm{CH}_{3}$

Esquema 19: Exemplo de Reação de Diels-Alder sob Alta Pressão e Catálise.

Atualmente, o número de trabalhos encontrados na literatura que envolve reações de Diels-Alder sob altas pressões, é realmente elevado. Uma excelente revisão foi realizada por Fringueli e outros autores. ${ }^{36 \mathrm{e}}$

\section{Sínteses Envolvendo Reacões de Diels-Alder.}

Conforme foi dito logo no início desta seção, não se pretendia realizar uma revisão completa sobre o assunto "Reação de Diels-Alder", mas apenas abordar os principais aspectos desta reação, em especial os que seriam de interesse para este trabalho. Não foram abordadas algumas versões importantes da Reação de Diels-Alder, como as reações Intramoleculares, as reações do tipo Hetero Diels-Alder, e as reações de Retro DielsAlder. Sendo assim, foram selecionados nesta última seção sobre o assunto, alguns exemplos que destaquem a aplicabilidade da reação de Diels-Alder como um todo, e também destas versões não abordadas ao longo deste texto. Os exemplos selecionados são aleatórios e tirados de algumas revisões sobre o assunto.

O primeiro exemplo selecionado é a síntese da $(+)$-cocleamicina A (95), realizada por Roush e colaboradores. ${ }^{60}$ Esta substância apresenta atividades biológicas significativas como antimicrobial e citotóxica (contra células leucêmicas).

Como a síntese é relativamente longa, serão destacadas as etapas mais importantes. Partindo dos intermediários 96 e 97 os autores realizam algumas transformações, dentre elas uma reação de acoplamento de Stille, e em seguida uma ciclização com $\mathrm{Cs}_{2} \mathrm{CO}_{3}$, originando 99. Após algumas transformações o intermediário 99 foi convertido em 100, já devidamente funcionalizado para realizar a reação de DielsAlder intramolecular e originar de maneira eficiente o policiclo 101. A partir do intermediário 101 obteve-se em mais algumas etapas o produto natural 95. 


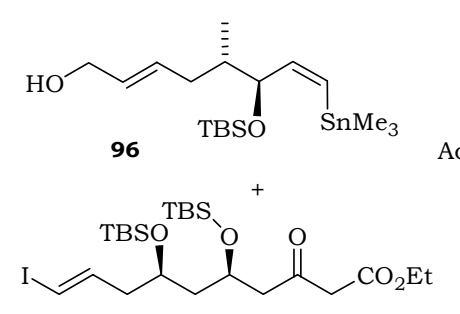

97

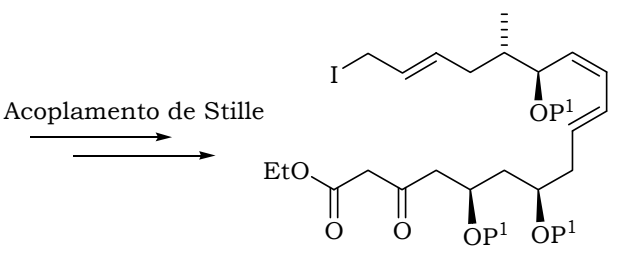

$\mathrm{P}^{1}=\mathrm{TBS}$

98

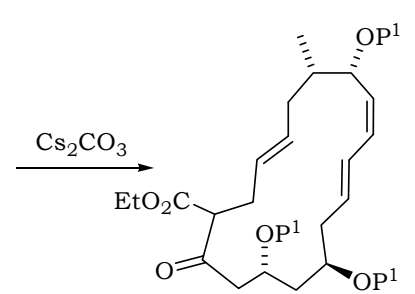

99

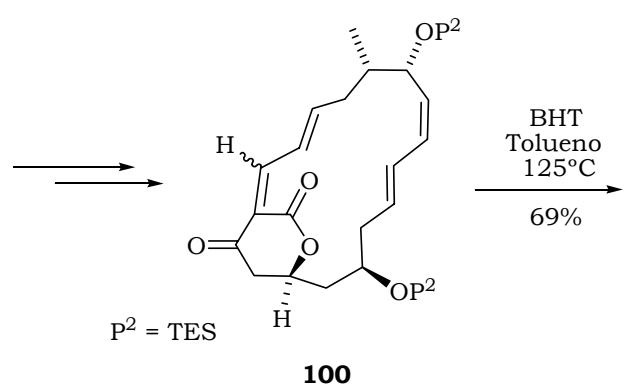

100

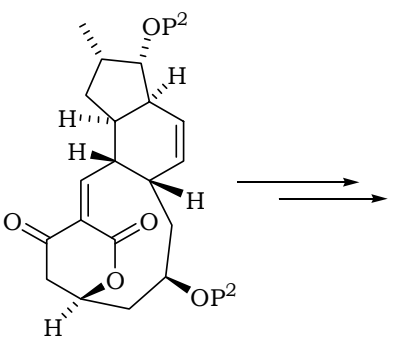

101

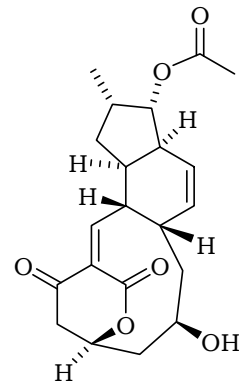

Cocleamicina A

Esquema 20: Sintese da Cocleamicina A.

Não poderíamos deixar de destacar ao menos um dos trabalhos de Nicolaou, ${ }^{36 c}$ que frequentemente utiliza a reação de Diels-Alder em suas sínteses. Das várias substâncias naturais já preparadas pelo seu grupo, pode-se destacar a síntese da $( \pm)$ colombiasina A (102). Este diterpeno tem se mostrado uma droga bastante eficiente no combate a colônias de Microbacterium tuberculosis H37Rv. ${ }^{61}$

A síntese foi realizada em poucas etapas, dentre as quais, duas envolviam a reação de Diels-Alder. Logo na primeira etapa foi utilizada uma reação de Diels-Alder entre o dieno 103 e a quinona 104, que forneceu exclusivamente o aduto endo 105. Após algumas transformações o composto 105 foi convertido em 106, que no mesmo meio reacional sofreu uma eliminação queletrópica, seguida de uma Diels-Alder intramolecular. O composto 108 foi depois convertido no produto natural 102.

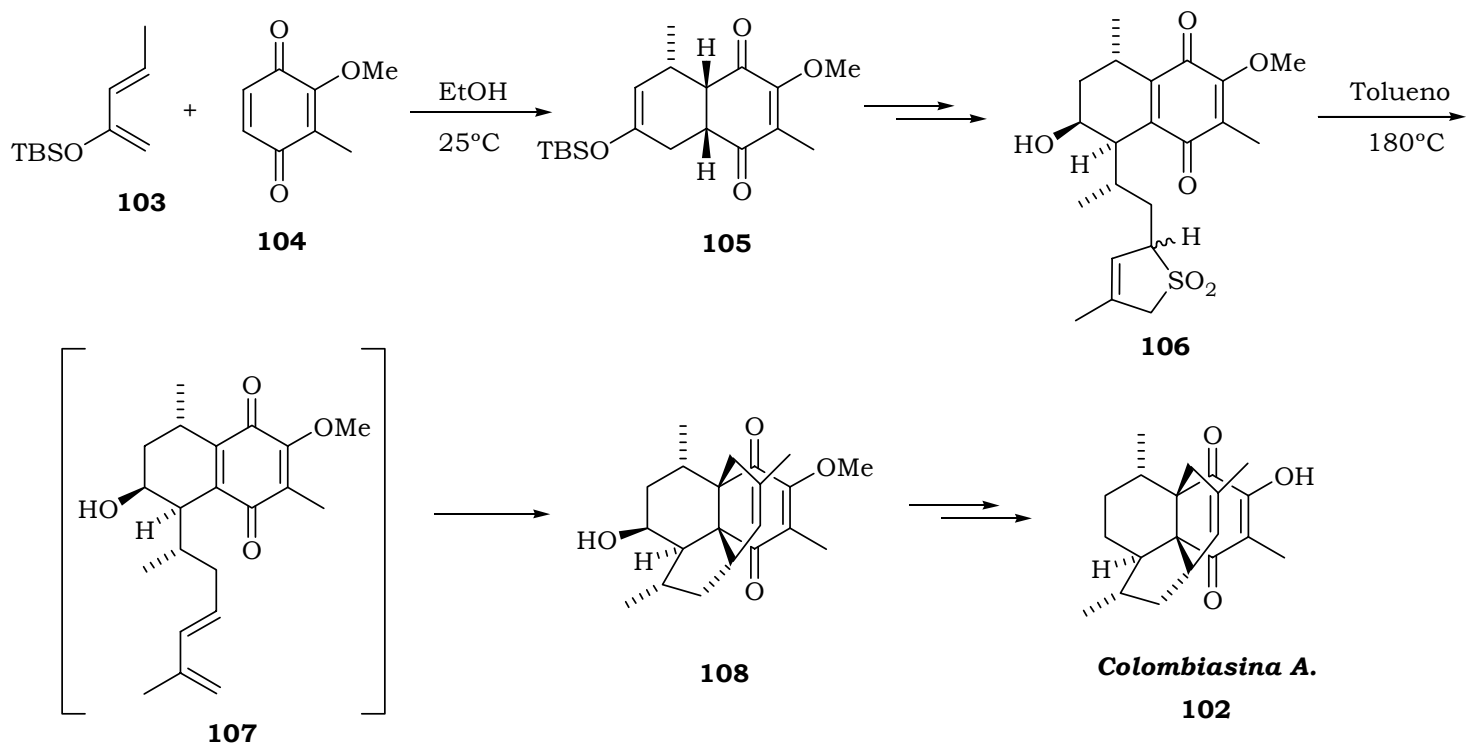

Esquema 21: Sintese da Colombiasina A. 
O terceiro exemplo selecionado envolve uma reação do tipo hetero Diels-Alder e uma Retro Diels-Alder. Na síntese da (-)-norsericurinina (109) Jacobi e colaboradores ${ }^{62}$ realizam inicialmente uma adição de Michael do composto 110 em 111, o que forneceu 112. Em seguida, o composto 112 sofreu uma reação do tipo hetero Diels-Alder originando 113, que no mesmo meio sofreu uma retro Diels-Alder originando 114. O composto 114 após algumas transformações deu origem ao produto natural 109 que tem apresentado algumas atividades relacionadas ao sistema nervoso central; dentre estas atividades destaca-se a inibição da acetilcolinesterase. ${ }^{62}$<smiles>COc1oc([C@@H]2CCCN2)nc1C</smiles>

110

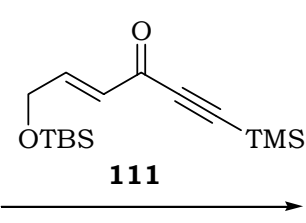

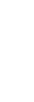$$
\text { (1) }
$$

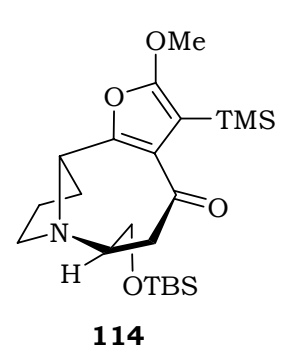

114

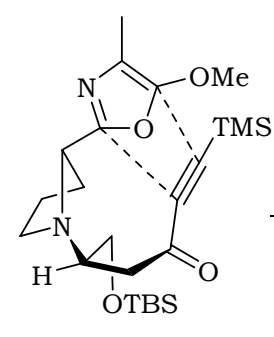

112

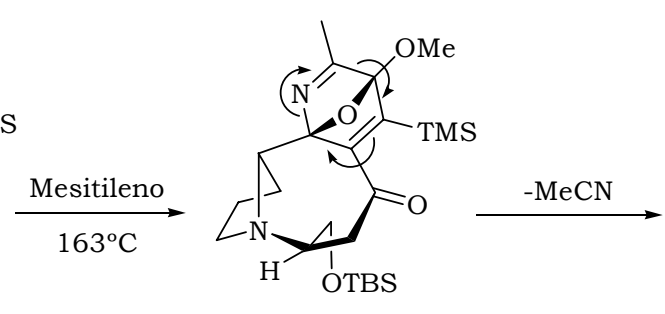

113

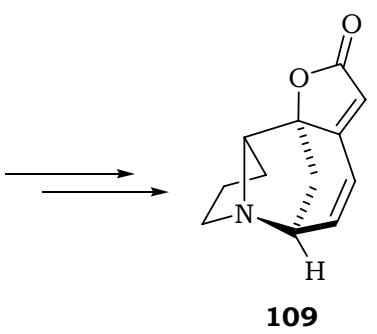

Esquema 22: Sintese da (-)-Norsericurinina.

Um último exemplo selecionado é o da síntese da eunicenona (115) realizada por Corey e colaboradores. ${ }^{63}$ Este produto natural atua como inibidor de algumas glicoproteínas e tem sido testado no combate a doenças cardivasculares. ${ }^{63}$

Nesta síntese os autores utilizaram um catalisador quiral na reação de Diels-Alder (derivado de boro) para preparar de maneira enantioseletiva o produto natural 115 (esquema 23). Inicialmente o geranil-geranilacetileno (116) sofreu uma reação de acoplamento com o composto 117. Em seguida o produto 118 foi convertido em 119 após algumas transformações. O composto 119 foi submetido à reação de Diels-Alder com a 2-bromoacroleína (120) na presença do catalisador 121, o que forneceu o aduto 122 com 97\% de excesso enantiomérico e na proporção 98:2 dos adutos endo/exo, respectivamente. Após algumas etapas, o composto 122 foi convertido em 123 e depois em 124. O intermediário 124 foi desprotegido fornecendo o produto natural 115 (com $98,5 \%$ de pureza enantiomérica). 

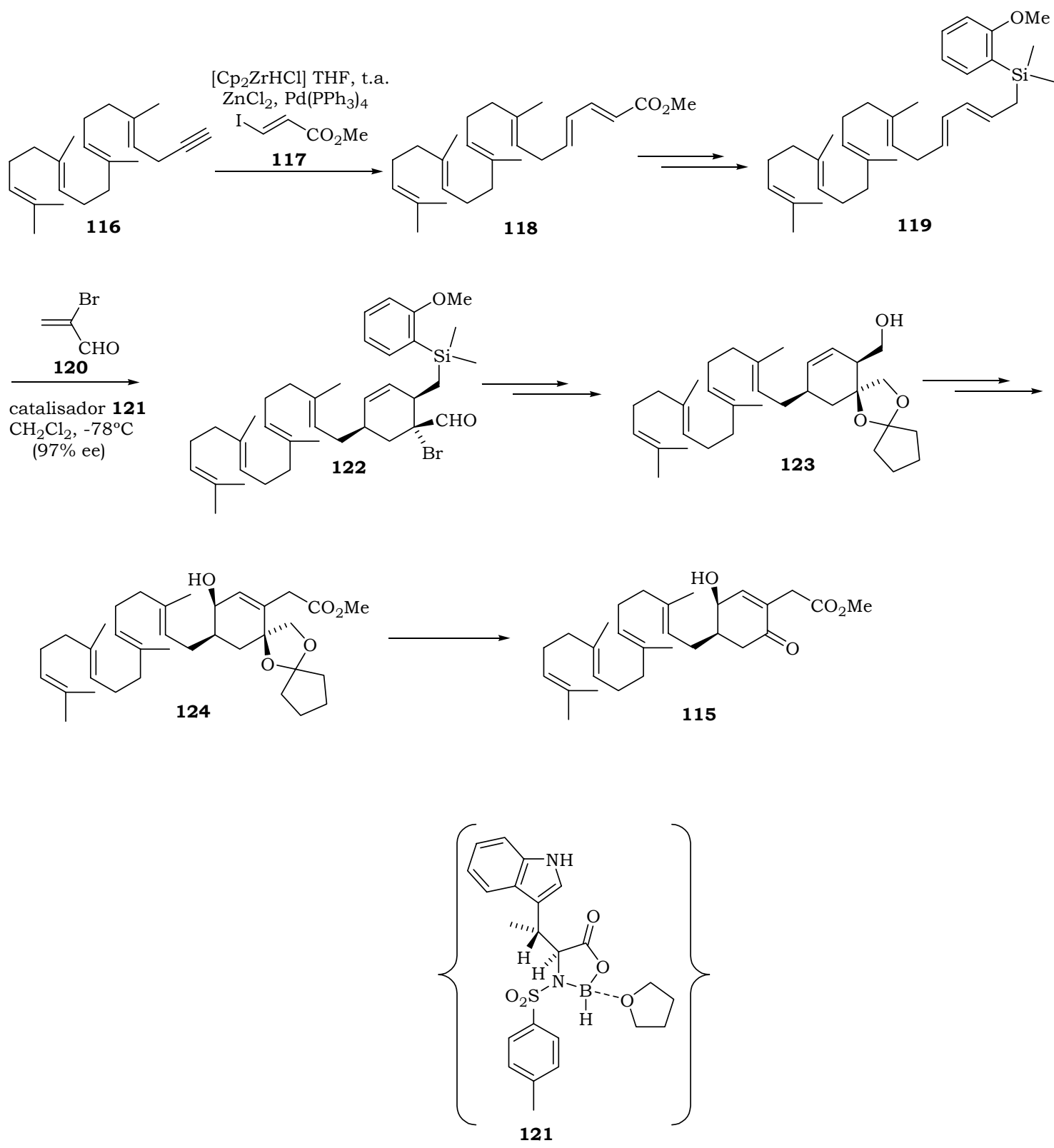

Esquema 23: Sintese da Eunicenona.

É preciso encerrar por aqui esta seção sobre a reação de Diels-Alder para não tornar este texto por demais cansativo. De fato, muitos aspectos da reação de Diels-Alder não foram abordados, e desta maneira, é preciso reafirmar o caráter ilustrativo desta seção da tese.

Pode-se concluir que a reação de Diels-Alder agrega características muito especiais, e, portanto, é impossível realizar uma revisão ampla sobre o assunto que ocupe tão poucas páginas. 
Objetivos - Parte $A$ 



\section{2 - Objetivos}

Esta parte do trabalho teve como objetivo principal desenvolver algumas metodologias sintéticas que possibilitassem a preparação do 1,4-metano[10]anuleno (41), uma estrutura hipotética e com diversas peculiaridades estruturais, cuja síntese ainda não foi descrita na literatura. A idéia central era produzir 41, para então estudar suas propriedades químicas e físicas, e, fundamentalmente, avaliar a existência de estabilização aromática neste composto.

Do ponto de vista sintético, o anuleno 41 é constituído de um sistema carbônico do tipo biciclo[6.2.1]undecano (42) contendo várias insaturações.

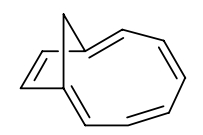

41

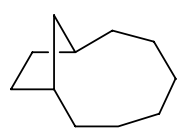

42

Figura 33: Sistemas Bicíclicos.

Estes sistemas carbônicos possuem várias semelhanças com alguns produtos naturais que possuem heteroátomos nas pontes, como o goiazensolido (125) e outros furanoeliangolidos. ${ }^{64}$ Há ainda na literatura alguns trabalhos que envolvem intermediários do tipo biciclo[6.2.1]undecano (42) na síntese de outros produtos naturais como o Taxol ${ }^{\circledR}$ e seus derivados. ${ }^{65}$

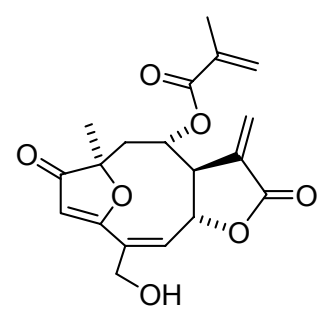

125

Figura 34: Estrutura do Goiazensolido.

Desta maneira, as metodologias desenvolvidas para a síntese de sistemas como 42 , poderiam conduzir à síntese do anuleno desejado 41, e servir como modelo para a preparação de produtos mais complexos, inclusive aqueles que contenham alguns heteroátomos.

Independentemente dos estudos de caráter sintético, tínhamos também como objetivo avaliar a existência de aromaticidade no anuleno 41 do ponto de vista teórico, utilizando alguns dos métodos descritos na seção 1.2 (Aromaticidade). 

Plano de Pesquisa - Parte $A$ 



\section{3 - Plano de Pesquisa}

Do ponto de vista sintético, o sistema do tipo biciclo[6.2.1]undecano (42) poderia ser preparado através da ruptura de uma ligação $\sigma$ entre carbonos, localizada na junção dos anéis de uma estrutura como 126.

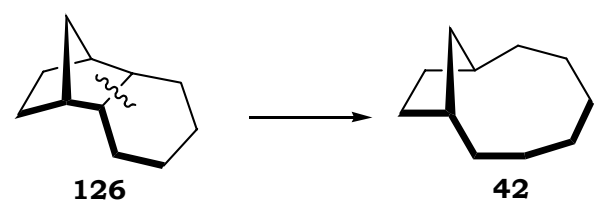

Esquema 24: Preparação Direta de um Biciclo[6.2.1]undecano.

Clivagens deste tipo podem ser realizadas de várias maneiras, dentre as quais, escolheu-se para estudar neste trabalho:

- Uma eliminação-fragmentação 1,4 em intermediários como 127 e 129.

- Uma reação de retro-aldol em intermediários como 131.

- Algumas transformações que possibilitassem uma reação de clivagem na posição carbonílica de compostos como 133 (esquema 25).

I)

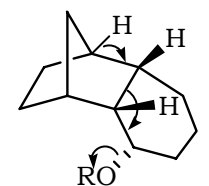

127

II)

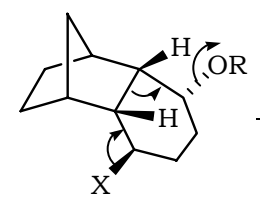

129

III)

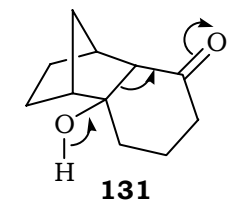

IV)

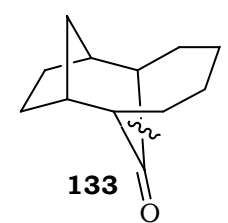

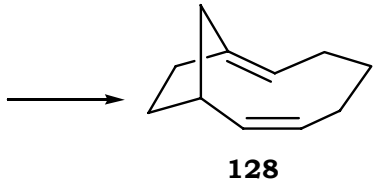

128

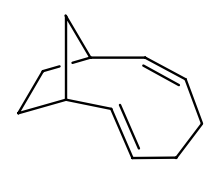

130

Esquema 25: Reações de Fragmentação.

Sendo assim, a primeira abordagem sintética sugerida neste trabalho, parte da reação de Diels-Alder entre o ciclopentadieno (43) e a benzoquinona (44), o que conduz 
à formação o aduto 45. Após a redução das carbonilas de 45 e formação do mesilato 137, seria obtido um bom intermediário para realizar os testes de eliminação-fragmentação 1,4. Se obtido o composto 138, algumas outras transformações seriam necessárias para obtenção do anuleno 41.

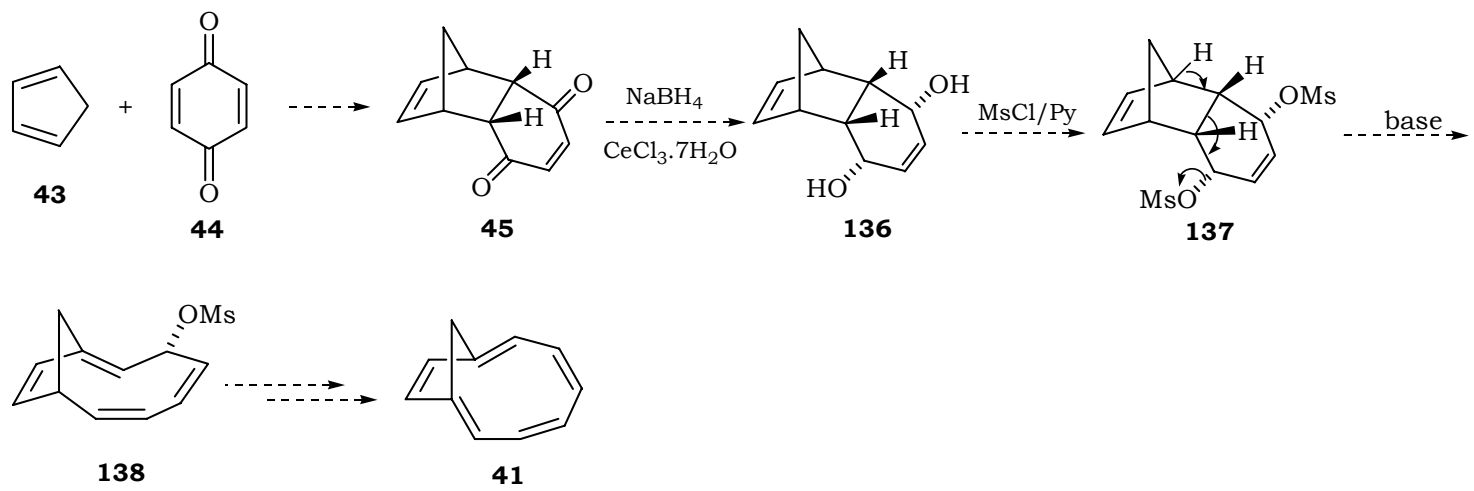

Esquema 26: Primeira Abordagem Sintética Proposta.

Outros intermediários contendo grupos acetato (OAc), halogênios, e outros substituintes, foram também sugeridos no lugar de 137.

Com relação aos estudos de fragmentação, apresentado no item (II) do esquema 25, foram sugeridas algumas reações em intermediários contendo halogênios no lugar de $\mathrm{X}$ (fragmentação com Zn).

Uma outra abordagem sintética proposta neste trabalho, iniciava-se com uma cicloadição do tipo [6+4], conforme mostrado no esquema 27. Nesta proposta, tinha-se a vantagem de que os intermediários sintéticos (especialmente 143) já possuíam as substituições, e as estereoquímicas das ligações dupla, adequadas para a obtenção do anuleno 41.
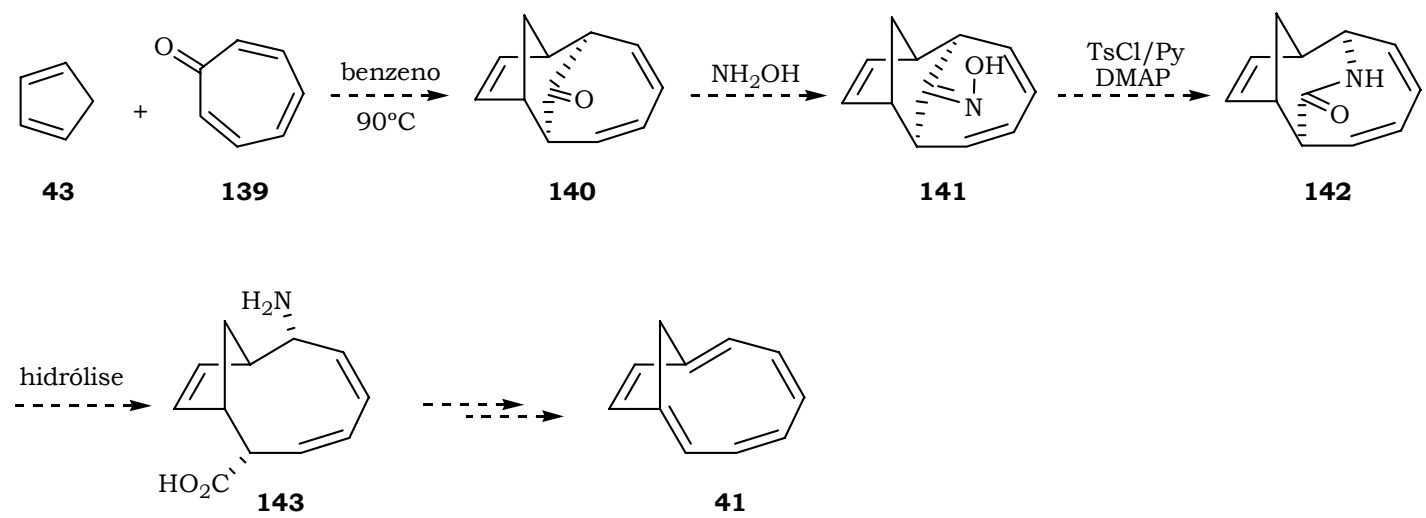

Esquema 27: Segunda Abordagem Sintética Proposta.

A reação entre o ciclopentadieno (43) e a tropona (139) já era conhecida, e em condições térmicas fornece o composto 140. Este composto, após algumas transformações, provavelmente seria transformado na lactama 142 . Uma simples reação de hidrólise em 142 daria origem ao intermediário 143, bastante apropriado para a síntese do anuleno 41. 
Estas foram as propostas iniciais deste trabalho. Evidentemente que, com a execução das reações, muitos problemas foram surgindo e algumas modificações foram inevitáveis. 



\title{
Atividades Realizadas e Resultados Obtidos
}

\author{
Parte $A$
}





\section{4 - Atividades Realizadas e Resultados Obtidos}

Nesta seção serão descritas as atividades de caráter experimental, incluindo sempre que necessário, algumas discussões sobre as etapas realizadas. Por questões de ordem esta seção será subdividida em algumas partes com o objetivo de facilitar caso o leitor queira verificar apenas uma determinada etapa. Uma nota importante é que todas as substâncias dotadas de estereoquímica foram sintetizadas de forma racêmica, e serão representadas apenas as configurações relativas dos compostos.

Conforme mostrado na seção "Plano de Pesquisa", a primeira abordagem sintética (esquema 26) envolve na primeira etapa uma reação de Diels-Alder. Em seguida, são sugeridas algumas transformações e a obtenção de alguns intermediários importantes para a realização da fragmentação desejada. Logo depois são descritas as atividades referentes à segunda abordagem sintética (esquema 27).

\section{$\underline{\text { Abordagem Sintética Baseada na Reação de Diels-Alder. }}$}

A reação de Diels-Alder entre o ciclopentadieno (43) e a benzoquinona (44) já está descrita em alguns trabalhos da literatura. ${ }^{66}$ No entanto, praticamente todos estes trabalhos relatam apenas a formação do aduto endo 45, afirmando que ele é obtido exclusivamente. Todas as metodologias aqui citadas, ${ }^{66}$ foram testadas e a que forneceu o aduto 45 em melhor rendimento e maior pureza (com $2 \%$ do isômero exo $45 \mathrm{a}$ ), foi a realizada em metanol e baixa temperatura (esquema 28). ${ }^{66 a}$

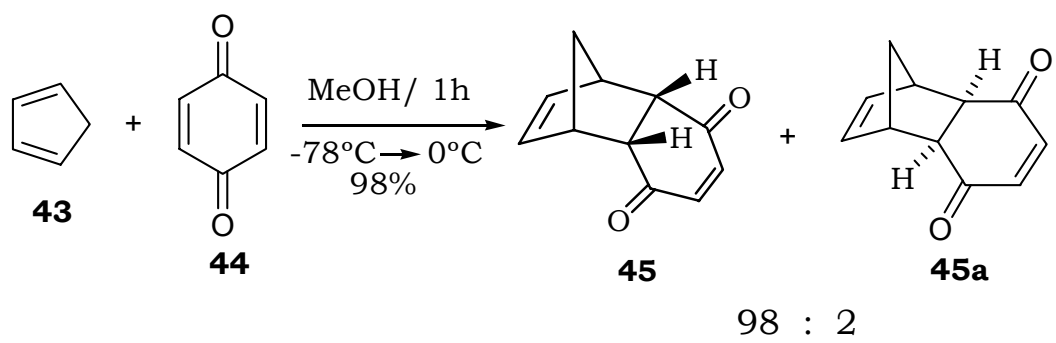

Esquema 28: Sintese do Aduto 45.

Trabalhar com misturas ao longo de uma síntese nem sempre é confortável, pois as análises dos intermediários acabam sendo dificultadas. Neste caso, a quantidade do aduto exo 45a na mistura é relativamente baixa, e por isso, resolveu-se prosseguir considerando apenas o aduto endo 45. Nas etapas posteriores os intermediários foram obtidos devidamente puros (livres das "impurezas" derivadas do aduto exo 45a). 


\section{Transformações Realizadas no Aduto de Diels-Alder 45.}

Dando continuidade, o aduto 45 foi reduzido ao diol 136 utilizando $\mathrm{NaBH}_{4}$ na presença de $\mathrm{CeCl}_{3} \cdot 7 \mathrm{H}_{2} \mathrm{O}$ e a $-25^{\circ} \mathrm{C}$ (rendimento de $94 \%$ após cristalização em $\mathrm{CH}_{2} \mathrm{Cl}_{2}$ ). Esta redução é 100\% estereoseletiva, uma vez que na estrutura cis-endo de 45, uma das faces (face endo) encontra-se impedida para a redução.

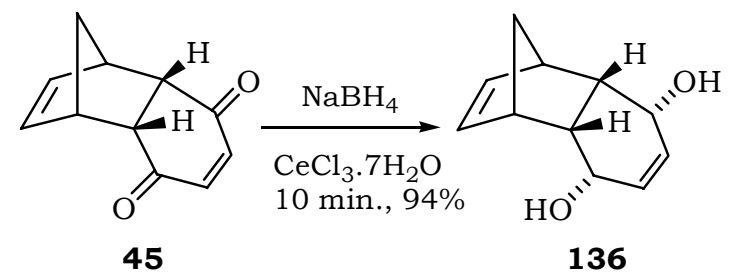

Esquema 28: Preparação do Diol 136.

Sabe-se que o cloreto de cério é um eficiente catalisador e atua na redução 1,2 regioseletiva de cetonas $\alpha, \beta$-insaturadas por $\mathrm{NaBH}_{4}$ em metanol. ${ }^{67,68}$ Alguns estudos realizados por nosso grupo de pesquisa, ${ }^{68}$ apontam também para a influência do $\mathrm{CeCl}_{3}$ na estereoquímica dos produtos da redução de ciclopentanonas, quando o redutor utilizado é $\mathrm{NaBH}_{4}$. No caso da conversão de $45 \mathrm{em} \mathrm{136,} \mathrm{o} \mathrm{CeCl}_{3}$ foi utilizado apenas para evitar a redução 1,4 de 45 , que é favorável sem o uso deste lantanídeo. ${ }^{69}$

Em seguida, tentou-se realizar a conversão do diol 136 no dimesilato 137 . No entanto, esta etapa se mostrou bastante problemática produzindo misturas complexas nas várias tentativas realizadas.

A primeira condição testada foi utilizando $\mathrm{MsCl} /$ piridina/(com ou sem DMAP) a $0^{\circ} \mathrm{C}^{70}$ Após alguns minutos de reação, observou-se a formação de vários produtos reacionais, dentre os quais, nenhum parecia ser o dimesilato 137 (análise de $\mathrm{RMN}$ de ${ }^{1} \mathrm{H}$ do produto bruto).

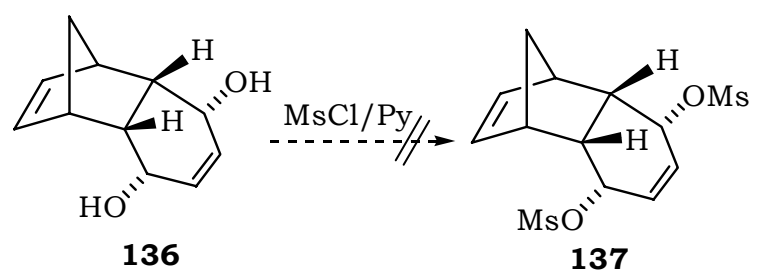

Esquema 29: Primeira Tentativa de Preparação do Dimesilato 137.

Houve a suspeita de que na condição realizada, poderiam ocorrer reações de substituição alílica dos grupos mesilato por íons cloreto. Havia ainda a possibilidade, de que em piridina, estivessem ocorrendo algumas reações de eliminação. Para evitar ao menos as possíveis eliminações ocorridas em piridina, resolveu-se utilizar um solvente neutro e base $\left(\mathrm{Et}_{3} \mathrm{~N}\right)$ em quantidades estequiométricas para tentar produzir $137 .{ }^{71}$

Mesmo nesta condição não foi possível obter o dimesilato 137; o que se observou, foi novamente a formação de uma mistura complexa. 


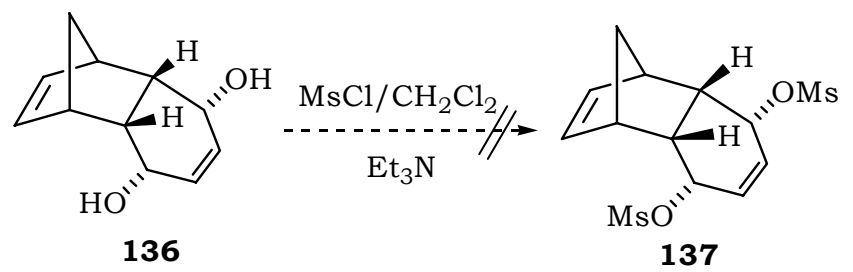

Esquema 30: Segunda Tentativa de Preparação do Dimesilato 137.

Este resultado sugere também que os íons cloreto possivelmente realizam algumas reações de substituição, especialmente de bons grupos de saída como o mesilato. Nos dois casos testados tentou-se isolar por cromatografia em coluna alguns dos produtos reacionais, porém, não se obteve êxito em nenhuma das separações.

Com o objetivo de prosseguir com a metodologia proposta inicialmente, e até certo ponto, dar suporte a algumas das hipóteses anteriores, resolveu-se sintetizar o diacetato 144, isto porque, o grupo acetato sendo um grupo de saída menos eficiente, poderiam ser evitadas algumas das reações indesejadas.

O composto 144 foi facilmente preparado pela reação de $136 \mathrm{com} \mathrm{Ac}_{2} \mathrm{O}$ em $\mathrm{CH}_{2} \mathrm{Cl}_{2} / \mathrm{Et}_{3} \mathrm{~N} / \mathrm{DMAP}$ (rendimento de $98 \%$ ). ${ }^{72}$

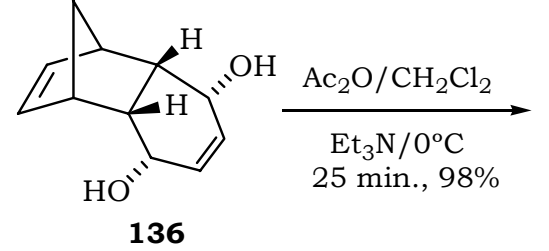

136

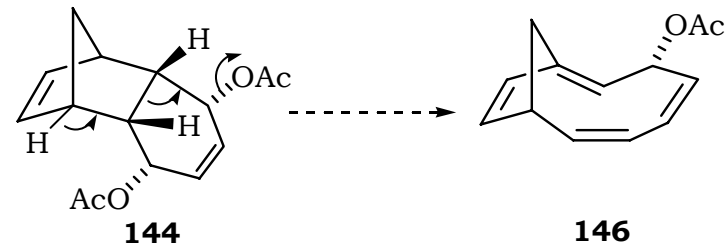

146

Esquema 31: Preparação do Diacetato 144.

Esta preparação confirma a hipótese de que os derivados mesilados (mono e di) até poderiam estar se formando, no entanto, a facilidade com que ocorrem outras reações impossibilitava a obtenção do produto 137.

O objetivo agora era testar se o diacetato 144 sofreria a eliminação-fragmentação 1,4 na presença de bases não nucleofílicas. Havia alguns indícios de que a fragmentação desejada poderia ocorrer (esquema 31) primeiramente porque seriam aliviadas as tensões no anel tipo norborneno de 144, depois as ligações dos hidrogênios das "cabeças de ponte" de 144 estavam suficientemente alinhadas (praticamente no mesmo plano) em relação às ligações que mantinham os grupos acetato ligados ao anel de seis membros (ver figura 35). 


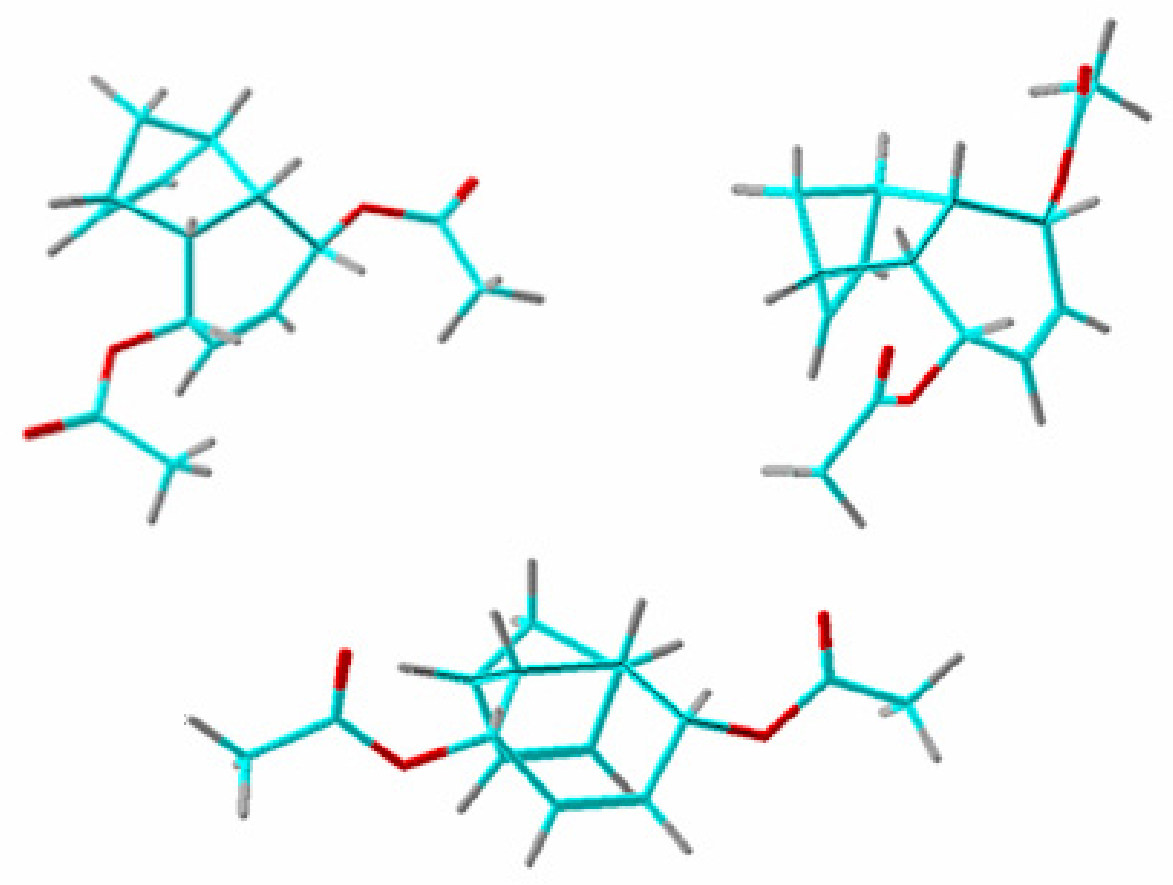

Figura 35: Projeções de uma das Conformações do Diacetato $144 .^{\text {vi73 }}$

Os testes com o composto 144 foram realizados utilizando $\mathrm{NaH}$ em THF ou tolueno $^{74}$ e também t-BuOK em THF. Em todos os casos foram obtidos apenas os produtos de hidrólise parcial dos grupos acetato. $\mathrm{Na}$ reação com $\mathrm{NaH}$ a hidrólise parcial deve ser provocada pelo $\mathrm{NaOH}$, presente no $\mathrm{NaH}$ comercial. Já na reação realizada em t$\mathrm{BuOK} / \mathrm{THF}$, a hidrólise deve ocorrer pela ação de $\mathrm{KOH}$ presente no t-BuOK. Em nenhum destes casos houve a formação do produto esperado 146.

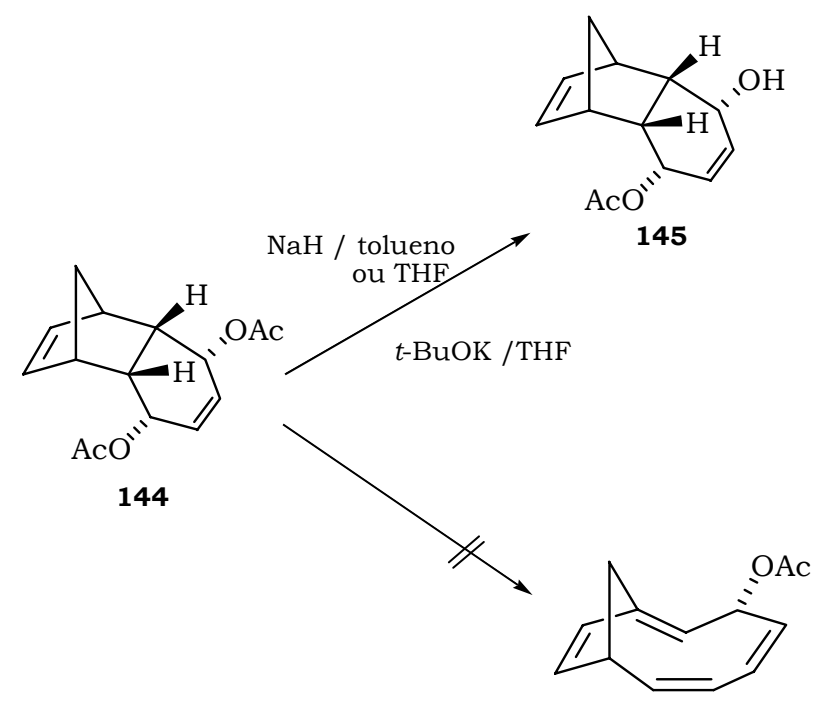

146

Esquema 32: Tentativa de Eliminação-Fragmentação 1,4 no Diacetato 144.

\footnotetext{
${ }^{v i}$ Esta conformação foi obtida através de uma busca conformacional utilizando programa GMMX com interface no PCModel 7.0. O campo de força utilizado foi o MM3.
} 
Uma alternativa direta para aproveitar o intermediário 144 e ao mesmo tempo possibilitar uma fragmentação (como no item II do esquema 25) era a substituição de um dos acetatos de 144 por um iodeto. Esta substituição deixaria o iodeto em trans com o acetato remanescente (esquema 33).

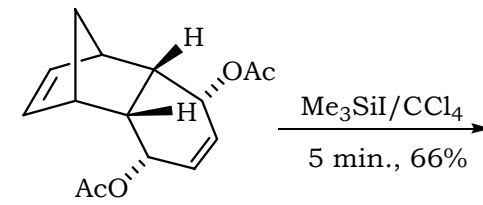

144

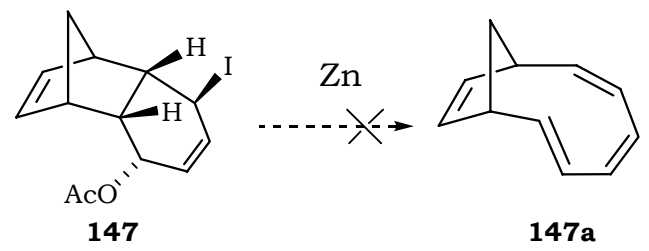

$147 \mathbf{a}$

Esquema 33: Alternativa Inviável Por Questões de Estereoquimica.

No entanto, a dupla ligação vizinha ao grupo acetato e ao iodeto de 147 , dificulta muito a existência de uma conformação que favoreça a reação desejada, ou seja, com os grupos acetato e iodeto devidamente alinhados para a eliminação-fragmentação 1,4 (ver figura 36). O composto 147 até foi preparado pela reação de $144 \mathrm{com} \mathrm{SilMe} 3 / \mathrm{CCl}_{4}$ (rendimento de 66\%), ${ }^{75}$ mas de fato, a reação com $\mathrm{Zn}$ metálico não forneceu o produto 147. Foi obtida uma mistura de onde não se conseguiu isolar nenhum produto devidamente puro.
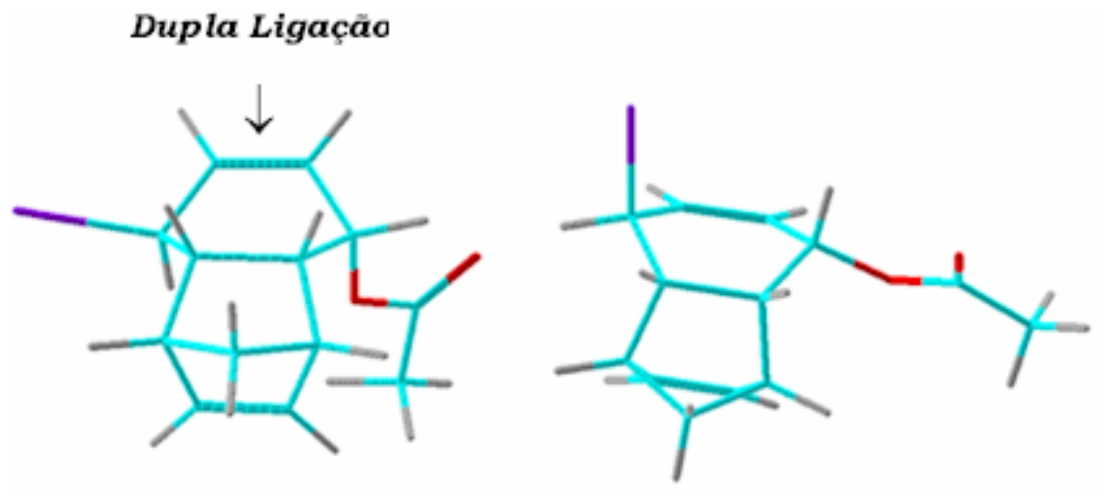

Figura 36: Conformações de Menor Energia para Composto $147 .^{\text {vii }}$

Ao que tudo indicava, a presença da dupla conjugada do composto 45 (esquema 28) inviabilizava várias das etapas pretendidas (a formação do dimesilato 137 e a fragmentação com zinco). Parecia claro que a redução desta insaturação simplificaria 45, possibilitando algumas transformações até então sem sucesso.

O composto 45 foi reduzido seletivamente com $\mathrm{Zn} / \mathrm{AcOH}$ e o uso de ultra som, obtendo a dicetona $148 \mathrm{com} 98 \%$ de rendimento. ${ }^{76} \mathrm{Em}$ seguida, as carbonilas de 148 foram reduzidas com $\mathrm{NaBH}_{4} / \mathrm{CeCl}_{3} \cdot 7 \mathrm{H}_{2} \mathrm{O}$ (96\% de rendimento). Neste caso, não era de fundamental importância a utilização de $\mathrm{CeCl}_{3}$ na reação, porém, verificou-se que na presença deste catalisador a reação era muito mais rápida e eficiente, fornecendo 149 com boa pureza após uma simples cristalização em $\mathrm{CH}_{2} \mathrm{Cl}_{2}$.

\footnotetext{
vii Estas foram as duas principais conformações obtidas na busca conformacional (campo de força MM3 PCModel 7.0).
} 


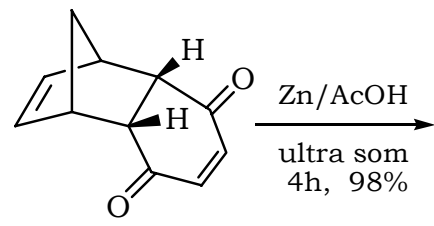

45

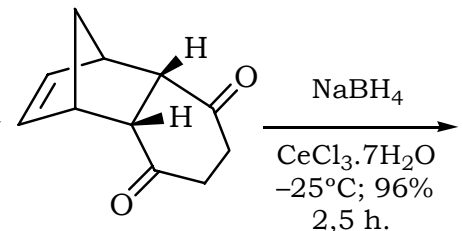

148<smiles>O[C@H]1CC[C@@H](O)[C@H]2C3C=CC(C3)[C@H]12</smiles>

149

Esquema 34: Modificações no Aduto 45.

Depois de obtido o composto 149, o objetivo era realizar algumas das transformações testadas anteriormente sem sucesso. Primeiramente, tentou-se transformar o composto 149 em 150 pela reação com $\mathrm{MsCl}$ e piridina. ${ }^{77}$ Esta reação ocorreu com relativa facilidade e com bom rendimento (86\%), reforçando a hipótese de que a ligação dupla presente nos intermediários da abordagem anterior, de fato facilitava algumas reações laterais.

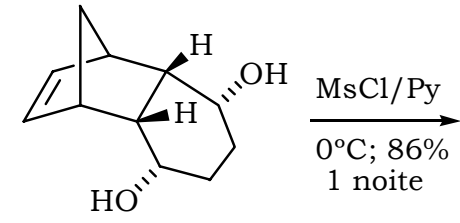

149

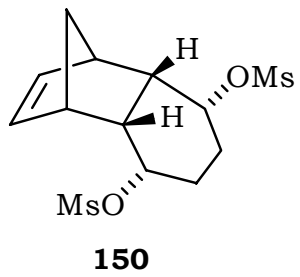

150

Esquema 35: Síntese do Dimesilato 150.

O composto 150 estava agora substituído com um bom grupo de saída e com a estereoquímica adequada, tanto a eliminação de um dos hidrogênios da "cabeça de ponte", quanto para uma eliminação-fragmentação 1,4 em um halo-mesilato (ver na figura 37 e esquema 37 adiante). 

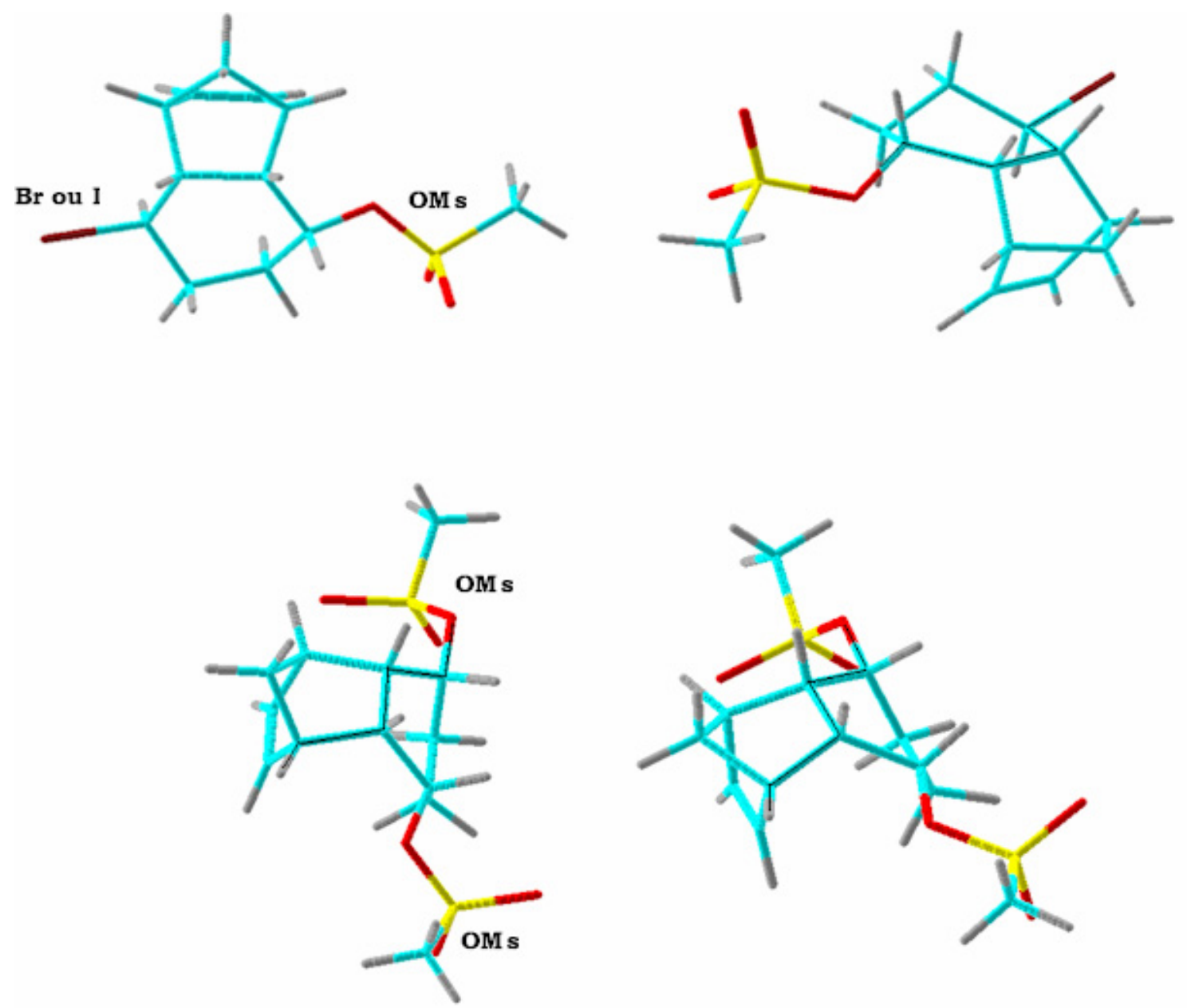

Figura 37: Conformações dos Derivados 151 e 150 que Permitem as Eliminações Desejadas (Campo de Forças MM3 - PCModel 7.0).

No entanto, esta nova abordagem também apresentava seus problemas. A presença de dois grupos $\mathrm{CH}_{2}$ vizinhos a dois bons grupos de saída (OMs) tornava possível a ocorrência de algumas reações laterais (eliminações). A única maneira de saber se as fragmentações pretendidas ocorreriam era realizando os testes reacionais.

Como previsto a reação do dimesilato $150 \mathrm{com}$ bases fortes $(\mathrm{NaH} / \mathrm{THF}$ ou t$\mathrm{BuOK} / \mathrm{THF}$ ) produziram misturas bastante complexas, de onde não foi possível isolar e analisar nenhum produto devidamente puro.

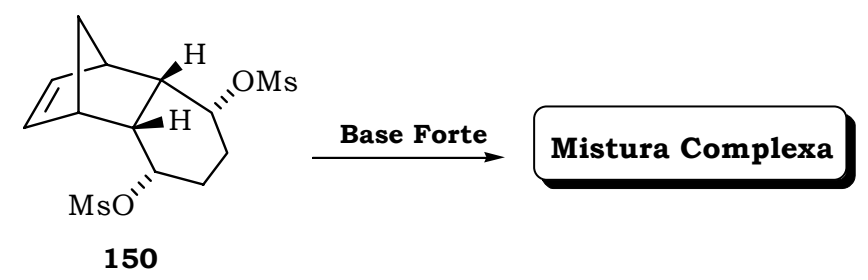

Esquema 36: Tentativas de Eliminação-Fragmentação 1,4 no Composto 150.

A próxima alternativa era tentar transformar o composto 150 no halo-mesilato 151, para então realizar alguns testes de fragmentação com zinco. 


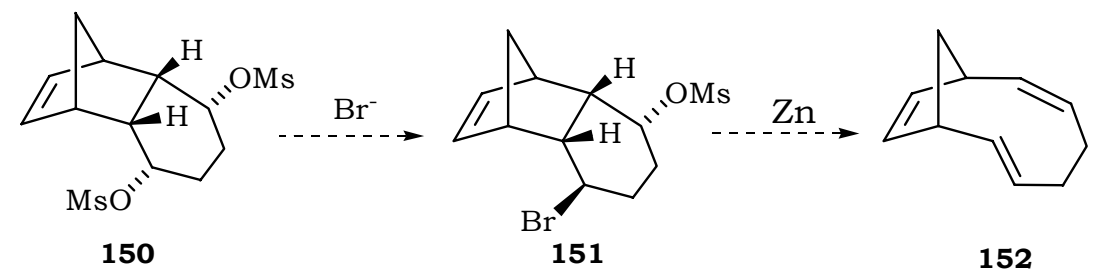

Esquema 37: Tentativas de Eliminação-Fragmentação 1,4 no Composto 150.

Esta nova estratégia parecia bastante adequada, pois o composto 151 possuía as características necessárias para realizar a eliminação-fragmentação desejada. Também são conhecidos alguns exemplos de fragmentação deste tipo, ${ }^{77}$ conforme exemplificado no esquema 38.

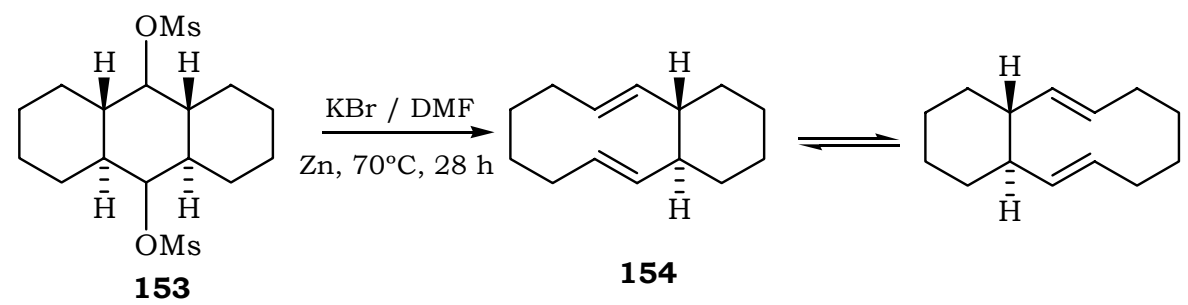

Esquema 38: Fragmentação com o Dimesilato $153 .^{77}$

Sendo assim, reagiu-se o composto $150 \mathrm{com} \mathrm{KBr} / \mathrm{DMF} / \mathrm{Zn},{ }^{77}$ obtendo-se uma mistura com vários produtos, da qual se conseguiu isolar apenas o composto 155 devidamente puro (rendimento de 11\%). Este resultado deixava clara a facilidade com que algumas reações laterais poderiam ocorrer nestas condições reacionais. Neste sentido, tentou-se realizar primeiro a preparação do derivado 151 em condições mais suaves (com $\mathrm{KBr}$ ou utilizando KI) para depois realizar a reação com zinco. Todas as tentativas foram inaproveitáveis.

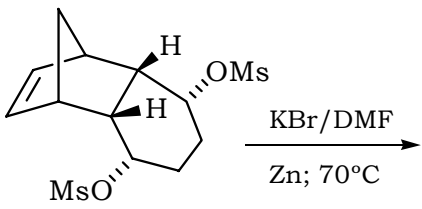

150

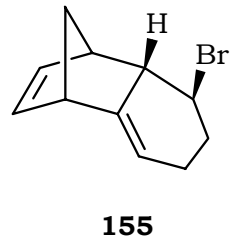

$11 \%$
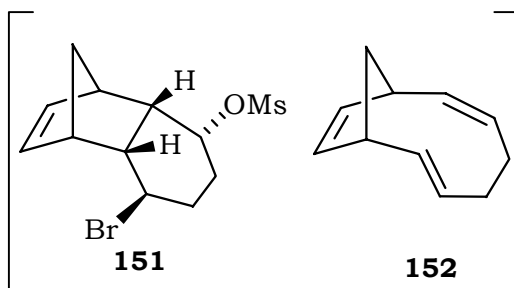

Compostos esperados, porém, não foram isolados!

Esquema 39: Tentativa de Eliminação 1,4 com KBr e Zinco.

Neste ponto do trabalho resolveu-se não mais insistir com esta abordagem e partir para algumas tentativas baseadas na reação de retro-aldol (item III do esquema 25). 


\section{Abordagens Sintéticas Utilizando Quinonas Substituídas nas Reações de Diels-Alder.}

Diante dos insucessos obtidos nas abordagens anteriores, resolveu-se investir em uma nova proposta sintética, que envolve uma reação de Diels-Alder com quinonas substituídas. Esta nova proposta partia da reação entre o ciclopentadieno (43) e a 2,5-di-hidroxibenzoquinona (156), que após sofrer a reação de Diels-Alder, forneceria um intermediário adequado para a síntese de sistemas como 158 (via retro-aldol). A reação de retro-aldol pretendida (esquema 40), já havia sido aplicada pelo nosso grupo de pesquisa a um sistema semelhante. ${ }^{74}$

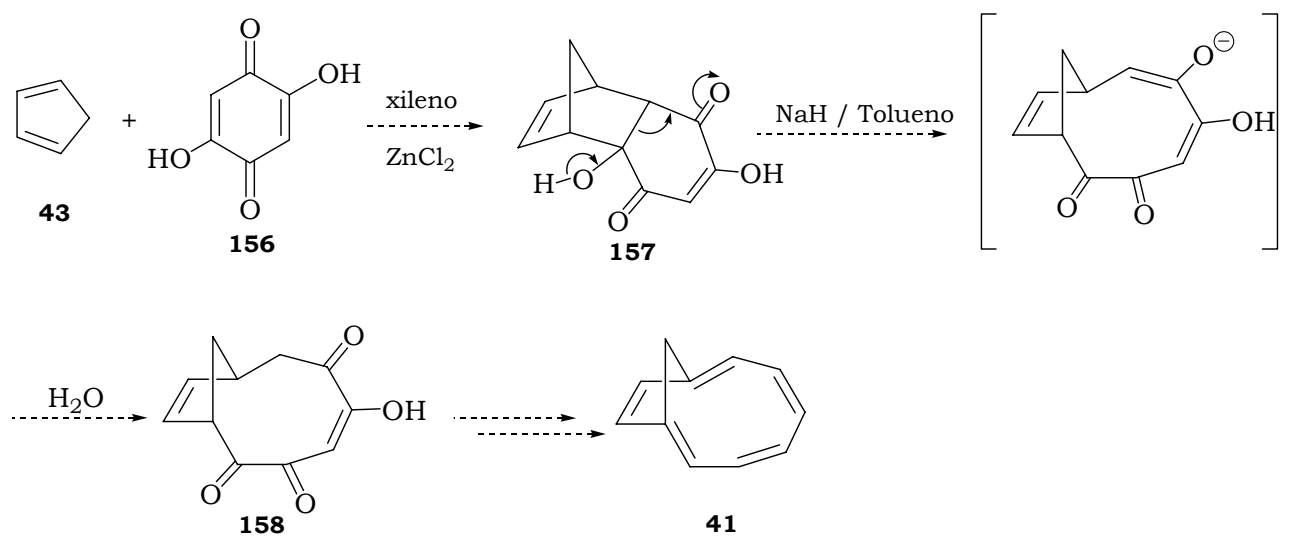

Esquema 40: Nova Proposta Sintética Utilizando a 2,5-di-hidroxibenzoquinona (156).

Um exemplo de certa maneira particular também reforçou o caráter promissor desta nova proposta. Apesar da quinona 160 , que é um produto natural, ${ }^{78}$ possuir uma grande cadeia alquílica a reação desta substância com o dieno 159 é conhecida (esquema $41)^{78}$

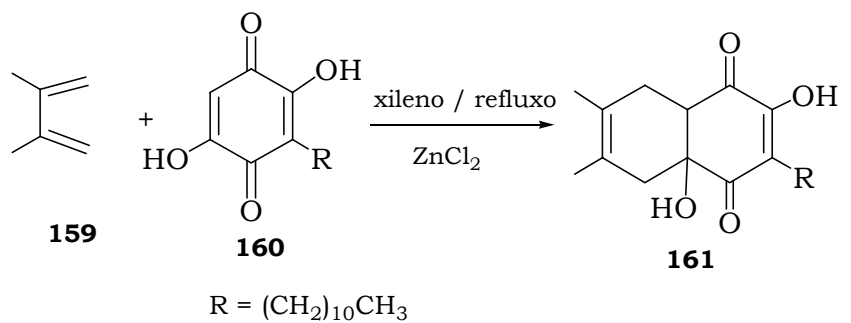

Esquema 41: Reação de Diels-Alder Realizada com a Quinona (157).

Os novos estudos foram iniciados fazendo reagir o ciclopentadieno (43) com a 2,5-di-hidroxibenzoquinona (156) em xileno/ $\mathrm{ZnCl}_{2}$ a refluxo. Já nesta primeira etapa, percebeu-se que o grupo alquil da quinona 160 exercia papel importante, isto porque, a quinona de interesse 156 era extremamente insolúvel em xileno. Muito provavelmente a grande cadeia alcânica da quinona 160 deve deixá-la solúvel em xileno e em muitos outros solventes.

Mesmo diante da insolubilidade de 156 insistiu-se com este teste reacional deixando-se reagir por 24 horas, observando-se apenas a formação do dímero do ciclopentadieno, e de alguns polímeros, além da recuperação parcial de 156. 
Esta reação foi repetida nas mesmas condições em um tubo selado $\left(150^{\circ} \mathrm{C}\right)$ e da mesma forma não se obteve nenhum resultado proveitoso.

Após estes primeiros testes reacionais resolveu-se testar a solubilidade da quinona 156 em vários outros solventes (acetato de etila, metanol, DMSO e THF), sendo que em THF obteve-se o melhor resultado. Neste último solvente foram realizados três testes reacionais, resumidos na tabela 10. Em nenhum dos casos obteve-se o aduto 157.

Tabela 10: Testes Realizados em THF.

\begin{tabular}{|c|c|c|c|c|}
\hline $\begin{array}{c}\text { Materiais de } \\
\text { Partida }\end{array}$ & Temperatura & Catalisador & Tempo & Produtos \\
\hline $\begin{array}{c}43 \\
\text { (4 equivalentes) }\end{array}$ & refluxo & nenhum & $24 \mathrm{~h}$ & $\begin{array}{c}\text { Polímeros e } 156 \\
\text { remanescente }\end{array}$ \\
\hline+ & refluxo & $\mathrm{ZnCl}_{2}$ & $24 \mathrm{~h}$ & $\begin{array}{l}\text { Polímeros e } 156 \\
\text { remanescente }\end{array}$ \\
\hline $\begin{array}{c}156 \\
\text { (1 equivalente) }\end{array}$ & $\begin{array}{c}150{ }^{\circ} \mathrm{C} \\
\text { (tubo selado) }\end{array}$ & $\mathrm{ZnCl}_{2}$ & $24 \mathrm{~h}$ & Polímeros \\
\hline
\end{tabular}

Como a abordagem sintética com quinonas substituídas parecia promissora, resolveu-se modificar a quinona 156, acetilando suas hidroxilas. Esta modificação certamente a tornaria mais solúvel e possivelmente mais reativa para uma reação de Diels-Alder. A acetilação da quinona 156 pôde ser facilmente realizada com $\mathrm{Ac}_{2} \mathrm{O}$ e $\mathrm{HClO}_{4} 10 \%,{ }^{79}$ fornecendo $162 \mathrm{com} 84 \%$ de rendimento.<smiles>CC(=O)OC1=CC(=O)C(OC(C)=O)=CC1=O</smiles>

Esquema 42: Acetilação da Quinona 159.

Em seguida testou-se a reação do composto $162 \mathrm{com}$ ciclopentadieno (43) em benzeno e a $130^{\circ} \mathrm{C}$ (tubo selado), ${ }^{79}$ por 7 horas, obtendo-se o aduto 163 (apenas o isômero endo), com $89 \%$ de rendimento.
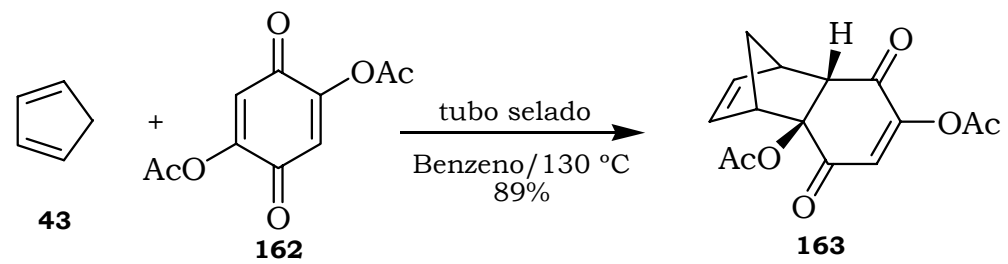

Esquema 43: Sintese do Aduto 163.

Neste ponto, acreditava-se que uma simples hidrólise dos grupos acetato presentes em 163 , forneceria o aduto 157 , ou até já possibilitaria a reação de retro-aldol 
pretendida. Já era esperado que o grupo acetato localizado na junção dos anéis (carbono terciário) fosse mais resistente à reação de hidrólise.

Começou-se por testar uma solução de metanol e $\mathrm{NaOH}$ aquoso (20\%) para realizar a hidrólise dos acetatos de $163 .{ }^{131}$ Assim que se adicionou a solução alcalina a uma mistura contendo 163 e metanol, verificou-se uma mudança na coloração do meio e poucos minutos depois já não havia mais material de partida. Num primeiro momento, acreditava-se que o aduto 163 tinha sofrido apenas uma hidrólise parcial (apenas do acetato ligado à dupla ligação). Após o isolamento do produto formado, as análises de RMN de ${ }^{1} \mathrm{H}$ e ${ }^{13} \mathrm{C}$ (uni e bidimensionais), revelaram um resultado surpreendente, $\mathrm{o}$ composto formado era 164 e com rendimento de $76 \%$ (esquema 43).
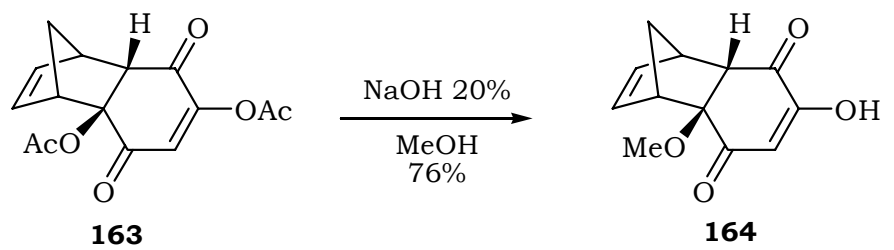

Esquema 43: Primeira Tentativa de Hidrólise dos Acetatos de 163.

Este resultado era no mínimo inesperado principalmente pela entrada do íon metóxido, porém, os experimentos de HMBC e NOE DIFF não deixaram dúvidas quanto à estrutura 164 .

A proposta mecanística para a obtenção de 164 está demonstrada no esquema 44; a adição do tipo 1,4 com íons metóxido parece ser a maneira mais razoável de se explicar a presença de $\left(\mathrm{OCH}_{3}\right)$ neste produto.

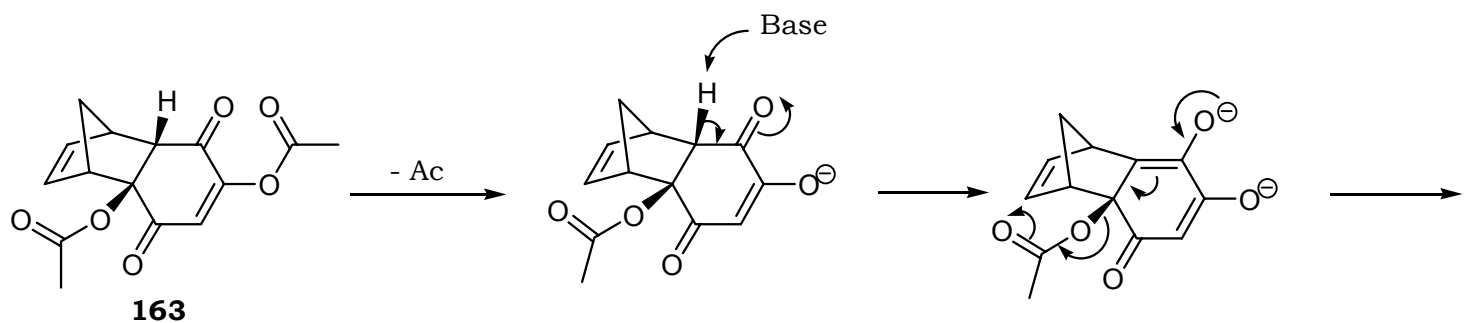

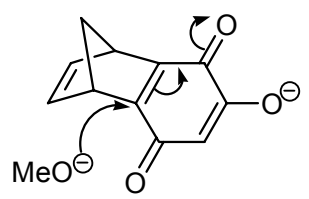<smiles>COC12C(=O)C=C([O-])C(O)=C1C1CC1C21CC1</smiles>
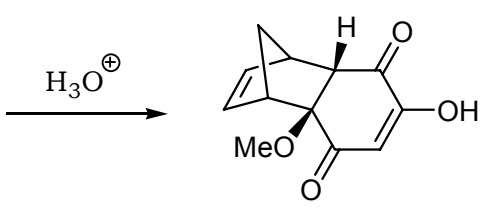

164

Esquema 44: Mecanismo de Adição de Alcóxidos no Composto 163.

Com o objetivo de reafirmar a facilidade com que íons alcóxido realizam adições 1,4 nestas estruturas, resolveu-se testar esta hidrólise nas mesmas condições anteriores, porém agora utilizando etanol como solvente. Como esperado, houve a adição de etóxido em 163, fornecendo $165 \mathrm{com} 70 \%$ de rendimento. 


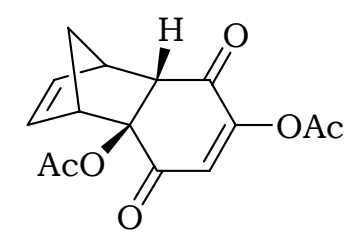

163

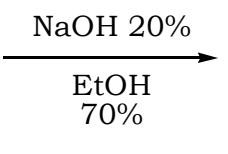

(1)

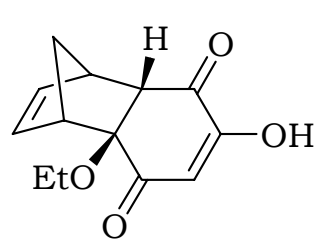

165

Esquema 45: Reação de 163 com Etóxido de Sódio.

Foram realizados ainda outros testes de hidrólise dos acetatos em meio básico $\left(\mathrm{NaOH} / \mathrm{THF} ; \mathrm{K}_{2} \mathrm{CO}_{3}\right.$ em MeOH), porém nenhum dos resultados foram proveitosos.

Algumas outras tentativas foram realizadas em meio ácido tentando-se, por exemplo, reagir $163 \mathrm{com}_{2} \mathrm{SO}_{4} 10 \mathrm{~mol} / \mathrm{L}$ e CTAB à temperatura ambiente. ${ }^{80}$ Após 10 minutos de reação, observou-se o consumo de todo o material de partida e isolou-se o produto 166, proveniente da hidrólise em apenas uma das posições (do acetato ligado à dupla ligação).

Em um outro experimento insistiu-se um pouco mais deixando reagir por um tempo maior ( 8 horas) e mesmo assim o produto formado foi apenas 166 . Ao aquecer o meio reacional até $80^{\circ} \mathrm{C}$ constatou-se a formação de uma mistura polimérica.<smiles>CC(=O)OC1=CC(=O)[C@@]2(OC(C)=O)[C@H]3C=CC(C3)[C@H]2C1=O</smiles>

163

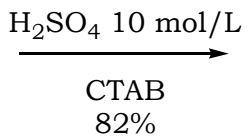

$82 \%$

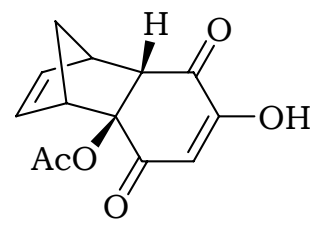

166

Esquema 46: Teste de Hidrólise de 163 em Meio Ácido.

Um outro teste em meio ácido foi realizado tentando promover uma reação de metanólise. O diacetato 163 foi colocado para reagir com metanol e $\mathrm{HCl}$ (quantidades catalíticas). Tanto a temperatura ambiente quanto a refluxo foi obtido apenas o produto 166.

Como última tentativa utilizou-se uma metodologia bastante apropriada para a hidrólise de ésteres relativamente impedidos, uma reação com $\mathrm{NaN}_{3}$ em MeOH/DMF. ${ }^{81}$

Quando o diacetato 163 foi tratado com excesso de $\mathrm{NaN}_{3}$ em $\mathrm{MeOH} / \mathrm{DMF}$ (temperatura ambiente), obteve-se novamente o composto 166, resultado da metanólise do acetato ligado à dupla ligação. Foram realizados outros testes com estes reagentes, porém a refluxo, obtendo-se apenas misturas complexas.

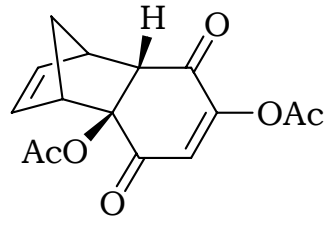

163

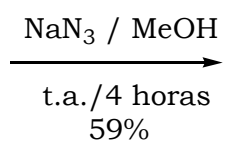

$\%$

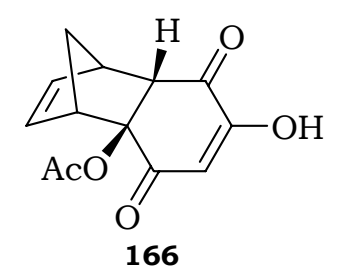

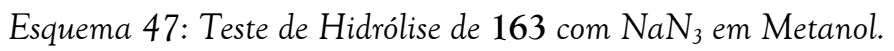


Muitas são as hipóteses para esta dificuldade em obter o produto completamente hidrolisado 156. Talvez, a que não possa ser descartada, é que, sob aquecimento, a hidrólise (ou metanólise) ocorre, mas é acompanhada de uma reação de retro-Diels-Alder e degradação dos compostos formados. De qualquer forma nenhum destes resultados era proveitoso do ponto de vista da síntese pretendida.

De uma maneira geral, todos estes estudos serviram para elevar o conhecimento do grupo no que diz respeito à reatividade de algumas quinonas, de algumas reações que os adutos de Diels-Alder sofrem com facilidade, enfim, para se tirar algum aprendizado. Quanto ao objetivo de produzir um aduto que possibilitasse a reação de retro-aldol (como 157), este não pôde ser alcançado. Foi diante das dificuldades com mais esta abordagem, que se resolveu investir na proposta sintética que envolvia uma cicloadição do tipo $[6+4]$. 


\section{Cicloadição do tipo [6+4] - Uma Nova Abordagem Para a Síntese do Anuleno 41.}

Esta nova abordagem sintética (esquema 27) partiu da cicloadição [6+4] entre o ciclopentadieno (43) e a tropona (139), que forneceu como produto o composto 140 (84\% de rendimento). ${ }^{82}$ Para realizar esta preparação, inicialmente sintetizou-se a tropona (139) através de uma oxidação alílica do ciclo-heptatrieno (167) com $\mathrm{SeO}_{2}$ (39\% de rendimento). ${ }^{83}$

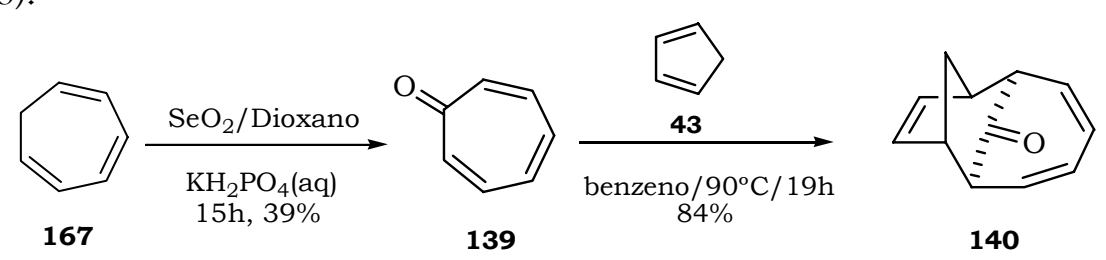

Esquema 48: Sintese do Composto 140.

Em seguida foram realizadas as primeiras tentativas de conversão da cetona 140 na oxima 141. ${ }^{\text {viii }}$ Estas transformações são comumente realizadas com $\mathrm{NH}_{2} \mathrm{OH}$, no entanto, este composto é comercializado na forma de cloridrato $\left(\mathrm{NH}_{2} \mathrm{OH} . \mathrm{HCl}\right)$ e precisa ser gerado no meio reacional na sua forma não protonada. Um procedimento muito comum é utilizar uma solução contendo metanol, $\mathrm{NH}_{2} \mathrm{OH} . \mathrm{HCl}$ e acetato de sódio; ${ }^{84}$ geralmente, nestas condições, a concentração de hidroxilamina é suficiente para que a reação ocorra.

Ao tentar reagir a cetona 140 nas condições descritas acima $\left(\mathrm{NH}_{2} \mathrm{OH} . \mathrm{HCl} / \mathrm{MeOH} / \mathrm{NaOAc}\right)$, o composto 141 foi obtido após 3 dias de reação, porém, os rendimentos referentes aos vários testes realizados, oscilaram entre 30 e $46 \%$, recuperando-se em todos os casos uma boa quantidade de material de partida. Foram realizados muitos experimentos tentando aumentar as quantidades dos reagentes $\left(\mathrm{NH}_{2} \mathrm{OH} . \mathrm{HCl}\right.$ e $\left.\mathrm{NaOAc}\right)$, porém, os melhores resultados não superaram os $46 \%$ de rendimento.

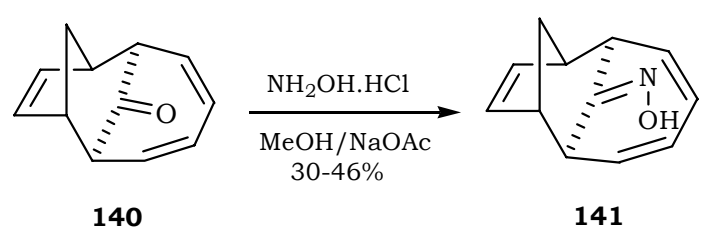

Esquema 49: Síntese do Composto 141 - Método $1 .^{84}$

Nesta reação a espécie nucleofílica é a hidroxilamina $\left(\mathrm{NH}_{2} \mathrm{OH}\right)$. Nas condições utilizadas, provavelmente é estabelecido um equilíbrio em solução entre o cloridato $\left(\mathrm{NH}_{2} \mathrm{OH} . \mathrm{HCl}\right)$ e o acetatato $\left(\mathrm{AcO}^{-}\right)$, de maneira que, a concentração de $\mathrm{NH}_{2} \mathrm{OH}$ não seja suficientemente alta para deslocar os equilíbrios envolvidos na conversão da cetona $\mathbf{1 4 0}$ (bastante impedida) na oxima 141. Se observado o mecanismo desta conversão (esquema 50) fica claro que uma maior concentração de $\mathrm{NH}_{2} \mathrm{OH}$ pode deslocar o equilíbrio no

\footnotetext{
viii Uma outra opção seria a transformação direta da cetona 140 em uma lactona (Rearranjo de BayerVilliger), ao invés de transformá-la antes em uma oxima e depois em uma lactama. No entanto, esta alternativa foi exaustivamente estudada em outra circunstância e em nenhum dos testes obteve-se sucesso.
} 
sentido da oxima 141. Uma outra possibilidade é que os íons piridínio, formados no meio reacional, atuem catalisando a etapa de transferência de $\mathrm{H}^{+}$.

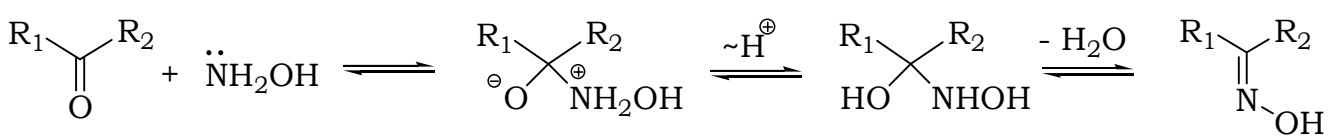

\section{Esquema 50: Equilibrios Envolvidos na Formação de Oximas.}

Sendo assim, resolveu-se utilizar apenas, piridina, que atua como base e solvente ao mesmo tempo, ao invés de metanol e acetato de sódio. ${ }^{85}$ Os resultados foram excelentes, pois a cetona 140 foi totalmente convertida na oxima 141 em apenas 3 horas com um rendimento de $80 \%$.

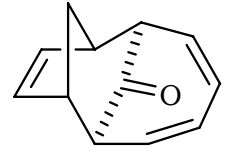

140

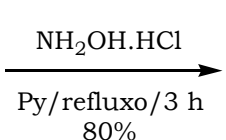

$80 \%$

Esquema 51: Síntese do Composto 141 - Método $2 .^{85}$

Em seguida, a oxima 141 foi transformada na lactama 142 através do rearranjo de Beckmann, ${ }^{86}$ na presença de $\mathrm{TsCl}$, piridina e DMAP. Nesta conversão obteve-se um rendimento de 59\%, comum em reações deste tipo.

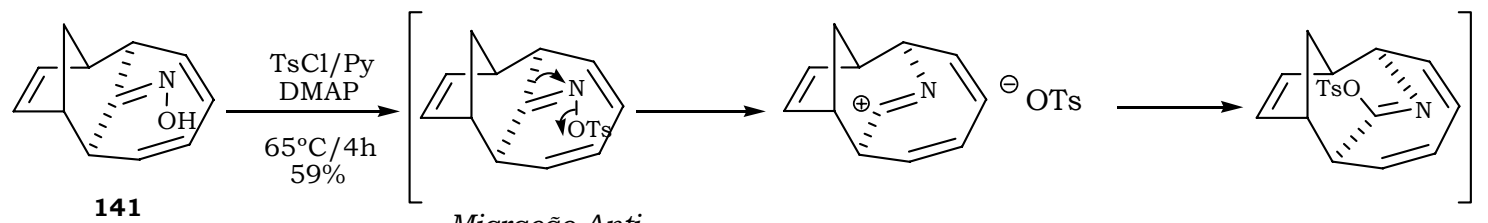

41

Migração Anti

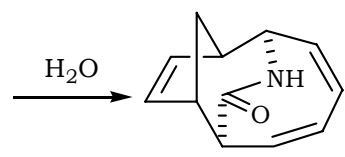

142

Esquema 52: Sintese do Composto 142 - Rearranjo de Beckmann.

Após obtido o composto 142, acreditava-se que uma simples reação de hidrólise da função lactama pudesse fornecer o sistema bicíclico 143, que já possuía grande semelhança com anuleno 41 (esquema 53).

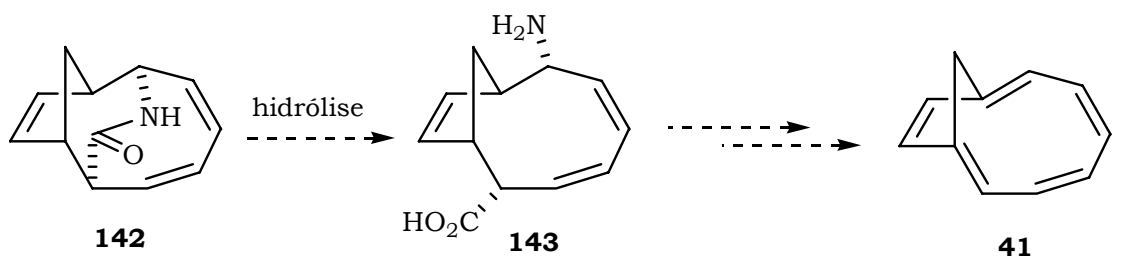

Esquema 53: Próximas Etapas Pretendidas. 
As primeiras tentativas de hidrólise foram realizadas em meio básico, utilizandose soluções aquosas de $\mathrm{NaOH}(10,20,30 \%)$. Já neste primeiro teste, notou-se que a lactama 142 apresenta uma considerável resistência à hidrólise.

As reações com estas soluções alcalinas foram realizadas à temperatura ambiente e a refluxo $(24 \mathrm{~h})$, sendo que, em nenhum dos casos observou-se a formação de um produto reacional; apenas o material de partida 142 foi recuperado.

Convencidos de que esta hidrólise não ocorreria com facilidade, tentou-se utilizar soluções de metóxido de sódio em metanol (10 e 20\%). Acreditava-se que o íon metóxido, sendo um nucleófilo mais forte, poderia favorecer a formação do produto desejado. Novamente os resultados não foram satisfatórios; mesmo após ficar sob refluxo por várias horas, o material de partida foi recuperado e nenhum produto reacional foi obtido.

A próxima alternativa era tentar uma hidrólise ácida, evitada até o momento devido à presença de algumas ligações duplas na lactama 142. O primeiro teste realizado foi em ácido sulfúrico aquoso $(3 \mathrm{~mol} / \mathrm{L})$ a temperatura ambiente. Após várias horas de reação não se observou nenhum produto reacional. A reação foi levada a refluxo (24 h), e neste caso, observou-se a presença de alguns polímeros insolúveis e de material de partida 142.

Quando se tentou utilizar uma mistura de $\mathrm{MeOH}$ e $\mathrm{H}_{2} \mathrm{SO}_{4}(9 \mathrm{~mol} / \mathrm{L}){ }^{87}$ apropriada para a metanólise de amidas impedidas, observou-se a completa degradação da lactama 142.

Uma última tentativa foi testar a redução de $142 \mathrm{com} \mathrm{LiAlH}_{4}$. Neste caso tinha-se o indicativo de que a formação de uma amina cíclica do tipo 169 (esquema 55) era possível segundo alguns exemplos já conhecidos na literatura (esquema 54). ${ }^{88}$

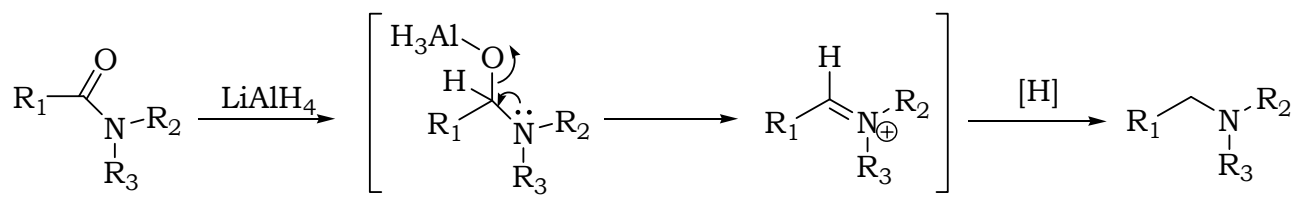

Esquema 54: Conversão de Algumas Amidas em Aminas Utilizando $\mathrm{LiAlH}_{4}{ }^{88}$

A reação de 142 na presença de $\mathrm{LiAlH}_{4}$ e THF forneceu uma mistura complexa de produtos, dentre os quais não foi identificado nenhum dos produtos esperados (168 e 169).

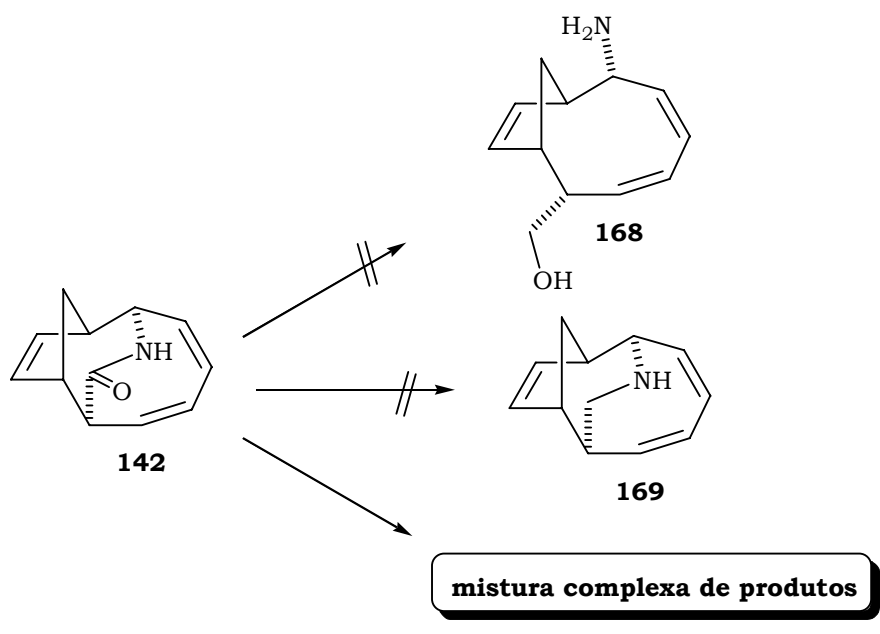


Esquema 55: Reação de $142 \mathrm{com} \mathrm{LiAlH}_{4}$.

Parecia evidente a necessidade de se realizar alguma transformação em 142 que pudesse favorecer a quebra da ligação $\mathrm{C}-\mathrm{N}$ desta lactama. A primeira alternativa foi inserir um grupo captor de elétrons (p-toluenosulfonil) no nitrogênio da lactama 142. Isso aumentaria o caráter eletrofílico da carbonila e ao mesmo tempo facilitaria a quebra da ligação $\mathrm{C}-\mathrm{N}$.

Ao reagir a lactama $142 \mathrm{com}$ a base LiHMDS e em seguida com TsCl, obteve-se a lactama tosilada 170 com rendimento de $98 \%{ }^{89}$

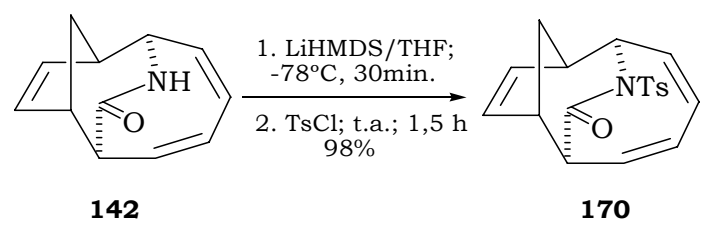

Esquema 56: Preparação da Lactama Tosilada 170.

Conforme mostrado no esquema 54, em geral, amidas podem ser transformadas em aminas, quando reduzidas por $\mathrm{LiAlH}_{4}$. No entanto, amidas substituídas no nitrogênio por grupos captores de elétrons, podem fornecer o produto de quebra da ligação C-N, seguida da redução do grupo aldeído formado.

Sendo assim, reagiu-se o composto $170 \mathrm{com} \mathrm{LiAlH}_{4} / \mathrm{THF}$ à temperatura ambiente, obtendo-se o sistema bicíclico 171 com $96 \%$ de rendimento. ${ }^{90}$

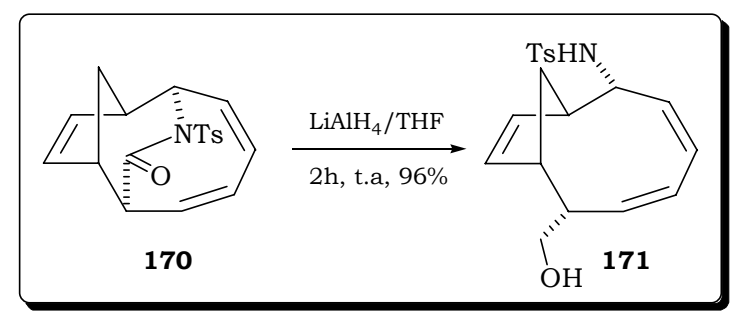

Esquema 57: Preparação do Composto 171.

A preparação do biciclo 171 foi recebida com certo otimismo com relação à continuidade da síntese pretendida. Além disso, uma busca na literatura realizada mais recentemente, revelou a existência de poucas preparações de sistemas como 171, dentre as quais, duas foram realizadas pelo nosso grupo de pesquisa, uma anterior, ${ }^{74}$ e esta até aqui descrita. ${ }^{91}$ A metodologia aqui desenvolvida parece representar uma boa e eficiente alternativa para a clivagem de amidas com grande impedimento estérico. Cabe ainda destacar a importância que estruturas como 171 possuem dentro da química sintética, uma vez que são intermediários de algumas sínteses de produtos naturais relevantes. ${ }^{65}$

Quando se observa a estrutura 171, pode-se planejar várias modificações que forneçam o anuleno desejado (o foco desta parte do trabalho). Do ponto de vista sintético, faltava ainda inserir duas insaturações no anel de 10 membros de 171 .

A primeira alternativa experimentada foi eliminar o grupo $\mathrm{OH}$ de 171 , deixando uma dupla exocíclica, que poderia ser isomerizada mais tarde. Para esta transformação, o álcool 171 foi convertido no mesilato 172 , pela reação com $\mathrm{MsCl}$ e piridina $(93 \%$ de 
rendimento). ${ }^{70}$ Em seguida, o mesilato 172 foi transformado em 173 (rendimento de $57 \%),{ }^{92}$ conforme mostrado no esquema 58.

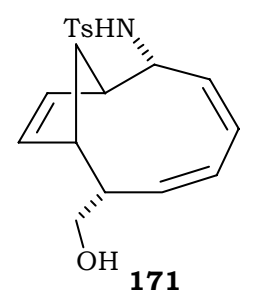

171

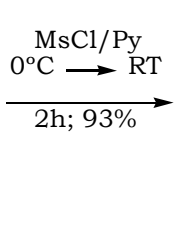

Esquema 58: Preparação do Composto 173

O próximo passo era introduzir uma dupla ligação no anel carbônico eliminando o grupo sulfonamida (NHTs). No entanto, este grupo não é um bom grupo de saída em se tratando de uma eliminação $1,2^{93}$ e precisa ser tosilado novamente ou transformado em um sal quaternário para ser eliminado.

A transformação da sulfonamida 173 na disulfonimida 174 possibilitaria realizar uma eliminação térmica do grupo $\left(\mathrm{NTs}_{2}\right) .{ }^{93}$ Nesta transformação o hidrogênio da "cabeça de ponte" de 174 está devidamente disposto para eliminação térmica, conforme mostrado no esquema 59.

O composto 174 foi preparado, ${ }^{93 \mathrm{~d}}$ mas em baixo rendimento $(12$ - 17\%) e, além disso, sofria decomposição em poucas horas.

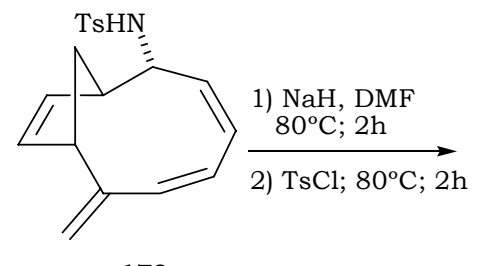

173

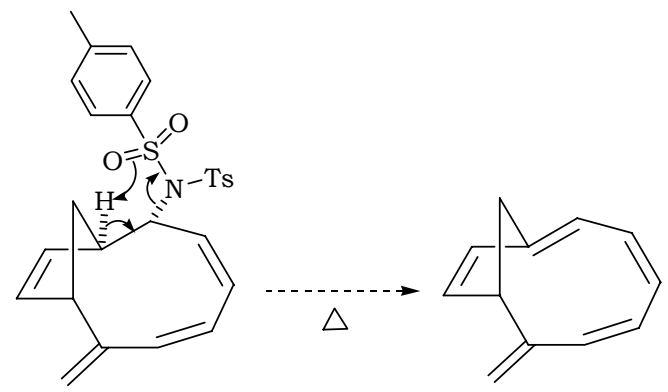

174
175

Esquema 59: Preparação do Composto 174.

A ineficiência na obtenção de $\mathbf{1 7 4}$, bem como sua baixa estabilidade, levou ao abandono da tentativa de eliminar o grupo sulfonamida (NHTs) por este caminho.

Uma outra possibilidade era tentar alquilar exaustivamente o nitrogênio do grupo NHTs de 173, e realizar uma eliminação do tipo Hoffmann. Para esta eliminação resolveu-se verificar se a estereoquímica cis do produto de alquilação de 173 , permitiria a eliminação desejada.

De fato, a eliminação de Hoffmann é favorecida para grupos que se encontrem numa relação trans (antiperiplanares). ${ }^{94}$ Contudo, existem alguns casos em que esta eliminação pode ocorrer via E1 ${ }^{95}$ ou E1cb. ${ }^{96} \mathrm{Um}$ dos exemplos que dão um bom indicativo de uma eliminação do tipo E1 pode ser visto no esquema $60 .{ }^{95 a}$ 
<smiles>COc1ccc(C=C(C)C)cc1OC</smiles>

Esquema 60: Eliminação de Hoffmann via E1.

Esta eliminação de Hoffmann ocorre na ausência de base, evidenciando bem o mecanismo proposto (E1). O composto 176 é simplesmente aquecido em dietil cetona a $100^{\circ} \mathrm{C}$, fornecendo 177 .

Em outro trabalho, ${ }^{96}$ pode ser observada a conversão da trans-2-fenil-ciclohexilamina (178) em 1-fenil-ciclo-hexeno (179), evidenciando a ocorrência de uma eliminação de Hoffmann mecanismo do tipo E1cb (esquema 61).<smiles>C[N+]1(C)C2CCC1CC(c1ccccc1)C2</smiles>

178<smiles>C1=C(c2ccccc2)CCCC1</smiles><smiles>CCCC1C2CCCC(C2)C1[N+](C)(C)C</smiles>

Esquema 61: Eliminação de Hoffmann via E1cb.

Diante destes exemplos favoráveis, resolveu-se converter o composto 173 em 181 pela reação com excesso de $\mathrm{CH}_{3} \mathrm{I}$ em metanol e $\mathrm{K}_{2} \mathrm{CO}_{3} \cdot{ }^{97}$ De forma não muito inesperada, foi obtido apenas o composto 180 , deixando claro que o nitrogênio ligado ao grupo tosilato não era muito nucleofílico, e que por isso, o composto 181 não foi obtido.

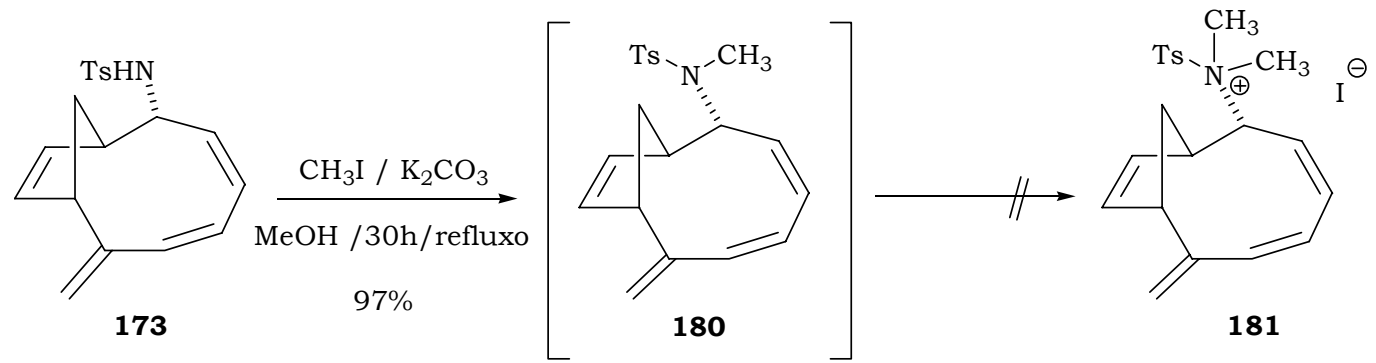

Esquema 62: Alquilação de 173 com Iodeto de Metila. 
Para preparar o sal de amônio 181 a partir de 180 , resolveu-se testar um alquilante bem mais reativo; o sal $\left(\mathrm{CH}_{3}\right)_{3} \mathrm{O}^{+} \mathrm{BF}_{4}^{-}$. A síntese do trimetiloxônio tetrafluorborato $\left.\left(\mathrm{CH}_{3}\right)_{3} \mathrm{O}^{+} \mathrm{BF}_{4}^{-}\right)$requer o uso de éter dimetílico, que foi preparado a partir da desidratação de metanol com $\mathrm{H}_{2} \mathrm{SO}_{4}$ concentrado (equação 7). ${ }^{98}$

$$
2 \mathrm{CH}_{3} \mathrm{OH}_{(\mathrm{l})} \stackrel{\mathrm{H}_{2} \mathrm{SO}_{4} \text { (conc.) }}{\longrightarrow} \mathrm{CH}_{3} \mathrm{OCH}_{3(\mathrm{~g})}+\mathrm{H}_{2} \mathrm{O}_{(\mathrm{l})}
$$

(Equação 7)

Em seguida o sal de oxônio foi preparado pela reação do éter dimetílico com $\mathrm{BF}_{3} . \mathrm{OEt}_{2}$ e epicloridrina (equação 8$) .{ }^{98}$

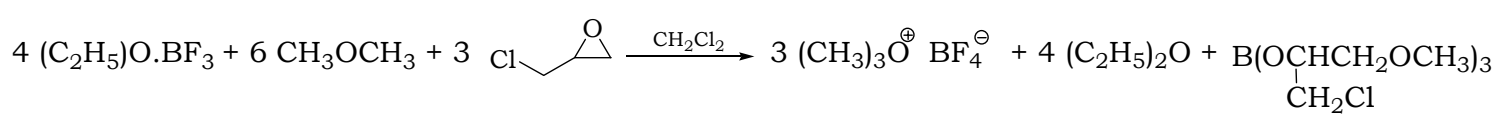

(Equação 8)

A reação entre o composto 180 e o $\mathrm{Me}_{3} \mathrm{O}^{+} \mathrm{BF}_{4}^{-}$(2 equivalentes) em diclorometano anidro, forneceu uma mistura contendo o composto 183 e alguns polímeros insolúveis.

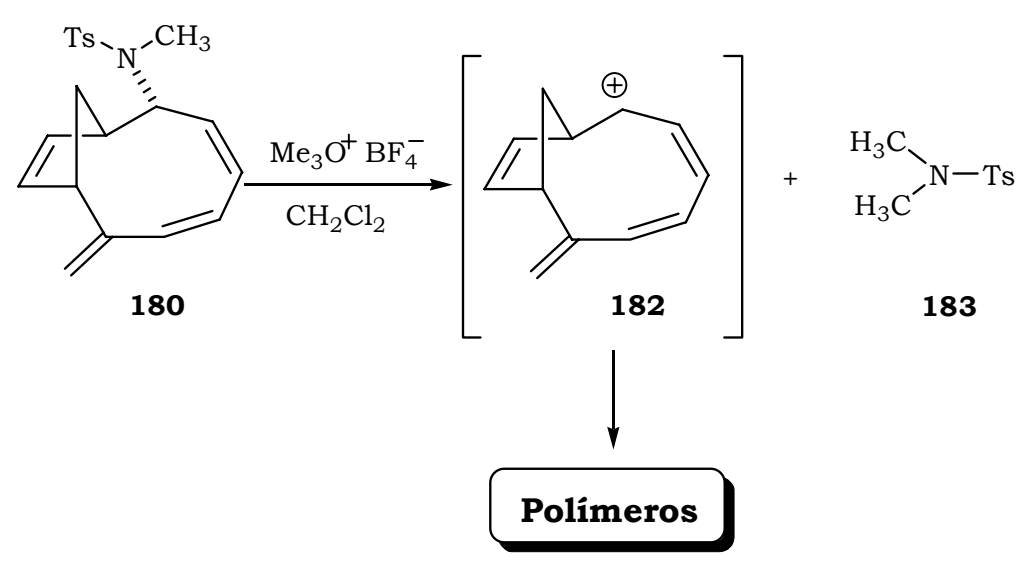

Esquema 63: Reação de 180 com $\mathrm{Me}_{3} \mathrm{O}^{+} \mathrm{BF}_{4}^{-}$.

Este resultado foi recebido com certo pessimismo, pois, a formação do composto 183 dava uma forte indicação de que o composto 180 estava sofrendo a alquilação e o sal quaternário formado era eliminado facilmente na forma da sulfonamida 183. A indicação de que o carbocátion 182, um possível intermediário para a eliminação desejada, estava efetivamente se formando era muito forte. No entanto, ao invés de sofrer uma eliminação e possibilitar a formação do anuleno 41, este carbocátion sofria apenas polimerização, deixando fortes dúvidas sobre a possibilidade de sintetizar o anuleno 41, desta ou de qualquer outra forma.

Restava ainda testar esta reação na presença de uma base (compatível com o meio reacional) para tentar favorecer a eliminação do hidrogênio da "cabeça da ponte" do provável carbocátion 182 .

A reação de $180 \mathrm{com} \mathrm{Me}_{3} \mathrm{O}^{+} \mathrm{BF}_{4}^{-}$foi realizada novamente, agora na presença de $\mathrm{K}_{2} \mathrm{CO}_{3}$ anidro, e da mesma maneira foi observada a formação da sulfonamida 183 e de polímeros. 
Este último teste reacional torna evidente a dificuldade de eliminar o hidrogênio da "cabeça da ponte" da estrutura 182. Já eram esperadas altas tensões de anel quando fossem introduzidas as duas ligações duplas que faltavam para dar origem ao anuleno 41, tensões estas que poderiam ser compensadas pela existência de uma estabilização aromática em 41.

Os resultados experimentais aqui apresentados não devem ser tomados como uma prova definitiva da não possibilidade de preparar o 1,4-metano[10]anuleno (41). No entanto, foi suficiente para que estes estudos fossem, por hora, interrompidos.

Se realmente a dificuldade de se preparar o anuleno 41 provém da alta tensão introduzida pelas ligações duplas nas posições 1,4 (cabeça de ponte), especialmente quando a ponte do biciclo é do tipo metano, pode ser interessante, no futuro, investir algum esforço para preparar os anulenos 41a e 41 b.

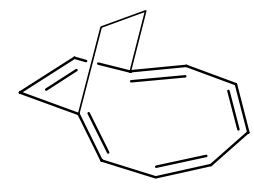

$41 \mathrm{a}$

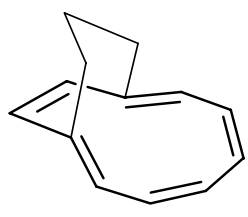

41b

Figura 38: 1,4-Etano e 1,4-Propano[10]Anuleno.

Seria assim possível verificar definitivamente não só a viabilidade de preparação de [10]anulenos com pontes nas posições 1,4, como também a existência e a variação do caráter aromático conforme as diferenças estruturais.

Por hora, estes insucessos com as abordagens sintéticas incentivaram ainda mais a realização de alguns estudos teóricos que pudessem apontar (qualitativamente e quantitativamente) a existência de aromaticidade no anuleno 41. Estes estudos estão descritos na próxima seção. 



\section{Aromaticidade em Metano[10]Anulenos}





\section{Aromaticidade em Metano[10]Anulenos.}

Nesta parte do trabalho serão descritos os estudos sobre a existência e a determinação quantitativa da aromaticidade em três metano[10]anulenos; o 1,4metano[10]anuleno (41), o 1,5-metano[10]anuleno (40) e o 1,6-metano[10]anuleno (14). Realizar estes estudos com este conjunto de compostos foi de fundamental importância, pois, os anulenos 14 e 40 já foram sintetizados e suas propriedades aromáticas são bem conhecidas. Os resultados teóricos obtidos para os anulenos 14 e 40 serviram como parâmetro de comparação para a avaliação das propriedades do anuleno 41. Estes estudos encontram-se atualmente submetidos para publicação ${ }^{99}$ e por isso serão destacados aqui os principais resultados obtidos através de diferentes critérios de avaliação da aromaticidade. Todos os métodos e índices teóricos, aqui utilizados, encontram-se descritos na seção 1.2 sobre "Aromaticidade".

\section{Estrutura dos Metano[10]Anulenos 41, 40 e 14.}

Primeiramente as estruturas dos anulenos 41,40 e 14 foram otimizadas ${ }^{100}$ com o modelo B3LYP/6-311+G(d,p). ${ }^{\text {ix }}$ Em seguida, foram avaliados alguns parâmetros como os comprimentos de ligação ao longo do perímetro dos anéis dos três anulenos (de C1 até C10), alguns ângulos de ligação e alguns ângulos diedros, especialmente nas imediações das pontes (figura 39).

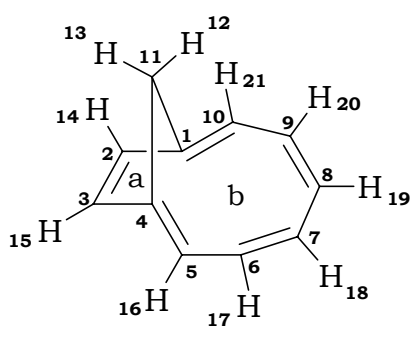

41
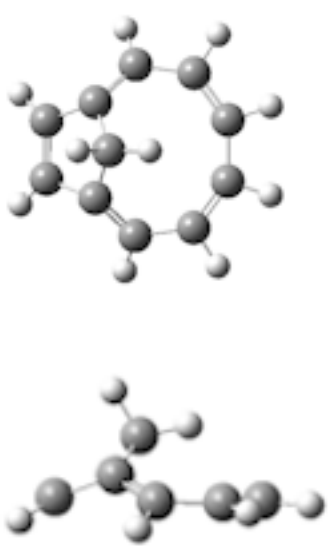

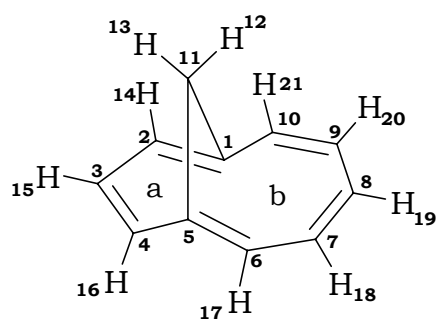

40
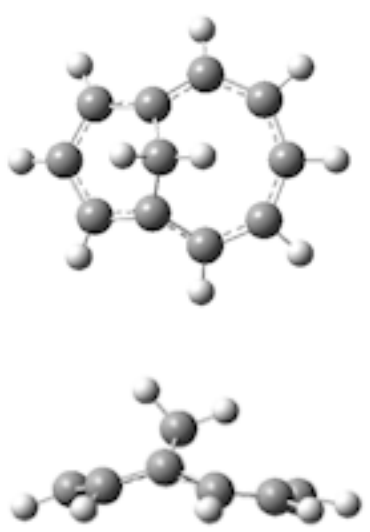

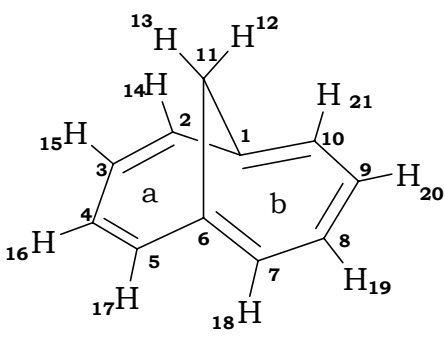

14
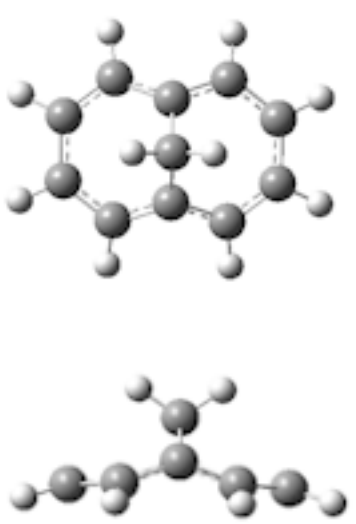

Figura 39: Estruturas dos Metano[10]Anulenos 41, 40 e $14 .{ }^{101}$

\footnotetext{
ix Em todos os cálculos realizados nesta parte do trabalho (sobre aromaticidade) foi utilizado o modelo B3LYP/6-311+G(d,p).
} 
É bem conhecido que, os compostos com estabilização aromática apresentam uma série de propriedades características, e uma delas é a equalização dos comprimentos de ligação ao longo do anel ressonante. Desta forma, uma maneira simples utilizada para avaliar a aromaticidade dos anulenos 41,40 e 14, foi verificar a variação dos comprimentos de ligação. Na tabela 11 estão listados todos os comprimentos das ligações $\mathrm{C}-\mathrm{C}$ ao longo dos anéis (de $\mathrm{C} 1$ até $\mathrm{C} 10$ ) dos anulenos em estudo.

Tabela 11: Comprimentos de Ligação ao Longo dos Anéis de 41, 40 e 14.

\begin{tabular}{ccccc}
\hline & & \multicolumn{3}{c}{ Anulenos } \\
\cline { 3 - 5 } Ligações & Comprimento das Ligações $(\AA)$ & 41 & 40 & 14 \\
\hline 1 & C1-C2 & 1,446 & 1,403 & 1,408 \\
2 & C2-C3 & 1,383 & 1,412 & 1,392 \\
3 & C3-C4 & 1,446 & 1,412 & 1,424 \\
4 & C4-C5 & 1,358 & 1,403 & 1,392 \\
5 & C5-C6 & 1,441 & 1,392 & 1,409 \\
6 & C6-C7 & 1,389 & 1,406 & 1,409 \\
7 & C7-C8 & 1,456 & 1,415 & 1,392 \\
8 & C8-C9 & 1,389 & 1,416 & 1,424 \\
9 & C9-C10 & 1,441 & 1,406 & 1,390 \\
10 & C10-C1 & 1,358 & 1,392 & 1,408 \\
\hline & média & 1,411 & 1,406 & 1,405 \\
& (Variância) $\sigma^{2}(C-C)$ & $136,0 \times 10^{-5}$ & $6,63 \times 10^{-5}$ & $15,0 \times 10^{-5}$ \\
& (Desvio Padrão) $\sigma(C-C)$ & $3,68 \times 10^{-2}$ & $0,81 \times 10^{-2}$ & $1,22 \times 10^{-2}$ \\
\hline
\end{tabular}

A estrutura do 1,4-metano[10]anuleno (41) foi a que apresentou a maior variância e o maior desvio padrão, indicando que os comprimentos de ligação neste anuleno estão mais alternados. Para os metano[10]anulenos 40 e 14 os valores encontrados para a variância e o desvio padrão foram bem menores e semelhantes entre si. Por este critério estatístico é esperado que a aromaticidade em 41(caso haja) seja menor que em 40 e 14.

Quanto aos ângulos de ligação pode-se dizer que, quaisquer valores que se distanciarem do valor ideal para um carbono $\mathrm{sp}^{2}\left(120^{\circ}\right)$, estarão contribuindo para o surgimento de tensões no anel (tabela 12 e figura 40). 
Tabela 12: Ângulos de Ligação ao Longo dos Anéis de 41, 40 e 14.

\begin{tabular}{ccccc}
\hline & & \multicolumn{3}{c}{ Anulenos } \\
\cline { 3 - 5 } Ângulos & Ângulos de Ligação & $\mathbf{4 1}$ & $\mathbf{4 0}$ & $\mathbf{1 4}$ \\
\hline 1 & C1C2C3 & 107,9 & 116,9 & 122,5 \\
2 & C2C3C4 & 108,0 & 121,3 & 127,7 \\
3 & C3C4C5 & 130,0 & 117,0 & 127,7 \\
4 & C4C5C6 & 123,2 & 128,7 & 122,5 \\
5 & C5C6C7 & 135,0 & 123,7 & 122,5 \\
6 & C6C7C8 & 142,7 & 133,9 & 127,7 \\
7 & C7C8C9 & 142,7 & 138,3 & 127,7 \\
8 & C8C9C10 & 134,9 & 133,9 & 127,7 \\
9 & C9C10C1 & 123,2 & 123,7 & 122,6 \\
10 & C10C1C2 & 129,9 & 128,7 & 126,6 \\
\hline 11 & C1C11C4 & 98,6 & - & - \\
12 & C1C11C5 & - & 105,0 & - \\
13 & C1C11C6 & - & - & 99,6 \\
\hline
\end{tabular}

Pela análise dos valores lançados em gráfico, fica fácil perceber que os ângulos de ligação especialmente do anulenos 40 e 14 diferem menos do valor ideal (120 ) do que no anuleno 41 , indicando que os anulenos 40 e 14 devem estar menos tencionados que 41 (figura 39).
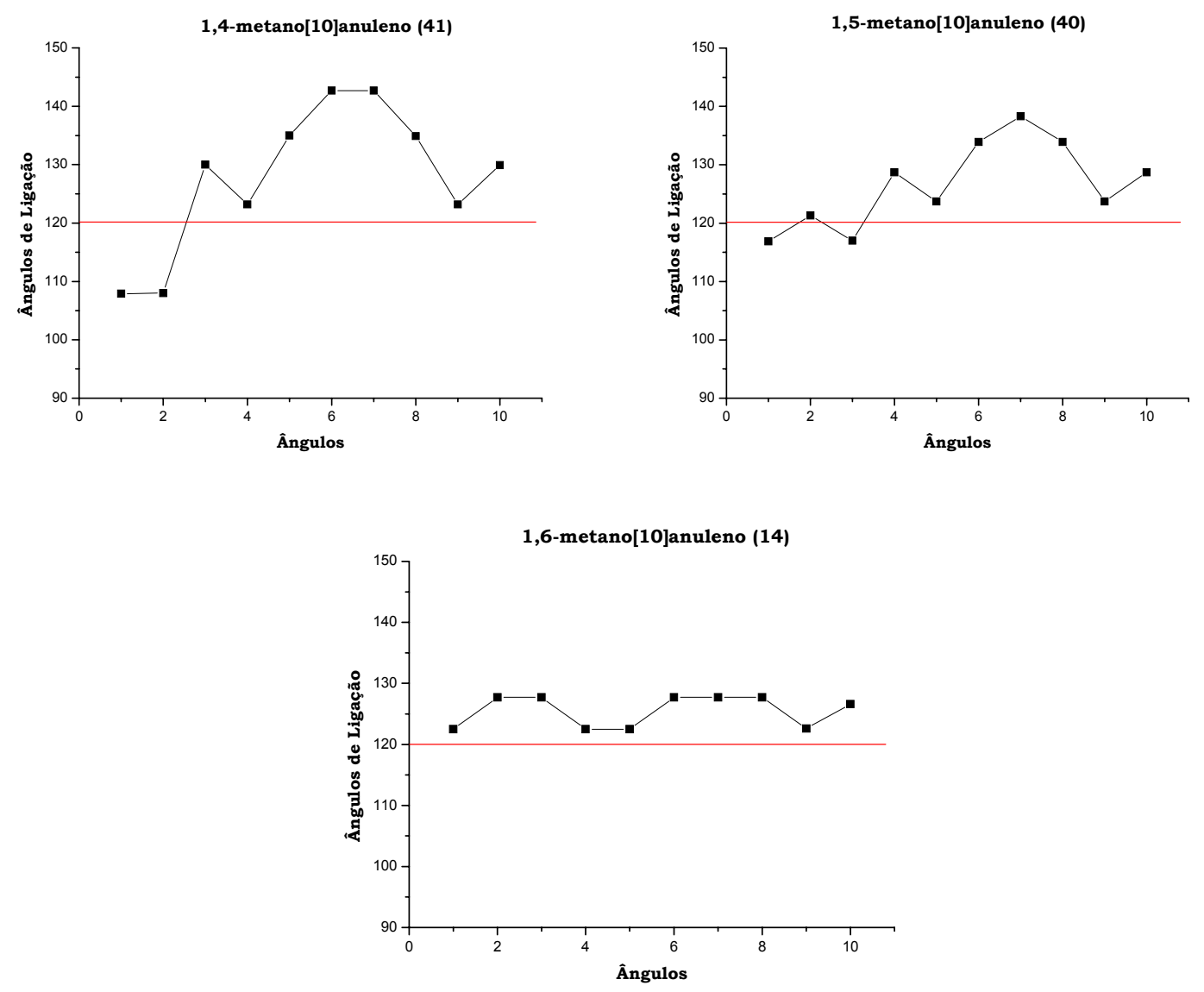

Figura 40: Variação dos Ângulos de Ligação nos Anéis de 41, 40 e 14. 
Também, a análise de alguns dos ângulos diedros, localizados nas imediações das pontes, pode dar uma boa idéia a respeito da planaridade de cada anuleno. Alguns destes ângulos encontram-se destacados em negrito na tabela 13; se considerarmos as suas variações em relação a um valor ideal de $\pm 180^{\circ}$ (situação onde os sistemas em análise são totalmente planares), todos estão fora da situação ideal. No entanto, pode-se dizer que a planaridade dos anulenos em estudo segue a seguinte ordem: $41<40<14$.

Tabela 13: Alguns Ângulos Diedros nas Imediações das Pontes de 41, 40 e 14.

\begin{tabular}{ccccc}
\hline & & \multicolumn{3}{c}{ Anulenos } \\
\cline { 1 - 3 } \cline { 3 - 5 } Ângulos Diedros & & 41 & 40 & 14 \\
\hline C1C2C3C4 & & 0,0 & $-12,7$ & $-19,2$ \\
C2C3C4C5 & & $-129,0$ & 12,7 & 0,0 \\
C3C4C5C6 & & 139,7 & $-137,6$ & 19,2 \\
C4C5C6C7 & & $-25,2$ & 142,1 & $-144,6$ \\
C5C6C7C8 & & $-5,0$ & $-17,2$ & 144,6 \\
\hline
\end{tabular}

\section{Energias Relativas dos Anulenos 41, 40 e 14.}

Uma outra maneira de avaliar a aromaticidade relativa destes anulenos é pela comparação das energias obtidas nas otimizações de cada estrutura. Como estes compostos são isômeros, e contém átomos com as mesmas hibridizações, a diferença de energia entre eles pode ser tomada como uma medida direta dos efeitos de estabilização/desestabilização existentes em cada um destes compostos. Na tabela 14 estão relacionadas as energias dos anulenos 41, 40 e 14; também estão presentes as diferenças entre elas.

Tabela 14: Energias e Energias Relativas dos Anulenos 41, 40 e 14 Obtidas com B3LYP/6-311+G(d,p).

\begin{tabular}{ccc}
\hline Anulenos & $\mathrm{E}+\mathrm{ZPE}($ Hartree $)$ & $\Delta \mathrm{E}\left(\mathrm{kcal} . \mathrm{mol}^{-1}\right)$ \\
\hline 41 & $-424,997006$ & 40,44 \\
40 & $-425,035037$ & 16,58 \\
14 & $-425,061458$ & 0,00 \\
\hline
\end{tabular}

Por estes valores pode-se concluir que a estabilidade relativa entre estas estruturas segue a seguinte ordem: $41 \ll 40<14$.

Quanto à esta diferença expressiva de energia entre 41 e $14(40,44 \mathrm{kcal} / \mathrm{mol})$ e 41 e $40(23,86 \mathrm{kcal} / \mathrm{mol})$ pode-se dizer que ela é proveniente ou das tensões de anel, mais acentuadas no 1,4-metano[10]anuleno (41), ou da menor ou não existência de estabilização aromática em 41. No entanto, os valores das energias relativas dão apenas uma idéia do efeito global (balanço entre as energias de tensões de anel/pontes e da estabilização aromática existente), mas não descrevem cada efeito de maneira independente.

Para avaliar separadamente os efeitos de tensão nos anéis e nas pontes, foram sugeridas algumas reações homodesmóticas, conforme mostrado adiante. 


\section{Reações Homodesmóticas. ${ }^{27}$}

As reações homodesmóticas propostas para estes anulenos estão mostradas na tabela 15. Note que nestas reações hipotéticas o número de átomos e as hibridizações são mantidos durante a reação. Para a montagem e realização dos cálculos termoquímicos $\left(\Sigma \mathrm{E}_{\text {(produtos) }}-\Sigma \mathrm{E}_{\text {(reagentes) }}\right)$ que é chamada de $\mathrm{SE}(\mathrm{HD})$ ("homodesmotic steric energy") foram considerados os reagentes e produtos otimizados com o mesmo modelo quântico, B3LYP/6-311+G(d,p).

De certa forma, os valores obtidos nas três reações traduzem exatamente a diferença de energia entre cada anuleno. No entanto, na forma de reação química, fica mais evidente o quanto o conteúdo energético do 1,4-metano[10]anuleno (41) é maior. Pela tabela 15, podem ser verificados valores positivos das energias das reações dos anulenos 40 e 14 (10,02 e 26,60 kcal/mol, respectivamente), indicando que o conteúdo de energia dos produtos (não aromáticos) é maior que o conteúdo de energia dos reagentes, sendo isto um forte indício da existência de aromaticidade nos anulenos 40 e 14. Para a reação do anuleno 41 é obtida uma diferença de energia negativa $(-13,84 \mathrm{kcal} / \mathrm{mol})$ indicando que, ao perder a ponte, este composto libera energia, e que havia uma forte tensão no sistema, provavelmente, sem estabilização aromática. Por estes resultados é possível inferir sobre a estabilização aromática nestes anulenos da mesma maneira que pelas energias relativas das estruturas. $41 \ll 40<14$. Há também um forte indício de que 41 não deve ser aromático.

Tabela 15: Reações Homodesmóticas Propostas para os Anulenos 41, 40 e 14.

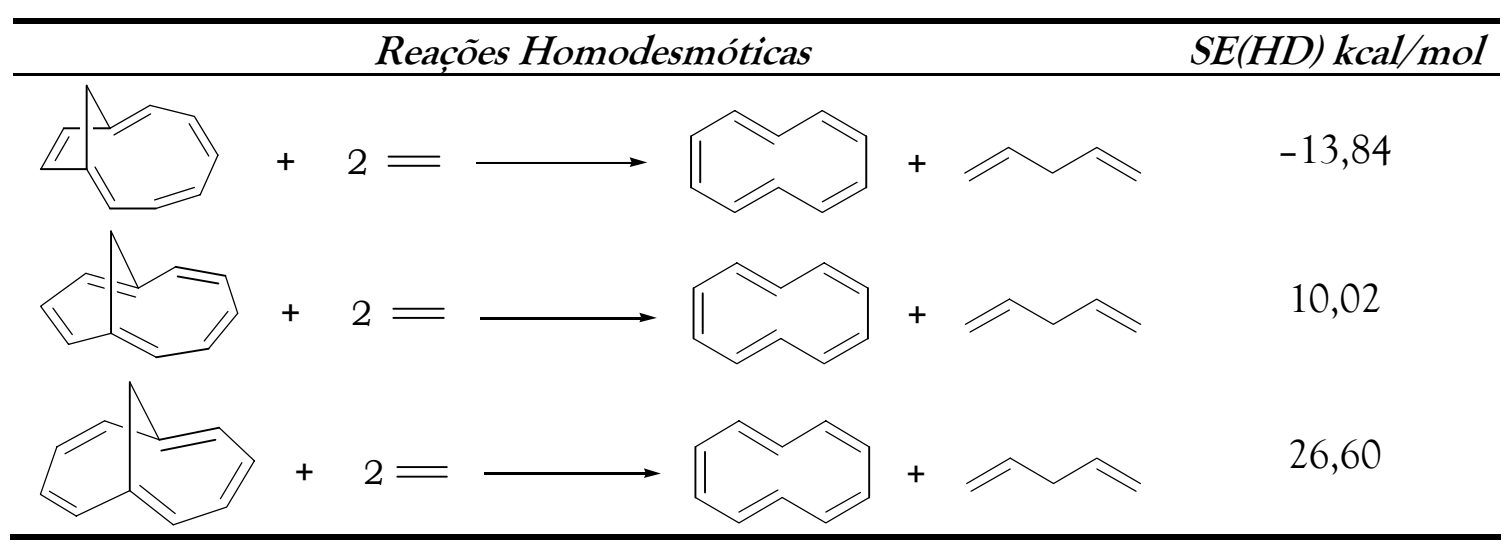

Para avaliar o quanto os anéis e as pontes absorvem tensão separadamente, foram realizados alguns outros cálculos. Primeiramente realizou-se a desconexão das pontes metilênicas de cada metano[10]anuleno. Em seguida, foram adicionados hidrogênios às valências livres dos anéis e calcularam-se as energias de cada anel, agora sem as pontes. Note que foram mantidas as conformações que cada anel possuía no seu anuleno de origem. As energias de cada um dos anéis foram comparadas com a energia do [10]anuleno otimizado. Esta diferença de energia foi chamada de SE(ba) (steric energy of the bent anulene) e pode ser entendida como sendo a energia absorvida pelo anel para ficar na conformação menos estável. ${ }^{102} \mathrm{Na}$ figura 41 são mostradas as estruturas envolvidas nestes cálculos. 

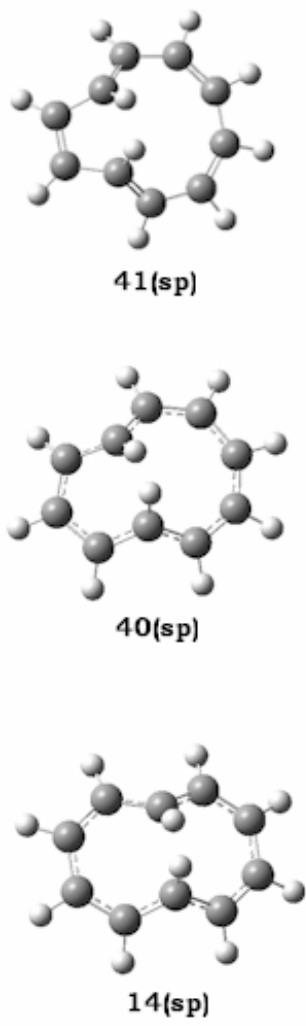

sp $=$ sem ponte

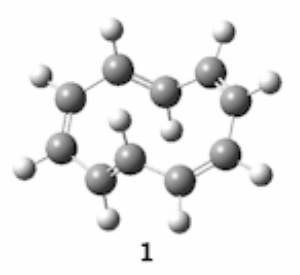

$\mathrm{E}(1)-\mathrm{E}(41 \mathrm{sp})=\mathrm{SE}(\mathrm{ba})=55,72 \mathrm{kcal} / \mathrm{mol}$

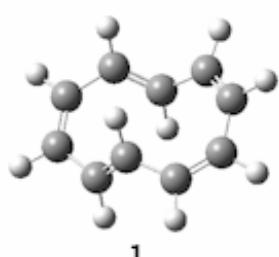

$\mathrm{E}(1)-\mathrm{E}(40 \mathrm{sp})=\mathrm{sE}(\mathrm{ba})=36,33 \mathrm{kcal} / \mathrm{mol}$

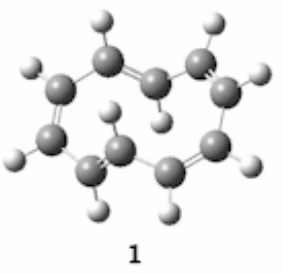

$\mathrm{E}(1)-\mathrm{E}(14 \mathrm{sp})=\mathrm{SE}(\mathrm{ba})=11,09 \mathrm{kcal} / \mathrm{mol}$

Figura 41: Estruturas dos Anulenos Envolvidos no Cálculo de SE(ba).

Neste caso pode-se observar que o anel principal do 1,4-metano[10]anuleno (41), aqui chamado de $41(\mathrm{sp})$, é aquele que se encontra mais tencionado $(55,72 \mathrm{kcal} / \mathrm{mol})$ seguido pelos anéis $40(\mathrm{sp})(36,33 \mathrm{kcal} / \mathrm{mol})$ e $14(\mathrm{sp})(11,09 \mathrm{kcal} / \mathrm{mol})$.

Já para o cálculo das energias de tensão nas pontes comparou-se a energia de cada uma das pontes desconectadas dos anulenos 41,40 e 14 com o propano otimizado. Evidentemente, que a cada ponte metilênica foram adicionados dois grupos $\mathrm{CH}_{3}$ para que pudessem ser comparadas com o propano otimizado. Na figura 42 estão mostradas as estruturas envolvidas nos cálculos. Pode-se observar que a ponte do 1,6metano[10]anuleno (14) é que se encontra mais tencionada $(16,11 \mathrm{kcal} / \mathrm{mol})$ seguida pela ponte do 1,4-metano[10]anuleno(41) $(14,98 \mathrm{kcal} / \mathrm{mol})$ e do 1,5 -metano[10]anuleno (40) $(8,32 \mathrm{kcal} / \mathrm{mol})$. Este resultado pode ser interpretado como um reflexo direto do ângulo assumido por cada uma das pontes quando ligadas aos anulenos (ver na figura 42).

O resultado da soma das tensões de anel ( $\mathrm{SE}(\mathrm{ba})$ ) mais as tensões nas pontes (SE(br)) pode ser representado por SE(sum). Na tabela 16 são mostrados todos estes resultados. Mais uma vez a ordem de estabilidade entre os anulenos em estudo foi $41<<$ $40<14$. Apesar da ponte do anuleno 14 estar mais tencionada do que as outras, no geral, o anuleno 14 é o mais estável. 
Ponte do anuleno (41)

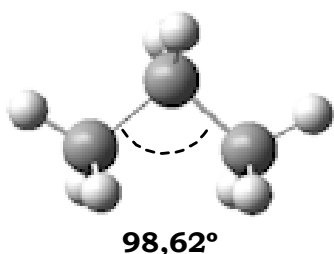

$\Uparrow$

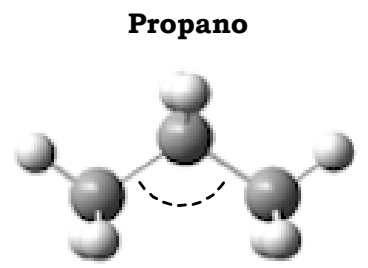

$112,99^{\circ}$

$\mathrm{SE}(\mathrm{br})=14,98 \mathrm{kcal} / \mathrm{mol}$

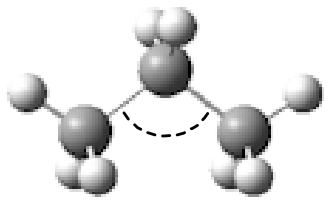

$105,06^{\circ}$<smiles>C1=CC=C1</smiles>

Propano

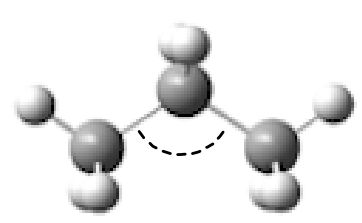

$112,9^{\circ}$

$\mathrm{SE}(\mathrm{br})=8,32 \mathrm{kcal} / \mathrm{mol}$
Ponte do anuleno (14)

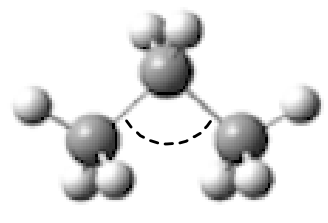

$96,58^{\circ}$<smiles>C=C</smiles>

Propano

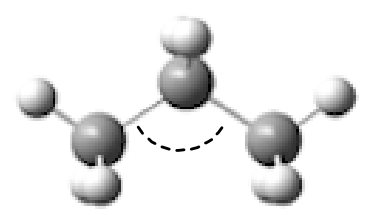

$112,99^{\circ}$

Figura 42: Estruturas das Pontes Envolvidas nos Cálculos de SE(br).

Tabela 16: Cálculo das Tensões nos Anéis e nas Pontes dos Anulenos 41, 40 e 14.

\begin{tabular}{cccc}
\hline Anulenos & SE(ba) $\mathbf{k c a l} / \mathbf{m o l}$ & $\boldsymbol{S E}(\mathbf{b r}) \mathbf{k c a l} / \mathbf{m o l}$ & $\boldsymbol{S E}(\mathbf{s u m}) \mathbf{k c a l} / \mathbf{m o l}$ \\
\hline 1,4-metano[10]anuleno (41) & 55,72 & 14,98 & 70,70 \\
1,5-metano[10]anuleno (40) & 36,33 & 8,32 & 44,65 \\
1,6-metano[10]anuleno (14) & 11,09 & 16,11 & 27,27 \\
\hline
\end{tabular}

Em princípio, a diferença entre cada um dos SE(sum) deveria fornecer as mesmas diferenças de energia da tabela 14 (energias relativas). Se realizadas estas diferenças serão obtidos valores muito próximos, mostrando que o modelo proposto para avaliar individualmente as tensões de anel e nas pontes é válido.

\section{Energias de Ressonância (RE).}

As energias de Ressonância (RE) foram calculadas para os anulenos 41, 40 e 14 . Para o cálculo foram utilizadas as diferenças de energia dos orbitais de fronteira $\left(\varepsilon_{\text {Hомо }}-\right.$ $\left.\varepsilon_{\text {LUMO }}\right)$ de cada anuleno e uma média das ordens de ligação ao longo do perímetro dos anéis $\left(\pi \rho_{\mathrm{rs}}\right)$, obtidas pelo método NRT (Natural Resonance Theory).

$$
R E=-\frac{\left(\pi \rho_{r S}\right)^{2}}{24}\left(\varepsilon_{\text {LUMO }}-\varepsilon_{\text {НОМO }}\right)
$$


Para efeito de comparação, foi calculada também a RE para o naftaleno que possui um sistema $\pi$ muito semelhante aos anulenos em estudo. Os resultados estão mostrados na tabela 17 .

Tabela 17: Cálculo das RE para os Anulenos 41, 40 e 14 e para o Naftaleno (B3LYP/6-311+G(d,p).

\begin{tabular}{cccc}
\hline Compostos & $R E(\mathrm{kcal} / \mathbf{m o l})$ & $E_{L U M O}-E_{\text {HOMO }}(\mathbf{k c a l} / \mathbf{m o l})$ & $\pi \rho_{\mathrm{rs}}$ \\
\hline 1,4-metano[10]anuleno (41) & 72,32 & $-84,34$ & 1,444 \\
1,5-metano[10]anuleno (40) & 79,40 & $-87,55$ & 1,485 \\
1,6-metano[10]anuleno (14) & 88,39 & $-102,23$ & 1,450 \\
naftaleno & 95,62 & $-109,49$ & 1,457 \\
\hline
\end{tabular}

Os valores destas energias de ressonância estão diretamente relacionados com a aromaticidade; quanto maior o valor de RE maior é a estabilização aromática nos compostos. Quando se compara as RE de cada um dos metano[10]anulenos com a RE do naftaleno, percebe-se que a aromaticidade no naftaleno é maior. No entanto, a ordem de aromaticidade obtida para os anulenos é a mesma obtida pelos demais critérios energéticos; $41<40<14$.

\section{Análises dos NBO (Natural Bond Orbital)..$^{103}$}

As interações entre os Orbitais Naturais de Ligação (NBO) podem fornecer inúmeras informações a respeito das interações estereoeletrônicas em uma substância. No caso da avaliação da aromaticidade, através das interações estabilizadoras $\left(\Delta \mathrm{E}^{(2)}\right)$, quanto maiores as interações dos NBOs ligantes e antiligantes ao longo das ligações $\pi$ do anel, maior será a estabilização aromática.

Na tabela 18 estão relacionadas as interações existentes ao longo dos anéis de cada um dos anulenos em estudo.

Tabela 18: Energias de Estabilização $\left(\Delta E^{(2)}\right)$ para os Anulenos 41, 40 e $14(B 3 L Y P / 6-311+G(d, p)$

\begin{tabular}{|c|c|c|c|}
\hline \multirow[b]{2}{*}{ Interações } & \multicolumn{3}{|c|}{$\Delta \mathrm{E}^{(2)}(\mathrm{kcal} / \mathrm{mol})$} \\
\hline & 41 & 40 & 14 \\
\hline$\pi_{\mathrm{C}(1)-\mathrm{C}(2)} \rightarrow \pi_{\mathrm{C}(3)-\mathrm{C}(4)}^{*}$ & & 23,45 & \\
\hline$\pi_{\mathrm{C}(2)-\mathrm{C}(3)} \rightarrow \pi_{\mathrm{C}(4)-\mathrm{C}(5)}^{*}$ & 17,12 & & 18,20 \\
\hline$\pi_{\mathrm{C}(3)-\mathrm{C}(4)} \rightarrow \pi_{\mathrm{C}(5)-\mathrm{C}(6)}^{*}$ & & 22,42 & \\
\hline$\pi_{\mathrm{C}(4)-\mathrm{C}(5)} \rightarrow \pi_{\mathrm{C}(6)-\mathrm{C}(7)}^{*}$ & 15,21 & & 17,30 \\
\hline$\pi_{\mathrm{C}(5)-\mathrm{C}(6)} \rightarrow \pi_{\mathrm{C}(7)-\mathrm{C}(8)}^{*}$ & & 20,47 & \\
\hline$\pi_{\mathrm{C}(6)-\mathrm{C}(7)} \rightarrow \pi_{\mathrm{C}(8)-\mathrm{C}(9)}^{*}$ & 15,01 & & 23,69 \\
\hline$\pi_{\mathrm{C}(7)-\mathrm{C}(8)} \rightarrow \pi_{\mathrm{C}(9)-\mathrm{C}(10)}^{*}$ & & 18,56 & \\
\hline$\pi_{\mathrm{C}(8)-\mathrm{C}(9)} \rightarrow \pi_{\mathrm{C}(1)-\mathrm{C}(10)}^{*}$ & 11,62 & & 20,15 \\
\hline$\pi_{\mathrm{C}(9)-\mathrm{C}(10)} \rightarrow \pi_{\mathrm{C}(1)-\mathrm{C}(2)}^{*}$ & & 19,64 & \\
\hline$\pi_{\mathrm{C}(10)-\mathrm{C}(1)} \rightarrow \pi_{\mathrm{C}(2)-\mathrm{C}(3)}^{*}$ & 13,46 & & 17,73 \\
\hline
\end{tabular}


Para os anulenos 40 e 14 as interações $\Delta \mathrm{E}^{(2)}$ são praticamente da mesma ordem e variam de 17 a $24 \mathrm{kcal} / \mathrm{mol}$; já para o anuleno 41 estas interações são mais fracas variando de 11 a $17 \mathrm{kcal} / \mathrm{mol}$. Uma vez que a magnitude destas interações entre os NBOs podem ser tomadas como critério de avaliação da aromaticidade, a ordem obtida é: $41<$ $40 \approx 14$. Na figura 43 são apresentadas algumas interações entre NBOs ao longo do perímetro dos anéis.

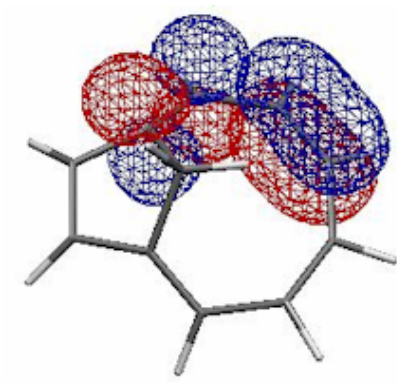

41

$\pi_{\mathrm{C}(9)-\mathrm{C}(10)} \rightarrow \pi_{\mathrm{C}(1)-\mathrm{C}(2)}^{*}$

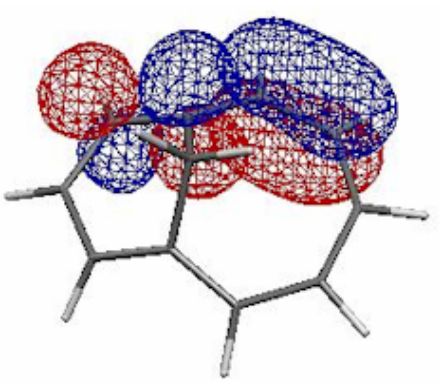

40

$\pi_{\mathrm{C}(9)-\mathrm{C}(10)} \rightarrow \pi_{\mathrm{C}(1)-\mathrm{C}(2)}^{*}$

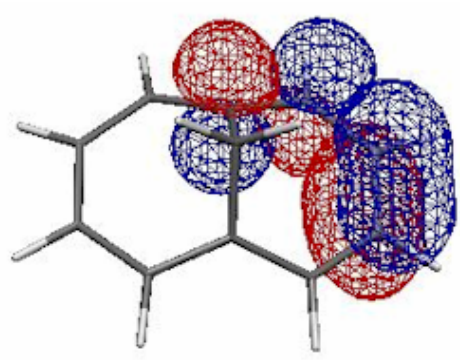

14

$\pi_{\mathrm{C}(8)-\mathrm{C}(9)} \rightarrow \pi_{\mathrm{C}(1)-\mathrm{C}(10)}^{*}$

Figura 43: Interações entre os NBOs dos Anulenos 41, 40 e $14 .^{29}$

Um último aspecto, avaliado com a análise $\mathrm{NBO}$, foi a existência de homoaromaticidade (interações entre orbitais $\pi$ nas imediações dos carbonos "cabeça de ponte"). Para os três metano[10]anulenos foram encontradas interações fracas e médias variando de 0,5 a 3,4 kcal/mol. No entanto, a detecção deste fenômeno por métodos teóricos é bastante difícil e observada para um número pequeno de estruturas. ${ }^{99}$ Os valores destas interações estão relacionados na tabela 19 e as superfícies dos orbitais mostradas na figura 44.

Tabela 19: $\left(\Delta E^{(2)}\right)$ nas Imediações das Pontes dos Anulenos 41, 40 e 14.

\begin{tabular}{ccc}
\hline Compostos & Interações & $\begin{array}{c}\Delta \mathrm{E}^{(2)} \\
(\mathbf{k c a l} / \mathbf{m o l})\end{array}$ \\
\hline 41 & $\pi_{\mathrm{C}(1)-\mathrm{C}(10)} \rightarrow \pi_{\mathrm{C}(4)-\mathrm{C}(5)}^{*}$ & 0,52 \\
40 & $\pi_{\mathrm{C}(1)-\mathrm{C}(2)} \rightarrow \pi_{\mathrm{C}(5)-\mathrm{C}(6)}^{*}$ & 1,40 \\
14 & $\pi_{\mathrm{C}(6)-\mathrm{C}(7)} \rightarrow \pi_{\mathrm{C}(1)-\mathrm{C}(10)}^{*}$ & 3,40 \\
\hline
\end{tabular}




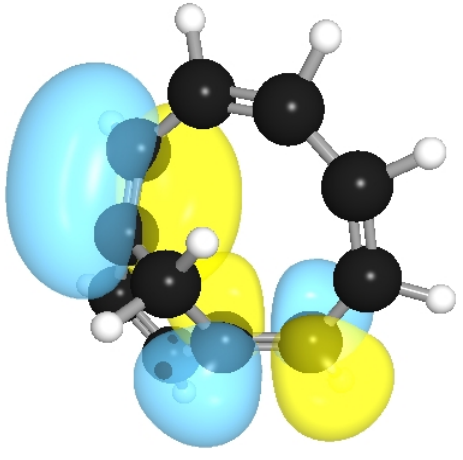

41

$\pi \mathrm{C}(1)-\mathrm{C}(10) \rightarrow \pi^{*} \mathrm{C}(4)-\mathrm{C}(5)$

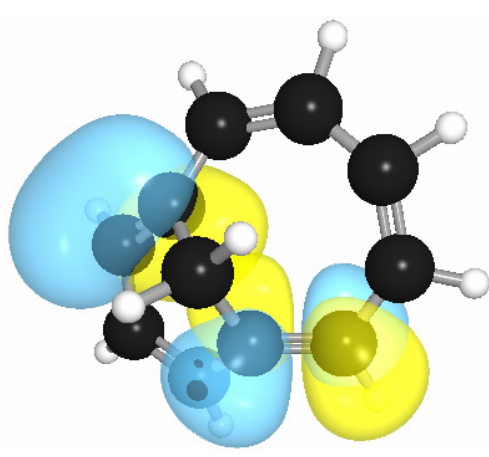

40

$\pi_{\mathrm{C}(1)-\mathrm{C}(2)} \rightarrow \pi^{*} \mathrm{C}(5)-\mathrm{C}(6)$

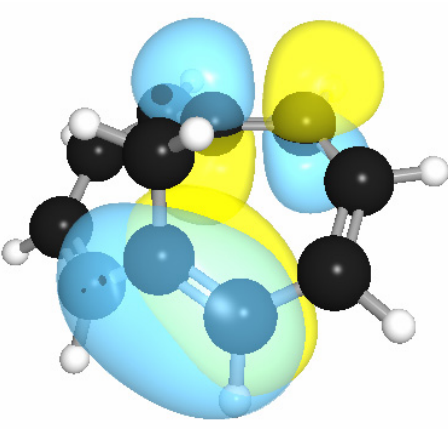

14

$\pi_{\mathrm{C}(6)-\mathrm{C}(7)} \rightarrow \pi^{*} \mathrm{C}(1)-\mathrm{C}(10)$

Figura 44: Interações entre os NBOs nas Imediações das Pontes de 41, 40 e $14 .{ }^{104}$

\section{Análise NRT (Natural Resonance Theory). ${ }^{25}$}

A primeira informação valiosa que pode ser tirada da análise NRT é com relação às ordens de ligação no perímetro dos anéis. É esperado para compostos aromáticos que estas ordens não oscilem muito fora de 1,5, o que caracteriza um híbrido de ressonância (sem muitas distinções entre as ligações duplas e simples). Na medida em que os valores das ordens de ligação se distanciam de 1,5 é esperado um decréscimo da aromaticidade. É evidente que pequenas variações podem ser consideradas normais, devido a outros fatores estruturais. Na tabela 20 são apresentados os valores das ordens de ligação encontrados para os anulenos em estudo.

Tabela 20: Ordens de Ligação no Perímetro dos Anéis dos Anulenos 41, 40 e 14 (B3LYP/6-311+G(d,p).

\begin{tabular}{ccccc}
\hline \multirow{2}{*}{ Ligações } & Ordens de & 41 & 40 & 14 \\
\cline { 3 - 5 } & Ligação & 1,111 & 1,483 & 1,438 \\
& C1-C2 & 1,778 & 1,485 & 1,498 \\
2 & C2-C3 & 1,111 & 1,485 & 1,377 \\
3 & C3-C4 & 1,780 & 1,484 & 1,498 \\
4 & C4-C5 & 1,109 & 1,485 & 1,438 \\
5 & C5-C6 & 1,774 & 1,493 & 1,438 \\
6 & C6-C7 & 1,116 & 1,480 & 1,498 \\
7 & C7-C8 & 1,774 & 1,480 & 1,377 \\
8 & C8-C9 & 1,109 & 1,493 & 1,498 \\
9 & C9-C10 & 1,780 & 1,485 & 1,438 \\
10 & C10-C1 & & &
\end{tabular}

Estes resultados, quando lançados em gráfico, deixam ainda mais clara a alternância acentuada das ordens de ligação do 1,4-metano[10]anuleno (41), indicando um baixo caráter aromático deste anuleno (figura 45). 

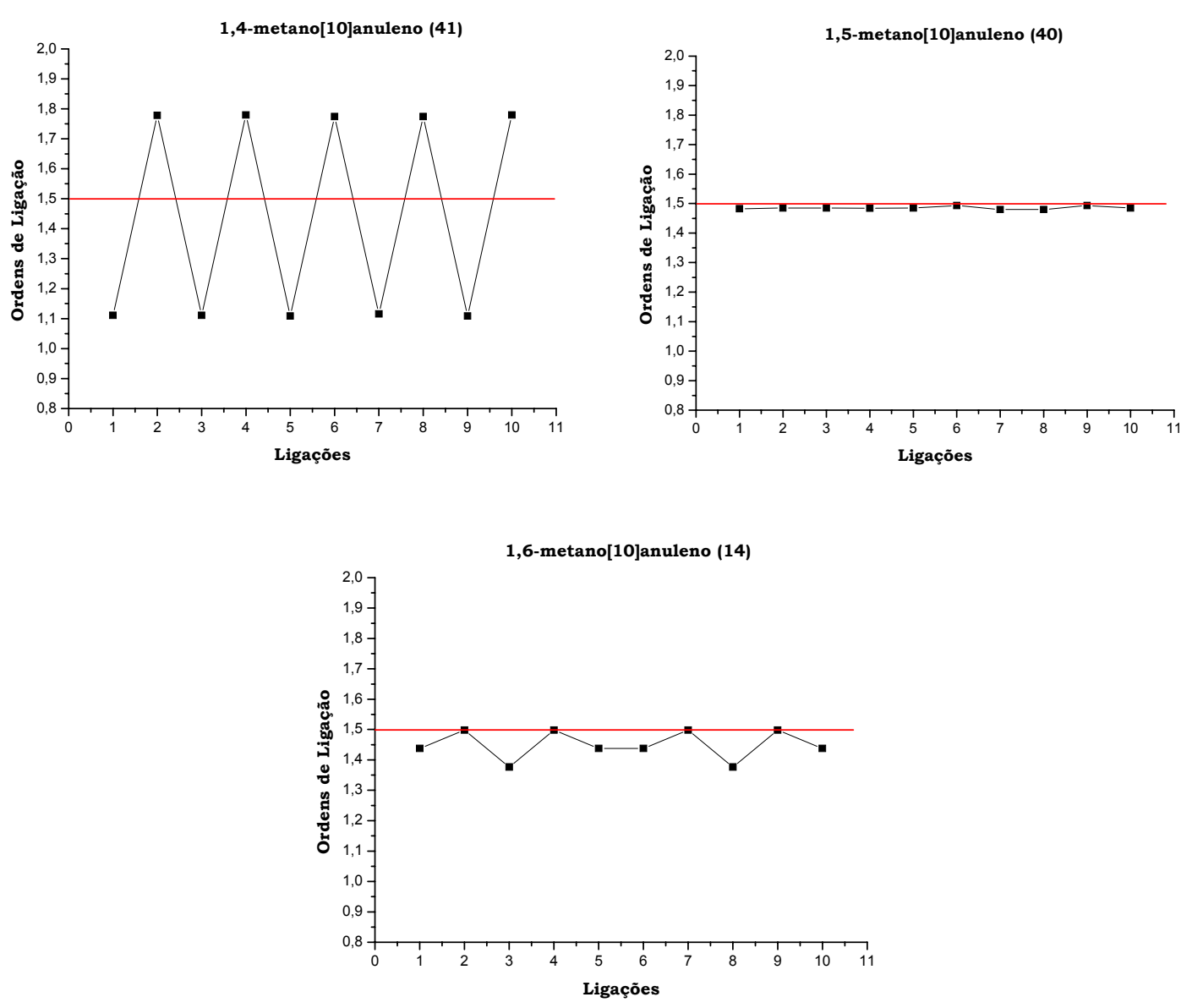

Figura 45: Variação das Ordens de Ligação ao Longo do Perímetro dos Anéis de 41, 40 e 14.

Uma outra informação tirada da análise NRT é com relação às estruturas de ressonância dos compostos. Para o anuleno 41 foram encontradas 10 estruturas de ressonância, e dentre elas, apenas uma é neutra e com peso de $44,3 \%$. Para o anuleno 40 foram encontradas $\underline{16}$ estruturas de ressonância, dentre as quais, duas são neutras e com pesos de 42,7\% cada. Por fim, para o anuleno 14 foram encontradas 18 estruturas de ressonância, sendo apenas duas neutras e com pesos de $24,5 \%$.

Pelo próprio número de estruturas de ressonância encontradas para os anulenos em estudo, é possível inferir algo sobre a aromaticidade nestes compostos. Sabe-se que quanto maior o número de estruturas canônicas de ressonância, maior é a estabilização aromática. Um dado interessante é a presença de apenas uma estrutura neutra para o anuleno 41 , indicando que a estrutura que contém duas ligações duplas no setor $(a)$ do anel de 41 é desfavorável. Também não foram encontradas, para nenhum dos anulenos em estudo, estruturas de ressonância que indicassem ligação entre os carbonos das pontes.

Na tabela 21 são mostradas as duas principais estruturas de ressonância de cada anuleno, encontradas pelo método NRT. 
Tabela 20: Principais Estruturas de Ressonância Encontradas para os Anulenos 41, 40 e 14.

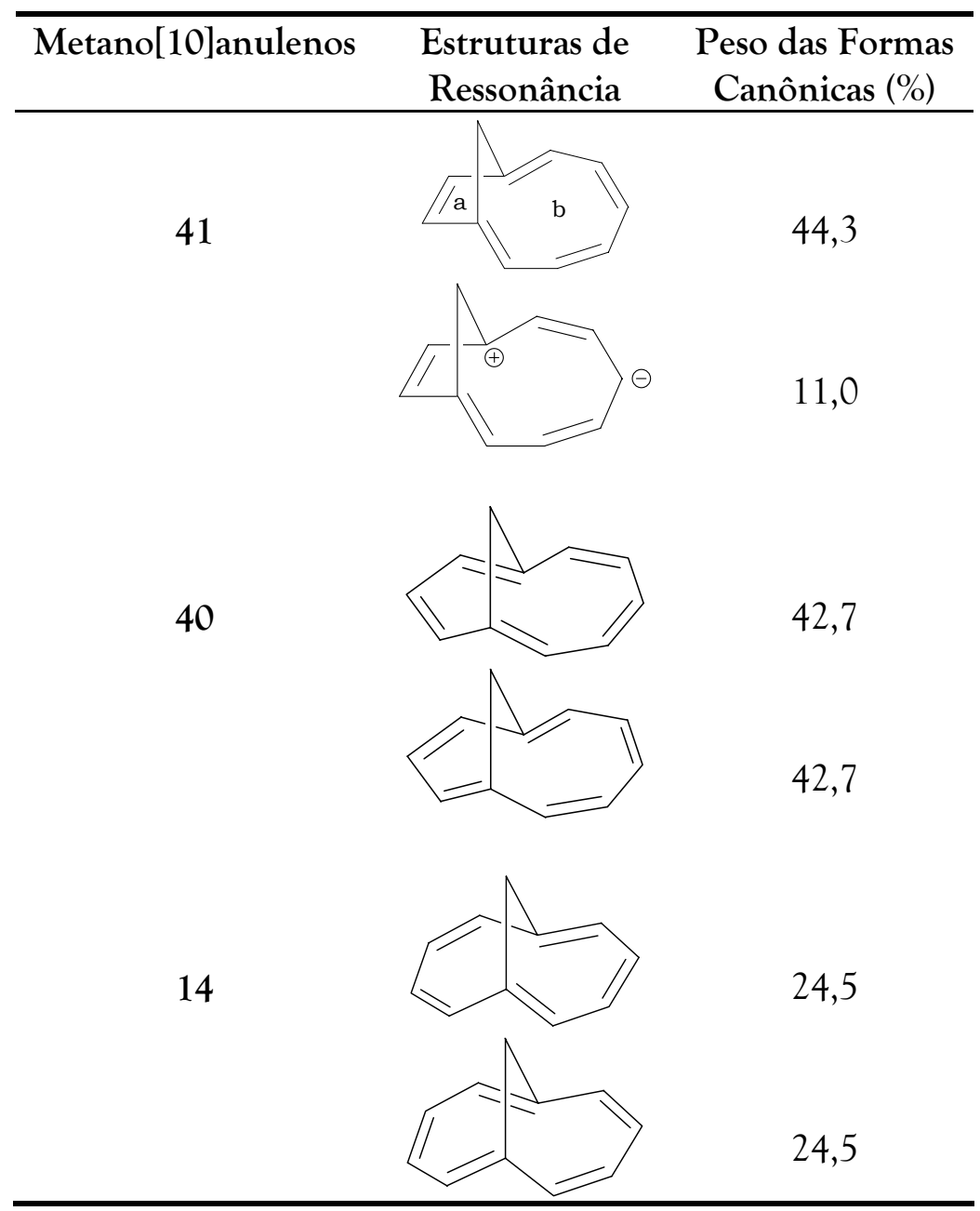

Pela análise NRT é possível ordenar os compostos quanto à aromaticidade da seguinte maneira: $41<40<14$.

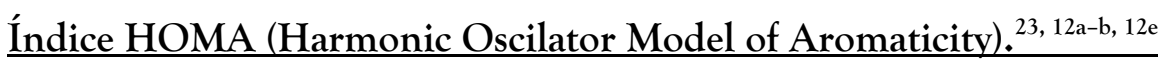

Os índices HOMA para cada um dos anulenos 41, 40 e 14, bem como para cada setor (a) e (b) dos anéis (figura 39), foram calculados utilizando como $\mathrm{R}_{\text {opt }}$ (raio ótimo) igual a $1,388 \AA, \mathrm{R}_{\mathrm{av}}$ (raio médio) sendo as médias dos comprimentos de ligação no perímetro dos anéis e $\mathrm{R}_{\mathrm{i}}$ os comprimentos de ligação ao longo do perímetro dos anéis. Para a constante $\alpha$ foi utilizado o valor 257,70 e $n$ o número de ligações no perímetro de cada anel. ${ }^{12 a-b, 12 e}$

$$
H O M A=1-\left[\alpha\left(R_{o p t}-R_{a v}\right)^{2}+\frac{\alpha}{n} \sum\left(R_{a v}-R_{i}\right)^{2}\right]=1-E N-G E O \quad(\text { Equação } 3)
$$

O cálculo de HOMA também foi realizado para o naftaleno com o objetivo de comparar os índices dos metano[10]anulenos com um outro composto conhecidamente aromático. $\mathrm{Na}$ tabela 21 encontram-se todos os índices obtidos para o anel como um 
todo (de C1 até C10) e para os setores $(a)$ e (b) dos anéis; são mostrados também os termos EN e GEO separadamente.

Tabela 21: Índices HOMA (B3LYP/6-311+G(d,p)).

\begin{tabular}{|c|c|c|c|c|c|c|c|c|c|}
\hline & \multicolumn{3}{|c|}{ Setor (a) } & \multicolumn{3}{|c|}{ Setor (b) } & \multicolumn{3}{|c|}{ Total } \\
\hline & HOMA & $\mathrm{EN}$ & GEO & HOMA & $\mathrm{EN}$ & GEO & HOMA & EN & GEO \\
\hline 41 & 0,410 & 0,359 & 0,231 & 0,554 & 0,070 & 0,376 & 0,511 & 0,133 & 0,356 \\
\hline 40 & 0,897 & 0,098 & 0,005 & 0,905 & 0,070 & 0,025 & 0,901 & 0,081 & 0,018 \\
\hline 14 & 0,886 & 0,076 & 0,038 & 0,886 & 0,076 & 0,038 & 0,886 & 0,076 & 0,038 \\
\hline naftaleno & 0,783 & 0,082 & 0,135 & 0,783 & 0,082 & 0,135 & 0,783 & 0,082 & 0,135 \\
\hline
\end{tabular}

O 1,4-metano[10]anuleno (41) possui o menor valor de HOMA indicando que a aromaticidade neste anuleno é menor e pode não existir. Surpreendentemente o anuleno 40 parece ser ligeiramente mais aromático que 14 por este critério. No entanto, os valores dos índices HOMA para 40 e 14, são muito próximos, indicando que estes anulenos apresentam estabilizações aromáticas quase da mesma ordem. Um outro dado interessante é o decréscimo da aromaticidade nos "anéis" (a) dos anulenos 41 e 40, respectivamente 0,410 e 0,897. Provavelmente por serem "anéis" menores acabam sofrendo maiores variações da geometria.

Comparando os termos EN e GEO (Total) pode-se observar que o anuleno 41 possui uma maior alternância $(\mathrm{GEO})$ entre os comprimentos de ligação $(0,356)$, e da mesma forma, uma grande elongação (EN) entre os comprimentos de ligação $(0,133)$, resultando em um índice HOMA bem distante do valor ideal que é 1 .

Se o naftaleno for tomado como referência, teremos os anulenos 40 e $14 \mathrm{com}$ bons índices de aromaticidade e o anuleno $41 \mathrm{com}$ um índice razoavelmente abaixo. Note que o índice HOMA do naftaleno já é baixo devido ao alto valor de GEO para sua estrutura; este resultado é proveniente da grande alternância dos comprimentos de ligação quando se compararam as ligações ao longo do perímetro do naftaleno com a ligação localizada entre os dois anéis.

\section{Critério NICS (Nucleus Independent Chemical Shift). ${ }^{31}$}

Um último critério aplicado aos anulenos 41,40 e 14 foi o critério NICS. Para os cálculos foram considerados alguns pontos no espaço localizados no centro, $1 \AA$ acima e $1 \AA ̊$ abaixo do "plano" de cada setor $(a)$ e $(b)$ dos anéis dos anulenos em estudo. Para a obtenção dos índices foram calculados os tensores de blindagem nestes pontos (figura 46). Os cálculos foram realizados também para o naftaleno e para o "naftaleno torcido" com o objetivo de realizar algumas comparações. Na tabela 22 estão relacionados os valores de NICS obtidos para todas estas estruturas. 


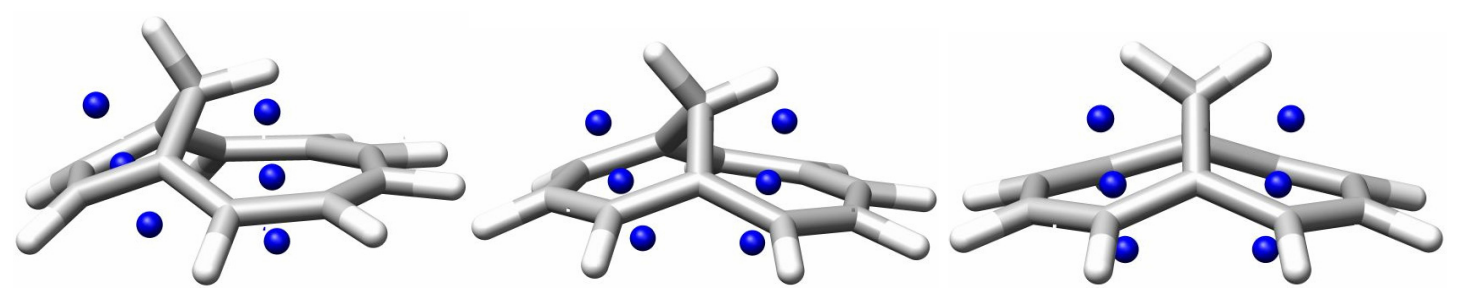

41

40

14

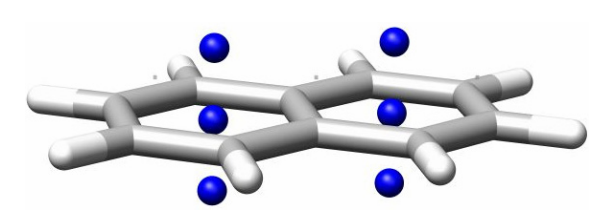

naftaleno

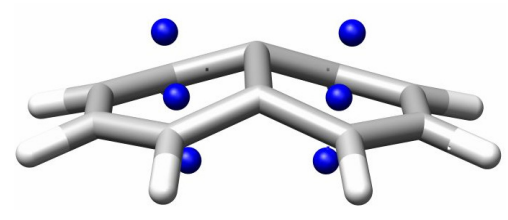

naftaleno torcido

Figura 46: Representação das Estruturas e dos Pontos onde foram Calculados os Índices NICS.

Tabela 22: Índices NICS (B3LYP/6-311+G(d,p)).

\begin{tabular}{ccccccc}
\hline Compostos & \multicolumn{3}{c}{ Setor (a) } & \multicolumn{3}{c}{ Setor $(\mathrm{b})$} \\
\hline \multirow{2}{*}{41} & NICS(-1) & NICS(0) & NICS(1) & NICS(-1) & NICS(0) & NICS(1) \\
\cline { 2 - 7 } 40 & $-19,3$ & $-17,1$ & $-8,45$ & $-16,4$ & $-7,72$ & $-14,5$ \\
14 & $-19,5$ & $-17,9$ & $-9,69$ & $-14,3$ & $-12,8$ & $-12,0$ \\
naftaleno & $-16,4$ & $-14,8$ & $-10,3$ & $-16,4$ & $-14,8$ & $-10,3$ \\
naftaleno torcido & $-10,7$ & $-8,56$ & $-10,7$ & $-10,7$ & $-8,55$ & $-10,7$ \\
\hline
\end{tabular}

Os índices NICS são muito interessantes no processo de avaliação da aromaticidade, principalmente por estarem relacionados com uma propriedade marcante dos compostos aromáticos, o diamagnetismo, e pela facilidade com que podem ser calculados os tensores de blindagem para uma determinada estrutura. No entanto, há muitos efeitos que afetam estes valores dos tensores e para alguns compostos são obtidos valores não muito condizentes com a estabilização aromática do sistema. Em outras palavras, a presença de grupos funcionais próximos dos pontos onde estão sendo calculados os índices NICS afeta a precisão dos valores. Como já foi mencionado na seção 1.2, quanto mais negativos forem os índices maiores serão as blindagens locais, e consequentemente maior a aromaticidade.

No caso dos metano[10]anulenos 41, 41 e 14 foram verificadas muitas variações de NICS devido à presença das pontes metilênicas e à falta de planaridade dos anulenos em estudo.

De uma maneira geral, a falta de planaridade nestes metano[10]anulenos faz com que sejam obtidos NICS(0) e NICS(1) menos negativos, ou seja, a aromaticidade medida no centro do anel e $1 \AA ̊$ acima é menor quando comparada com a medida a $1 \AA$ abaixo. 
Para facilitar a análise, primeiro serão comparados os resultados obtidos para o setor (a) de cada estrutura. Admitindo o naftaleno como referência, os valores de NICS(1) para os três metano[10]anulenos são menos negativos, indicando uma forte influência das pontes neste índices. Estas influências impedem quaisquer conclusões sobre a aromaticidade nestes pontos; cabe lembrar que a influência das pontes não são iguais nos três metano[10]anulenos.

Um outro fato interessante foi que o índice NICS(-1) é bem menor que NICS(1). Este efeito pôde ser justificado quando os índices para o "naftaleno torcido" foram calculados. Ficou claro que no naftaleno torcido o NICS(-1) também era menos negativo que o NICS(+1), justificando que esta variação ocorria em virtude da falta de planaridade; novamente ficou difícil inferir algo sobre a aromaticidade pois a planaridade em cada metano[10]anuleno é variável.

Quando se analisa o setor (b) dos anéis destas estruturas é verificado um comportamento muito semelhante com uma diferença nos índices NICS(+1). No caso deste anel os índices são menos negativos do que no setor $(a)$, isto porque, os pontos onde os índices foram calculados estão agora mais distantes das pontes, sendo menos influenciados.

Por fim, não foi possível tirar nenhuma conclusão concreta sobre a aromaticidade destes metano[10]anulenos pelo uso do critério NICS. As peculiaridades estruturais destes compostos fazem com que a análise não se aplique muito bem, o que não quer dizer que este método não tenha o seu devido valor.

\section{Conclusões Sobre os Estudos Teóricos com os Metano[10]Anulenos.}

Os resultados teóricos aqui apresentados trouxeram informações valiosas a respeito das estruturas e da aromaticidade nos metano[10]anulenos 14, 40, 41. Alguns índices e técnicas utilizadas apontaram para uma não existência de estabilização aromática em 41. 

Parte B: Estudos Sintéticos e Teóricos sobre a (土)-Baquenolida A. 



\section{Introdução - Parte B}





\section{1 - Introdução}

Os bacanos constituem uma classe relativamente rara de sesquiterpenos derivados biogeneticamente dos eremofilanos. ${ }^{105}$ Algumas das estruturas ligadas aos bacanos possuem um anel $\beta$-metileno- $\gamma$-butirolactônico ligado em espiro a um sistema cishidrindano com dois carbonos metilados. O produto natural mais simples derivado da classe dos bacanos é a baquenolida A (184) (figura 47). ${ }^{106}$

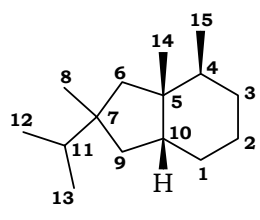

Bacanos

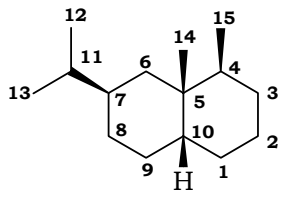

Eremofilanos

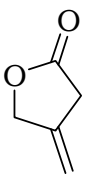

$\beta$-metileno- $\gamma$-butirolactona

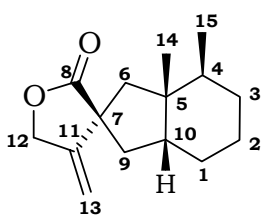

Baquenolida A (184)

Figura 47: Bacanos, Eremofilanos e Lactonas

A baquenolida A (184) foi isolada pela primeira vez a partir dos brotos de uma planta da família Compositae (Petasites japonicus) de maneira independente por dois grupos de pesquisa japoneses. Considerando um dos nomes locais da espécie de onde se isolou 184 ("bakke"), Kitahara e colaboradores ${ }^{106 a}$ denominaram esta nova substância como baquenolida A ("bakkenolide A"). Por outro lado, Naya e colaboradores ${ }^{106 \mathrm{~b}}$ resolveram denominá-la como fuquinanolida ("fukinanolide") baseando-se em outro nome atribuído à planta ("fuki"). Na literatura são utilizados os dois nomes, no entanto, neste texto será utilizado aquele que aparece mais frequentemente nos trabalhos, a baquenolida A.

Este produto natural representa um grande desafio do ponto de vista sintético, pois além do sistema cis-hidrindânico (figura 48), há duas metilas em cis nos carbonos C4 e C5. Também, o anel $\beta$-metileno- $\gamma$-butirolactônico encontra-se ligado em espiro, com o grupo metileno oposto às metilas.
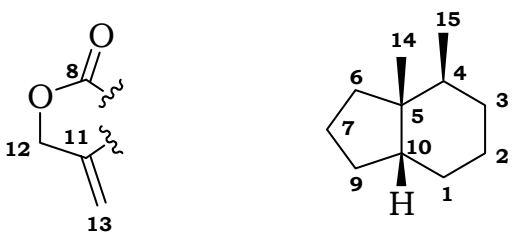

cis-hidrindano dimetilado

Figura 48: Sistemas Cis-Hidrindânico Dimetilado e Lactônico.

Em geral as atividades biológicas de lactonas sesquiterpênicas são acentuadas quando um grupo metileno encontra-se ligado na posição $\alpha{ }^{107}$ No entanto, além de possuir uma estrutura muito peculiar, a baquenolida A (184) apresenta algumas atividades biológicas significativas, entre as quais, pode-se destacar: atividade citotóxica acentuada contra células cancerosas da epiderme humana, ${ }^{108}$ atividade inibidora do apetite de algumas espécies de insetos e atividade larvicida. ${ }^{109}$ 
Atualmente, são conhecidas várias fontes naturais de onde são isoladas, além da baquenolida A (184), outras estruturas correlacionadas (ver tabela 23). Existem ainda, mais de quarenta produtos naturais que possuem estrutura semelhante à da baquenolida A (184) ${ }^{105 a}$

Acredita-se que os bacanos, logo, também a baquenolida A (184), sejam derivados biogeneticamente dos eremofilanos. Kitahara e colaboradores ${ }^{106 a, 110}$ sugeriram que $\mathrm{O}$ precursor biogenético da baquenolida A (184) é a fuquinona (185).

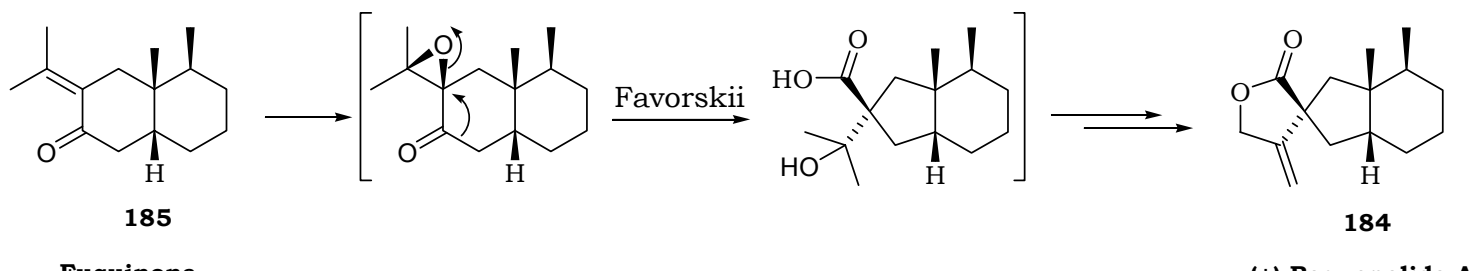

Fuquinona

(+)-Baquenolida A

Esquema 64: Biogênese da Baquenolida A (184).

De acordo com esta sugestão, uma epoxidação seguida de um rearranjo de Favorskii transformaria o esqueleto carbônico de $185 \mathrm{em}$ um bom precursor da baquenolida A (184). É importante notar que as baquenolidas são sesquiterpenóides que não seguem a "regra do isopreno", pois sofrem rearranjos moleculares em etapas avançadas da biossíntese, conforme a proposta apresentada no esquema $65 .{ }^{111}$

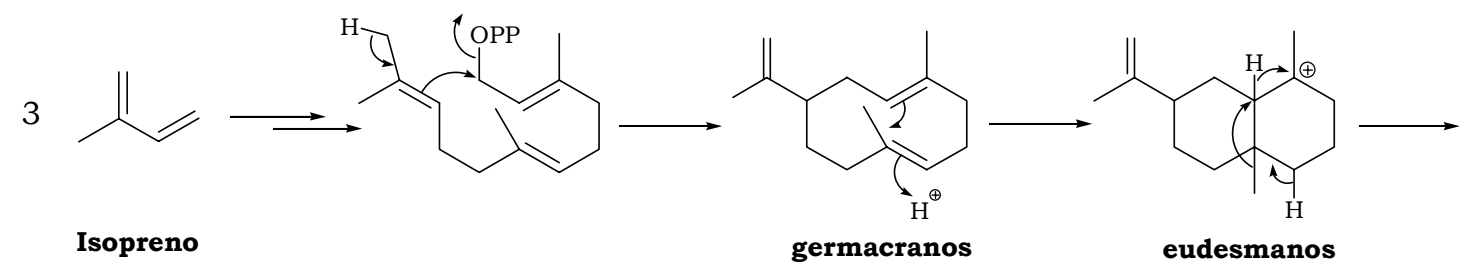<smiles>C=C(C)C1CCC2=CCCC(C)C2(C)C1</smiles>

Esquema 65: Biossintese dos Bacanos.

Desde o isolamento da baquenolida A (184) e de outras baquenolidas, houve um interesse acentuado de alguns grupos de pesquisa em sintetizar esta estrutura. Além do desafio sintético representado, a preparação de 184 foi de grande importância para confirmar a estrutura sugerida para este produto natural. ${ }^{106 a}$

$\mathrm{Na}$ próxima seção, serão descritas as sínteses da baquenolida A (184), até o momento publicadas. 
Tabela 23: Baquenolida A e Estruturas Correlatas.

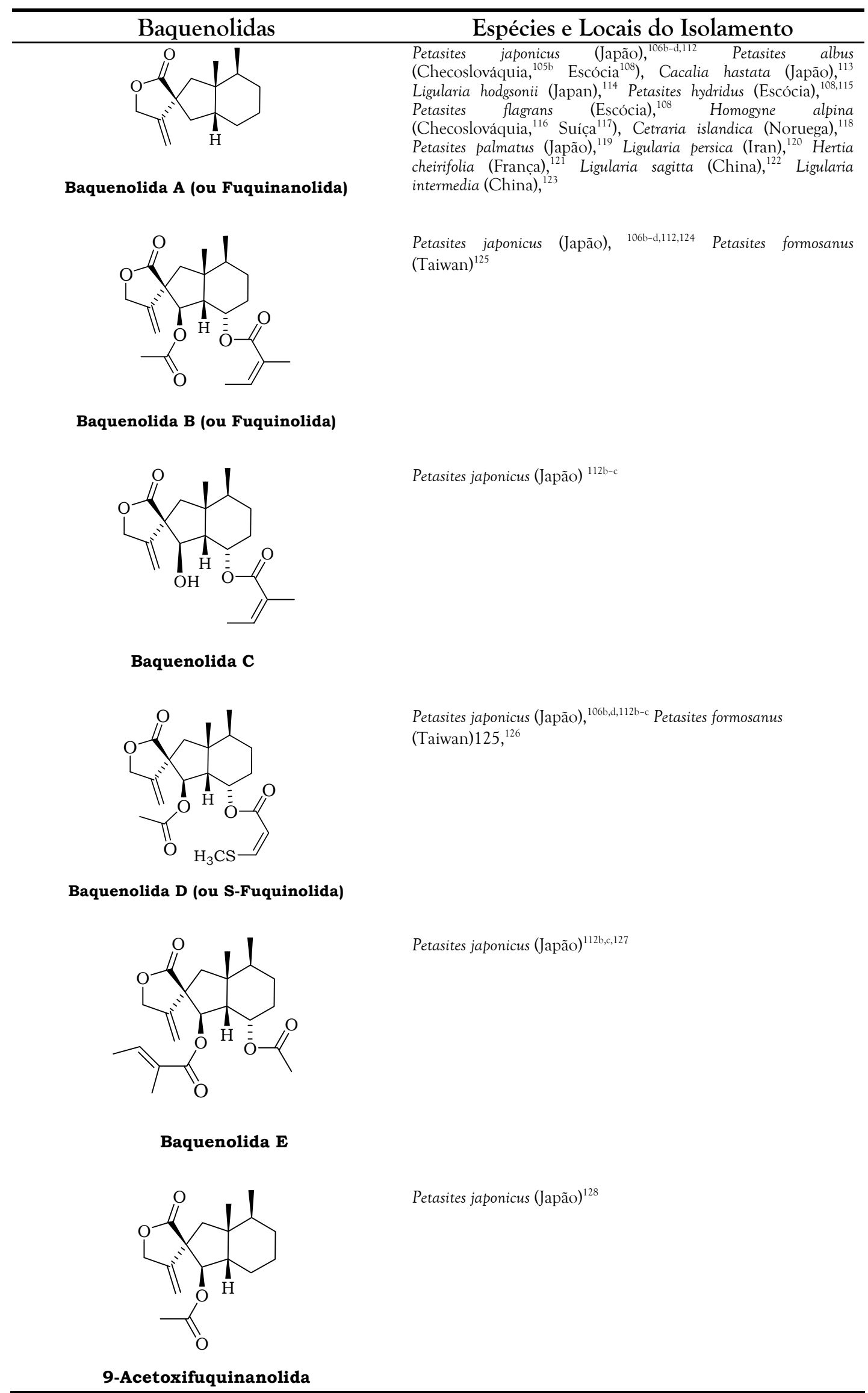




\section{1 - Sínteses da Baquenolida A (184).}

Em 1973 foram publicadas as duas primeiras sínteses da baquenolida A (184). Hayashi ${ }^{129}$ e colaboradores utilizaram a rota biossintética sugerida por Kitahara ${ }^{110}$ e realizaram uma síntese biomimética a partir da $(+)$-fuquinona (185) natural. Nesta síntese o composto 185 foi convertido no epóxido 186, que após um rearranjo de Favorskii com $\mathrm{NaOH} / \mathrm{EtOH}$, forneceu três produtos, os quais foram esterificados e isolados. O álcool 187 foi desidratado com $\mathrm{SOCl}_{2}$ e piridina originando o isopropenil éster 190. Este último produto foi convertido na (+)-baquenolida A (184) pela reação com $\mathrm{SeO}_{2}$ e $\mathrm{AcOH}$. Nesta transformação o aldeído 191 é produzido majoritariamente, porém, este produto também pôde ser convertido na (+)-baquenolida $\mathrm{A}(184)$, pela reação com $\mathrm{NaBH}_{4}$ (esquema 66).
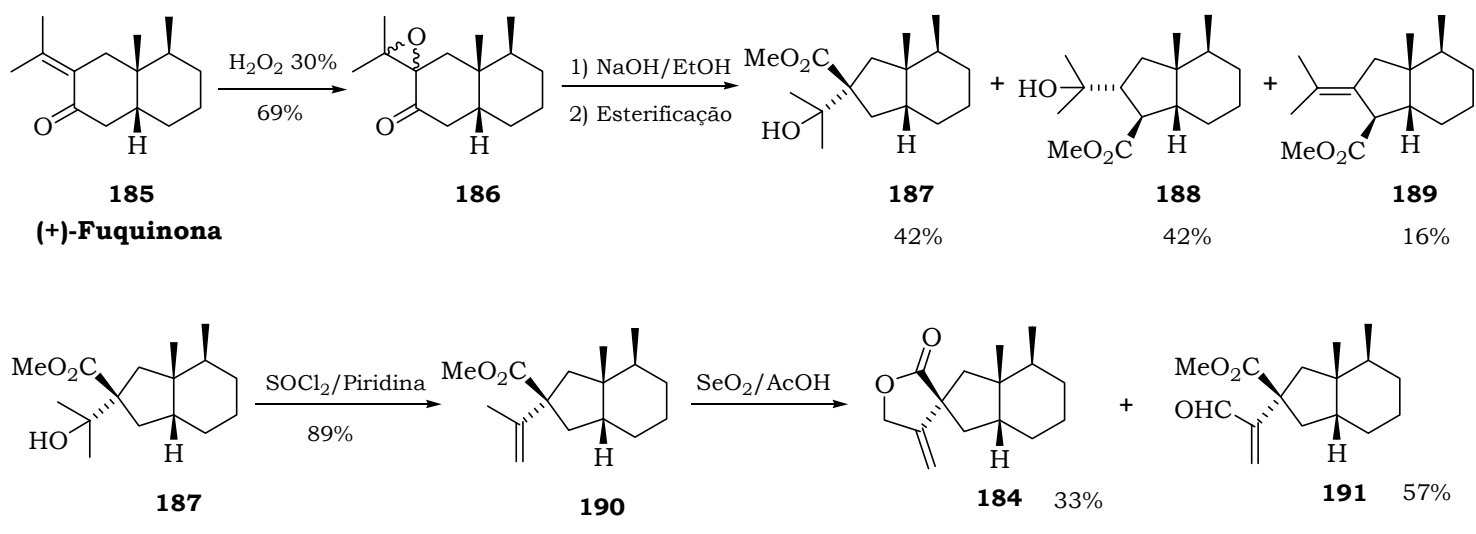

(+)-Baquenolida A

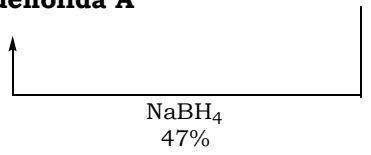

Esquema 66: Sintese Biomimética da (+)-Baquenolida A (184) - Sintese de Hayashi.

No mesmo ano Evans e colaboradores ${ }^{130}$ publicaram a primeira síntese total da baquenolida A (184). Nesta síntese, o produto natural 184 foi preparado em 13 etapas a partir da 2,3-dimetilciclo-hexanona (192) (esquema 67). Nas primeiras etapas da síntese, a cetona 192 foi convertida nos produtos 197 e 198, que foram devidamente separados; os autores deram continuidade à síntese utilizando apenas o composto 197 (tendo os grupos metila com estereoquímica apropriada). Após uma seqüência de reações foi obtido o composto 202, que é o principal intermediário da síntese de Evans. O composto 202 foi então convertido em 203 após um rearranjo [2,3]-sigmatrópico na presença de $\mathrm{NaH}$. Após algumas outras transformações a $( \pm)$-baquenolida A (184) foi obtida com um rendimento total de $1,8 \%$. 


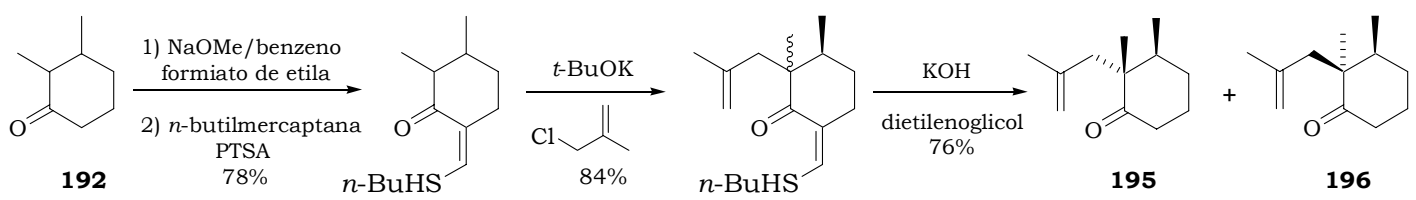

193

194
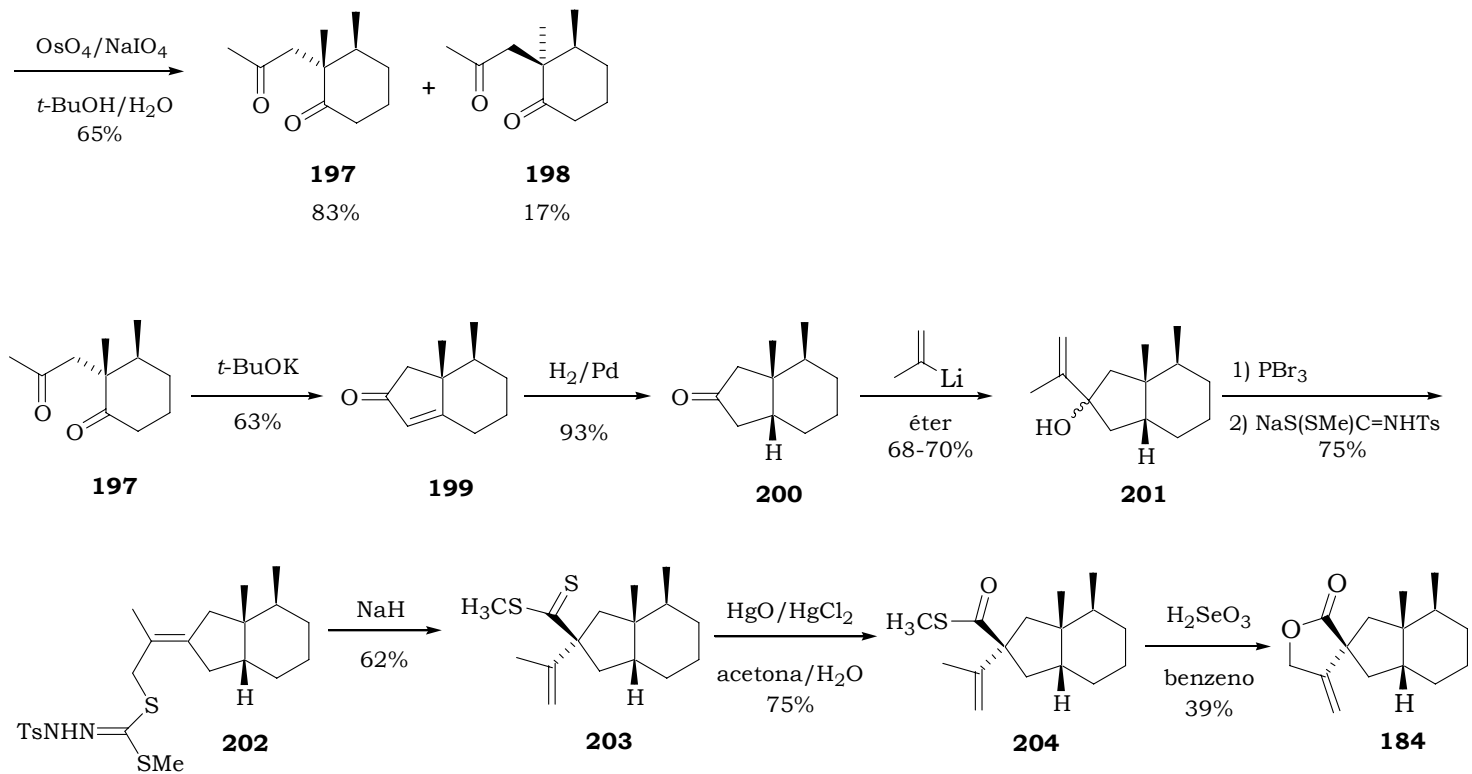

(士)-Baquenolida A

Esquema 67: Sintese de Evans.

$\mathrm{Na}$ mesma época alguns outros grupos de pesquisa se empenharam no desenvolvimento de outras metodologias para a preparação da baquenolida A (184) e de outras baquenolidas.

Ainda na década de 70 um grupo de pesquisa brasileiro publicou um trabalho relacionado com a síntese de baquenolidas. ${ }^{131, \mathrm{x}}$ Neste trabalho foram relatados estudos visando à síntese do sistema $\alpha$-espiro- $\beta$-metileno- $\gamma$-butirolactona (211), visivelmente um fragmento do produto natural 184.
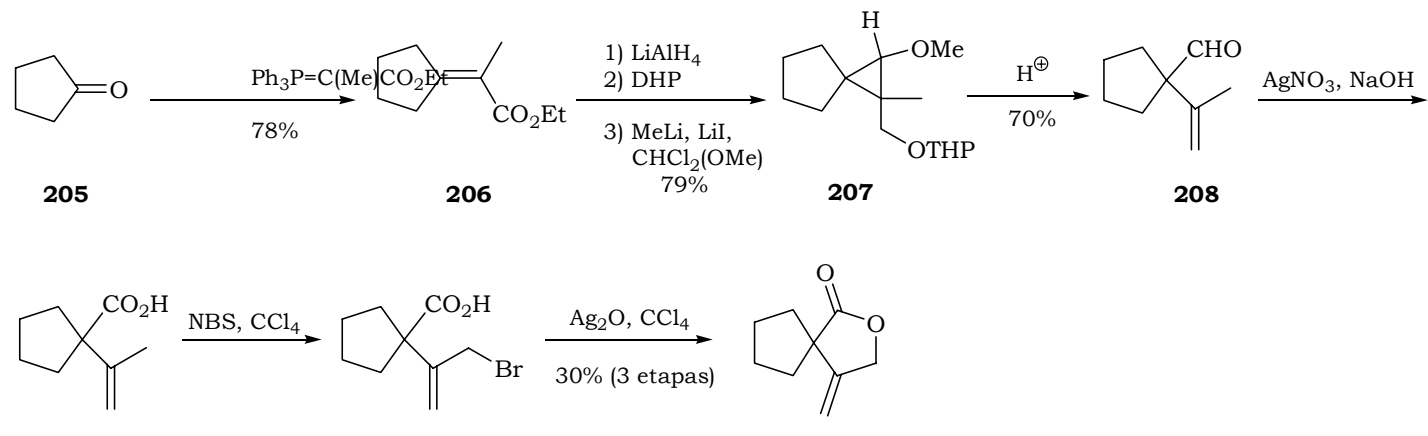

209

210

211

Esquema 68: Sintese de Campbell.

\footnotetext{
${ }^{x}$ Este trabalho foi proposto pelo Prof. Campbell em uma de suas visitas ao Brasil, no entanto, toda a pesquisa foi desenvolvida por brasileiros no IQ da Universidade de São Paulo - Prof. Nicola Petragnani, Prof. Timothy J. Brocksom e Prof. Mauricio G. Constantino.
} 
Pouco tempo depois, Petragnani e colaboradores ${ }^{132}$ publicaram uma nova abordagem para a síntese da espiro lactona 211, envolvendo a abertura de um anel epóxido para a formação do anel lactônico. Nesta síntese o epóxido 215 é obtido em três etapas a partir do éster 212. Após a reação de 215 com base forte obteve-se a lactona 216 que foi convertida em 211 e 217.
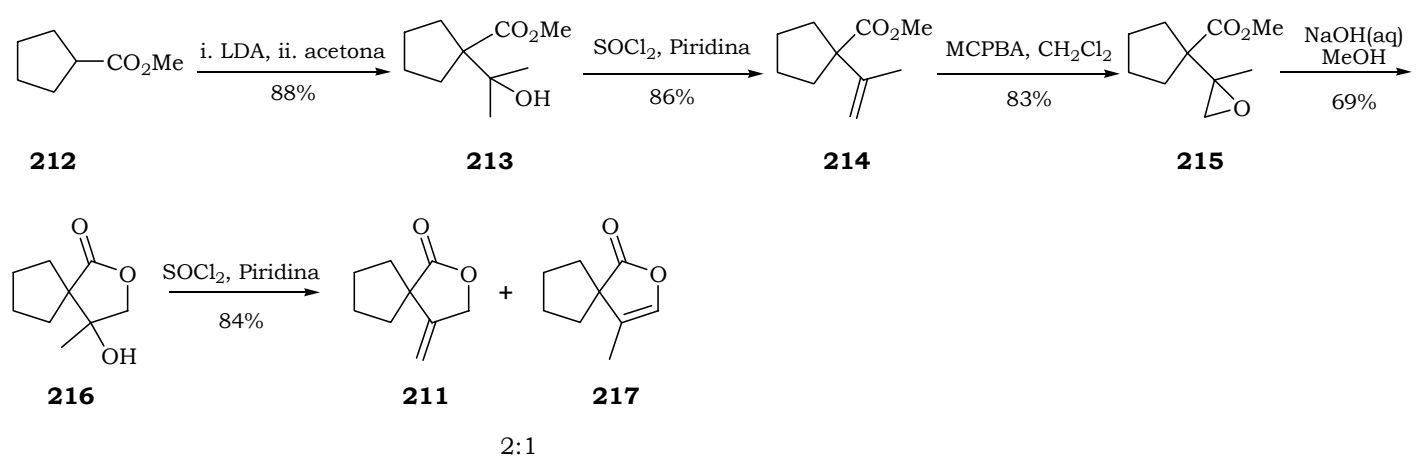

Esquema 69: Sintese de Petragnani.

No final da década de 70 , Brocksom e colaboradores ${ }^{133}$ publicaram mais um modelo sintético visando à aplicação na síntese de baquenolidas. Nesta nova abordagem, o anel de cinco membros ligado em espiro com a lactona é construído após duas alquilações do éster 218 utilizando dibromobutano. A $\alpha$-espiro- $\beta$-metileno- $\gamma$ butirolactona (211) foi obtida diretamente a partir do epóxido 215 .
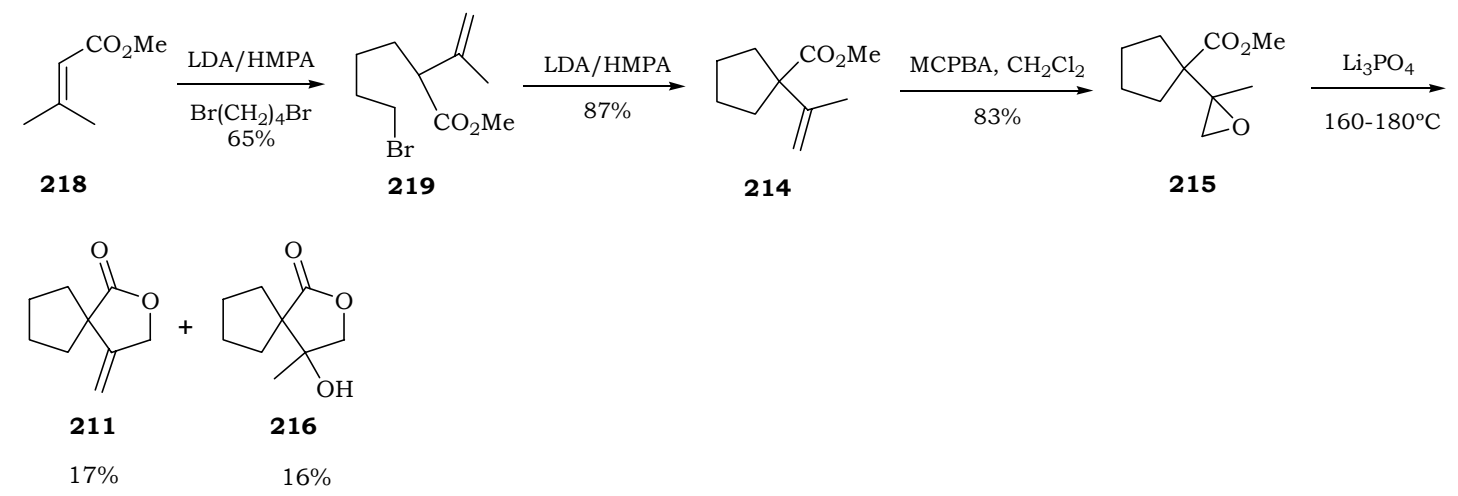

Esquema 70: Sintese de Brocksom.

Em 1985 Greene e colaboradores ${ }^{134,135}$ publicaram uma rota alternativa para a síntese de Evans. Seguindo uma metodologia descrita em 1979 pelos próprios autores, ${ }^{134,135}$ o intermediário 200 , antes preparado em 7 etapas por Evans, foi sintetizado agora em apenas três. Nesta preparação, o 1,6-dimetilciclo-hexeno (220) sofreu uma cicloadição $[2+2]$ com diclorocetena originando o composto 221 , que após duas etapas, foi convertido na cetona 200 .

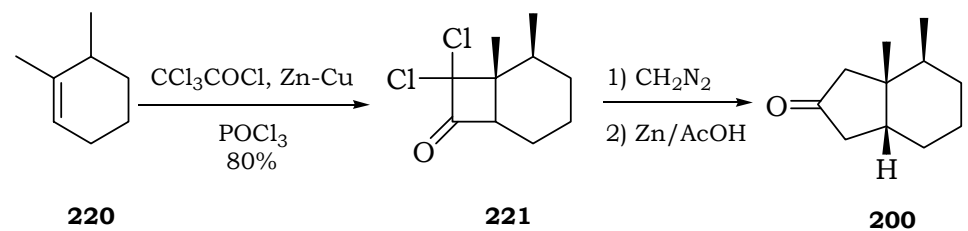

Esquema 71: Sintese Formal de Greene. 
A grande vantagem desta abordagem sintética é que ela tornava possível a síntese enantioseletiva da baquenolida A (184), através de algumas adaptações da síntese de Evans, partindo de 220 enantiomericamente puro.

No mesmo trabalho Greene e colaboradores ${ }^{135}$ publicaram a segunda síntese total da baquenolida A (184), na sua forma racêmica. Nesta preparação os autores abandonaram a abordagem anterior, que culminava na síntese da cetona 200, e optaram por aplicar uma metodologia semelhante à desenvolvida por Brocksom e colaboradores (esquema 70). ${ }^{133}$ A etapa determinante desta síntese foi a preparação do composto 225. Nesta etapa, formou-se uma mistura epimérica (em C7), onde obteve-se majoritariamente o epímero favorável à síntese da ( \pm )-baquenolida A (184). Uma outra etapa particularmente interessante desta síntese foi a conversão do di-iodeto 224 em 225, utilizando um éster sililado, o que possibilitou a obtenção direta das baquenolidas $184 \mathrm{e}$ 226.
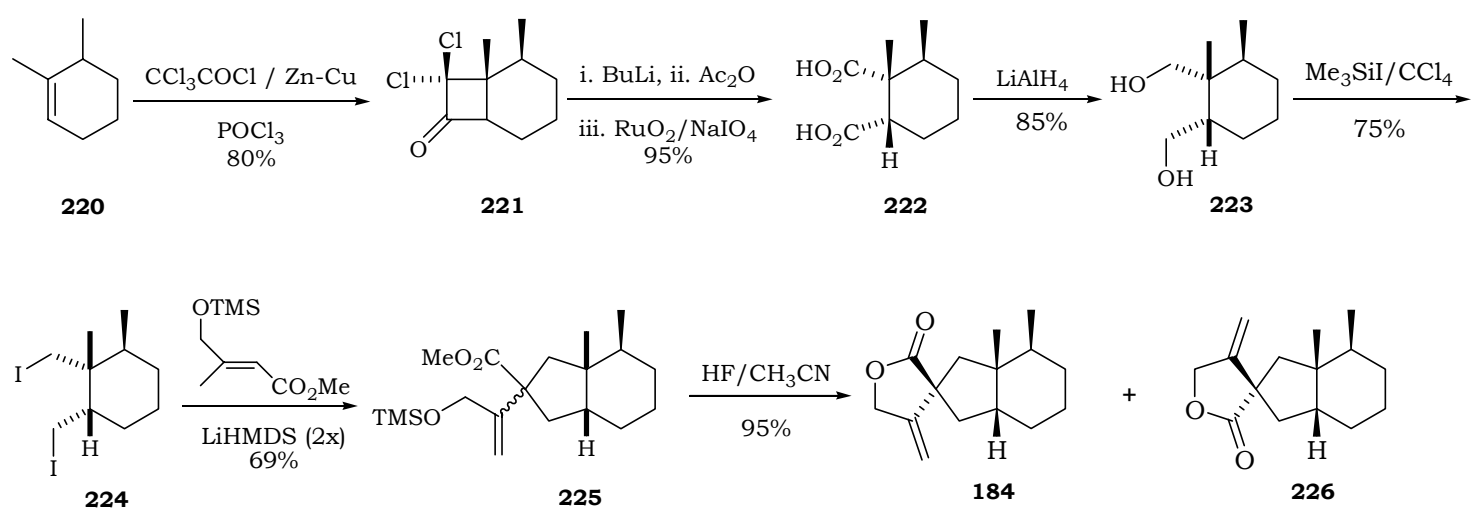

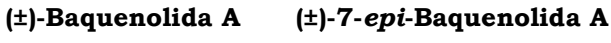
$71 \%$ $29 \%$

Esquema 72: Sintese de Greene.

Em seguida (1988) os mesmos autores publicaram a síntese da (+)-baquenolida $\mathrm{A}$ (184) e da (+)-7-epi-baquenolida A (226), partindo de 220 enantimericamente puro (esquema 73).
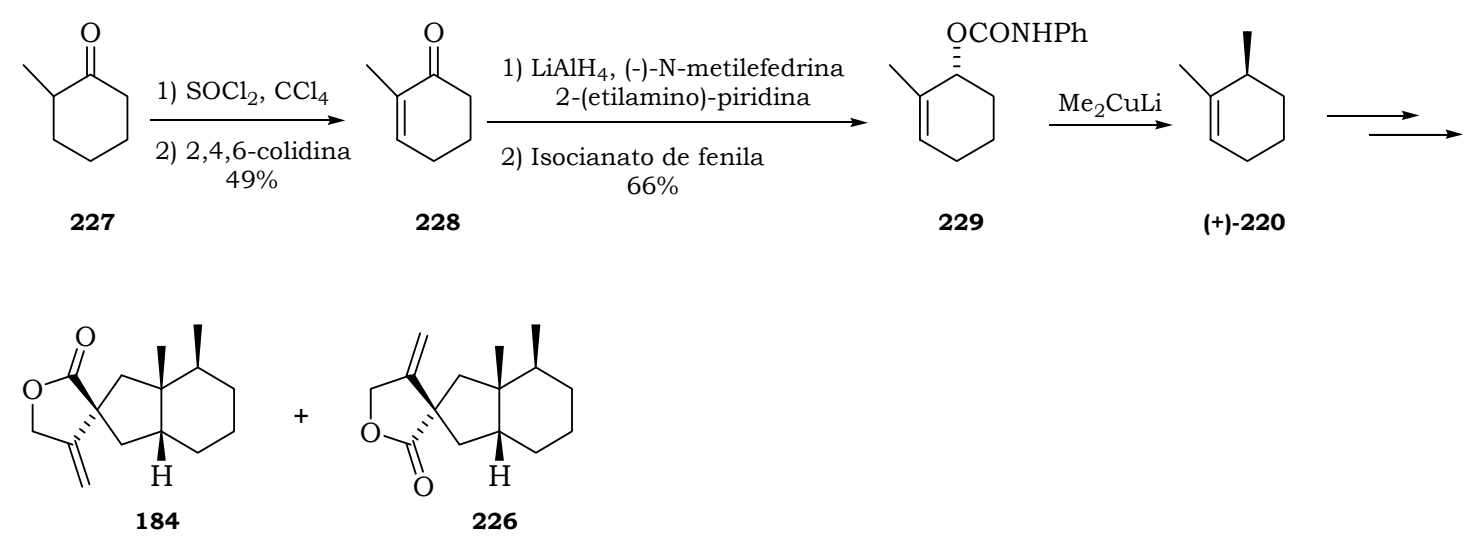

(+)-Baquenolida A (+)-7-epi-Baquenolida A

$71 \%$

$29 \%$

Esquema 73: Sintese Enantioseletiva de Greene. 
Os primeiros estudos sobre a síntese de baquenolidas envolvendo reações de Diels-Alder foram relatados por Brocksom e Constantino. ${ }^{136}$ Neste trabalho, os autores propuseram a construção do anel cis-dimetilato 232 através de uma cicloadição intermolecular entre o anidrido citracônico (231) e o cis-piperileno (230). O composto 232 foi obtido, porém em baixo rendimento (3\%).

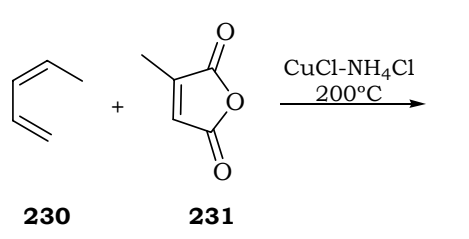

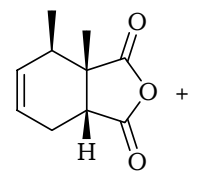

232

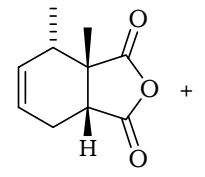

233

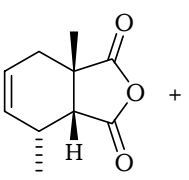

234

$4 \%$

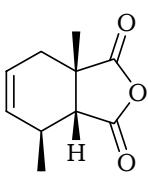

235

$7 \%$

Esquema 74: Reações de Diels-Alder Aplicadas à Síntese de Baquenolidas.

Somente em 1999 é que foi relatada a primeira síntese total da baquenolida A (184) envolvendo uma reação de Diels-Alder na sua versão intramolecular. ${ }^{137}$ Inicialmente os materiais de partida 237, 239 e 241 foram convenientemente sintetizados e, então, utilizados na preparação do intermediário 243. A reação de Diels-Alder intramolecular de 243 forneceu uma mistura de quatro isômeros que não foram separados nesta etapa da síntese. Os produtos desta cicloadição passaram por mais duas transformações até serem obtidas as quatro baquenolidas 184, 226, 246 e 247, nas proporções indicadas no esquema 75 . Apesar da mistura formada, a ( \pm )-baquenolida (184) foi obtida majoritariamente e em apenas seis etapas, desprezando-se as preparações dos materiais de partida.
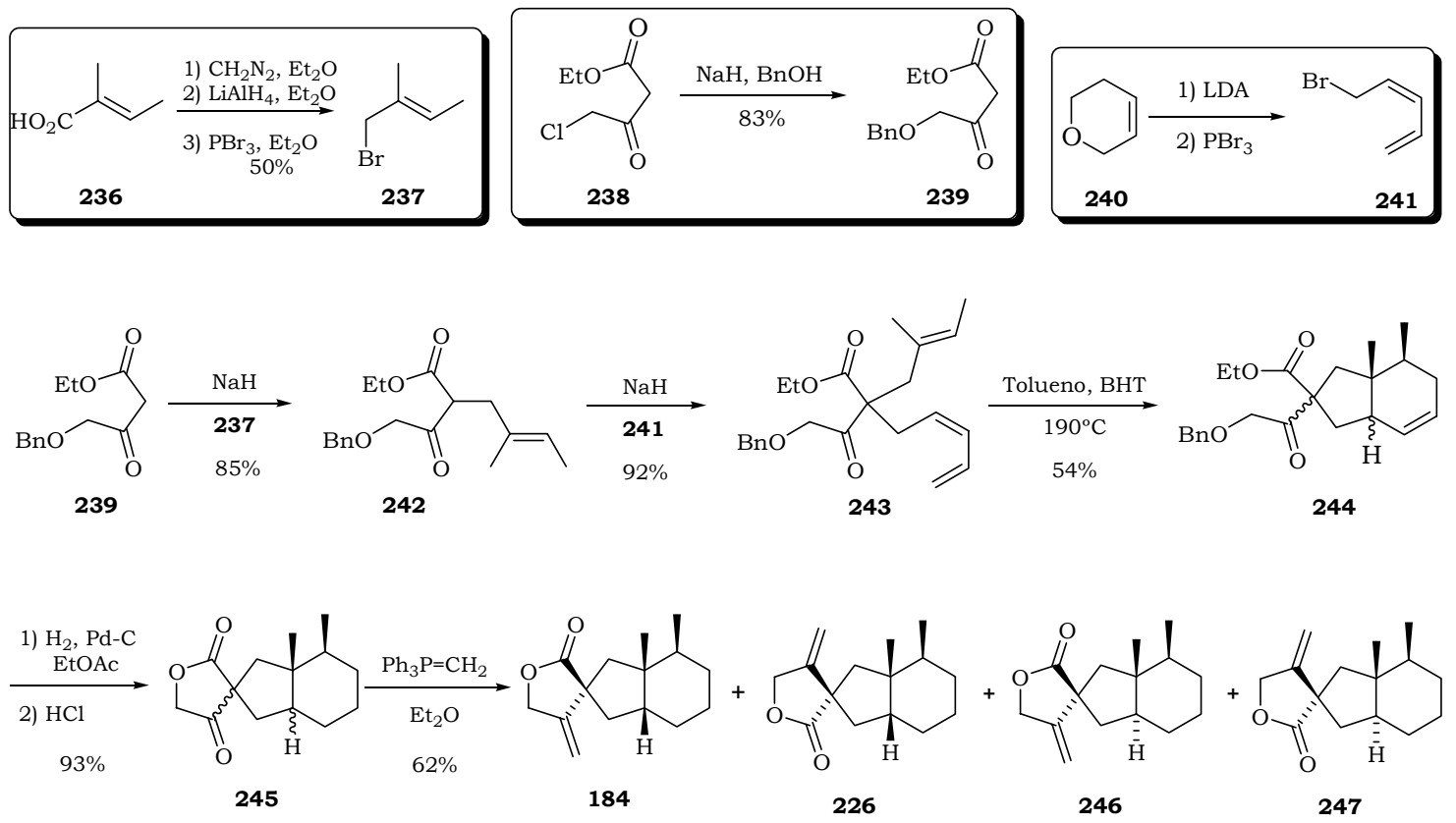

Proporção 184:226:246:247 = 54:19:16:11

Esquema 75: Sintese de Back Utilizando o (3Z)-5-bromopenta-1,3-dieno (241). 
Posteriormente, Back e colaboradores ${ }^{138}$ utilizaram um outro dieno para a síntese do intermediário que sofria a Diels-Alder intramolecular. A única diferença nesta abordagem foi a utilização do (3E)-5-bromopenta-1,3-dieno para a síntese de 248 .
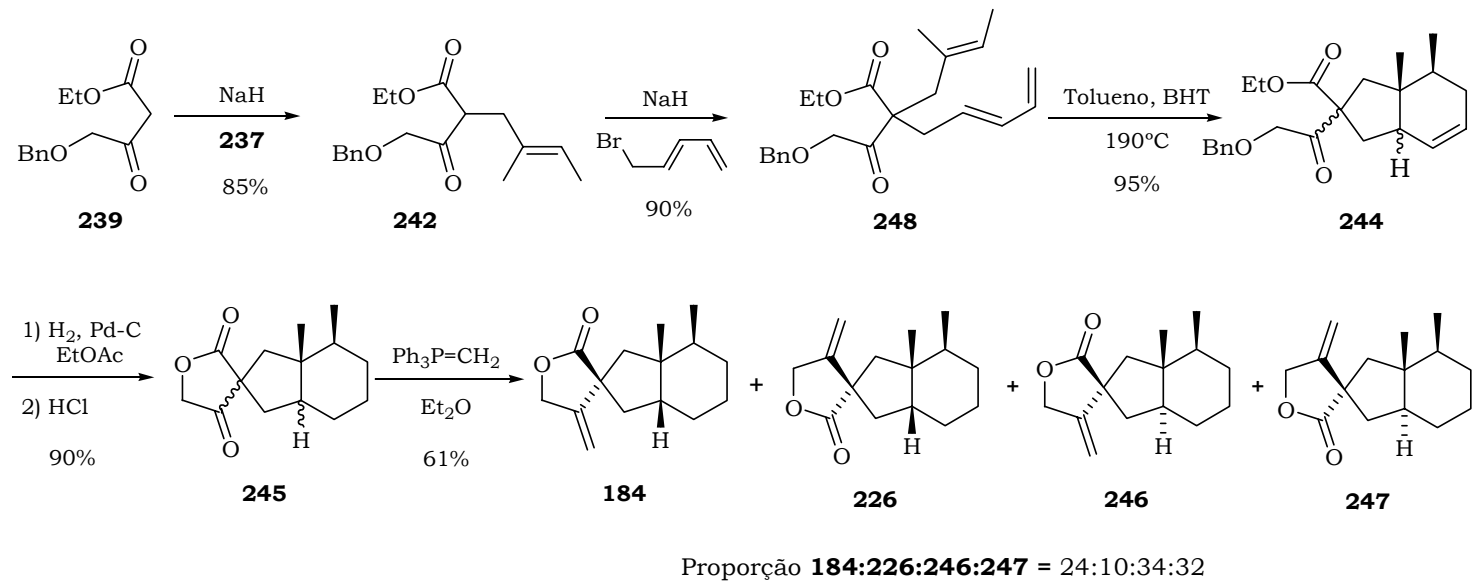

Esquema 76: Sintese de Back Utilizando o (3E)-5-bromopenta-1,3-dieno.

Nesta nova abordagem, a estereoseletividade no sentido de produção da $( \pm)$ baquenolida (184) foi menor (24\%). Ainda no mesmo trabalho onde foi publicada a síntese do esquema 76, foram relatadas algumas outras reações de Diels-Alder relacionadas com a síntese de baquenolidas, no entanto, nenhuma destas tentativas conduziu à formação de 184 .

A última síntese total da ( \pm )-baquenolida A (184), até então relatada na literatura, é a Sintese de Reddy (esquema 77). ${ }^{139}$ Esta preparação tem como etapa principal uma reação de Diels-Alder na sua versão intermolecular.

Inicialmente o dieno 251 foi preparado através de um Rearranjo de Claisen do intermediário 250. Em seguida, a reação de Diels-Alder de 251 com o tiglaldeído (252) originou aduto 253 (excesso diastereoisomérico de $\approx 95 \%$ ), que foi imediatamente convertido em 254. Após algumas transformações, o intermediário 254 foi convertido no produto natural 184. Na útima etapa da síntese a metodologia utilizada foi a mesma de Hayashi. ${ }^{129}$ 

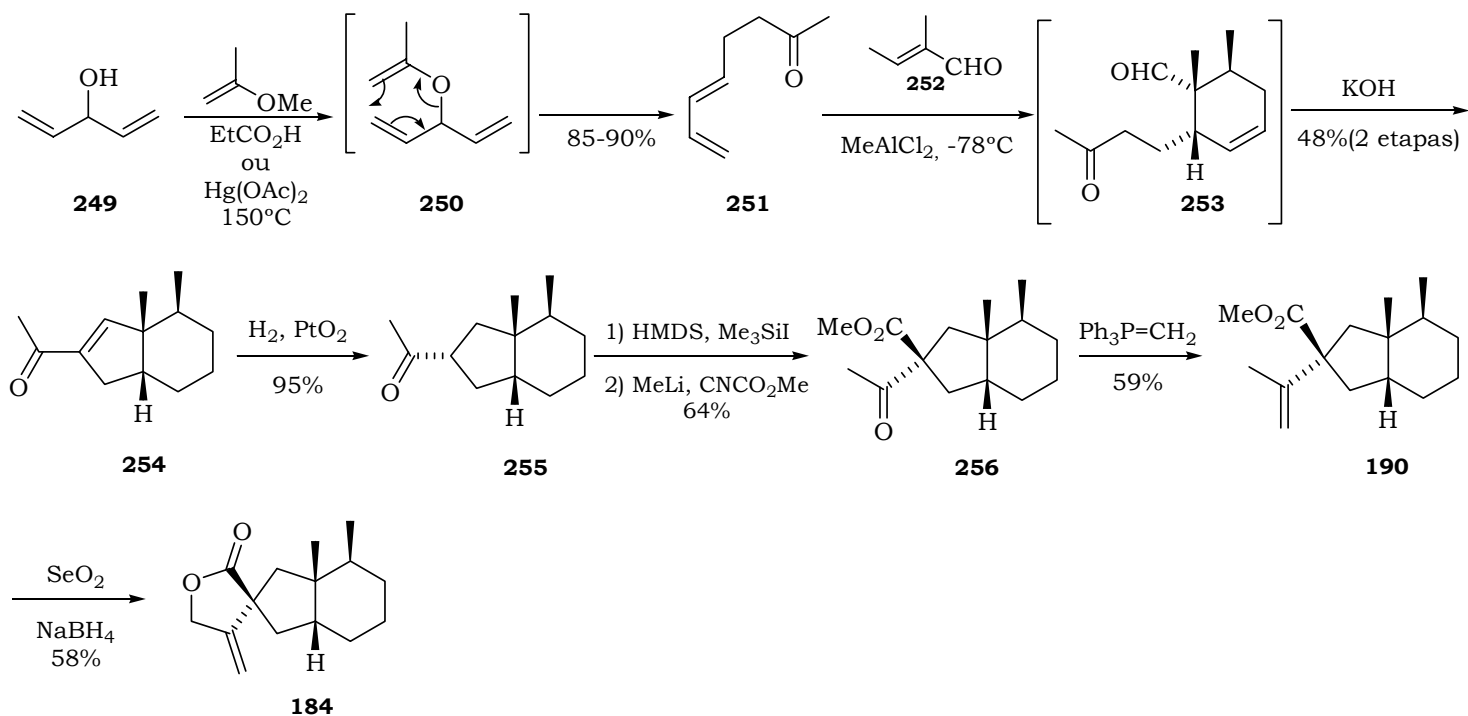

(士)-Baquenolida A

Esquema 77: Sintese de Reddy.

Para concluir esta seção sobre as sínteses da baquenolida A (184), serão apresentados três trabalhos que não poderiam ser omitidos. $\mathrm{O}$ primeiro deles é sobre a $( \pm)$-baquenolida (184) realizada por Petragnani e Silva, até o momento não publicado. ${ }^{140}$ Os outros dois são sobre a síntese da (-)-7-epi-baquenolida A (226), realizada por Srikrishna e colaboradores. ${ }^{141}$

A síntese desenvolvida por Petragnani e Silva envolveu cinco etapas iniciais até a preparação da diazocetona 260, que sofreu um rearranjo fotoquímico para originar o éster 261. A formilação de 261 forneceu o intermediário 262, cuja estereoquímica é apropriada para a preparação da ( \pm )-baquenolida (184). No total foram utilizadas 13 etapas reacionais até a obtenção de $\mathbf{1 8 4}$, com rendimento global de 2,85\%. 

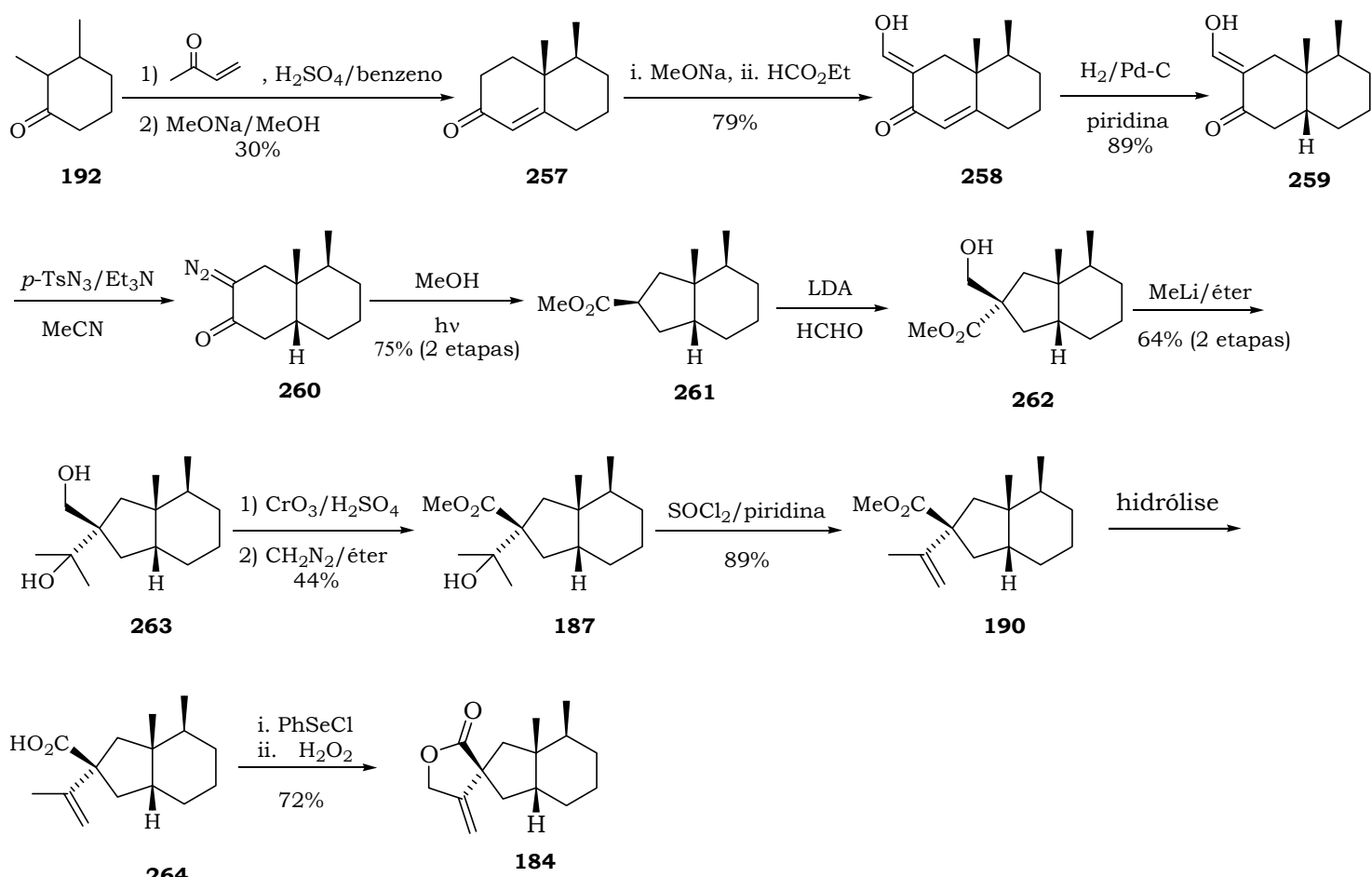

( \pm )-Baquenolida A

Esquema 78: Síntese de Petragnani e Silva.

As duas sínteses descritas por Srikrishna e colaboradores são um tanto quanto contraditórias. O primeiro trabalho publicado em 1994 traz a síntese 100\% estereoseletiva da ( \pm )-baquenolida (184) com a afirmação de que as análises de RMN de ${ }^{1} \mathrm{H}$ a $270 \mathrm{MHz}$ estavam de acordo com as de uma amostra autêntica.

Nesta síntese (esquema 79), os autores prepararam o mesmo intermediário de Evans, a cetona 200, e sintetizaram o anel lactônico por uma outra metodologia. Na etapa principal da abordagem sintética ocorre uma ciclização radicalar, que segundo os autores, fornecia exclusivamente o intermediário 270. Após duas etapas reacionais era obtida a ( \pm -baquenolida (184). 


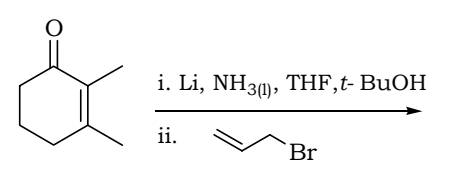

265<smiles>C=CC[C@]1(C)C(=O)CCC[C@H]1C</smiles>

266

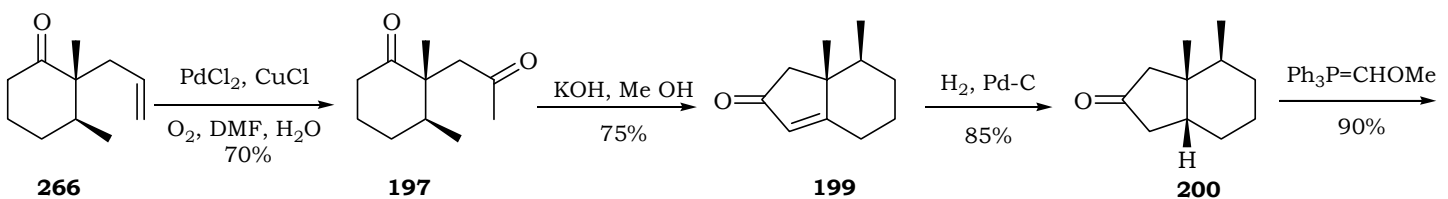

266<smiles>[2H][C@H]1CCC[C@@H](C)[C@@]2(C)CC(=COC)C[C@]12C</smiles>
268

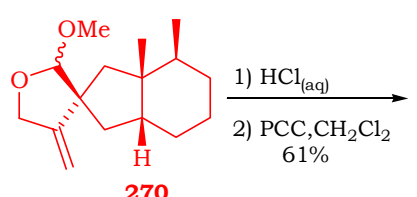

270<smiles>C#CO[C@H](OC)[C@]1(Br)C[C@]2(C)[C@H](C)CCC[C@H](C)[C@@]12C</smiles>

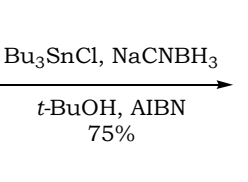<smiles>C#CCOC(OC)[C@]1(C)CC2CCCC(C)C1(C)C2</smiles><smiles>C1CC1</smiles>

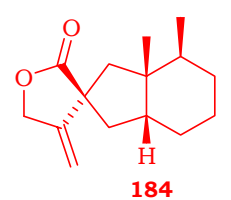

(士)-Baquenolida A

Atribuição Errada !

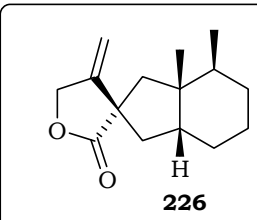

(士)-7-epi-Baquenolida A

Composto Sintetizado

Esquema 79: Primeira Sintese de Srikrishna e Colaboradores.

No entanto, em 1998 os próprios autores afirmaram ter havido um equívoco na elucidação estrutural do produto natural obtido na síntese anterior. Na publicação de 1998, os autores relataram uma síntese muito semelhante à anterior (do ponto de vista da etapa chave da abordagem sintética - ciclização radicalar) afirmando ter obtido a (-)-7epi-baquenolida A (226).

Neste caso, partiu-se da (+)-carvona 271 e após algumas transformações foi obtido o intermediário 197 enatiomericamente puro (esquema 80). Utilizando as mesmas etapas reacionais realizadas na síntese anterior os autores obtiveram a $(-)-7$-epibaquenolida A (226), corretamente elucidada. 


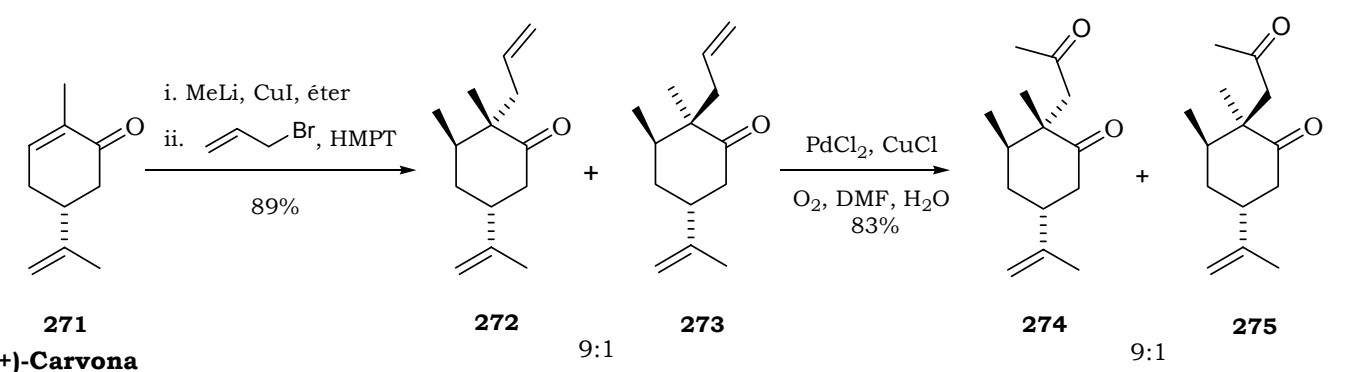

(+)-Carvona<smiles>C=C(C)[C@@H]1CC(=O)[C@@](CC)(CC(C)=O)[C@H](C)C1</smiles>

274

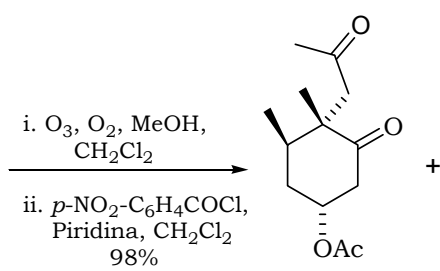

276<smiles>CC(=O)C[C@]1(C)C(=O)C[C@@H](C(C)=O)CC1C</smiles>

277

$7,75: 2: 0,25$

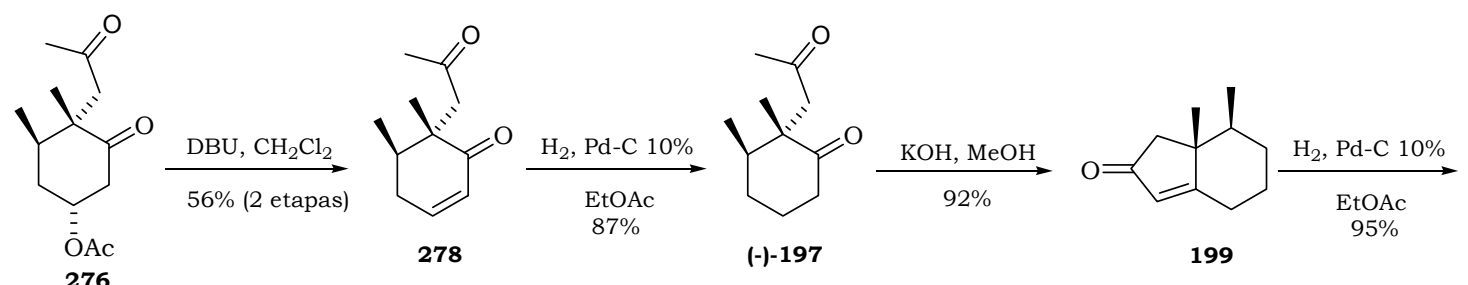<smiles>C[C@H]1CCC[C@H]2CC(=O)C[C@]12C</smiles>

$(+)-200$

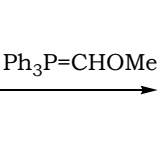

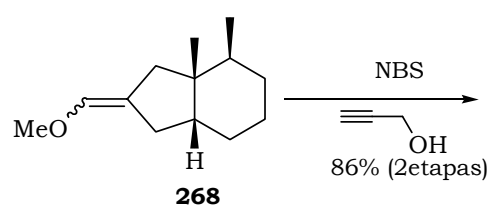<smiles>C#CO[C@H](OC)C1(Br)C[C@H]2CCC[C@H](C)[C@]2(C)C1</smiles>

$\underset{t \text {-BuOH, AIBN }}{\stackrel{\mathrm{Bu}_{3} \mathrm{SnCl}, \mathrm{NaCNBH}_{3}}{\longrightarrow}}$ $90 \%$<smiles>C=C1CO[C@@H](OC)[C@@]12C[C@@H]1CC[C@H](C)[C@@H](C)C[C@@]1(C)C2</smiles><smiles>C=C1COC(=O)[C@@]12C[C@H]1CC[C@H](C)[C@@H](C)C[C@@]1(C)C2</smiles>

(-)-7-epi-Baquenolida A

Esquema 80: Segunda Sintese de Srikrishna e Colaboradores.

$\mathrm{Na}$ próxima seção, serão apresentadas as abordagens sintéticas que foram propostas e executadas na parte $B$ deste trabalho e que conduziram a uma nova síntese da ( \pm )-baquenolida A (184). 



\section{Objetivos - Parte B}





\section{2.- Objetivos}

Nesta parte do trabalho teve-se como objetivo realizar a síntese da $( \pm)$ baquenolida A (184), através da reação de Diels-Alder. A síntese deste produto natural já era pretendida há algum tempo pelo nosso grupo de pesquisa, no entanto, apenas alguns modelos sintéticos haviam sido desenvolvidos. ${ }^{131,133}$

Fundamentalmente pretendia-se produzir os compostos cis-dimetilados 279 ou 280 através de reações de Diels-Alder intra ou intermoleculares, e depois construir o sistema $\alpha$-espiro- $\beta$-metileno- $\gamma$-butirolactônico a partir detas estruturas.

Diels-Alder Intramolecular

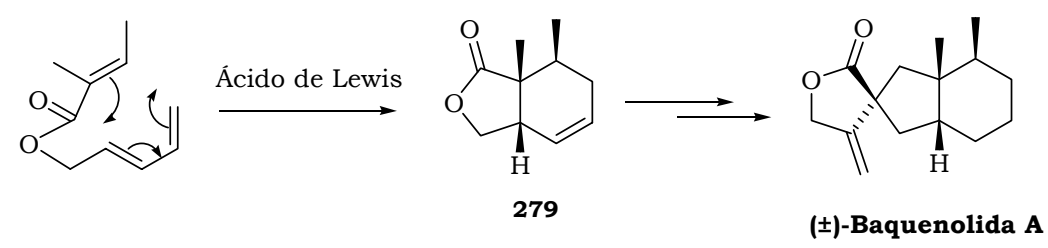

Diels-Alder Intermolecular

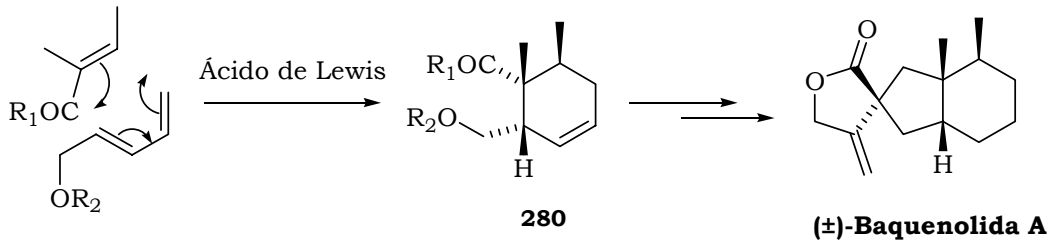

Esquema 81: Objetivos da Parte B deste Trabalho. 



\section{Plano de Pesquisa - Parte B}





\section{3 - Plano de Pesquisa}

A síntese do aduto 279 através de uma reação de Diels-Alder Intramolecular foi sugerida por Brocksom e Constantino em 1984, ${ }^{136}$ e estudada por Nakamura durante seu doutorado. ${ }^{142}$ No entanto, mesmo após várias tentativas, o aduto desejado não foi obtido.

Mesmo conhecendo este resultado negativo, acreditávamos que sob a ação de um ácido de Lewis bem eficiente, a Diels-Alder intramolecular mostrada no esquema 82 pudesse ocorrer, e por isso, propusemos alguns testes com $\mathrm{NbCl}_{5}$. A eficiência deste ácido de Lewis nas reações de Diels-Alder já foi bem estabelecida por pesquisas anteriores de nosso grupo. ${ }^{143,144}$

A preparação do composto 285 poderia ser realizada partindo-se de derivados do ácido $\beta$-vinilacrílico 281 e do ácido tíglico 282. Em seguida, a ciclização intramolecular catalisada por $\mathrm{NbCl}_{5}$ poderia dar origem ao aduto 279 .

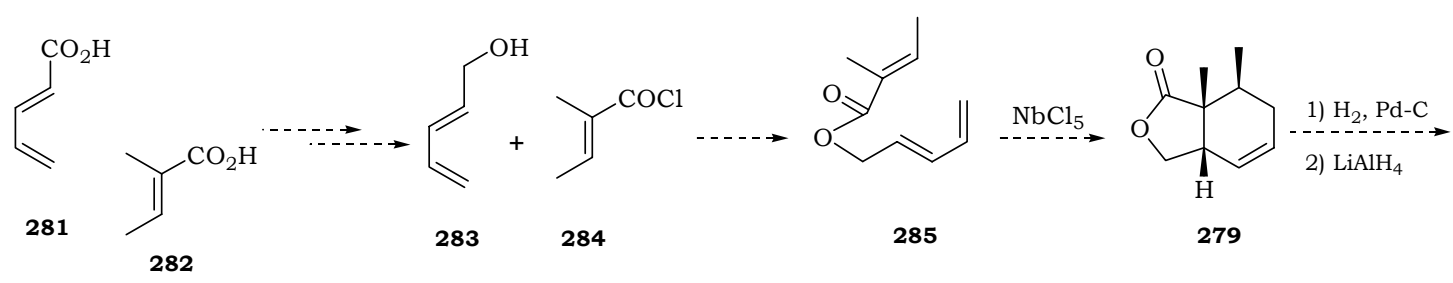

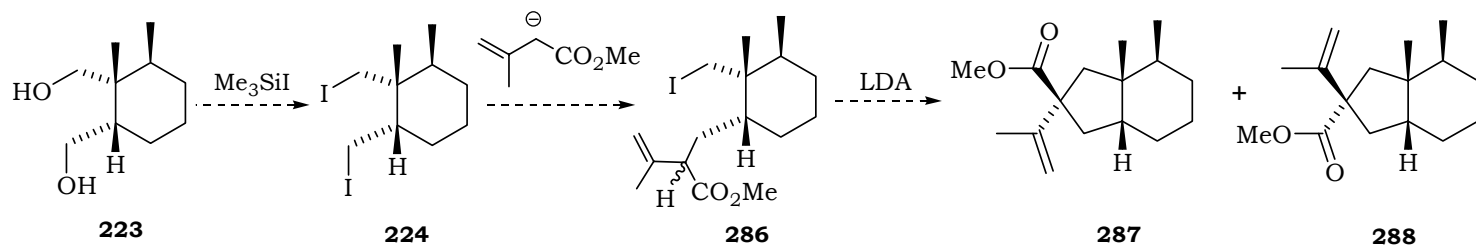

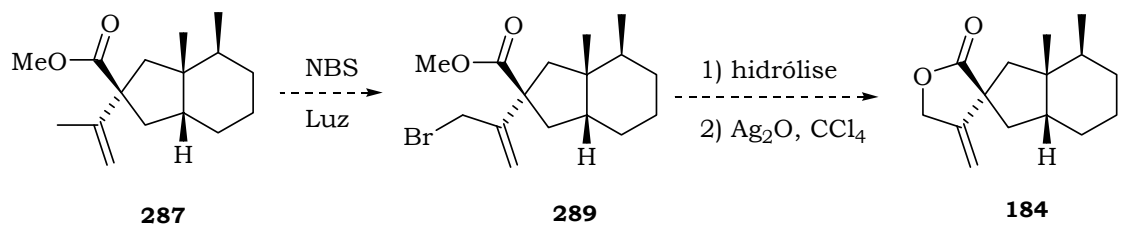

( \pm )-Baquenolida A

Esquema 82: Primeira Proposta Sintética via Diels-Alder Intramolecular.

Uma vez obtido o composto 279 , algumas outras transformações poderiam dar origem ao di-iodeto 224, um intermediário apropriado para realizar as etapas de alquilação/anelação e obter os epímeros 287 e 288. Neste sentido, nenhum dos modelos desenvolvidos anteriormente (esquemas 68, 69 e 70) ${ }^{131,132,133}$ eram suficientes para prever se haveria alguma estereoseletividade e qual dos epímeros seria favorecido.

Após a obtenção dos epímeros 287 e 288, os mesmos poderiam ser separados ou não, e a síntese poderia ser desenvolvida até a produção da baquenolida A (184) na sua forma racêmica.

Uma outra possibilidade seria efetuar uma reação de Diels-Alder intermolecular, também catalisada por $\mathrm{NbCl}_{5}$, obtendo após algumas transformações, o mesmo produto 223 já mencionado. Neste processo, seria provavelmente mais eficiente utilizar não o 
ácido 281, mas o álcool correspondente, conhecidamente mais reativo; uma proteção da hidroxila deste álcool poderia ser necessária para reduzir a sua polimerização (esquema 83).

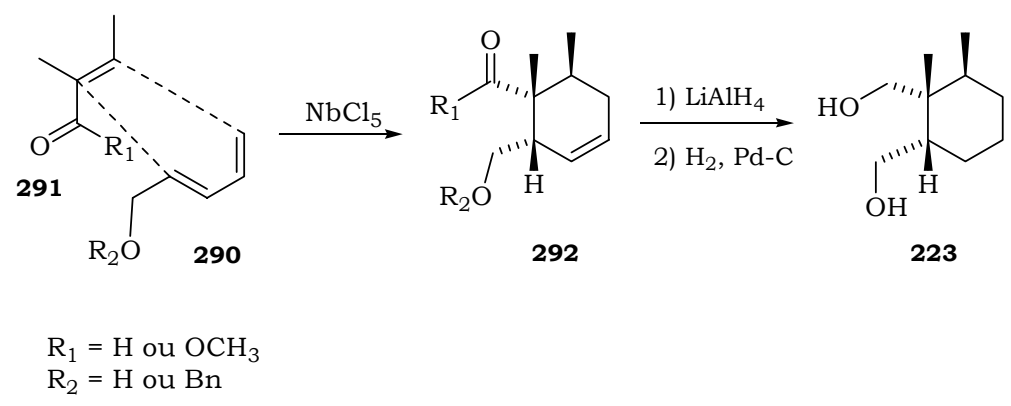

Esquema 83: Segunda Proposta Sintética via Diels-Alder Intermolecular. 


\title{
Atividades Realizadas e Resultados Obtidos
}

\author{
Parte $B$
}





\section{4 - Atividades Realizadas e Resultados Obtidos}

\section{Preparação dos Ácidos $\beta$-vinilacrílico (281) e Tíglico (282).}

Os estudos relativos a esta segunda parte do trabalho, foram iniciados pela preparação dos ácidos $\beta$-vinilacrílico (281) e tíglico (282). O ácido 281 foi preparado a partir da acroleína (293) seguindo a seqüência de reações mostradas no esquema $84 .{ }^{145}$
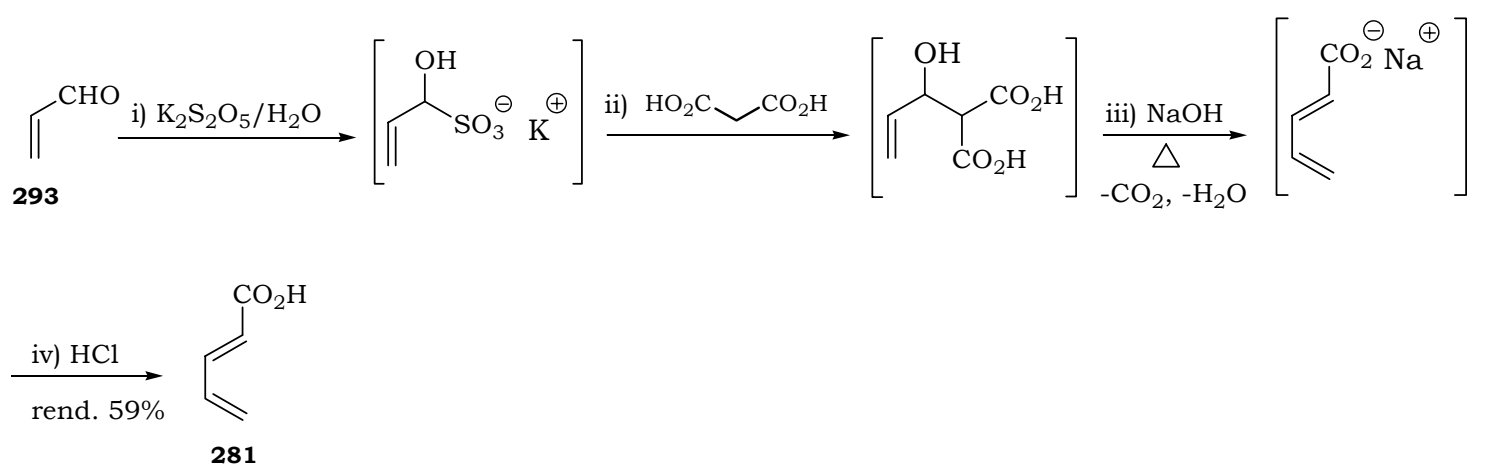

Esquema 84: Preparação do Ácido $\beta$-vinilacrílico (281).

Para a síntese do ácido tíglico (282), primeiro preparou-se a cianidrina 295 a partir da butanona (294). ${ }^{146}$ Em seguida o composto 295 foi desidratado e a respectiva nitrila foi hidrolisada originando o ácido 282 (esquema 85). ${ }^{146}$

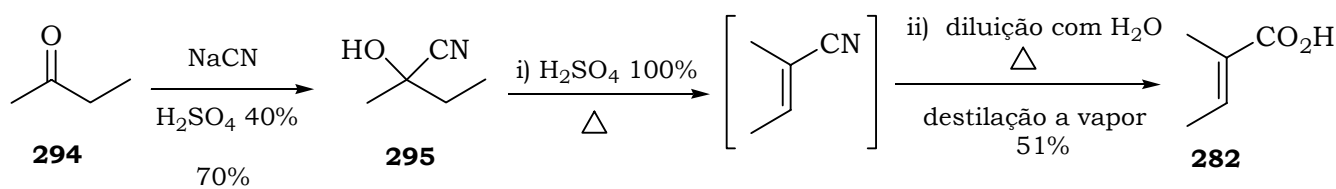

Esquema 85: Preparação do Ácido tíglico (282).

\section{Preparação do Composto 285 e Testes da Reação de Diels-Alder Intramolecular.}

A preparação do composto 285 foi realizada em três etapas reacionais, partindo do ácido $\beta$-vinilacrílico (281).

O ácido 281 foi esterificado com $\mathrm{MeOH} / \mathrm{H}_{2} \mathrm{SO}_{4}$ fornecendo o éster 296 (75\% de rendimento). ${ }^{147}$ Em seguida, o composto 296 foi reduzido com $\mathrm{LiAlH}_{4}$ fornecendo o álcool 283 com $89 \%$ de rendimento (esquema 86). ${ }^{148}$ 


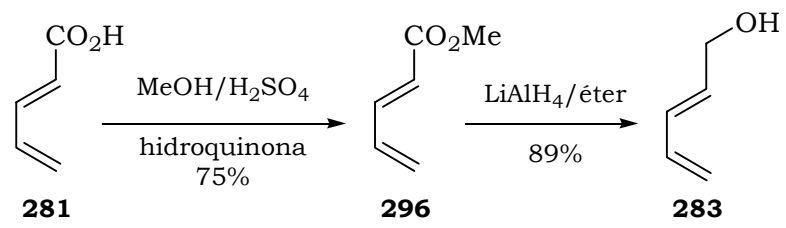

Esquema 86: Preparação do Álcool 283.

Após a preparação do álcool 283, o ácido tíglico (282) foi transformado no seu cloreto de ácido pela reação com cloreto de oxalila, e em seguida no éster 285 , com rendimento de $70 \%$ (esquema 87 ). ${ }^{149}$
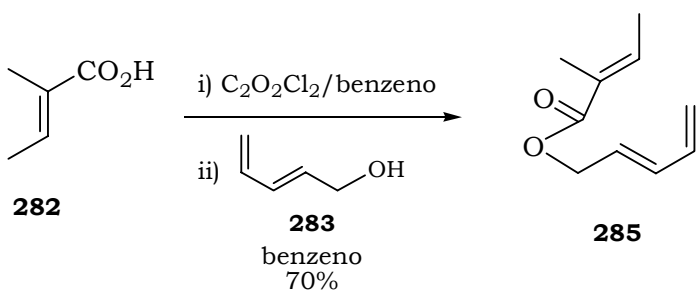

Esquema 87: Preparação do Composto 285.

Como já mencionado, a reação de Diels-Alder intramolecular com o composto 285 já havia sido estudada ${ }^{142}$ em diferentes condições reacionais (térmicas e sob catálise). Restava ainda testar um ácido de Lewis altamente eficiente, como o $\mathrm{NbCl}_{5}$.

Foram realizados vários testes variando-se a quantidade de $\mathrm{NbCl}_{5}$ (0,1-1 equivalente), as temperaturas reacionais (de $-78^{\circ} \mathrm{C}$ até refluxo) e utilizando-se alguns solventes compatíveis com este ácido de Lewis $\left(\mathrm{CH}_{2} \mathrm{Cl}_{2}, \mathrm{Et}_{2} \mathrm{O}\right)$. Em quase todos os experimentos obteve-se apenas a formação de polímeros ou a formação de polímeros com recuperação parcial do material de partida. Em alguns casos foi observada a formação de pequenas quantidades de ácido tíglico (282) provavelmente devido à presença de alguns vestígios de água no meio reacional.

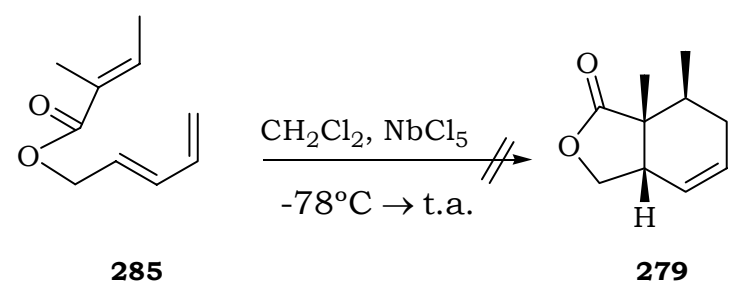

Esquema 88: Teste da Reação de Diels-Alder Intramolecular de 279 com NbCl.

Para concluir estes estudos que envolviam a versão intramolecular da reação de Diels-Alder, resolveu-se realizar um teste em condições térmicas bem drásticas (210-220 $\left.{ }^{\circ} \mathrm{C}\right)$ e alta diluição $\left(1 \mathrm{mg} / \mathrm{mL} \sim 6.10^{-3} \mathrm{~mol} / \mathrm{L}\right)$. Esta reação foi realizada em benzeno/BHT utilizando-se um tubo selado Aldrich ${ }^{\circledR}$. Após três dias, observou-se um consumo parcial do material de partida 285 e a formação de um produto cuja análise de $\mathrm{RMN}$ de ${ }^{1} \mathrm{H}$ indicava não ser o aduto desejado 279 . Uma breve análise destes dados de $\mathrm{RMN}{ }^{1} \mathrm{H}$ indicou a formação de um provável dímero, ${ }^{150}$ conforme mostrado no esquema 89. 


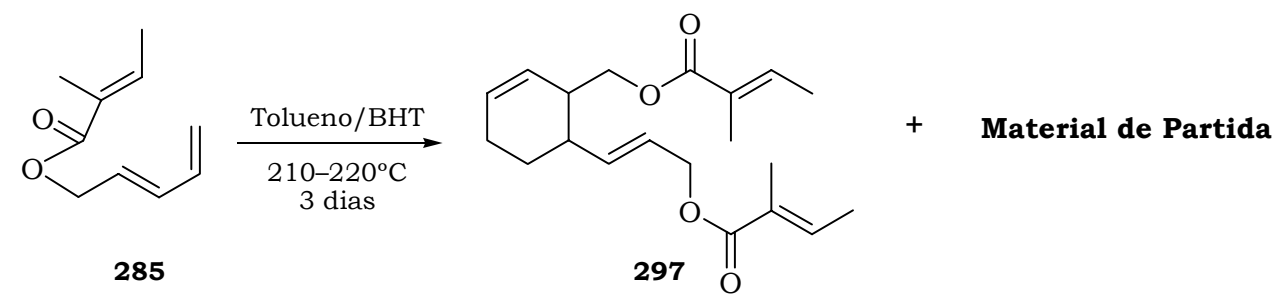

Esquema 89: Teste da Reação de Diels-Alder Intramolecular de 285 em Condições Térmicas.

As reações testadas nesta parte do trabalho somadas às muitas outras realizadas anteriormente $^{142}$ podem levar a duas conclusões sobre esta reação de Diels-Alder Intramolecular:

- A primeira delas é que sob catálise o material de partida ou se degrada ou não sofre a cicloadição desejada.

- A segunda é que em condições térmicas a reação que ocorre não é a esperada, mas provavelmente uma ciclização intermolecular. Este último resultado reforça ainda mais a hipótese de que a energia de ativação para ciclização desejada é muito alta e não pode ser atingida sem que outras reações laterais ocorram preferencialmente.

Desta maneira, a abordagem que envolvia uma reação de Diels-Alder intramolecular foi definitivamente abandonada e deu-se continuidade aos estudos, testando a cicloadição proposta no esquema 83. 


\section{Reação de Diels-Alder entre o Dieno 298 e o Tiglaldeído (299). ${ }^{151}$}

Para de realizar os testes da reação de Diels-Alder intermolecular, proposta no esquema 83, resolveu-se preparar o dieno 298 a partir do seu correspondente álcool 283. Algumas experiências anteriores mostraram que o composto 283 sofria facilmente polimerização em meio ácido.

O ânion do álcool 283 foi preparado com $\mathrm{NaH} / \mathrm{THF}$ e em seguida protegido com brometo de benzila, fornecendo 298 com $90 \%$ de rendimento. ${ }^{152}$

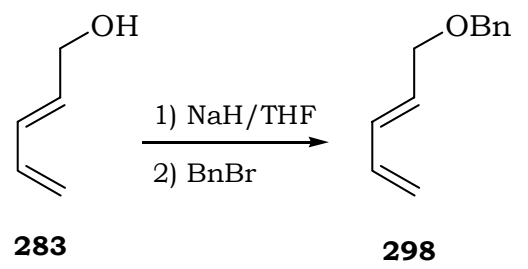

Esquema 90: Preparação do Dieno 298.

Em seguida, foram realizados vários experimentos entre o dieno 298 e o tiglaldeído (299) na presença de $\mathrm{NbCl}_{5}$, variando-se a temperatura, as quantidades de ácido de Lewis, o solvente e as proporções molares entre o dieno e o dienófilo; os melhores resultados foram obtidos quando a reação foi conduzida em $\mathrm{CH}_{2} \mathrm{Cl}_{2}$ à baixa temperatura $\left(-78^{\circ} \mathrm{C} \rightarrow-50^{\circ} \mathrm{C}\right)$, utilizando 0,25 equivalentes de $\mathrm{NbCl}_{5}$ e 4 equivalentes do dienófilo 299. Nestas condições, o aduto 300 foi obtido com $45 \%$ de rendimento após purificação (esquema 91).

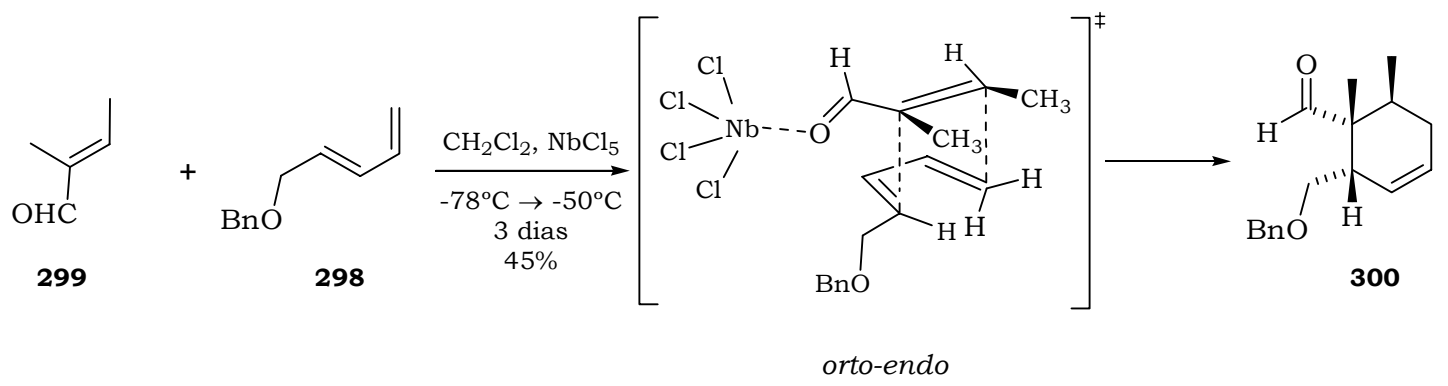

Esquema 91: Reação de Diels-Alder entre o Dieno 298 e o Dienófilo 299.

A estrutura do aduto 300 foi devidamente elucidada com o auxílio de várias técnicas de RMN de ${ }^{1} \mathrm{H}$ e ${ }^{13} \mathrm{C}$ (uni e bidimensionais), experimentos de NOE DIFF, além de IV e massa (ESI-TOF).

Durante a execução dos experimentos reacionais de 298 com 299 suspeitou-se que parte do aduto 300, um aldeído, estivesse se decompondo especialmente durante a purificação por cromatografia em coluna de sílica, por isso, tentou-se realizar um teste reduzindo o produto bruto da reação de Diels-Alder com $\mathrm{LiAlH}_{4}$, isolando-se o correspondente álcool 301. Neste caso, obteve-se um rendimento global de $42 \%$ (média de $64 \%$ por etapa), um pouco superior quando são consideradas as duas reações envolvidas separadamente (45\% na Diels-Alder e $84 \%$ na redução a partir do aduto 300 puro; total de 37,8\%), conforme mostrado no esquema 92. 


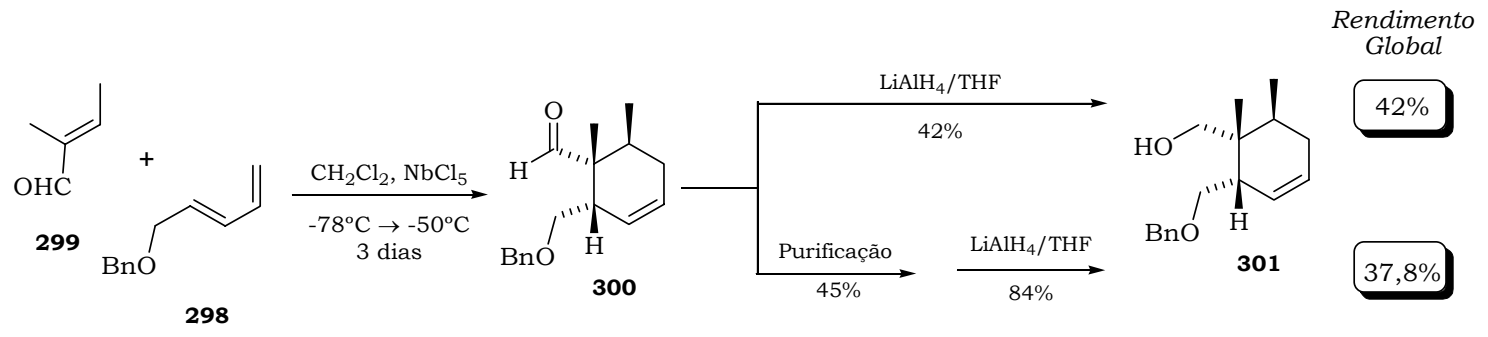

Esquema 92: Reações de Redução de 300 com $\mathrm{LiAlH}_{4}$.

Este é um resultado excelente, pois o intermediário 301, obtido com rendimento satisfatório em apenas duas etapas, possui toda a estereoquímica relativa correta para a síntese de produtos naturais da classe dos eremofilanos e dos bacanos, incluindo as baquenolidas.

\section{Transformações Realizadas no Aduto 300 - Síntese da (士)-Baquenolida A (184).}

Dando continuidade aos estudos propostos, o composto 301 foi convertido no diol 223 em uma única etapa, através da reação com $\mathrm{H}_{2}$ na presença $\mathrm{Pd}-\mathrm{C} /$ etanol (rendimento de 99\%). ${ }^{153}$ Em seguida, o diol 223 foi tratado com excesso de $\mathrm{Me}_{3} \mathrm{Sil}$ e forneceu o di-iodeto $224 \mathrm{com} 70 \%$ de rendimento. ${ }^{154}$

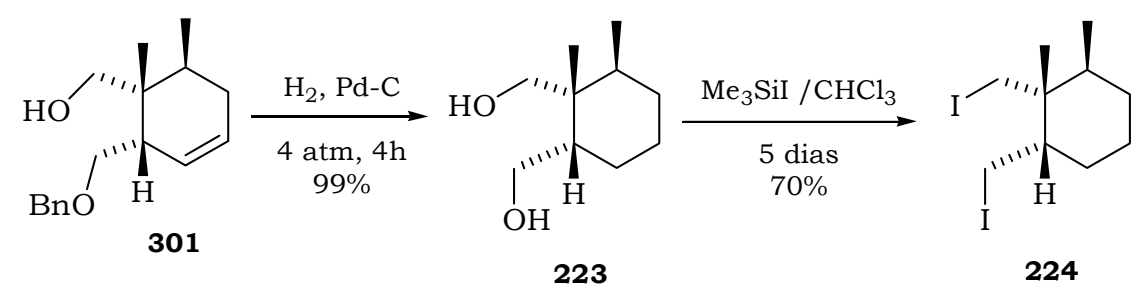

Esquema 93: Preparação dos Intermediários 223 e 224.

A próxima etapa consistia em adicionar o ânion do 3,3-dimetilacrilato de metila (303) ao di-iodeto 224. Para isto o éster 303 foi previamente preparado, esterificando o ácido $302 \mathrm{com} \mathrm{MeOH} / \mathrm{H}_{2} \mathrm{SO}_{4}$ (76\% de rendimento). ${ }^{155}$

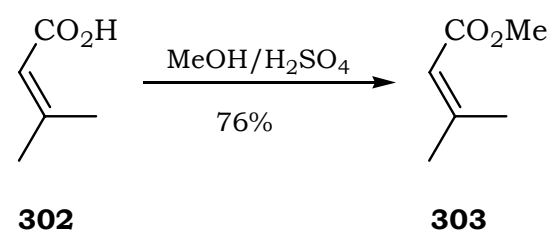

Esquema 94: Preparação do Éster 303.

O composto 224 foi então alquilado pela adição do ânion de 303 (preparado em THF/LDA/HMPA a $-78^{\circ} \mathrm{C}$ ), fornecendo uma mistura equimolar dos diastereoisômeros 286a e 286b (esquema 95 - 85\% de rendimento). ${ }^{133,156}$ Estes compostos foram separados para facilitar a identificação dos produtos reacionais. No entanto, para os propósitos 
sintéticos, esta separação era desnecessária uma vez que na próxima etapa da síntese seria gerado um carbânion exatamente no centro quiral que diferenciava os dois isômeros.

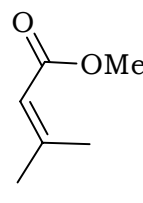

303

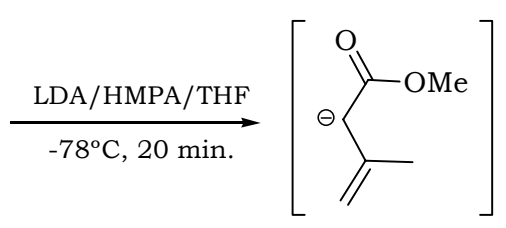

$-78^{\circ} \mathrm{C}, 20 \mathrm{~min}$.

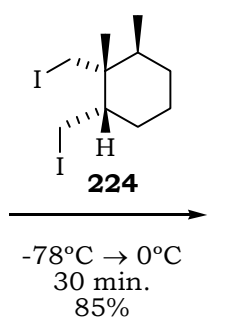<smiles>C=C(C)[C@H](C[C@@]1(CI)CCCC(C)[C@@]1(C)C(C)=O)C(C)=O</smiles>

$286 a$<smiles>C=CC(C)C(C[C@H]1CCCC(C)[C@]1(C)CI)C(C)=O</smiles>

286b

Esquema 95: Preparação dos Diastereoisômeros 286a e 286b.

Para a realização da próxima etapa prevista na síntese (esquemas 82 e 83), utilizouse uma mistura dos compostos $286 \mathrm{a}$ e $286 \mathrm{~b}$ que foram tratados com uma solução de LDA/HMPA/THF a $-78^{\circ} \mathrm{C}$. Após três horas de reação foi obtida a mistura epimérica contendo 287 e 288 nas proporções de 18:82 respectivamente (esquema 96). ${ }^{133,139,156}$ Esta reação foi testada também em condições onde a temperatura foi elevada de $-78^{\circ} \mathrm{C}$ até $0^{\circ} \mathrm{C}$. Neste caso o tempo reacional foi menor ( 2 horas) e a proporção entre os epímeros foi ligeiramente diferente, favorecendo ainda mais a formação do epímero 288 (proporção de 15:85 em relação aos epímeros 287 e 288, respectivamente).<smiles>C=C(C)[C@H](C[C@H]1[C@H](C)CCC[C@]1(C)CI)[C@H](C)OC</smiles>

$286 a$<smiles>C=CC(C)C(C[C@H]1CCCC(C)[C@]1(C)CI)C(=O)O</smiles><smiles>C=C(C)[C@]1(C(=O)OC)C[C@H]2CCC[C@H](C)[C@]2(C)C1</smiles>

287<smiles>C=C(C)[C@]1(C(=O)OC)C[C@H]2CCC[C@@H](C)[C@]2(C)C1</smiles>

288

$18: 82$

Esquema 96: Reação de Ciclização a partir dos Diastereoisômeros 286a e 286b.

Estes resultados não foram muito satisfatórios do ponto de vista da síntese pretendida, pois o epímero cinéticamente favorável 288 , não era o que conduziria à síntese da ( \pm )-baquenolida A (184). 
Pôde-se concluir que o composto 288, formado a partir do ânion cuja conformação do grupo carboxila está oposta às metilas em cis (esquema 97), é favorecido, e que provavelmente a utilização de um éster mais volumoso poderia permitir que o outro epímero fosse formado em proporções mais adequadas aos objetivos da síntese proposta.
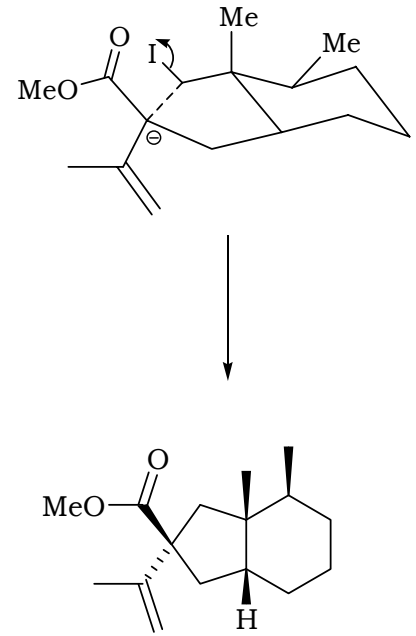

287
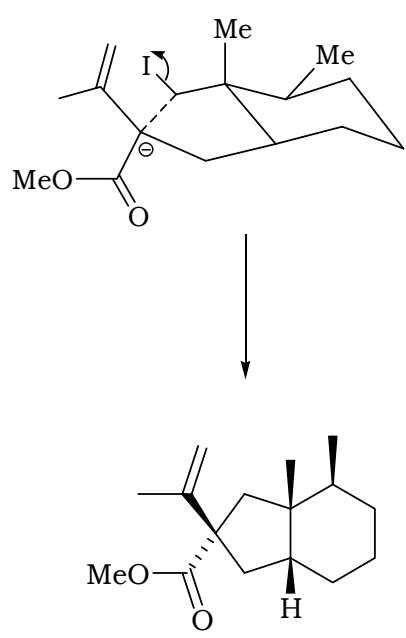

288

Esquema 97: Conformações dos Ânions que Conduzem à Formação de 287 e 288.

Para um próximo teste foi escolhido o éster t-butílico 304, obtido pela reação de 303 com isobutileno em meio ácido. ${ }^{157}$

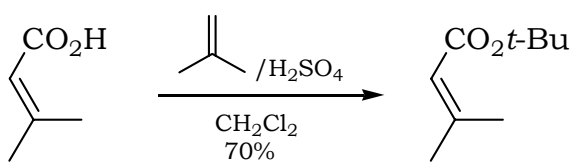

302

304

Esquema 98: Preparação do Éster t-Butílico 304.

O composto 224 foi então alquilado com o ânion do éster 304 . A reação foi iniciada a $-78^{\circ} \mathrm{C}$ e mantida a $0^{\circ} \mathrm{C}$ por 30 minutos, fornecendo os diastereoisômeros $305 \mathrm{a}$ e $305 \mathrm{~b}$ com $92 \%$ de rendimento.

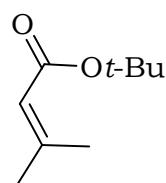

304

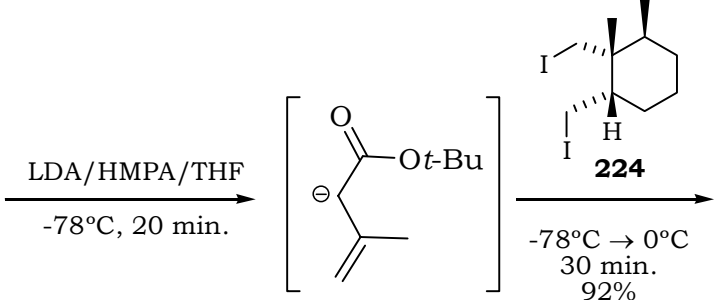

$92 \%$

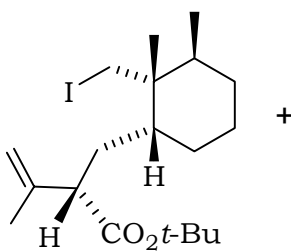

$305 a$<smiles>C=CC(C)[C@H](CCI)[C@H]1CCC[C@@H](C)[C@]1(C)CI</smiles>

$305 b$

Esquema 99: Preparação dos Diastereoisômeros 305a e 305b. 
A mistura dos diastereoisômeros 305a e 305b foi tratada com uma solução de LDA/HMPA/THF a $-78^{\circ} \mathrm{C}$ por 1 hora. Após este período não se observou a formação de uma quantidade apreciável de produtos reacionais (ao contrário do que foi observado na reação envolvendo os compostos 286 a e 286 b - esquema 96) e por isso a temperatura foi sendo elevada lentamente até $0^{\circ} \mathrm{C}$. A reação foi mantida por mais duas horas nesta temperatura até o consumo total dos materiais de partida. Os epímeros 306 e 307 foram obtidos com $77 \%$ de rendimento e na proporção de $\underline{42: 58}$, respectivamente.<smiles>C=C(C)[C@H](C[C@H]1CCC[C@@H](C)[C@]1(C)CI)C(=O)OC(C)(C)C</smiles>

$305 a$<smiles>COC(=O)C(C=C(C)C)C[C@H]1CCCC(C)[C@@]1(C)CI</smiles>

$305 b$

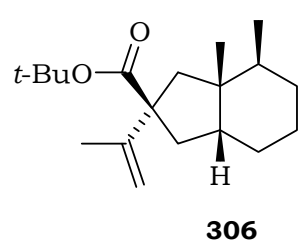

306

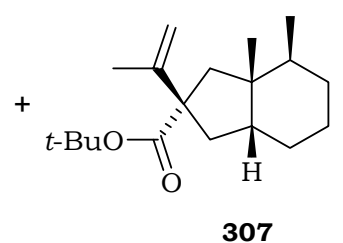

$42: 58$

Esquema 100: Reação de Ciclização a partir dos Diastereoisômeros 305a e 305b.

Este resultado confirmou a hipótese de que um éster mais volumoso tornaria menos favorecida a conformação do enolato que dá origem ao epímero indesejado 307. Além disso, permitiu dar continuidade à síntese agora com uma proporção relativamente superior do epímero adequado, neste caso 306. 
Na figura 49 são mostradas as prováveis curvas que representam a formação dos ésteres metílicos 287 e 288 e dos ésteres t-butílicos 306 e 307. Provavelmente, o aumento da proporção do epímero 306, se deve ao fato de que a energia do estado de transição $\mathrm{TS}_{(307)}$ foi aumentada em relação à do $\mathrm{TS}{ }_{(288)}$, ao passo que, a energia do estado de transição TS ${ }_{(306)}$ deve ter se alterado muito pouco com relação ao $\operatorname{TS}_{(287)}$.
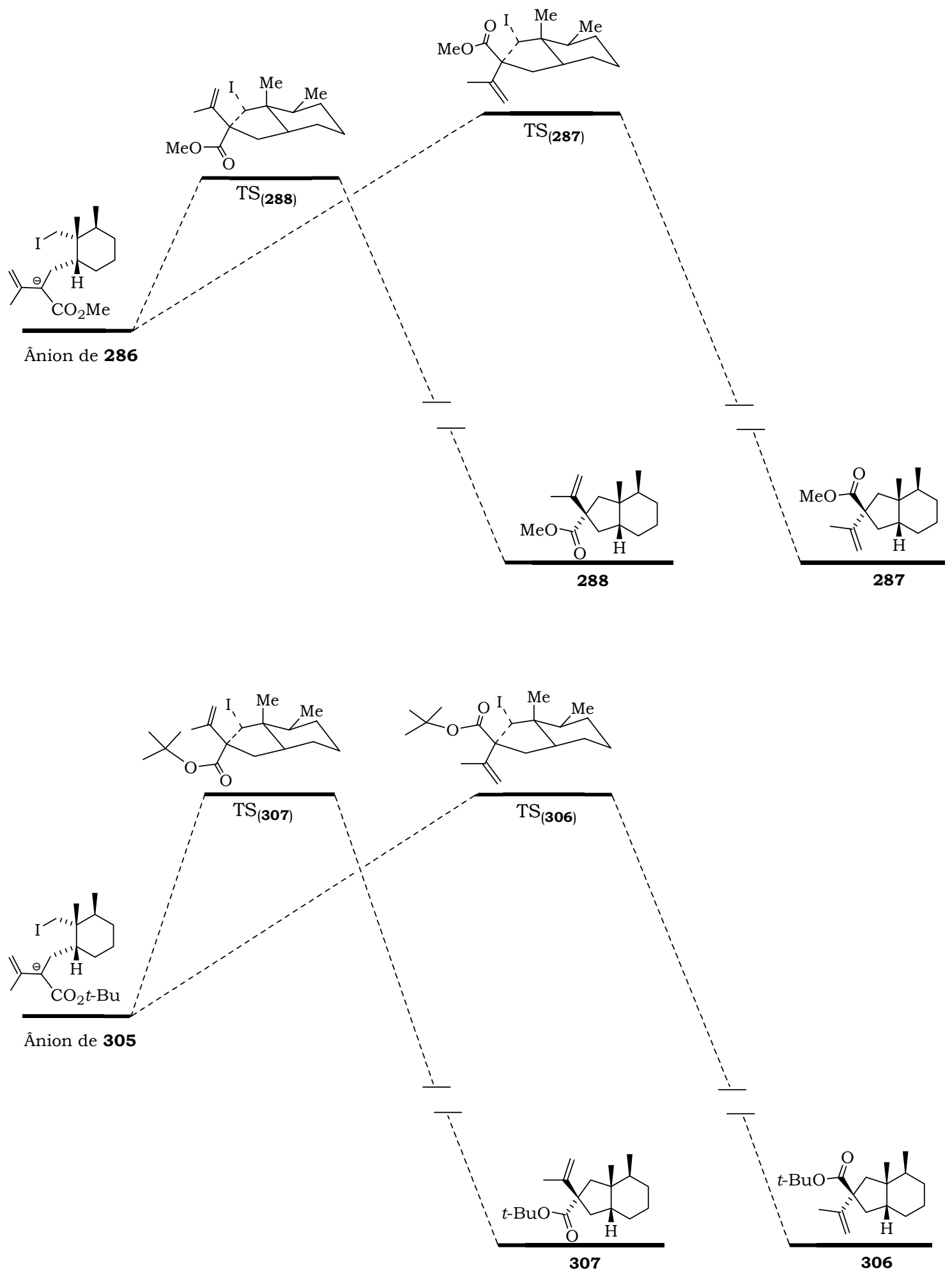

Figura 49: Prováveis Curvas de Reação dos Ésteres 287, 288, 306 e 307. 
Na próxima seção serão apresentados alguns cálculos das energias das espécies envolvidas nestas reações, incluindo a localização dos prováveis estados de transição. Por hora, serão descritas as demais atividades de caráter sintético.

Sendo assim, uma mistura dos epímeros 306 e 307 foi submetida à reação com NBS e luz o que forneceu os produtos bromados 308 e $309 \mathrm{com} 95 \%$ de rendimento. ${ }^{131}$

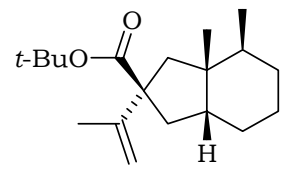

306

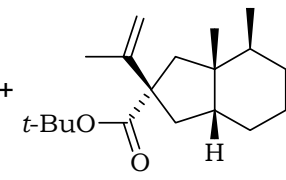

307

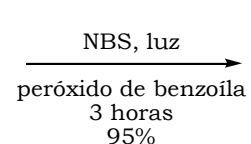

$95 \%$

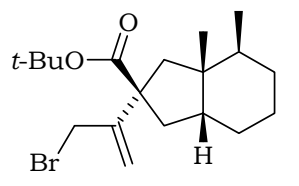

308

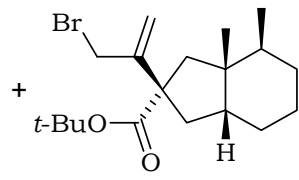

309

$42: 58$

$42: 58$

Esquema 101: Bromação Alílica dos Epímeros 306 e 307.

Em seguida, reagiu-se a mistura dos produtos 308 e 309 com $A_{2} \mathrm{O} / \mathrm{CCl}_{4}$ sob refluxo por 3 horas, o que forneceu uma mistura da ( \pm )-baquenolida $\mathrm{A}(184)$ e da 7 -epi( \pm )-baquenolida A (226), com $68 \%$ de rendimento. ${ }^{131}$

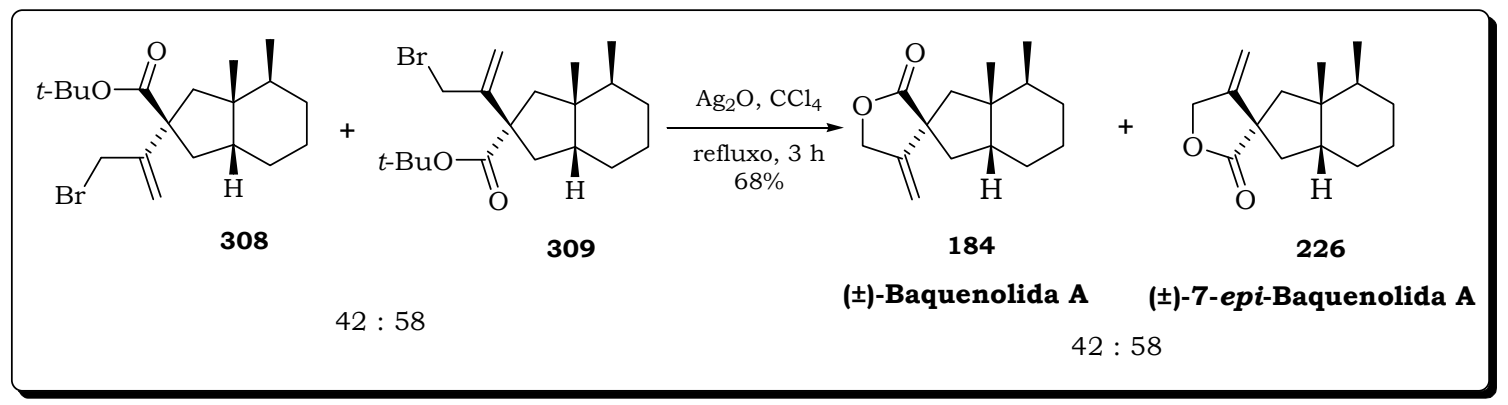

Esquema 102: Preparação dos Produtos Finais 184 e 226.

Um provável mecanismo para esta última etapa reacional está representado no esquema 103.
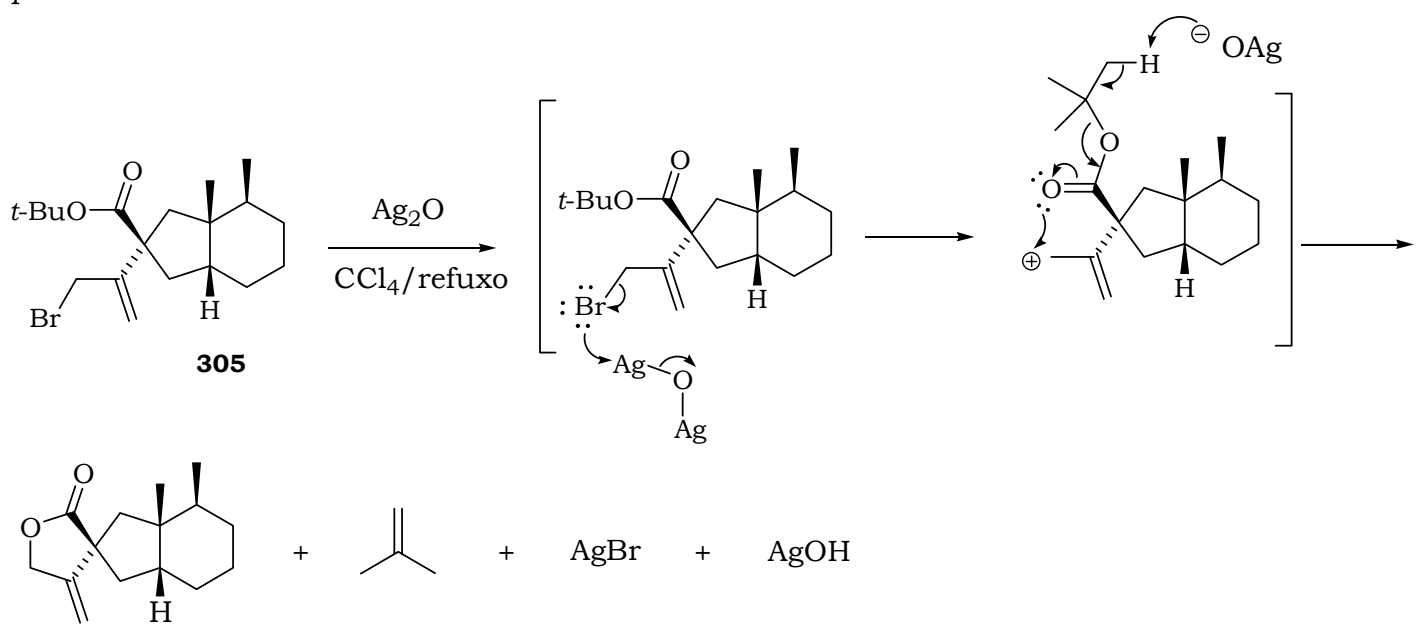

184

(士)-Baquenolida A

Esquema 103: Mecanismo de Formação dos Produtos 184 e 226. 
Com a exceção dos isômeros 286a e 286b, não foi possível separar por cromatografia em coluna de sílica as demais misturas diasteroisoméricas produzidas ao longo da síntese. Desta maneira, somente os produtos 184 e 226 foram separados por HPLC, conforme o método desenvolvido e descrito na parte experimental deste trabalho. $\mathrm{O}$ produto natural 184 e seu isômero 226 foram caracterizados por $\mathrm{RMN}$ de ${ }^{1} \mathrm{H} \mathrm{e}{ }^{13} \mathrm{C}$, e tiveram seus espectros comparados com alguns relatados na literatura. ${ }^{137,138}$ Além dos produtos finais, praticamente todos os intermediários foram analisados por espectrometria de massa (ESI - Electron-Spray Ionization ), obtendo-se valores dentro do padrão de alta resolução (detecção por TOF - Time of Flight), e por espectroscopia de infra-vermelho.

\section{Estudos sobre a Variação das Proporções dos Epímeros 306 e 307.}

Após ter concluído a síntese do produto natural 184, e fundamentalmente testado a eficácia de todas as metodologias propostas, resolveu-se investir um pouco mais em algumas modificações que pudessem produzir uma melhora na proporção do epímero 306.

Desta maneira, insistiu-se com a reação de ciclização dos ésteres t-butílicos 305a e $305 \mathrm{~b}$, mantendo a temperatura do meio reacional à $-78^{\circ} \mathrm{C}$ por um tempo bem superior $(7$ horas), elevando-se em seguida a temperatura até $0^{\circ} \mathrm{C}$. Os resultados foram um pouco melhores, pois nestas condições os epímeros foram obtidos em proporções mais favoráveis (1:1 de 306 e 307 respectivamente).

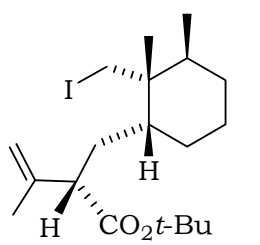

305a

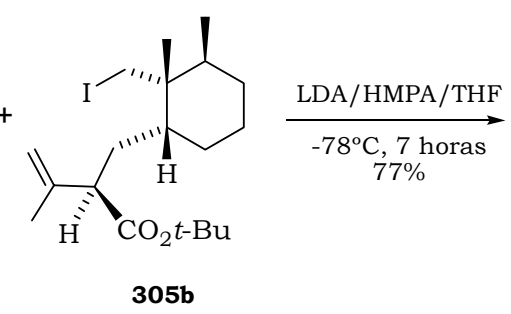

305b

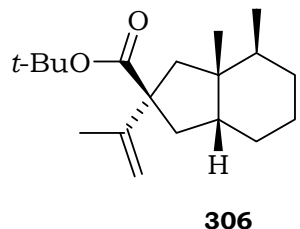

306

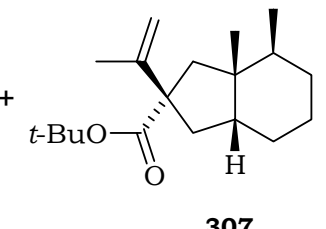

$1: 1$

Esquema 104: Sintese de 306 e 307 - Modificação

Outros testes reacionais onde a temperatura do meio foi mantida à $-78^{\circ} \mathrm{C}$ por $10 \mathrm{~h}$, renderam os mesmos resultados, visto que, com 7 horas praticamente todo o material de partida era consumido.

Estes experimentos deixaram claro que as energias dos estados de transição para a formação de 306 e 307 eram muito próximas, e que, o uso de grupos um pouco mais volumosos ligados à carboxila poderia favorecer ainda mais a formação de estruturas com a mesma estereoquímica que 306. No entanto, estes estudos foram por hora interrompidos, deixando a possibilidade de que outras reações de ciclização sejam melhor investigadas. Por exemplo, poderiam ser estudados ésteres contendo grupos derivados do trietilcarbinol ou mesmo diciclo-hexilcarbinol, mais volumosos que o t-butílico.

Uma outra possibilidade é também direcionar a reação de ciclização no sentido de produzir "apenas" um epímero do tipo 311, até então indesejado, e após algumas transformações obter o produto natural 184 (esquema 105). 


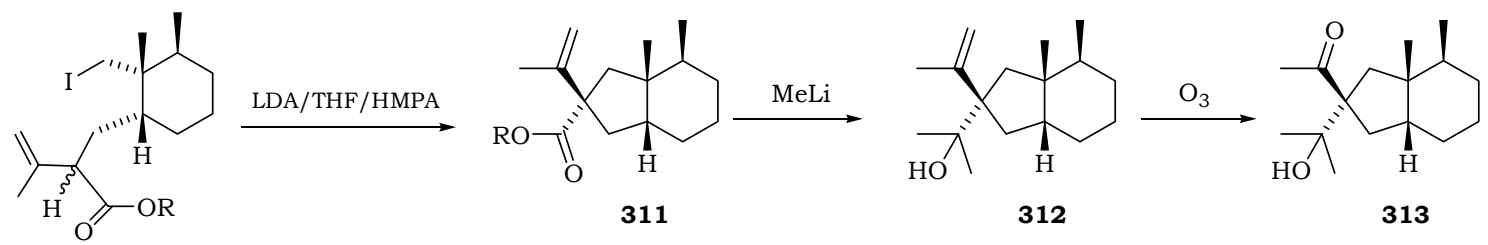

310<smiles>C=CC#CCCC(=C)[C@]1(C(=O)O)C[C@H]2CCC[C@@H](C)[C@]2(C)C1</smiles>

314

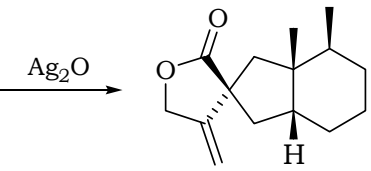

184

(士)-Baquenolida A

Esquema 105: Perspectivas Futuras.

Deve-se destacar ainda a possibilidade de sintetizar vários produtos naturais do tipo eremofilanos a partir dos primeiros intermediários envolvidos nesta síntese.

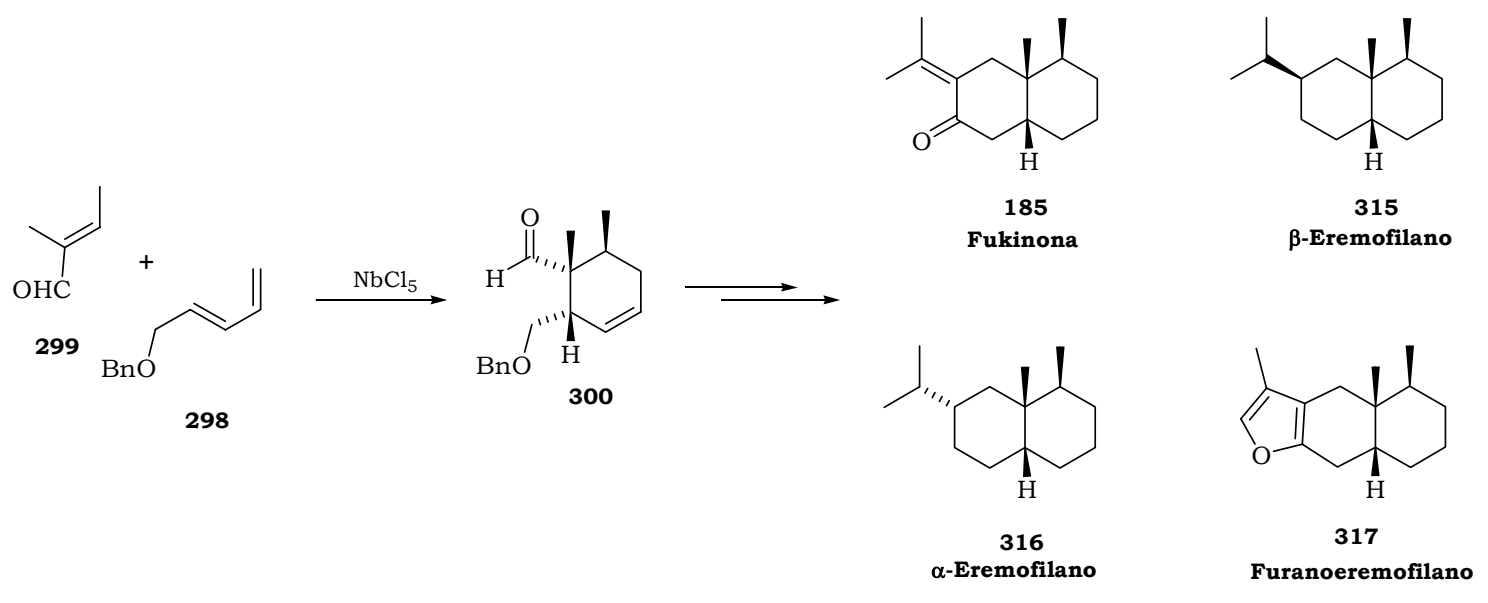

Esquema 110: Perspectivas Futuras - Sintese de Eremofilanos 


\section{5 - Cinética das Reaçôes de Formação dos Compostos 287, 288, 306 e 307: Um Estudo Teórico}

Nesta seção do trabalho serão apresentados alguns estudos teóricos sobre a cinética das reações de ciclização (esquemas 96, 100 e 104) apresentadas na seção anterior. Os resultados experimentais referentes a estas reações permitiram que algumas conclusões fossem tiradas a respeito das prováveis energias de ativação para a formação de cada um dos epímeros 287, 288, 306 e 307. Além disso, foi demonstrada experimentalmente a influência da temperatura do meio reacional nas proporções dos produtos reacionais e a mudança das energias relativas dos estados de transição provocadas por ésteres mais volumosos, como aquele que possui o grupo $\mathrm{Ot}-\mathrm{Bu}$.

Primeiramente, realizou-se uma busca conformacional (Campo de forças MM3) ${ }^{73}$ dos estados de transição, ${ }^{\text {xi,158 }}$ que dão origem aos epímeros 287, 288, 306 e 307. Em seguida as estruturas de mínima energia foram otimizadas com o modelo B3LYP/cc$\mathrm{pVDZ}^{100}$ e todos os estados de transição foram localizados, reproduzindo fundamentalmente uma reação de substituição nucleofílica. As freqüências vibracionais foram calculadas caracterizando cada um dos mesmos pela obtenção de uma única freqüência negativa associada às ligações quebradas e formadas. Em seguida, os ânions dos compostos 286 e 305 foram otimizados ${ }^{100} \mathrm{com}$ o mesmo modelo teórico, considerando cada uma das conformações que dão origem aos epímeros 287, 288, 306 e 307. As estruturas dos produtos também foram otimizadas.

As energias obtidas para cada uma das estruturas (enolatos de partida, estados de transição e produtos) estão mostradas na tabela 24 .

\footnotetext{
${ }^{x i}$ Um estado de transição pode ser caracterizado quando uma determinada freqüência vibracional calculada ( v) é negativa e a mesma está associada a um processo de quebra/formação de ligações químicas. A freqüência vibracional entre dois átomos ligados $i$ e $j$ é proporcional a uma constante de forças $F_{\mathrm{ij}}$ que é o elemento da matriz de constante de força, extraída dos cálculos químico-quânticos.
}

$$
v=\frac{1}{2 \pi} \sqrt{\frac{F_{i j}}{\left(m_{i} m_{j}\right)^{\frac{1}{2}}}} \quad F_{i j}=\frac{1}{\left(m_{i} m_{j}\right)^{\frac{1}{2}}}\left(\frac{\partial^{2} E}{\partial x_{i} \partial x_{j}}\right)
$$

Como pode ser visto, $F_{\mathrm{ij}}$ é proporcional à derivada segunda da energia em função da posição. Esta derivada fornece matematicamente a curvatura da superfície de energia. Se $F_{\mathrm{ij}}$ é positivo a curvatura da superfície de energia é positiva, logo, esta superfície terá um ponto de mínimo nas imediações onde a derivada primeira é zero. Se $F_{\mathrm{ij}}$ é negativo a curvatura da superfície de energia é negativa indicando que nas imediações onde a derivada primeira é zero haverá um ponto de máximo (ponto de máxima energia $=$ corresponde a um Estado de Transição). Além disso, se a freqüência $(v)$ é negativa ela deve ser considerada como sendo uma freqüência imaginária, pois a raiz quadrada de $F_{\mathrm{ij}}$ não pode ser negativa se $F_{\mathrm{ij}}$ for um número real. Uma freqüência imaginária de ligação pode ser entendida como uma freqüência associada a ligações que não se formaram nem se romperam efetivamente, o que caracteriza quimicamente um estado de transição (TS). 
Tabela 24: Energias dos Enolatos de Partida, Estados de Transição, Produtos e de Ativação.

\begin{tabular}{ccccccc}
\hline \multicolumn{2}{c}{$\begin{array}{c}\text { Energia dos Enolatos de } \\
\text { Partida (Hartree) }\end{array}$} & \multicolumn{2}{c}{$\begin{array}{c}\text { Energia dos Estados de } \\
\text { Transição (Hartree) }\end{array}$} & $\begin{array}{c}\text { Energia dos Produtos } \\
\text { (Hartree) }\end{array}$ & $\begin{array}{c}\text { Energia de Ativação } \\
\text { (kcal/mol) }\end{array}$ \\
\hline$(286) \rightarrow(287)$ & $-786,848435$ & $\mathrm{TS}_{(287)}$ & $-786,844972$ & $(287)$ & $-775,440766$ & 2,17 \\
$(286) \rightarrow(288)$ & $-786,844762$ & $\mathrm{TS}_{(288)}$ & $-786,843315$ & $(288)$ & $-775,442590$ & 0,91 \\
$(305) \rightarrow(306)$ & $-904,715431$ & $\mathrm{TS}_{(306)}$ & $-904,713905$ & $(306)$ & $-893,309866$ & 0,96 \\
$(305) \rightarrow(307)$ & $-904,714055$ & $\mathrm{TS}_{(307)}$ & $-904,712056$ & $(307)$ & $-893,310862$ & 1,25 \\
\hline
\end{tabular}

$\mathrm{Na}$ figura 51 estão representadas energias de ativação e as energias relativas das estruturas envolvidas e na tabela 25 são apresentadas as proporções teóricas e experimentais dos produtos $287,288,306$ e 307 , obtidos à $-78^{\circ} \mathrm{C}$.

Do ponto de vista qualitativo, os resultados obtidos pelos cálculos teóricos descrevem bem as proporções entre os epímeros $287 / 288$ e 306/307. No caso da proporção entre 287 e 288 são observados valores de 18:82 experimentalmente e de 4:96 pelos cálculos teóricos. Esta diferença entre as proporções (experimentais e teóricas) é até considerável, no entanto, os cálculos descrevem bem qual dos estados de transição é o de menor energia. Quando foram calculadas as energias dos estados de transição $\mathrm{TS}_{(306)}$ e $\mathrm{TS}_{(307)}$, conforme previsto, houve um aumento considerável da energia relativa do estado de transição que possui a carboxila oposta às metilas do hidrindano $\left(\mathrm{TS}_{(307)}\right)$ em relação ao outro estado de transição $\mathrm{TS}_{(306)}$, tornando-as quase idênticas. Estes resultados confirmam a hipótese de que o grupo $(\mathrm{Ot}-\mathrm{Bu})$ sendo mais volumoso faz com que o epímero desejado 306 seja obtido em proporções mais satisfatórias.

É importante notar que pelos cálculos há uma inversão nas proporções dos epímeros quando se troca o grupo OMe por Ot-Bu (tabela 25). Experimentalmente, não foram observadas inversões nas proporções quando se utilizou o composto 305 (éster tbutílico) e esta inversão nem era esperada, pois, quando a temperatura do meio não foi mantida por muito tempo à $-78^{\circ} \mathrm{C}$ obteve-se o epímero 306 em menor proporção. Este resultado indicava que muito provavelmente a melhor proporção seria de $1: 1$, conforme foi realmente observado.

De uma maneira geral pode-se concluir que os resultados teóricos foram precisos, porém não exatos. Especialmente no caso dos $\mathrm{TS}_{(306)}$ e $\mathrm{TS}_{(307)}$ as "energias reais" devem ser muito próximas (quase idênticas) o que dificulta sua descrição teórica. Sabe-se que quando as diferenças de energia entre conformações ou isômeros configuracionais é muito pequena são necessários níveis de teoria muito refinados para que sejam obtidos resultados com melhor exatidão. A complexidade destas estruturas impede a utilização destes níveis de teoria, quando os recursos computacionais não são suficientes. Atualmente estão sendo realizados alguns outros cálculos buscando melhorar um pouco as proporções teóricas. Provavelmente a utilização de funções difusas (aug, ou "+” no caso de bases como 6-31 G(d,p)) deve ajudar a descrever melhor os átomos pesados e com isso refinar um pouco mais os cálculos. Infelizmente, com os recursos computacionais que dispomos, ${ }^{159}$ não é possível efetuar cálculos para estas moléculas utilizando métodos mais apropriados, como MP2. 

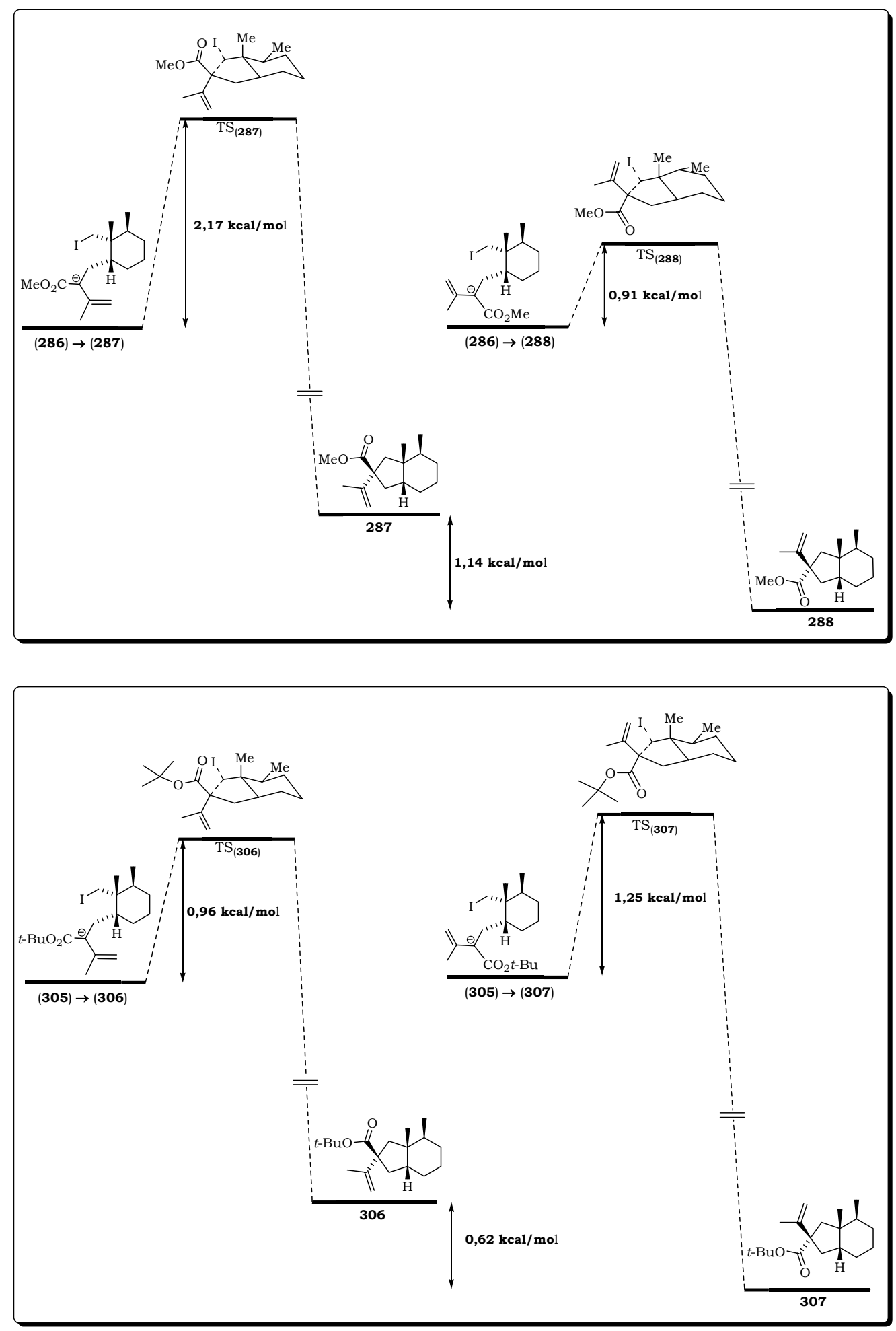

Figura 51: Energias de Ativação

Tabela 25: Proporções Teóricas e Experimentais dos Produtos 287, 288, 306 e 307.

\begin{tabular}{lccc}
\hline Produtos & $\begin{array}{c}\text { Proporções } \\
\text { Experimentais }\end{array}$ & $\begin{array}{c}\text { Proporções } \\
\text { Teóricas* }\end{array}$ & $\begin{array}{c}\text { Energia Cinética } \\
\text { Relativa (Teórica) }\end{array}$ \\
\hline$(287):(288)$ & $18: 82$ & $4: 96$ & 2,38 \\
$(306):(307)$ & $50: 50$ & $68: 32$ & 0,77 \\
\hline
\end{tabular}

${ }^{*}$ Calculadas à $-78^{\circ} \mathrm{C}$ pela distribuição de Boltzmann. 



\section{Conclusões e Considerações Finais}





\section{6 - Conclusões e Considerações Finais - Parte A e B.}

"Os produtos naturais, a maior fonte de inspiração para os químicos orgânicos sintéticos, constituem uma variedade tão extensa de estruturas que faz a natureza parecer, na perspectiva humana, uma fonte inesgotável de novos produtos. Essa variedade deixa atônitos até os mais criativos quimicos. Não nos deve surpreender que, dentre tanta riqueza seja possivel encontrar produtos úteis para todos os fins e em abundância". ${ }^{160}$

A mesma natureza, que numa aparente simplicidade, sintetiza inúmeras estruturas orgânicas, desafia a inteligência humana e provoca-nos a imitá-la.

Às vezes, a própria criatividade humana sugere alguns compostos, no entanto, sem conhecer a viabilidade de prepará-lo. De tão complexos, eles se tornam inviáveis.

Para iniciar esta seção de conclusões cabe considerar as palavras descritas acima que na opinião do autor traduzem bem o conjunto deste trabalho.

$\mathrm{Na}$ primeira parte deste trabalho foram estudadas várias metodologias de preparação do 1,4-metano[10]anuleno (41) e, conforme pôde ser visto, houve muita dificuldade para realizar algumas transformações nos compostos derivados dos adutos de Diels-Alder 45 e 163. Estas transformações tinham como objetivo preparar alguns intermediários para que pudessem sofrer as fragmentações desejadas (esquema 25) e produzir sistemas do tipo 42, um precursor direto do anuleno 41.

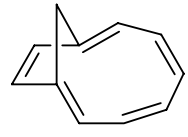

41

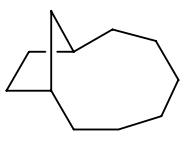

42

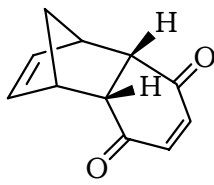

45

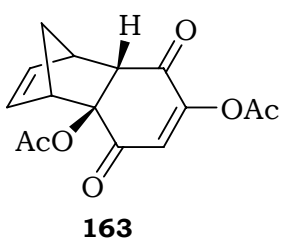

163

Em muitos casos observou-se a ocorrência de várias reações indesejadas resultando no abandono de algumas abordagens. Um caso bastante particular é do aduto 163 que ao invés de sofrer apenas uma reação de hidrólise básica dos grupos acetato, sofreu também uma eliminação seguida de adição conjugada de alcóxidos. De uma maneira geral, pôde-se avaliar um pouco mais a química e as peculiaridades de alguns adutos de Diels-Alder e seus derivados, e os insucessos com as abordagens envolvendo reações de eliminação-fragmentação, não devem ser vistos como uma prova da inviabilidade destes sistemas na obtenção de estruturas como 42; há exemplos relatados pelo nosso próprio grupo de pesquisa onde uma estrutura derivada de 45 forneceu um biciclo do tipo $42 .^{74}$

A abordagem que permitiu avançar com os propósitos desta primeira parte do trabalho foi a que envolvia uma cicloadição do tipo [6+4], fornecendo resultados bem mais promissores. $\mathrm{O}$ composto bicíclico $\mathbf{1 7 1}$ foi obtido de maneira eficiente e em poucas etapas (5 etapas e rendimento global de 37,3\%). Conforme destacado, este composto guarda grande semelhança estrutural se comparado com o anuleno 41, o que reforçou o propósito de prosseguir com a síntese deste anuleno. 


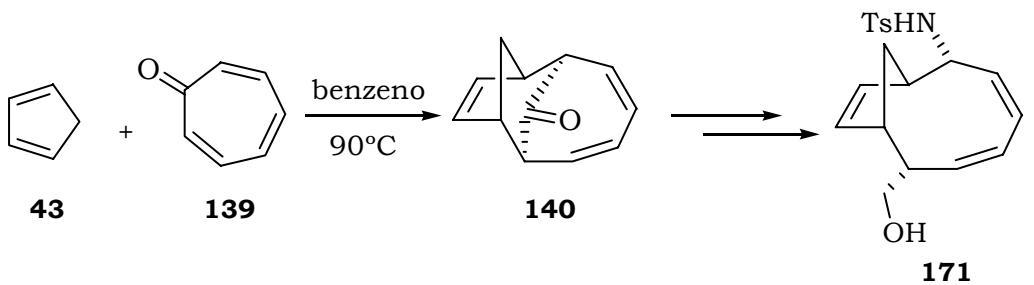

No entanto, após algumas tentativas ficou evidente a dificuldade em gerar todas as insaturações necessárias a partir de 171. A evidência de formação do carbocátion $182 \mathrm{e}$ sua resistência para sofrer eliminação foram decisivas para que por hora fossem interrompidas as tentativas de preparação do anuleno 41. Estas evidências experimentais instigaram a realização de alguns estudos teóricos utilizando-se vários métodos de avaliação da aromaticidade em compostos orgânicos. Foram obtidos vários indícios de que o anuleno 41, principalmente se comparado aos anulenos 40 e 14, deve possuir estabilizações bem menores podendo ser não aromático ou até anti-aromático.

Sob certos aspectos, esta primeira parte do trabalho possibilitou um conhecimento mais aprofundado a respeito de algumas transformações em adutos de Diels-Alder provenientes de ciclopentadieno e benzoquinonas, e principalmente, culminou na síntese de uma estrutura de grande valor sintético, o composto 171 , além de algumas evidências sobre a não existência de aromaticidade no anuleno 41.

$\mathrm{Na}$ segunda parte deste trabalho (Parte B) foram estudadas algumas abordagens sintéticas que conduziram à obtenção do produto natural ( \pm )-baquenolida $A(184)$ e um de seus epímeros a ( \pm )-7-epi-baquenolida A (226). A síntese de 184 foi realizada de maneira original envolvendo um total de 8 etapas e rendimento global de $13,3 \%$. Também ficou comprovada a eficiência de alguns modelos sintéticos propostos há alguns anos por Brocksom e Constantino. ${ }^{131,133}$

Com relação à abordagem inicialmente estudada, ficou clara a dificuldade de se produzir sistemas como 279 a partir de uma reação de Diels-Alder intramolecular. Um conjunto de fatores parece contribuir para impossibilitar esta cicloadição, como a presença das metilas na dupla dienofílica de 285 e a facilidade com que algumas reações indesejadas ocorrem.

A segunda abordagem estudada teve como etapa principal uma reação de DielsAlder intermolecular catalisada por $\mathrm{NbCl}_{5}$, que forneceu um precursor adequado para a síntese de eremofilanos e de baquenolidas. Mais uma vez o $\mathrm{NbCl}_{5}$ mostrou ser um ácido de Lewis extremamente eficiente e de grande utilidade para a química orgânica sintética.

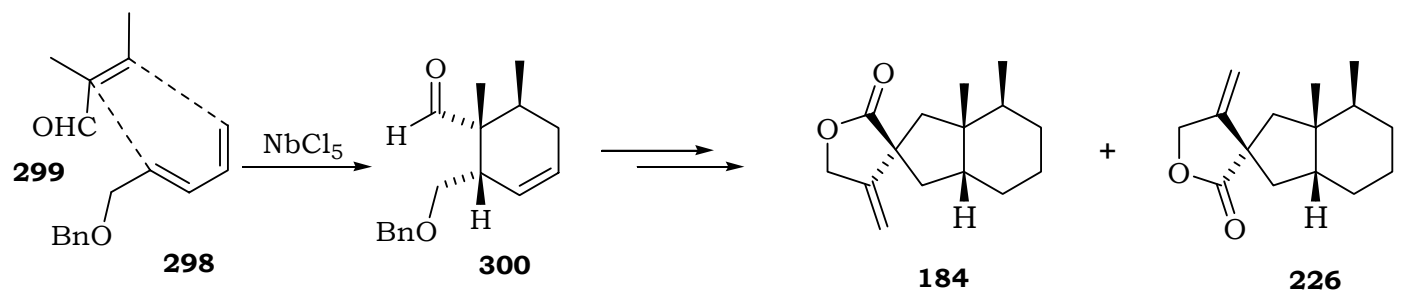

(+)-Baquenolida A (+)-7-epi-Baquenolida A

Há outras transformações que foram fundamentais para a conclusão desta síntese de 184 e que merecem ser destacadas, como as ciclizações sofridas pelos compostos $286 \mathrm{a} / 286 \mathrm{~b}$ e $305 \mathrm{a} / 305 \mathrm{~b}$. A obtenção do epímero que possibilitou a preparação de 184 se mostrou problemática e foram necessários alguns estudos variando-se a temperatura das 
reações e os grupos funcionais dos intermediários. Aparentemente a presença de um grupo mais volumoso (diferente do OMe do composto 286) é que favoreceu a obtenção de uma mistura epimérica mais adequada para a continuidade da síntese de 184 .

Os estados de transição que conduziam à formação das estruturas 287, 288, 306 e 307 também foram avaliados com alguns estudos teóricos, e dentro das limitações que estruturas desta complexidade impõem, pode-se dizer que os resultados foram bastante úteis e estiveram de acordo com os estudos experimentais.

Finalmente, cabe destacar que este trabalho agrega importantes estudos de caráter sintético e teórico envolvendo reações de grande expressão na química orgânica sintética. Todos os estudos aqui desenvolvidos contribuíram para a ampliação dos interesses de nosso grupo de pesquisa e deixam em aberto, várias outras temáticas de estudo. 



\section{Parte Experimental}





\section{7 - Parte Experimental - Parte $A$ e $B$}

- Nesta seção, os compostos foram nomeados conforme recomendações oficiais da International Union of Pure and Applied Chemistry (IUPAC) para nomenclatura de compostos orgânicos.

- Todas as substâncias dotadas de assimetria foram sintetizadas de forma racêmica.

- Os espectros de ressonância magnética nuclear de hidrogênio $\left({ }^{1} \mathrm{H}\right)$ foram obtidos a 300, 400 e 500 MHz em espectrômetros Bruker DPX-300, Bruker DRX-400 e Bruker DRX-500 respectivamente. Os deslocamentos químicos $(\delta)$ estão relatados em parte por milhão ( $\mathrm{ppm}$ ) em relação ao tetrametilsilano (TMS), utilizado como padrão interno, colocando-se entre parênteses a multiplicidade ( $\mathrm{s}=$ singleto, ${ }^{\mathrm{xii}} \mathrm{s} .1$ = singleto largo, $\mathrm{d}=$ dubleto, $\mathrm{t}=$ tripleto, $\mathrm{q}$ = quadrupleto, quint= quintupleto, d.d = duplo dubleto, d.d.d = duplo duplo dubleto, d.d.d.d = duplo duplo duplo dubleto, d.d.d.d.d = duplo duplo duplo duplo dubleto, d.d.t.d. = duplo duplo triplo dubleto, d.t $=$ duplo tripleto, d.d.t $=$ duplo duplo tripleto, d.d.d.t $=$ duplo duplo duplo tripleto, d.t.t $=$ duplo triplo tripleto, d.q $=$ duplo quadrupleto, d.d.q= duplo duplo quadrupleto, t.t $=$ triplo tripleto, t.d.d = triplo duplo dubleto, dquint = duplo quintupleto, $\mathrm{q} \cdot \mathrm{q}=$ quadruplo quadrupleto, $\mathrm{m}=$ multipleto.), a constante de acoplamento $(J)$ em Hertz $(\mathrm{Hz})$ e o número de hidrogênios deduzidos da integral relativa.

- Os espectros de ressonância magnética nuclear de ${ }^{13} \mathrm{C}$ foram obtidos a 75, $100 \mathrm{e}$ $125 \mathrm{MHz}$ em espectrômetros Bruker DPX-300, Bruker DRX-400 e Bruker DRX500, respectivamente. Estes espectros foram traçados utilizando-se as seguintes técnicas:

${ }^{13} \mathrm{C}\left\{{ }^{1} \mathrm{H}\right\}$ - Carbono Totalmente Desacoplado de Hidrogênio

DEPT-135 - Distortionless Enhancement by Polarization Transfer

- Os experimentos de NOE DIFF foram realizados nos espectrômetros Bruker DPX-300 e Bruker DRX-500, conforme a necessidade.

- $\quad$ As análises de espectroscopia de correlação $\left({ }^{1} \mathrm{H}-{ }^{13} \mathrm{C}\right)(\mathrm{RMN}-2 \mathrm{D})$ foram realizadas no espectrômetro Bruker DRX-500, de acordo com a necessidade durante a atribuição dos compostos. Foram utilizadas técnicas como ${ }^{1} \mathrm{H}-{ }^{1} \mathrm{H}$ gCOSY, gJ-res, ${ }^{1} \mathrm{H}-{ }^{13} \mathrm{C}$ gHMQC, ${ }^{1} \mathrm{H}-{ }^{13} \mathrm{C}$ gHMBC.

- Os espectros de absorção no infravermelho foram registrados em um espectrofotômetro Perkin-Elmer modelo 1600-FT, em celas de KBr para líquidos (filme) e pastilhas de $\mathrm{KBr}$ para sólidos.

\footnotetext{
xii Segundo recomendação da AUREMN - Associação dos Usuários de Ressonância Magnética Nuclear deve-se utilizar "simpleto".
} 
- $\quad$ Os espectros de massas de baixa resolução foram obtidos em um aparelho HP GC/MS SYSTEM 5988-A.

- Os espectros de massa de alta resolução foram obtidos em um equipamento Electron Spray ESI-Q-TOF Micromass, no modo positivo. As análises foram realizadas utilizando uma solução das substâncias em metanol às vezes contendo ácido fórmico.

- As análises elementares (micro análises) foram realizadas em um aparelho Fisons modelo EA 1108 CHNS.

- As cromatografias em camada delgada (CCD) foram realizadas utilizando-se placas de sílica gel 60 da Merck $^{\circledR}$. As purificações por cromatografia em coluna foram realizadas utilizando sílica gel 80-230 e 200-400 mesh da ACROS ${ }^{\circledR}$.

- $\quad$ Os pontos de fusão foram determinados em uma placa de aquecimento segundo Klofer com um termômetro não aferido, instalada em um microscópio modelo Bristoline.

- Para a destilação horizontal empregou-se um aparelho de destilação horizontal Kugelrohrofen Büchi modelo GKR-50. As temperaturas registradas referem-se à temperatura do forno.

- Para concentrar as soluções orgânicas foram utilizados evaporadores do tipo Buchler e Büchi, operando à pressão de aproximadamente $30 \mathrm{mmHg}$.

- Os solventes e reagentes comerciais foram convenientemente purificados conforme métodos usuais. ${ }^{161}$ 


\section{Índice das Reações.}

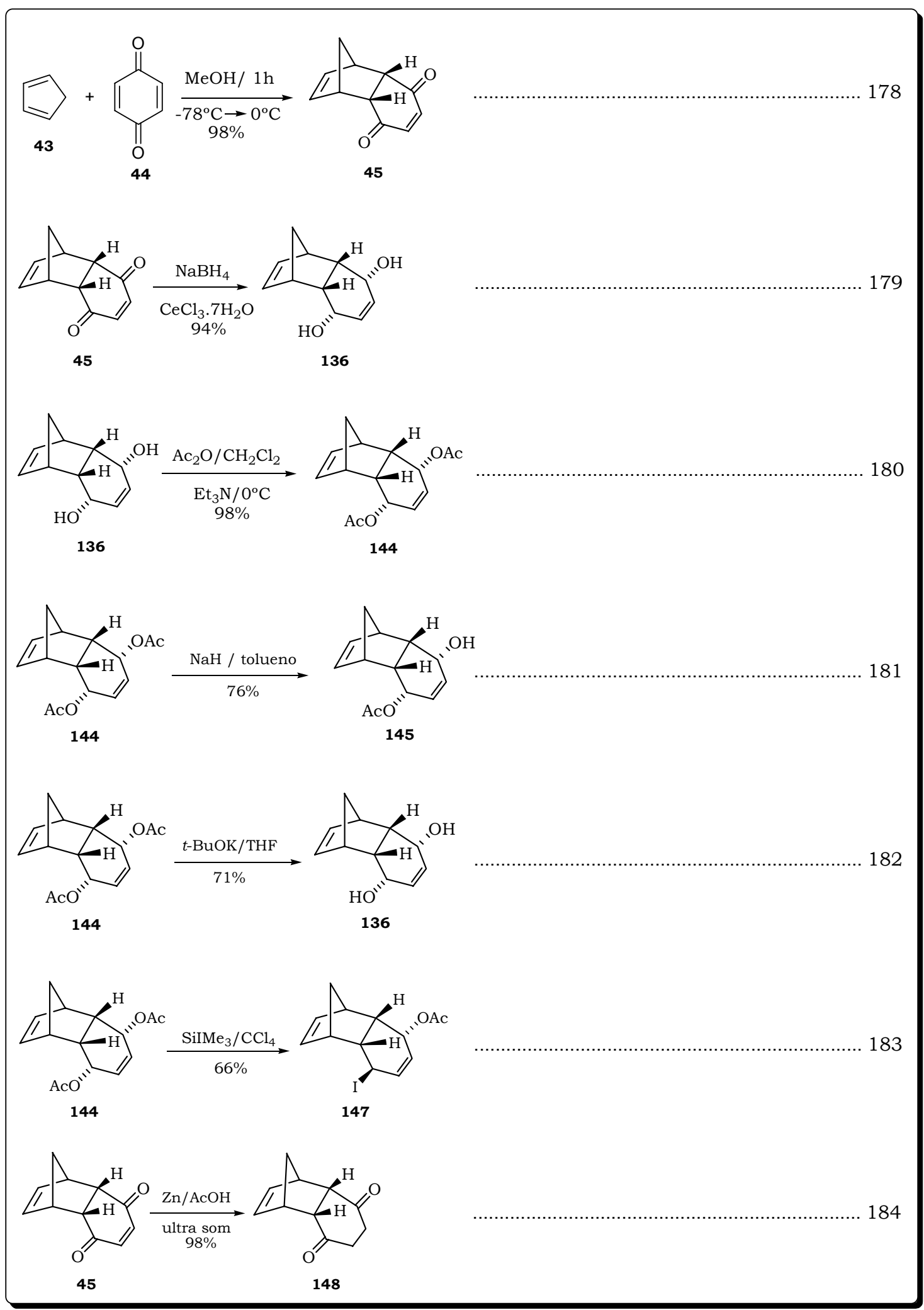




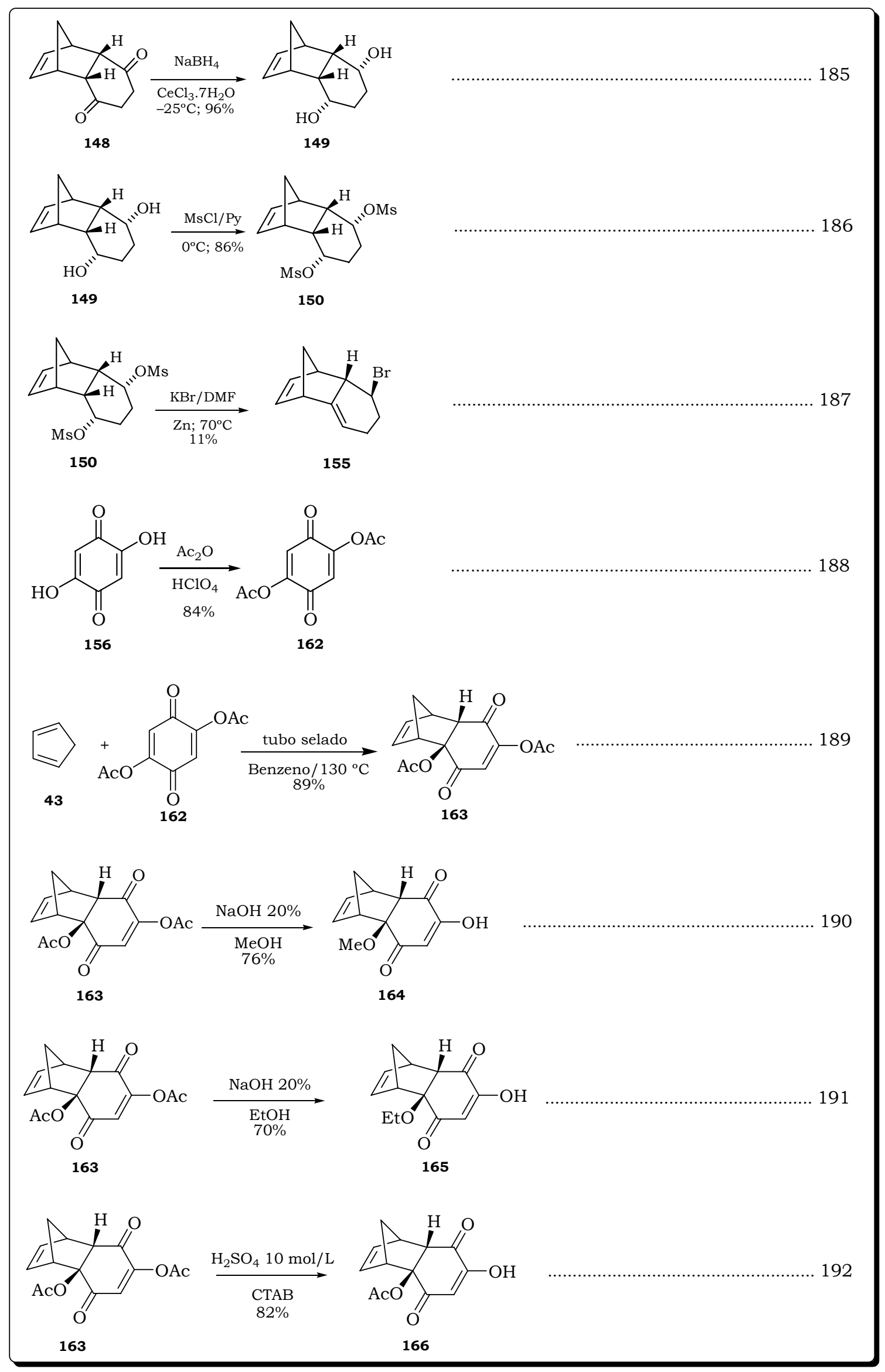




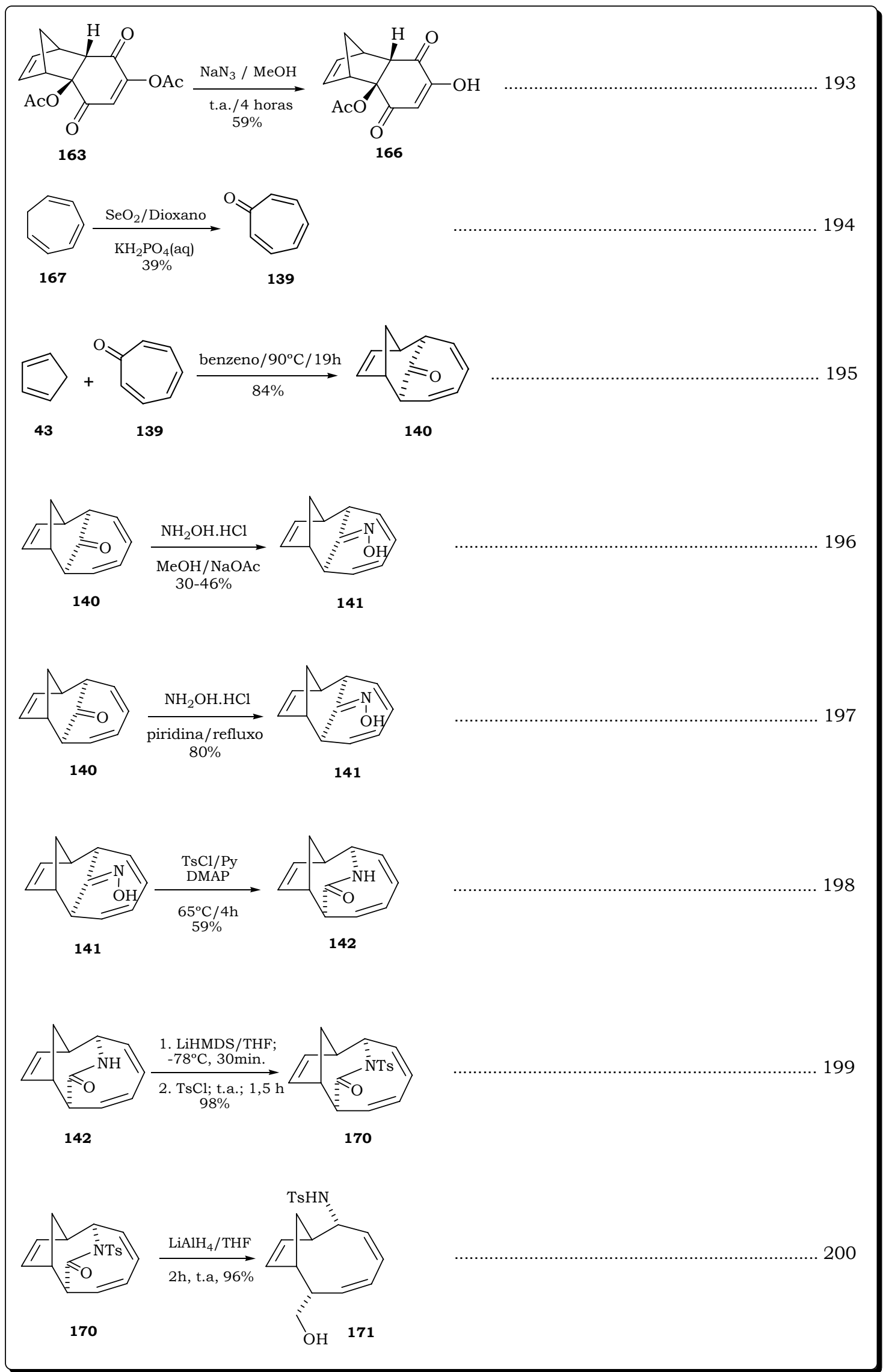




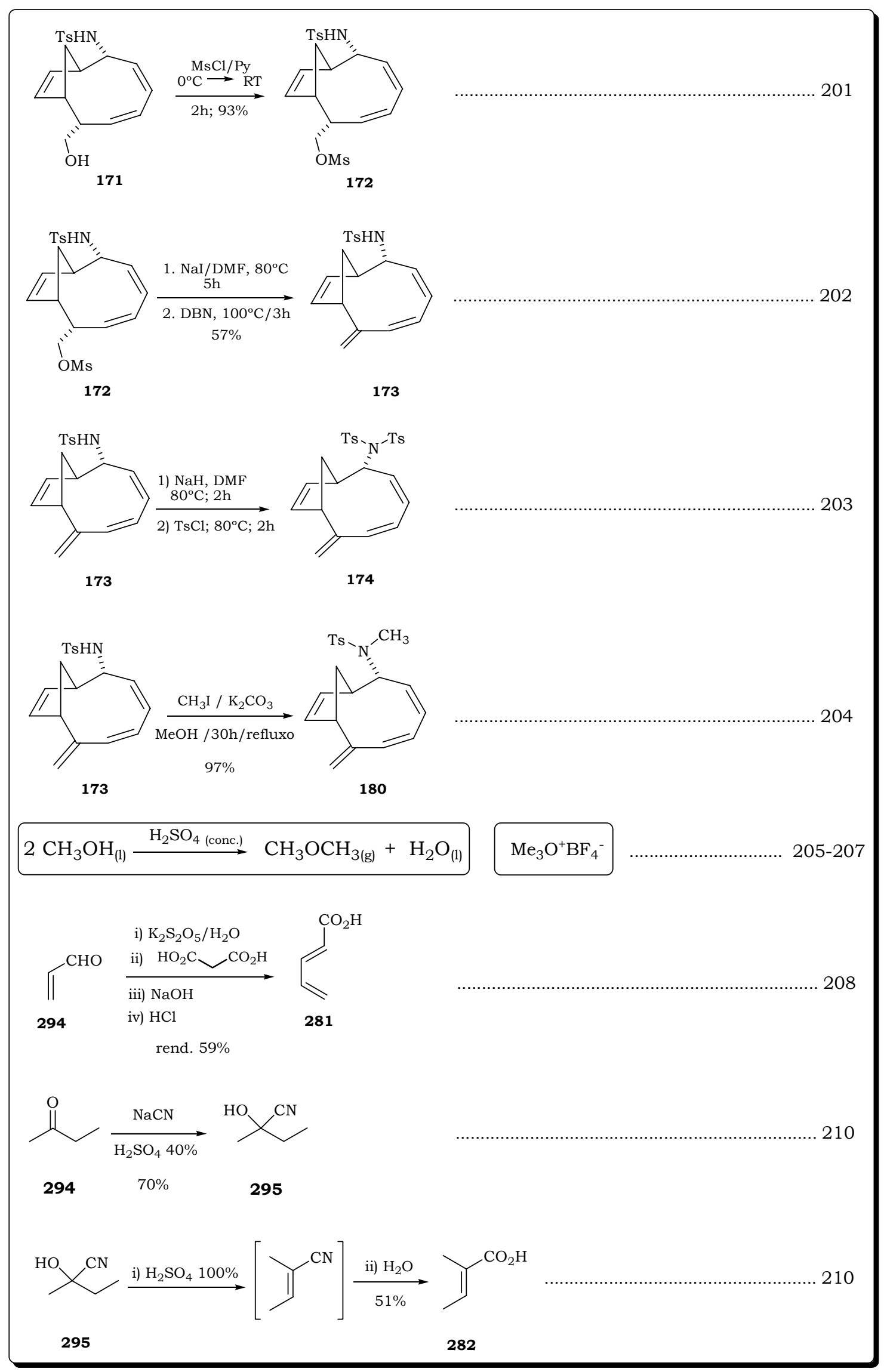


$\underset{\mathbf{2 8 1}}{\stackrel{\substack{\text { heOH/Hoquinona } \\ 75 \%}}{\mathrm{CO}_{2} \mathrm{SO}_{4}}}$

$\underset{89 \%}{\stackrel{\mathrm{LiAlH}_{4} / \text { éter }}{\longrightarrow \mathrm{O}_{2} \mathrm{Me}}}$

296

283
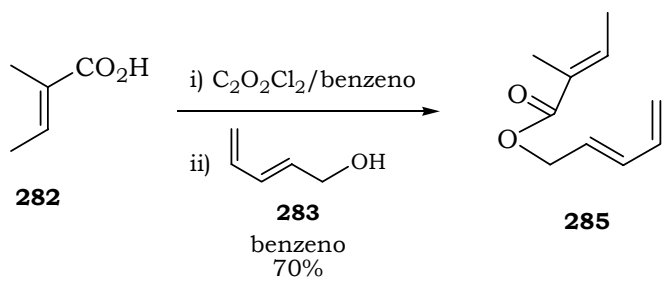

$\underset{\text { 2) } \mathrm{BnBr}}{\stackrel{\mathrm{OH}}{\longrightarrow}}$<smiles>C=C/C=C/COCc1ccccc1</smiles>

283

298

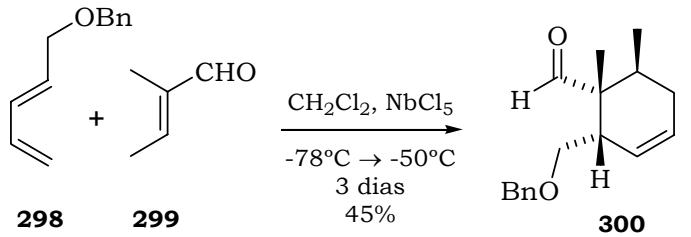

$\underset{84 \%}{\stackrel{\mathrm{LiAlH}_{4} / \mathrm{THF} / \mathrm{O}^{\circ} \mathrm{C}}{\longrightarrow}}$

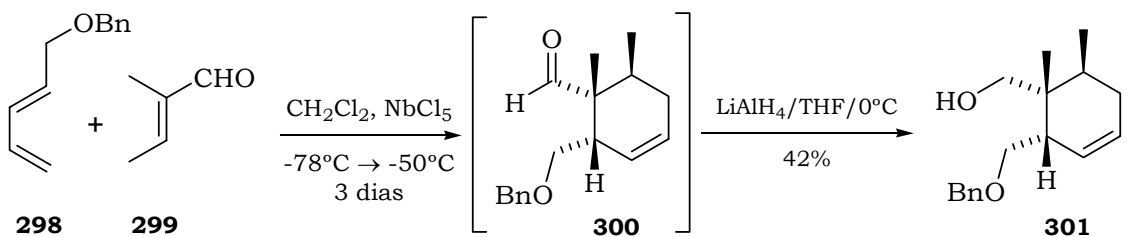




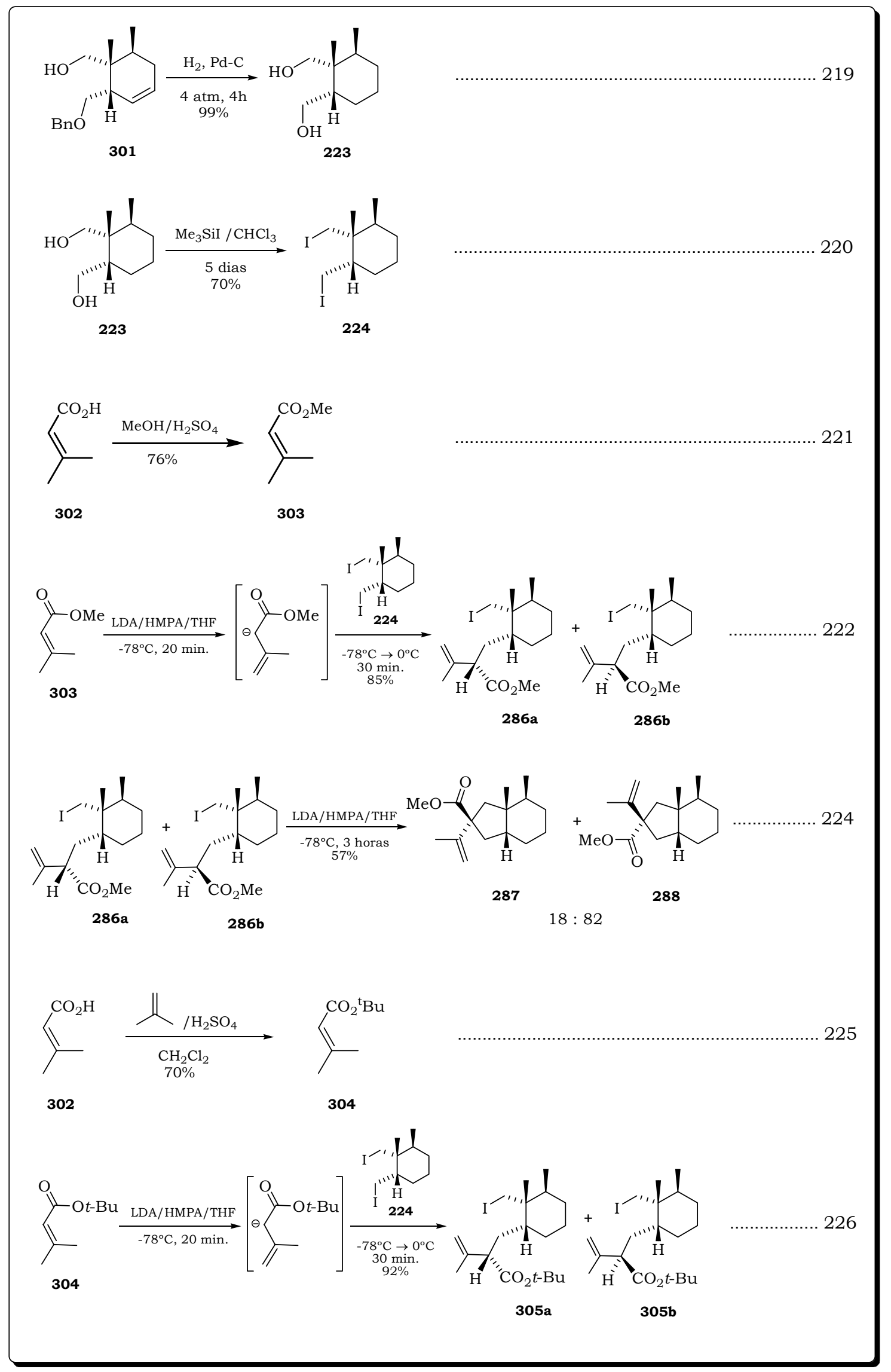




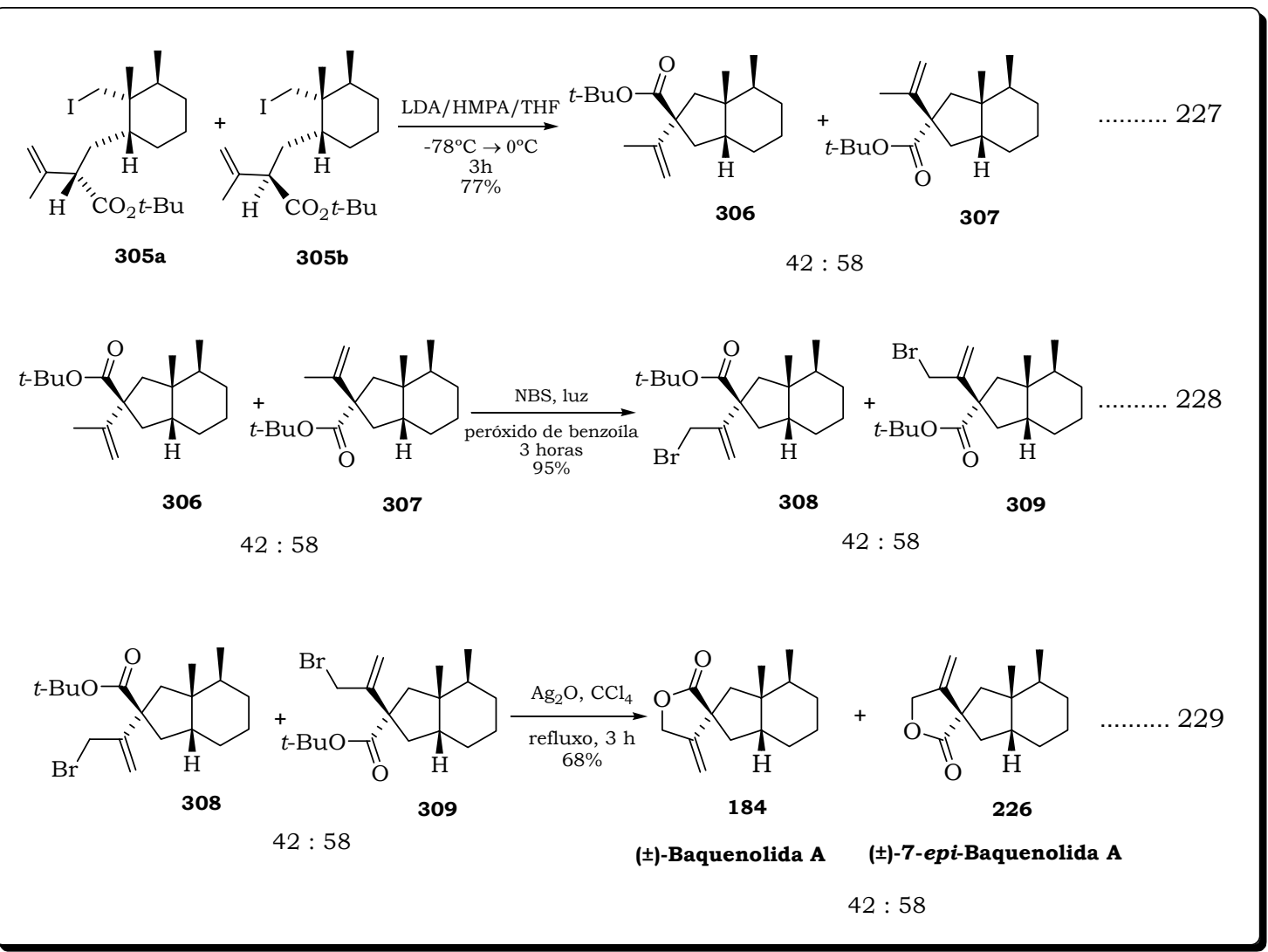


7.1 - Preparação da $(1 R, 2 S, 7 R, 8 S)$-triciclo[6.2.1.0 $\left.0^{2,7}\right]$ undeca-4,9-dieno-3,6-diona $(45){ }^{66 a}$

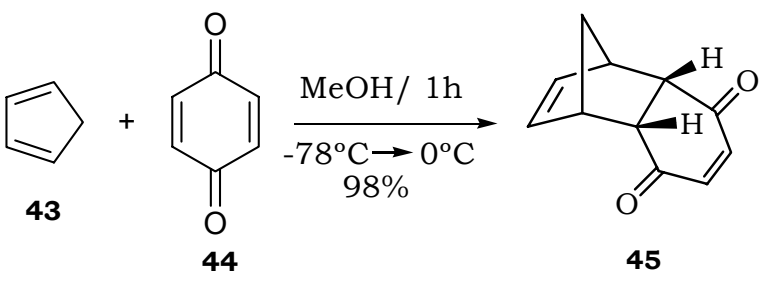

Procedimento: Para uma solução de 1,00 g (9,25 mmol) da benzoquinona (43) em $33 \mathrm{~mL}$ de metanol, mantida a $-78^{\circ} \mathrm{C}$, adicionou-se gota a gota uma solução do ciclopentadieno (43) recentemente desdimerizado $(0,63 \mathrm{~g}, 9,5 \mathrm{mmol}$ em $8 \mathrm{~mL}$ de metanol também resfriado). A reação foi abandonada deixando reagir até o banho atingir a temperatura ambiente (cerca de 1 hora). Ao final da reação o solvente foi removido sob pressão reduzida e os cristais foram lavados com hexano gelado e secados a vácuo.

Rendimento: $1,58 \mathrm{~g}(9,07 \mathrm{mmol})-98 \%$

Pf: $63-65^{\circ} \mathrm{C}$

$\mathrm{RMN}-{ }^{1} \mathrm{H}\left(\mathrm{CDCl}_{3}, 400 \mathrm{MHz}\right), \delta(\mathrm{ppm}): 1,44\left(\mathrm{dtt}, 1 \mathrm{H}, \mathrm{J}_{1}=8,4 \mathrm{~Hz} ; \mathrm{J}_{2}=\mathrm{J}_{3}=1,7 \mathrm{~Hz} ; \mathrm{J}_{4}=\mathrm{J}_{5}=\right.$ $0,7 \mathrm{~Hz}) ; 1,55\left(\mathrm{dt}, 1 \mathrm{H}, \mathrm{J}_{1}=8,4 \mathrm{~Hz} ; \mathrm{J}_{2}=\mathrm{J}_{3}=1,8 \mathrm{~Hz}\right) ; 3,20-3,26(\mathrm{~m}, 2 \mathrm{H}) ; 3,53-3,58(\mathrm{~m}$, $2 \mathrm{H}) ; 6,07\left(\mathrm{t}, 2 \mathrm{H}, \mathrm{J}_{1}=\mathrm{J}_{2}=1,7 \mathrm{~Hz}\right) ; 6,58(\mathrm{sl}, 2 \mathrm{H})$.

RMN- ${ }^{13} \mathrm{C}\left(\mathrm{CDCl}_{3}, 100 \mathrm{MHz}\right) \delta(\mathrm{ppm}): 48,3(\mathrm{CH}) ; 48,7\left(\mathrm{CH}_{2}\right) ; 48,7(\mathrm{CH}) ; 135,3(\mathrm{CH})$; 142,0 (CH); 199,4 (C=O).

IR $v_{\text {máx. }}(\mathrm{KBr}): 1053 \mathrm{~cm}^{-1}, 1279 \mathrm{~cm}^{-1}, 1662 \mathrm{~cm}^{-1}, 2948 \mathrm{~cm}^{-1}, 2991 \mathrm{~cm}^{-1}, 3421 \mathrm{~cm}^{-1}$.

MS m/z (intensidade relativa): $\left[\mathrm{M}^{+}\right]$(18,2\%); 146 (5,4\%), 108 (3,5\%), 91 (8,7\%); 66 $(100 \%)$. 
7.2 - Preparação do $(1 R, 2 S, 3 R, 6 S, 7 R, 8 S)$-triciclo[6.2.1.0 $\left.0^{2,7}\right]$ undeca-4,9-dieno-3,6diol (136). ${ }^{68}$

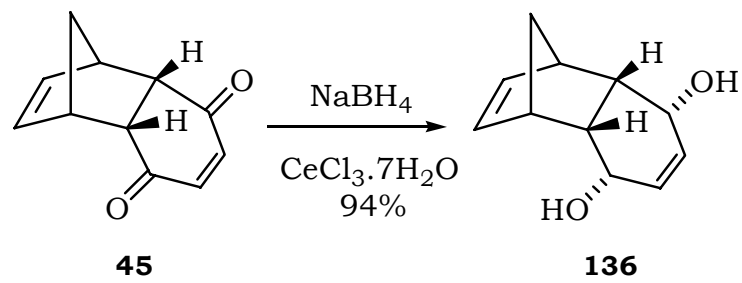

Procedimento: Para uma solução do aduto $45(358 \mathrm{mg}, 2,00 \mathrm{mmol}$ em $40 \mathrm{~mL}$ de metanol) resfriada a $-25^{\circ} \mathrm{C}$, foi adicionado $\mathrm{CeCl}_{3} .7 \mathrm{H}_{2} \mathrm{O}(1,51 \mathrm{~g}, 4,05 \mathrm{mmol})$ deixando-se agitar fortemente por 5 minutos. Em seguida, adicionou-se $\mathrm{NaBH}_{4}(200 \mathrm{mg}, 5,20 \mathrm{mmol})$ e após cerca de 1 minuto o resfriamento foi removido e a reação mantida sob agitação por mais 10 minutos. Adicionou-se água ao meio reacional $(5 \mathrm{~mL})$ deixando-se agitar por mais 5 minutos e depois removeu-se boa parte do metanol misturado à água, utilizando pressão reduzida. Após remoção de boa parte do solvente reacional, adicionou-se mais água $(15 \mathrm{~mL})$ ao meio e extraiu-se com $\mathrm{CH}_{2} \mathrm{Cl}_{2}(5$ porções de $30 \mathrm{~mL}$ ). As fases orgânicas foram reunidas e secadas com $\mathrm{MgSO}_{4}$ anidro e o solvente foi removido sob pressão reduzida. Foi obtido um sólido branco que foi lavado com hexano gelado e novamente secado a vácuo.

Rendimento: $335 \mathrm{mg}(1,88 \mathrm{mmol})-94 \%$

Ponto de fusão: $129-131^{\circ} \mathrm{C}$

RMN- ${ }^{1} \mathrm{H}\left(\mathrm{MeOD}-\mathrm{d}_{4}, 400 \mathrm{MHz}\right), \delta$ (ppm): 1,25-1,30 (sl, 2H); 2,76-2,83 (m, 2H); 2,963,02 (m, 2H); 4,34-4,42 (m, 2H); 4,89(sl, OH + metanol); 5,24 (sl, 2H); 5,73-5,77 (m, $2 \mathrm{H})$.

RMN- ${ }^{13} \mathrm{C}\left(\mathrm{MeOD}-\mathrm{d}_{4}, 100 \mathrm{MHz}\right) \delta(\mathrm{ppm}): 43,4(\mathrm{CH}) ; 49,8\left(\mathrm{CH}_{2}\right) ; 67,7(\mathrm{CH})$; $131,4(\mathrm{CH}) ; 136,7(\mathrm{CH})$.

IR $v_{\text {máx }}(\mathrm{KBr}): 707 \mathrm{~cm}^{-1} ; 1054 \mathrm{~cm}^{-1} ; 1352 \mathrm{~cm}^{-1} ; 2944 \mathrm{~cm}^{-1} ; 3000-3600 \mathrm{~cm}^{-1}$.

MS m/z (intensidade relativa): $\left[\mathrm{M}^{+}\right]$(1\%); 112 (1,9\%), $111(5,3 \%), 95$ (30,2\%); 66 $(100 \%)$. 
7.3 - Preparação do diacetato de $(1 R, 2 S, 3 R, 6 S, 7 R, 8 S)$ - triciclo[6.2.1.0 $\left.0^{2,7}\right]$ undeca-4,9dieno-3,6-di-ilo (144). ${ }^{72}$

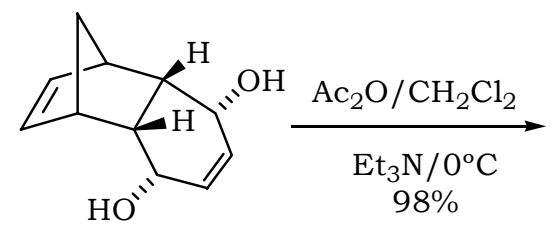

136

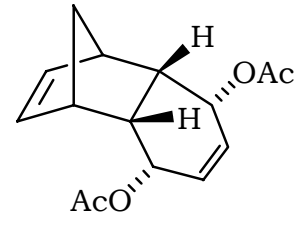

144

Procedimento: Foram misturados $612 \mathrm{mg}(6,00 \mathrm{mmol}, 0,56 \mathrm{~mL})$ de anidrido acético em $606 \mathrm{mg}(6,00 \mathrm{mmol}, 0,84 \mathrm{~mL})$ de $\mathrm{Et}_{3} \mathrm{~N}$ a $0^{\circ} \mathrm{C}$ e sob atmosfera inerte de $\mathrm{N}_{2}$ Em seguida adicionou-se o diol 136 (360 mg, 2,02 mmol) juntamente com quantidades catalíticas de DMAP. Deixou-se reagir por 5 minutos a $0^{\circ} \mathrm{C}$ e depois por mais $25 \mathrm{~min}$. à temperatura ambiente. Ao final da reação adicionou-se ao meio $10 \mathrm{~mL}$ de solução saturada de $\mathrm{NaCl}$ e extraiu-se com éter dietílico várias vezes ( 5 porções de $25 \mathrm{~mL}$ ). As fases orgânicas foram reunidas e lavadas com água (duas porções de $20 \mathrm{~mL}$ ) e depois solução saturada deNaCl $(20 \mathrm{~mL})$ e em seguida, foi secada com $\mathrm{MgSO}_{4}$ anidro. O solvente removido sob pressão reduzida obtendo-se um sólido branco e puro.

Rendimento: $518 \mathrm{mg}(1,98 \mathrm{mmol})-98 \%$

Ponto de fusão: $70-72^{\circ} \mathrm{C}$

$\mathrm{RMN}-{ }^{1} \mathrm{H}\left(\mathrm{CDCl}_{3}, 400 \mathrm{MHz}\right) \delta(\mathrm{ppm}): 1,19(\mathrm{dl}, 1 \mathrm{H}, \mathrm{J}=8,4 \mathrm{~Hz}) ; 1,24\left(\mathrm{dt}, 1 \mathrm{H}, \mathrm{J}_{1}=8,4 ; \mathrm{J}_{2}\right.$ $\left.=\mathrm{J}_{3}=1,8 \mathrm{~Hz}\right) ; 2,73-2,78(\mathrm{~m}, 2 \mathrm{H}) ; 2,94-3,00(\mathrm{~m}, 2 \mathrm{H}) ; 5,25-5,35(\mathrm{~m}, 4 \mathrm{H}) ; 5,75\left(\mathrm{t}, 2 \mathrm{H}, \mathrm{J}_{1}=\right.$ $\left.\mathrm{J}_{2}=1,6 \mathrm{~Hz}\right)$.

$\mathrm{RMN}-{ }^{13} \mathrm{C}\left(\mathrm{CDCl}_{3}, 100 \mathrm{MHz}\right) \delta(\mathrm{ppm}): 21,0\left(\mathrm{CH}_{3}\right) ; 38,0(\mathrm{CH}) ; 45,8(\mathrm{CH}) ; 48,4\left(\mathrm{CH}_{2}\right)$; $69,4\left(\mathrm{CH}_{2}\right) ; 128,0(\mathrm{CH}) ; 135,4(\mathrm{CH}) ; 170,5(\mathrm{C}=\mathrm{O})$.

IR $v_{\text {máx }} \cdot(\mathrm{KBr}): 724 \mathrm{~cm}^{-1} ; 1022 \mathrm{~cm}^{-1} ; 1243 \mathrm{~cm}^{-1} ; 1740 \mathrm{~cm}^{-1} ; 2979 \mathrm{~cm}^{-1}, 3054 \mathrm{~cm}^{-1}$.

MS m/z (intensidade relativa): $\left[\mathrm{M}^{+}\right]$(0,3\%); 203 (2,7\%), 137 (9,7\%), 95 (51,1\%); 66 $(100 \%)$. 


\section{$7.4 \quad-\quad$ Preparação acetatato de $\quad( \pm)-(1 S, 2 R, 3 S, 6 R, 7 S, 8 R)-6-$ hidroxitriciclo[6.2.1.0 $\left.0^{2,7}\right]$ undeca-4,9-dien-3-ilo (145). ${ }^{74}$}
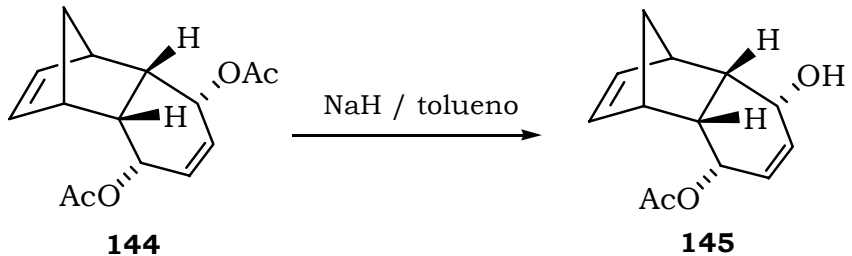

Procedimento: A uma solução contendo $100 \mathrm{mg}(0,38 \mathrm{mmol})$ do diacetato $144 \mathrm{em} \mathrm{2,0}$ $\mathrm{mL}$ de tolueno anidro, sob atmosfera de $\mathrm{N}_{2}$, adicionou-se $\mathrm{NaH}$ 50-60\% (18 mg, 0,38 $\mathrm{mmol})$. A reação foi mantida à temperatura ambiente por 3 horas e neste caso não se observou consumo do material de partida e nem a formação de produtos. Adicionou-se mais 3 equivalentes de $\mathrm{NaH}$ e aqueceu-se o sistema a refluxo, deixando reagir por mais 3 horas. Após o consumo de todo o material de partida o sistema foi resfriado a $0^{\circ} \mathrm{C}$ e à mistura reacional adicionou-se água gelada $(10 \mathrm{~mL})$ deixando agitar por 1 minuto. A mistura reacional foi extraída com acetato de etila (4 porções de $25 \mathrm{~mL}$ ) e as fases orgânicas foram reunidas e secadas com sulfato de magnésio anidro. O solvente foi removido sob pressão reduzida e o resíduo obtido foi purificado por cromatografia em coluna de sílica "flash" (200-400 mesh), utilizando-se como eluente uma mistura de hexano/acetato de etila 7:3.

Rendimento: $64 \mathrm{mg}(0,29 \mathrm{mmol})-76 \%$

$\mathrm{RMN}-{ }^{1} \mathrm{H}\left(\mathrm{CDCl}_{3}, 400 \mathrm{MHz}\right) \delta(\mathrm{ppm}): 1,30(\mathrm{~d}, 1 \mathrm{H}, \mathrm{J}=8,2 \mathrm{~Hz}) ; 1,36\left(\mathrm{dt}, 1 \mathrm{H}, \mathrm{J}_{1}=8,2\right.$ $\left.\mathrm{Hz} ; \mathrm{J}_{2}=\mathrm{J}_{3}=1,8 \mathrm{~Hz}\right) ; 2,12(\mathrm{~s}, 3 \mathrm{H}) ; 2,80-2,90(\mathrm{~m}, 2 \mathrm{H}) ; 3,02\left(\mathrm{ddd}, 1 \mathrm{H} ; \mathrm{J}_{1}=9,1 \mathrm{~Hz} ; \mathrm{J}_{2}=8,7\right.$ $\left.\mathrm{Hz} ; \mathrm{J}_{3}=3,6 \mathrm{~Hz}\right) ; 3,05-3,10(\mathrm{~m}, 1 \mathrm{H}) ; 4,47\left(\mathrm{dq}, 1 \mathrm{H}, \mathrm{J}_{1}=8,6 \mathrm{~Hz} ; \mathrm{J}_{2}=\mathrm{J}_{3}=\mathrm{J}_{4}=2,8 \mathrm{~Hz}\right) ; 5,29$ $\left(\mathrm{dt}, 1 \mathrm{H}, \mathrm{J}_{1}=10,5 ; \mathrm{J}_{2}=\mathrm{J}_{3}=2,8 \mathrm{~Hz}\right) ; 5,36\left(\mathrm{dq}, 1 \mathrm{H}, \mathrm{J}_{1}=8,7 \mathrm{~Hz} ; \mathrm{J}_{2}=\mathrm{J}_{3}=\mathrm{J}_{4}=2,8 \mathrm{~Hz}\right) ; 5,47(\mathrm{dt}$, $\left.1 \mathrm{H}, \mathrm{J}_{1}=10,5 \mathrm{~Hz} ; \mathrm{J}_{2}=\mathrm{J}_{3}=2,8 \mathrm{~Hz}\right) ; 5,81\left(\mathrm{dd}, 1 \mathrm{H} ; \mathrm{J}_{1}=5,6 \mathrm{~Hz}_{2} \mathrm{~J}_{2}=2,8 \mathrm{~Hz}\right) ; 5,88\left(\mathrm{dd}, 1 \mathrm{H}, \mathrm{J}_{1}\right.$ $=5,6 \mathrm{~Hz} ; \mathrm{J}_{2}=2,8 \mathrm{~Hz}$ ).

IR $v_{\text {máx. }}(\mathrm{KBr}): 736 \mathrm{~cm}^{-1}, 1030 \mathrm{~cm}^{-1} ; 1238 \mathrm{~cm}^{-1}, 1668 \mathrm{~cm}^{-1}, 1738 \mathrm{~cm}^{-1} ; 2948,3102-3702$ $\mathrm{cm}^{-1}$. 


\section{$7.5 \quad-\quad$ Preparação acetatato de $\quad( \pm)-(1 S, 2 R, 3 S, 6 R, 7 S, 8 R)-6-$} hidroxitriciclo[6.2.1.0 $\left.0^{2,7}\right]$ undeca-4,9-dien-3-ilo (145) - Reação com $t$-BuOK.

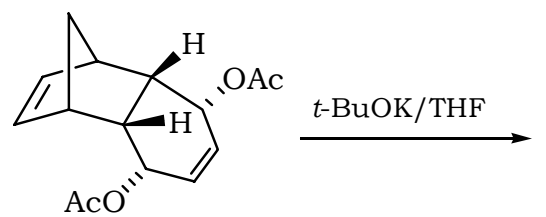

144

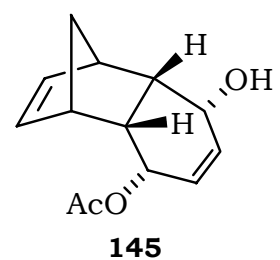

145

Procedimento: A uma solução contendo $45 \mathrm{mg}(0,38 \mathrm{mmol})$ de t-BuOK 95\% em 1,0 mL de THF anidro, sob atmosfera de $\mathrm{N}_{2}$, adicionou-se o diacetato 144 (100 $\left.\mathrm{mg}, 0,38 \mathrm{mmol}\right)$ dissolvido em 1,0 mL do mesmo solvente. A reação foi mantida a temperatura ambiente por 3 horas e neste caso não se observou consumo do material de partida. Adicionou-se mais 3 equivalentes de $t-\mathrm{BuOK}$ deixando reagir por mais 3 horas à refluxo. Após este período observou-se o consumo total do material de partida e sendo assim adicionou-se água ao meio reacional e extraiu-se com acetato de etila (4 porções de $25 \mathrm{~mL}$ ). As fases orgânicas foram reunidas e lavadas com solução saturada de $\mathrm{NaCl}$ e em seguida secada com $\mathrm{MgSO}_{4}$ anidro. O solvente foi removido sob pressão reduzida obtendo-se um produto com boa pureza.

Rendimento: $59 \mathrm{mg}(0,27 \mathrm{mmol})-71 \%$

$\mathrm{RMN}-{ }^{1} \mathrm{H}\left(\mathrm{CDCl}_{3}, 400 \mathrm{MHz}\right) \delta(\mathrm{ppm}): 1,30(\mathrm{~d}, 1 \mathrm{H}, \mathrm{J}=8,2 \mathrm{~Hz}) ; 1,36\left(\mathrm{dt}, 1 \mathrm{H}, \mathrm{J}_{1}=8,2\right.$ $\left.\mathrm{Hz} ; \mathrm{J}_{2}=\mathrm{J}_{3}=1,8 \mathrm{~Hz}\right) ; 2,12(\mathrm{~s}, 3 \mathrm{H}) ; 2,80-2,90(\mathrm{~m}, 2 \mathrm{H}) ; 3,02\left(\mathrm{ddd}, 1 \mathrm{H} ; \mathrm{J}_{1}=9,1 \mathrm{~Hz} ; \mathrm{J}_{2}=8,7\right.$ $\left.\mathrm{Hz} ; \mathrm{J}_{3}=3,6 \mathrm{~Hz}\right) ; 3,05-3,10(\mathrm{~m}, 1 \mathrm{H}) ; 4,47\left(\mathrm{dq}, 1 \mathrm{H}, \mathrm{J}_{1}=8,6 \mathrm{~Hz}_{2} \mathrm{~J}_{2}=\mathrm{J}_{3}=\mathrm{J}_{4}=2,8 \mathrm{~Hz}\right) ; 5,29$ $\left(\mathrm{dt}, 1 \mathrm{H}, \mathrm{J}_{1}=10,5 ; \mathrm{J}_{2}=\mathrm{J}_{3}=2,8 \mathrm{~Hz}\right) ; 5,36\left(\mathrm{dq}, 1 \mathrm{H}, \mathrm{J}_{1}=8,7 \mathrm{~Hz} ; \mathrm{J}_{2}=\mathrm{J}_{3}=\mathrm{J}_{4}=2,8 \mathrm{~Hz}\right) ; 5,47(\mathrm{dt}$, $\left.1 \mathrm{H}, \mathrm{J}_{1}=10,5 \mathrm{~Hz} ; \mathrm{J}_{2}=\mathrm{J}_{3}=2,8 \mathrm{~Hz}\right) ; 5,81\left(\mathrm{dd}, 1 \mathrm{H} ; \mathrm{J}_{1}=5,6 \mathrm{~Hz} ; \mathrm{J}_{2}=2,8 \mathrm{~Hz}\right) ; 5,88\left(\mathrm{dd}, 1 \mathrm{H}, \mathrm{J}_{1}\right.$ $=5,6 \mathrm{~Hz} ; \mathrm{J}_{2}=2,8 \mathrm{~Hz}$ ).

IR $v_{\text {máx. }}(\mathrm{KBr}): 736 \mathrm{~cm}^{-1}, 1030 \mathrm{~cm}^{-1} ; 1238 \mathrm{~cm}^{-1}, 1668 \mathrm{~cm}^{-1}, 1738 \mathrm{~cm}^{-1} ; 2948,3102-3702$ $\mathrm{cm}^{-1}$. 
7.6 - Preparação do acetato de $( \pm)-(1 R, 2 S, 3 R, 6 R, 7 R, 8 S)-6-$ iodotriciclo[6.2.1.0 $\left.0^{2,7}\right]$ undeca-4,9-dien-3-ilo (147). ${ }^{75}$

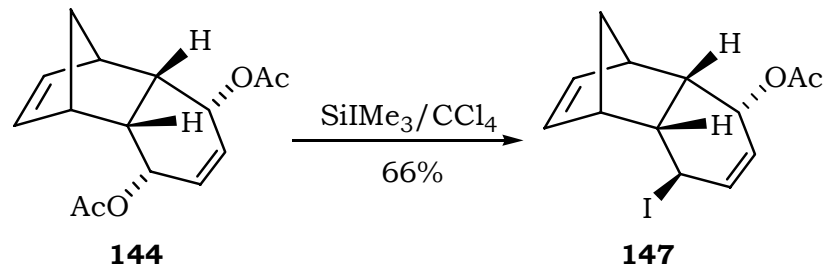

Procedimento: A uma solução contendo $100 \mathrm{mg}(0,38 \mathrm{mmol})$ do diacetato $144 \mathrm{em} \mathrm{3,0}$ $\mathrm{mL}$ de $\mathrm{CCl}_{4}$ anidro, a $0^{\circ} \mathrm{C}$ e sob atmosfera inerte de $\mathrm{N}_{2}$, adicionou-se $56 \mu \mathrm{L}(0,39 \mathrm{mmol})$ de $\mathrm{Me}_{3} \mathrm{SiI}$. A mistura foi agitada por 5 minutos e após este tempo adicionou-se $15 \mathrm{~mL}$ de água ao meio reacional deixando-se agitar por mais 5 minutos. A mistura reacional foi extraída com várias porções de $\mathrm{CCl}_{4}$ (4 porções de $20 \mathrm{~mL}$ ). As fases orgânicas foram reunidas e lavadas com uma solução de bissulfito de sódio 15\%. Em seguida a fase orgânica foi secada com $\mathrm{MgSO}_{4}$ e o solvente removido sob pressão reduzida. $\mathrm{O}$ resíduo obtido foi purificado por cromatografia em uma coluna de sílica "flash" (200-400 mesh), utilizando-se como eluente uma mistura de hexano/acetato de etila 9,5:0,5. Obteve-se um líquido amarelado de fácil decomposição.

Rendimento: $84 \mathrm{mg}(0,25 \mathrm{mmol})-66 \%$

$\mathrm{RMN}-{ }^{1} \mathrm{H}\left(\mathrm{CDCl}_{3}, 400 \mathrm{MHz}\right) \delta(\mathrm{ppm}): 2,07$ (s, 3H); 2,19-2,25 (m, 2H); $2,78\left(\mathrm{tt}, 1 \mathrm{H}, \mathrm{J}_{1}\right.$ $\left.=\mathrm{J}_{2}=6,7 \mathrm{~Hz} ; \mathrm{J}_{3}=\mathrm{J}_{4}=1,5 \mathrm{~Hz}\right) ; 2,88-2,94(\mathrm{~m}, 1 \mathrm{H}) ; 3,15\left(\mathrm{dddd}, 1 \mathrm{H}, \mathrm{J}_{1}=10,1 \mathrm{~Hz}, \mathrm{~J}_{2}=8,1\right.$ $\left.\mathrm{Hz}, \mathrm{J}_{3}=6,7 \mathrm{~Hz}, \mathrm{~J}_{4}=5,3 \mathrm{~Hz}\right) ; 3,36-3,46(\mathrm{~m}, 1 \mathrm{H}) ; 5,09\left(\mathrm{dd}, 1 \mathrm{H}, \mathrm{J}_{1}=3,8 \mathrm{~Hz}, \mathrm{~J}_{2}=2,5 \mathrm{~Hz}\right)$; $5,54-5,67(\mathrm{~m}, 4 \mathrm{H}) ; 5,81\left(\mathrm{ddd}, 1 \mathrm{H}, \mathrm{J}_{1}=9,4 \mathrm{~Hz}, \mathrm{~J}_{2}=3,8 \mathrm{~Hz}, \mathrm{~J}_{3}=1,5 \mathrm{~Hz}\right)$.

RMN- ${ }^{13} \mathrm{C}\left(\mathrm{CDCl}_{3}, 100 \mathrm{MHz}\right) \delta(\mathrm{ppm}): 21,3\left(\mathrm{CH}_{3}\right) ; 32,10\left(\mathrm{CH}_{2}\right) ; 32,4(\mathrm{CH}) ; 41,8(\mathrm{CH})$; 46,1 (CH); 50,8 (CH); 53,6 (CH); 81,4 (CH); 129,2 (CH); 129,6 (CH); 131,7 (CH); 133,5 $(\mathrm{CH}) ; 170,3(\mathrm{C}=\mathrm{O})$. 
7.7 - Preparação da $(1 R, 2 S, 7 R, 8 S)$-triciclo[6.2.1.0 $\left.0^{2,7}\right]$ undec-9-eno-3,6-diona $(148) .{ }^{76}$

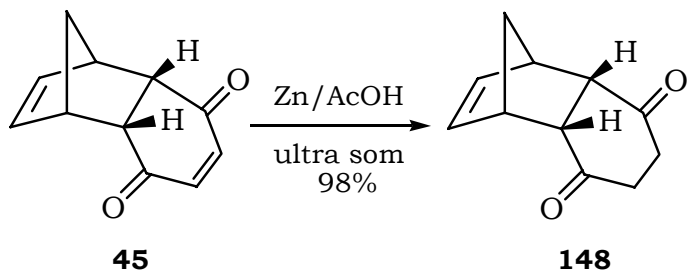

Procedimento: A uma solução contendo $970 \mathrm{mg}(5,56 \mathrm{mmol})$ do aduto $45 \mathrm{em} 7 \mathrm{~mL}$ de HOAc glacial, adicionou-se $\mathrm{Zn}$ ativado $(750 \mathrm{mg} 11,5 \mathrm{mmol})$. A mistura foi posta para reagir em um aparelho de ultra-som por duas horas. Após este tempo adicionou-se mais $\mathrm{Zn}$ ativado $(750 \mathrm{mg})$ e $7,0 \mathrm{~mL}$ de HOAc, glacial deixando reagir por mais duas horas sob ultra-som. A mistura foi então filtrada e o resíduo foi lavado com 4 porções de $25 \mathrm{~mL}$ de dicloro metano. O filtrado foi extraído com água (3 porções de $25 \mathrm{~mL}$ ) e com solução saturada de bicarbonato de sódio (2 porções de $25 \mathrm{~mL}$ ). Estas fases aquosas foram reunidas e novamente extraídas com dicloro metano (2 porções de $50 \mathrm{~mL}$ ). Finalmente as fases orgânicas foram reunidas e lavadas com solução saturada de bicarbonato de sódio e depois secadas com sulfato de magnésio anidro. O solvente foi removido sob pressão reduzida e o resíduo foi purificado por cromatografia em coluna de sílica "flash" (200400 mesh), utilizando-se como eluente uma mistura de hexano/acetato de etila 8:2. Obteve-se um óleo amarelado.

Rendimento: $960 \mathrm{mg}(5,45 \mathrm{mmol})-98 \%$.

RMN $-{ }^{1} \mathrm{H}\left(\mathrm{CDCl}_{3}, 400 \mathrm{MHz}\right) \delta(\mathrm{ppm}): 1,29(\mathrm{~d}, 1 \mathrm{H}, \mathrm{J}=8,7 \mathrm{~Hz}) ; 1,42\left(\mathrm{dt}, 1 \mathrm{H}, \mathrm{J}_{1}=8,7\right.$ $\left.\mathrm{Hz} ; \mathrm{J}_{2}=\mathrm{J}_{3}=1,8 \mathrm{~Hz}\right) ; 2,18-2,31(\mathrm{~m}, 2 \mathrm{H}) ; 2,51-2,64(\mathrm{~m}, 2 \mathrm{H}) ; 3,10-3,20(\mathrm{~m}, 2 \mathrm{H}) ; 3,35-$ $3,45(\mathrm{~m}, 2 \mathrm{H}) ; 6,11\left(\mathrm{t}, 2 \mathrm{H}, \mathrm{J}_{1}=\mathrm{J}_{2}=1,8 \mathrm{~Hz}\right)$.

$\mathrm{RMN}-{ }^{13} \mathrm{C}\left(\mathrm{CDCl}_{3}, 100 \mathrm{MHz}\right) \delta(\mathrm{ppm}): 37,9\left(\mathrm{CH}_{2}\right) ; 47,4(\mathrm{CH}) ; 48,7\left(\mathrm{CH}_{2}\right) ; 51,8(\mathrm{CH})$; 136,6 (CH); 209,4 (C=O).

IR $v_{\text {máx }} .(\mathrm{KBr}): 726 \mathrm{~cm}^{-1} ; 1158 \mathrm{~cm}^{-1} ; 1302 \mathrm{~cm}^{-1} ; 1704 \mathrm{~cm}^{-1} ; 2991 \mathrm{~cm}^{-1}, 3541 \mathrm{~cm}^{-1}$.

MS m/z (intensidade relativa): $\left[\mathrm{M}^{+}\right]$(9,8\%); 148 (4,1\%), 110 (19,2\%), 82 (18,1\%); 66 $(100 \%)$. 
7.8 - Preparação do $(1 R, 2 S, 3 R, 6 S, 7 R, 8 S)$-triciclo[6.2.1.0 $\left.0^{2,7}\right]$ undec-9-eno-3,6-diol (149).

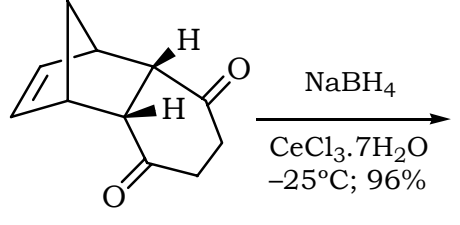

148<smiles>O[C@H]1CC[C@@H](O)[C@H]2C3C=CC(C3)[C@H]12</smiles>

149

Procedimento: A uma solução da diona 148 (460 mg, 2,61 mmol) em $45 \mathrm{~mL}$ de metanol, resfriada a $-25^{\circ} \mathrm{C}$, foi adicionado $\mathrm{CeCl}_{3} .7 \mathrm{H}_{2} \mathrm{O}(2,05 \mathrm{~g}, 5,50 \mathrm{mmol})$ deixando-se agitar fortemente por 5 minutos. Em seguida adicionou-se $\mathrm{NaBH}_{4}(217 \mathrm{mg}, 5,63 \mathrm{mmol})$ deixando reagir por 2,5 horas. Após este tempo, adicionou-se água ao meio reacional (cerca de $20 \mathrm{~mL}$ ) deixando-se agitar por mais 5 minutos, e depois removeu-se boa parte do metanol misturado à água, utilizando pressão reduzida. Em seguida, adicionou-se mais água ao meio $(10 \mathrm{~mL})$ e extraiu-se com $\mathrm{CH}_{2} \mathrm{Cl}_{2}(5$ porções de $40 \mathrm{~mL})$. As fases orgânicas foram reunidas e secadas com $\mathrm{MgSO}_{4}$ anidro e o solvente foi removido sob pressão reduzida. Foi obtido um sólido branco que foi lavado com hexano gelado e novamente secado a vácuo. $\mathrm{O}$ diol 149 se decompõe facilmente em $\mathrm{CDCl}_{3}$.

Rendimento: $453 \mathrm{mg}(2,51 \mathrm{mmol})-96 \%$

Ponto de fusão: $118-120^{\circ} \mathrm{C}$

$\mathrm{RMN}-{ }^{1} \mathrm{H}\left(\mathrm{CD}_{3} \mathrm{CN}, 400 \mathrm{MHz}\right), \delta(\mathrm{ppm}): 1,28\left(\mathrm{~d}, 1 \mathrm{H}, \mathrm{J}_{1}=7,8 \mathrm{~Hz}\right) ; 1,32\left(\mathrm{dt}, 1 \mathrm{H}, \mathrm{J}_{1}=7,8\right.$ $\left.\mathrm{Hz}, \mathrm{J}_{2}=\mathrm{J}_{3}=1,7 \mathrm{~Hz}\right) ; 1,35-1,44(\mathrm{~m}, 2 \mathrm{H}) ; 1,60-1,68(\mathrm{~m}, 2 \mathrm{H}) ; 2,42-2,46(\mathrm{~m}, 2 \mathrm{H}) ; 2,83-2,88$ $(\mathrm{m}, 2 \mathrm{H}) ; 3,01\left(\mathrm{~d}, 2 \mathrm{OH}, \mathrm{J}_{1}=5,8 \mathrm{~Hz}\right) ; 3,90-4,01(\mathrm{sl}, 2 \mathrm{H}) ; 6,09\left(\mathrm{t}, 2 \mathrm{H}, \mathrm{J}_{1}=\mathrm{J}_{2}=1,7 \mathrm{~Hz}\right)$.

$\mathrm{RMN}-{ }^{13} \mathrm{C}\left(\mathrm{CD}_{3} \mathrm{CN}, 100 \mathrm{MHz}\right) \delta(\mathrm{ppm}): 28,1\left(\mathrm{CH}_{2}\right) ; 46,0(\mathrm{CH}) ; 46,3(\mathrm{CH}) ; 52,6\left(\mathrm{CH}_{2}\right)$; $66,9(\mathrm{CH}) ; 134,6(\mathrm{CH})$.

IR $v_{\text {máx }}(\mathrm{KBr}): 744 \mathrm{~cm}^{-1} ; 908 \mathrm{~cm}^{-1} ; 1039 \mathrm{~cm}^{-1} ; 1340 \mathrm{~cm}^{-1} ; 2947 \mathrm{~cm}^{-1}, 3000-3700 \mathrm{~cm}^{-1}$.

MS m/z (intensidade relativa): $\left[\mathrm{M}^{+}\right](0,4 \%) ; 123$ (15,7\%), 97 (9,5\%), 79 (13,1\%); 66 $(100 \%)$. 
7.9 - Preparação do dimetanosulfonato de $(1 R, 3 R, 6 S, 8 S)$-triciclo[6.2.1.0 $\left.0^{2,7}\right]$ undec-9eno-3,6-di-ilo (150). ${ }^{77}$<smiles>O[C@H]1CC[C@@H](O)[C@H]2C3C=CC(C3)[C@H]12</smiles>

149<smiles>CO[C@H]1CC[C@@H](OC)[C@@H]2[C@@H]1C1C=C[C@H]2C1</smiles>

150

Procedimento: A uma solução contendo $150 \mathrm{mg}(0,83 \mathrm{mmol})$ do diol $149 \mathrm{em} 4 \mathrm{~mL}$ de piridina anidra, mantida a $0^{\circ} \mathrm{C}$ e sob atmosfera inerte de $\mathrm{N}_{2}$, adicionou-se lentamente $\mathrm{MsCl}(0,42 \mathrm{~mL}, 5,4 \mathrm{mmol})$. Após 15 minutos a mistura foi abandonada, sem agitar, por 1 noite (mantida a $6^{\circ} \mathrm{C}$ ). Após este tempo adicionou-se $\mathrm{H}_{2} \mathrm{O}$ gelada $(15 \mathrm{~mL})$ à mistura reacional deixando agitar até chegar à temperatura ambiente (aproximadamente 40 minutos). O sólido formado foi filtrado em funil de vidro sinterizado e lavado com duas porções de $\mathrm{H}_{2} \mathrm{O}$ (3 mL cada). Em seguida o sólido foi lavado com $\mathrm{HCl} 1 \mathrm{~mol} / \mathrm{L}$ (2 porções de $5 \mathrm{~mL}$ ) e depois novamente com duas porções de $3 \mathrm{~mL}$ de água. Após alguns minutos sob sucção, lavou-se com duas porções de $3 \mathrm{~mL}$ de éter dietílico deixando secar sob por 10 minutos. O sólido foi recolhido e secado a vácuo.

Rendimento: $240 \mathrm{mg}(0,71 \mathrm{mmol})-86 \%$

Ponto de fusão: $110-112{ }^{\circ} \mathrm{C}$ (ocorreu decomposição)

RMN- ${ }^{1} \mathrm{H}\left(\mathrm{CDCl}_{3}, 400 \mathrm{MHz}\right), \delta(\mathrm{ppm}): 1,36\left(\mathrm{dl}, 1 \mathrm{H}, \mathrm{J}_{1}=8,5 \mathrm{~Hz}\right) ; 1,56\left(\mathrm{dt}, 1 \mathrm{H}, \mathrm{J}_{1}=8,5 ; \mathrm{J}_{2}\right.$ $\left.=\mathrm{J}_{3}=1,7 \mathrm{~Hz}\right) ; 1,61-1,72(\mathrm{~m}, 2 \mathrm{H}) ; 1,90-2,02(\mathrm{~m}, 2 \mathrm{H}) ; 2,90-2,95(\mathrm{~m}, 2 \mathrm{H}) ; 3,04(\mathrm{~s}, 6 \mathrm{H})$; 3,09-3,13 (m, 2H); 4,97-5,10 (m, 2H); 6,26 (t, 2H, J $\left.=\mathrm{J}_{2}=1,7 \mathrm{~Hz}\right)$.

$\mathrm{RMN}-{ }^{13} \mathrm{C}\left(\mathrm{CDCl}_{3}, 100 \mathrm{MHz}\right) \delta(\mathrm{ppm}): 24,9\left(\mathrm{CH}_{2}\right) ; 38,6(\mathrm{CH}) ; 43,8(\mathrm{CH}) ; 45,7(\mathrm{CH})$; 52,2 $\left(\mathrm{CH}_{2}\right) ; 77,8(\mathrm{CH}) ; 134,3(\mathrm{CH})$.

IR $v_{\text {máx }} \cdot(\mathrm{KBr}): 525 \mathrm{~cm}^{-1} ; 830 \mathrm{~cm}^{-1} ; 943 \mathrm{~cm}^{-1} ; 1169 \mathrm{~cm}^{-1} ; 1359 \mathrm{~cm}^{-1}, 2935 \mathrm{~cm}^{-1}, 3017 \mathrm{~cm}^{-1}$.

HRMS (ESI-TOF): calc. para $\mathrm{C}_{13} \mathrm{H}_{20} \mathrm{O}_{6} \mathrm{~S}_{2} \mathrm{Na}^{+}\left(\mathrm{MNa}^{+}\right)$, 359,0599; experimental: 359,0666 ( $\Delta$ de 19 ppm - limite de 50 ppm). 
7.10 - Preparação do $( \pm)-(1 S, 6 S, 7 S, 8 R)$-6-bromotriciclo[6.2.1.0 $\left.0^{2,7}\right]$ undeca-2,9-dieno (155).

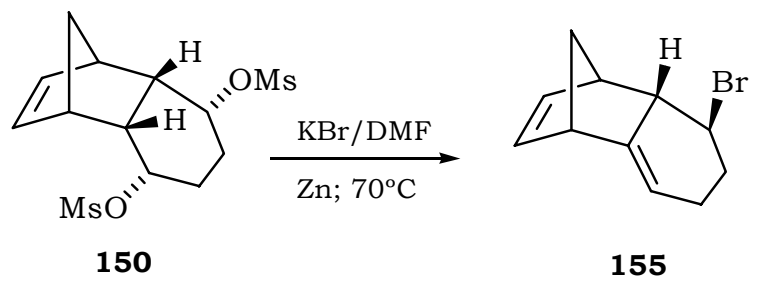

Procedimento: A uma solução contendo $202 \mathrm{mg}(0,60 \mathrm{mmol})$ do dimesilato $150 \mathrm{em} \mathrm{3,5}$ $\mathrm{mL}$ de DMF anidro, sob atmosfera inerte de $\mathrm{N}_{2}$, adicionou-se $\mathrm{KBr}(287 \mathrm{mg}, 2,4 \mathrm{mmol})$ e Zn ativado (240 mg, 3,68 mmol). A mistura reacional foi então aquecida a $70^{\circ} \mathrm{C}$ por 48 horas, tempo necessário para que houvesse o consumo de todo o material de partida. A mistura reacional foi filtrada e os sólidos retidos foram lavados com hexano. Em seguida adicionou-se água ao meio $(20 \mathrm{~mL})$ e extraiu-se com 4 porções de $25 \mathrm{~mL}$ de hexano. As fases orgânicas foram então reunidas e lavadas com duas porções de água ( $25 \mathrm{~mL}$ cada) e em seguida secada com sulfato de magnésio anidro. $O$ solvente foi removido sob pressão reduzida e o resíduo foi purificado por cromatografia em coluna de sílica "flash" (200400 mesh), utilizando-se como eluente uma mistura de hexano/acetato de etila 9:1.

Rendimento: $15 \mathrm{mg}(0,067 \mathrm{mmol}) 11 \%$

$\mathrm{RMN}-{ }^{1} \mathrm{H}\left(\mathrm{CDCl}_{3}, 400 \mathrm{MHz}\right), \delta(\mathrm{ppm}): 1,47\left(\mathrm{~d}, 1 \mathrm{H}, \mathrm{J}_{1}=8,5 \mathrm{~Hz}\right) ; 1,60\left(\mathrm{dt}, 1 \mathrm{H}, \mathrm{J}_{1}=8,5\right.$ $\left.\mathrm{Hz} ; \mathrm{J}_{2}=\mathrm{J}_{3}=1,8 \mathrm{~Hz}\right) ; 2,06-2,36(\mathrm{~m}, 4 \mathrm{H}) ; 2,69(\mathrm{dl}, 1 \mathrm{H}, \mathrm{J}=10,5 \mathrm{~Hz}) ; 3,14(\mathrm{sl}, 1 \mathrm{H}) ; 3,22(\mathrm{sl}$, $1 \mathrm{H}) ; 3,32\left(\mathrm{ddd}, 1 \mathrm{H}, \mathrm{J}_{1}=11,3 \mathrm{~Hz} ; \mathrm{J}_{2}=10,5 \mathrm{~Hz} ; \mathrm{J}_{3}=4,0 \mathrm{~Hz}\right) ; 5,46\left(\mathrm{dd}, 1 \mathrm{H}, \mathrm{J}_{1}=5,3 \mathrm{~Hz} ; \mathrm{J}_{2}=\right.$ $2,7 \mathrm{~Hz}) ; 5,90\left(\mathrm{dd}, 1 \mathrm{H}, \mathrm{J}_{1}=5,6 \mathrm{~Hz} ; \mathrm{J}_{2}=3,1 \mathrm{~Hz}\right) ; 6,11\left(\mathrm{dd}, 1 \mathrm{H}, \mathrm{J}_{1}=5,6 \mathrm{~Hz}, \mathrm{~J}_{2}=3,3 \mathrm{~Hz}\right.$ ).

$\mathrm{RMN}-{ }^{13} \mathrm{C}\left(\mathrm{CDCl}_{3}, 100 \mathrm{MHz}\right) \delta(\mathrm{ppm}): 27,4\left(\mathrm{CH}_{2}\right) ; 34,9\left(\mathrm{CH}_{2}\right) ; 45,3(\mathrm{CH}) ; 48,2\left(\mathrm{CH}_{2}\right)$; 48,7 (CH); 51,6 (CH); 55,7 (CH); 116,4 (CH); 129,8 (CH); 137,2 (CH); 142,4 (C). 
7.11 - Preparação do diacetato de 3,6-dioxociclo-hexa-1,4-dieno-1,4-di-ilo (162). ${ }^{79}$<smiles>CC(=O)OC1=CC(=O)C(OC(=O)OC(C)(C)C)C(=O)C1</smiles>

Procedimento: Em um erlenmeyer contendo anidrido acético $(4,0 \mathrm{~mL})$ e a quinona 156 (1,00 g, 7,14 mmol) foi adicionado $\mathrm{HClO}_{4} 10 \%(0,2 \mathrm{~mL})$ sob forte agitação e à temperatura ambiente. Após 5 minutos, a reação foi resfriada a $0^{\circ} \mathrm{C}$ e assim mantida por mais 5 minutos. A mistura reacional foi filtrada e lavada com uma porção de $2 \mathrm{~mL}$ de anidrido acético gelado e depois várias porções de hexano, tudo em um funil de placa sinterizada. Após secagem com vácuo obteve-se um sólido amarelo.

Rendimento: $1,35 \mathrm{~g}(6,02 \mathrm{mmol})-84 \%$

Ponto de fusão: $151-152^{\circ} \mathrm{C}$

$\mathrm{RMN}-{ }^{1} \mathrm{H}\left(\mathrm{CDCl}_{3}, 400 \mathrm{MHz}\right), \delta(\mathrm{ppm}): 2,35$ (s, 6H); 6,63 (s, 2H).

$\mathrm{RMN}-{ }^{13} \mathrm{C}\left(\mathrm{CDCl}_{3}, 100 \mathrm{MHz}\right) \delta(\mathrm{ppm}): 21,1\left(\mathrm{CH}_{3}\right) ; 122,2(\mathrm{CH}) ; 152,3(\mathrm{C}) ; 167,4(\mathrm{C}=\mathrm{O})$; $179,8(\mathrm{C}=\mathrm{O})$.

IR $v_{\text {maxx }}(\mathrm{KBr}): 1124 \mathrm{~cm}^{-1} ; 1195 \mathrm{~cm}^{-1} ; 1623 \mathrm{~cm}^{-1} ; 1683 \mathrm{~cm}^{-1} ; 1771 \mathrm{~cm}^{-1} ; 2938 \mathrm{~cm}^{-1} ; 3073$ $\mathrm{cm}^{-1}$

MS m/z (intensidade relativa): 140 (8,6\%), 69 (13,8\%), 43 (100\%). 
7.12 - Preparação do diacetato de $( \pm)-(1 S, 2 S, 7 S, 8 R)-3,6-$ dioxotriciclo[6.2.1.0 $\left.0^{2,7}\right]$ undeca-4,9-dieno-2,5-di-ilo $(163){ }^{79}$
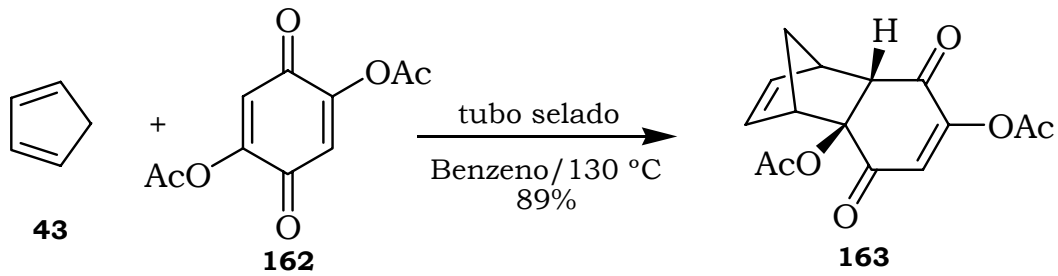

Procedimento: Foram misturados $200 \mathrm{mg}(0,89 \mathrm{mmol})$ do composto 162, $6 \mathrm{~mL}$ de benzeno anidro e ciclopentadieno $(43)(400 \mathrm{mg} ; 6,05 \mathrm{mmol})$ recentemente destilado. A mistura foi realizada em um tubo de vidro (ampola) pirex que devidamente selado. A ampola foi mantida a $130^{\circ} \mathrm{C}$ por 7 horas. Após este tempo reacional, o produto resultante foi concentrado sob pressão reduzida e purificado por cromatografia em coluna de sílicagel, utilizando-se como eluente uma mistura de hexano/acetato de etila (8:2). Obteve-se um sólido branco.

Rendimento: $230 \mathrm{mg}(0,79 \mathrm{mmol})-89 \%$

Ponto de fusão: $112-113{ }^{\circ} \mathrm{C}$

$\mathrm{RMN}-{ }^{1} \mathrm{H}\left(\mathrm{CDCl}_{3}, 400 \mathrm{MHz}\right), \delta(\mathrm{ppm}): 1,76\left(\mathrm{dt}, 1 \mathrm{H}, \mathrm{J}_{1}=9,1 \mathrm{~Hz}, \mathrm{~J}_{2}=\mathrm{J}_{3}=1,5 \mathrm{~Hz}\right) ; 1,96$ (dtdd, $\left.1 \mathrm{H},{ }_{1}=9,1 \mathrm{~Hz}, \mathrm{~J}_{2}=\mathrm{J}_{3}=1,5 \mathrm{~Hz}, \mathrm{~J}_{4}=0,9 \mathrm{~Hz}, \mathrm{~J}_{4}=0,8 \mathrm{~Hz}\right) ; 2,10(\mathrm{~s}, 3 \mathrm{H}) ; 2,28(\mathrm{~s}, 3 \mathrm{H})$; $3,08(\mathrm{~d}, 1 \mathrm{H}, \mathrm{J}=4,0 \mathrm{~Hz}) ; 3,34\left(\mathrm{dtd}, 1 \mathrm{H}, \mathrm{J}_{1}=3,0 \mathrm{~Hz}, \mathrm{~J}_{2}=\mathrm{J}_{3}=1,5 \mathrm{~Hz}, \mathrm{~J}_{4}=0,8 \mathrm{~Hz}\right) ; 3,43$ (ddtd, $1 \mathrm{H}, \mathrm{J}_{1}=4,0 \mathrm{~Hz}, \mathrm{~J}_{2}=2,9 \mathrm{~Hz}, \mathrm{~J}_{3}=\mathrm{J}_{4}=1,5 \mathrm{~Hz}, \mathrm{~J}_{5}=0,9 \mathrm{~Hz}$ ); 5,99 (ddt, $1 \mathrm{H}, \mathrm{J}_{1}=5,6 \mathrm{~Hz}$, $\left.\mathrm{J}_{2}=3,0 \mathrm{~Hz}, \mathrm{~J}_{3}=\mathrm{J}_{4}=0,9 \mathrm{~Hz}\right) ; 6,38\left(\mathrm{ddt}, 1 \mathrm{H}, \mathrm{J}_{1}=5,6 \mathrm{~Hz}, \mathrm{~J}_{2}=2,9 \mathrm{~Hz}, \mathrm{~J}_{3}=\mathrm{J}_{4}=0,8 \mathrm{~Hz}\right) ; 6,46$ $(\mathrm{s}, 1 \mathrm{H})$.

$\mathrm{RMN}-{ }^{13} \mathrm{C}\left(\mathrm{CDCl}_{3}, 100 \mathrm{MHz}\right) \delta(\mathrm{ppm}): 20,4\left(\mathrm{CH}_{3}\right) ; 48,0\left(\mathrm{CH}_{2}\right) ; 49,1(\mathrm{CH}) ; 53,1(\mathrm{CH})$; 57,8 (CH); 85,3 (C); 128,7 (CH); 131,7 (CH); 139,7 (CH); 157,2 (C); 167,5 (C=O); 170,8 $(\mathrm{C}=\mathrm{O}) ; 190,1(\mathrm{C}=\mathrm{O}) ; 194,4(\mathrm{C}=\mathrm{O})$.

IR $v_{\text {máx }}(\mathrm{KBr}): 738 \mathrm{~cm}^{-1} ; 1266 \mathrm{~cm}^{-1} ; 1684 \mathrm{~cm}^{-1} ; 1734 \mathrm{~cm}^{-1} ; 1775 \mathrm{~cm}^{-1} ; 2987 \mathrm{~cm}^{-1} ; 3054$ $\mathrm{cm}^{-1}$.

MS m/z (intensidade relativa): 182 (13,2\%), 140 (30,7\%), 112 (15,8\%); 69 (43\%), 43 $(100 \%)$. 
7.13 - Preparação da $( \pm)-(1 S, 2 S, 7 S, 8 R)$-5-hidroxi-2-metoxitriciclo[6.2.1.0 $\left.0^{2,7}\right]$ undeca4,9-dieno-3,6-diona (164). ${ }^{131}$

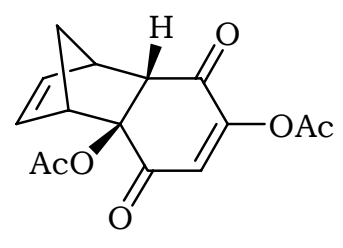

163

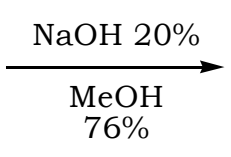

163 (100 mg; 0,34 mmol) em metanol (2 mL) foi adicionada uma solução de $\mathrm{NaOH} 20 \%(0,34 \mathrm{~mL})$. No momento da adição, a solução tornou-se violeta e após consumo total do material de partida (3 minutos), a solução tornou-se marrom. Boa parte do solvente foi então removido a sob pressão reduzida, adicionando-se em seguida água destilada $(10 \mathrm{~mL})$ ao meio reacional. A solução foi acidificada até $\mathrm{pH}$ entre $3-4 \mathrm{com} \mathrm{HCl} 3 \mathrm{~mol} / \mathrm{L}$, e em seguida extraída com éter etílico (5 x $30 \mathrm{~mL}$ ). As fases orgânicas foram reunidas e lavadas com solução saturada de $\mathrm{NaCl}$ e em seguida secada com $\mathrm{MgSO}_{4}$ anidro. $\mathrm{O}$ solvente foi removido sob pressão reduzida e o produto foi purificado por cromatografia em coluna de sílica-gel, utilizando-se como eluente uma mistura de hexano/acetato de etila (1:1).

Rendimento: $57 \mathrm{mg}(0,26 \mathrm{mmol})-76 \%)$

Ponto de fusão: $112-113^{\circ} \mathrm{C}$

$\left.\mathrm{RMN}-{ }^{1} \mathrm{H}\left(\mathrm{CDCl}_{3}, 400 \mathrm{MHz}\right), \delta(\mathrm{ppm}): 1,72\left(\mathrm{dt}, 1 \mathrm{H}, \mathrm{J}_{1}=9,0 \mathrm{~Hz}, \mathrm{~J}_{2}=\mathrm{J}_{3}=1,6 \mathrm{~Hz}\right)\right) ; 2,01$ $\left(\mathrm{dtt}, 1 \mathrm{H}, \mathrm{J}_{1}=9,0 \mathrm{~Hz}, \mathrm{~J}_{2}=\mathrm{J}_{3}=1,5 \mathrm{~Hz}, \mathrm{~J}_{4}=\mathrm{J}_{5}=0,6 \mathrm{~Hz}\right) ; 3,13(\mathrm{~d} ; 1 \mathrm{H}, \mathrm{J}=4,2 \mathrm{~Hz}) ; 3,31(\mathrm{~s}$; $3 \mathrm{H}) ; 3,35$ (dddd, $1 \mathrm{H}, \mathrm{J}_{1}=3,1 \mathrm{~Hz}, \mathrm{~J}_{2}=1,6 \mathrm{~Hz}, \mathrm{~J}_{3}=1,5 \mathrm{~Hz}, \mathrm{~J}_{4}=0,8 \mathrm{~Hz}$ ); 3,50 (ddddd, $1 \mathrm{H}, \mathrm{J}_{1}$ $=4,2 \mathrm{~Hz}, \mathrm{~J}_{2}=2,8 \mathrm{~Hz}, \mathrm{~J}_{3}=1,6 \mathrm{~Hz}, \mathrm{~J}_{4}=1,5 \mathrm{~Hz}, \mathrm{~J}_{5}=0,8 \mathrm{~Hz}$ ); 6,05 (dddd, $1 \mathrm{H}, \mathrm{J}_{1}=5,8 \mathrm{~Hz}, \mathrm{~J}_{2}$ $\left.=3,1 \mathrm{~Hz}, \mathrm{~J}_{3}=0,8 \mathrm{~Hz}, \mathrm{~J}_{4}=0,6 \mathrm{~Hz}\right) ; 6,11\left(\mathrm{dddd}, 1 \mathrm{H}, \mathrm{J}_{1}=5,8 \mathrm{~Hz}, \mathrm{~J}_{2}=2,8 \mathrm{~Hz}, \mathrm{~J}_{3}=0,8 \mathrm{~Hz}, \mathrm{~J}_{4}\right.$ $=0,6 \mathrm{~Hz}) ; 6,24(\mathrm{~s}, 1 \mathrm{H}) ; 7,38(\mathrm{sl}, 1 \mathrm{H})$.

$\mathrm{RMN}-{ }^{13} \mathrm{C}\left(\mathrm{CDCl}_{3}, 100 \mathrm{MHz}\right) \delta(\mathrm{ppm}): 47,1\left(\mathrm{CH}_{2}\right) ; 48,1(\mathrm{CH}) ; 51,7(\mathrm{CH}) ; 53,3\left(\mathrm{CH}_{3}\right)$; 54,9 (CH); 87,4 (C); 116,5 (CH); 135,5 (CH); 137,4 (CH); 159,1 (C); 195,4 (C=O); 196,8 $(\mathrm{C}=\mathrm{O})$.

IR $v_{\text {máx }}(\mathrm{KBr}): 1066 \mathrm{~cm}^{-1} ; 1254 \mathrm{~cm}^{-1} ; 1367 \mathrm{~cm}^{-1} ; 1716 \mathrm{~cm}^{-1} ; 1760 \mathrm{~cm}^{-1} ; 3106-3659 \mathrm{~cm}^{-1}$.

MS m/z (intensidade relativa): $\left[\mathrm{M}^{+}\right]$(1\%), 192 (25,9\%), 164 (53,4\%), 77 (48,3\%), 69 (100\%), 66 (50\%). 
7.14 - Preparação da $( \pm)-(1 S, 2 S, 7 S, 8 R)$-2-etoxi-5-hidroxitriciclo[6.2.1.0 $\left.0^{2,7}\right]$ undeca4,9-dieno-3,6-diona (165).
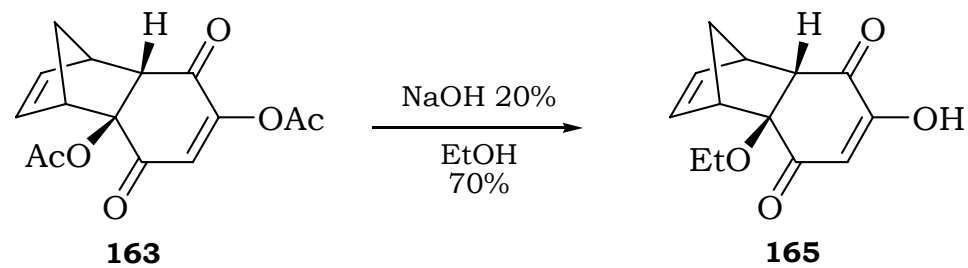

Procedimento: A uma solução do aduto 163 (100 mg; 0,34 mmol) em etanol (2 mL) foi adicionada solução $\mathrm{NaOH} 20 \%(0,34 \mathrm{~mL})$. No momento da adição, a solução tornou-se violeta e após consumo total do material de partida (aproximadamente 10 minutos), a solução tornou-se marrom. Boa parte do solvente foi então removido a sob pressão reduzida, adicionando-se em seguida água destilada $(10 \mathrm{~mL})$ ao meio reacional. A solução foi então acidificada até $\mathrm{pH}$ entre 3-4 com $\mathrm{HCl} 3 \mathrm{~mol} / \mathrm{L}$, sendo em seguida extraída com éter etílico $(5 \times 30 \mathrm{~mL})$. As fases orgânicas foram reunidas e lavadas com solução saturada de $\mathrm{NaCl}$ e em seguida secada com $\mathrm{MgSO}_{4}$ anidro. $\mathrm{O}$ solvente foi removido sob pressão reduzida e o produto foi purificado por cromatografia em coluna de sílica-gel, utilizando-se como eluente uma mistura de hexano/acetato de etila (1:1).

Rendimento: $56 \mathrm{mg}$ ( 0,24 mmol, 70\%)

RMN- ${ }^{1} \mathrm{H}\left(\mathrm{CDCl}_{3}, 400 \mathrm{MHz}\right), \delta(\mathrm{ppm}): 1,17\left(\mathrm{t}, 3 \mathrm{H}, \mathrm{J}_{1}=\mathrm{J}_{2}=7,1 \mathrm{~Hz}\right) ; 1,71\left(\mathrm{dt} ; 1 \mathrm{H}, \mathrm{J}_{1}=8,8\right.$ $\left.\mathrm{Hz}, \mathrm{J}_{2}=\mathrm{J}_{3}=1,5 \mathrm{~Hz}\right) ; 2,04(\mathrm{dl} ; 1 \mathrm{H}, \mathrm{J}=8,8 \mathrm{~Hz}) ; 3,11(\mathrm{~d} ; 1 \mathrm{H}, \mathrm{J}=4,1 \mathrm{~Hz}) ; 3,35(\mathrm{~m} ; 1 \mathrm{H})$; $3,43-3,52(\mathrm{~m}, 3 \mathrm{H}) ; 6,04\left(\mathrm{dd} ; 1 \mathrm{H}, \mathrm{J}_{1}=5,6 \mathrm{~Hz}, \mathrm{~J}_{2}=3,3 \mathrm{~Hz}\right) ; 6,09\left(\mathrm{dd} ; 1 \mathrm{H}, \mathrm{J}_{1}=5,6 \mathrm{~Hz}, \mathrm{~J}_{2}=\right.$ 2,7 Hz); 6,22 (s; 1H), 7,16 (sl, 1H).

RMN- ${ }^{13} \mathrm{C}\left(\mathrm{CDCl}_{3}, 100 \mathrm{MHz}\right) \delta(\mathrm{ppm}): 15,4\left(\mathrm{CH}_{3}\right) ; 47,1\left(\mathrm{CH}_{2}\right) ; 48,1(\mathrm{CH}) ; 52,0(\mathrm{CH})$; 55,4(CH); 61,2 $\left(\mathrm{CH}_{2}\right) ; 87,0(\mathrm{C}) ; 116,5(\mathrm{CH}) ; 135,5(\mathrm{CH}) ; 137,3(\mathrm{CH}) ; 159,3(\mathrm{C}) ; 195,5$ $(\mathrm{C}=\mathrm{O}) ; 197,3(\mathrm{C}=\mathrm{O})$

IR $v_{\text {máx }} \cdot(\mathrm{KBr}): 738 \mathrm{~cm}^{-1} ; 1082 \mathrm{~cm}^{-1} ; 1266 \mathrm{~cm}^{-1} ; 1752 \mathrm{~cm}^{-1} ; 2980 \mathrm{~cm}^{-1} ; 3102-3712 \mathrm{~cm}^{-1}$. 
7.15 - Preparação do acetato de $( \pm)-(1 S, 2 S, 7 S, 8 R)$-5-hidroxi-3,6dioxotriciclo[6.2.1.0 $\left.0^{2,7}\right]$ undeca-4,9-dien-2-ilo (166) - Método $1 .^{80}$

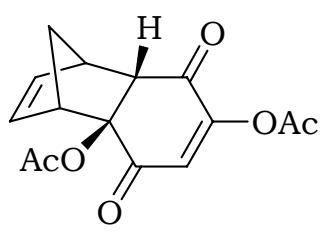

163

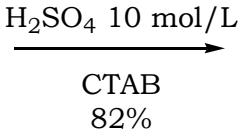

$82 \%$

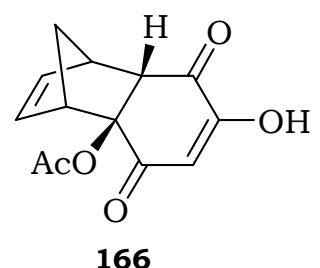

166

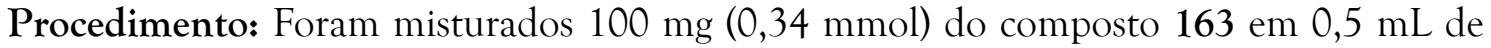
$\mathrm{H}_{2} \mathrm{SO}_{4} 10 \mathrm{~mol} / \mathrm{L}$ e $13 \mathrm{mg}(0,034 \mathrm{mmol})$ de CTAB. Após 10 minutos foi observado o consumo total do material de partida 163. Ao meio reacional foram adicionados $15 \mathrm{~mL}$ de $\mathrm{H}_{2} \mathrm{O}$ e a mistura foi extraída com 4 porções de $20 \mathrm{~mL}$ de éter dietílico. As fases orgânicas foram reunidas e lavadas com solução saturada de $\mathrm{NaCl}$ (1 porção de $20 \mathrm{~mL}$ ) e em seguida secadas com $\mathrm{MgSO}_{4}$ anidro. $\mathrm{O}$ solvente foi removido sob pressão reduzida e o resíduo purificado por cromatografia em coluna de sílica-gel, utilizando-se como eluente uma mistura de hexano/acetato de etila (1:1).

Rendimento: $70 \mathrm{mg}(0,28 \mathrm{mmol})-82 \%$

Ponto de fusão: $152-153{ }^{\circ} \mathrm{C}$

RMN- ${ }^{1} \mathrm{H}\left(\mathrm{CDCl}_{3}, 400 \mathrm{MHz}\right), \delta(\mathrm{ppm}): 1,77\left(\mathrm{dt} ; 1 \mathrm{H}, \mathrm{J}_{1}=9,3 \mathrm{~Hz}, \mathrm{~J}_{2}=\mathrm{J}_{3}=1,5 \mathrm{~Hz}\right) ; 2,00$ $(\mathrm{dl} ; 1 \mathrm{H}, \mathrm{J}=9,3 \mathrm{~Hz}) ; 2,10(\mathrm{~s}, 3 \mathrm{H}) ; 3,17(\mathrm{~d} ; 1 \mathrm{H}, \mathrm{J}=4,3 \mathrm{~Hz}) ; 3,49(\mathrm{~m} ; 1 \mathrm{H}) ; 3,35(\mathrm{~m}, 1 \mathrm{H})$; $6,05\left(\mathrm{dd} ; 1 \mathrm{H}, \mathrm{J}_{1}=5,6 \mathrm{~Hz}, \mathrm{~J}_{2}=3,0 \mathrm{~Hz}\right) ; 6,16\left(\mathrm{dd} ; 1 \mathrm{H}, \mathrm{J}_{1}=5,6 \mathrm{~Hz}, \mathrm{~J}_{2}=2,7 \mathrm{~Hz}\right) ; 6,19(\mathrm{~s} ; 1 \mathrm{H})$, $7,43(\mathrm{sl}, \mathrm{OH})$.

RMN- ${ }^{13} \mathrm{C}\left(\mathrm{CDCl}_{3}, 100 \mathrm{MHz}\right) \delta(\mathrm{ppm}): 20,6\left(\mathrm{CH}_{3}\right) ; 48,0\left(\mathrm{CH}_{2}\right) ; 49,0(\mathrm{CH}) ; 52,9(\mathrm{CH})$; 56,1(CH); 85,0(C); 115,0 (CH); 133,6 (CH); 137,8 (CH); 159,0 (C); 170,6 (C=O); 194,3 $(\mathrm{C}=\mathrm{O}) ; 194,5(\mathrm{C}=\mathrm{O})$.

IR $v_{\text {máx }} \cdot(\mathrm{KBr}): 729 \mathrm{~cm}^{-1} ; 1032 \mathrm{~cm}^{-1} ; 1231 \mathrm{~cm}^{-1} ; 1374 \mathrm{~cm}^{-1} ; 1659 \mathrm{~cm}^{-1} ; 1688 \mathrm{~cm}^{-1} ; 1739$ $\mathrm{cm}^{-1} ; 2839-3670 \mathrm{~cm}^{-1}$.

MS m/z (intensidade relativa): 206 (55,8\%), 150 (36,7\%), 69 (42,5\%), 66 (35\%), 43 (100\%). 
7.16 - Preparação do acetato de $( \pm)-(1 S, 2 S, 7 S, 8 R)$-5-hidroxi-3,6dioxotriciclo[6.2.1.0 $\left.0^{2,7}\right]$ undeca-4,9-dien-2-ilo (166) - Método $2 .{ }^{81}$

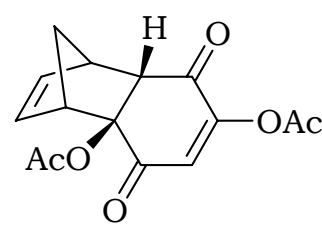

163

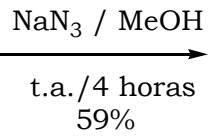

$59 \%$

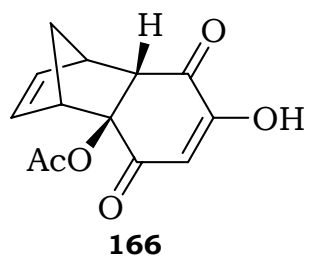

166

Procedimento: Foram misturados $100 \mathrm{mg}(0,34 \mathrm{mmol})$ do composto $163 \mathrm{em} 3 \mathrm{~mL}$ de $\mathrm{MeOH} / \mathrm{DMF}$ (3:1). Em seguida adicionou-se $110 \mathrm{mg}(1,70 \mathrm{mmol})$ de $\mathrm{NaN}_{3}$ deixando reagir à temperatura ambiente por 4 horas. Após este tempo isolou-se o produto formado adicionado $10 \mathrm{~mL}$ de água e extraiu-se em seguida com 4 porções de $20 \mathrm{~mL}$ de éter etílico. As fases orgânicas foram reunidas e lavadas com solução saturada de $\mathrm{NaCl}$ e em seguida secadas com $\mathrm{MgSO}_{4}$ anidro. $\mathrm{O}$ solvente foi removido sob pressão reduzida e o resíduo purificado por cromatografia em coluna de sílica-gel, utilizando-se como eluente uma mistura de hexano/acetato de etila (1:1).

Rendimento: $50 \mathrm{mg}(0,20 \mathrm{mmol})-59 \%$

Ponto de fusão: $152-153{ }^{\circ} \mathrm{C}$

$\mathrm{RMN}-{ }^{1} \mathrm{H}\left(\mathrm{CDCl}_{3}, 400 \mathrm{MHz}\right), \delta(\mathrm{ppm}): 1,77\left(\mathrm{dt} ; 1 \mathrm{H}, \mathrm{J}_{1}=9,3 \mathrm{~Hz}, \mathrm{~J}_{2}=\mathrm{J}_{3}=1,5 \mathrm{~Hz}\right) ; 2,00$ $(\mathrm{dl} ; 1 \mathrm{H}, \mathrm{J}=9,3 \mathrm{~Hz}) ; 2,10(\mathrm{~s}, 3 \mathrm{H}) ; 3,17(\mathrm{~d} ; 1 \mathrm{H}, \mathrm{J}=4,3 \mathrm{~Hz}) ; 3,49(\mathrm{~m} ; 1 \mathrm{H}) ; 3,35(\mathrm{~m}, 1 \mathrm{H})$; $6,05\left(\mathrm{dd} ; 1 \mathrm{H}, \mathrm{J}_{1}=5,6 \mathrm{~Hz}, \mathrm{~J}_{2}=3,0 \mathrm{~Hz}\right) ; 6,16\left(\mathrm{dd} ; 1 \mathrm{H}, \mathrm{J}_{1}=5,6 \mathrm{~Hz}, \mathrm{~J}_{2}=2,7 \mathrm{~Hz}\right) ; 6,19(\mathrm{~s} ; 1 \mathrm{H})$, $7,43(\mathrm{sl}, \mathrm{OH})$.

$\mathrm{RMN}-{ }^{13} \mathrm{C}\left(\mathrm{CDCl}_{3}, 100 \mathrm{MHz}\right) \delta(\mathrm{ppm}): 20,6\left(\mathrm{CH}_{3}\right) ; 48,0\left(\mathrm{CH}_{2}\right) ; 49,0(\mathrm{CH}) ; 52,9(\mathrm{CH})$; 56,1(CH); 85,0(C); 115,0 (CH); 133,6 (CH); 137,8 (CH); 159,0 (C); 170,6 (C=O); 194,3 $(\mathrm{C}=\mathrm{O}) ; 194,5(\mathrm{C}=\mathrm{O})$.

IR $v_{\text {máx }}(\mathrm{KBr}): 729 \mathrm{~cm}^{-1} ; 1032 \mathrm{~cm}^{-1} ; 1231 \mathrm{~cm}^{-1} ; 1374 \mathrm{~cm}^{-1} ; 1659 \mathrm{~cm}^{-1} ; 1688 \mathrm{~cm}^{-1} ; 1739$ $\mathrm{cm}^{-1} ; 2839-3670 \mathrm{~cm}^{-1}$.

MS m/z (intensidade relativa): 206 (55,8\%), 150(36,7\%), 69 (42,5\%), 66 (35\%), 43 $(100 \%)$. 
7.17 - Preparação da ciclo-hepta-2,4,6-trien-1-ona (139). ${ }^{83}$

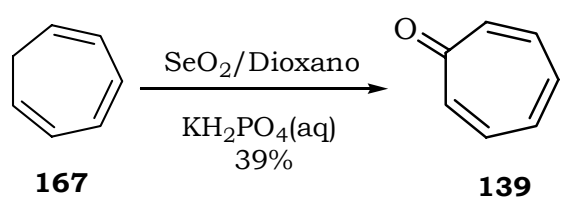

Procedimento: A uma solução contendo $95 \mathrm{~mL}$ de 1,4-dioxano, 14,0 mL de 1,3,5cicloeptatrieno 97\% (12,1 g, $131 \mathrm{mmol})$, uma mistura de 3,80 g de $\mathrm{KH}_{2} \mathrm{PO}_{4} /$ 9,3 g de $\mathrm{H}_{2} \mathrm{O}$ e $10 \mathrm{mg}$ de hidroquinona foram adicionados 15,15 g (133,8 mmol) de $\mathrm{SeO}_{2}$ (98\%). A mistura foi agitada fortemente e aquecida a $90^{\circ} \mathrm{C}$ por 15 horas. Ao final das 15 horas o aquecimento foi interrompido e $300 \mathrm{~mL}$ de $\mathrm{H}_{2} \mathrm{O}$ destilada foram adicionados ao meio reacional filtrando-se em seguida a vácuo. $\mathrm{O}$ filtrado foi então extraído com 4 porções de $100 \mathrm{~mL}$ de $\mathrm{CH}_{2} \mathrm{Cl}_{2}$. As fases orgânicas foram reunidas e lavadas com 3 porções de $50 \mathrm{~mL}$ de solução saturada de $\mathrm{NaHCO}_{3}$. Por fim a fase orgânica foi secada com $\mathrm{MgSO}_{4}$ anidro e o solvente foi removido sob pressão reduzida. Foi obtido um resíduo escuro que foi destilado em sistema de destilação curta (short-path) a $0,5 \mathrm{mmHg}$ e $90^{\circ} \mathrm{C}$, obtendo-se um líquido amarelo e viscoso.

Rendimento: 5,43 g (51,2 mmols) - 39\%

$\mathrm{RMN}-{ }^{1} \mathrm{H}\left(\mathrm{CDCl}_{3}, 300 \mathrm{MHz}\right), \delta$ (ppm): 6,95-7,20 (m, 6H).

$\mathrm{RMN}-{ }^{13} \mathrm{C}\left(\mathrm{CDCl}_{3}, 75 \mathrm{MHz}\right) \delta(\mathrm{ppm}): 134,9(\mathrm{CH}) ; 136,8(\mathrm{CH}) ; 142,2(\mathrm{CH}) ; 188,3$ $(\mathrm{C}=\mathrm{O})$. 
7.18 - Preparação da $(1 S, 2 R, 5 R, 6 S)$-triciclo[4.4.1.1 $\left.1^{2,5}\right]$ dodeca-3,7,9-trien-11-ona $(140){ }^{82}$

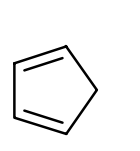

43<smiles></smiles>

139

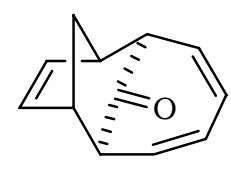

140

Procedimento: A uma solução, sob atmosfera inerte de $\mathrm{N}_{2}$, contendo 5,35 g (50,4 mmol) de tropona (139) e $20 \mathrm{~mL}$ de benzeno seco, foram misturados 6,70 g (101 mmol) de ciclopentadieno (43) recém destilado, aquecendo-se a $90^{\circ} \mathrm{C}$ por 15 horas. Após este tempo mais um equivalente de ciclopentadieno (43) (3,35 g, 50,4 mmol) foi adicionado deixando reagir por mais 4 horas nesta mesma temperatura. Em seguida, o solvente e boa parte do ciclopentadieno em excesso foram removidos sob pressão reduzida e o resíduo foi purificado por cromatografia em coluna de sílica "flash" (200-400 mesh), utilizandose como eluente uma mistura de hexano/acetato de etila 9:1. Obteve-se um sólido branco.

Rendimento: $7,28 \mathrm{~g}(42,3 \mathrm{mmols})-84 \%$

Ponto de fusão: $72-73^{\circ} \mathrm{C}$.

$\mathrm{RMN}-{ }^{1} \mathrm{H},\left(\mathrm{CDCl}_{3}, 500 \mathrm{MHz}\right), \delta(\mathrm{ppm}): 1,53\left(\mathrm{dtt}, 1 \mathrm{H}, \mathrm{J}_{1}=11,5 \mathrm{~Hz} ; \mathrm{J}_{2}=\mathrm{J}_{3}=4,9 \mathrm{~Hz} ; \mathrm{J}_{4}=\mathrm{J}_{5}\right.$ $=1,3 \mathrm{~Hz}) ; 2,29\left(\mathrm{dqt}, 1 \mathrm{H}, \mathrm{J}_{1}=11,5 \mathrm{~Hz} ; \mathrm{J}_{2}=\mathrm{J}_{3}=\mathrm{J}_{4}=\mathrm{J}_{5}=0,9 \mathrm{~Hz}\right.$ ); 3,05 (dddd, $2 \mathrm{H}, \mathrm{J}_{1}=4,9$; $\left.\mathrm{J}_{2}=3,3 ; \mathrm{J}_{4}=2,2 ; \mathrm{J}_{5}=0,9 \mathrm{~Hz}\right) ; 3,24\left(\mathrm{ddt}, 2 \mathrm{H}, \mathrm{J}_{1}=7,0 ; \mathrm{J}_{2}=2,2 ; \mathrm{J}_{3}=\mathrm{J}_{4}=0,9\right) ; 5,69(\mathrm{ddd}, 2 \mathrm{H}$, $\left.\mathrm{J}_{1}=9,1 \mathrm{~Hz}, \mathrm{~J}_{2}=7,0 \mathrm{~Hz}, \mathrm{~J}_{3}=3,0 \mathrm{~Hz}\right) ; 5,98-6,05(\mathrm{~m}, 4 \mathrm{H})$.

RMN- ${ }^{13} \mathrm{C},\left(\mathrm{CDCl}_{3}, 100 \mathrm{MHz}\right) \delta(\mathrm{ppm}): 33,2\left(\mathrm{CH}_{2}\right) ; 48,6(\mathrm{CH}) ; 57,9(\mathrm{CH}) ; 126,9(\mathrm{CH})$; $128,3(\mathrm{CH}) ; 135,5(\mathrm{CH}) ; 208,8(\mathrm{C}=\mathrm{O})$.

IR $v_{\text {máx. }}(\mathrm{KBr}): 732 \mathrm{~cm}^{-1}, 1684 \mathrm{~cm}^{-1}, 1711 \mathrm{~cm}^{-1}, 2935 \mathrm{~cm}^{-1}, 3024 \mathrm{~cm}^{-1}, 3406 \mathrm{~cm}^{-1}$.

MS m/z (intensidade relativa): $172\left[\mathrm{M}^{+}\right]$(5,3\%), 128 (6,2\%), 107 (100\%), 79 (8,4\%), 77 (19,2), 66 (48,0\%), $51(19,8 \%) 39$ (41,3\%).

Análise Elementar: calc. para $\mathrm{C}_{12} \mathrm{H}_{12} \mathrm{O}, \mathrm{C}: 83,69, \mathrm{H}: 7,02$; experimental: C: $83,81, \mathrm{H}$ : 6,90 . 
7.19 - Preparação da oxima da $( \pm)-(1 S, 2 R, 5 R, 6 S)$-triciclo[4.4.1.1 $\left.1^{2,5}\right]$ dodeca-3,7,9trien-11-ona (141) - Método $1 .^{84}$

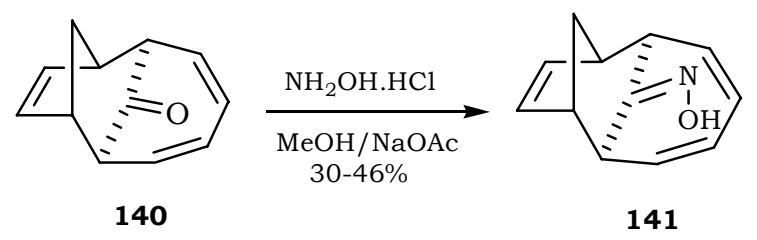

Procedimento: A uma solução contendo 5,02 g (29,1 mmol) da cetona 140 e $150 \mathrm{~mL}$ de metanol, adicionou-se $\mathrm{NaOAc}(1,43 \mathrm{~g}, 17,4 \mathrm{mmol})$ e $\mathrm{NH}_{2} \mathrm{OH} . \mathrm{HCl}(10,10 \mathrm{~g}, 145$ mmols). A mistura ficou sob agitação magnética por 3 dias observando-se a formação de produtos, mas não o consumo total do material de partida 140. À mistura reacional adicionou-se um excesso de 4,03 g (58,2 mmol) de $\mathrm{NH}_{2} \mathrm{OH} . \mathrm{HCl}$ aquecendo-se a refluxo por 12 horas. Ainda assim, o composto 140 não foi totalmente consumido. A reação foi interrompida cessando o aquecimento e evaporando-se a maior parte do solvente. Em seguida adicionou-se $120 \mathrm{~mL}$ de $\mathrm{H}_{2} \mathrm{O}$ destilada e extraiu-se com acetato de etila (4 vezes de 100 $\mathrm{mL}$ ). As fases orgânicas foram reunidas e lavada com uma porção de $50 \mathrm{~mL}$ de solução saturada de $\mathrm{NaCl}$ e depois secada com $\mathrm{MgSO}_{4}$. O solvente foi removido sob pressão reduzida e as substâncias 140 e 141 foram separadas por cromatografia em coluna de sílica, utilizando-se como eluente uma mistura de hexano/acetato de etila (8:2).

Rendimento: composto 141 - 1,63 g (8,73 mmols) - 30\%

Composto 140 (recuperado) - 3,03 g.

Ponto de fusão: $125-165^{\circ} \mathrm{C}(\mathrm{O}$ produto se decompõe nesta faixa de temperatura)

$\mathrm{RMN}-{ }^{1} \mathrm{H}\left(\mathrm{CDCl}_{3}, 500 \mathrm{MHz}\right), \delta(\mathrm{ppm}): 1,38\left(\mathrm{dtt}, 1 \mathrm{H}, \mathrm{J}_{1}=11,1 \mathrm{~Hz} ; \mathrm{J}_{2}=\mathrm{J}_{3}=5,0 \mathrm{~Hz} ; \mathrm{J}_{4}=\mathrm{J}_{5}\right.$ $=1.0 \mathrm{~Hz}) ; 2,03\left(\mathrm{dqt}, 1 \mathrm{H}, \mathrm{J}_{1}=11,1 \mathrm{~Hz} ; \mathrm{J}_{2}=\mathrm{J}_{3}=\mathrm{J}_{4}=\mathrm{J}_{5}=0,8 \mathrm{~Hz}\right) ; 2,86-2,91(\mathrm{~m}, 1 \mathrm{H}) ; 2,91-$ $2,96(\mathrm{~m}, 1 \mathrm{H}) ; 3,21$ (dddd, $\left.1 \mathrm{H}, \mathrm{J}_{1}=6,6 \mathrm{~Hz} ; \mathrm{J}_{2}=3,8 ; \mathrm{J}_{3}=3,0 ; \mathrm{J}_{4}=0,8 \mathrm{~Hz}\right) ; 4,23\left(\mathrm{ddt}, 1 \mathrm{H}, \mathrm{J}_{1}=\right.$ $\left.8,0 \mathrm{~Hz} ; \mathrm{J}_{2}=\mathrm{J}_{3}=3,0 \mathrm{~Hz} ; \mathrm{J}_{4}=0,8 \mathrm{~Hz}\right) ; 5,85-6,04(\mathrm{~m}, 6 \mathrm{H}) ; 8,10(\mathrm{sl}, 1 \mathrm{H})$.

RMN- ${ }^{13} \mathrm{C}\left(\mathrm{CDCl}_{3}, 100 \mathrm{MHz}\right), \delta(\mathrm{ppm}): 33,8\left(\mathrm{CH}_{2}\right) ; 39,5(\mathrm{CH}) ; 45,7(\mathrm{CH}) ; 47,2(\mathrm{CH})$; 47,7 $(\mathrm{CH}) ; 126,2(\mathrm{CH}) ; 127,5(\mathrm{CH}) ; 131,2(\mathrm{CH}) ; 133,3(\mathrm{CH}) ; 134,9(\mathrm{CH}) ; 135,0(\mathrm{CH})$; $158,7(\mathrm{C}=\mathrm{NOH})$.

IR $v_{\text {máx. }}(\mathrm{KBr}): 732 \mathrm{~cm}^{-1}, 852 \mathrm{~cm}^{-1}, 1346 \mathrm{~cm}^{-1}, 1455 \mathrm{~cm}^{-1}, 1588 \mathrm{~cm}^{-1}, 2933 \mathrm{~cm}^{-1}, 3267$ $\mathrm{cm}^{-1}$.

MS m/z (intensidade relativa): $187\left[\mathrm{M}^{+}\right]$(6,3\%), $170\left[\mathrm{M}^{+}-\mathrm{OH}\right](24 \%), 121(93,4 \%), 104$ (12\%), 91 (14,8\%), 78 (100\%), 66 (14,1\%), 39 (24,5\%).

Análise Elementar: calc. para $\mathrm{C}_{12} \mathrm{H}_{13} \mathrm{NO}, \mathrm{C}: 76,98, \mathrm{H}: 7,00 ; \mathrm{N}: 7,48$ experimental: C: 77,40, H: 7,15, N: 7,59. 
7.20 - Preparação da oxima da $( \pm)-(1 S, 2 R, 5 R, 6 S)$-triciclo[4.4.1.1 $\left.1^{2,5}\right]$ dodeca-3,7,9trien-11-ona (141) - Método $2 .^{85}$

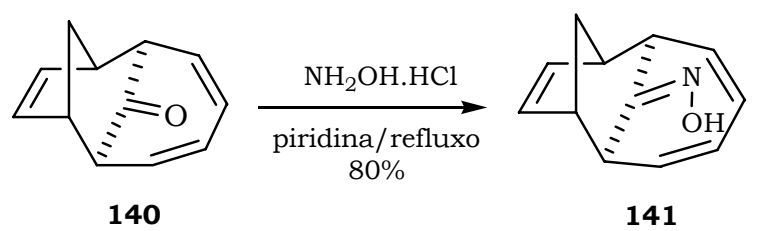

Procedimento: Foram misturados 4,86 g (69,3 mmol) de $\mathrm{NH}_{2} \mathrm{OH} . \mathrm{HCl}(96 \%)$ e $25 \mathrm{~mL}$ de piridina deixando sob agitação e a temperatura ambiente por 10 minutos. Em seguida adicionou-se 3,0 g (17,4 mmol) da cetona 140 deixando reagir por 3 horas a refluxo. A piridina foi então destilada e ao resíduo adicionou-se $150 \mathrm{~mL}$ de $\mathrm{CH}_{2} \mathrm{Cl}_{2}$, lavando em seguida com 2 porções de $50 \mathrm{~mL}$ de $\mathrm{H}_{2} \mathrm{O}$. A fase orgânica foi secada com $\mathrm{MgSO}_{4}$ e o solvente foi removido sob pressão reduzida. O resíduo obtido foi purificado por cromatografia em coluna de sílica "flash" (200-400 mesh), utilizando-se como eluente uma mistura de hexano/acetato de etila 8:2.

Rendimento: $2,62 \mathrm{~g}(14,0$ mmols $)-80 \%$

Ponto de fusão: $125-165^{\circ} \mathrm{C}(\mathrm{O}$ produto se decompõe nesta faixa de temperatura)

$\mathrm{RMN}-{ }^{1} \mathrm{H}\left(\mathrm{CDCl}_{3}, 500 \mathrm{MHz}\right), \delta(\mathrm{ppm}): 1,38\left(\mathrm{dtt}, 1 \mathrm{H}, \mathrm{J}_{1}=11,1 \mathrm{~Hz} ; \mathrm{J}_{2}=\mathrm{J}_{3}=5,0 \mathrm{~Hz} ; \mathrm{J}_{4}=\mathrm{J}_{5}\right.$ $=1.0 \mathrm{~Hz}) ; 2,03\left(\mathrm{dqt}, 1 \mathrm{H}, \mathrm{J}_{1}=11,1 \mathrm{~Hz} ; \mathrm{J}_{2}=\mathrm{J}_{3}=\mathrm{J}_{4}=\mathrm{J}_{5}=0,8 \mathrm{~Hz}\right) ; 2,86-2,91(\mathrm{~m}, 1 \mathrm{H}) ; 2,91-$ $2,96(\mathrm{~m}, 1 \mathrm{H}) ; 3,21\left(\mathrm{dddd}, 1 \mathrm{H}, \mathrm{J}_{1}=6,6 \mathrm{~Hz} ; \mathrm{J}_{2}=3,8 ; \mathrm{J}_{3}=3,0 ; \mathrm{J}_{4}=0,8 \mathrm{~Hz}\right) ; 4,23$ (ddt, $1 \mathrm{H}, \mathrm{J}_{1}=$ $\left.8,0 \mathrm{~Hz} ; \mathrm{J}_{2}=\mathrm{J}_{3}=3,0 \mathrm{~Hz} ; \mathrm{J}_{4}=0,8 \mathrm{~Hz}\right) ; 5,85-6,04(\mathrm{~m}, 6 \mathrm{H}) ; 8,10(\mathrm{sl}, 1 \mathrm{H})$.

RMN- ${ }^{13} \mathrm{C}\left(\mathrm{CDCl}_{3}, 100 \mathrm{MHz}\right), \delta(\mathrm{ppm}): 33,8\left(\mathrm{CH}_{2}\right) ; 39,5(\mathrm{CH}) ; 45,7(\mathrm{CH}) ; 47,2(\mathrm{CH})$; 47,7 (CH); 126,2 (CH); 127,5 (CH); 131,2 (CH); 133,3 (CH); 134,9(CH); 135,0 (CH); $158,7(\mathrm{C}=\mathrm{NOH})$.

IR $v_{\text {máx. }}(\mathrm{KBr}): 732 \mathrm{~cm}^{-1}, 852 \mathrm{~cm}^{-1}, 1346 \mathrm{~cm}^{-1}, 1455 \mathrm{~cm}^{-1}, 1588 \mathrm{~cm}^{-1}, 2933 \mathrm{~cm}^{-1}, 3267$ $\mathrm{cm}^{-1}$.

MS m/z (intensidade relativa): $187\left[\mathrm{M}^{+}\right]$(6,3\%), $170\left[\mathrm{M}^{+}-\mathrm{OH}\right](24 \%), 121$ (93,4\%), 104 (12\%), 91 (14,8\%), 78 (100\%), 66 (14,1\%), 39 (24,5\%).

Análise Elementar: calc. para $\mathrm{C}_{12} \mathrm{H}_{13} \mathrm{NO}, \mathrm{C}: 76,98, \mathrm{H}: 7,00 ; \mathrm{N}: 7,48$ experimental: C: $77,40, \mathrm{H}: 7,15, \mathrm{~N}: 7,59$. 
7.21 - Preparação da $( \pm)-(1 S, 2 R, 5 R, 6 S, 7 Z, 9 Z)-11$-azatriciclo[4.4.2.1 $\left.{ }^{2,5}\right]$ trideca-3,7,9trien-12-ona (142). ${ }^{86}$

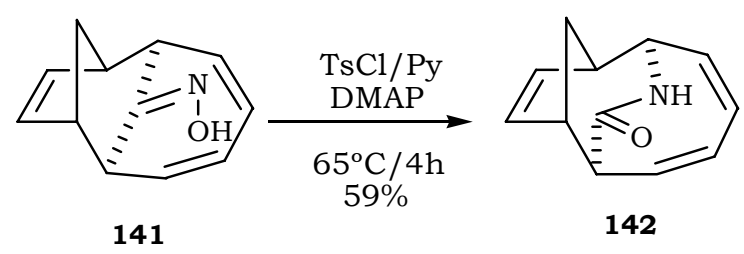

Procedimento: A uma solução contendo 1,0 g (5,3 mmol) da oxima $141 \mathrm{em} 30 \mathrm{~mL}$ de piridina foram adicionados 2,60 $\mathrm{g}(13,4 \mathrm{mmol}) \mathrm{de} \mathrm{TsCl}$ (recristalizado) e $10 \mathrm{mg}$ de DMAP, deixando agitar à temperatura ambiente por 30 minutos. Em seguida a mistura por aquecida a $65^{\circ} \mathrm{C}$ por 3,5 horas. A piridina foi destilada a vácuo e ao meio reacional foram adicionados $50 \mathrm{~mL}$ de $\mathrm{H}_{2} \mathrm{O}$. O resíduo foi extraído com de AcOEt (3 porções de $50 \mathrm{~mL}$ ) e as fases orgânicas foram reunidas e secadas com $\mathrm{MgSO}_{4}$ anidro. O resíduo foi purificado por cromatografia em uma coluna de sílica "flash" (200-400 mesh), utilizando-se como eluente uma mistura de hexano/acetato de etila - gradiente de concentração 3:7, 2:8.

Rendimento: $590 \mathrm{mg}(3,15 \mathrm{mmol})-59 \%$

Ponto de fusão: $161-162{ }^{\circ} \mathrm{C}$.

$\mathrm{RMN}-{ }^{1} \mathrm{H}\left(\mathrm{CDCl}_{3}, 500 \mathrm{MHz}\right), \delta(\mathrm{ppm}): 1,60\left(\mathrm{ddt}, 1 \mathrm{H}, \mathrm{J}_{1}=12,1 \mathrm{~Hz} ; \mathrm{J}_{2}=\mathrm{J}_{3}=6,3 \mathrm{~Hz} ; \mathrm{J}_{4}=\right.$ $1,9 \mathrm{~Hz}) ; 2,25\left(\mathrm{dtt}, 1 \mathrm{H}, \mathrm{J}_{1}=12,1 \mathrm{~Hz} ; \mathrm{J}_{2}=\mathrm{J}_{3}=1,5 \mathrm{~Hz} ; \mathrm{J}_{4}=\mathrm{J}_{5}=0,7 \mathrm{~Hz}\right.$ ); 2,99 (ddt, $2 \mathrm{H}, \mathrm{J}_{1}=\mathrm{J}_{2}$ $=6,3 \mathrm{~Hz} ; \mathrm{J}_{3}=2,9 \mathrm{~Hz} ; \mathrm{J}_{4}=1,5 \mathrm{~Hz}$ ); 3,64 (dddd, $1 \mathrm{H}, \mathrm{J}_{1}=9,6 \mathrm{~Hz} ; \mathrm{J}_{2}=6,3 \mathrm{~Hz} ; \mathrm{J}_{3}=1,9 \mathrm{~Hz} ; \mathrm{J}_{4}=$ $1,0 \mathrm{~Hz}) ; 3,81\left(\mathrm{dt}, \mathrm{J}_{1}=7,8 \mathrm{~Hz} ; \mathrm{J}_{2}=\mathrm{J}_{3}=6,3 \mathrm{~Hz}\right) ; 5,81\left(\mathrm{ddd}, 1 \mathrm{H}, \mathrm{J}_{1}=5,9 \mathrm{~Hz} ; \mathrm{J}_{2}=2,9 \mathrm{~Hz}, \mathrm{~J}_{3}=\right.$ $0,7 \mathrm{~Hz}) ; 5,95-6,09(\mathrm{~m}, 4 \mathrm{H}) ; 6,10\left(\mathrm{dd}, 1 \mathrm{H}, \mathrm{J}_{1}=5,9 \mathrm{~Hz} ; \mathrm{J}_{2}=2,9 \mathrm{~Hz} ; \mathrm{J}_{3}=0,7 \mathrm{~Hz}\right) ; 6,27(\mathrm{sl}$, $1 \mathrm{H})$.

RMN- ${ }^{13} \mathrm{C}\left(\mathrm{CDCl}_{3}, 100 \mathrm{MHz}\right) \delta(\mathrm{ppm}): 33,9\left(\mathrm{CH}_{2}\right) ; 45,5(\mathrm{CH}) ; 47,9(\mathrm{CH}) ; 50,7(\mathrm{CH})$; 53,8 $(\mathrm{CH}) ; 127,4(\mathrm{CH}) ; 128,3(\mathrm{CH}) ; 132,9(\mathrm{CH}) ; 133,5(\mathrm{CH}) ; 135,5(\mathrm{CH}) ; 137,5(\mathrm{CH}) ;$ $174,4(\mathrm{C}=\mathrm{O})$.

IR $v_{\text {máx. }}(\mathrm{KBr}): 715 \mathrm{~cm}^{-1}, 1652 \mathrm{~cm}^{-1}, 2917 \mathrm{~cm}^{-1}, 3191 \mathrm{~cm}^{-1}$.

MS m/z (intensidade relativa): $187\left[\mathrm{M}^{+}\right]$(7.5\%), 93 (25.7\%), 86 (46.5\%), 84 (69.1\%), 67 (25.3\%), 51 (34.4\%), 49 (100\%), 35 (15.7\%). 
7.22 - Preparação da $( \pm)-(1 S, 2 R, 5 R, 6 S, 7 Z, 9 Z)-11-[(4-m e t i l f e n i l) s u l f o n i l]-11-$ azatriciclo[4.4.2.1 $\left.1^{2,5}\right]$ trideca-3,7,9-trien-12-ona $(170){ }^{89}$

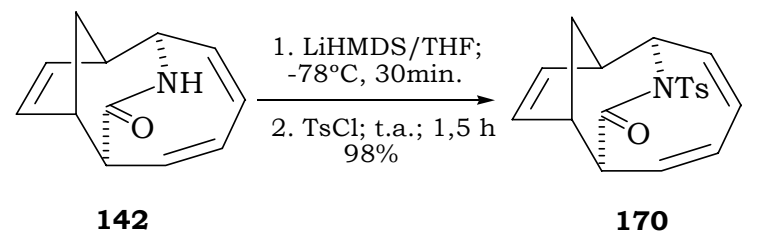

Procedimento: A uma solução contendo $6,0 \mathrm{~mL}$ de THF anidro e 1,03 mL (4,73 mmol) de HMDS (hexametildisilazano), sob atmosfera de $\mathrm{N}_{2}$, foram adicionados 2,0 $\mathrm{mL}(3,66$ mmol) de uma solução de $\mathrm{n}-\mathrm{BuLi}$, a $25^{\circ} \mathrm{C}$. Em seguida a mistura foi refluxada por 30 minutos e então resfriada até $-78^{\circ} \mathrm{C}$. Adicionou-se a esta mistura refrigerada uma solução contendo $500 \mathrm{mg}(2,67 \mathrm{mmol})$ da lactama $142 \mathrm{em} \mathrm{3,0} \mathrm{mL} \mathrm{de} \mathrm{THF} \mathrm{anidro,} \mathrm{deixando}$ reagir por 1,0 hora nesta temperatura. Após este tempo foram adicionados $935 \mathrm{mg}(4,80$ $\mathrm{mmol}$ ) de $\mathrm{TsCl}$ deixando a temperatura do sistema reacional chegar até a ambiente. Após 1,5 horas de agitação $\left(\mathrm{a} 25^{\circ} \mathrm{C}\right)$ adicionou-se $30 \mathrm{~mL}$ de uma solução saturada de $\mathrm{NH}_{4} \mathrm{Cl}$ extraindo a fase aquosa com éter etílico $(5$ porções de $60 \mathrm{~mL}$ ). As fases orgânicas foram reunidas e lavadas uma vez com solução saturada de $\mathrm{NaCl}$ e em seguida secadas com $\mathrm{MgSO}_{4}$ anidro. $\mathrm{O}$ solvente foi removido sob pressão reduzida e o resíduo obtido foi purificado por cromatografia em uma coluna de sílica "flash" (200-400 mesh), utilizando-se como eluente uma mistura de hexano/acetato de etila - 8:2.

Rendimento: $895 \mathrm{mg}(2,62 \mathrm{mmol})-98 \%$

Ponto de fusão: $214-215^{\circ} \mathrm{C}$.

$\mathrm{RMN}-{ }^{1} \mathrm{H}\left(\mathrm{CDCl}_{3}, 500 \mathrm{MHz}\right), \delta(\mathrm{ppm}): 1,63\left(\mathrm{dddd}, 1 \mathrm{H}, \mathrm{J}_{1}=12,3 \mathrm{~Hz} ; \mathrm{J}_{2}=6,9 \mathrm{~Hz} ; \mathrm{J}_{3}=5,8\right.$ $\left.\mathrm{Hz} ; \mathrm{J}_{4}=1,7 \mathrm{~Hz}\right) ; 2,23\left(\mathrm{dt}, 1 \mathrm{H}, \mathrm{J}_{1}=12,3 \mathrm{~Hz} ; \mathrm{J}_{2}=\mathrm{J}_{3}=1,6 \mathrm{~Hz}\right) ; 2,38(\mathrm{~s}, 3 \mathrm{H}) ; 3,00(\mathrm{ddd}, 1 \mathrm{H}$, $\left.\mathrm{J}_{1}=7,1 \mathrm{~Hz} ; \mathrm{J}_{2}=5,8 \mathrm{~Hz} ; \mathrm{J}_{3}=2,9 \mathrm{~Hz}\right) ; 3,28\left(\mathrm{dt}, 1 \mathrm{H}, \mathrm{J}_{1}=\mathrm{J}_{2}=6,9 \mathrm{~Hz} ; \mathrm{J}_{3}=3,0 \mathrm{~Hz}\right) ; 3,68$ $\left(\mathrm{ddd}, 1 \mathrm{H}, \mathrm{J}_{1}=10,3 \mathrm{~Hz} ; \mathrm{J}_{2}=7,1 \mathrm{~Hz}, \mathrm{~J}_{3}=1,7 \mathrm{~Hz}\right) ; 5,41\left(\mathrm{dd}, 1 \mathrm{H}, \mathrm{J}_{1}=8,3 \mathrm{~Hz} ; \mathrm{J}_{2}=6,9 \mathrm{~Hz}\right)$; 5,79 (dddd, $\left.1 \mathrm{H}, \mathrm{J}_{1}=13,0 \mathrm{~Hz} ; \mathrm{J}_{2}=10,3 \mathrm{~Hz} ; \mathrm{J}_{3}=1,7 \mathrm{~Hz}, \mathrm{~J}_{4}=0,7 \mathrm{~Hz}\right) ; 5,83\left(\mathrm{ddd}, 1 \mathrm{H}, \mathrm{J}_{1}=\right.$ $\left.5,7 \mathrm{~Hz} ; \mathrm{J}_{2}=3,0 \mathrm{~Hz}, \mathrm{~J}_{3}=1,6 \mathrm{~Hz}\right) ; 6,03\left(\mathrm{ddd}, 1 \mathrm{H}, \mathrm{J}_{1}=13,0 \mathrm{~Hz}, \mathrm{~J}_{2}=8,7 \mathrm{~Hz} ; \mathrm{J}_{3}=0,8 \mathrm{~Hz}\right) ; 6,07$ (ddd, $\left.1 \mathrm{H}, \mathrm{J}_{1}=5,7 \mathrm{~Hz} ; \mathrm{J}_{2}=2,9 \mathrm{~Hz} ; \mathrm{J}_{3}=1,6 \mathrm{~Hz}\right) ; 6,16\left(\mathrm{ddd}, 1 \mathrm{H}, \mathrm{J}_{1}=12,6 \mathrm{~Hz} ; \mathrm{J}_{2}=8,7 \mathrm{~Hz} ; \mathrm{J}_{3}\right.$ $=0,7 \mathrm{~Hz}) ; 6,26\left(\mathrm{dddd}, 1 \mathrm{H}, \mathrm{J}_{1}=12,6 \mathrm{~Hz}, \mathrm{~J}_{2}=8,3 \mathrm{~Hz}, \mathrm{~J}_{3}=1,7 \mathrm{~Hz}, \mathrm{~J}_{4}=0,8 \mathrm{~Hz}\right) ; 7,23(\mathrm{~d}, 2 \mathrm{H}$, $\mathrm{J}=8,1 \mathrm{~Hz}) ; 7,71(\mathrm{~d}, 2 \mathrm{H}, \mathrm{J}=8,1 \mathrm{~Hz})$.

$\mathrm{RMN}-{ }^{13} \mathrm{C}\left(\mathrm{CDCl}_{3}, 100 \mathrm{MHz}\right) \delta(\mathrm{ppm}): 21,6\left(\mathrm{CH}_{3}\right) ; 33,2\left(\mathrm{CH}_{2}\right) ; 45,2(\mathrm{CH}) ; 47,2(\mathrm{CH})$; 52,6 $(\mathrm{CH}) ; 55,3(\mathrm{CH}) ; 128,2(\mathrm{CH}) ; 128,4(\mathrm{CH}) ; 128,6(\mathrm{CH}) ; 128,9(\mathrm{CH}) ; 130,9(\mathrm{CH})$; $132,0(\mathrm{CH}) ; 136,0(\mathrm{CH}) ; 136,1(\mathrm{CH}) ; 136,4(\mathrm{CH}) ; 144,0(\mathrm{CH}) ; 171,2(\mathrm{C}=\mathrm{O})$.

IR $v_{\text {máx. }}(\mathrm{KBr}): 547 \mathrm{~cm}^{-1}, 598 \mathrm{~cm}^{-1}, 687 \mathrm{~cm}^{-1}, 1162 \mathrm{~cm}^{-1}, 1675 \mathrm{~cm}^{-1}, 2993 \mathrm{~cm}^{-1}, 3009 \mathrm{~cm}^{-1}$, $3358 \mathrm{~cm}^{-1}$.

MS m/z (intensidade relativa): $186\left[\mathrm{M}^{+}-\mathrm{Ts}\right]$ (54,7\%), 155 (21,3\%), 120 (49,6\%), 91 (100 \%), 66 (47,9\%), 65 (92\%), 39 (68,6\%). 
7.23 - Preparação da $( \pm)-N-[(1 S, 2 R, 3 Z, 5 Z, 7 S, 8 R)$-7-(hidroximetil)biciclo[6.2.1]undeca3,5,9-trien-2-ilo]-4-metilbenzenosulfonamida (171). ${ }^{90}$

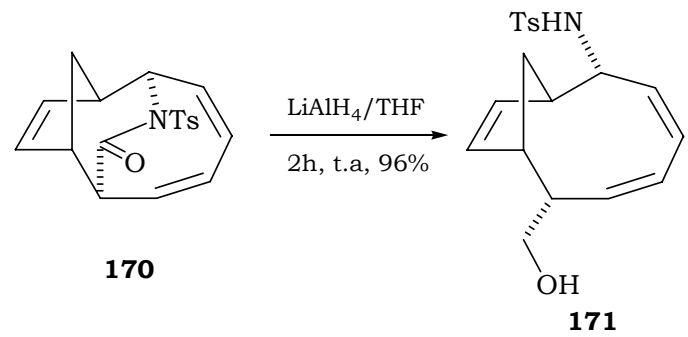

Procedimento: A uma suspensão contendo $10 \mathrm{~mL}$ de THF anidro e $253 \mathrm{mg}$ (6,33 mmol) de $\mathrm{LiAlH}_{4}$ 95\%, sob atmosfera inerte de $\mathrm{N}_{2}$, foi adicionada uma mistura contendo $1,08 \mathrm{~g}$ (3,16 mmol) da lactama tosilada 170 dissolvida em $20 \mathrm{~mL}$ de THF anidro. A adição foi efetuada de maneira lenta e a temperatura ambiente. Após 2 horas de reação o sistema foi resfriado a $0^{\circ} \mathrm{C}$ e adicionou-se lentamente uma solução saturada de $\mathrm{Na}_{2} \mathrm{SO}_{4}$ (aproximadamente $30 \mathrm{~mL}$ ). A mistura foi extraída com 3 porções de $60 \mathrm{~mL}$ de $\mathrm{CHCl}_{3} \mathrm{e}$ as fases orgânicas foram reunidas e secadas com $\mathrm{MgSO}_{4}$ anidro. $\mathrm{O}$ solvente foi removido sob pressão reduzida e o resíduo foi purificado por cromatografia em uma coluna de sílica "flash" (200-400 mesh), utilizando-se como eluente uma mistura de hexano/acetato de etila $1: 1$.

Rendimento: $1,05 \mathrm{~g}(3,04 \mathrm{mmol}) 96 \%$

RMN- ${ }^{1} \mathrm{H}\left(\mathrm{CDCl}_{3}, 500 \mathrm{MHz}\right), \delta(\mathrm{ppm}): 1,74\left(\mathrm{ddd}, 1 \mathrm{H}, \mathrm{J}_{1}=13,9 \mathrm{~Hz} ; \mathrm{J}_{2}=1,0 \mathrm{~Hz} ; \mathrm{J}_{3}=0,8\right.$ $\mathrm{Hz}) ; 1,80(\mathrm{sl}, 1 \mathrm{H}) ; 2,06\left(\mathrm{dt}, 1 \mathrm{H}, \mathrm{J}_{1}=13,9 ; \mathrm{J}_{2}=\mathrm{J}_{3}=9,5 \mathrm{~Hz}\right) ; 2,29\left(\mathrm{dddt}, 1 \mathrm{H}, \mathrm{J}_{1}=8,8 \mathrm{~Hz}\right.$, $\left.\mathrm{J}_{2}=\mathrm{J}_{3}=7,1 \mathrm{~Hz}, \mathrm{~J}_{4}=2,5 \mathrm{~Hz} ; \mathrm{J}_{5}=0,9 \mathrm{~Hz}\right) ; 2,41(\mathrm{~s}, 3 \mathrm{H}) ; 2,73\left(\mathrm{dddd}, 1 \mathrm{H}, \mathrm{J}_{1}=9,5 \mathrm{~Hz} ; \mathrm{J}_{2}=3,2\right.$ $\left.\mathrm{Hz} ; \mathrm{J}_{3}=2,5 \mathrm{~Hz} ; \mathrm{J}_{4}=1,0 \mathrm{~Hz}\right) ; 3,17\left(\mathrm{tddd}, 1 \mathrm{H}, \mathrm{J}_{1}=\mathrm{J}_{2}=9,5 \mathrm{~Hz} ; \mathrm{J}_{3}=3,0 \mathrm{~Hz} ; \mathrm{J}_{4}=1,3 \mathrm{~Hz} ; \mathrm{J}_{5}=\right.$ $0,8 \mathrm{~Hz}) ; 3,56(\mathrm{~d}, 2 \mathrm{H}, \mathrm{J}=7,1 \mathrm{~Hz}) ; 4,19\left(\mathrm{dt}, 1 \mathrm{H}, \mathrm{J}_{1}=\mathrm{J}_{2}=9,5 ; \mathrm{J}_{3}=8,1 \mathrm{~Hz}\right) ; 4,89(\mathrm{~d}, 1 \mathrm{H}, \mathrm{J}=$ 9,5 Hz); 5,32 (dddd, $1 \mathrm{H}, \mathrm{J}_{1}=11,3 \mathrm{~Hz} ; \mathrm{J}_{2}=8,8 \mathrm{~Hz} ; \mathrm{J}_{3}=2,0 \mathrm{~Hz} ; \mathrm{J}_{4}=0,8 \mathrm{~Hz}$ ); 5,53 (dddd, $1 \mathrm{H}, \mathrm{J}_{1}=11,6 \mathrm{~Hz} ; \mathrm{J}_{2}=8,1 \mathrm{~Hz} ; \mathrm{J}_{3}=1,8 \mathrm{~Hz} ; \mathrm{J}_{4}=0,8 \mathrm{~Hz}$ ); 5,66 (dddt, $1 \mathrm{H}, \mathrm{J}_{1}=5,5 \mathrm{~Hz} ; \mathrm{J}_{2}=3,0$ $\left.\mathrm{Hz} ; \mathrm{J}_{3}=2,0 \mathrm{~Hz}, \mathrm{~J}_{4}=0,8 \mathrm{~Hz}\right) ; 5,76\left(\mathrm{ddd}, 1 \mathrm{H}, \mathrm{J}_{1}=5,5 \mathrm{~Hz}, \mathrm{~J}_{2}=3,2 \mathrm{~Hz} ; \mathrm{J}_{3}=1,3 \mathrm{~Hz}\right) ; 5,81$ (ddd, $1 \mathrm{H}, \mathrm{J}_{1}=11,6 \mathrm{~Hz} ; \mathrm{J}_{2}=2,0 \mathrm{~Hz} ; \mathrm{J}_{3}=1,8 \mathrm{~Hz}$ ); 5,97 (dddd, $1 \mathrm{H}, \mathrm{J}_{1}=11,3 \mathrm{~Hz}, \mathrm{~J}_{2}=2,0 \mathrm{~Hz}$; $\left.\mathrm{J}_{3}=1,8 \mathrm{~Hz} ; \mathrm{J}_{4}=0,9 \mathrm{~Hz}\right) ; 7,26(\mathrm{~d}, 2 \mathrm{H}, \mathrm{J}=8,3 \mathrm{~Hz}) ; 7,70(\mathrm{~d}, 2 \mathrm{H}, \mathrm{J}=8,3 \mathrm{~Hz})$.

RMN- ${ }^{13} \mathrm{C}\left(\mathrm{CDCl}_{3}, 125 \mathrm{MHz}\right) \delta(\mathrm{ppm}): 21,4\left(\mathrm{CH}_{3}\right) ; 34,6\left(\mathrm{CH}_{2}\right) ; 45,0(\mathrm{CH}) ; 46,3(\mathrm{CH})$; 47,2 (CH); 53,2(CH); 66,0 $\left(\mathrm{CH}_{2}\right) ; 127,0(\mathrm{CH}) ; 128,4(\mathrm{CH}) ; 128,7(\mathrm{CH}) ; 129,4(\mathrm{CH})$; 131,6 (CH); 133,6(CH); 134,9 (CH); 135,0(CH); 138,1 (C); 143,1 (C).

IR $v_{\text {máx }} \cdot(\mathrm{KBr}): 680 \mathrm{~cm}^{-1}, 730 \mathrm{~cm}^{-1}, 1154 \mathrm{~cm}^{-1}, 1328 \mathrm{~cm}^{-1}, 2600-3700 \mathrm{~cm}^{-1}$.

MS m/z (intensidade relativa): 279 (34,4\%), 124 (18,9\%), 106 (53\%), 91 (100\%), 80 (69,9\%), 66 (36,1\%), 43 (40,8\%), 39 (32\%). 
7.24 - Preparação do $( \pm)-\{(1 R, 2 S, 3 Z, 5 Z, 7 R, 8 S)-7-[(4-m e t i l b e n z e n o$ sulfonil)amino]biciclo[6.2.1]undeca-3,5,9-trien-2-ilo\}metil metanosulfonato (172). ${ }^{70}$

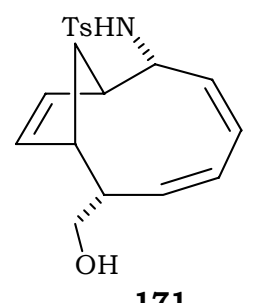

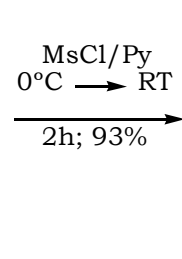

171

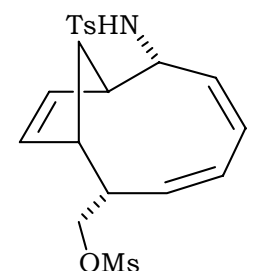

172

Procedimento: A uma solução contendo $675 \mathrm{mg}(1,95 \mathrm{mmol})$ do álcool 171 e 3,5 mL de piridina, sob atmosfera inerte de $\mathrm{N}_{2}$ e a $0^{\circ} \mathrm{C}$, adicionou-se lentamente $0,23 \mathrm{~mL}(2,93$ $\mathrm{mmol}$ ) de $\mathrm{MsCl}$ deixando, em seguida, a temperatura se elevar até a ambiente. Após 2 horas à temperatura ambiente adicionou-se $\mathrm{H}_{2} \mathrm{O}$ ao meio reacional (aproximadamente $20 \mathrm{~mL}$ ) deixando agitar por 15 minutos. A mistura reacional foi extraída com de éter dietílico ( 3 porções de $50 \mathrm{~mL}$ ) e as fases orgânicas foram reunidas e lavadas com 2 porções de $25 \mathrm{~mL}$ de uma solução $10 \%$ de $\mathrm{CuSO}_{4}$. A fase orgânica foi secada com $\mathrm{MgSO}_{4}$ anidro e o solvente removido sob pressão reduzida. O resíduo foi purificado por cromatografia em coluna de sílica "flash" (200-400 mesh), utilizando-se como eluente uma mistura de hexano/acetato de etila 1:1.

Rendimento: $1,22 \mathrm{~g}(2,88 \mathrm{mmol})-93 \%$

$\mathrm{RMN}-{ }^{1} \mathrm{H}\left(\mathrm{CDCl}_{3}, 500 \mathrm{MHz}\right), \delta(\mathrm{ppm}): 1,76\left(\mathrm{dddd}, 1 \mathrm{H}, \mathrm{J}_{1}=13,9 \mathrm{~Hz} ; \mathrm{J}_{2}=1,0 \mathrm{~Hz} ; \mathrm{J}_{3}=1,3\right.$ $\left.\mathrm{Hz} ; \mathrm{J}_{3}=0,5 \mathrm{~Hz}\right) ; 2,09\left(\mathrm{dt}, 1 \mathrm{H}, \mathrm{J}_{1}=13,9 ; \mathrm{J}_{2}=\mathrm{J}_{3}=9,6 \mathrm{~Hz}\right) ; 2,42(\mathrm{~s}, 3 \mathrm{H}) ; 2,57\left(\mathrm{ddt}, 1 \mathrm{H}, \mathrm{J}_{1}=\right.$ $8,9 \mathrm{~Hz}, \mathrm{~J}_{2}=\mathrm{J}_{3}=6,8 \mathrm{~Hz}, \mathrm{~J}_{4}=3,2 \mathrm{~Hz}$ ); 2,78 (dddt, $1 \mathrm{H}, \mathrm{J}_{1}=9,6 \mathrm{~Hz}, \mathrm{~J}_{2}=3,2 \mathrm{~Hz} ; \mathrm{J}_{3}=2,8 \mathrm{~Hz}, \mathrm{~J}_{4}$ $\left.=\mathrm{J}_{5}=1,0 \mathrm{~Hz}\right) ; 3,01(\mathrm{~s}, 3 \mathrm{H}) ; 3,14\left(\mathrm{dddt}, 1 \mathrm{H}, \mathrm{J}_{1}=9,6 \mathrm{~Hz}, \mathrm{~J}_{2}=8,2 \mathrm{~Hz} ; \mathrm{J}_{3}=2,8 \mathrm{~Hz}, \mathrm{~J}_{4}=\mathrm{J}_{5}=1,3\right.$ $\mathrm{Hz}) ; 4,11\left(\mathrm{dd}, 1 \mathrm{H}, \mathrm{J}_{1}=9,3 \mathrm{~Hz} ; \mathrm{J}_{2}=6,8 \mathrm{~Hz}\right) ; 4,14\left(\mathrm{dd}, 1 \mathrm{H}, \mathrm{J}_{1}=9,3 \mathrm{~Hz} ; \mathrm{J}_{2}=6,8 \mathrm{~Hz}\right) ; 4,15$ $\left(\mathrm{dt}, 1 \mathrm{H}, \mathrm{J}_{1}=10,1 \mathrm{~Hz} ; \mathrm{J}_{2}=\mathrm{J}_{3}=8,2 \mathrm{~Hz}\right) ; 4,84(\mathrm{~d}, 1 \mathrm{H}, \mathrm{J}=10,1 \mathrm{~Hz}) ; 5,36\left(\mathrm{ddd}, 1 \mathrm{H}, \mathrm{J}_{1}=11,4\right.$ $\left.\mathrm{Hz} ; \mathrm{J}_{2}=8,9 \mathrm{~Hz} ; \mathrm{J}_{3}=2,1 \mathrm{~Hz}\right) ; 5,50\left(\mathrm{ddd}, 1 \mathrm{H}, \mathrm{J}_{1}=11,6 \mathrm{~Hz} ; \mathrm{J}_{2}=8,2 \mathrm{~Hz} ; \mathrm{J}_{3}=2,1 \mathrm{~Hz}\right) ; 5,71$ (dddd, $1 \mathrm{H}, \mathrm{J}_{1}=6,0 \mathrm{~Hz} ; \mathrm{J}_{2}=2,8 \mathrm{~Hz} ; \mathrm{J}_{3}=1,0 \mathrm{~Hz} ; \mathrm{J}_{4}=0,5 \mathrm{~Hz}$ ); 5,76 (ddd, $1 \mathrm{H}, \mathrm{J}_{1}=6,0 \mathrm{~Hz}, \mathrm{~J}_{2}$ $\left.=2,8 \mathrm{~Hz} ; \mathrm{J}_{3}=1,3 \mathrm{~Hz}\right) ; 5,81\left(\mathrm{dt}, 1 \mathrm{H}, \mathrm{J}_{1}=11,6 \mathrm{~Hz} ; \mathrm{J}_{2}=\mathrm{J}_{3}=2,1 \mathrm{~Hz}\right) ; 6,01\left(\mathrm{dt}, 1 \mathrm{H}, \mathrm{J}_{1}=11,4\right.$ $\left.\mathrm{Hz}, \mathrm{J}_{2}=\mathrm{J}_{3}=2,1 \mathrm{~Hz}\right) ; 7,27(\mathrm{~d}, 2 \mathrm{H}, \mathrm{J}=8,3 \mathrm{~Hz}) ; 7,70(\mathrm{~d}, 2 \mathrm{H}, \mathrm{J}=8,3 \mathrm{~Hz})$.

RMN- ${ }^{13} \mathrm{C}\left(\mathrm{CDCl}_{3}, 125 \mathrm{MHz}\right) \delta(\mathrm{ppm}): 21,4\left(\mathrm{CH}_{3}\right) ; 34,4\left(\mathrm{CH}_{2}\right) ; 37,4\left(\mathrm{CH}_{3}\right) ; 43,4(\mathrm{CH})$; 44,8 $(\mathrm{CH}) ; 46,9(\mathrm{CH}) ; 53,8(\mathrm{CH}) ; 71,7\left(\mathrm{CH}_{2}\right) ; 127,0(\mathrm{CH}) ; 127,8(\mathrm{CH}) ; 129,5(2 \mathrm{CH})$; $132,5(\mathrm{CH}) ; 132,6(\mathrm{CH}) ; 132,8(\mathrm{CH}) ; 135,2(\mathrm{CH}) ; 138,0(\mathrm{C}) ; 143,2(\mathrm{C})$.

IR $v_{\text {máx }}(\mathrm{KBr}): 736 \mathrm{~cm}^{-1}, 1160 \mathrm{~cm}^{-1}, 1335 \mathrm{~cm}^{-1}, 2939 \mathrm{~cm}^{-1}, 3054 \mathrm{~cm}^{-1}, 3284 \mathrm{~cm}^{-1}$

HRMS (ESI-TOF): calc. para $\mathrm{C}_{20} \mathrm{H}_{26} \mathrm{NO}_{5} \mathrm{~S}_{2}{ }^{+}\left(\mathrm{MH}^{+}\right)$, 424,1252; experimental: 424,1319 $(\Delta$ de $16 \mathrm{ppm}$ - limite de $50 \mathrm{ppm}$ ) 
7.25 - Preparação da $( \pm)-4$-metil- $N$-[(1S,2R,3Z,5Z,8R)-7-metilenobiciclo[6.2.1]undeca3,5,9-trien-2-ilo]benzenosulfonamida (173). ${ }^{92}$

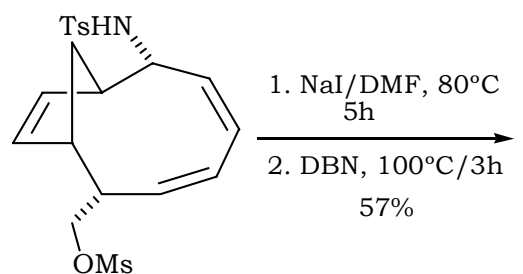

172

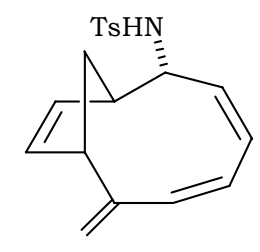

173

Procedimento: A uma solução contendo $700 \mathrm{mg}(1,65 \mathrm{mmol})$ do mesilato 172 e $3 \mathrm{~mL}$ de DMF seco, sob atmosfera inerte de $\mathrm{N}_{2}$, adicionou-se $619 \mathrm{mg}(4,13 \mathrm{mmol})$ de $\mathrm{NaI}$ anidro deixando reagir a $80^{\circ} \mathrm{C}$ por 5 horas. Em seguida adicionou-se $0,43 \mathrm{~mL}(3,30 \mathrm{mmol}) \mathrm{de}$ DBN deixando reagir por 3 horas a $100^{\circ} \mathrm{C}$. Após este tempo foram adicionados $15 \mathrm{~mL}$ de $\mathrm{H}_{2} \mathrm{O}$ ao meio reacional e extraiu-se com AcOEt (3 porções de $50 \mathrm{~mL}$ ). As fases orgânicas foram reunidas e lavadas com duas porções de $50 \mathrm{~mL}$ de $\mathrm{HCl} 1 \mathrm{~mol} / \mathrm{L}$ e depois com uma porção de $50 \mathrm{~mL}$ de uma solução saturada de $\mathrm{NaHCO}_{3}$. Após secar a fase orgânica com $\mathrm{MgSO}_{4}$ anidro, o solvente foi removido sob pressão reduzida e o resíduo purificado por cromatografia em coluna de sílica "flash" (200-400 mesh), utilizando-se como eluente uma mistura de hexano/acetato de etila - 8:2.

Rendimento: $308 \mathrm{mg}(0,94 \mathrm{mmol})-57 \%$

$\mathrm{RMN}-{ }^{1} \mathrm{H}\left(\mathrm{CDCl}_{3}, 400 \mathrm{MHz}\right), \delta(\mathrm{ppm}): 1,86$ (dquint, $1 \mathrm{H}, \mathrm{J}_{1}=13,9 \mathrm{~Hz} ; \mathrm{J}_{2}=\mathrm{J}_{3}=\mathrm{J}_{4}=\mathrm{J}_{4}=$ $1,0 \mathrm{~Hz}) ; 2,07\left(\mathrm{dt}, 1 \mathrm{H}, \mathrm{J}_{1}=13,9 ; \mathrm{J}_{2}=\mathrm{J}_{3}=9,6 \mathrm{~Hz}\right) ; 2,42(\mathrm{~s}, 3 \mathrm{H}) ; 2,81\left(\mathrm{ddq}, 1 \mathrm{H}, \mathrm{J}_{1}=9,6 \mathrm{~Hz}\right.$, $\left.\mathrm{J}_{2}=2,0 \mathrm{~Hz} ; \mathrm{J}_{3}=\mathrm{J}_{4}=\mathrm{J}_{5}=1,0 \mathrm{~Hz}\right) ; 3,48\left(\mathrm{dddt}, 1 \mathrm{H}, \mathrm{J}_{1}=9,6 \mathrm{~Hz} ; \mathrm{J}_{2}=3,0 \mathrm{~Hz} ; \mathrm{J}_{3}=2,0 \mathrm{~Hz} ; \mathrm{J}_{4}=\mathrm{J}_{5}\right.$ $=1,0 \mathrm{~Hz}) ; 3,70\left(\mathrm{tt}, 1 \mathrm{H}, \mathrm{J}_{1}=\mathrm{J}_{2}=7,5 \mathrm{~Hz} ; \mathrm{J}_{3}=\mathrm{J}_{4}=1,0 \mathrm{~Hz}\right) ; 4,73\left(\mathrm{q}, 1 \mathrm{H}, \mathrm{J}_{1}=\mathrm{J}_{2}=\mathrm{J}_{3}=1,8 \mathrm{~Hz}\right.$ ); $4,85\left(\mathrm{q}, 1 \mathrm{H}, \mathrm{J}_{1}=\mathrm{J}_{2}=\mathrm{J}_{3}=1,8 \mathrm{~Hz}\right) ; 4,98\left(\mathrm{ddd}, 1 \mathrm{H}, \mathrm{J}_{1}=11,6 \mathrm{~Hz} ; \mathrm{J}_{2}=7,5 \mathrm{~Hz} ; \mathrm{J}_{3}=1,8 \mathrm{~Hz}\right)$; $5,03(\mathrm{~d}, 1 \mathrm{H}, \mathrm{J}=7,5 \mathrm{~Hz}) ; 5,59\left(\mathrm{ddt}, 1 \mathrm{H}, \mathrm{J}_{1}=5,6 \mathrm{~Hz} ; \mathrm{J}_{2}=\mathrm{J}_{3}=2,0 \mathrm{~Hz} ; \mathrm{J}_{4}=0,7 \mathrm{~Hz}\right) ; 5,70$ (dddd, $1 \mathrm{H}, \mathrm{J}_{1}=11,6 \mathrm{~Hz} ; \mathrm{J}_{2}=2,5 \mathrm{~Hz} ; \mathrm{J}_{3}=1,8 \mathrm{~Hz} ; \mathrm{J}_{4}=1,0 \mathrm{~Hz}$ ); 5,76 (ddt, $1 \mathrm{H}, \mathrm{J}_{1}=5,6 \mathrm{~Hz}, \mathrm{~J}_{2}$ $\left.=3,0 \mathrm{~Hz} ; \mathrm{J}_{3}=\mathrm{J}_{4}=1,0 \mathrm{~Hz}\right) ; 5,86\left(\mathrm{ddd}, 1 \mathrm{H}, \mathrm{J}_{1}=11,6 \mathrm{~Hz} ; \mathrm{J}_{2}=2,5 \mathrm{~Hz} ; \mathrm{J}_{3}=1,8 \mathrm{~Hz}\right) ; 6,17(\mathrm{dq}$, $\left.1 \mathrm{H}, \mathrm{J}_{1}=11,6 \mathrm{~Hz}, \mathrm{~J}_{2}=\mathrm{J}_{3}=\mathrm{J}_{4}=1,8 \mathrm{~Hz}\right) ; 7,28(\mathrm{~d}, 2 \mathrm{H}, \mathrm{J}=8,4 \mathrm{~Hz}) ; 7,73(\mathrm{~d}, 2 \mathrm{H}, \mathrm{J}=8,4 \mathrm{~Hz})$.

$\mathrm{RMN}-{ }^{13} \mathrm{C}\left(\mathrm{CDCl}_{3}, 125 \mathrm{MHz}\right) \delta(\mathrm{ppm}): 21,5\left(\mathrm{CH}_{3}\right) ; 33,5\left(\mathrm{CH}_{2}\right) ; 48,1(\mathrm{CH}) ; 52,2(\mathrm{CH})$; 59,4 (CH); 113,6 $\left(\mathrm{CH}_{2}\right) ; 127,0(\mathrm{CH}) ; 127,1(\mathrm{CH}) ; 127,8(2 \mathrm{CH}) ; 129,5(\mathrm{CH}) ; 132,2(\mathrm{CH})$; 136,5(CH); 136,7 (CH); 137,6(C); 143,2 (C); 148,3 (C).

IR $v_{\text {máx }} \cdot(\mathrm{KBr}): 1155 \mathrm{~cm}^{-1}, 1327 \mathrm{~cm}^{-1}, 1597 \mathrm{~cm}^{-1}, 3242 \mathrm{~cm}^{-1}$

HRMS (ESI-TOF): calc. para $\mathrm{C}_{19} \mathrm{H}_{22} \mathrm{NO}_{2} \mathrm{~S}^{+}\left(\mathrm{MH}^{+}\right)$, 328,1371; experimental: 328,1417 ( $\Delta$ de 14 ppm - limite de 50 ppm) 


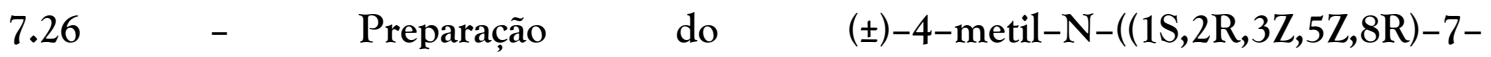
metilenobiciclo[6.2.1] undeca-3,5,9-trien-2-ilo)-N-tosilbenzenosulfonamida (174). ${ }^{93 \mathrm{~d}}$

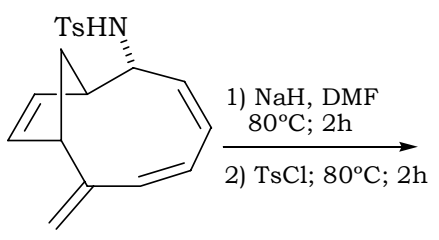

173

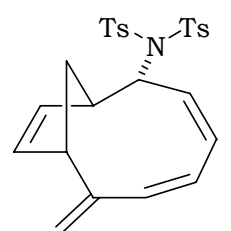

174

Procedimento: A uma suspensão contendo 0,5 mL de DMF seco e 10,0 $\mathrm{mg}(0,25 \mathrm{mmol})$ de $\mathrm{NaH} 60 \%$, sob atmosfera de $\mathrm{N}_{2}$, adicionou-se uma solução contendo $50 \mathrm{mg}(0,15$ mmol) de 173 dissolvidos em 1,0 mL de DMF seco. A mistura foi aquecida a $80^{\circ} \mathrm{C}$ por 2 horas e após este tempo foram adicionados $57 \mathrm{mg}(0,30 \mathrm{mmol})$ de $\mathrm{TsCl}$ (recristalizado em éter) deixando sob agitação por mais duas horas nesta temperatura. Em seguida, adicionou-se $\mathrm{H}_{2} \mathrm{O}$ ao meio reacional $\left(10 \mathrm{~mL}\right.$ ) extraindo-se $\mathrm{CHCl}_{3}$ (3 porções de $20 \mathrm{~mL}$ ). As fases orgânicas foram reunidas e lavadas com uma solução saturada de $\mathrm{NaCl}(20 \mathrm{~mL})$ e posteriormente secada com $\mathrm{MgSO}_{4}$. O solvente foi removido sob pressão reduzida e o resíduo foi purificado por cromatografia em coluna de sílica "flash" (200-400 mesh), utilizando-se como eluente uma mistura de hexano/acetato de etila - 8:2.

Rendimento: $12 \mathrm{mg}(0,025 \mathrm{mmol})-17 \%$

RMN - ${ }^{1} \mathrm{H}\left(\mathrm{CDCl}_{3}, 400 \mathrm{MHz}\right) \delta(\mathrm{ppm}): 1,63(\mathrm{~d}, 1 \mathrm{H}, \mathrm{J}=13,9 \mathrm{~Hz}) ; 2,03\left(\mathrm{dt}, 1 \mathrm{H}, \mathrm{J}_{1}=13,9\right.$; $\left.\mathrm{J}_{2}=\mathrm{J}_{3}=9,5 \mathrm{~Hz}\right) ; 2,44(\mathrm{sl}, 6 \mathrm{H}) ; 2,97(\mathrm{~d}, 1 \mathrm{H}, \mathrm{J}=9,5 \mathrm{~Hz}) ; 3,48(\mathrm{~d}, 1 \mathrm{H}, \mathrm{J}=9,5 \mathrm{~Hz}) ; 4,69(\mathrm{~d}$, $1 \mathrm{H}, \mathrm{J}=9,5 \mathrm{~Hz}) ; 4,78\left(\mathrm{q}, 1 \mathrm{H}, \mathrm{J}_{1}=\mathrm{J}_{2}=\mathrm{J}_{3}=1,8 \mathrm{~Hz}\right) ; 4,91\left(\mathrm{q}, 1 \mathrm{H}, \mathrm{J}_{1}=\mathrm{J}_{2}=\mathrm{J}_{3}=1,8 \mathrm{~Hz}\right) ; 5,70-$ $5,85(\mathrm{~m}, 3 \mathrm{H}) ; 5,94\left(\mathrm{ddd}, 1 \mathrm{H} ; \mathrm{J}_{1}=11,1 \mathrm{~Hz} ; \mathrm{J}_{2}=9,1 \mathrm{~Hz} ; \mathrm{J}_{3}=1,7 \mathrm{~Hz}\right) ; 6,01-6,06\left(\mathrm{dt}, 1 \mathrm{H}, \mathrm{J}_{1}\right.$ $\left.=5,3 ; \mathrm{J}_{2}=\mathrm{J}_{3}=2,2 \mathrm{~Hz}\right) ;$ ); $6,29\left(\mathrm{dq}, 1 \mathrm{H}, \mathrm{J}_{1}=12,1 \mathrm{~Hz} ; \mathrm{J}_{2}=\mathrm{J}_{3}=\mathrm{J}_{4}=1,6 \mathrm{~Hz}\right) ; 7,33(\mathrm{~d}, 4 \mathrm{H}, \mathrm{J}=$ $8,3 \mathrm{~Hz}) ; 7,90(\mathrm{~d}, 4 \mathrm{H}, \mathrm{J}=8,3 \mathrm{~Hz})$.

$\mathrm{RMN}-{ }^{13} \mathrm{C}\left(\mathrm{CDCl}_{3}, 100 \mathrm{MHz}\right) \delta(\mathrm{ppm}): 21,6\left(\mathrm{CH}_{3}\right) ; 36,7\left(\mathrm{CH}_{2}\right) ; 49,5(\mathrm{CH}) ; 51,1(\mathrm{CH})$; 68,6 (CH); 115,4 $\left(\mathrm{CH}_{2}\right) ; 126,8(\mathrm{CH}) ; 128,3(4 \mathrm{CH}) ; 129,5(5 \mathrm{CH}) ; 129,7(2 \mathrm{CH}) ; 131,1$ $(\mathrm{CH}) ; 135,8(\mathrm{CH}) ; 136,85(\mathrm{CH}) ; 144,7$ (2 C); 148,0 (2C). 
7.27 - Preparação $( \pm)-N-[(1 S, 2 R, 3 Z, 5 Z, 8 R)-7$-metilenobiciclo[6.2.1]undeca-3,5,9trien-2-ilo]- $N$-(metilsulfonil)metanosulfonamida (180). ${ }^{97}$
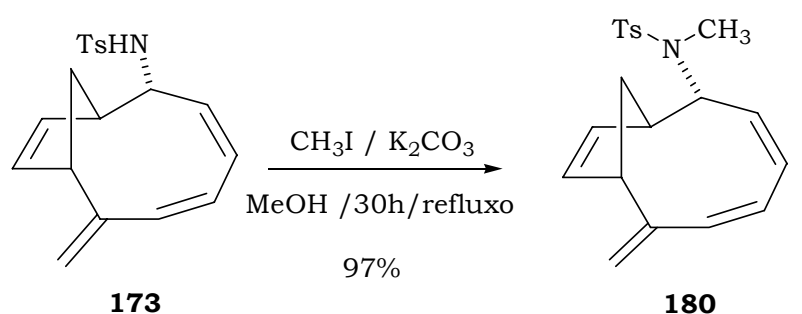

Procedimento: A uma solução contendo $100 \mathrm{mg}(0,305 \mathrm{mmol})$ de $173,2,0 \mathrm{~mL}$ de $\mathrm{MeOH}$ e $82 \mathrm{mg}(0,60 \mathrm{mmol})$ de $\mathrm{K}_{2} \mathrm{CO}_{3}$ anidro foi adicionado $\mathrm{MeI}(1,0 \mathrm{~mL})$. O sistema foi aquecido a $55^{\circ} \mathrm{C}$ observando-se o refluxo do MeI. Periodicamente (a cada 6 horas mais ou menos) o MeI foi reposto ao meio reacional adicionando-se porções de de 1,0 $\mathrm{mL}$. Após $30 \mathrm{~h}$ de reação observou-se o consumo total do material de partida. O solvente e o MeI remanescente foram removidos sob pressão reduzida e ao resíduo foram adicionados $20 \mathrm{~mL}$ de $\mathrm{H}_{2} \mathrm{O}$ extraindo-se com $\mathrm{CHCl}_{3}$ (3 porções de $30 \mathrm{~mL}$ ). As fases orgânicas foram reunidas e secadas com $\mathrm{MgSO}_{4}$ anidro. $\mathrm{O}$ resíduo foi purificado por cromatografia em coluna de sílica "flash" (200-400 mesh), utilizando-se como eluente uma mistura de hexano/acetato de etila - 8:2.

Rendimento: $101 \mathrm{mg}(0,296 \mathrm{mmol})-97 \%$

$\mathrm{RMN}-{ }^{1} \mathrm{H}\left(\mathrm{CDCl}_{3}, 500 \mathrm{MHz}\right), \delta(\mathrm{ppm}): 1,98\left(\mathrm{dt}, 1 \mathrm{H}, \mathrm{J}_{1}=13,8 \mathrm{~Hz} ; \mathrm{J}_{2}=\mathrm{J}_{3}=1,0 \mathrm{~Hz}\right) ; 2,11$ $\left(\mathrm{dt}, 1 \mathrm{H}, \mathrm{J}_{1}=13,8 ; \mathrm{J}_{2}=\mathrm{J}_{3}=9,5 \mathrm{~Hz}\right) ; 2,41(\mathrm{~s}, 3 \mathrm{H}) ; 2,81\left(\mathrm{ddq}, 1 \mathrm{H}, \mathrm{J}_{1}=9,5 \mathrm{~Hz}, \mathrm{~J}_{2}=2,2 \mathrm{~Hz} ; \mathrm{J}_{3}\right.$ $\left.=\mathrm{J}_{4}=\mathrm{J}_{5}=1,0 \mathrm{~Hz}\right) ; 2,87(\mathrm{~s}, 3 \mathrm{H}) ; 3,48-3,52(\mathrm{~m}, 1 \mathrm{H}) ; 4,50\left(\mathrm{dt}, 1 \mathrm{H}, \mathrm{J}_{1}=8,7 ; \mathrm{J}_{2}=\mathrm{J}_{3}=1,0 \mathrm{~Hz}\right)$; $4,77\left(\mathrm{q}, 1 \mathrm{H}, \mathrm{J}_{1}=\mathrm{J}_{2}=\mathrm{J}_{3}=1,8 \mathrm{~Hz}\right) ; 4,87\left(\mathrm{q}, 1 \mathrm{H}, \mathrm{J}_{1}=\mathrm{J}_{2}=\mathrm{J}_{3}=1,8 \mathrm{~Hz}\right) ; 5,17\left(\mathrm{ddd}, 1 \mathrm{H}, \mathrm{J}_{1}=11,4\right.$ $\left.\mathrm{Hz} ; \mathrm{J}_{2}=8,7 \mathrm{~Hz} ; \mathrm{J}_{3}=1,8 \mathrm{~Hz}\right) ; 5,52\left(\mathrm{ddd}, 1 \mathrm{H}, \mathrm{J}_{1}=5,6 \mathrm{~Hz} ; \mathrm{J}_{2}=2,2 \mathrm{~Hz} ; \mathrm{J}_{3}=1,5 \mathrm{~Hz}\right) ; 5,73-$ $5,77(\mathrm{~m}, 2 \mathrm{H}) ; 6,02\left(\mathrm{ddd}, 1 \mathrm{H}, \mathrm{J}_{1}=11,9 \mathrm{~Hz}, \mathrm{~J}_{2}=2,5 \mathrm{~Hz} ; \mathrm{J}_{3}=1,9 \mathrm{~Hz}\right) ; 6,28\left(\mathrm{dq}, 1 \mathrm{H}, \mathrm{J}_{1}=11,9\right.$ $\left.\mathrm{Hz}, \mathrm{J}_{2}=\mathrm{J}_{3}=\mathrm{J}_{4}=1,8 \mathrm{~Hz}\right) ; 7,27(\mathrm{~d}, 2 \mathrm{H}, \mathrm{J}=8,3 \mathrm{~Hz}) ; 7,65(\mathrm{~d}, 2 \mathrm{H}, \mathrm{J}=8,3 \mathrm{~Hz})$.

$\mathrm{RMN}-{ }^{13} \mathrm{C}\left(\mathrm{CDCl}_{3}, 125 \mathrm{MHz}\right) \delta(\mathrm{ppm}): 21,5\left(\mathrm{CH}_{3}\right) ; 29,9\left(\mathrm{CH}_{3}\right) ; 34,9\left(\mathrm{CH}_{2}\right) ; 48,5(\mathrm{CH})$; 49,4 (CH); 62,9 (CH); 114,1 $\left(\mathrm{CH}_{2}\right) ; 127,4(2 \mathrm{CH}) ; 127,5(\mathrm{CH}) ; 127,6(\mathrm{CH}) ; 128,2(\mathrm{CH}) ;$ $128,9(\mathrm{CH}) ; 129,4(2 \mathrm{CH}) ; 136,5(\mathrm{CH}$ e C); 137,0 (CH); 143,0 (C); 148,3 (C).

HRMS (ESI-TOF): calc. para $\mathrm{C}_{20} \mathrm{H}_{24} \mathrm{NO}_{2} \mathrm{~S}^{+}\left(\mathrm{MH}^{+}\right)$, 342,1528; experimental: 342,1581 ( $\Delta$ de 15 ppm - limite de 50 ppm) 


\subsection{8 - Preparação do éter dimetílico. ${ }^{98}$}

$$
2 \mathrm{CH}_{3} \mathrm{OH}_{(1)} \stackrel{\mathrm{H}_{2} \mathrm{SO}_{4} \text { (conc.) }}{\longrightarrow} \mathrm{CH}_{3} \mathrm{OCH}_{3(\mathrm{~g})}+\mathrm{H}_{2} \mathrm{O}_{(\mathrm{l})}
$$

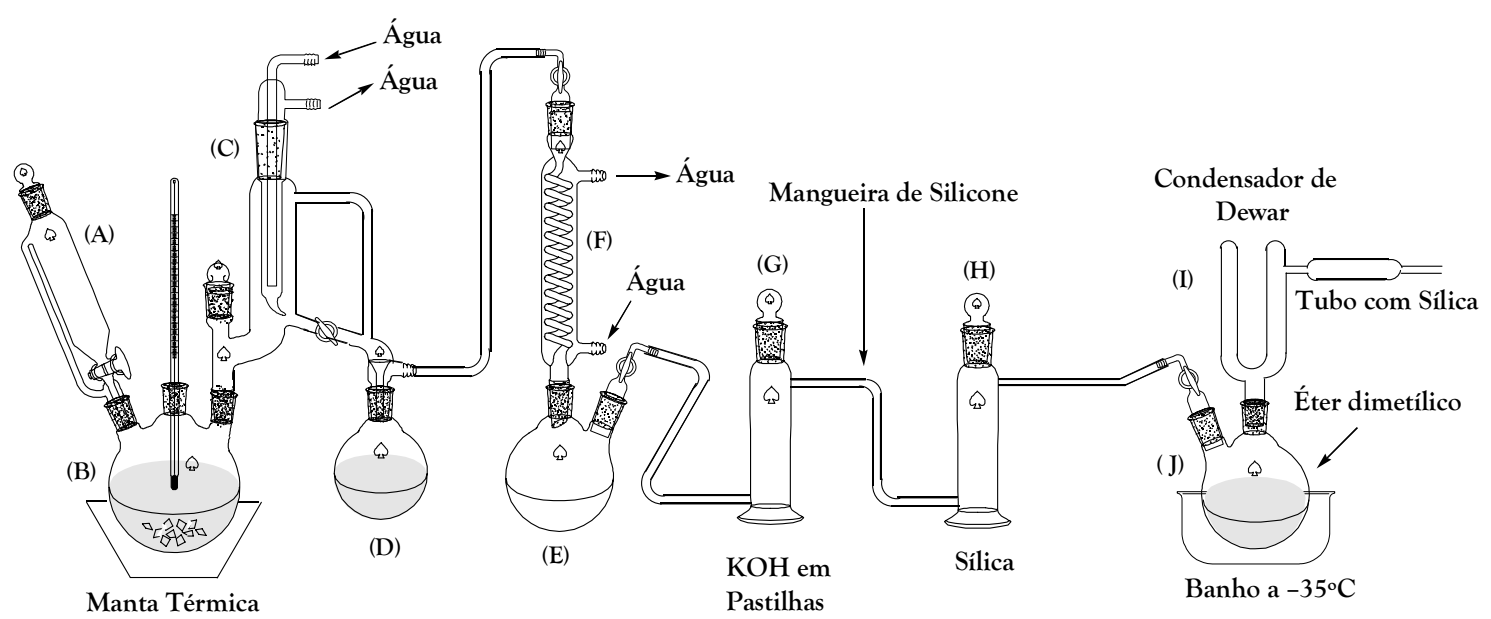

Procedimento: Foram misturados cautelosamente $75 \mathrm{~mL}$ de metanol e $75 \mathrm{~mL}$ de $\mathrm{H}_{2} \mathrm{SO}_{4}$ concentrado ${ }^{\text {xiii }} \mathrm{A}$ solução de metanol/ $\mathrm{H}_{2} \mathrm{SO}_{4}$ foi então adicionada ao balão de três bocas (B) adaptado com condensador (C) e funil de adição (A) (esquema acima), e, em seguida aquecida com uma manta térmica, de maneira que a temperatura da mistura reacional ficasse entre $145-155^{\circ} \mathrm{C}$. Em poucos minutos percebeu-se a condensação do éter dimetílico no balão $(\mathrm{J})$, que se encontrava resfriado a $-35^{\circ} \mathrm{C}$ e que tinha adaptado um condensador de Dewar (I) ("dedo frio") com gelo seco e etanol. $\mathrm{Na}$ medida em que se coletou o éter dimetílico adicionou-se lentamente mais metanol ao meio reacional, processo que é feito através do funil de adição (A). Com o desenvolver da reação verificase o refluxo de água, que pode ser coletada pela abertura da torneira do condensador (C). Por este processo conseguiu-se transformar em 5 horas, $800 \mathrm{~mL}$ de metanol em aproximadamente $300 \mathrm{~mL}$ de éter dimetílico. O éter dimetílico foi mantido devidamente refrigerado (ponto de ebulição $=-23^{\circ} \mathrm{C} / 760 \mathrm{mmHg}$ ) até o seu uso na síntese do sal de oxônio, que deve ser feito logo em seguida a esta preparação. ${ }^{\text {xiv }}$

\footnotetext{
xiii Esta adição deve ser realizada em um béquer resfriado a $0^{\circ} \mathrm{C}$, vertendo-se o ácido no metanol.

xiv $\mathrm{O}$ éter dimetílico é bastante solúvel em água, etanol, acetona, dicloro metano e ácido sulfúrico.
} 


\subsection{9 - Preparação do tetrafluorborato de trimetiloxônio. ${ }^{98}$}

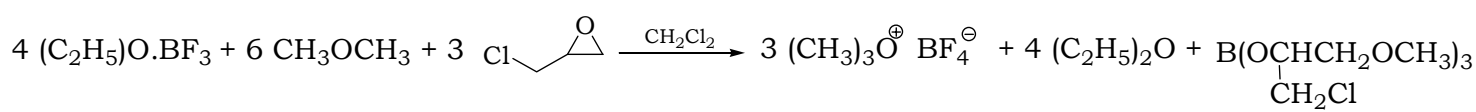

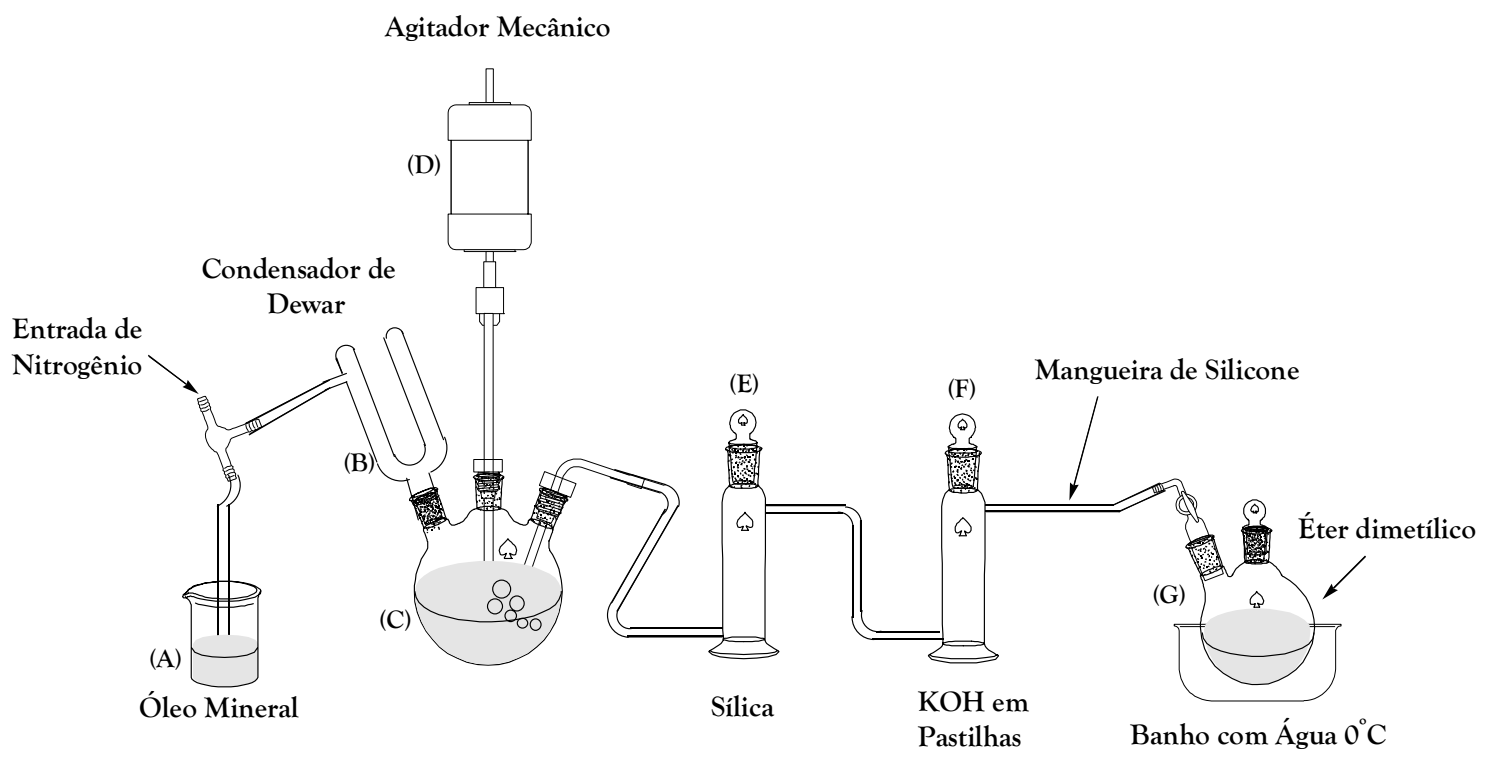

Procedimento: Ao balão de três bocas, ${ }^{\mathrm{xv}}$ adaptado com agitador mecânico (D), ${ }^{\mathrm{xvi}}$ condensador de Dewar (B) (“dedo frio”) e os demais acessórios mostrados na figura acima, foram adicionados $80 \mathrm{~mL}$ de $\mathrm{CH}_{2} \mathrm{Cl}_{2}$ anidro e 38,4 g (0,271 mol, 33,3 mL) de $\mathrm{BF}_{3} . \mathrm{OEt}_{2}$ recém destilado. ${ }^{\text {xvi }}$ Após a passagem de uma forte corrente de $\mathrm{N}_{2}$ pelo sistema, o condensador de Dewar é preenchido com etanol e gelo seco. Em seguida, um fluxo suave de éter dimetílico ${ }^{\text {xviii }}$ é borbulhado na mistura reacional até que sejam dissolvidos $75 \mathrm{~mL}$ deste reagente, ou seja, até que seja atingida a marca de $190 \mathrm{~mL}$ do balão. ${ }^{\text {xix }}$ Após este procedimento, uma linha de gás inerte $\left(\mathrm{N}_{2}\right)$ é conectada a um funil de adição de $50 \mathrm{~mL}$, que deverá conter 28,4 g $(0,307 \mathrm{~mol} ; 24,1 \mathrm{~mL})$ de epicloridrina recém destilada. Em seguida este funil deverá ser adaptado rapidamente na boca do balão reacional por onde foi borbulhado o éter dimetílico e então iniciar a adição da epicloridrina, que deverá ser feita lentamente (em aproximadamente 15 minutos). Assim que iniciada a adição da epicloridrina deve-se iniciar também a agitação do meio reacional. ${ }^{\mathrm{xx}}$ Após a adição da epicloridrina a reação é mantida por 2 horas sob forte agitação e em seguida é

\footnotetext{
${ }^{x v} \mathrm{O}$ balão deve ser previamente marcado de forma que se reconheça um volume em torno de $190 \mathrm{~mL}$, pois, mais tarde, será borbulhado éter dimetílico ao meio reacional $(75 \mathrm{~mL})$.

xvi $\mathrm{O}$ agitador só deverá ser ligado quando requerido.

xvii É extremamente necessário que o $\mathrm{BF}_{3} . \mathrm{OEt}_{2}$ seja destilado minutos antes da preparação, por exemplo, quando a preparação do éter dimetílico estiver quase concluída.

xviii Conforme pode ser visto pela montagem acima, é importante que os sistemas de secagem estejam devidamente preenchidos com $\mathrm{KOH}$ em pastilhas e sílica gel com indicador azul.

xix Para borbulhar o éter dimetílico na mistura reacional basta mergulhar o balão $(\mathrm{G})$ em um banho a $0^{\circ} \mathrm{C}$ ou a temperatura ambiente. Quando o fluxo se torna muito forte deve-se utilizar um banho de gelo seco e etanol para resfriar.

${ }^{x x} \mathrm{O}$ meio reacional deverá ser fortemente agitado. Note que durante todo o processo, especialmente após o início da agitação mecânica, deve-se manter o condensador de Dewar devidamente preenchido com gelo seco e etanol.
} 
abandonada sob agitação média por uma noite. ${ }^{\text {xxi }}$ Será observada a formação de um sólido branco que é o $\mathrm{Me}_{3} \mathrm{O}^{+} \mathrm{BF}_{4}^{-}$. No dia seguinte, em uma das bocas do balão reacional, é adaptado um tubo de vidro contendo um cartucho de vidro sinterizado em uma das pontas e que deve estar preso a uma rolha de borracha furada. ${ }^{\text {xxii }} \mathrm{Na}$ outra extremidade do tubo de vidro é adaptada uma mangueira do tipo TIGON e que se encontra ligada a mais dois "traps" de segurança. O solvente reacional é removido por sucção ${ }^{x x i i i}$ e deve ficar contido nos "traps". O sal de oxônio é lavado com mais duas porções de $100 \mathrm{~mL}$ de $\mathrm{CH}_{2} \mathrm{Cl}_{2}$ anidro e o solvente removido da mesma maneira, por sucção. Em seguida o sal é secado em alto vácuo e armazenado em um dessecador que é colocado dentro de um freezer. ${ }^{\text {xiv }}$

Rendimento: $29,1 \mathrm{~g}(0,197 \mathrm{~mol})-97 \%$

\footnotetext{
${ }^{x x i}$ A partir deste momento a refrigeração no condensador de Dewar pode ser interrompida simplesmente deixando-se de adicionar mais gelo seco. No total (síntese do éter dimetílico e do sal de oxônio) são necessários mais ou menos $4 \mathrm{~kg}$ de gelo seco, além de um banho termostático para manter o éter dimetílico resfriado.

xxii Nas outras duas bocas do balão podem ser colocadas duas tampas de borracha ("septa ruber" da Aldrich ${ }^{\circledR}$.

xxiii Este procedimento pode ser feito com uma bomba de água. Alternativamente o solvente pode ser removido com o auxílio de uma seringa de $50 \mathrm{~mL}$ que deverá ser adaptada diretamente ao tubo de vidro que contém o cartucho sinterizado.

${ }_{\text {xxiv }} \mathrm{O} \mathrm{Me}_{3} \mathrm{O}^{+} \mathrm{BF}_{4}^{-}$pode ser utilizado em até um mês mantendo-se devidamente puro.
} 
7.30 - Preparação do ácido $\beta$-vinilacrílico $(281) .{ }^{145}$

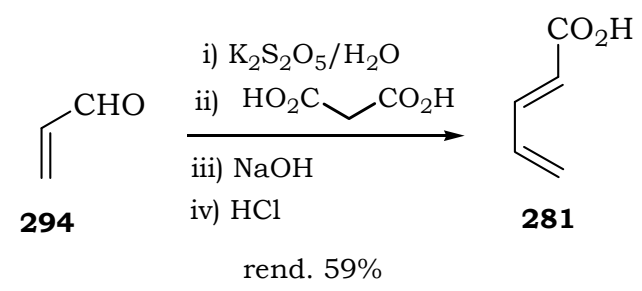

Procedimento:. Em um balão de 3 bocas adaptado com agitação mecânica e condensador de refluxo, foram dissolvidos $118 \mathrm{~g}(0,53 \mathrm{~mol})$ de $\mathrm{K}_{2} \mathrm{~S}_{2} \mathrm{O}_{5}$ em $220 \mathrm{~mL}$ de água. Após a completa dissolução do sal o sistema foi resfriado com um banho de gelo e adicionaramse, gota a gota, 29,0 g (0,52 mol) de acroleína (294) recém destilada. Após esta adição a reação foi agitada à temperatura ambiente por duas horas. Em seguida, adicionaram-se $52,0 \mathrm{~g}$ de ácido malônico $(0,50 \mathrm{~mol})$ e a mistura foi refluxada por duas horas (refluxo forte com a temperatura do banho em torno de $130^{\circ} \mathrm{C}$ ). Após isso a mistura reacional foi concentrada removendo-se o condensador e mantendo-se o aquecimento em torno de $110-115^{\circ} \mathrm{C}$, até a mistura se tornar uma massa espessa. A mistura foi abandonada por uma noite. Após este tempo o resíduo foi dissolvido em $120 \mathrm{~mL}$ de água e depositado em uma cuba de cobre ( $2 \mathrm{~L}$ de capacidade). Foram adicionados gradualmente a este resíduo, $300 \mathrm{~g}$ de $\mathrm{NaOH}$, mantendo-o constantemente sob agitação a mecânica. Neste momento há um forte aquecimento da mistura e é importante manter a agitação. Após alguns minutos a mistura reacional torna-se muito espessa sendo impossível manter sob agitação. A mistura foi abandonada mantendo-a em um banho com água $\left(\sim 90^{\circ} \mathrm{C}\right)$ até que se observe uma massa semi-cristalizada, ou seja, após mais ou menos $4 \mathrm{~h}$. Em seguida a massa foi transferida para um béquer (5L) e adicionou-se gelo moído (700-800 g) e 500 $\mathrm{mL}$ de clorofórmio colocando-se a mistura sob forte agitação mecânica. A esta mistura adicionou-se $\mathrm{HCl}\left(500 \mathrm{~g}\right.$ de gelo $+500 \mathrm{~mL}$ de $\mathrm{HCl}$ concentrado $=\mathrm{HCl} \sim 25 \%$ e a $\left.\sim 0^{\circ} \mathrm{C}\right)$. A adição foi realizada muito lentamente e sempre com a reposição de gelo junto ao meio, para evitar que a temperatura se eleve. Após verificar que o $\mathrm{pH}$ do meio estava suficientemente ácido $(\mathrm{pH} \sim 2)$, separou-se a fase orgânica e extraiu-se a aquosa com mais duas porções de $500 \mathrm{~mL}$ de clorofórmio. As fases orgânica foram reunidas e lavadas com solução saturada de $\mathrm{NaCl}$ e em seguida secadas com $\mathrm{MgSO}_{4}$ anidro. $\mathrm{O}$ solvente foi removido sob pressão reduzida sem aquecer em banho térmico para evitar a polimerização do produto. Obteve-se um sólido amarelo que foi dissolvido em benzeno e congelado (procedimento necessário para um armazenamento adequado sem que o produto sofra uma polimerização exagerada).

Rendimento: $29,0 \mathrm{~g}(0,295$ mols $)-59 \%$

Ponto de fusão: $70-72^{\circ} \mathrm{C}$

$\mathrm{RMN}-{ }^{1} \mathrm{H}\left(\mathrm{CDCl}_{3}, 400 \mathrm{MHz}\right), \delta(\mathrm{ppm}): 5,56\left(\mathrm{ddt}, 1 \mathrm{H}, \mathrm{J}_{1}=10,0 \mathrm{~Hz} ; \mathrm{J}_{2}=1,4 \mathrm{~Hz} ; \mathrm{J}_{3}=\mathrm{J}_{4}=\right.$ 0,6 Hz); 5,67 (ddt, 1H, J $\left.=16,9 \mathrm{~Hz} ; \mathrm{J}_{2}=1,4 \mathrm{~Hz} ; \mathrm{J}_{3}=\mathrm{J}_{4}=0,8 \mathrm{~Hz}\right) ; 5,92\left(\mathrm{dtd}, 1 \mathrm{H}, \mathrm{J}_{1}=15,4\right.$ $\left.\mathrm{Hz} ; \mathrm{J}_{2}=\mathrm{J}_{3}=0,8 \mathrm{~Hz} ; \mathrm{J}_{4}=0,6 \mathrm{~Hz}\right) ; 6,49$ (dddd, $1 \mathrm{H}, \mathrm{J}_{1}=16,9 \mathrm{~Hz} ; \mathrm{J}_{2}=10,8 \mathrm{~Hz} ; \mathrm{J}_{3}=10,0 \mathrm{~Hz}$; $\mathrm{J}_{4}=0,8 \mathrm{~Hz}$ ); 7,36 (dddd, $1 \mathrm{H}, \mathrm{J}_{1}=15,4 \mathrm{~Hz} ; \mathrm{J}_{2}=10,8 \mathrm{~Hz} ; \mathrm{J}_{3}=0,8 \mathrm{~Hz} ; \mathrm{J}_{4}=0,6 \mathrm{~Hz}$ ). 
RMN- ${ }^{13} \mathrm{C}\left(\mathrm{CDCl}_{3}, 100 \mathrm{MHz}\right), \delta(\mathrm{ppm}): 121,3(\mathrm{CH}) ; 126,8\left(\mathrm{CH}_{2}\right) ; 134,5(\mathrm{CH}) ; 147,0$ $(\mathrm{CH}) ; 172,6(\mathrm{C})$.

IR $v_{\text {máx }}(\mathrm{KBr}): 694 \mathrm{~cm}^{-1} ; 866 \mathrm{~cm}^{-1} ; 1010 \mathrm{~cm}^{-1} ; 1276 \mathrm{~cm}^{-1} ; 1600 \mathrm{~cm}^{-1} ; 1634 \mathrm{~cm}^{-1} ; 1702$ $\mathrm{cm}^{-1} ; 2200-3310 \mathrm{~cm}^{-1}$. 


\subsection{1 - Preparação do ácido tíglico (282). ${ }^{146}$}

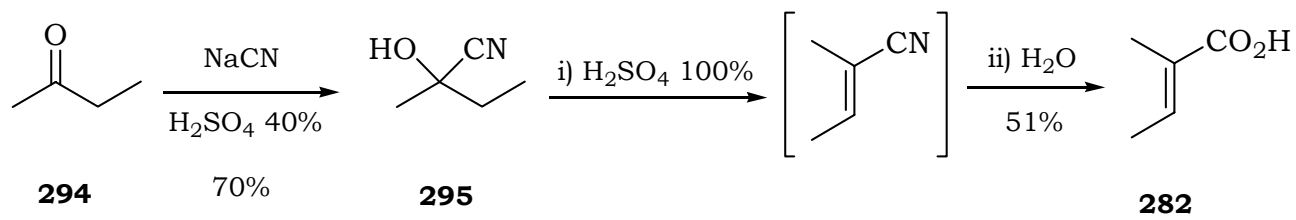

\section{$\underline{1^{a} \text { Etapa }}$ - Síntese da ( \pm )-2-hidroxi-2-metilbutanonitrila (295).}

Procedimento: Dissolveu-se $50 \mathrm{~g}(0,97 \mathrm{~mol})$ de $\mathrm{NaCN}$ em $120 \mathrm{~mL}$ de água e em seguida adicionou-se a 2-butanona (295) $(88,6 \mathrm{~g}, 110,1 \mathrm{~mL}, 1,23$ mols). A esta mistura foram adicionados, gota a gota, $210 \mathrm{~g}$ de uma solução $40 \%$ de $\mathrm{H}_{2} \mathrm{SO}_{4}{ }^{\mathrm{xxv}}$ Após o término desta adição ( 30 min.) deixou-se agitando por mais 30 minutos. Ao meio reacional foram adicionados $300 \mathrm{~mL}$ de éter extraindo-se e separando-se as fases. A fase orgânica foi reservada e a aquosa extraída com mais duas porções de éter $(2 \times 100 \mathrm{~mL})$. As fases orgânicas foram reunidas e lavadas com solução saturada de $\mathrm{NaCl}$ e em seguida secada com $\mathrm{MgSO}_{4}$ anidro. Solvente foi removido sob pressão reduzida e o resíduo foi destilado (pressão reduzida de $23 \mathrm{mmHg}$ ) reservando-se a fração que destilou entre 96 e $97^{\circ} \mathrm{C}$.

Rendimento: $66 \mathrm{~g}(0,68 \mathrm{~mol}, 70 \%)$

\section{2a Etapa: Síntese do ácido tíglico (282).}

Procedimento: À $58 \mathrm{~g}(0,58 \mathrm{~mol})$ da cianidrina 295, contida em um balão de 3 bocas, adaptado com agitação mecânica, condensador de refluxo e funil de adição foram

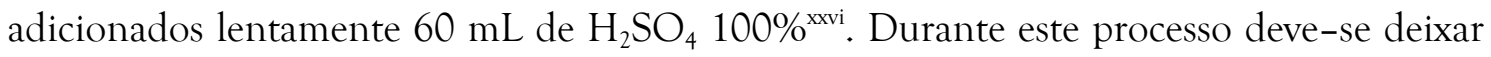
o balão imerso em um banho com água (temperatura ambiente) para evitar $\mathrm{o}$ aquecimento excessivo do meio reacional. Após isto a reação foi aquecida entre 125$130^{\circ} \mathrm{C}$ por 1 hora e então adicionaram-se $60 \mathrm{~mL}$ de $\mathrm{H}_{2} \mathrm{O}(3,3 \mathrm{~mol})$ deixando-se sob refluxo por mais 2 horas. Em seguida adaptou-se junto ao meio reacional um tubo de vidro em forma de (U) e um condensador para destilação. Pelo tubo de vidro passou-se uma corrente continua de vapor de água (gerado em um sistema ao lado) realizando a destilação por arraste do ácido 282. ${ }^{x x v i i}$ O produto, juntamente com a água, foi coletado e deixado em um freezer por 24 horas. O resíduo foi filtrado e secado, obtendo-se um sólido branco.

Rendimento: $28,8 \mathrm{~g}(0,288 \mathrm{~mol})-51 \%$

Ponto de fusão: $63-65^{\circ} \mathrm{C}$

\footnotetext{
${ }^{x x v}$ Este processo deve ser realizado em uma capela com exaustão eficiente, pois, durante a reação é liberado $\mathrm{HCN}$.

xxvi Preparado a partir da mistura de $56 \mathrm{~mL}$ de $\mathrm{H}_{2} \mathrm{SO}_{4}$ fumegante $\left(20 \%\right.$ de $\left.\mathrm{SO}_{3}\right)$ e $30 \mathrm{~mL}$ de $\mathrm{H}_{2} \mathrm{SO}_{4} 96 \%$.

xxvii Durante a destilação por arraste ocorre a cristalização do ácido tíglico (282) no condensador, o que pode impedir a passagem de vapor. De tempos em tempos é preciso deixar escoar a água que resfria o condensador para que o vapor arraste também os cristais formados.
} 
RMN- ${ }^{1} \mathrm{H}\left(\mathrm{CDCl}_{3}, 400 \mathrm{MHz}\right), \delta$ (ppm): 1,81-1,87 (m, 6H); 6,97-7,07 (m, 1H); 10,8-12,1 $(\mathrm{sl}, 1 \mathrm{H})$.

$\mathrm{RMN}-{ }^{13} \mathrm{C}\left(\mathrm{CDCl}_{3}, 100 \mathrm{MHz}\right) \delta(\mathrm{ppm}): 11,6\left(\mathrm{CH}_{3}\right) ; 14,5\left(\mathrm{CH}_{3}\right) ; 128,0(\mathrm{C}) ; 140,0(\mathrm{CH}) ;$ $173,9(\mathrm{C}=\mathrm{O})$.

IR $v_{\text {máx }} \cdot(\mathrm{KBr}): 934 \mathrm{~cm}^{-1} ; 1160 \mathrm{~cm}^{-1} ; 1294 \mathrm{~cm}^{-1} ; 1430 \mathrm{~cm}^{-1} ; 1638 \mathrm{~cm}^{-1} ; 1686 \mathrm{~cm}^{-1} ; 2200-$ $3500 \mathrm{~cm}^{-1}$. 
7.32 - Preparação do $(2 E)$-penta-2,4 dienoato de metila (296). ${ }^{147}$

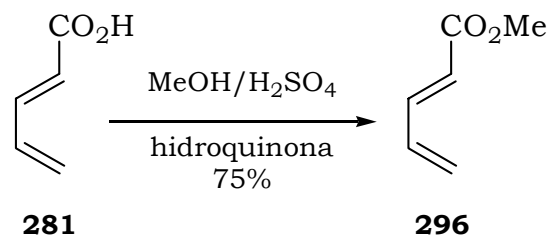

Procedimento: Foram misturados 7,0 g $(71$ mmols $)$ do ácido 281 e $500 \mathrm{mg}$ de hidroquinona em $40 \mathrm{~mL}$ de metanol. Em seguida adicionou-se $1 \mathrm{~mL}$ de $\mathrm{H}_{2} \mathrm{SO}_{4}$ concentrado e deixou-se reagir por 24 horas. Após este tempo removeu-se parte do metanol sob pressão reduzida $\left(30 \mathrm{mmHg}\right.$ ) e a baixa temperatura (banho de água $\sim 0^{\circ} \mathrm{C}$ ) e adicionou-se gelo picado ao meio reacional $(\sim 50 \mathrm{~g})$ e depois $20 \mathrm{~mL}$ de água. A mistura reacional foi extraída com 4 porções de $40 \mathrm{~mL}$ de éter e as fases orgânicas foram reunidas e lavadas com solução saturada de bicarbonato de sódio $(1 \times 40 \mathrm{~mL})$ e solução saturada de $\mathrm{NaCl}(2$ x $40 \mathrm{~mL})$. A fase orgânica foi secada com $\mathrm{MgSO}_{4}$ e o solvente removido sob pressão reduzida $\left(30 \mathrm{mmHg}\right.$ e banho de água à $\left.0^{\circ} \mathrm{C}\right)$. $\mathrm{O}$ resíduo foi destilado em sistema de destilação curta ("short path") sob pressão reduzida de $30 \mathrm{mmHg}$ e a uma temperatura de $72-75^{\circ} \mathrm{C}$, rendendo um líquido incolor.

Rendimento: $5,9 \mathrm{~g}$ (53 mmols) - 75\%

RMN- ${ }^{1} \mathrm{H}\left(\mathrm{CDCl}_{3}, 400 \mathrm{MHz}\right), \delta(\mathrm{ppm}): 5,50\left(\mathrm{dddd}, 1 \mathrm{H}, \mathrm{J}_{1}=10,0 \mathrm{~Hz} ; \mathrm{J}_{2}=1,5 \mathrm{~Hz} ; \mathrm{J}_{3}=0,8\right.$ $\left.\mathrm{Hz} ; \mathrm{J}_{4}=0,7 \mathrm{~Hz}\right) ; 5,62\left(\mathrm{ddt}, 1 \mathrm{H}, \mathrm{J}_{1}=17,0 \mathrm{~Hz} ; \mathrm{J}_{2}=1,5 \mathrm{~Hz} ; \mathrm{J}_{3}=\mathrm{J}_{4}=0,8 \mathrm{~Hz}\right) ; 5,92\left(\mathrm{ddt}, 1 \mathrm{H}, \mathrm{J}_{1}\right.$ $\left.=15,4 \mathrm{~Hz} ; \mathrm{J}_{2}=0,8 \mathrm{~Hz} ; \mathrm{J}_{3}=\mathrm{J}_{4}=0,7 \mathrm{~Hz}\right) ; 6,46\left(\mathrm{dddd}, 1 \mathrm{H}, \mathrm{J}_{1}=17,0 \mathrm{~Hz} ; \mathrm{J}_{2}=11,0 \mathrm{~Hz} ; \mathrm{J}_{3}=\right.$ $\left.10,0 \mathrm{~Hz} ; \mathrm{J}_{4}=0,7 \mathrm{~Hz}\right) ; 7,27\left(\mathrm{ddt}, 1 \mathrm{H}, \mathrm{J}_{1}=15,4 \mathrm{~Hz} ; \mathrm{J}_{2}=11,0 \mathrm{~Hz} ; \mathrm{J}_{3}=\mathrm{J}_{4}=0,8 \mathrm{~Hz}\right)$.

$\mathrm{RMN}-{ }^{13} \mathrm{C}\left(\mathrm{CDCl}_{3}, 100 \mathrm{MHz}\right), \delta(\mathrm{ppm}): 51,4\left(\mathrm{CH}_{3}\right) ; 121,6(\mathrm{CH}) ; 125,5\left(\mathrm{CH}_{2}\right) ; 134,6$ $(\mathrm{CH}) ; 144,8(\mathrm{CH}) ; 167,1(\mathrm{C})$.

IR $v_{\text {máx }}(\mathrm{KBr}): 1034 \mathrm{~cm}^{-1} ; 1438 \mathrm{~cm}^{-1} ; 1656 \mathrm{~cm}^{-1} ; 1732 \mathrm{~cm}^{-1} ; 2954 \mathrm{~cm}^{-1}$.

MS m/z (intensidade relativa): $\left[\mathrm{M}^{+}\right]$(57,2\%), 111 (23,6\%); 97 (15,7\%), 81 (100\%), 53 $(98,5 \%)$. 
7.33 - Preparação do (2E)-penta-2,4-dien-1-ol (283). ${ }^{148}$<smiles>C=CC=CC(=CCO)CCCO</smiles>

Procedimento: A uma suspensão mantida a $0^{\circ} \mathrm{C}$ contendo $1,2 \mathrm{~g}(30 \mathrm{mmol})$ de $\mathrm{LiAlH}_{4} \mathrm{e}$ $15 \mathrm{~mL}$ de éter anidro, adicionaram-se 3,01 g (26,9 mmol) do éster 296 dissolvidos em 20 $\mathrm{mL}$ de éter anidro. A mistura foi agitada sob atmosfera inerte de $\mathrm{N}_{2}$ à temperatura ambiente por $3 \mathrm{~h}$. Em seguida resfriou-se novamente a mistura reacional $\left(0^{\circ} \mathrm{C}\right)$ e adicionou-se de acetato de etila $(5 \mathrm{~mL})$ para decompor o $\mathrm{LiAlH}_{4}$ remanescente. A mistura reacional foi diluída com mais $25 \mathrm{~mL}$ de éter e tratada com água $(\sim 10 \mathrm{~mL})$. Em seguida adicionou-se $\mathrm{H}_{2} \mathrm{SO}_{4} 20 \%(20 \mathrm{~mL})$ e separou-se a fase orgânica $\mathrm{A}$ fase aquosa foi extraída com mais 2 porções de éter $(2 \times 30 \mathrm{~mL})$ e então as fases orgânicas foram reunidas e lavadas com solução saturada de bicarbonato de sódio $(2 \times 20 \mathrm{~mL})$ e solução saturada de $\mathrm{NaCl}(2 \times 20 \mathrm{~mL})$. A fase orgânica foi secada com $\mathrm{MgSO}_{4}$ anidro e o solvente removido sob pressão reduzida. $\mathrm{O}$ produto foi purificado por cromatografia em coluna de sílica gel utilizando-se como eluente uma mistura de hexano/acetato de etila 8:2.

Rendimento: $2,02 \mathrm{~g}(23,9 \mathrm{mmols})-89 \%$

RMN- ${ }^{1} \mathrm{H}\left(\mathrm{CDCl}_{3}, 400 \mathrm{MHz}\right), \delta$ (ppm): 1,50-2,00 (sl, 1H); 4,11-4,22 (m, 2H); 5,09 (dd, $\left.1 \mathrm{H}, \mathrm{J}_{1}=10,3 \mathrm{~Hz} ; \mathrm{J}_{2}=1,5 \mathrm{~Hz}\right) ; 5,21\left(\mathrm{dd}, 1 \mathrm{H}, \mathrm{J}_{1}=16,7 \mathrm{~Hz} ; \mathrm{J}_{2}=1,5 \mathrm{~Hz}\right) ; 5,83\left(\mathrm{dt}, 1 \mathrm{H}, \mathrm{J}_{1}=\right.$ $\left.15,1 \mathrm{~Hz} ; \mathrm{J}_{2}=\mathrm{J}_{3}=5,8 \mathrm{~Hz}\right) ; 6,24\left(\mathrm{dd}, 1 \mathrm{H}, \mathrm{J}_{1}=15,1 \mathrm{~Hz} ; \mathrm{J}_{2}=10,3 \mathrm{~Hz}\right) ; 6,35\left(\mathrm{dt}, 1 \mathrm{H}, \mathrm{J}_{1}=16,7\right.$ $\mathrm{Hz} ; \mathrm{J}_{2}=\mathrm{J}_{3}=10,3 \mathrm{~Hz}$ ).

$\mathrm{RMN}-{ }^{13} \mathrm{C}\left(\mathrm{CDCl}_{3}, 100 \mathrm{MHz}\right), \delta(\mathrm{ppm}): 63,2\left(\mathrm{CH}_{2}\right) ; 117,6\left(\mathrm{CH}_{2}\right) ; 131,9(\mathrm{CH}) ; 132,4$ $(\mathrm{CH}) ; 136,2(\mathrm{CH})$. 
7.34 - Preparação do (2E)-2-metilbut-2-enoate de $(2 E)$-penta-2,4-dien-1-ila (285). ${ }^{149}$
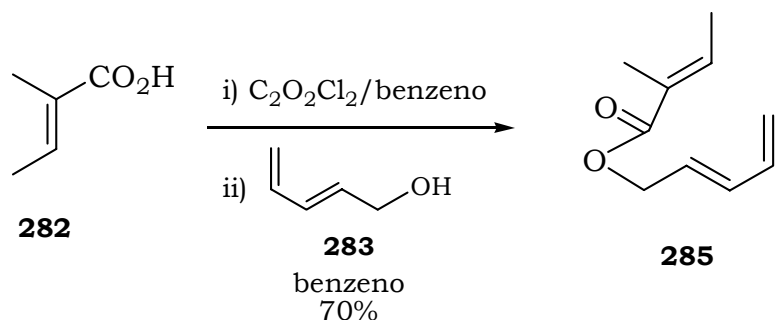

Procedimento: Foram misturados $1,0 \mathrm{~g}(10 \mathrm{mmol})$ de ácido tíglico (282) e $10 \mathrm{~mL}$ de benzeno seco e em seguida adicionados, gota a gota, $5,7 \mathrm{~mL}$ de cloreto de oxalila $96 \%$ (62 $\mathrm{mmol})$. Após a evolução de forte efervescência a mistura foi aquecida a $50^{\circ} \mathrm{C}$ por 1 hora. Em seguida, o excesso de cloreto de oxalila, juntamente com o benzeno, foi removido sob pressão reduzida. Foram adicionados mais $10 \mathrm{~mL}$ de benzeno seco ao meio reacional e repetiu-se o procedimento de evaporação. Em seguida adicionaram-se $10 \mathrm{~mL}$ de benzeno seco e resfriou-se o sistema à $0^{\circ} \mathrm{C}$. Logo após adicionou-se o álcool $275(672 \mathrm{mg}, 8$ mmol) e 1,0 mL de piridina anidra deixando-se reagir por uma noite. A mistura reacional foi então diluída com $100 \mathrm{~mL}$ de éter e lavada com duas porções $(30 \mathrm{~mL})$ de solução $15 \%$ de $\mathrm{CuSO}_{4}$ e uma porção $(30 \mathrm{~mL})$ de solução saturada de $\mathrm{NaCl}$. A fase orgânica foi secada com $\mathrm{MgSO}_{4}$ anidro e o solvente removido sob pressão reduzida. $\mathrm{O}$ resíduo foi purificado por cromatografia em coluna de sílica gel utilizando-se como eluente uma mistura de hexano/acetato de etila 8:2.

Rendimento: $931 \mathrm{mg}(5,60 \mathrm{mmol})-70 \%$

$\mathrm{RMN}-{ }^{1} \mathrm{H}\left(\mathrm{CDCl}_{3}, 500 \mathrm{MHz}\right), \delta(\mathrm{ppm}): 1,80\left(\mathrm{dq}, 3 \mathrm{H}, \mathrm{J}_{1}=7,0 \mathrm{~Hz}, \mathrm{~J}_{2}=\mathrm{J}_{3}=\mathrm{J}_{4}=1,5 \mathrm{~Hz}\right)$; $1,85\left(\mathrm{dq}, 3 \mathrm{H}, \mathrm{J}_{1}=1,4 \mathrm{~Hz}, \mathrm{~J}_{2}=\mathrm{J}_{3}=\mathrm{J}_{4}=1,2 \mathrm{~Hz}\right) ; 4,65-4,69(\mathrm{~m}, 2 \mathrm{H}) ; 5,14(\mathrm{~d}, 1 \mathrm{H} ; \mathrm{J}=10,3$ $\mathrm{Hz}) ; 5,25(\mathrm{~d}, 1 \mathrm{H} ; \mathrm{J}=16,4 \mathrm{~Hz}) ; 5,81\left(\mathrm{dt}, 1 \mathrm{H}, \mathrm{J}_{1}=14,6 \mathrm{~Hz}, \mathrm{~J}_{2}=\mathrm{J}_{3}=6,2 \mathrm{~Hz}\right) ; 6,30(\mathrm{ddt}, 1 \mathrm{H}$, $\left.\mathrm{J}_{1}=14,6 \mathrm{~Hz}, \mathrm{~J}_{2}=10,5 \mathrm{~Hz}, \mathrm{~J}_{3}=\mathrm{J}_{4}=1,3 \mathrm{~Hz}\right) ; 6,35\left(\mathrm{dt}, 1 \mathrm{H}, \mathrm{J}_{1}=16,4 \mathrm{~Hz}, \mathrm{~J}_{2}=\mathrm{J}_{3}=10,5 \mathrm{~Hz}\right)$; $6,89\left(\mathrm{qq}, 1 \mathrm{H}, \mathrm{J}_{1}=\mathrm{J}_{2}=\mathrm{J}_{3}=7,0 ; \mathrm{J}_{4}=\mathrm{J}_{5}=\mathrm{J}_{6}=1,4 \mathrm{~Hz}\right)$.

$\mathrm{RMN}-{ }^{13} \mathrm{C}\left(\mathrm{CDCl}_{3}, 125 \mathrm{MHz}\right) \delta(\mathrm{ppm}): 12,0\left(\mathrm{CH}_{3}\right) ; 14,3\left(\mathrm{CH}_{3}\right) ; 64,4\left(\mathrm{CH}_{2}\right) ; 118,3\left(\mathrm{CH}_{2}\right)$; $127,5(\mathrm{CH}) ; 128,5(\mathrm{C}) ; 134,2(\mathrm{CH}) ; 136,0(\mathrm{CH}) ; 137,4(\mathrm{CH}) ; 167,7(\mathrm{C}=\mathrm{O})$.

IR $v_{\text {máx }}(\mathrm{KBr}): 734 \mathrm{~cm}^{-1} ; 910 \mathrm{~cm}^{-1} ; 1134 \mathrm{~cm}^{-1} ; 1260 \mathrm{~cm}^{-1} ; 1442 \mathrm{~cm}^{-1} ; 1606 \mathrm{~cm}^{-1} ; 1652$ $\mathrm{cm}^{-1} ; 1712 \mathrm{~cm}^{-1} ; 2932 \mathrm{~cm}^{-1} ; 3088 \mathrm{~cm}^{-1}$.

MS m/z (intensidade relativa): $\left[\mathrm{M}^{+}\right]$(12,5\%), 121 (9\%); 83 (100\%), 67 (32,8\%), 55 (74\%). 
7.35 - Preparação do $\left\{[(2 E)\right.$-penta-2,4-dien-1-iloxi]metil $\}$ benzeno $(298) .{ }^{152}$

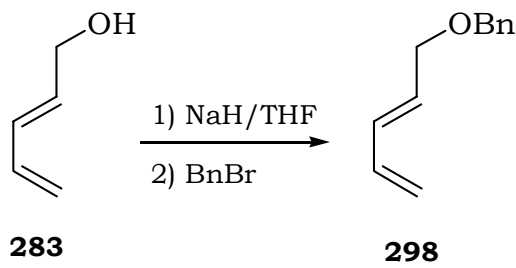

Procedimento: A uma suspensão contendo 6,50 g $(135 \mathrm{mmol})$ de $\mathrm{NaH} 50 \%$ e $50 \mathrm{~mL}$ de THF anidro adicionaram-se 7,50 g $(89,3 \mathrm{mmol})$ do álcool 283 dissolvidos em $50 \mathrm{~mL}$ de THF anidro e deixou-se reagir por 2 horas à temperatura ambiente. Em seguida resfriouse o meio reacional à $0^{\circ} \mathrm{C}$ e adicionou-se brometo de benzila $(21,6 \mathrm{~mL}, 181 \mathrm{mmol})$ deixando-se reagir por 18 horas à temperatura ambiente. Após este tempo adicionou-se água $(100 \mathrm{~mL})$ ao meio reacional e extraiu-se com 3 porções de $100 \mathrm{~mL}$ de éter etílico. As fases orgânicas foram reunidas e lavadas com 2 porções $(2 \times 50 \mathrm{~mL})$ de solução saturada de $\mathrm{NaCl}$ e secadas com $\mathrm{MgSO}_{4}$ anidro. $\mathrm{O}$ solvente foi removido sob pressão reduzida e o resíduo foi purificado por cromatografia em coluna de sílica gel, utilizando-se como eluente uma mistura de hexano/acetato de etila $(9,5: 0,5)$.

Rendimento: $14,0 \mathrm{~g}(80,3 \mathrm{mmol})-90 \%$

RMN- ${ }^{1} \mathrm{H}\left(\mathrm{CDCl}_{3}, 400 \mathrm{MHz}\right), \delta$ (ppm): 4,03-4,09 (m, 2H); 4,49-4,53 (sl, 2H); 5,09 (dd, $\left.1 \mathrm{H}, \mathrm{J}_{1}=10,5 \mathrm{~Hz} ; \mathrm{J}_{2}=2,3 \mathrm{~Hz}\right) ; 5,21\left(\mathrm{dd}, 1 \mathrm{H}, \mathrm{J}_{1}=16,5 \mathrm{~Hz} ; \mathrm{J}_{2}=2,3 \mathrm{~Hz}\right) ; 5,81\left(\mathrm{dt}, 1 \mathrm{H}, \mathrm{J}_{1}=\right.$ $\left.14,7 \mathrm{~Hz} ; \mathrm{J}_{2}=\mathrm{J}_{3}=6,0 \mathrm{~Hz}\right) ; 6,27\left(\mathrm{ddt}, 1 \mathrm{H}, \mathrm{J}_{1}=14,7 \mathrm{~Hz} ; \mathrm{J}_{2}=10,5 \mathrm{~Hz} ; \mathrm{J}_{3}=\mathrm{J}_{4}=1,2 \mathrm{~Hz}\right) ; 6,36$ $\left(\mathrm{dt}, 1 \mathrm{H}, \mathrm{J}_{1}=16,5 \mathrm{~Hz} ; \mathrm{J}_{2}=\mathrm{J}_{3}=10,5 \mathrm{~Hz}\right) ; 7,24-7,39(\mathrm{~m}, 5 \mathrm{H})$.

RMN- ${ }^{13} \mathrm{C}\left(\mathrm{CDCl}_{3}, 100 \mathrm{MHz}\right), \delta(\mathrm{ppm}): 70,2\left(\mathrm{CH}_{2}\right) ; 72,1\left(\mathrm{CH}_{2}\right) ; 117,5\left(\mathrm{CH}_{2}\right) ; 127,6$ $(\mathrm{CH}) ; 127,7(\mathrm{CH}) ; 128,3(\mathrm{CH}) ; 130,0(\mathrm{CH}) ; 133,2 ; 136,3(\mathrm{CH}) ; 138,2(\mathrm{C})$.

IR $v_{\text {máx }}(\mathrm{KBr}): 698 \mathrm{~cm}^{-1} ; 736 \mathrm{~cm}^{-1} ; 908 \mathrm{~cm}^{-1} ; 1110 \mathrm{~cm}^{-1} ; 1604 \mathrm{~cm}^{-1}$. 
7.36 - Preparação do ( \pm$)-(1 R, 2 S, 6 S)-2-[($ benziloxi)metil]-1,6-dimetilciclo-hex-3eno-1-carbaldeido (300). ${ }^{151}$

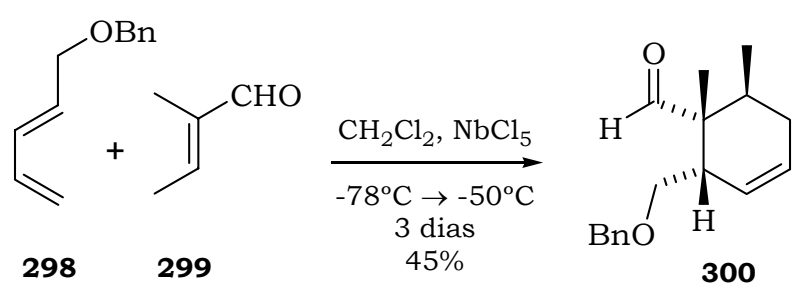

Procedimento: Foram misturados à $-78^{\circ} \mathrm{C} 117 \mathrm{mg}(0,43 \mathrm{mmol})$ de $\mathrm{NbCl}_{5}$ e $2 \mathrm{~mL}$ de $\mathrm{CH}_{2} \mathrm{Cl}_{2}$ anidro e, em seguida, adicionou-se o tiglaldeído (299) (579 mg, 6,88 mmol) dissolvido em $2 \mathrm{~mL}$ do mesmo solvente anidro, deixando-se agitar por 2 minutos. Após isso, adicionou-se o dieno $298(300 \mathrm{mg}, 1,72 \mathrm{mmol})$ em $2 \mathrm{~mL}$ de $\mathrm{CH}_{2} \mathrm{Cl}_{2}$ anidro (também à $-78^{\circ} \mathrm{C}$ ) deixando-se nesta temperatura por 30 minutos. Após este tempo a reação foi transferida para um banho térmico e mantida à $-50^{\circ} \mathrm{C}$ por 3 dias. Ao meio reacional foram adicionados $20 \mathrm{~mL}$ de água e a mistura foi extraída com 4 porções de 20 $\mathrm{mL}$ de $\mathrm{CH}_{2} \mathrm{Cl}_{2}$. As fases orgânicas foram reunidas e lavadas com solução saturada de $\mathrm{NaCl}(2 \times 20 \mathrm{~mL})$ e em seguida secada com $\mathrm{MgSO}_{4}$ anidro. $\mathrm{O}$ solvente foi removido sob pressão reduzida e o resíduo foi purificado por cromatografia em coluna de sílica gel, utilizando-se como eluente uma mistura de hexano/acetato de etila $(9,5: 0,5)$.

Rendimento: $200 \mathrm{mg}(0,774 \mathrm{mmol})-45 \%$

$\mathrm{RMN}-{ }^{1} \mathrm{H}\left(\mathrm{CDCl}_{3}, 500 \mathrm{MHz}\right), \delta(\mathrm{ppm}): 0,89\left(\mathrm{dl}, 3 \mathrm{H}, \mathrm{J}_{1}=6,6 \mathrm{~Hz}\right) ; 1,02(\mathrm{~s} ; 3 \mathrm{H}) ; 1,68-1,78$ $(\mathrm{m} ; 1 \mathrm{H}) ; 2,10-2,17(\mathrm{~m} ; 1 \mathrm{H}) ; 2,14-2,24(\mathrm{~m} ; 1 \mathrm{H}) ; 2,33-2,41(\mathrm{~m}, 1 \mathrm{H}) ; 3,45\left(\mathrm{dd} ; 1 \mathrm{H}, \mathrm{J}_{1}=\right.$ $\left.9,9 \mathrm{~Hz}, \mathrm{~J}_{2}=4,1 \mathrm{~Hz}\right) ; 3,52\left(\mathrm{dd} ; 1 \mathrm{H}, \mathrm{J}_{1}=9,9 \mathrm{~Hz}, \mathrm{~J}_{2}=7,5 \mathrm{~Hz}\right) ; 4,40(\mathrm{~d} ; 1 \mathrm{H} ; \mathrm{J}=11,8 \mathrm{~Hz}) ; 4,44$ $(\mathrm{d} ; 1 \mathrm{H} ; \mathrm{J}=11,8 \mathrm{~Hz}), 5,56-5,61(\mathrm{~m}, 1 \mathrm{H}) ; 5,72-5,76(\mathrm{~m}, 1 \mathrm{H}) ; 7,20-7,38(\mathrm{~m}, 5 \mathrm{H}) ; 9,62$ (s, $1 \mathrm{H})$.

RMN ${ }^{13} \mathrm{C}\left(\mathrm{CDCl}_{3}, 125 \mathrm{MHz}\right) \delta(\mathrm{ppm}): 14,7\left(\mathrm{CH}_{3}\right) ; 16,2\left(\mathrm{CH}_{3}\right) ; 29,0(\mathrm{CH}) ; 30,8\left(\mathrm{CH}_{2}\right)$; 44,6 (CH); 49,2 (C); 70,0 ( $\left.\mathrm{CH}_{2}\right) ; 72,9\left(\mathrm{CH}_{2}\right) ; 125,3(\mathrm{CH}) ; 127,5(\mathrm{CH}) ; 127,6(\mathrm{CH}) ; 127,7$ $(\mathrm{CH}) ; 128,4(\mathrm{CH}) ; 137,8(\mathrm{C}) ; 206,7(\mathrm{CHO})$.

IR $v_{\text {máx }} \cdot(\mathrm{KBr}): 676 \mathrm{~cm}^{-1} ; 1100 \mathrm{~cm}^{-1} ; 1478 \mathrm{~cm}^{-1} ; 1720 \mathrm{~cm}^{-1} ; 2854 \mathrm{~cm}^{-1} ; 2924 \mathrm{~cm}^{-1} ; 3036$ $\mathrm{cm}^{-1}$.

HRMS (ESI-TOF): calc. para $\mathrm{C}_{17} \mathrm{H}_{23} \mathrm{O}_{2}{ }^{+}\left(\mathrm{MH}^{+}\right)$, 259,1698; experimental: 259,1787 ( $\Delta$ de $34 \mathrm{ppm}$ - limite de $50 \mathrm{ppm})$. 
7.37 - Preparação do $( \pm)-\{(1 R, 2 S, 6 S)-2-[($ benziloxi $)$ metil]-1,6-dimetilciclo-hex-3-en1-ilo\}metanol (301).<smiles>CC1CC=C[C@H](COCc2ccccc2)[C@H]1COCc1ccccc1</smiles>

Procedimento: A uma suspensão, mantida à $0^{\circ} \mathrm{C}$, contendo $30 \mathrm{mg}(0,75 \mathrm{mmol})$ de $\mathrm{LiAlH}_{4}$ 95\% e $2 \mathrm{~mL}$ de THF anidro, adicionou-se o composto 300 (165 mg, 0,64 mmol) dissolvido em $2 \mathrm{~mL}$ do mesmo solvente. A mistura foi agitada por 1 hora e ao final adicionou-se lentamente ao meio reacional água $(10 \mathrm{~mL})$. A mistura reacional foi extraída com éter $(4 \times 20 \mathrm{~mL})$ e as fases orgânicas foram reunidas e lavadas com solução saturada de $\mathrm{NaCl}(2 \times 10 \mathrm{~mL})$. Depois de secada com $\mathrm{MgSO}_{4}$ anidro o solvente foi removido sob pressão reduzida e o resíduo foi purificado por cromatografia em coluna de sílica-gel, utilizando-se como eluente uma mistura de hexano/acetato de etila (9:1).

Rendimento: $140 \mathrm{mg}(0,54 \mathrm{mmol})-84 \%$

$\mathrm{RMN}-{ }^{1} \mathrm{H}\left(\mathrm{CDCl}_{3}, 400 \mathrm{MHz}\right), \delta(\mathrm{ppm}): 0,82(\mathrm{~d} ; 3 \mathrm{H}, \mathrm{J}=6,6 \mathrm{~Hz}) ; 0,89(\mathrm{~s} ; 3 \mathrm{H}) ; 1,60-1,74$ (m, 2H); 1,94 (dddd; $1 \mathrm{H}, \mathrm{J}_{1}=13,0 \mathrm{~Hz} ; \mathrm{J}_{2}=4,8 \mathrm{~Hz} ; \mathrm{J}_{3}=2,3 \mathrm{~Hz} ; \mathrm{J}_{4}=1,0 \mathrm{~Hz}$ ); 2,27 (dddd; $\left.1 \mathrm{H}, \mathrm{J}_{1}=8,8 \mathrm{~Hz} ; \mathrm{J}_{2}=5,2 \mathrm{~Hz} ; \mathrm{J}_{3}=2,4 \mathrm{~Hz} ; \mathrm{J}_{4}=1,7 \mathrm{~Hz}\right) ; 3,36\left(\mathrm{dd}, 1 \mathrm{H}, \mathrm{J}_{1}=10,1 \mathrm{~Hz}, \mathrm{~J}_{2}=2,4\right.$ $\mathrm{Hz}) ; 3,38(\mathrm{~d} ; 1 \mathrm{H}, \mathrm{J}=11,9 \mathrm{~Hz}) ; 3,50(\mathrm{~d} ; 1 \mathrm{H}, \mathrm{J}=11,9 \mathrm{~Hz}) ; 3,55\left(\mathrm{dd} ; 1 \mathrm{H}, \mathrm{J}_{1}=10,1 \mathrm{~Hz}, \mathrm{~J}_{2}=\right.$ $8,8 \mathrm{~Hz}) ; 4,53(\mathrm{sl}, 2 \mathrm{H}) ; 5,48\left(\mathrm{ddt} ; 1 \mathrm{H}, \mathrm{J}_{1}=10,0 \mathrm{~Hz} ; \mathrm{J}_{2}=5,2 \mathrm{~Hz} ; \mathrm{J}_{3}=\mathrm{J}_{4}=1,0 \mathrm{~Hz}\right) 5,65(\mathrm{ddt}$; $\left.1 \mathrm{H}, 1 \mathrm{H}, \mathrm{J}_{1}=10,0 \mathrm{~Hz} ; \mathrm{J}_{2}=4,8 \mathrm{~Hz} ; \mathrm{J}_{3}=\mathrm{J}_{4}=1,7 \mathrm{~Hz}\right) ; 7,27-7,40(\mathrm{~m}, 5 \mathrm{H})$.

RMN- ${ }^{13} \mathrm{C}\left(\mathrm{CDCl}_{3}, 100 \mathrm{MHz}\right) \delta(\mathrm{ppm}): 15,0\left(\mathrm{CH}_{3}\right) ; 16,1\left(\mathrm{CH}_{3}\right) ; 29,3(\mathrm{CH}) ; 31,9\left(\mathrm{CH}_{2}\right)$; $39,0(\mathrm{C}) ; 43,7(\mathrm{CH}) ; 68,2\left(\mathrm{CH}_{2}\right) ; 71,0\left(\mathrm{CH}_{2}\right) ; 73,6\left(\mathrm{CH}_{2}\right) ; 126,4(\mathrm{CH}) ; 128,0(\mathrm{CH}) ; 128,0$ $(\mathrm{CH}) ; 127,6(\mathrm{CH}) ; 128,1(\mathrm{CH}) ; 128,6(\mathrm{CH}) ; 137,2(\mathrm{C})$.

IR $v_{\text {máx }}(\mathrm{KBr}): 698 \mathrm{~cm}^{-1} ; 736 \mathrm{~cm}^{-1} ; 1092 \mathrm{~cm}^{-1} ; 1494 \mathrm{~cm}^{-1} ; 2880 \mathrm{~cm}^{-1} ; 2962 \mathrm{~cm}^{-1} ; 3024$ $\mathrm{cm}^{-1} ; 3140-3658 \mathrm{~cm}^{-1}$.

HRMS (ESI-TOF): calc. para $\mathrm{C}_{17} \mathrm{H}_{25} \mathrm{O}_{2}{ }^{+}\left(\mathrm{MH}^{+}\right), 261,1855$; experimental: 261,1924 ( $\Delta$ de $26 \mathrm{ppm}$ - limite de $50 \mathrm{ppm})$.

Análise Elementar: calc. para $\mathrm{C}_{17} \mathrm{H}_{24} \mathrm{O}_{2}, \mathrm{C}: 78,42, \mathrm{H}: 9,29$; experimental: C: $78,80, \mathrm{H}$ : 9,54 . 
7.38 - Preparação do ( \pm )-\{(1R,2S,6S)-2-[(benziloxi)metil]-1,6-dimetilciclo-hex-3-en1-ilo\}metanol (293) sem a purificação do aduto 300.

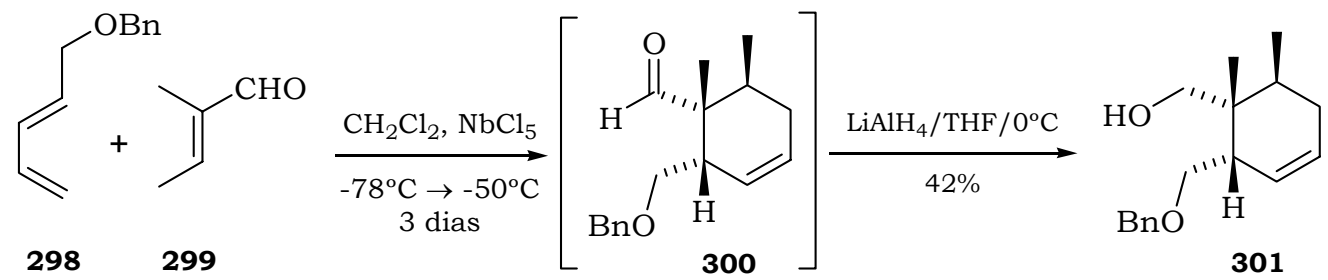

Procedimento: Foram misturados à $-78^{\circ} \mathrm{C} 405 \mathrm{mg}(1,50 \mathrm{mmol})$ de $\mathrm{NbCl}_{5}$ e $7 \mathrm{~mL}$ de $\mathrm{CH}_{2} \mathrm{Cl}_{2}$ anidro e, em seguida, adicionou-se o tiglaldeído (299) (2,02 g, 24,0 mmol) dissolvido em $7 \mathrm{~mL}$ do mesmo solvente anidro, deixando-se agitar por 2 minutos. Após isso, adicionou-se o dieno 298 (1,05 g, 6,00 mmol) em $7 \mathrm{~mL}$ de $\mathrm{CH}_{2} \mathrm{Cl}_{2}$ anidro (também à $-78^{\circ} \mathrm{C}$ ) deixando-se nesta temperatura por 30 minutos. Após este tempo a reação foi transferida para um banho térmico e mantida à $-50^{\circ} \mathrm{C}$ por 3 dias. Ao meio reacional foram adicionados $50 \mathrm{~mL}$ de água e a mistura foi extraída com 4 porções de $50 \mathrm{~mL}$ de $\mathrm{CH}_{2} \mathrm{Cl}_{2}$. As fases orgânicas foram reunidas e lavadas com solução saturada de $\mathrm{NaCl}(2 \mathrm{x}$ $30 \mathrm{~mL}$ ) e em seguida secada com $\mathrm{MgSO}_{4}$ anidro. $\mathrm{O}$ solvente foi removido sob pressão reduzida e o resíduo foi dissolvido em $20 \mathrm{~mL}$ de THF anidro e adicionado a uma suspensão, mantida à $0^{\circ} \mathrm{C}$, contendo $1,0 \mathrm{~g}(25 \mathrm{mmol})$ de $\mathrm{LiAlH}_{4} 95 \%$ e $10 \mathrm{~mL}$ do mesmo solvente. A mistura foi agitada por 1 hora e ao final adicionou-se lentamente ao meio reacional água $(40 \mathrm{~mL})$. A mistura reacional foi extraída com éter $(4 \times 50 \mathrm{~mL})$ e as fases orgânicas foram reunidas e lavadas com solução saturada de $\mathrm{NaCl}(2 \times 30 \mathrm{~mL})$. Depois de secar com $\mathrm{MgSO}_{4}$ anidro o solvente foi removido sob pressão reduzida e o resíduo foi purificado por cromatografia em coluna de sílica-gel, utilizando-se como eluente uma mistura de hexano/acetato de etila $(9,5: 0,5)$.

Rendimento: $656 \mathrm{mg}(2,52 \mathrm{mmol})-42 \%$

RMN- ${ }^{1} \mathrm{H}\left(\mathrm{CDCl}_{3}, 400 \mathrm{MHz}\right), \delta(\mathrm{ppm}): 0,82(\mathrm{~d} ; 3 \mathrm{H}, \mathrm{J}=6,6 \mathrm{~Hz}) ; 0,89(\mathrm{~s} ; 3 \mathrm{H}) ; 1,60-1,74$ (m, 2H); 1,94 (dddd; $1 \mathrm{H}, \mathrm{J}_{1}=13,0 \mathrm{~Hz} ; \mathrm{J}_{2}=4,8 \mathrm{~Hz} ; \mathrm{J}_{3}=2,3 \mathrm{~Hz} ; \mathrm{J}_{4}=1,0 \mathrm{~Hz}$ ); 2,27 (dddd; $\left.1 \mathrm{H}, \mathrm{J}_{1}=8,8 \mathrm{~Hz} ; \mathrm{J}_{2}=5,2 \mathrm{~Hz} ; \mathrm{J}_{3}=2,4 \mathrm{~Hz} ; \mathrm{J}_{4}=1,7 \mathrm{~Hz}\right) ; 3,36\left(\mathrm{dd}, 1 \mathrm{H}, \mathrm{J}_{1}=10,1 \mathrm{~Hz}, \mathrm{~J}_{2}=2,4\right.$ $\mathrm{Hz}) ; 3,38(\mathrm{~d} ; 1 \mathrm{H}, \mathrm{J}=11,9 \mathrm{~Hz}) ; 3,50(\mathrm{~d} ; 1 \mathrm{H}, \mathrm{J}=11,9 \mathrm{~Hz}) ; 3,55\left(\mathrm{dd} ; 1 \mathrm{H}, \mathrm{J}_{1}=10,1 \mathrm{~Hz}, \mathrm{~J}_{2}=\right.$ $8,8 \mathrm{~Hz}) ; 4,53(\mathrm{sl}, 2 \mathrm{H}) ; 5,48\left(\mathrm{ddt} ; 1 \mathrm{H}, \mathrm{J}_{1}=10,0 \mathrm{~Hz} ; \mathrm{J}_{2}=5,2 \mathrm{~Hz} ; \mathrm{J}_{3}=\mathrm{J}_{4}=1,0 \mathrm{~Hz}\right) 5,65(\mathrm{ddt}$; $\left.1 \mathrm{H}, 1 \mathrm{H}, \mathrm{J}_{1}=10,0 \mathrm{~Hz} ; \mathrm{J}_{2}=4,8 \mathrm{~Hz} ; \mathrm{J}_{3}=\mathrm{J}_{4}=1,7 \mathrm{~Hz}\right) ; 7,27-7,40(\mathrm{~m}, 5 \mathrm{H})$.

$\mathrm{RMN}-{ }^{13} \mathrm{C}\left(\mathrm{CDCl}_{3}, 100 \mathrm{MHz}\right) \delta(\mathrm{ppm}): 15,0\left(\mathrm{CH}_{3}\right) ; 16,1\left(\mathrm{CH}_{3}\right) ; 29,3(\mathrm{CH}) ; 31,9\left(\mathrm{CH}_{2}\right)$; $39,0(\mathrm{C}) ; 43,7(\mathrm{CH}) ; 68,2\left(\mathrm{CH}_{2}\right) ; 71,0\left(\mathrm{CH}_{2}\right) ; 73,6\left(\mathrm{CH}_{2}\right) ; 126,4(\mathrm{CH}) ; 128,0(\mathrm{CH}) ; 128,0$ $(\mathrm{CH}) ; 127,6(\mathrm{CH}) ; 128,1(\mathrm{CH}) ; 128,6(\mathrm{CH}) ; 137,2(\mathrm{C})$.

IR $v_{\text {máx }}(\mathrm{KBr}): 698 \mathrm{~cm}^{-1} ; 736 \mathrm{~cm}^{-1} ; 1092 \mathrm{~cm}^{-1} ; 1494 \mathrm{~cm}^{-1} ; 2880 \mathrm{~cm}^{-1} ; 2962 \mathrm{~cm}^{-1} ; 3024$ $\mathrm{cm}^{-1} ; 3140-3658 \mathrm{~cm}^{-1}$.

HRMS (ESI-TOF): calc. para $\mathrm{C}_{17} \mathrm{H}_{25} \mathrm{O}_{2}{ }^{+}\left(\mathrm{MH}^{+}\right), 261,1855$; experimental: 261,1924 ( $\Delta$ de $26 \mathrm{ppm}$ - limite de $50 \mathrm{ppm}$ ).

Análise Elementar: calc. para $\mathrm{C}_{17} \mathrm{H}_{24} \mathrm{O}_{2}, \mathrm{C}: 78,42, \mathrm{H}$ : 9,29; experimental: C: $78,80, \mathrm{H}$ : 9,54 . 
7.39 - Preparação do $( \pm)-[(1 R, 2 S, 6 S)$-1,6-dimetilciclo-hexano-1,2-di-ilo]dimetanol $(223){ }^{153}$<smiles>C[C@H]1CCC[C@@H](CO)C1(CO)CO</smiles>

Procedimento: Foram misturados em um reator para hidrogenação $520 \mathrm{mg}$ (2,00 mmol) do composto 301 juntamente com $15 \mathrm{~mL}$ de etanol absoluto e quantidades catalíticas de $\mathrm{C} / \mathrm{Pd} 10 \%$. A este sistema aplicou-se um pressão de $\mathrm{H}_{2}$ (4 atm) deixando-se reagir por 4 horas. Em seguida o resíduo foi filtrado em uma pequena coluna contendo sílica gel e o solvente removido sob pressão reduzida. O produto 223 foi obtido devidamente puro.

Rendimento: $342 \mathrm{mg}(1,98 \mathrm{mmol})-99 \%$

RMN- ${ }^{1} \mathrm{H}\left(\mathrm{CDCl}_{3}, 400 \mathrm{MHz}\right), \delta(\mathrm{ppm}): 0,83(\mathrm{~d} ; 3 \mathrm{H}, \mathrm{J}=6,8 \mathrm{~Hz}) ; 0,94(\mathrm{~s} ; 3 \mathrm{H}) ; 1,20-1,70$ $(\mathrm{m}, 8 \mathrm{H}) ; 3,36(\mathrm{~d} ; 1 \mathrm{H}, \mathrm{J}=11,6 \mathrm{~Hz}) ; 3,57\left(\mathrm{dd} ; 1 \mathrm{H}, \mathrm{J}_{1}=11,1 \mathrm{~Hz}, \mathrm{~J}_{2}=2,0 \mathrm{~Hz}\right) ; 3,70(\mathrm{~d}, 1 \mathrm{H} ; \mathrm{J}$ $=11,6 \mathrm{~Hz}) ; 3,93\left(\mathrm{dd} ; 1 \mathrm{H}, \mathrm{J}_{1}=11,1 \mathrm{~Hz}, \mathrm{~J}_{2}=7,3 \mathrm{~Hz}\right) ; 3,97-4,14(\mathrm{~m} ; 2 \mathrm{H})$.

$\mathrm{RMN}-{ }^{13} \mathrm{C}\left(\mathrm{CDCl}_{3}, 100 \mathrm{mHz}\right) \delta(\mathrm{ppm}): 15,7\left(\mathrm{CH}_{3}\right) ; 18,3\left(\mathrm{CH}_{3}\right) ; 21,8\left(\mathrm{CH}_{2}\right) ; 26,5\left(\mathrm{CH}_{2}\right)$; 30,2 $\left(\mathrm{CH}_{2}\right) ; 32,8(\mathrm{CH}) ; 39,6(\mathrm{C}) ; 43,5(\mathrm{CH}) ; 64,1\left(\mathrm{CH}_{2}\right) ; 68,9\left(\mathrm{CH}_{2}\right)$.

IR $v_{\text {máx }}(\mathrm{KBr}): 1040 \mathrm{~cm}^{-1} ; 1246 \mathrm{~cm}^{-1} ; 1376 \mathrm{~cm}^{-1} ; 1460 \mathrm{~cm}^{-1} ; 2928 \mathrm{~cm}^{-1} ; 3060-3704 \mathrm{~cm}^{-1}$.

HRMS (ESI-TOF): calc. para $\mathrm{C}_{10} \mathrm{H}_{21} \mathrm{O}_{2}{ }^{+}\left(\mathrm{MH}^{+}\right), 173,1542$; experimental: $173,1488(\Delta$ de $31 \mathrm{ppm}$ - limite de 50 ppm). 
7.40 - Preparação do ( \pm$)-(1 R, 2 S, 6 S)-1,2-$ bis(iodometil)-1,6-dimetilciclo-hexano (224)..$^{154}$<smiles>CC1CCC[C@@H](CO)[C@]1(CO)CI</smiles>

Procedimento: Foram misturados $80 \mathrm{mg}(0,46 \mathrm{mmol})$ do diol $223 \mathrm{em} 4 \mathrm{~mL}$ de $\mathrm{CHCl}_{3}$ (filtrado previamente em uma coluna com $5 \mathrm{~cm}$ de sílica gel). $O$ balão reacional foi fechado com um "septa ruber Aldrich ${ }^{\circledR}$ e com o auxílio de agulhas foi passada uma corrente de argônio (uma agulha como entrada de argônio e outra para a saída do gás). Ainda com a entrada de argônio a mistura foi resfriada a $0^{\circ} \mathrm{C}$ e então foram adicionados lentamente 0,42 $\mathrm{mL}$ de $\mathrm{Me}_{3} \mathrm{SiI}(589 \mathrm{mg}, 2,94 \mathrm{mmol}$ ). O resfriamento foi retirado e a reação foi mantida a temperatura ambiente por 5 dias sem entrada nem saída de gás inerte e protegida da luz (envolvida com papel alumínio). Após este tempo foram adicionados $10 \mathrm{~mL}$ de uma solução $2 \%$ de tiossulfato de sódio e extraiu-se a mistura reacional com pentano ( 3 porções de $20 \mathrm{~mL}$ ). A fase orgânica foi secada com $\mathrm{MgSO}_{4}$ e o solvente foi removido sob pressão reduzida. O resíduo foi purificado por cromatografia em uma coluna de sílica gel, utilizando-se como eluente de hexano/acetato de etila 9,75:0,25.

Rendimento: $126 \mathrm{mg}(0,32 \mathrm{mols})-70 \%$

RMN- ${ }^{1} \mathrm{H}\left(\mathrm{CDCl}_{3}, 400 \mathrm{MHz}\right), \delta(\mathrm{ppm}): 0,87$ (d, 3H, J = 6,9 Hz); 1,02 (s, 3H); 1,22-1,94 $(\mathrm{m}, 8 \mathrm{H}) ; 3,11\left(\mathrm{dd}, 1 \mathrm{H}, \mathrm{J}_{1}=12,1 \mathrm{~Hz} ; \mathrm{J}_{2}=9,4 \mathrm{~Hz}\right) ; 3,13(\mathrm{~d}, 1 \mathrm{H}, \mathrm{J}=10,1 \mathrm{~Hz}) ; 3,49(\mathrm{dd}, 1 \mathrm{H}$, $\left.\mathrm{J}_{1}=9,4 \mathrm{~Hz} ; \mathrm{J}_{2}=3,0 \mathrm{~Hz}\right) ; 3,56(\mathrm{~d}, 1 \mathrm{H}, \mathrm{J}=10,1 \mathrm{~Hz})$.

RMN- ${ }^{13} \mathrm{C}\left(\mathrm{CDCl}_{3}, 100 \mathrm{MHz}\right), \delta(\mathrm{ppm}): 8,6\left(\mathrm{CH}_{2}\right) ; 15,5\left(\mathrm{CH}_{3}\right) ; 20,0\left(\mathrm{CH}_{2}\right) ; 21,4\left(\mathrm{CH}_{3}\right)$; $22,8\left(\mathrm{CH}_{2}\right) ; 25,9\left(\mathrm{CH}_{2}\right) ; 30,7\left(\mathrm{CH}_{2}\right) ; 34,8(\mathrm{CH}) ; 39,9(\mathrm{C}) ; 44,9(\mathrm{CH})$. 
7.41 - Preparação do 3-metilbut-2-enoato de metila (303). ${ }^{155}$

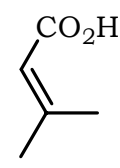

302

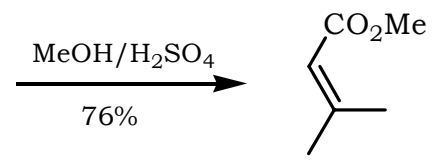

303

Procedimento: Foram misturados 5,0 g (50 mmol) do ácido $302 \mathrm{em} 25 \mathrm{~mL}$ de metanol e em seguida adicionado $1 \mathrm{~mL}$ de $\mathrm{H}_{2} \mathrm{SO}_{4}$ concentrado. A mistura foi refluxada por 6 horas. Após este tempo boa parte do metanol foi destilado do meio reacional e o resíduo foi resfriado até $0^{\circ} \mathrm{C}$. Adicionou-se então $30 \mathrm{~mL}$ de água/gelo (gelo fundente) e extraiu-se com éter etílico (3 porções de $30 \mathrm{~mL}$ ). As fases orgânicas foram reunidas, lavadas com solução saturada de $\mathrm{NaHCO}_{3}$ (2 porções de $20 \mathrm{~mL}$ ) e depois de $\mathrm{NaCl}$ (2 porções de 20 $\mathrm{mL}$ ). O éter foi destilado seguido da destilação do produto (p.e. $=131^{\circ} \mathrm{C}$, a pressão ambiente).

Rendimento: 4,3 g (38 mmols) - 76\%

RMN- ${ }^{1} \mathrm{H}\left(\mathrm{CDCl}_{3}, 400 \mathrm{MHz}\right), \delta(\mathrm{ppm}): 1,89$ (d, 3H, J = 1,5 Hz); 2,17 (d, 3H, J = 1,3 Hz); $3,67(\mathrm{~s}, 3 \mathrm{H}) ; 5,68\left(\mathrm{qq}, 1 \mathrm{H}, \mathrm{J}_{1}=\mathrm{J}_{2}=\mathrm{J}_{3}=1,5 \mathrm{~Hz} ; \mathrm{J}_{4}=\mathrm{J}_{5}=\mathrm{J}_{6}=1,3 \mathrm{~Hz}\right)$. 
7.42 - Preparação dos $( \pm)-(2 S)-2-\{[(1 R, 2 R, 3 S)-2$-(iodometil)-2,3-dimetilciclohexil]metil\}-3-metilbut-3-enoato de metila (286a) e $(2 R)-2-\{[(1 R, 2 R, 3 S)-2-$ (iodometil)-2,3-dimetilciclo-hexil]metil\}-3-metilbut-3-enoato de metila (286b). ${ }^{133,156}$<smiles>COC(=O)C=C(C)C</smiles>

303

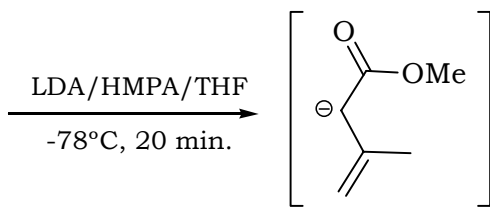

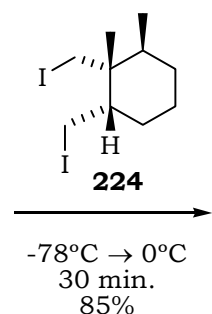

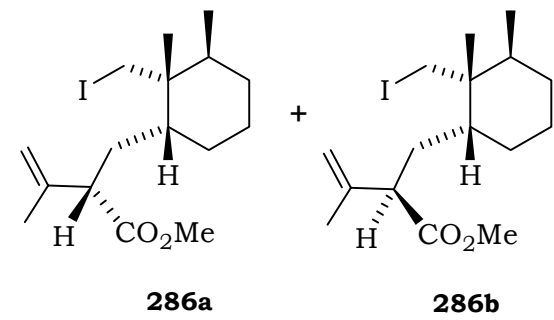

Procedimento:

Preparação da solução de LDA.

A uma solução mantida a $0^{\circ} \mathrm{C}$ contendo di-isopropilamina anidra $(289 \mathrm{mg}, 2,86 \mathrm{mmol}$, $0,40 \mathrm{~mL}$ ) e THF anidro ( $4 \mathrm{~mL}$ ), adicionou-se uma solução a $2,17 \mathrm{~mol} / \mathrm{L}$ de $n$-butil lítio (1,20 mL, 2,60 mmol) deixando-se agitar por 15 minutos. Em seguida adicionou-se HMPA anidra (465 mg, 0,46 mL, 2,65 mmol) deixando-se agitar por mais 15 minutos nesta temperatura.

Preparação do enolato:

A solução de LDA preparada anteriormente, foi resfriada à $-78^{\circ} \mathrm{C}$ e em seguida foram adicionados 0,40 mL de 3-metil-2-butenoato de metila 303 (350 mg, 3,07 mmol) deixando-se reagir por 20 minutos.

Adição do enolato:

Após isto, foram adicionados ao meio reacional $510 \mathrm{mg}(1,30 \mathrm{mmol})$ do di-iodeto 224 dissolvidos em $2 \mathrm{~mL}$ de THF anidro e mantido a $-78^{\circ} \mathrm{C}$. A mistura reacional ficou sob agitação nesta temperatura por 3 minutos e então a temperatura foi elevada lentamente até $0^{\circ} \mathrm{C}$ sendo mantida nesta por mais 30 minutos. Para o término da reação adicionouse $\mathrm{H}_{2} \mathrm{O}(20 \mathrm{~mL})$ e extraiu-se com éter etílico (3 porções de $\left.40 \mathrm{~mL}\right)$. As fases orgânicas foram reunidas e lavadas com solução saturada de $\mathrm{NaCl}$ e em seguida secadas com $\mathrm{MgSO}_{4}$ anidro. O solvente foi então removido sob pressão reduzida e o resíduo foi purificado por cromatografia em coluna de sílica gel, utilizando-se como eluente de hexano/acetato de etila 9,75:0,25. Os dois diastereoisômeros 286a e $286 \mathrm{~b}$ foram obtidos em quantidades equimolares e devidamente separados nas condições descritas acima.

Rendimento: $420 \mathrm{mg}(1,11$ mmols $)-85 \%$.

Primeiro diastereoisômero (286a ou 286b).

RMN- ${ }^{1} \mathrm{H}\left(\mathrm{CDCl}_{3}, 400 \mathrm{MHz}\right), \delta$ (ppm): 0,86 (d, 3H, J = 7,1 Hz); 0,95 (s, 3H); 1,20-1,60 $(\mathrm{m}, 8 \mathrm{H}) ; 1,70-1,88(\mathrm{~m}, 2 \mathrm{H}) ; 1,89(\mathrm{sl}, 3 \mathrm{H}) ; 3,12\left(\mathrm{dd}, 1 \mathrm{H}, \mathrm{J}_{1}=10,6 \mathrm{~Hz} ; \mathrm{J}_{2}=4,5 \mathrm{~Hz}\right) ; 3,23$ $(\mathrm{d}, 1 \mathrm{H}, \mathrm{J}=9,8 \mathrm{~Hz}) ; 3,59(\mathrm{~d}, 1 \mathrm{H}, \mathrm{J}=9,8) ; 3,68(\mathrm{~s}, 3 \mathrm{H}) ; 4,91(\mathrm{~m}, 1 \mathrm{H}) ; 4,95(\mathrm{~m}, 1 \mathrm{H})$. 
$\mathrm{RMN}-{ }^{13} \mathrm{C}\left(\mathrm{CDCl}_{3}, 100 \mathrm{MHz}\right), \delta(\mathrm{ppm}): 15,4\left(\mathrm{CH}_{3}\right) ; 19,9\left(\mathrm{CH}_{3}\right) ; 20,1\left(\mathrm{CH}_{2}\right) ; 23,2\left(\mathrm{CH}_{3}\right)$; 23,4 $\left(\mathrm{CH}_{2}\right) ; 24,5\left(\mathrm{CH}_{2}\right) ; 27,0\left(\mathrm{CH}_{2}\right) ; 30,1\left(\mathrm{CH}_{2}\right) ; 34,7(\mathrm{CH}), 37,7(\mathrm{CH}) ; 38,0(\mathrm{C}) ; 50,6$ $(\mathrm{CH}) ; 51,9\left(\mathrm{CH}_{3}\right) ; 115,1\left(\mathrm{CH}_{2}\right) ; 141,6(\mathrm{C}) ; 174,5(\mathrm{C})$.

Segundo diastereoisômero (286a ou 286b).

RMN- ${ }^{1} \mathrm{H}\left(\mathrm{CDCl}_{3}, 400 \mathrm{MHz}\right), \delta(\mathrm{ppm}): 0,87$ (d, 3H, J = 7,1 Hz); 0,97 (s, 3H); 1,20-1,65 $(\mathrm{m}, 8 \mathrm{H}) ; 1,76(\mathrm{sl}, 3 \mathrm{H}) ; 1,78-1,88(\mathrm{~m}, 1 \mathrm{H}) ; 2,02\left(\mathrm{ddd}, 1 \mathrm{H}, \mathrm{J}_{1}=13,4 \mathrm{~Hz} ; \mathrm{J}_{2}=10,8 \mathrm{~Hz} ; \mathrm{J}_{3}=\right.$ 2,5 Hz); 3,13 (dd, $\left.1 \mathrm{H}, \mathrm{J}_{1}=10,8 \mathrm{~Hz} ; \mathrm{J}_{2}=3,8 \mathrm{~Hz}\right) ; 3,21(\mathrm{~d}, 1 \mathrm{H}, \mathrm{J}=9,8 \mathrm{~Hz}) ; 3,60(\mathrm{~d}, 1 \mathrm{H}, \mathrm{J}=$ $9,8) ; 3,70(\mathrm{~s}, 3 \mathrm{H}) ; 4,88(\mathrm{~m}, 1 \mathrm{H}) ; 4,90(\mathrm{~m}, 1 \mathrm{H})$.

$\mathrm{RMN}-{ }^{13} \mathrm{C}\left(\mathrm{CDCl}_{3}, 100 \mathrm{MHz}\right), \delta(\mathrm{ppm}): 15,2\left(\mathrm{CH}_{3}\right) ; 20,2\left(\mathrm{CH}_{2}\right) ; 20,9\left(\mathrm{CH}_{3}\right) ; 22,9\left(\mathrm{CH}_{2}\right)$; 23,6 $\left(\mathrm{CH}_{3}\right) ; 25,6\left(\mathrm{CH}_{2}\right) ; 29,5\left(\mathrm{CH}_{2}\right) ; 29,7\left(\mathrm{CH}_{2}\right) ; 35,0(\mathrm{CH}), 38,1(\mathrm{C}) ; 38,5(\mathrm{CH}) ; 51,0$ $(\mathrm{CH}) ; 51,8\left(\mathrm{CH}_{3}\right) ; 113,0\left(\mathrm{CH}_{2}\right) ; 143,3(\mathrm{C}) ; 173,7(\mathrm{C})$.

IR $v_{\text {max }} \cdot(\mathrm{KBr}): 898 \mathrm{~cm}^{-1} ; 1166 \mathrm{~cm}^{-1} ; 1648 \mathrm{~cm}^{-1} ; 1736 \mathrm{~cm}^{-1} ; 2932 \mathrm{~cm}^{-1}$.

HRMS (ESI-TOF): calc. para $\mathrm{C}_{16} \mathrm{H}_{28} \mathrm{IO}_{2}{ }^{+}\left(\mathrm{MH}^{+}\right)$, 379,1134; experimental: 379,1309 ( $\Delta$ de 46 ppm - limite de 50 ppm). 
7.43 - Preparação dos $( \pm)-(2 R, 3 \mathrm{a} R, 4 S, 7 \mathrm{a} R)-2$-isopropenil-3a,4-dimetiloctaidro- $1 H$ indeno-2-carboxilato de metila (287) e $( \pm)-(2 S, 3 \mathrm{a} R, 4 S, 7 \mathrm{a} R)-2$-isopropenil-3a,4dimetiloctaidro- $1 H$-indeno-2-carboxilato metila (288). ${ }^{133,156}$<smiles>C=C(C)[C@H](C[C@H]1CCC[C@@H](C)[C@]1(C)CI)C(=O)OC</smiles>

286a

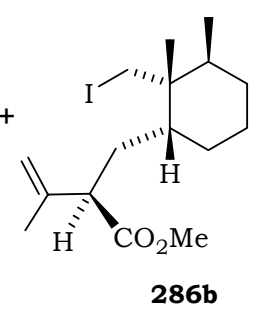<smiles>C=C(C)[C@]1(C(=O)OC)C[C@H]2CCC[C@@H](C)[C@]2(C)C1</smiles>

287<smiles>C=C(C)[C@]1(C(=O)OC)C[C@H]2CCC[C@H](C)[C@]2(C)C1</smiles>

288

$18: 82$

\section{Procedimento:}

Preparação da solução de LDA.

A uma solução mantida a $0^{\circ} \mathrm{C}$ contendo di-isopropilamina anidra $(212 \mathrm{mg}, 2,10 \mathrm{mmol}$, $0,30 \mathrm{~mL}$ ) e THF anidro (4 mL), adicionou-se uma solução a 2,15 mol/L de $n$-butil lítio (0,93 mL, 2,00 mmol) deixando-se agitar por 15 minutos. Em seguida adicionou-se HMPA anidra $(362 \mathrm{mg}, 0,35 \mathrm{~mL}, 2,02 \mathrm{mmol})$ deixando-se agitar por mais 15 minutos nesta temperatura.

Preparação do enolato/ciclização:

A solução de LDA foi resfriada a $-78^{\circ} \mathrm{C}$. Após isto se adicionou uma mistura dos compostos 286a e 286b (380mg, 1,00 mmol) dissolvidos em $2 \mathrm{~mL}$ de THF e a temperatura do sistema reacional foi mantida a $-78^{\circ} \mathrm{C}$ por 3 horas.. Para o término da reação adicionou-se $\mathrm{H}_{2} \mathrm{O}(20 \mathrm{~mL})$ e extraiu-se com éter etílico (3 porções de $\left.40 \mathrm{~mL}\right)$. As fases orgânicas foram reunidas e lavadas com solução saturada de $\mathrm{NaCl}$ e em seguida secadas com $\mathrm{MgSO}_{4}$ anidro. $\mathrm{O}$ solvente foi então removido sob pressão reduzida e o resíduo foi purificado por cromatografia em coluna de sílica gel, utilizando-se como eluente de hexano/acetato de etila 9,5:0,5. Obteve-se uma mistura 18:82 dos epímeros 287 e 288 respectivamente, não sendo possível, nestas condições, separar cada um dos epímeros. $\underline{A}$ análise de $\mathrm{RMN}$ de ${ }^{1} \mathrm{H} \mathrm{e}{ }^{13} \mathrm{C}$ da mistura dos dois epímeros foi comparada com dados da literatura. ${ }^{139}$

Rendimento: $143 \mathrm{mg}(0,57 \mathrm{~mol})-57 \%$

O espectro de RMN ${ }^{1} \mathrm{H}$ da mistura encontra-se na seção de espectros.

IR $v_{\text {máx }} \cdot(\mathrm{KBr}): 890 \mathrm{~cm}^{-1} ; 1158 \mathrm{~cm}^{-1} ; 1224 \mathrm{~cm}^{-1} ; 1642 \mathrm{~cm}^{-1} ; 1734 \mathrm{~cm}^{-1} ; 2926 \mathrm{~cm}^{-1}$.

HRMS (ESI-TOF): calc. para $\mathrm{C}_{16} \mathrm{H}_{27} \mathrm{O}_{2}{ }^{+}\left(\mathrm{MH}^{+}\right), 251,2011$; experimental: 251,1915 ( $\Delta$ de $38 \mathrm{ppm}$ - limite de $50 \mathrm{ppm})$. 
7.44 - Preparação do 3-metilbut-2-enoato $t$-butila (304). ${ }^{157}$<smiles>CC(C)=CC(=O)O</smiles>

302

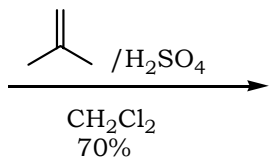

$70 \%$<smiles>CCOC(=O)C=C(C)C</smiles>

304

Procedimento: Foram misturados em um erlenmeyer 5,0 g do ácido 302 (50 mmol) 50 $\mathrm{mL}$ de diclorometano e $1 \mathrm{~mL}$ de $\mathrm{H}_{2} \mathrm{SO}_{4}$ concentrado. Em seguida borbulhou-se isobutileno ${ }^{\text {xxvii }}$ no meio reacional até que praticamente todo o ácido fosse consumido (4 horas). Após este tempo adicionou-se gelo fundente $(\sim 30 \mathrm{~mL})$ ao meio reacional separando se a fase orgânica. A fase aquosa foi ainda extraída com mais duas porções de diclorometano $(30 \mathrm{~mL})$. Em seguida as fases orgânicas foram reunidas e lavadas com solução saturada de $\mathrm{NaHCO}_{3}$ (2 porções de $20 \mathrm{~mL}$ ) e depois de $\mathrm{NaCl}$ (2 porções de 20 $\mathrm{mL}$ ). A fase orgânica foi secada com $\mathrm{MgSO}_{4}$ e o solvente removido sob pressão reduzida. $\mathrm{O}$ resíduo orgânico foi destilado a $80^{\circ} \mathrm{C}$ e pressão reduzida $(30 \mathrm{mmHg})$.

Rendimento: 5,5 g (35 mmol) - 70\%

RMN- ${ }^{1} \mathrm{H}\left(\mathrm{CDCl}_{3}, 400 \mathrm{MHz}\right), \delta(\mathrm{ppm}): 1,47$ (s, 9H); 1,85 (d, 3H, J = 1,3 Hz); 2,12 (d, 3H. $\mathrm{J}=1,3 \mathrm{~Hz}) ; 5,60$ (sept, $1 \mathrm{H}, \mathrm{J}=1,3 \mathrm{~Hz}$ ).

IR $v_{\text {máx }} \cdot(\mathrm{KBr}): 2978 \mathrm{~cm}^{-1} ; 1718 \mathrm{~cm}^{-1} ; 1656 \mathrm{~cm}^{-1} ; 1140 \mathrm{~cm}^{-1}$.

xxviii Para gerar o isobutileno foram misturados em um balão, adaptado com condensador de refluxo e uma mangueira de silicone no topo do condensador, $140 \mathrm{~mL}$ de t-butanol com $40 \mathrm{~mL}$ de $\mathrm{H}_{2} \mathrm{SO}_{4} 50 \%$ e aqueceu-se com uma manta térmica até começar a liberação de gás. 
7.45 - Preparação dos $( \pm)-(2 S)-2-\{[(1 R, 2 R, 3 S)-2$-(iodometil)-2,3-dimetilciclohexil]metil $\}-3-$ metilbut-3-enoato de $t$-butila (305a) e $(2 R)-2-\{[(1 R, 2 R, 3 S)-2-$ (iodometil)-2,3-dimetilciclo-hexil]metil\}-3-metilbut-3-enoato de $t$-butila (305b).

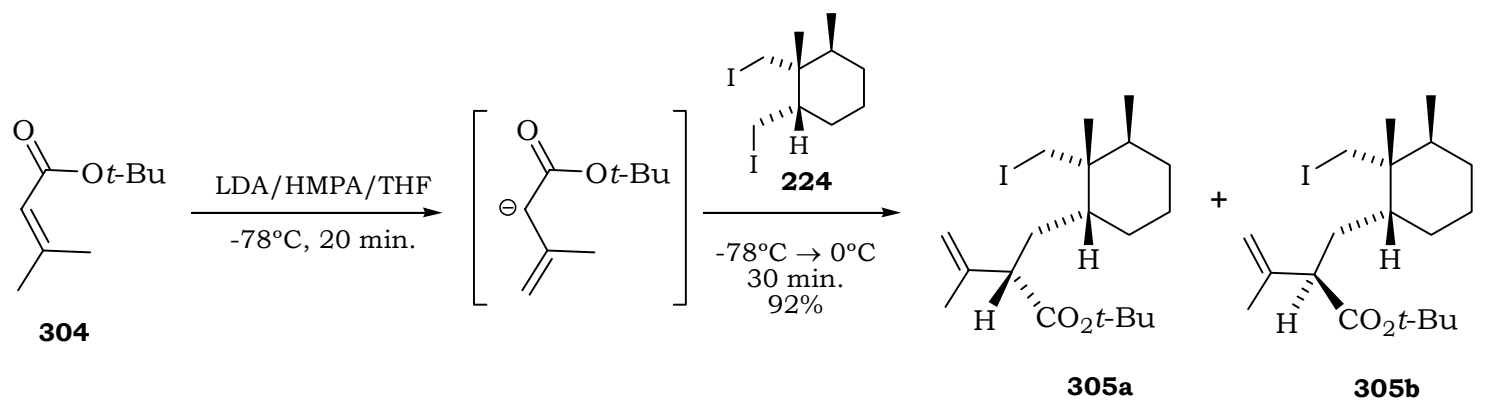

\section{Procedimento:}

Preparação da solução de LDA.

A uma solução mantida a $0^{\circ} \mathrm{C}$ contendo di-isopropilamina anidra $(239 \mathrm{mg}, 2,36 \mathrm{mmol}$, $0,33 \mathrm{~mL}$ ) e THF anidro ( $4 \mathrm{~mL}$ ), adicionou-se uma solução a $2,15 \mathrm{~mol} / \mathrm{L}$ de $n$-butil lítio $(1,0 \mathrm{~mL}, 2,15 \mathrm{mmol})$ deixando agitar por 15 minutos. Em seguida adicionou-se HMPA anidra (391 mg, 0,38 mL, 2,18 mmol) deixando-se agitar por mais 15 minutos nesta temperatura.

Preparação do enolato:

A solução de LDA preparada anteriormente, foi resfriada a $-78^{\circ} \mathrm{C}$ e em seguida adicionou-se $343 \mathrm{mg}(2,20 \mathrm{mmol})$ do éster t-butílico 304 dissolvido em 1,0 mL de THF anidro, deixou-se reagir por mais 20 minutos.

\section{Adição do enolato:}

Após isto, foram adicionados ao meio reacional $420 \mathrm{mg}(1,07 \mathrm{mmol})$ do di-iodeto 224 dissolvidos em $2 \mathrm{~mL}$ de THF anidro e mantido a $-78^{\circ} \mathrm{C}$. A mistura reacional ficou sob agitação nesta temperatura por 3 minutos e então a temperatura foi elevada lentamente até $0^{\circ} \mathrm{C}$ sendo mantida nesta por mais $30 \mathrm{~min}$. Para o término da reação adicionou-se $\mathrm{H}_{2} \mathrm{O}(20 \mathrm{~mL})$ e extraiu-se com éter etílico (3 porções de $40 \mathrm{~mL}$ ). As fases orgânicas foram reunidas e lavadas com solução saturada de $\mathrm{NaCl}$ e em seguida secadas com $\mathrm{MgSO}_{4}$ anidro. O solvente foi então removido sob pressão reduzida e o resíduo foi purificado por cromatografia em uma coluna de sílica gel, utilizando-se como eluente de hexano/acetato de etila 9,5:0,5. Os diastereoisômeros 305a e 305b foram obtidos em proporções próximas de 1:1, mas não puderam ser separados nestas e em outras condições experimentadas.

Rendimento: 416 mg (0,99 mmol) - 92\%

O espectro de RMN ${ }^{1} \mathrm{H}$ da mistura encontra-se na seção de espectros.

IR $v_{\text {máx }}(\mathrm{KBr}): 896 \mathrm{~cm}^{-1} ; 1148 \mathrm{~cm}^{-1} ; 1460 \mathrm{~cm}^{-1} ; 1648 \mathrm{~cm}^{-1} ; 1726 \mathrm{~cm}^{-1} ; 2930 \mathrm{~cm}^{-1} ; 2972$ $\mathrm{cm}^{-1}$.

HRMS (ESI-TOF): calc. para $\mathrm{C}_{19} \mathrm{H}_{34} \mathrm{IO}_{2}{ }^{+}\left(\mathrm{MH}^{+}\right), 421,1604$; experimental: 421,1638 ( $\Delta$ de 8 ppm - limite de 50 ppm). 
7.46 - Preparação dos $( \pm)-(2 R, 3 \mathrm{a} R, 4 S, 7 \mathrm{a} R)-2$-isopropenil-3a,4-dimetiloctaidro- $1 H$ indeno-2-carboxilato de $t$-butila (306) e $( \pm)-(2 S, 3 \mathrm{a} R, 4 S, 7 \mathrm{a} R)-2$-isopropenil-3a,4dimetiloctaidro- $1 H$-indeno-2-carboxilato $t$-butila (307).<smiles>C=C(C)[C@H](C[C@@H]1CCC[C@@H](C)[C@]1(C)CI)C(=O)OC(C)(C)C</smiles>

$305 a$

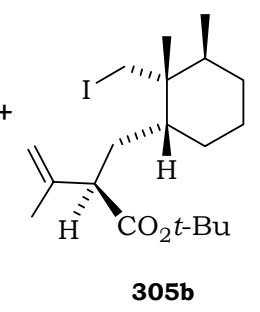<smiles>C=C(C)[C@]1(C(=O)OCC(C)(C)C)C[C@H]2CCC[C@@H](C)[C@]2(C)C1</smiles>

306<smiles>C=C(C)[C@]1(C(=O)OCC(C)(C)C)C[C@H]2CCC[C@@H](C)[C@]2(C)C1</smiles>

$42: 58$

\section{Procedimento:}

Preparação da solução de LDA.

A uma solução mantida a $0^{\circ} \mathrm{C}$ contendo di-isopropilamina anidra $(253 \mathrm{mg}, 2,50 \mathrm{mmol}$, $0,35 \mathrm{~mL})$ e THF anidro $(4 \mathrm{~mL})$, adicionou-se uma solução a $2,10 \mathrm{~mol} / \mathrm{L}$ de $n$-butil lítio $(1,10 \mathrm{~mL}, 2,32 \mathrm{mmol})$ deixando agitar por 15 minutos. Em seguida adicionou-se HMPA anidra (430 mg, 0,42 mL, 2,40 mmol) deixando-se agitar por mais 15 minutos nesta temperatura.

Preparação do enolato/ciclização:

Em seguida a solução de LDA foi resfriada a $-78^{\circ} \mathrm{C}$. Após isto se adicionou uma mistura dos compostos 305a e 305b (490 mg, 1,16 mmol) dissolvidos em 2,5 mL de THF e a temperatura do sistema reacional foi mantida a $-78^{\circ} \mathrm{C}$ por 1 hora. A temperatura do meio reacional foi elevada lentamente até $0^{\circ} \mathrm{C}$ e mantida assim por 2 horas. Para o término da reação adicionou-se $\mathrm{H}_{2} \mathrm{O}(20 \mathrm{~mL})$ e extraiu-se com éter etílico (3 porções de $30 \mathrm{~mL}$ ). As fases orgânicas foram reunidas e lavadas com solução saturada de $\mathrm{NaCl}$ e em seguida secadas com $\mathrm{MgSO}_{4}$ anidro. $\mathrm{O}$ solvente foi removido sob pressão reduzida e o resíduo foi purificado por cromatografia em coluna de sílica gel, utilizando-se como eluente de hexano/acetato de etila 9,5:0,5. Obteve-se uma mistura 42:58 dos epímeros 296 e 297 respectivamente, não sendo possível, nestas condições, separar cada um dos epímeros. $\underline{A}$ análise de RMN de ${ }^{1} \mathrm{H} \mathrm{e}{ }^{13} \mathrm{C}$ da mistura dos dois epímeros foi comparada com as dos compostos 287 e 288.

Rendimento: $260 \mathrm{mg}(0,89 \mathrm{mmol})-77 \%$

O espectro de RMN ${ }^{1} \mathrm{H}$ da mistura encontra-se na seção de espectros.

IR $v_{\text {máx }}(\mathrm{KBr}): 1152 \mathrm{~cm}^{-1} ; 1460 \mathrm{~cm}^{-1} ; 1638 \mathrm{~cm}^{-1} ; 1720 \mathrm{~cm}^{-1} ; 2926 \mathrm{~cm}^{-1} ; 2964 \mathrm{~cm}^{-1}$.

HRMS (ESI-TOF): calc. para $\mathrm{C}_{19} \mathrm{H}_{33} \mathrm{O}_{2}{ }^{+}\left(\mathrm{MH}^{+}\right), 293,2480$; experimental: 293,2421 ( $\Delta$ de $20 \mathrm{ppm}$ - limite de $50 \mathrm{ppm}$ ). 
7.47 - Preparação dos $( \pm)-(2 R, 3 \mathrm{a} R, 4 S, 7 \mathrm{a} R)-2-[1$-(bromometil)vinil]-3a,4dimetilocta-hidro-1 $H$-indene-2-carboxilato $t$-butila $(308)$ e $( \pm)-(2 S, 3 \mathrm{a} R, 4 S, 7 \mathrm{a} R)-2-$ [1-(bromometil)vinil]-3a,4-dimetilocta-hidro-1 $H$-indeno-2-carboxilato $t$-butila (309). ${ }^{131}$

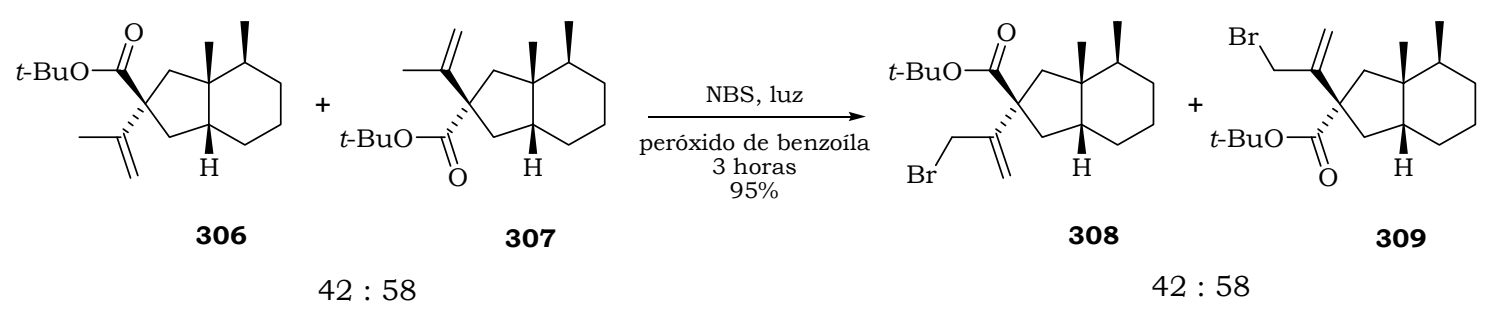

Procedimento: Foram colocados para reagir 50,0 $\mathrm{mg}(0,171 \mathrm{mmol})$ da mistura dos ésteres 306 e 307, $47 \mathrm{mg}(0,26 \mathrm{mmol})$ de NBS, $2 \mathrm{mg}$ de peróxido de benzoíla tudo dissolvido em 2,0 $\mathrm{mL}$ de $\mathrm{CCl}_{4}$, em uma balão adaptado com condensador de refluxo. A reação se decorreu pela ação da luz produzida por uma lâmpada incandescente de $200 \mathrm{~W}$ colocada ao lado do balão reacional. $O$ próprio calor gerado pela lâmpada é suficiente para promover o refluxo do solvente. Após 3 h observou-se o término da reação e então o resíduo foi filtrado em celite, que foi lavada com várias porções de $\mathrm{CCl}_{4}$. O solvente foi removido sob pressão reduzida e os produtos reacionais foram purificados por cromatografia em coluna de sílica gel, utilizando-se como eluente uma mistura de hexano/acetato de etila 9,5:0,5. Obteve-se uma mistura 42:58 dos compostos 305 e 306 respectivamente, não sendo possível, nestas condições, separar cada um dos epímeros.

Rendimento: $60,3 \mathrm{mg}(0,162 \mathrm{mmol})-95 \%$

O espectro de RMN ${ }^{1} \mathrm{H}$ da mistura encontra-se na seção de espectros.

IR $v_{\text {máx }}(\mathrm{KBr}): 740 \mathrm{~cm}^{-1} ; 848 \mathrm{~cm}^{-1} ; 1150 \mathrm{~cm}^{-1} ; 1368 \mathrm{~cm}^{-1} ; 1462 \mathrm{~cm}^{-1} ; 1648 \mathrm{~cm}^{-1} ; 1716$ $\mathrm{cm}^{-1} ; 2928 \mathrm{~cm}^{-1}$.

HRMS (ESI-TOF): calc. para $\mathrm{C}_{19} \mathrm{H}_{32} \mathrm{BrO}_{2}{ }^{+}\left(\mathrm{MH}^{+}\right), 371,1586$; experimental: $371,1640(\Delta$ de 14 ppm - limite de 50 ppm). 
7.48 - Preparação da $( \pm)-\left(1 R, 3 \mathrm{a}^{\prime} R, 4{ }^{\prime} S, 7 \mathrm{a}^{\prime} R\right)-3 \mathrm{a}^{\prime}, 4^{\prime}$-dimetil-5-metileno-octa-hidro$2 H$-spiro[ciclopentano-1,2'-inden]-2-ona (184) e $( \pm)-\left(1 S, 3 \mathrm{a}^{\prime} R, 4^{\prime} S, 7 \mathrm{a}^{\prime} R\right)-3 \mathrm{a}^{\prime}, 4^{\prime}-$ dimetil-5-metileno-octa-hidro-2 $H$-spiro[ciclopentano-1,2'-inden]-2-ona (226). ${ }^{131}$

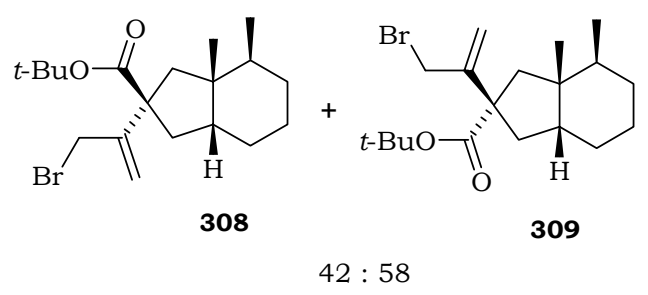

$42: 58$

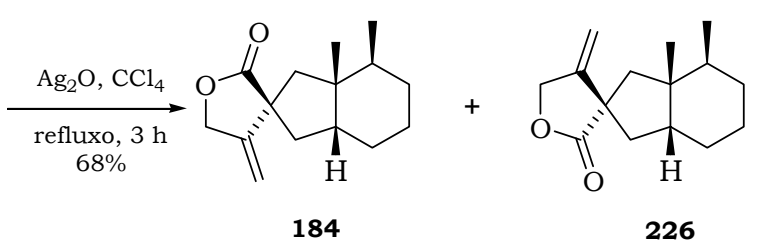

(+)-Baquenolida A (+)-7-epi-Baquenolida A

Procedimento: Foram colocados para reagir 70,0 $\mathrm{mg}(0,188 \mathrm{mmol})$ da mistura dos compostos 308 e 309 e $130 \mathrm{mg}(0,56 \mathrm{mmol})$ de $\mathrm{Ag}_{2} \mathrm{O}$ em 3,0 mL de $\mathrm{CCl}_{4}$. A mistura reacional foi aquecida a refluxo por 3,5 horas. O resíduo reacional foi filtrado em celite, que foi lavada com várias porções de $\mathrm{CCl}_{4}$. $\mathrm{O}$ solvente foi removido sob pressão reduzida e os produtos reacionais foram purificados por cromatografia em coluna de sílica gel, utilizando-se como eluente uma mistura de hexano/acetato de etila 9,5:0,5. Obteve-se uma mistura 42:58 dos compostos 184 e 226 respectivamente, não sendo possível, nestas condições, separar cada um dos epímeros. As baquenolidas 184 e 226 foram separadas por HPLC. ${ }^{\text {xxix }}$ Foram realizadas sucessivas injeções até que fossem separadas quantidades suficientes para as análises de $\mathrm{RMN}$ de ${ }^{1} \mathrm{H}$ e ${ }^{13} \mathrm{C}$.

Rendimento: $30,1 \mathrm{mg}(0,128 \mathrm{mmol})-68 \%$

(士)-Baquenolida A (184).

RMN- ${ }^{1} \mathrm{H}\left(\mathrm{CDCl}_{3}, 500 \mathrm{MHz}\right), \delta(\mathrm{ppm}): 0,85(\mathrm{~d}, 3 \mathrm{H}, \mathrm{J}=6,8 \mathrm{~Hz}) ; 0,99(\mathrm{~s}, 3 \mathrm{H}) ; 1,10-1,22$ $(\mathrm{m}, 1 \mathrm{H}) ; 1,40-1,68(\mathrm{~m}, 6 \mathrm{H}) ; 1,95(\mathrm{~d}, 1 \mathrm{H}, \mathrm{J}=14,2 \mathrm{~Hz}) ; 1,98\left(\mathrm{dd}, 1 \mathrm{H}, \mathrm{J}_{1}=12,9 \mathrm{~Hz} ; \mathrm{J}_{2}=7,0\right.$ $\mathrm{Hz}) ; 1,98(\mathrm{~d}, 1 \mathrm{H}, \mathrm{J}=14,2 \mathrm{~Hz}) ; 2,09\left(\mathrm{dd}, 1 \mathrm{H}, \mathrm{J}_{1}=13,3 \mathrm{~Hz} ; \mathrm{J}_{2}=12,9 \mathrm{~Hz}\right) ; 2,27$ (dddd, $1 \mathrm{H}, \mathrm{J}_{1}$ $\left.=13,3 \mathrm{~Hz} ; \mathrm{J}_{2}=7,0 \mathrm{~Hz} ; \mathrm{J}_{3}=4,9 \mathrm{~Hz} ; \mathrm{J}_{4}=2,3 \mathrm{~Hz}\right) ; 4,74\left(\mathrm{ddd}, 1 \mathrm{H}, \mathrm{J}_{1}=12,8 \mathrm{~Hz} ; \mathrm{J}_{2}=2,3 \mathrm{~Hz} ; \mathrm{J}_{3}\right.$ $=2,1 \mathrm{~Hz}) ; 4,80\left(\mathrm{dd}, 1 \mathrm{H}, \mathrm{J}_{1}=12,8 \mathrm{~Hz} ; \mathrm{J}_{2}=2,3 \mathrm{~Hz} ; \mathrm{J}_{3}=2,1 \mathrm{~Hz}\right) ; 5,03\left(\mathrm{t}, 1 \mathrm{H}, \mathrm{J}_{1}=\mathrm{J}_{2}=2,1\right.$ $\mathrm{Hz}) ; 5,11\left(\mathrm{t}, 1 \mathrm{H}, \mathrm{J}_{1}=\mathrm{J}_{2}=2,3 \mathrm{~Hz}\right)$.

$\mathrm{RMN}-{ }^{13} \mathrm{C}\left(\mathrm{CDCl}_{3}, 100 \mathrm{MHz}\right), \delta(\mathrm{ppm}): 16,4\left(\mathrm{CH}_{3}\right) ; 19,2\left(\mathrm{CH}_{3}\right) ; 21,0\left(\mathrm{CH}_{2}\right) ; 23,3\left(\mathrm{CH}_{3}\right)$; $30,9\left(\mathrm{CH}_{2}\right) ; 33,9(\mathrm{CH}) ; 42,4\left(\mathrm{CH}_{2}\right) ; 44,0(\mathrm{C}) ; 46,2(\mathrm{CH}), 48,5\left(\mathrm{CH}_{2}\right) ; 49,9(\mathrm{C}) ; 70,4$ $\left(\mathrm{CH}_{2}\right) ; 105,8\left(\mathrm{CH}_{2}\right) ; 150,4(\mathrm{C}) ; 182,6(\mathrm{C})$.

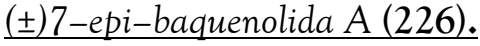

RMN- ${ }^{1} \mathrm{H}\left(\mathrm{CDCl}_{3}, 500 \mathrm{MHz}\right), \delta(\mathrm{ppm}): 0,82(\mathrm{~d}, 3 \mathrm{H}, \mathrm{J}=6,7 \mathrm{~Hz}) ; 0,97(\mathrm{~s}, 3 \mathrm{H}) ; 1,02-1,18$ $(\mathrm{m}, 1 \mathrm{H}) ; 1,42-1,65(\mathrm{~m}, 5 \mathrm{H}) ; 1,52(\mathrm{~d}, 1 \mathrm{H}, \mathrm{J}=14,1 \mathrm{~Hz}) ; 1,66\left(\mathrm{dd}, 1 \mathrm{H}, \mathrm{J}_{1}=12,5 \mathrm{~Hz} ; \mathrm{J}_{2}=6,6\right.$ $\mathrm{Hz}) ; 1,91\left(\mathrm{dqd}, 1 \mathrm{H}, \mathrm{J}_{1}=12,5 \mathrm{~Hz}, \mathrm{~J}_{2}=\mathrm{J}_{3}=\mathrm{J}_{4}=6,7 \mathrm{~Hz}, \mathrm{~J}_{5}=3,0 \mathrm{~Hz}\right) ; 1,95-2,03(\mathrm{~m}, 1 \mathrm{H})$; $2,40(\mathrm{~d}, 1 \mathrm{H}, \mathrm{J}=14,1 \mathrm{~Hz}) ; 2,46\left(\mathrm{dd}, 1 \mathrm{H}, \mathrm{J}_{1}=13,7 \mathrm{~Hz} ; \mathrm{J}_{2}=12,5 \mathrm{~Hz}\right) ; 4,76\left(\mathrm{ddd}, 1 \mathrm{H}, \mathrm{J}_{1}=\right.$

xxix O sistema de HPLC utilizado foi da marca Shimadzu e operou com uma bomba LC-10ADVP, controladora SCL-10AVP, detector SPD-10AVP-UV/vis. (212 nm), coluna analítica Shimpack CLCCN(M) Shimadzu de 4,6 mm de DI x $25 \mathrm{~cm}$ de comprimento, contendo partículas de $5 \mu \mathrm{m}$ de diâmetro e diâmetro do poro de $100 \AA$ A. A fase móvel utilizada foi hexano grau HPLC da marca Fisher Scientific H302-1, a um fluxo de 0,5 mL/min.e o "loop" de injeção de $20 \mu \mathrm{L}$. A temperatura ambiente durante os experimentos ficou obrigatoriamente entre $15-18^{\circ} \mathrm{C}$. 
$\left.12,9 \mathrm{~Hz} ; \mathrm{J}_{2}=2,2 \mathrm{~Hz} ; \mathrm{J}_{3}=1,8 \mathrm{~Hz}\right) ; 4,81\left(\mathrm{ddd}, 1 \mathrm{H}, \mathrm{J}_{1}=12,9 \mathrm{~Hz} ; \mathrm{J}_{2}=2,2 \mathrm{~Hz} ; \mathrm{J}_{3}=1,8 \mathrm{~Hz}\right)$; $4,99\left(\mathrm{t}, 1 \mathrm{H}, \mathrm{J}_{1}=\mathrm{J}_{2}=1,8 \mathrm{~Hz}\right) ; 5,07\left(\mathrm{t}, 1 \mathrm{H}, \mathrm{J}_{1}=\mathrm{J}_{2}=2,2 \mathrm{~Hz}\right)$.

$\mathrm{RMN}-{ }^{13} \mathrm{C}\left(\mathrm{CDCl}_{3}, 100 \mathrm{MHz}\right), \delta(\mathrm{ppm}): 16,6\left(\mathrm{CH}_{3}\right) ; 19,7\left(\mathrm{CH}_{3}\right) ; 21,0\left(\mathrm{CH}_{2}\right) ; 23,6\left(\mathrm{CH}_{3}\right)$; $30,8\left(\mathrm{CH}_{2}\right) ; 33,0(\mathrm{CH}) ; 41,5\left(\mathrm{CH}_{2}\right) ; 44,1(\mathrm{C}) ; 46,9(\mathrm{CH}) ; 50,0(\mathrm{C}) ; 50,1\left(\mathrm{CH}_{2}\right) ; 70,1$ $\left(\mathrm{CH}_{2}\right) ; 105,5\left(\mathrm{CH}_{2}\right) ; 152,0(\mathrm{C}) ; 182,3(\mathrm{C})$.

IR $v_{\text {máx }}(\mathrm{KBr}): 894 \mathrm{~cm}^{-1} ; 1030 \mathrm{~cm}^{-1} ; 1124 \mathrm{~cm}^{-1} ; 1236 \mathrm{~cm}^{-1} ; 1462 \mathrm{~cm}^{-1} ; 1672 \mathrm{~cm}^{-1} ; 1778$ $\mathrm{cm}^{-1} ; 2958 \mathrm{~cm}^{-1}$.

HRMS (ESI-TOF): calc. para $\mathrm{C}_{15} \mathrm{H}_{23} \mathrm{O}_{2}{ }^{+}\left(\mathrm{MH}^{+}\right)$, 235,1698; experimental: 235,1767 ( $\Delta$ de 29 ppm - limite de 50 ppm). 
Espectros de Ressonância Magnética Nuclear 


\section{8 - Espectros de RMN - Parte $A$ e $B$}

Nesta seção serão apresentados os espectros de RMN de ${ }^{1} \mathrm{H}$ e ${ }^{13} \mathrm{C}$ dos compostos referentes às Partes $A$ e $B$ deste trabalho. Também serão incluídas algumas tabelas de atribuição contendo dados obtidos pelas técnicas de correlação gCOSY, gHMQC, gHMBC e gJres, além de experimentos de NOE DIFF. Todos os espectros foram visualizados pelo "software" da ACD (SpecViewer). ${ }^{162}$ 


\section{Composto 45}

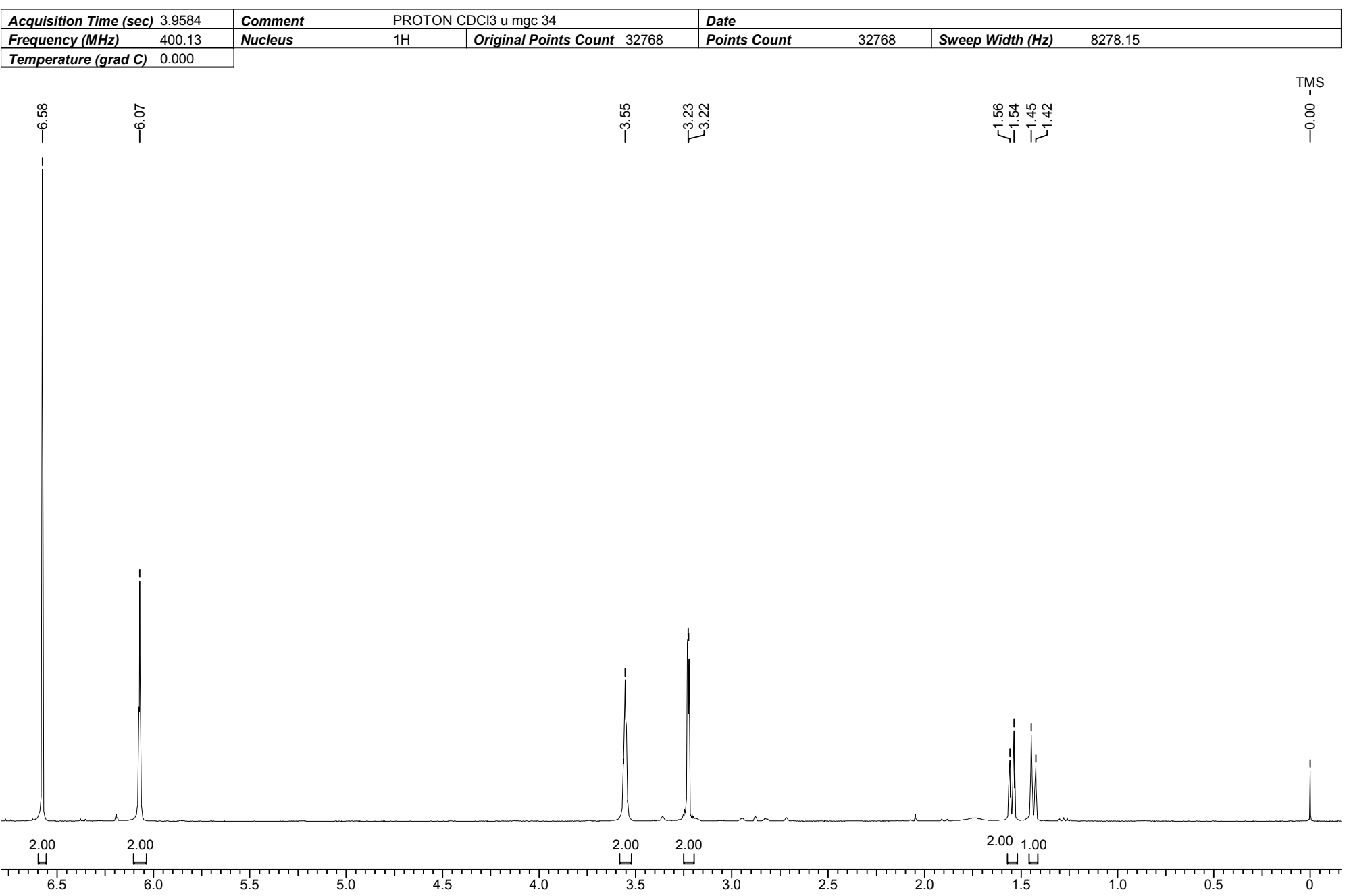

Figura 52: Espectro de $\mathrm{RMN}{ }^{1} \mathrm{H}\left(400 \mathrm{MHz}, \mathrm{CDCl}_{3}\right)$ do composto 45 . 
Espectro de $R M N{ }^{13} \mathrm{C}\left\{{ }^{1} \mathrm{H}\right\}$

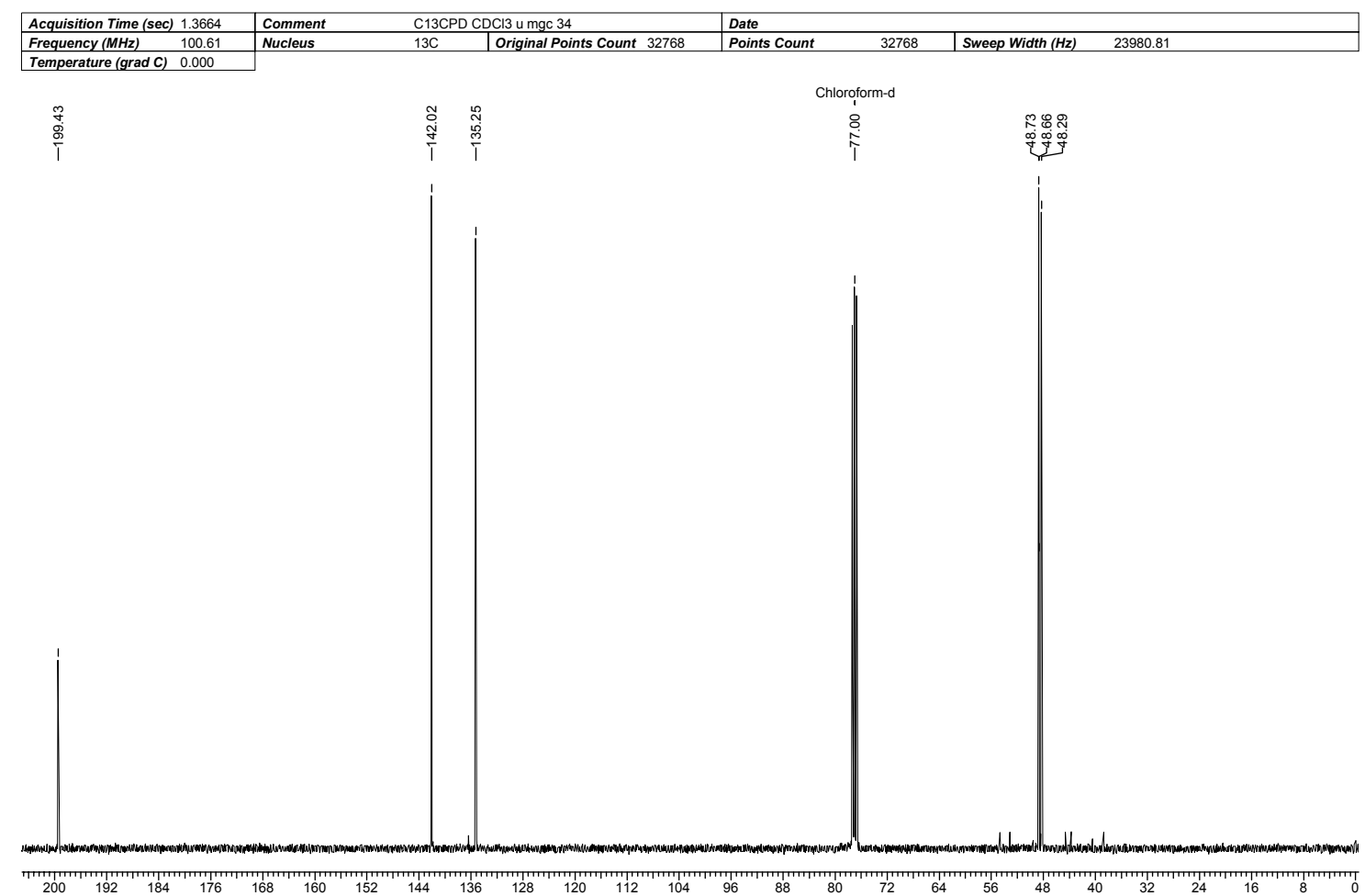

Espectro de RMN ${ }^{13} \mathrm{C}(\mathrm{DEPT}-135) .{ }^{*}$

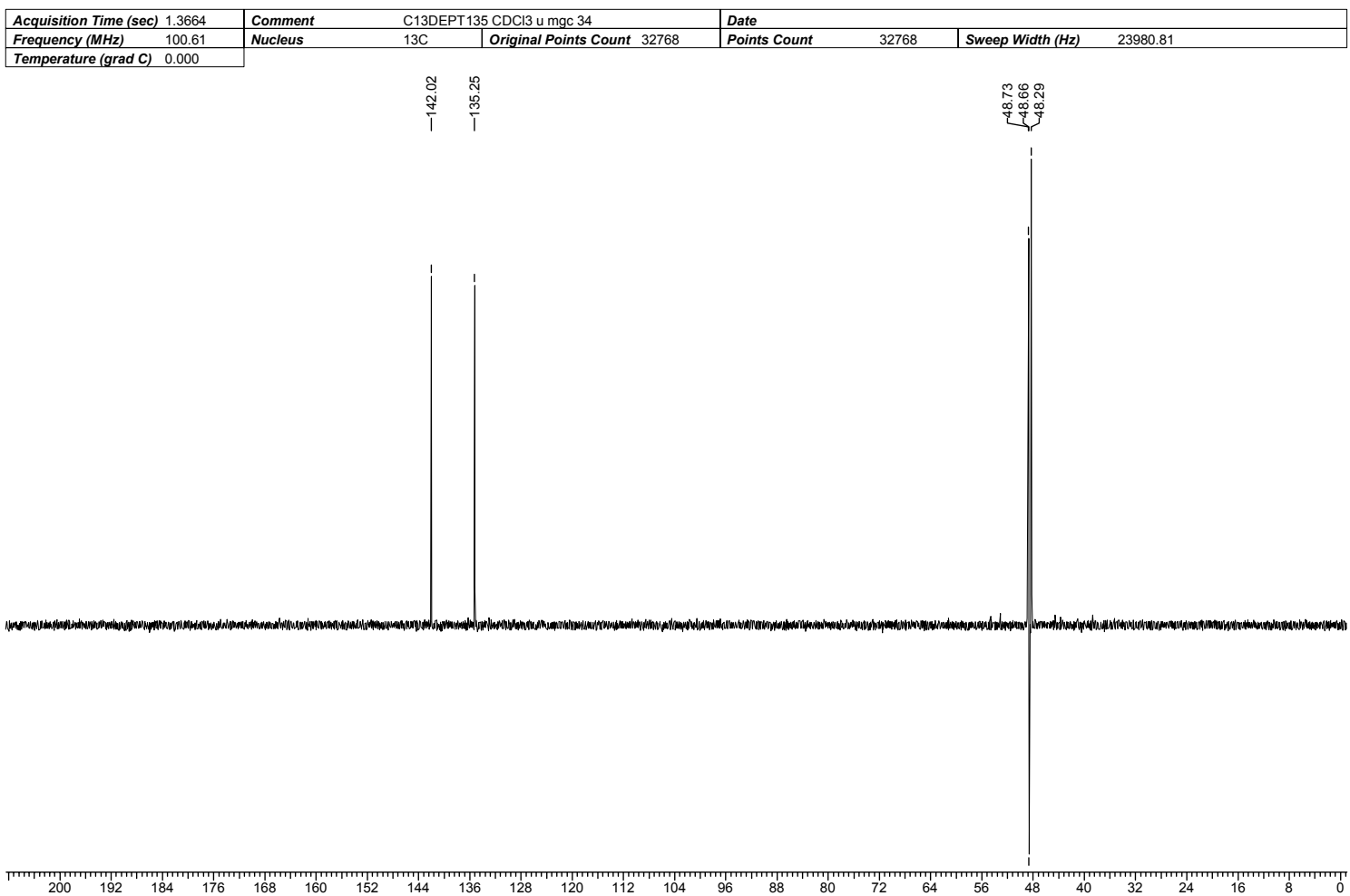

* Espectro de RMN ${ }^{13} \mathrm{C}\left(100 \mathrm{MHz}, \mathrm{CDCl}_{3}\right)$ DEPT-135 do composto $45 . \uparrow\left(\mathrm{CH}, \mathrm{CH}_{3}\right), \downarrow \cdot\left(\mathrm{CH}_{2}\right)$

Figura 53: Espectros de $\mathrm{RMN}^{13} \mathrm{C}\left(100 \mathrm{MHz}, \mathrm{CDCl}_{3}\right)$ do composto 45. 
Tabela 26: Dados Espectroscópicos do Composto 45.

\begin{tabular}{|c|c|c|c|c|c|c|c|}
\hline $\mathrm{C}$ & $\delta \mathrm{C}(\mathrm{ppm})$ & $\delta \mathrm{H}(\mathrm{ppm})$ & Integral Relativa & Multiplicidade & Constantes de Acoplamento $(\mathrm{Hz})$ & $\mathrm{gCOSY}$ & $\mathrm{gHMQC}$ \\
\hline 1 & 135,3 & 6,07 & $2 \mathrm{H}$ & $\mathrm{t}$ & $\mathrm{J}_{1 / 6 \mathrm{~b}}=1,7 ; \mathrm{J}_{1 / 2}=1,7$ & $\mathrm{H}_{6 \mathrm{~b}}, \mathrm{H}_{2}$ & $\mathrm{H}_{1}$ \\
\hline 2 & 48,7 & $3,53-3,58$ & $2 \mathrm{H}$ & $\mathrm{m}$ & - & $\mathrm{H}_{1}, \mathrm{H}_{6 \mathrm{a}}, \mathrm{H}_{6 \mathrm{~b}}, \mathrm{H}_{3}$ & $\mathrm{H}_{2}$ \\
\hline 3 & 48,3 & $3,20-3,26$ & $2 \mathrm{H}$ & $\mathrm{m}$ & - & $\mathrm{H}_{2}, \mathrm{H}_{5}$ & $\mathrm{H}_{3}$ \\
\hline 4 & 199,4 & & & & - & & \\
\hline 5 & 142,0 & 6,58 & $2 \mathrm{H}$ & sl & - & $\mathrm{H}_{3}$ & $\mathrm{H}_{5}$ \\
\hline \multirow[t]{2}{*}{6} & 48,7 & (6b) 1,44 & $1 \mathrm{H}$ & $\mathrm{dtt}$ & $\mathrm{J}_{6 \mathrm{~b} / 6 \mathrm{a}}=8,4 ; \mathrm{J}_{6 \mathrm{~b} / 1}=\mathrm{J}_{6 \mathrm{~b} / 1},=1,7 ; \mathrm{J}_{6 \mathrm{~b} / 2}=\mathrm{J}_{6 \mathrm{~b} / 2},=0,7$ & $\mathrm{H}_{1}, \mathrm{H}_{2}, \mathrm{H}_{6 \mathrm{a}}$ & $\mathrm{H}_{6}$ \\
\hline & & (6a) 1,55 & $1 \mathrm{H}$ & $\mathrm{dt}$ & $\mathrm{J}_{6 \mathrm{a} / 6 \mathrm{~b}}=8,4 ; \mathrm{J}_{6 \mathrm{a} / 2}=\mathrm{J}_{6 \mathrm{a} / 2},=1,8$ & $\mathrm{H}_{2}, \mathrm{H}_{6 \mathrm{~b}}$ & \\
\hline
\end{tabular}

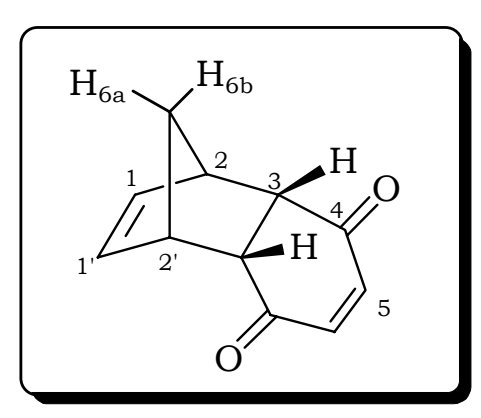




\section{Composto 136}

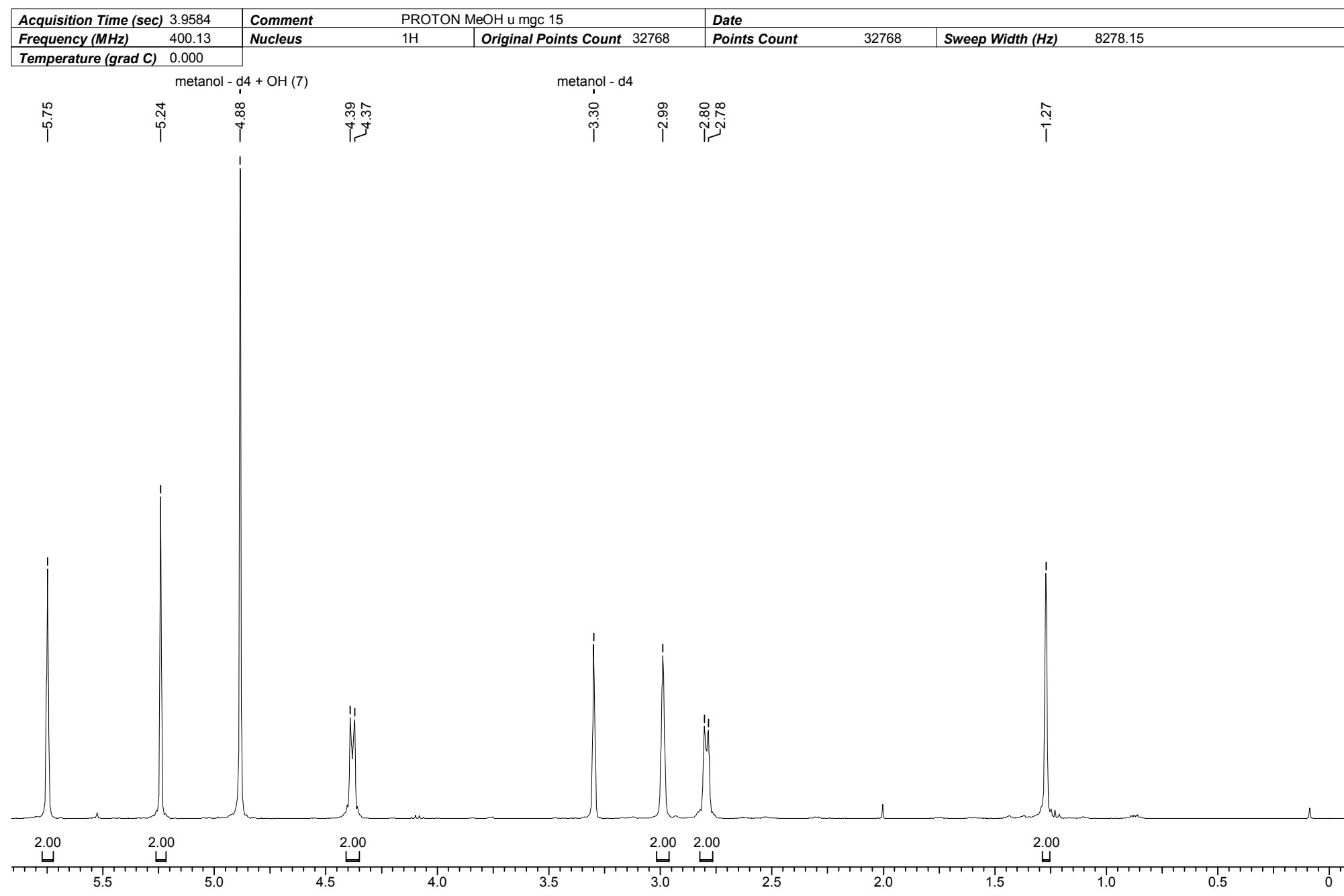

Figura 54: Espectro de $\mathrm{RMN}^{1} \mathrm{H}\left(400 \mathrm{MHz}, \mathrm{MeOD}-d_{4}\right)$ do composto 136 
Espectro de $R M N{ }^{13} \mathrm{C}\left\{{ }^{1} \mathrm{H}\right\}$

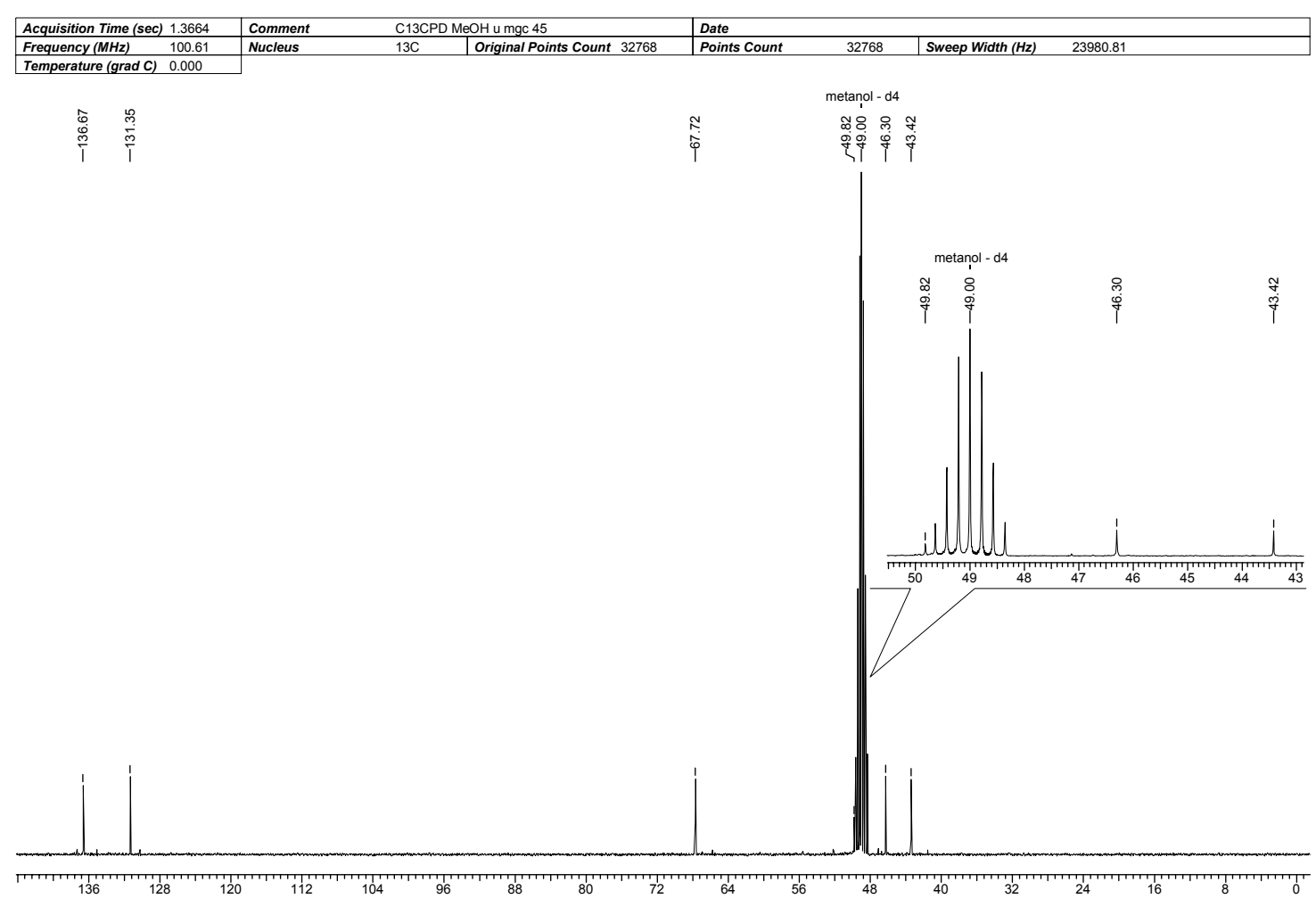

Espectro de RMN ${ }^{13} \mathrm{C}(\mathrm{DEPT}-135)$.

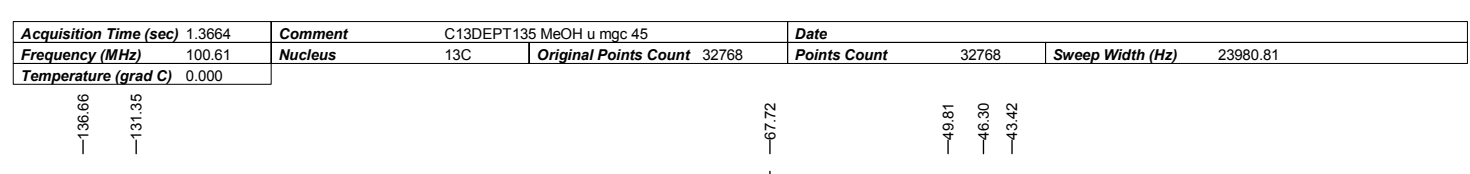

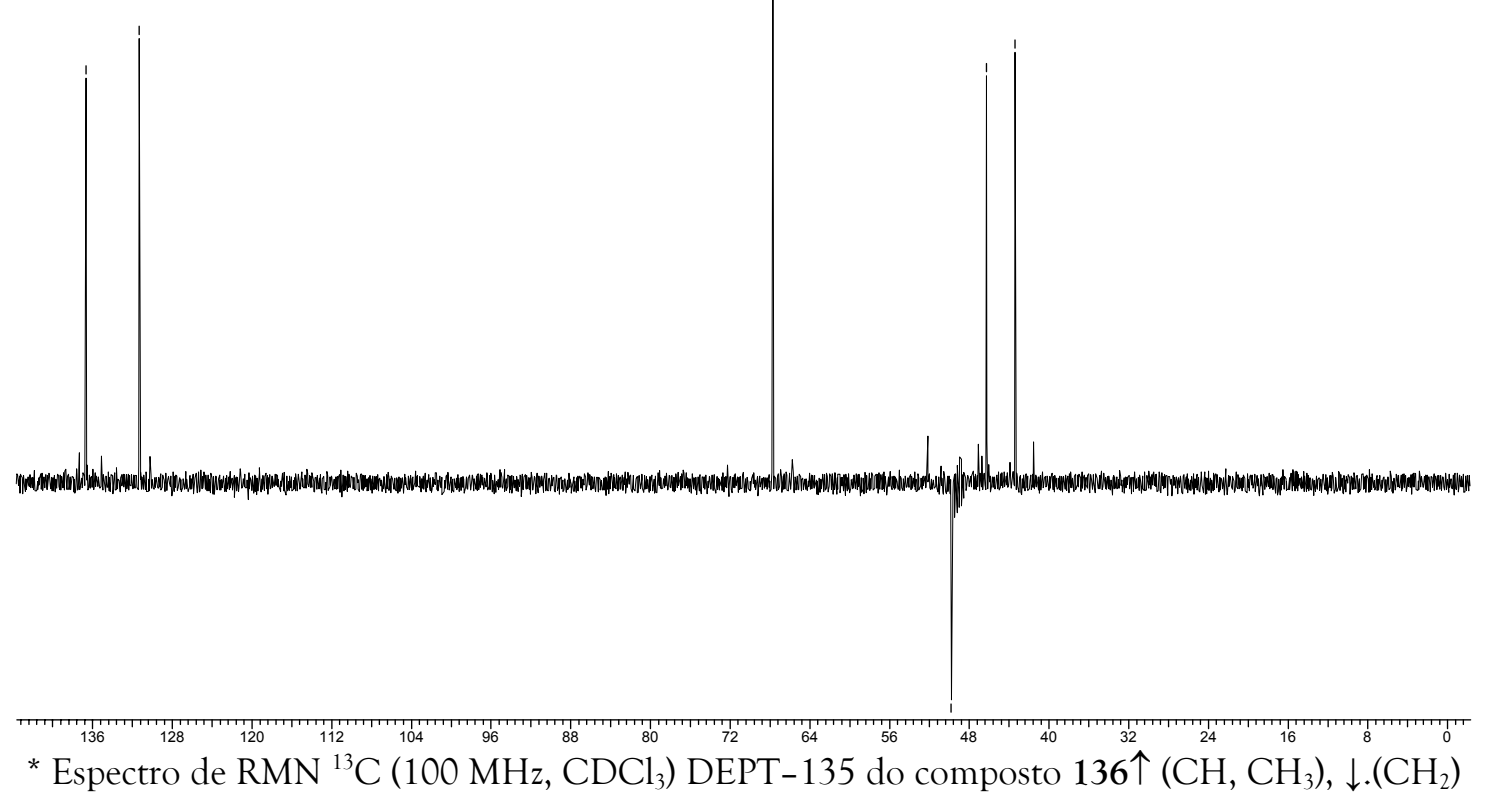

Figura 55: Espectros de RMN ${ }^{13} \mathrm{C}\left(100 \mathrm{MHz}, \mathrm{MeOD}-d_{4}\right)$ do composto 136. 
Tabela 27: Dados espectroscópicos do composto 136

\begin{tabular}{ccccccc}
\hline $\mathrm{C}$ & $\delta \mathrm{C}(\mathrm{ppm})$ & $\delta \mathrm{H}(\mathrm{ppm})$ & Integral Relativa & Multiplicidade & gCOSY & gHMQC \\
\hline 1 & 136,7 & $5,73-5,77$ & $2 \mathrm{H}$ & $\mathrm{m}$ & $\mathrm{H}_{6 \mathrm{a} / 6 \mathrm{~b}, \mathrm{H}_{2}}$ & $\mathrm{H}_{1}$ \\
2 & 46,3 & $2,96-3,02$ & $2 \mathrm{H}$ & $\mathrm{m}$ & $\mathrm{H}_{1}, \mathrm{H}_{6 \mathrm{a} / 6 \mathrm{~b}}, \mathrm{H}_{3}$ & $\mathrm{H}_{2}$ \\
3 & 43,4 & $2,76-2,83$ & $2 \mathrm{H}$ & $\mathrm{m}$ & $\mathrm{H}_{2}, \mathrm{H}_{4}, \mathrm{H}_{5}$ & $\mathrm{H}_{3}$ \\
4 & 67,7 & $4,34-4,42$ & $2 \mathrm{H}$ & $\mathrm{m}$ & $\mathrm{H}_{3}, \mathrm{H}_{5}$ & $\mathrm{H}_{4}$ \\
5 & 131,4 & 5,24 & $2 \mathrm{H}$ & $\mathrm{sl}$ & $\mathrm{H}_{3}, \mathrm{H}_{4}$ & $\mathrm{H}_{5}$ \\
6 & 49,8 & $(6 \mathrm{~b}) 1,27$ & $1 \mathrm{H}$ & $\mathrm{sl}$ & $\mathrm{H}_{1}, \mathrm{H}_{2}{ }^{*}$, & $\mathrm{H}_{6}$ \\
& & $(6 \mathrm{a}) 1,27$ & $1 \mathrm{H}$ & $\mathrm{sl}$ & $\mathrm{H}_{1}, \mathrm{H}_{2}$
\end{tabular}

$\mathrm{H}_{7}(\mathrm{OH}) \quad 4,89 \quad 2 \mathrm{OH}+\mathrm{MeOH} \quad$ sl

* muito pequeno

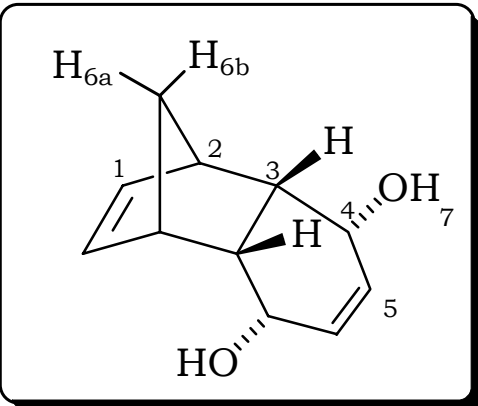




\section{Composto 144}

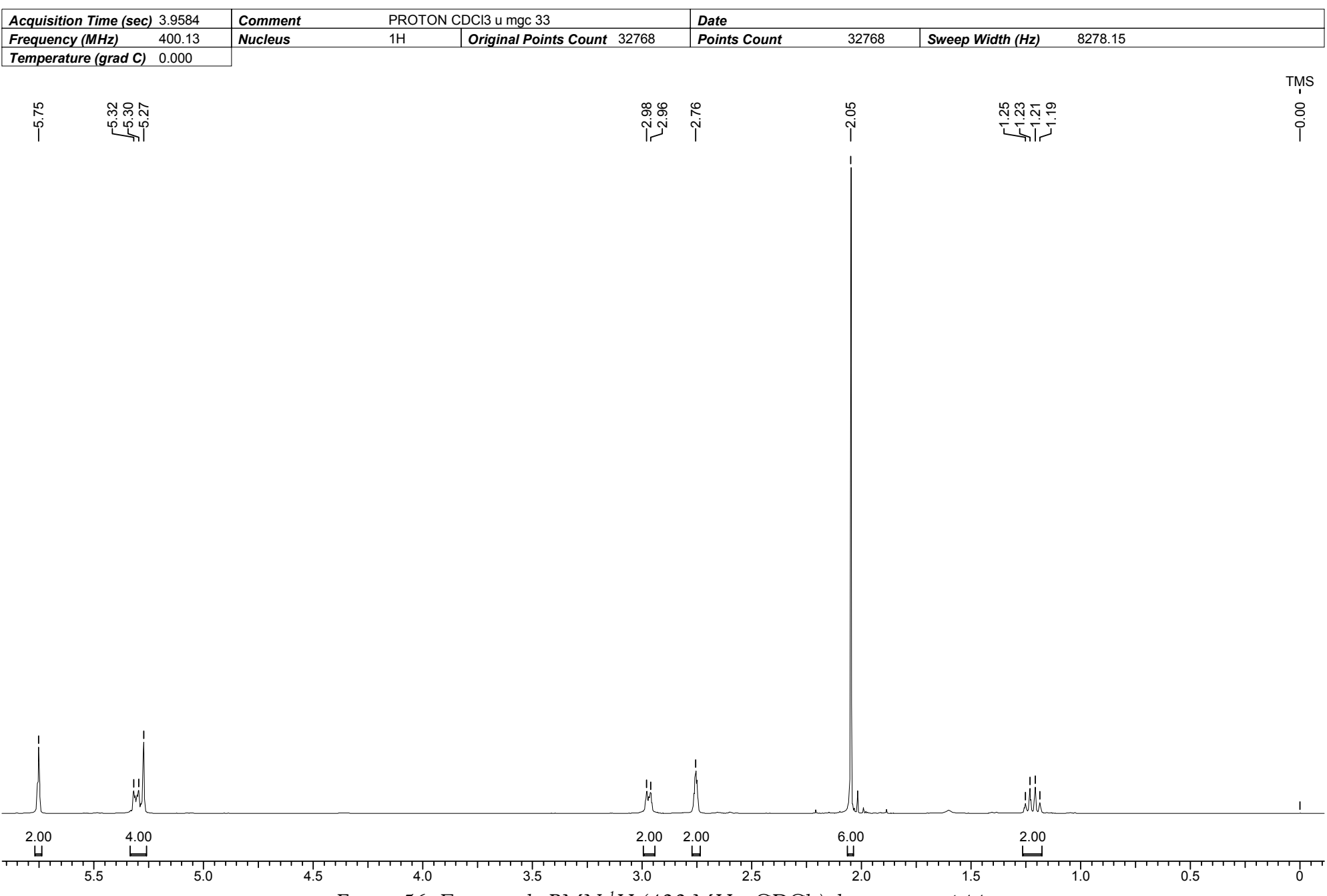

Figura 56: Espectro de $\mathrm{RMN}^{1} \mathrm{H}\left(400 \mathrm{MHz}, \mathrm{CDCl}_{3}\right)$ do composto 144 
Espectro de $R M N{ }^{13} \mathrm{C}\left\{{ }^{1} \mathrm{H}\right\}$

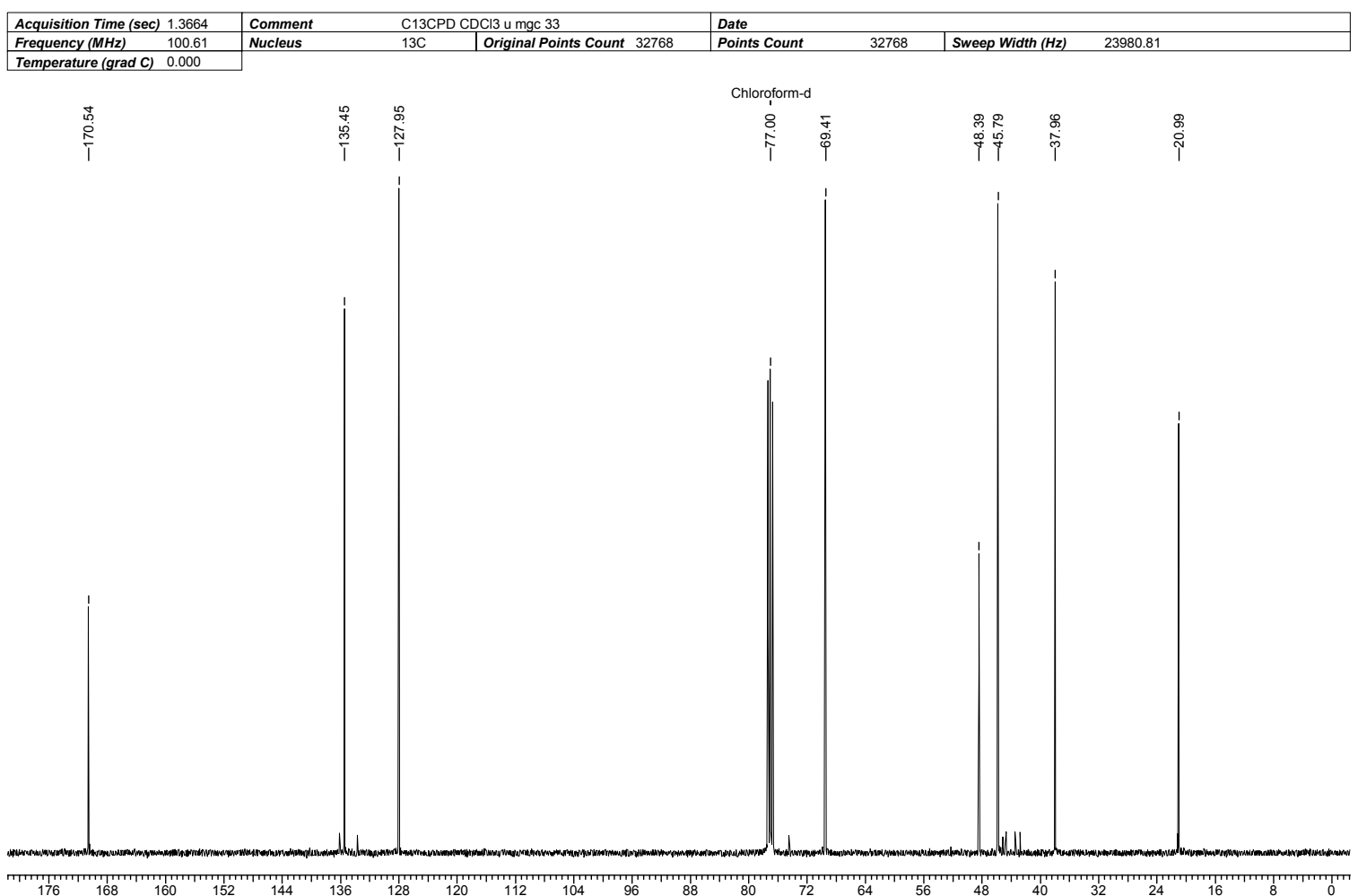

Espectro de RMN ${ }^{13} \mathrm{C}(\mathrm{DEPT}-135)$.

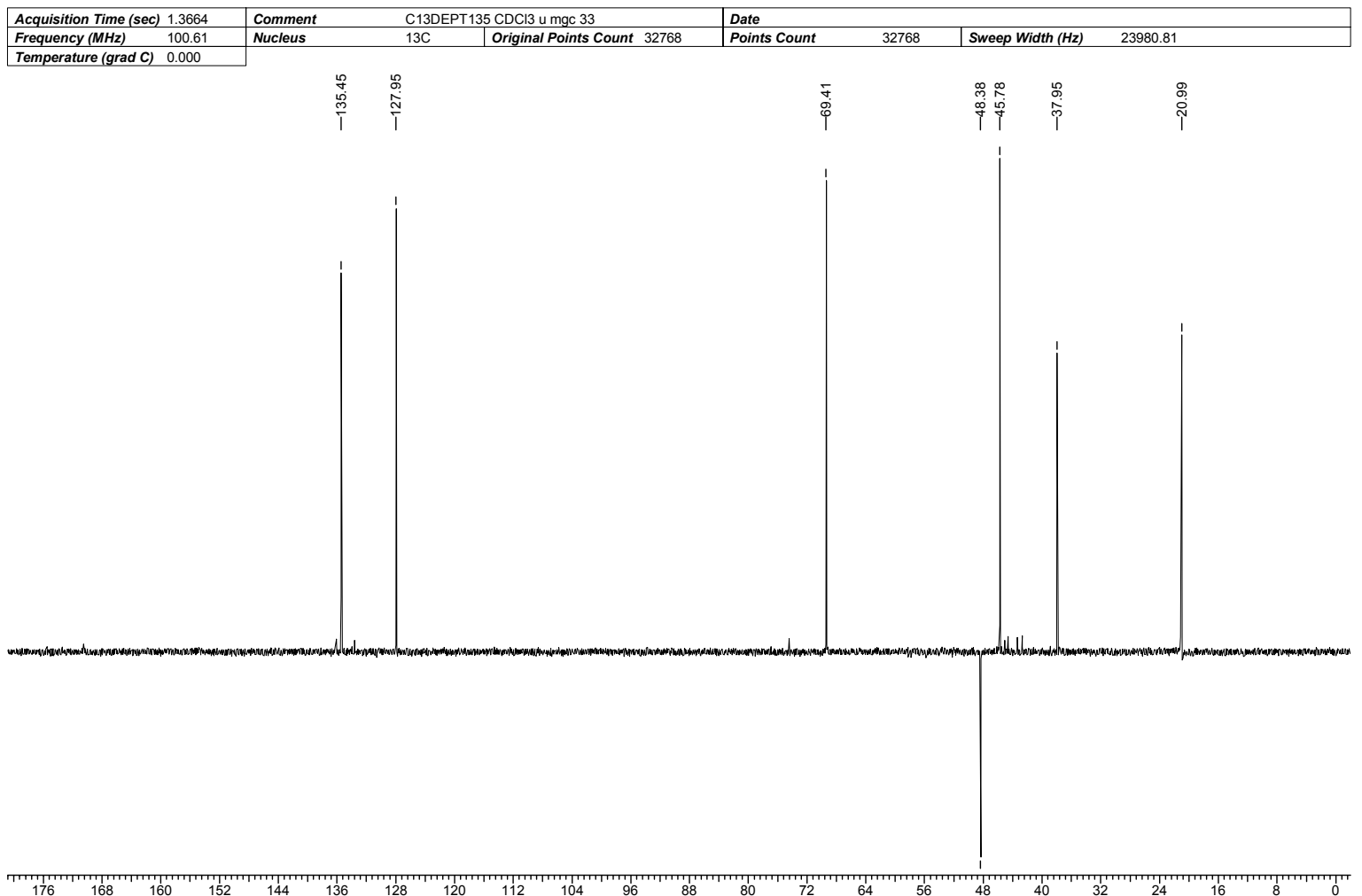

${ }^{*}$ Espectro de $\mathrm{RMN}{ }^{13} \mathrm{C}\left(100 \mathrm{MHz}, \mathrm{CDCl}_{3}\right)$ DEPT-135 do composto $144 \uparrow\left(\mathrm{CH}, \mathrm{CH}_{3}\right), \downarrow \cdot\left(\mathrm{CH}_{2}\right)$

Figura 57: Espectros de RMN ${ }^{13} \mathrm{C}\left(100 \mathrm{MHz}, \mathrm{CDCl}_{3}\right)$ do composto 144. 
Tabela 28: Dados Espectroscópicos do Composto 144.

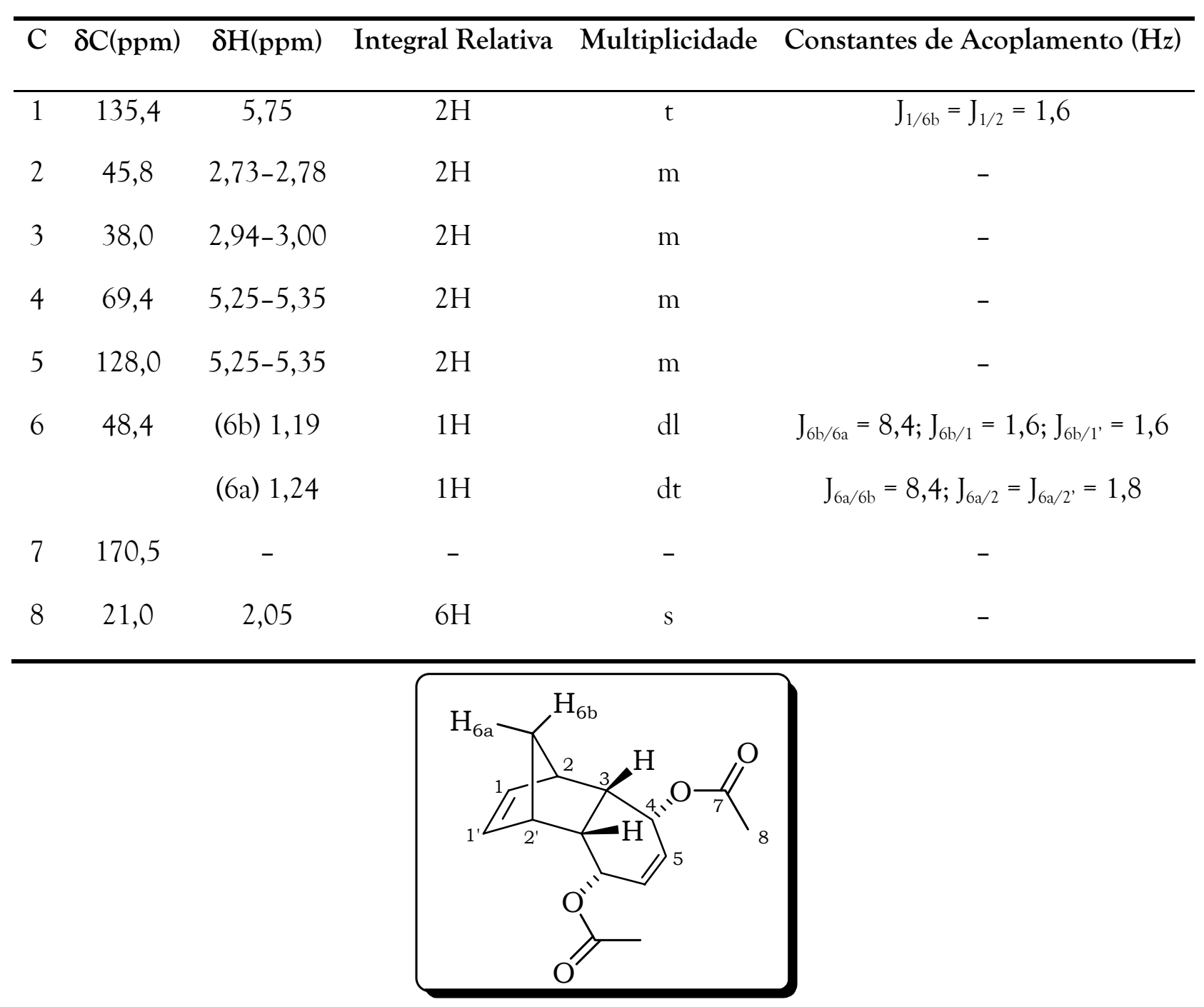




\section{Composto 145}

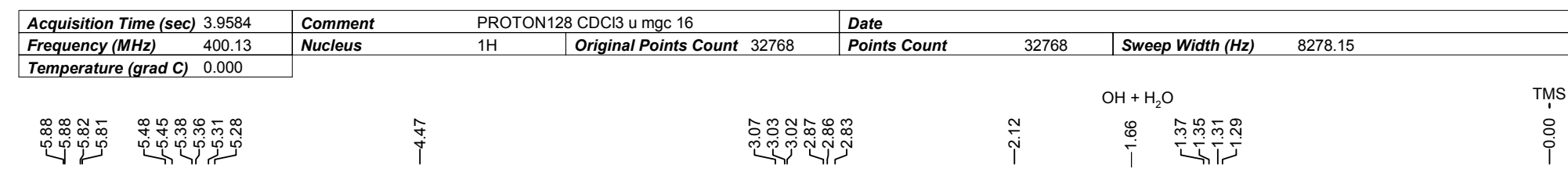

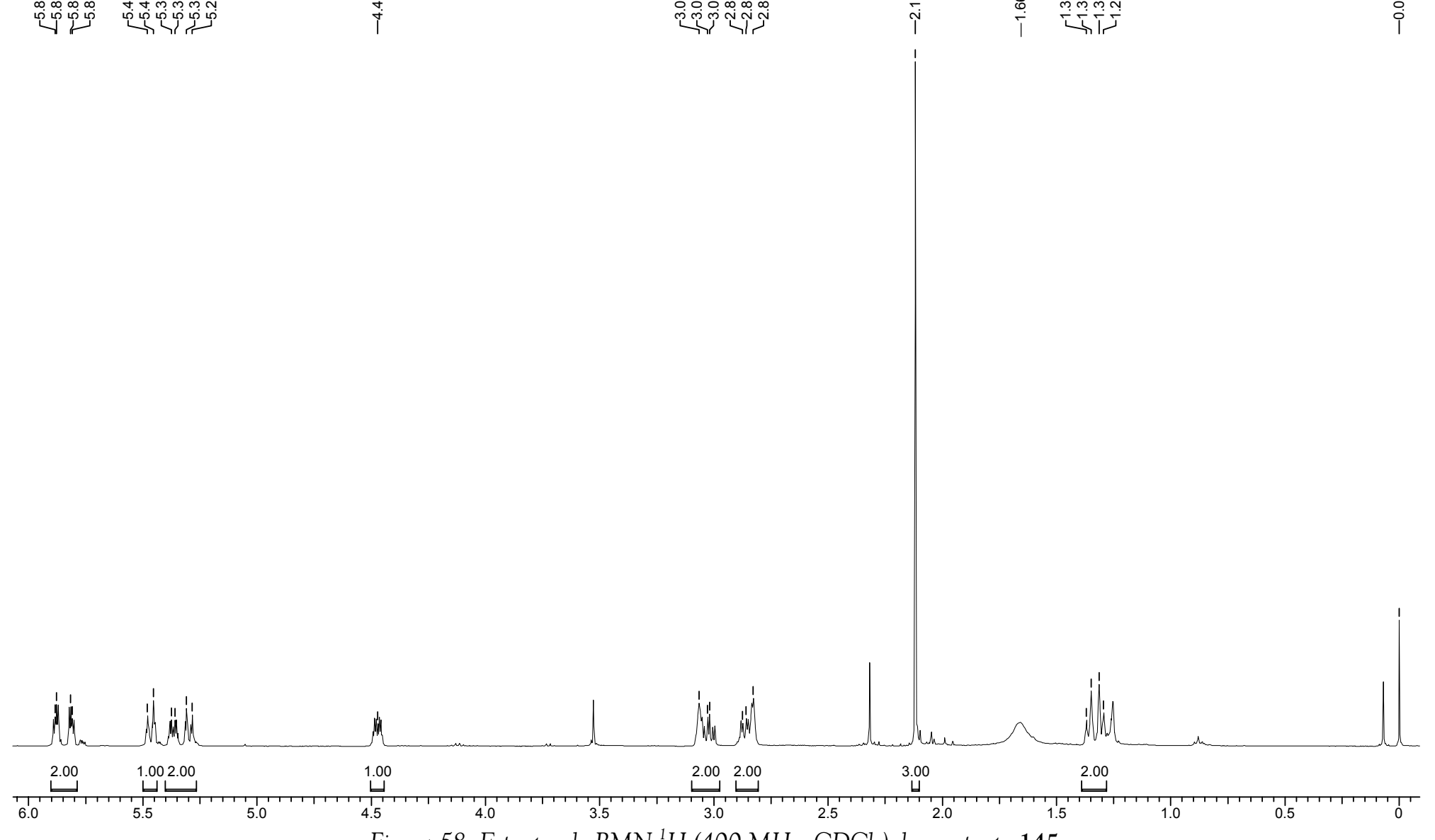

Figura 58: Espectro de RMN ${ }^{1} \mathrm{H}\left(400 \mathrm{MHz}, \mathrm{CDCl}_{3}\right)$ do composto 145. 
Tabela 29: Dados Espectroscópicos do Composto 145.

\begin{tabular}{|c|c|c|c|c|}
\hline $\mathrm{C}$ & $\delta \mathrm{H}(\mathrm{ppm})$ & Integral relativa & Multiplicidade & Constantes de Acoplamento $(\mathrm{Hz})$ \\
\hline 1 & 5,81 & $1 \mathrm{H}$ & $\mathrm{dd}$ & $\mathrm{J}_{1 / 10}=5,6 ; \mathrm{J}_{1 / 2}=2,8$ \\
\hline 2 & $2,80-2,90$ & $1 \mathrm{H}$ & $\mathrm{m}$ & - \\
\hline 3 & $2,80-2,90$ & $1 \mathrm{H}$ & $\mathrm{m}$ & - \\
\hline 4 & 4,47 & $1 \mathrm{H}$ & $\mathrm{dq}$ & $\mathrm{J}_{4 / 3}=8,6 ; \mathrm{J}_{4 / 5}=\mathrm{J}_{4 / 6}=\mathrm{J}_{4 / 7}=2,8$ \\
\hline $5^{*}$ & 5,29 & $1 \mathrm{H}$ & $\mathrm{dt}$ & $\mathrm{J}_{5 / 6}=10,5 ; \mathrm{J}_{5 / 4}=\mathrm{J}_{5 / 7}=2,8$ \\
\hline $6^{*}$ & 5,47 & $1 \mathrm{H}$ & $\mathrm{dt}$ & $\mathrm{J}_{6 / 5}=10,5 ; \mathrm{J}_{6 / 4}=\mathrm{J}_{6 / 7}=2,8$ \\
\hline 7 & 5,36 & $1 \mathrm{H}$ & $\mathrm{dq}$ & $\mathrm{J}_{7 / 8}=8,7 ; \mathrm{J}_{7 / 4}=\mathrm{J}_{7 / 5}=\mathrm{J}_{7 / 6}=2,8$ \\
\hline 8 & 3,02 & $1 \mathrm{H}$ & ddd & $\mathrm{J}_{8 / 3}=9,1 ; \mathrm{J}_{8 / 7}=8,7 ; \mathrm{J}_{8 / 9}=3,6$ \\
\hline 9 & $3,05-3,10$ & $1 \mathrm{H}$ & $\mathrm{m}$ & - \\
\hline 10 & 5,88 & $1 \mathrm{H}$ & dd & $\mathrm{J}_{10 / 1}=5,6 ; \mathrm{J}_{10 / 9}=2,8$ \\
\hline \multirow[t]{2}{*}{11} & $\left(\mathrm{H}_{11 \mathrm{a}}\right) 1,36$ & $1 \mathrm{H}$ & $\mathrm{dt}$ & $\mathrm{J}_{11 \mathrm{a} / 11 \mathrm{~b}}=8,2 ; \mathrm{J}_{11 \mathrm{a} / 2}=\mathrm{J}_{11 \mathrm{a} / 9}=1,8$ \\
\hline & $\left.\mathrm{H}_{11 \mathrm{~b}}\right) 1,30$ & $1 \mathrm{H}$ & d & $\mathrm{J}_{11 \mathrm{~b} / 11 \mathrm{a}}=8,2$ \\
\hline 12 & - & - & - & - \\
\hline 13 & 2,12 & $3 \mathrm{H}$ & $\mathrm{s}$ & - \\
\hline 14 & 1,66 & $\mathrm{OH}$ & sl & - \\
\hline
\end{tabular}

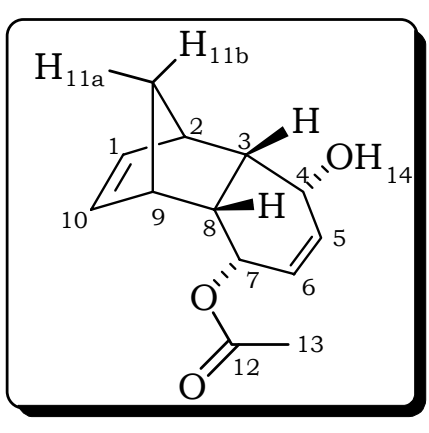




\section{Composto 147}

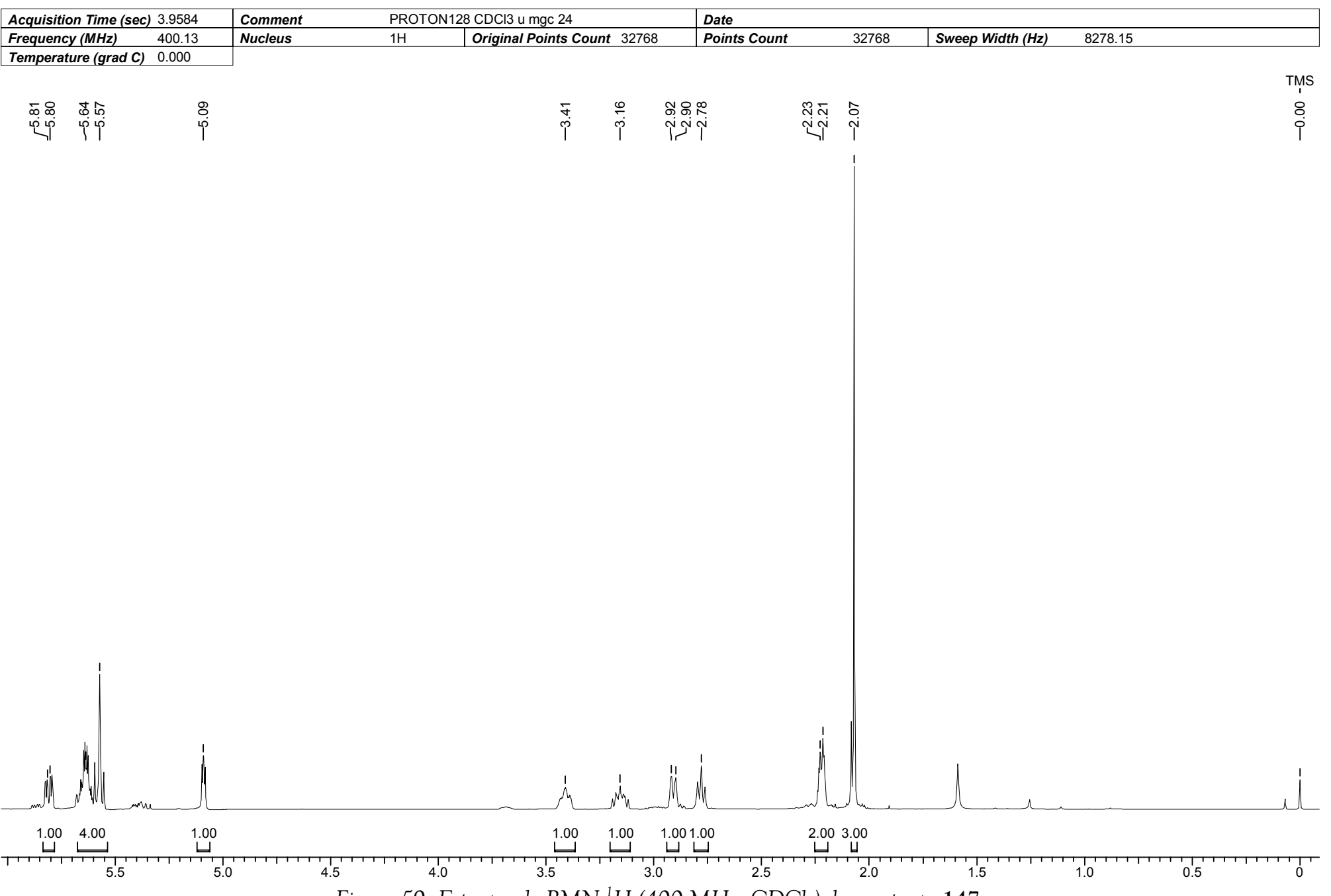

Figura 59: Espectro de $\mathrm{RMN}^{1} \mathrm{H}\left(400 \mathrm{MHz}, \mathrm{CDCl}_{3}\right)$ do composto 147 . 
Espectro de $R M N{ }^{13} \mathrm{C}\left\{{ }^{1} \mathrm{H}\right\}$

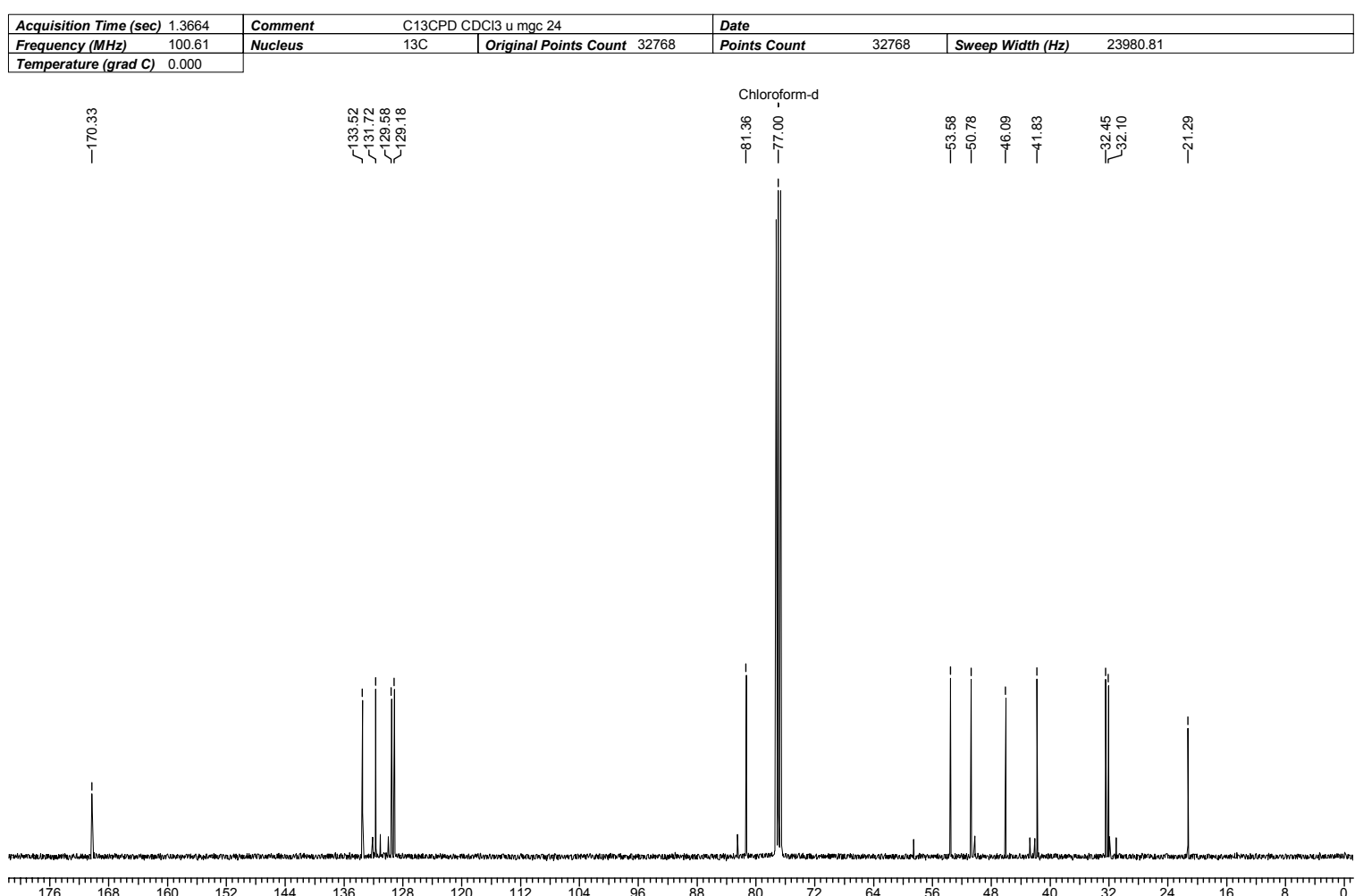

Espectro de $R M N{ }^{13} \mathrm{C}(\mathrm{DEPT}-135)$ *

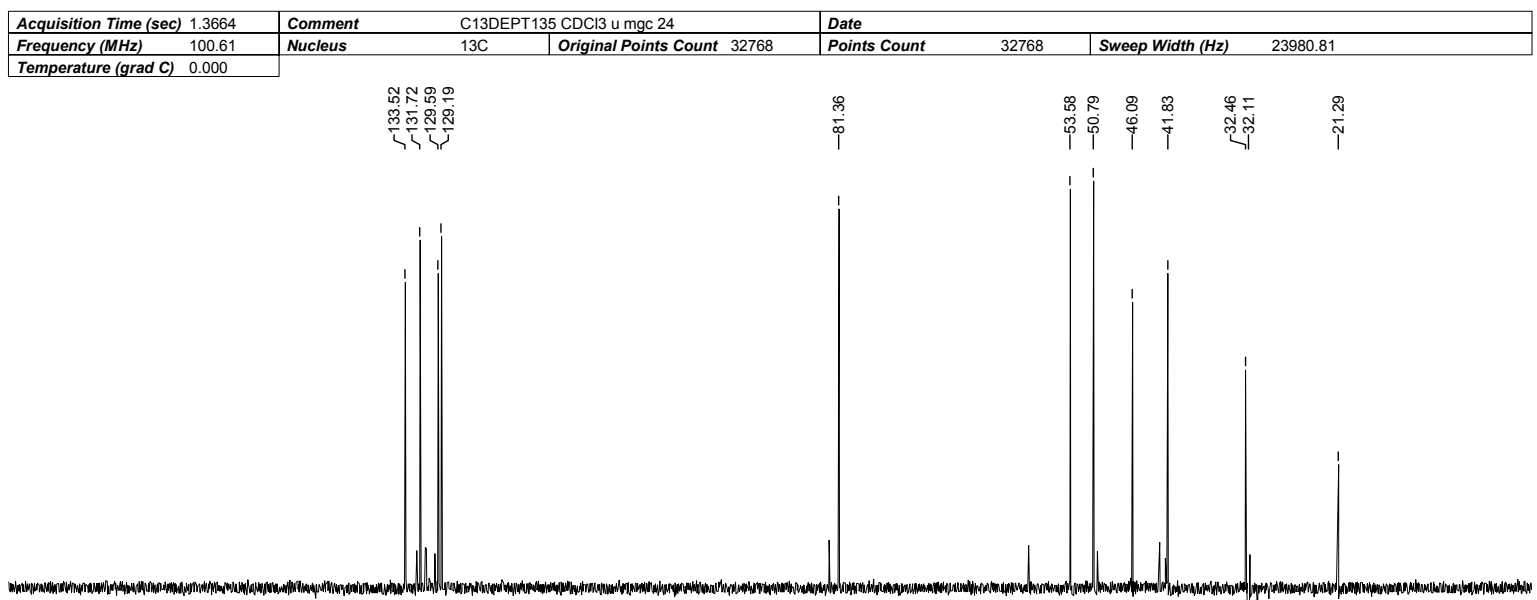

Figura 60: Espectros de $\mathrm{RMN}^{13} \mathrm{C}\left(100 \mathrm{MHz}, \mathrm{CDCl}_{3}\right)$ do composto 147 . 
Tabela30: Dados Espectroscópicos do Composto 147.

\begin{tabular}{|c|c|c|c|c|c|}
\hline $\mathrm{C}$ & $\delta \mathrm{C}(\mathrm{ppm})$ & $\delta \mathrm{H}(\mathrm{ppm})$ & Integral Relativa & Multiplicidade & Constantes de Acoplamento $(\mathrm{Hz})$ \\
\hline $1^{*}$ & 133,5 & $5,54-5,67$ & $1 \mathrm{H}$ & $\mathrm{m}$ & - \\
\hline 2 & 41,8 & $2,88-2,94$ & $1 \mathrm{H}$ & $\mathrm{m}$ & - \\
\hline 3 & 53,6 & $3,36-3,46$ & $1 \mathrm{H}$ & $\mathrm{m}$ & - \\
\hline 4 & 32,4 & 5,09 & $1 \mathrm{H}$ & dd & $\mathrm{J}_{4 / 5}=3,8 ; \mathrm{J}_{4 / 3}=2,5$ \\
\hline $5 *$ & 129,6 & 5,81 & $1 \mathrm{H}$ & ddd & $\mathrm{J}_{5 / 6}=9,4 ; \mathrm{J}_{5 / 4}=3,8 ; \mathrm{J}_{5 / 7}=1,5$ \\
\hline $6^{*}$ & 129,2 & $5,54-5,67$ & $1 \mathrm{H}$ & $\mathrm{m}$ & - \\
\hline 7 & 81,4 & $5,54-5,67$ & $1 \mathrm{H}$ & $\mathrm{m}$ & - \\
\hline 8 & 46,1 & 3,15 & $1 \mathrm{H}$ & $\mathrm{m}$ & \\
\hline 9 & 50,8 & 2,78 & $1 \mathrm{H}$ & $\mathrm{m}$ & - \\
\hline $10^{*}$ & 131,7 & $5,54-5,67$ & $1 \mathrm{H}$ & $\mathrm{m}$ & - \\
\hline \multirow[t]{2}{*}{11} & 32,1 & $\left(\mathrm{H}_{11 \mathrm{a}}\right) 2,19-2,25$ & $1 \mathrm{H}$ & $\mathrm{m}$ & - \\
\hline & & $\left(\mathrm{H}_{11 \mathrm{~b}}\right) 2,19-2,25$ & $1 \mathrm{H}$ & $\mathrm{m}$ & - \\
\hline 12 & 170,3 & - & - & - & - \\
\hline 13 & 21,3 & 2,07 & $3 \mathrm{H}$ & $s$ & - \\
\hline
\end{tabular}

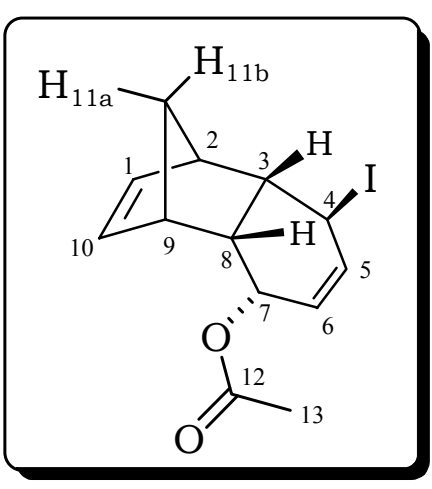

* podem estar trocados 


\section{Composto 148}

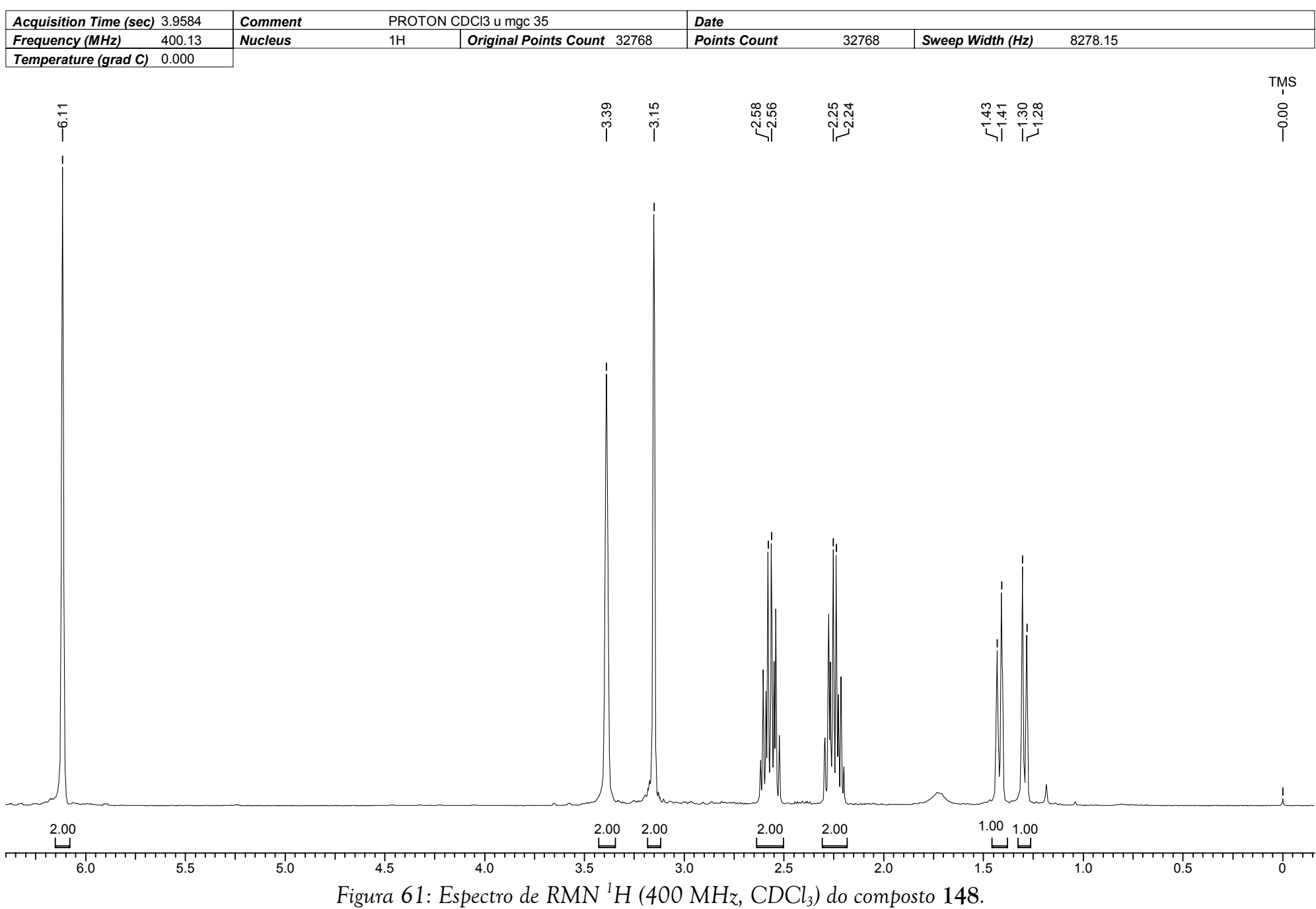

Figura 61: Espectro de $\mathrm{RMN}^{1} \mathrm{H}\left(400 \mathrm{MHz}, \mathrm{CDCl}_{3}\right)$ do composto 148 
Espectro de $R M N{ }^{13} \mathrm{C}\left\{{ }^{1} \mathrm{H}\right\}$

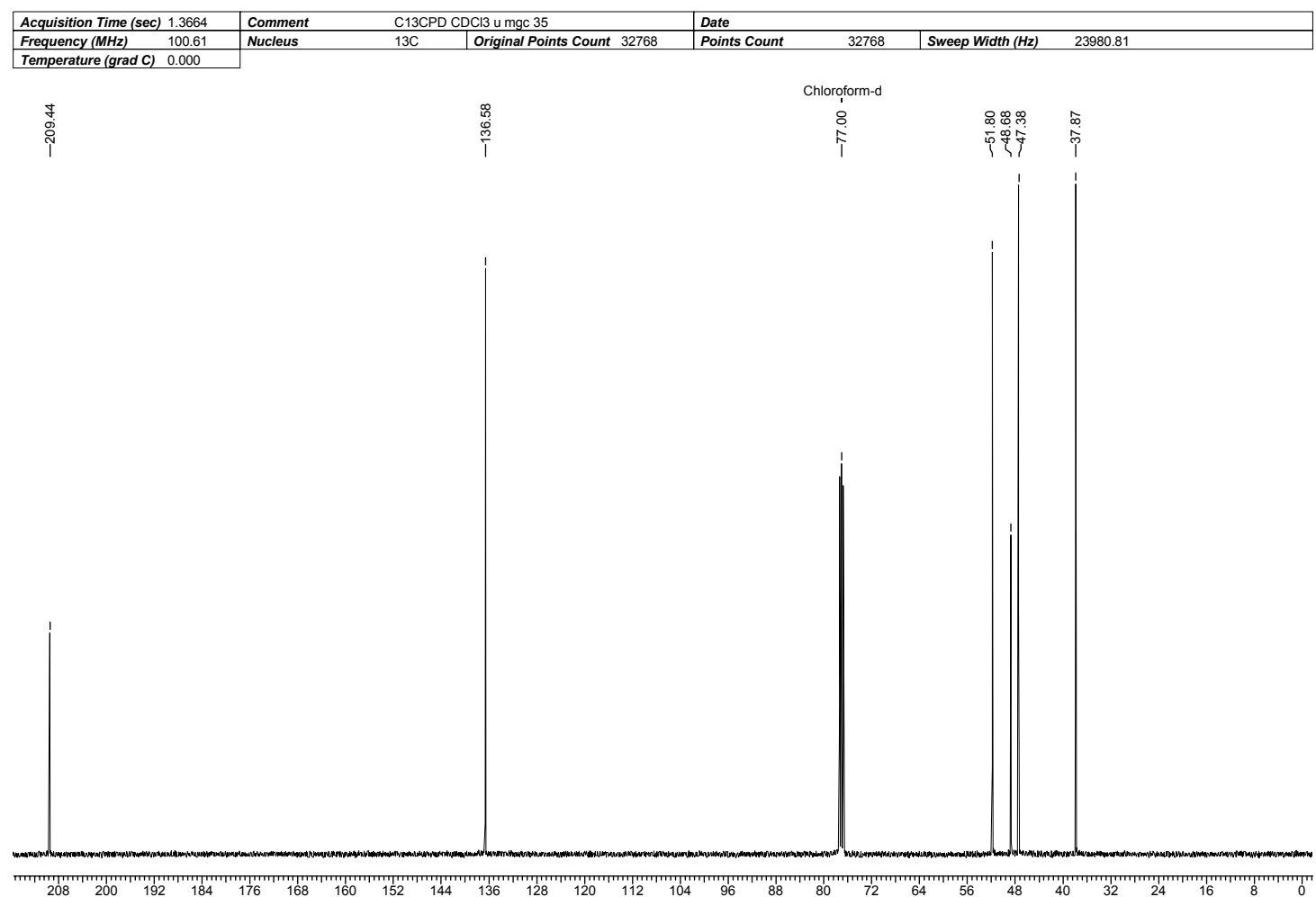

Espectro de RMN ${ }^{13} \mathrm{C}(\mathrm{DEPT}-135)$ *

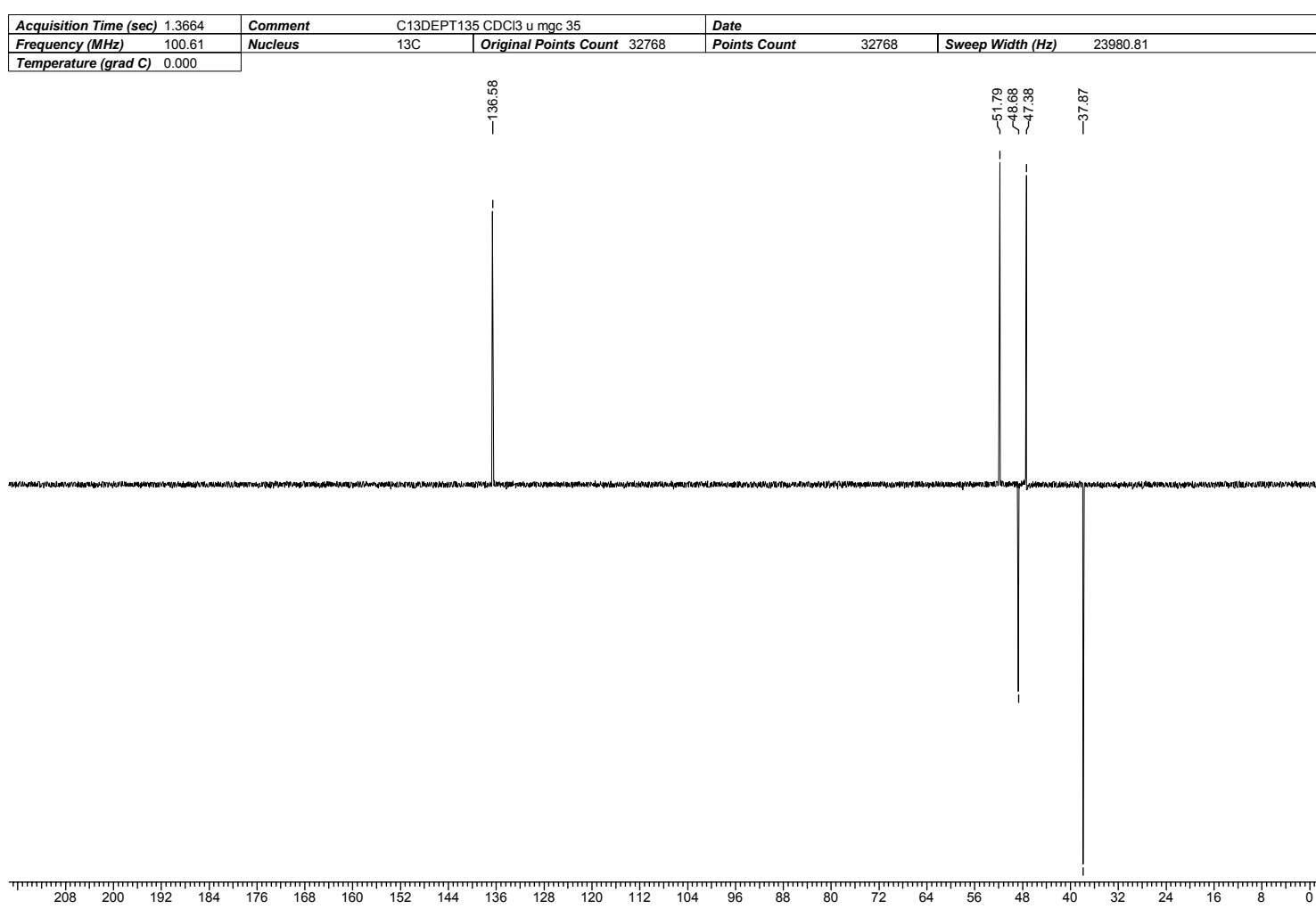

*Espectro de $\mathrm{RMN}{ }^{13} \mathrm{C}\left(125 \mathrm{MHz}, \mathrm{CDCl}_{3}\right)$ DEPT-135 do composto $148 . \uparrow\left(\mathrm{CH}, \mathrm{CH}_{3}\right), \downarrow \cdot\left(\mathrm{CH}_{2}\right)$

Figura 62: Espectros de $\mathrm{RMN}-{ }^{13} \mathrm{C}\left(100 \mathrm{MHz}, \mathrm{CDCl}_{3}\right)$ do composto 148. 
Tabela 31: Dados Espectroscópicos do Composto 148.

\begin{tabular}{|c|c|c|c|c|c|c|c|}
\hline $\mathrm{C}$ & $\delta \mathrm{C}$ & $\delta \mathrm{H}$ & Integral Relativa & Multiplicidade & Constantes de Acoplamento $(\mathrm{Hz})$ & $\overline{\mathrm{gCOSY}}$ & gHMQC \\
\hline 1 & 136,6 & 6,11 & $2 \mathrm{H}$ & $\mathrm{sl}$ & - & $\mathrm{H}_{6 \mathrm{~b}}, \mathrm{H}_{2}$ & $\mathrm{H}_{1}$ \\
\hline 2 & 47,4 & $3,35-3,45$ & $2 \mathrm{H}$ & $\mathrm{m}$ & - & $\mathrm{H}_{1}, \mathrm{H}_{3}, \mathrm{H}_{6 \mathrm{a}}, \mathrm{H}_{6 \mathrm{~b}}$ & $\mathrm{H}_{2}$ \\
\hline 3 & 51,8 & $3,10-3,20$ & $2 \mathrm{H}$ & $\mathrm{m}$ & - & $\mathrm{H}_{2}$ & $\mathrm{H}_{3}$ \\
\hline 4 & 209,4 & & & & - & & \\
\hline \multirow[t]{2}{*}{5} & 37,9 & $\left(\mathrm{H}_{5 \mathrm{eq}}\right) 2,51-2,64$ & $2 \mathrm{H}$ & $\mathrm{m}$ & - & $\mathrm{H}_{5 \mathrm{ax}}$ & $\mathrm{H}_{5}$ \\
\hline & & $\left(\mathrm{H}_{5 \mathrm{ax}}\right) 2,18-2,31$ & $2 \mathrm{H}$ & $\mathrm{m}$ & - & $\mathrm{H}_{5 \mathrm{eq}}$ & \\
\hline \multirow[t]{2}{*}{6} & 48,7 & $\left(\mathrm{H}_{6 \mathrm{a}}\right) 1,42$ & $1 \mathrm{H}$ & $\mathrm{dt}$ & $\mathrm{J}_{6 \mathrm{a} / 6 \mathrm{~b}}=8,7 ; \mathrm{J}_{6 \mathrm{a} / 2}=\mathrm{J}_{6 \mathrm{a} / 2},=1,8$ & $\mathrm{H}_{2}, \mathrm{H}_{6 \mathrm{~b}}$ & $\mathrm{H}_{6}$ \\
\hline & & $\left(\mathrm{H}_{6 \mathrm{~b}}\right) 1,29$ & $1 \mathrm{H}$ & $\mathrm{dl}$ & $\mathrm{J}_{6 \mathrm{~b} / 6 \mathrm{a}}=8,7$ & $\mathrm{H}_{1}, \mathrm{H}_{2}^{*}, \mathrm{H}_{6 \mathrm{a}}$ & \\
\hline
\end{tabular}

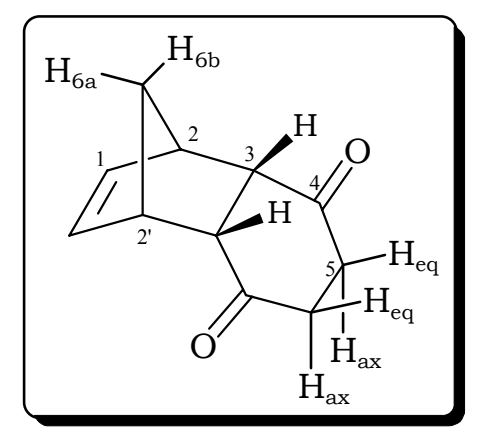




\section{Composto 149}

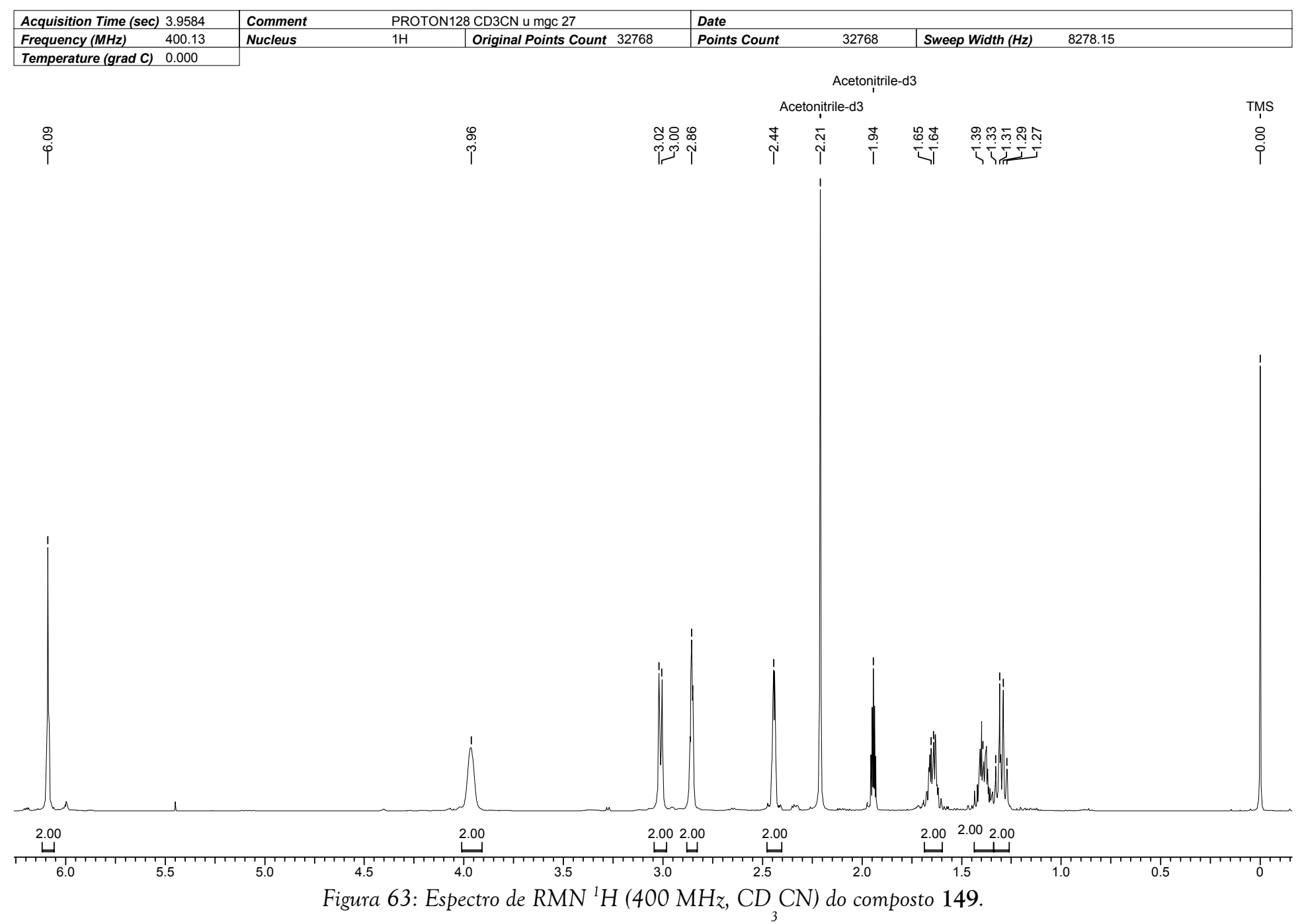


Espectro de $R M N{ }^{13} \mathrm{C}\left\{{ }^{1} \mathrm{H}\right\}$

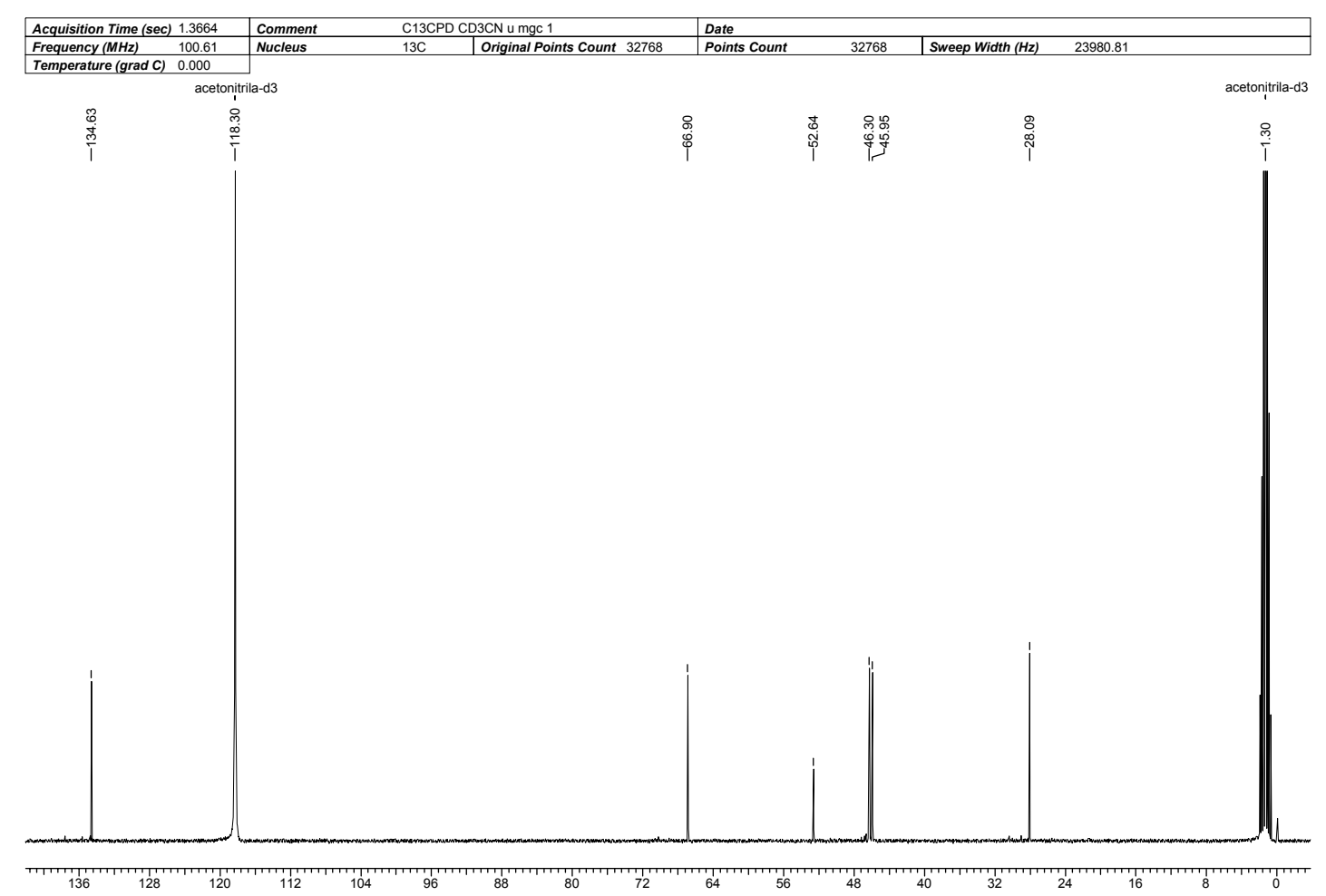

Espectro de RMN ${ }^{13} \mathrm{C}(\mathrm{DEPT}-135) .{ }^{*}$

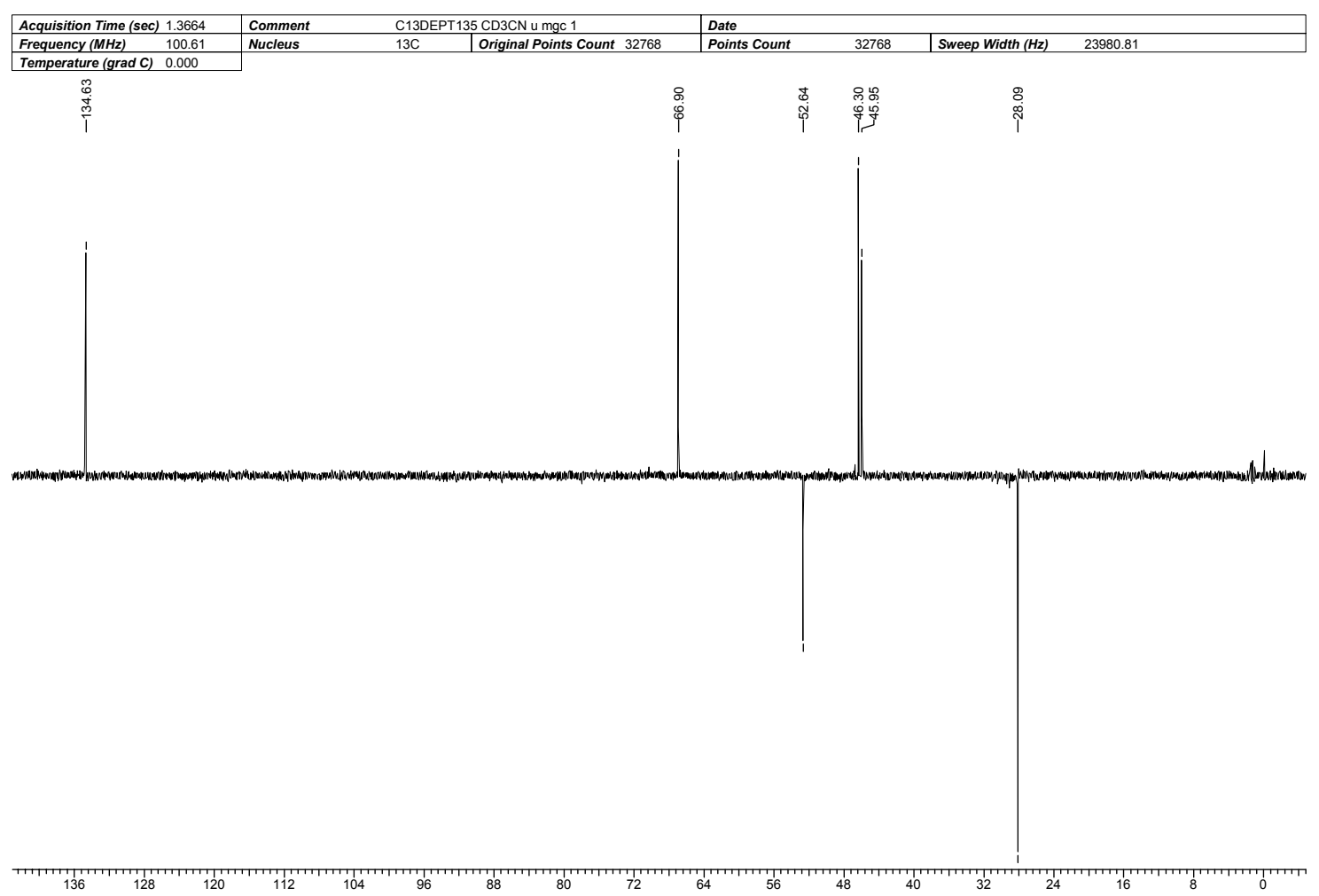

*Espectro de $\mathrm{RMN}{ }^{13} \mathrm{C}\left(125 \mathrm{MHz}, \mathrm{CDCl}_{3}\right)$ DEPT-135 do composto $149 . \uparrow\left(\mathrm{CH}, \mathrm{CH}_{3}\right), \downarrow \cdot\left(\mathrm{CH}_{2}\right)$

Figura 64: Espectros de RMN- ${ }^{13} \mathrm{C}(100 \mathrm{MHz}, \mathrm{CD} \mathrm{CN})$ do composto 149. 
Tabela 32: Dados Espectroscópicos do Composto 149

\begin{tabular}{|c|c|c|c|c|c|}
\hline $\mathrm{C}$ & $\delta \mathrm{C}$ & $\delta \mathrm{H}$ & Integral Relativa & Multiplicidade & Constantes de Acoplamento $(\mathrm{Hz})$ \\
\hline 1 & 134,6 & 6,09 & $2 \mathrm{H}$ & $\mathrm{t}$ & $\mathrm{J}_{1 / 2}=1,7 ; \mathrm{J}_{1 / 6 \mathrm{~b}}=1,2$ \\
\hline 2 & 46,0 & $2,83-2,88$ & $2 \mathrm{H}$ & $\mathrm{m}$ & - \\
\hline 3 & 46,3 & $2,42-2,46$ & $2 \mathrm{H}$ & $\mathrm{m}$ & - \\
\hline 4 & 66,9 & $3,90-4,01$ & $2 \mathrm{H}$ & $\mathrm{m}$ & - \\
\hline \multirow[t]{2}{*}{5} & 28,1 & $\left(\mathrm{H}_{5 \mathrm{eq}}\right) 1,60-1,68$ & $2 \mathrm{H}$ & $\mathrm{m}$ & - \\
\hline & & $\left(\mathrm{H}_{5 \mathrm{ax}}\right) 1,35-1,44$ & $2 \mathrm{H}$ & $\mathrm{m}$ & - \\
\hline \multirow[t]{3}{*}{6} & 52,6 & $\left(\mathrm{H}_{6 \mathrm{a}}\right) 1,32$ & $1 \mathrm{H}$ & $\mathrm{dt}$ & $\mathrm{J}_{6 \mathrm{a} / 6 \mathrm{~b}}=7,8 ; \mathrm{J}_{6 \mathrm{a} / 2}=\mathrm{J}_{6 \mathrm{a} / 2},=1,7$ \\
\hline & & $\left(\mathrm{H}_{6 \mathrm{~b}}\right) 1,28$ & $1 \mathrm{H}$ & $\mathrm{dl}$ & $\mathrm{J}_{6 \mathrm{~b} / 6 \mathrm{a}}=7,8 ; \mathrm{J}_{6 \mathrm{~b} / 1}=1,2 ; \mathrm{J}_{6 \mathrm{~b} / 1}=1,2$ \\
\hline & & ${ }^{*} \mathrm{H}_{7} 3,01$ & $2 \mathrm{OH}$ & $\mathrm{d}$ & $\mathrm{J}_{7 / 4}=5,8$ \\
\hline
\end{tabular}

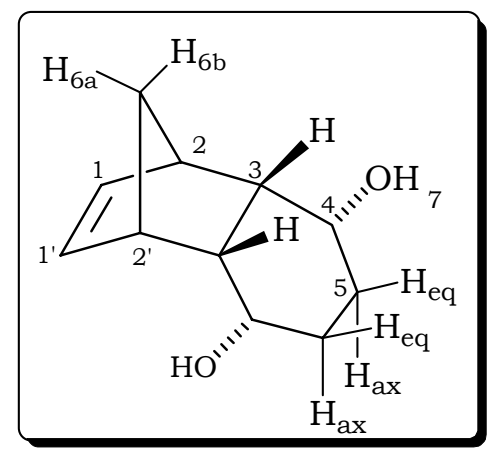

${ }^{*}$ confirmado pela adição de $\mathrm{D}_{2} \mathrm{O}$ na amostra em um segundo experimento de $\mathrm{RMN}$ de ${ }^{1} \mathrm{H}$. 


\section{Composto 150}

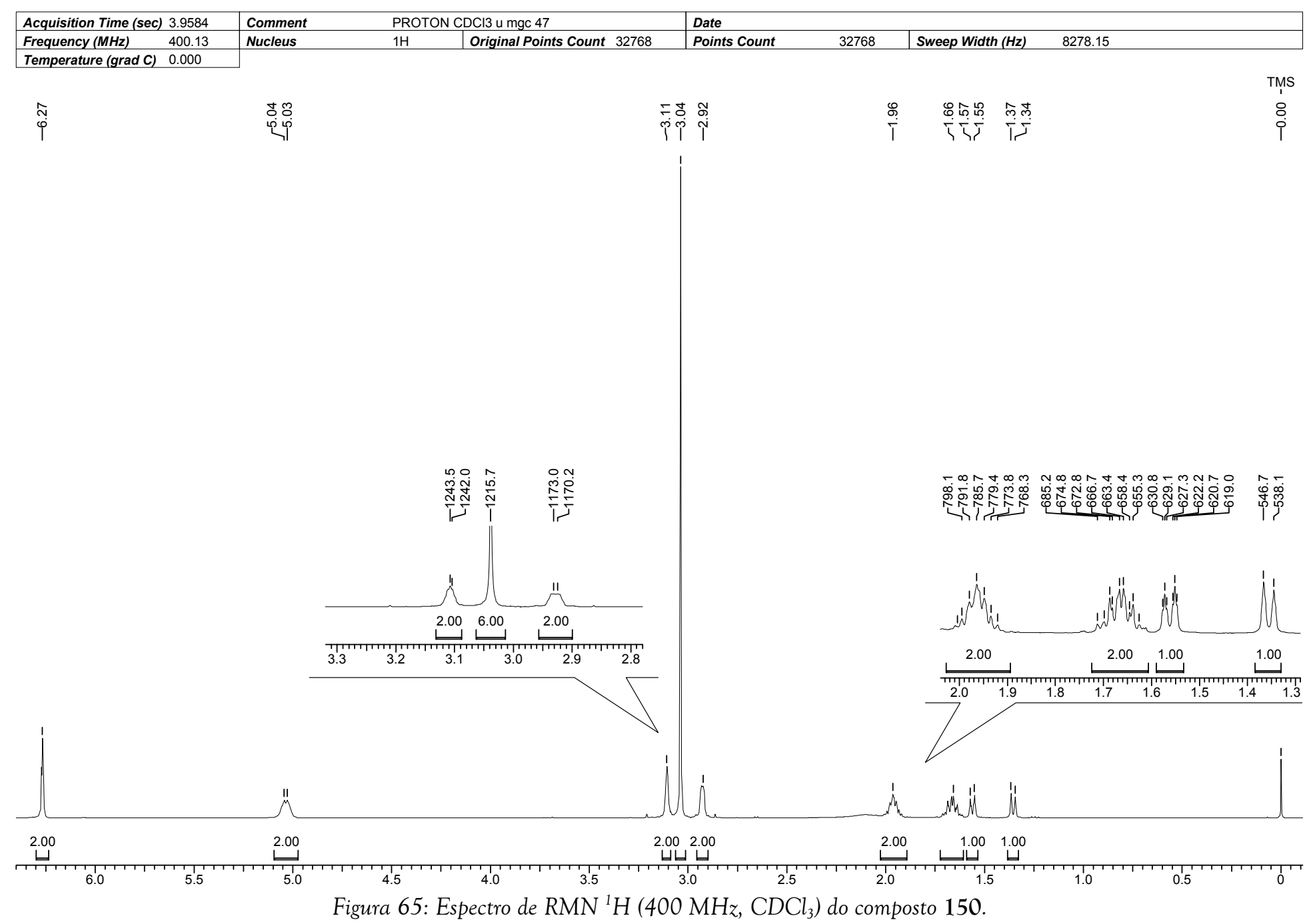


Espectro de $R M N{ }^{13} \mathrm{C}\left\{{ }^{1} \mathrm{H}\right\}$

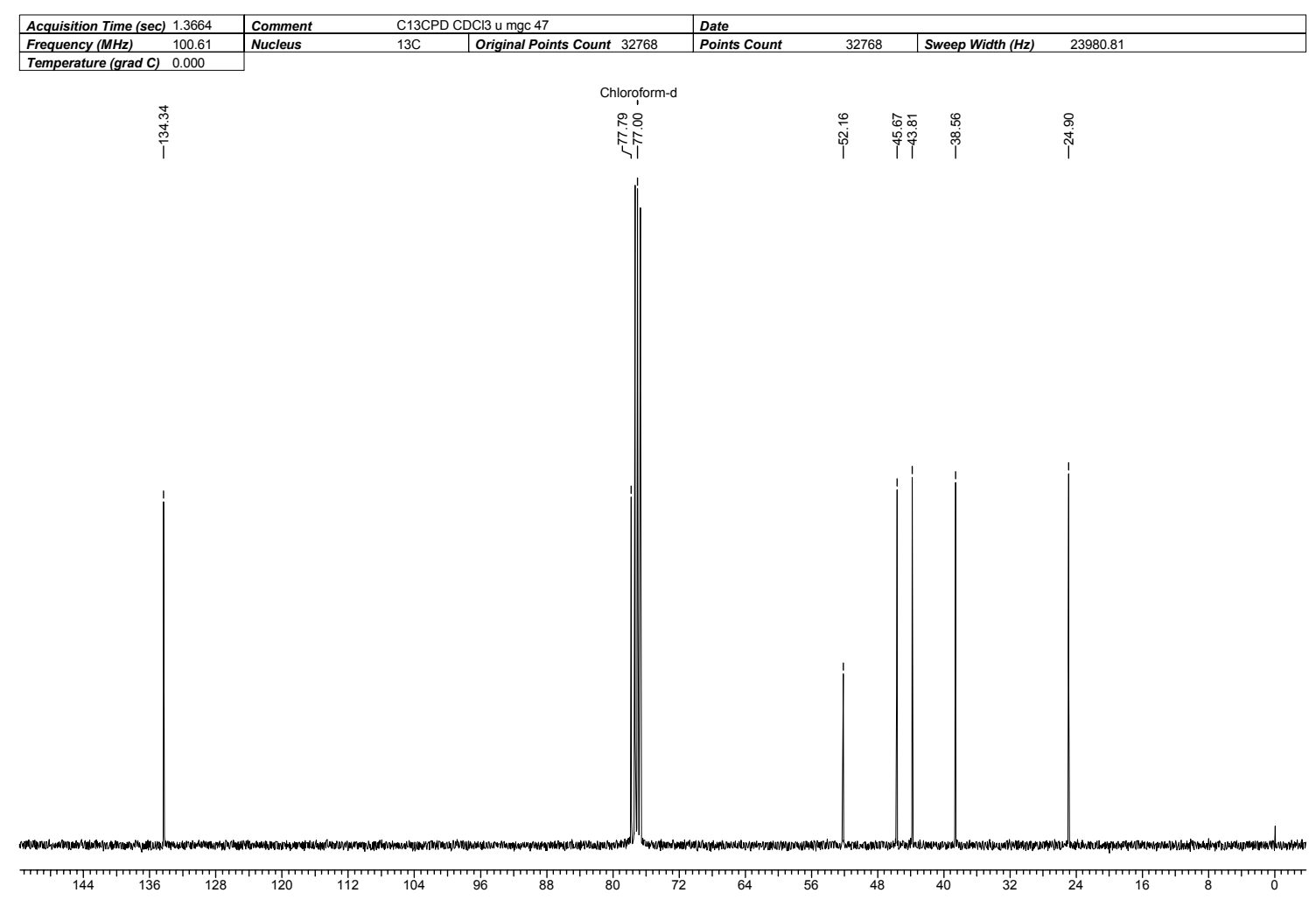

Espectro de RMN ${ }^{13} \mathrm{C}(\mathrm{DEPT}-135)$.

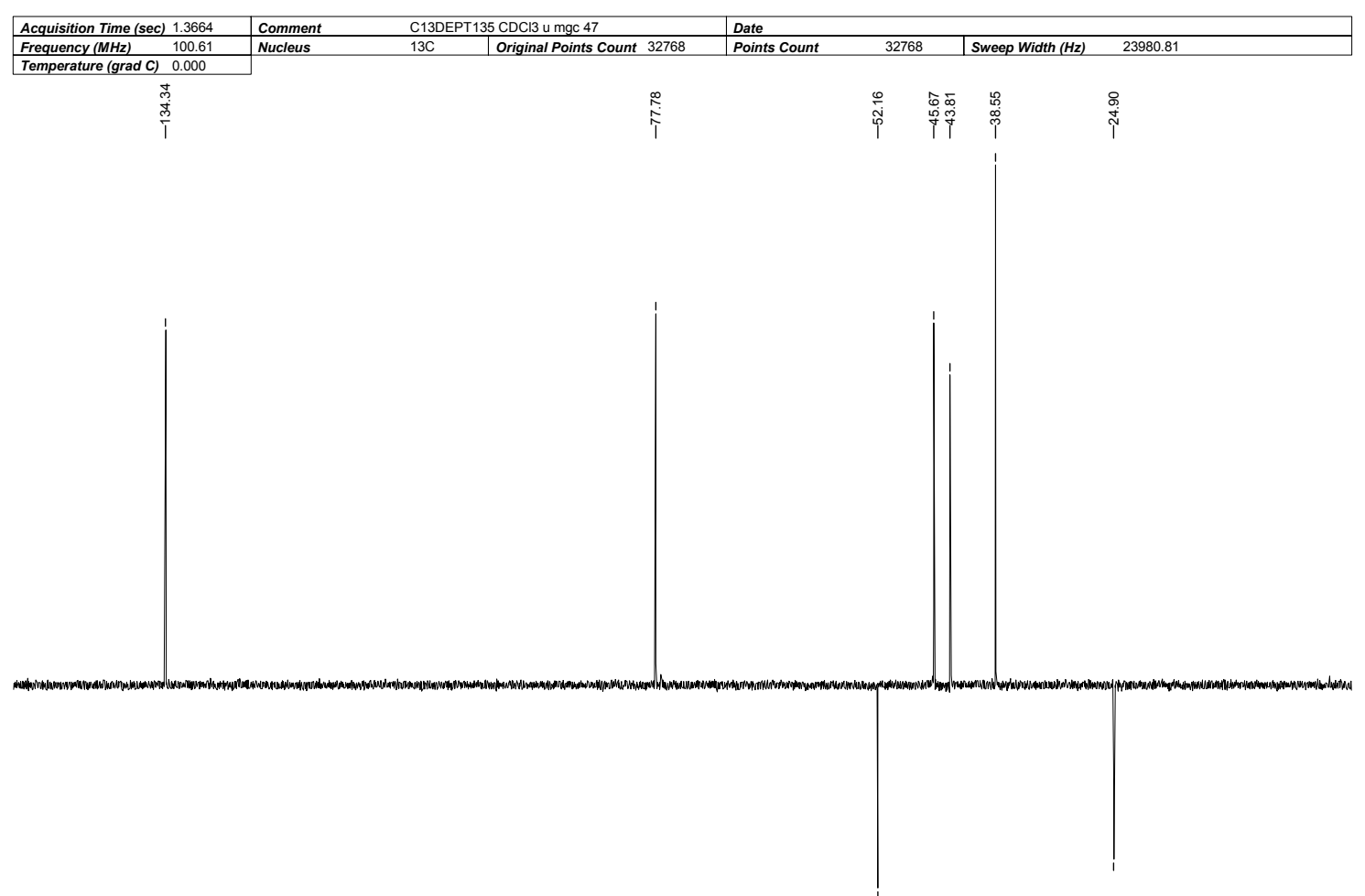

*Espectro de RMN ${ }^{13} \mathrm{C}\left(125 \mathrm{MHz}, \mathrm{CDCl}_{3}\right)$ DEPT-135 do composto $150 . \uparrow\left(\mathrm{CH}, \mathrm{CH}_{3}\right), \downarrow .\left(\mathrm{CH}_{2}\right)$

Figura 66: Espectros de $\mathrm{RMN}^{13} \mathrm{C}\left(100 \mathrm{MHz}, \mathrm{CDCl}_{3}\right)$ do composto 150. 
Tabela 33: Dados espectroscópicos do composto 150.

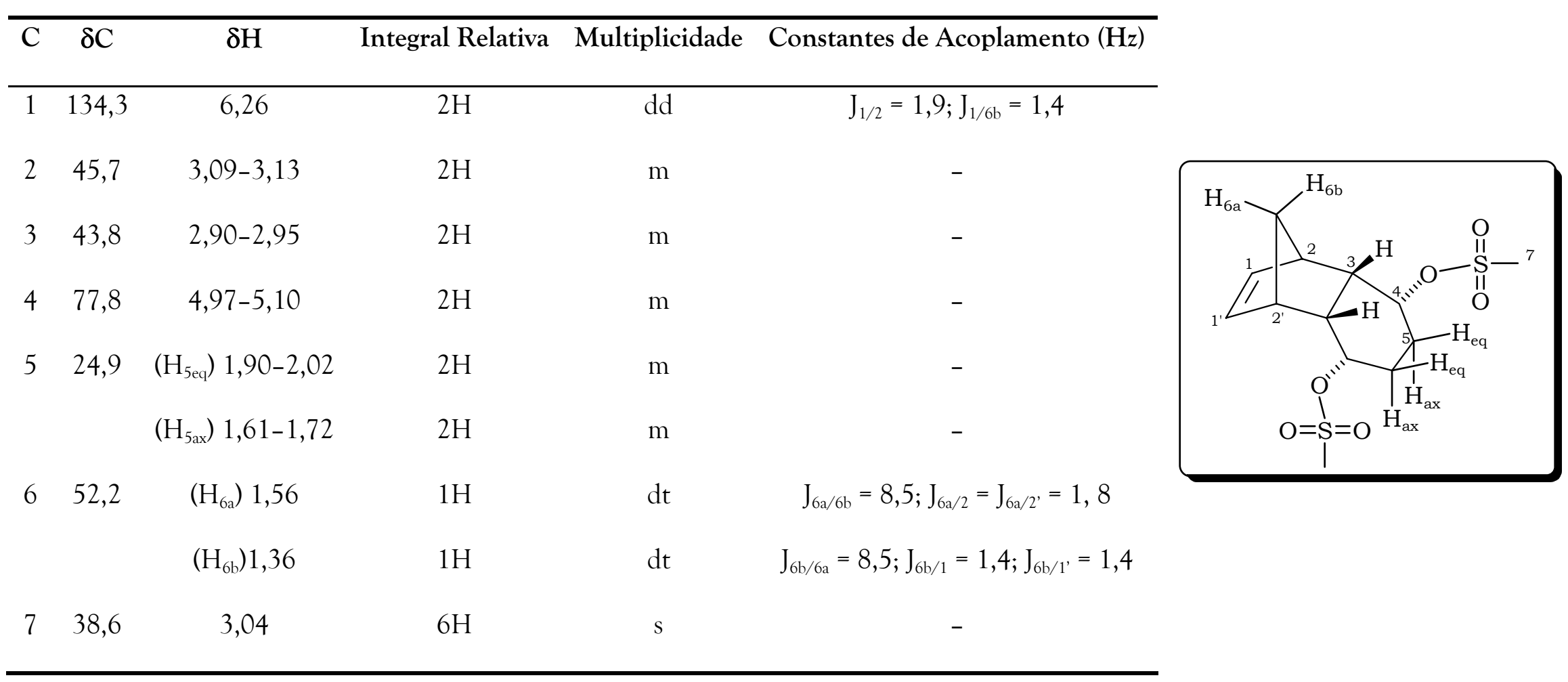




\section{Composto 155}

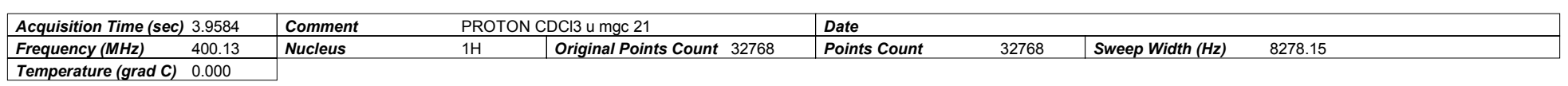
\begin{tabular}{|ll|}
\hline Frequency (MHz) & 400.13 \\
\hline Temperature (grad C) & 0.000 \\
\hline
\end{tabular}

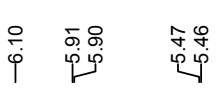
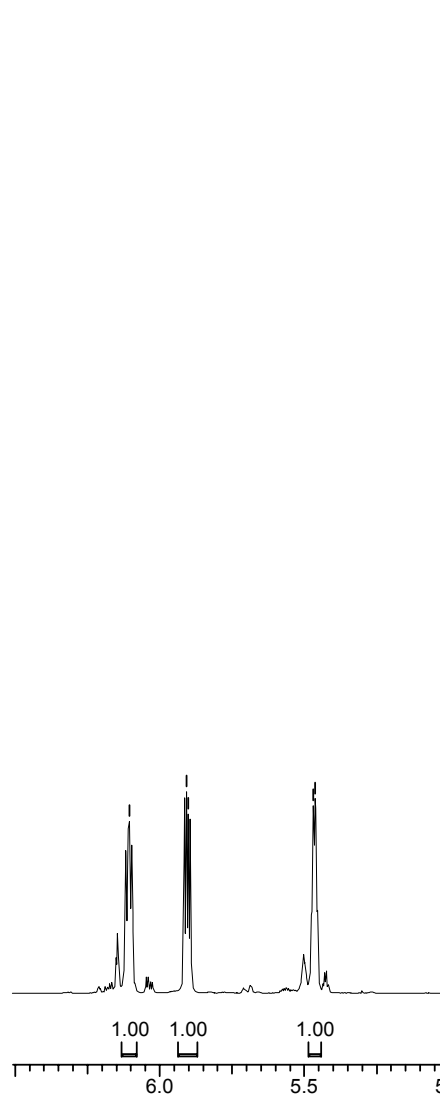

Figura 67: Espectro de $\mathrm{RMN}^{1} \mathrm{H}\left(400 \mathrm{MHz}, \mathrm{CDCl}_{3}\right)$ do composto 155. 
Espectro de $R M N{ }^{13} \mathrm{C}\left\{{ }^{1} \mathrm{H}\right\}$

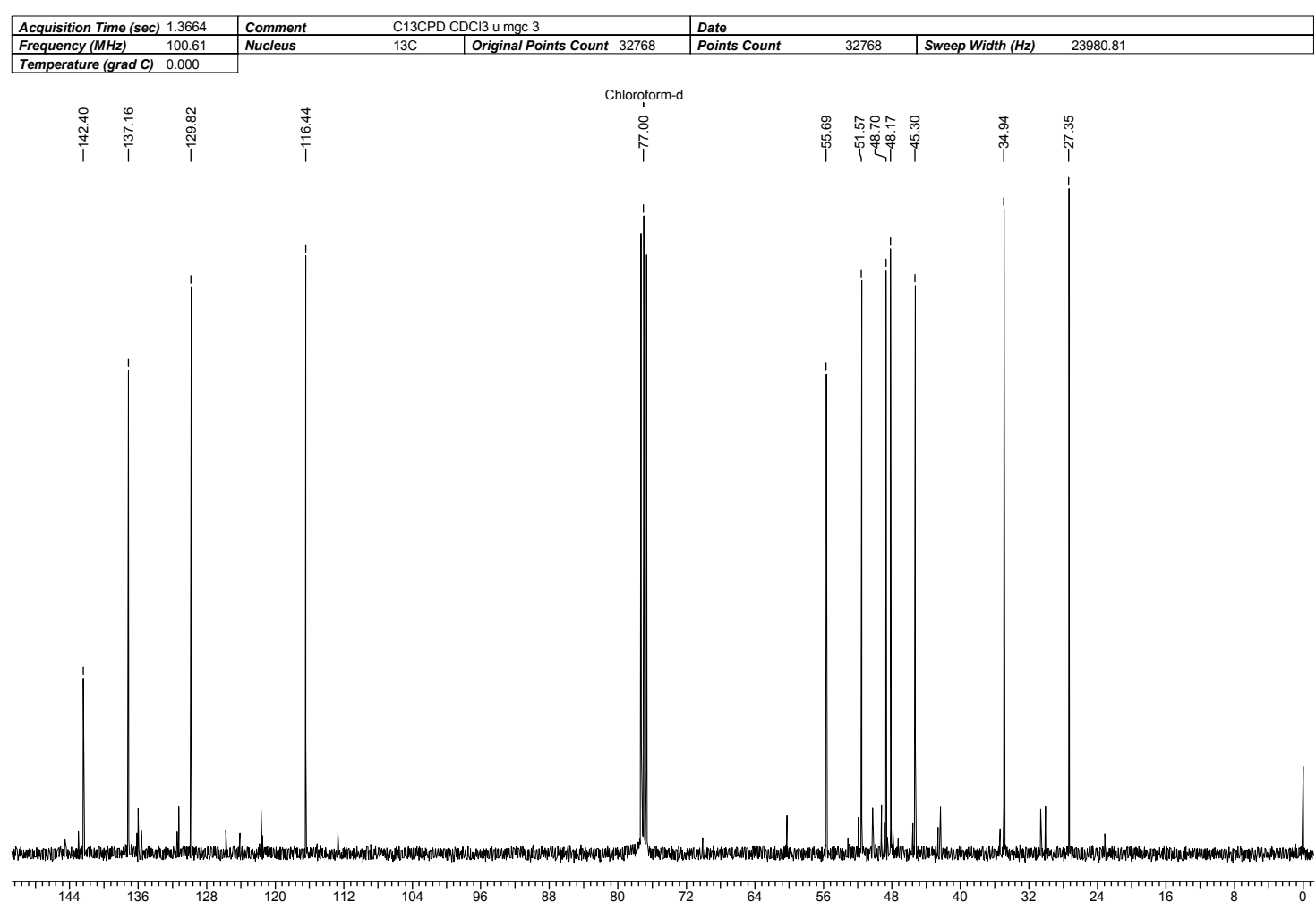

Espectro de RMN ${ }^{13} \mathrm{C}(\mathrm{DEPT}-135)$.

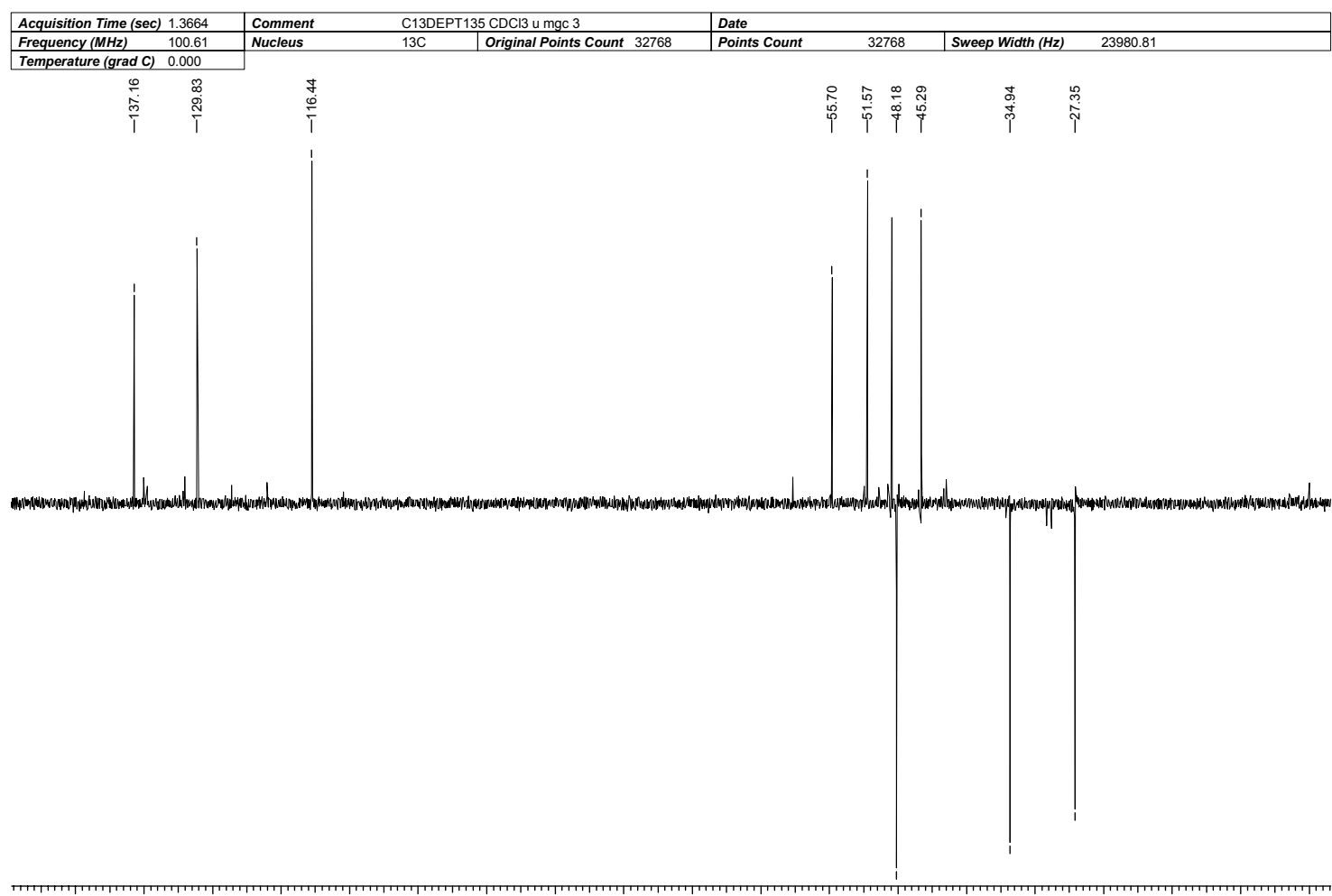

${ }^{*}$ Espectro de $\mathrm{RMN}^{13} \mathrm{C}\left(125 \mathrm{MHz}, \mathrm{CDCl}_{3}\right)$ DEPT- 135 do composto $155 . \uparrow\left(\mathrm{CH}, \mathrm{CH}_{3}\right), \downarrow \cdot\left(\mathrm{CH}_{2}\right)$

Figura 68: Espectros de $\mathrm{RMN}^{13} \mathrm{C}\left(100 \mathrm{MHz}, \mathrm{CDCl}_{3}\right)$ do composto 155 
Tabela 34: Dados Espectroscópicos do Composto 155.

\begin{tabular}{|c|c|c|c|c|c|}
\hline $\mathrm{C}$ & $\delta \mathrm{C}$ & $\delta \mathrm{H}$ & Integral Relativa & Multiplicidade & Constantes de Acoplamento $(\mathrm{Hz})$ \\
\hline $1^{*}$ & 129,8 & 6,11 & $1 \mathrm{H}$ & $\mathrm{dd}$ & $\mathrm{J}_{1 / 10}=5,6 ; \mathrm{J}_{1 / 2}=3,3$ \\
\hline $2^{*}$ & 48,7 & 3,22 & $1 \mathrm{H}$ & sl & - \\
\hline $3^{*}$ & 45,3 & 2,69 & $1 \mathrm{H}$ & $\mathrm{dl}$ & $\mathrm{J}_{3 / 4}=10,5$ \\
\hline 4 & 55,7 & 3,32 & $1 \mathrm{H}$ & ddd & $\mathrm{J}_{4 / 5 \mathrm{ax}}=11,3 ; \mathrm{J}_{4 / 3}=10,5 ; \mathrm{J}_{4 / 5 \mathrm{eq}}=4,0$ \\
\hline 5 & 34,9 & $2,06-2,36$ & $2 \mathrm{H}$ & $\mathrm{m}$ & \\
\hline 6 & 27,4 & $2,06-2,36$ & $2 \mathrm{H}$ & $\mathrm{m}$ & \\
\hline 7 & 116,4 & 5,46 & $1 \mathrm{H}$ & $\mathrm{dd}$ & $\mathrm{J}_{7 / 5 \mathrm{ax}}=5,3 ; \mathrm{J}_{7 / 5 \mathrm{eq}}=2,7$ \\
\hline 8 & 142,4 & & & & \\
\hline 9 & 51,6 & 3,14 & $1 \mathrm{H}$ & sl & \\
\hline $10^{*}$ & 137,2 & 5,90 & $1 \mathrm{H}$ & $\mathrm{dd}$ & $\mathrm{J}_{10 / 1}=5,6 ; \mathrm{J}_{10 / 9}=3,1$ \\
\hline \multirow[t]{2}{*}{11} & 48,2 & $\left(\mathrm{H}_{11 \mathrm{a}}\right) 1,60$ & $1 \mathrm{H}$ & $\mathrm{dt}$ & $\mathrm{J}_{11 \mathrm{a} / 11 \mathrm{~b}}=8,5 ; \mathrm{J}_{11 \mathrm{a} / 2}=\mathrm{J}_{11 \mathrm{a} / 9}=1,8$ \\
\hline & & $\left.\mathrm{H}_{11 \mathrm{~b}}\right) 1,47$ & $1 \mathrm{H}$ & $\mathrm{dl}$ & $\mathrm{J}_{11 \mathrm{~b} / 11 \mathrm{a}}=8,5$ \\
\hline
\end{tabular}

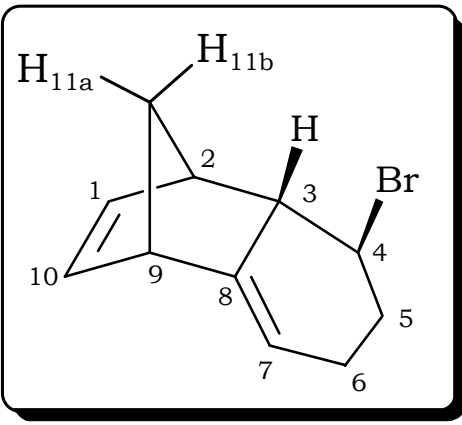

* podem estar trocados 


\section{Composto 162}

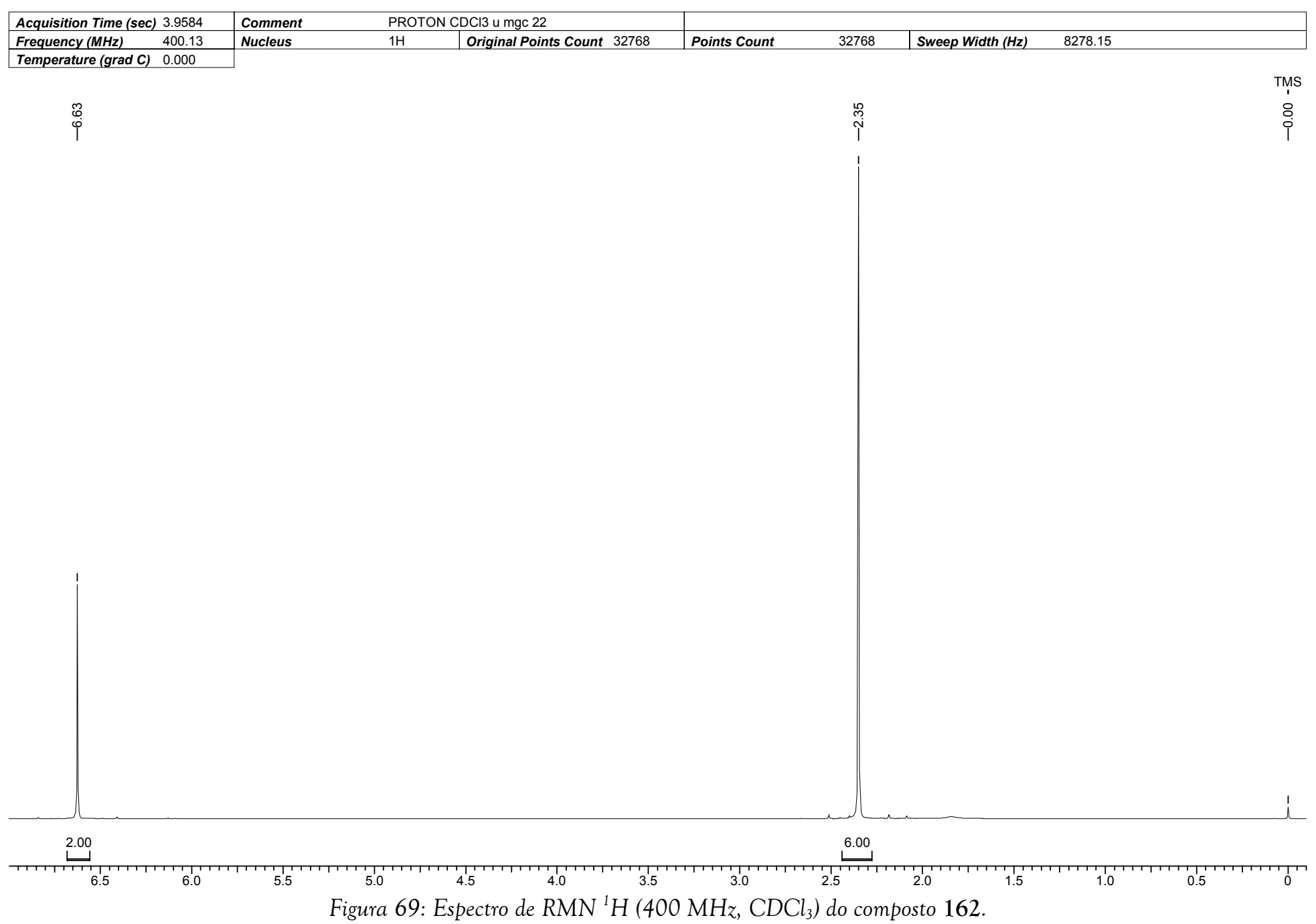

Figura 69: Espectro de $\mathrm{RMN}^{1} \mathrm{H}\left(400 \mathrm{MHz}, \mathrm{CDCl}_{3}\right)$ do composto 162 . 


\section{Espectro de $R M N{ }^{13} \mathrm{C}\left\{{ }^{1} \mathrm{H}\right\}$}

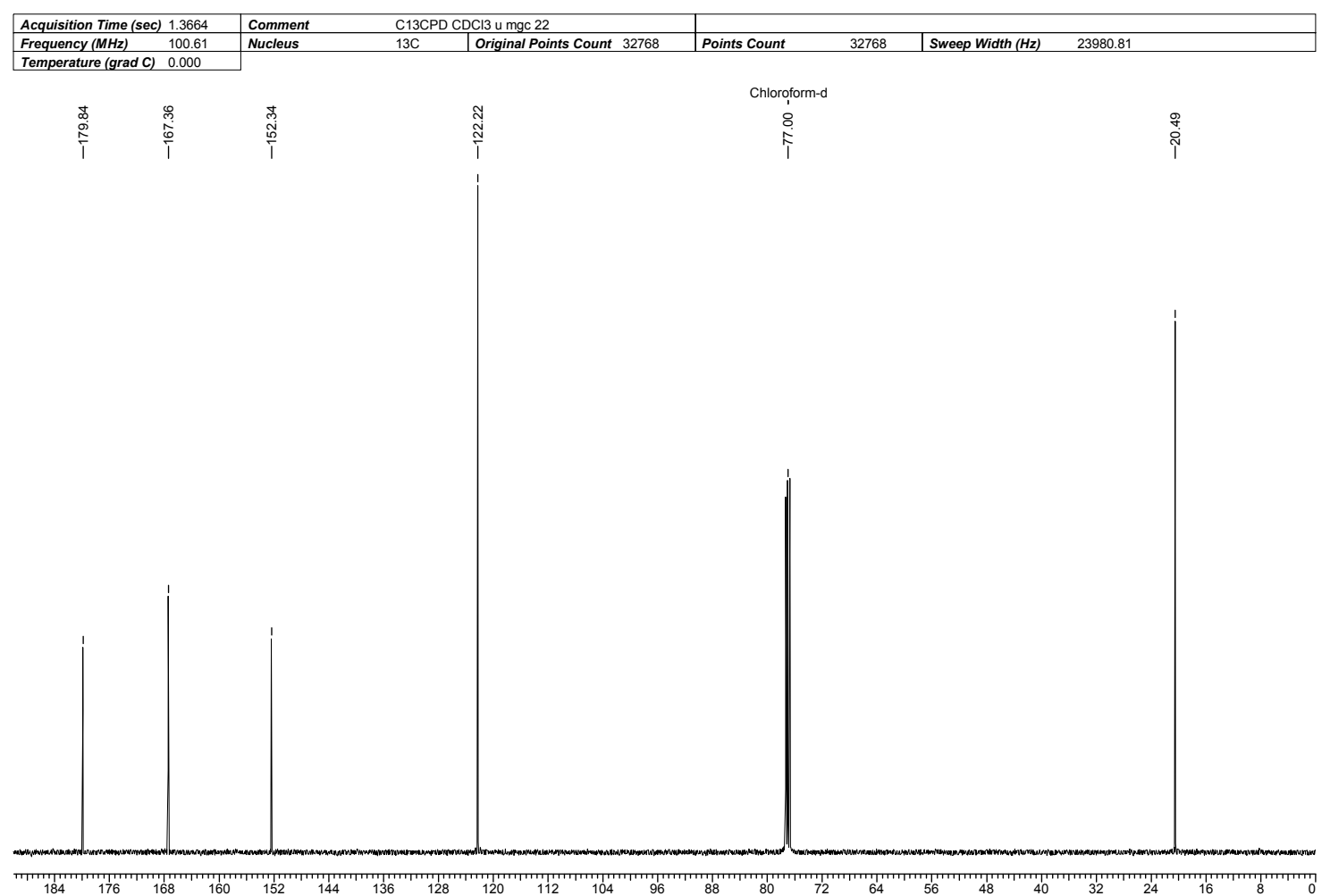

Espectro de RMN ${ }^{13} \mathrm{C}(\mathrm{DEPT}-135)$.

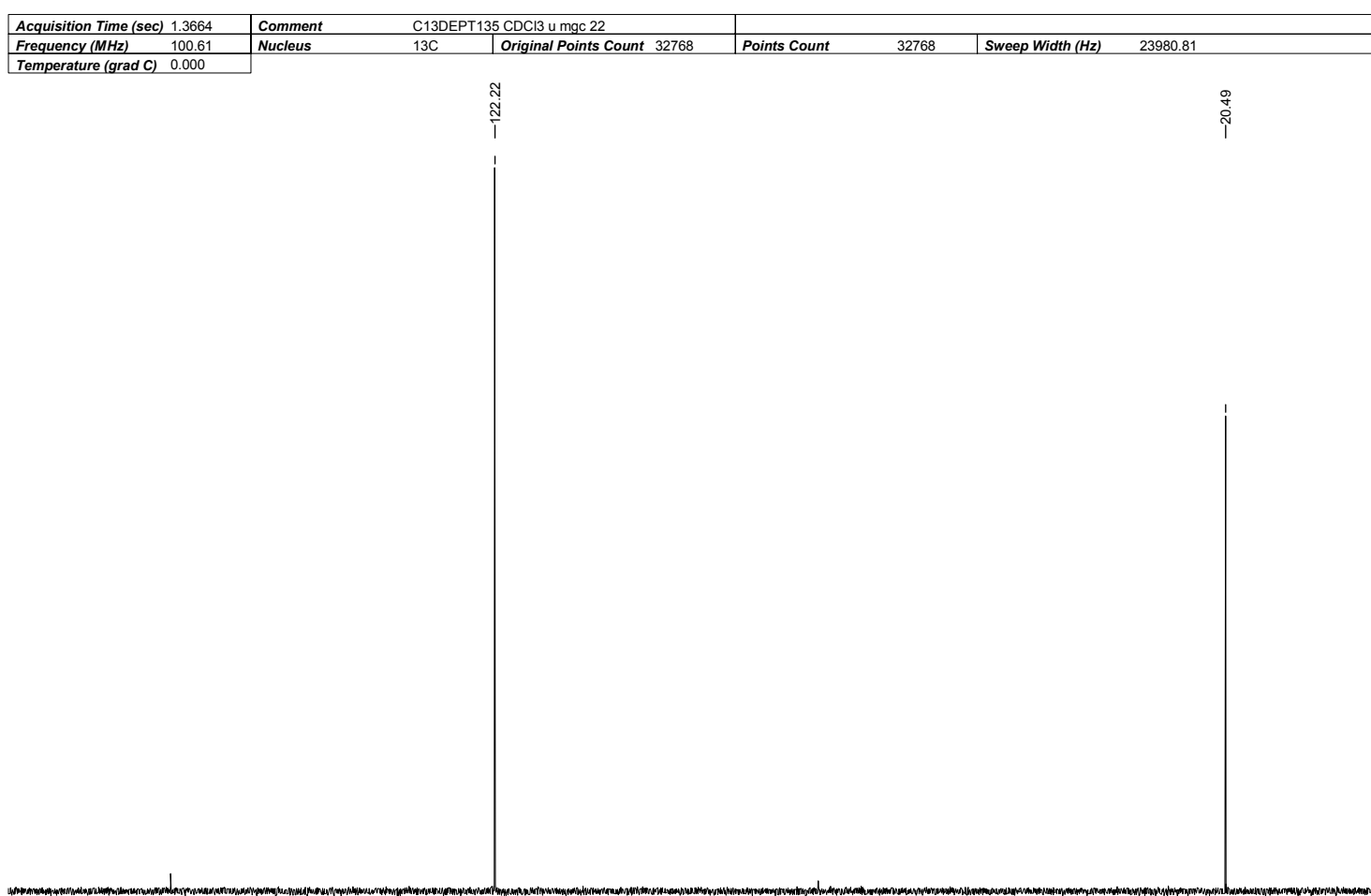

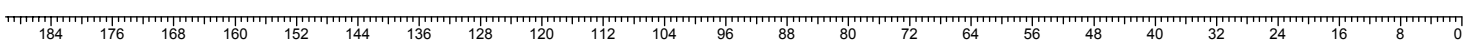

* Espectro de RMN ${ }^{13} \mathrm{C}\left(100 \mathrm{MHz}, \mathrm{CDCl}_{3}\right)$ DEPT-135 do composto $162 \uparrow\left(\mathrm{CH}, \mathrm{CH}_{3}\right), \downarrow .\left(\mathrm{CH}_{2}\right)$

Figura 70: Espectros de $\mathrm{RMN}^{13} \mathrm{C}\left(100 \mathrm{MHz}, \mathrm{CDCl}_{3}\right)$ do composto 162 
Tabela 35: Dados Espectroscópicos do Composto 162.

\begin{tabular}{ccccc}
\hline C & $\delta \mathrm{C}(\mathrm{ppm})$ & $\delta \mathrm{H}(\mathrm{ppm})$ & Integral Relativa & Multiplicidade \\
\hline 1 е 4 & 179,8 & - & - & - \\
2 е 5 & 152,3 & - & - & - \\
3 е 6 & 122,2 & 6,63 & $2 \mathrm{H}$ & $\mathrm{s}$ \\
7 е 9 & 167,4 & & & $\mathrm{~s}$ \\
8 е 10 & 21,10 & 2,35 & $6 \mathrm{H}$ & \\
\hline
\end{tabular}

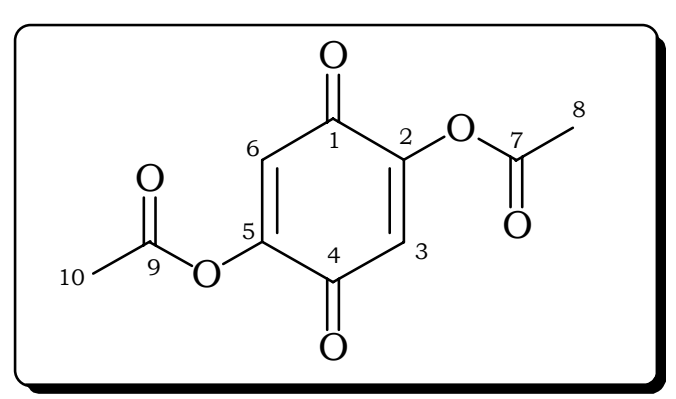




\section{Composto 163}

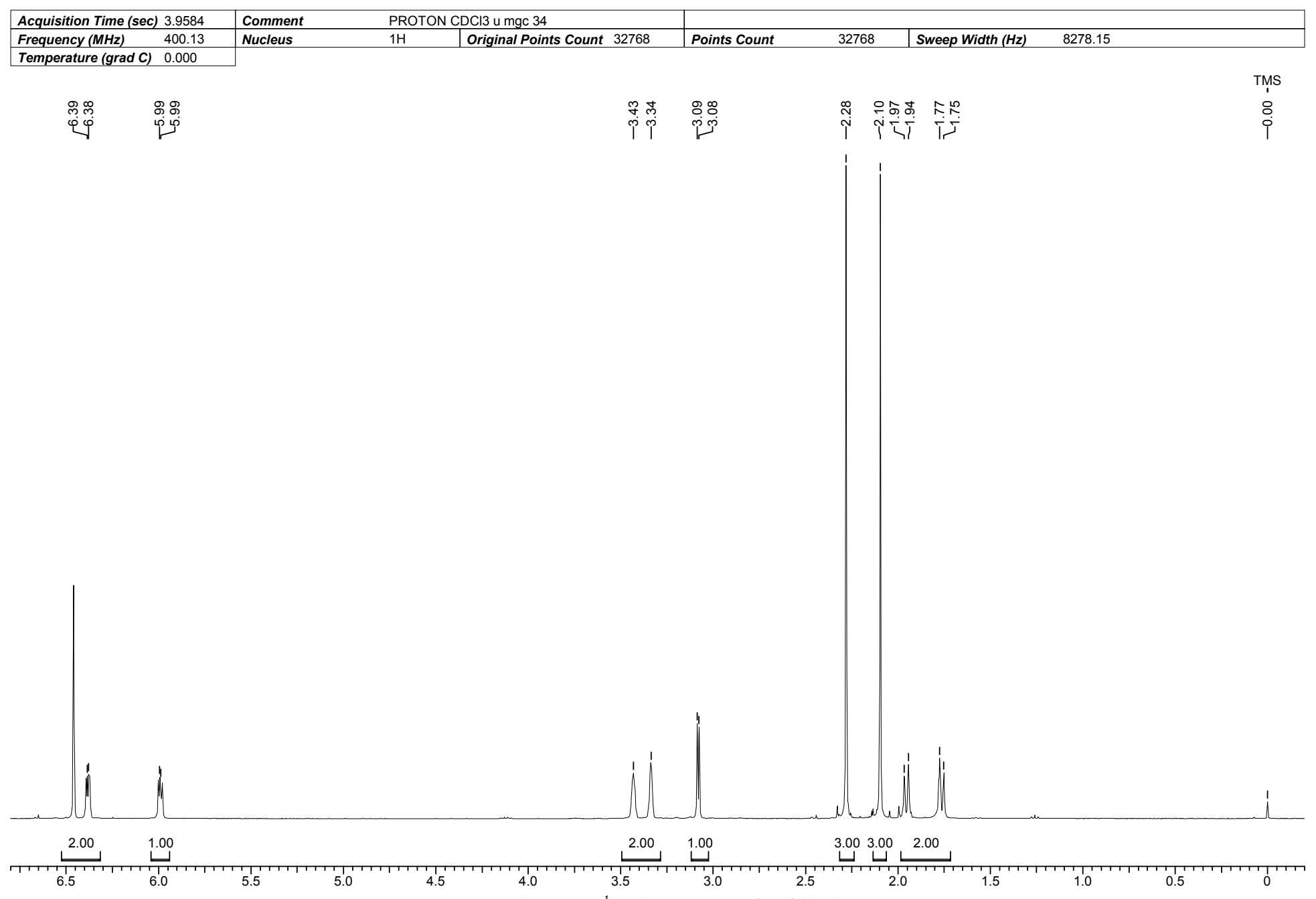

Figura 71: Espectro de $\mathrm{RMN}^{1} \mathrm{H}\left(400 \mathrm{MHz}, \mathrm{CDCl}_{3}\right)$ do composto 163. 
Espectro de $R M N{ }^{13} \mathrm{C}\left\{{ }^{1} \mathrm{H}\right\}$

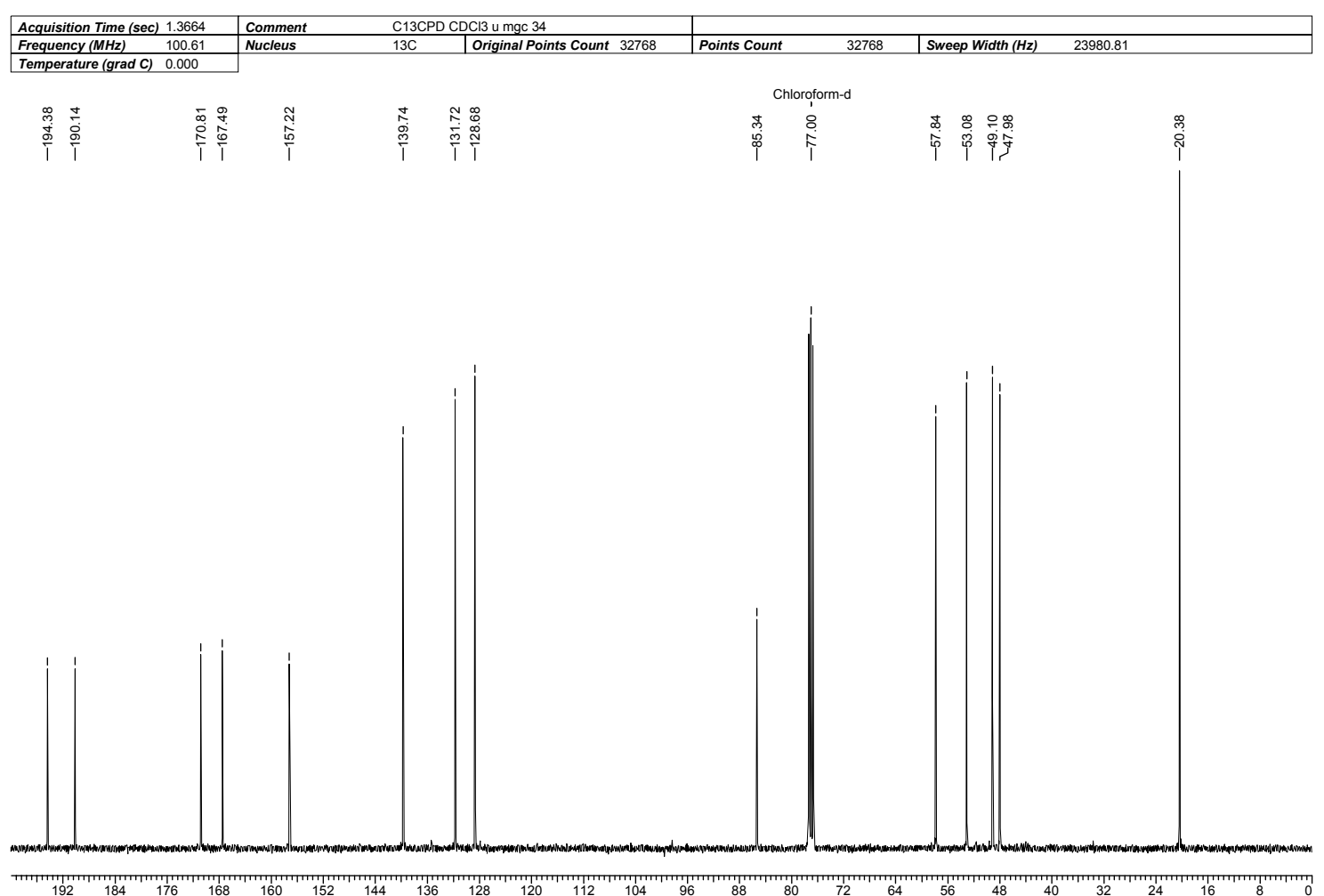

Espectro de RMN ${ }^{13} \mathrm{C}(\mathrm{DEPT}-135)$.

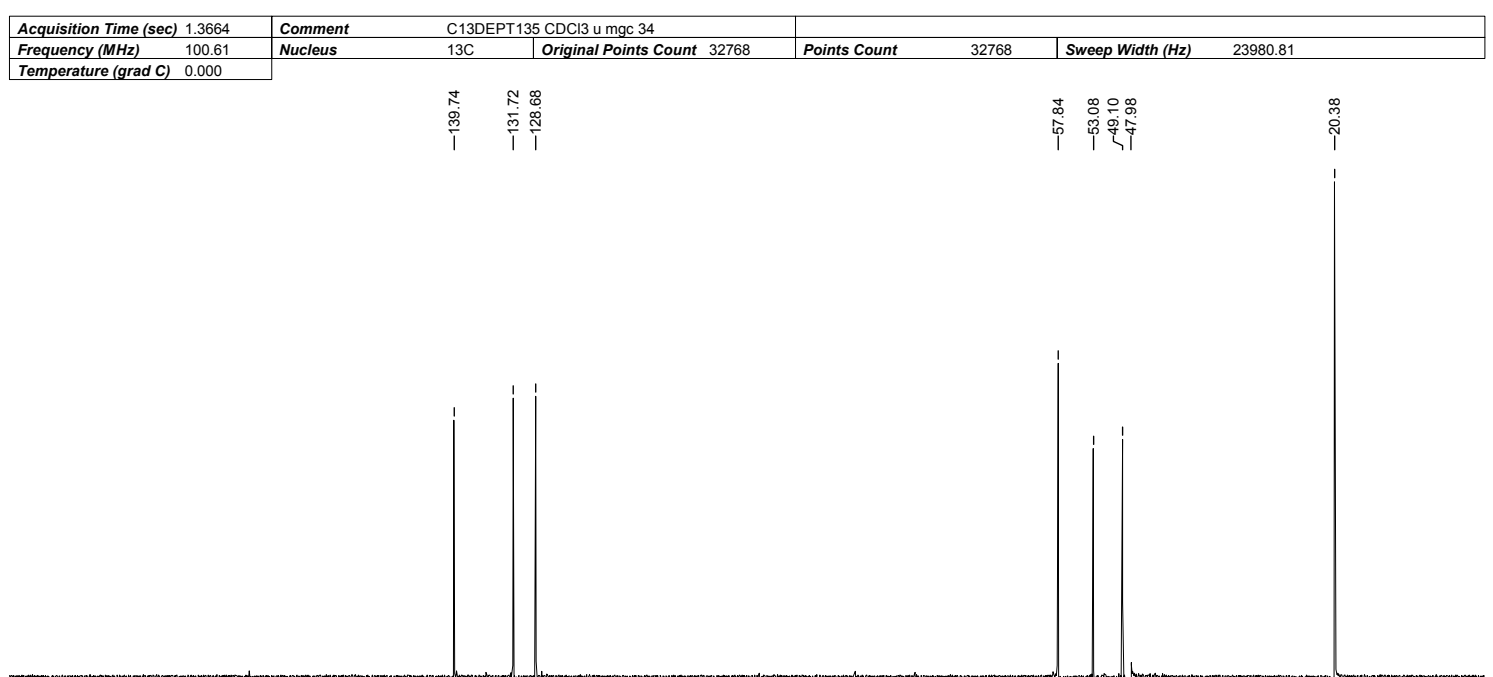

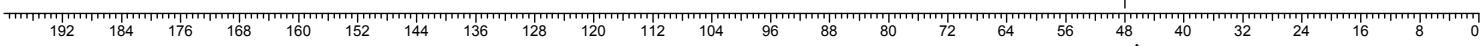

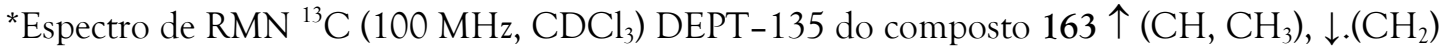

Figura 72: Espectros de $\mathrm{RMN}^{13} \mathrm{C}\left(100 \mathrm{MHz}, \mathrm{CDCl}_{3}\right)$ do composto 163. 
Tabela 36: Dados Espectroscópicos do Composto 163.

\begin{tabular}{|c|c|c|c|c|c|c|c|c|}
\hline $\mathrm{C}$ & $\delta \mathrm{C}(\mathrm{ppm})$ & $\delta \mathrm{H}(\mathrm{ppm})$ & $\begin{array}{l}\text { Integral } \\
\text { Relativa }\end{array}$ & Multiplicidade & $\begin{array}{c}\text { Constantes de } \\
\text { Acoplamento }(\mathrm{Hz})\end{array}$ & gCOSY & gHMBC & gHMQC \\
\hline 1 & 49,1 & 3,43 & $1 \mathrm{H}$ & ddtd & $\begin{array}{c}\mathrm{J}_{1,2}=4,0 ; \mathrm{J}_{1,10}=2,9 ; \mathrm{J}_{1,11 \mathrm{a}}= \\
1,5 ; \mathrm{J}_{1,11 \mathrm{~b}}=1,5 ; \mathrm{J}_{1,9}=0,9\end{array}$ & $\begin{array}{l}\mathrm{H}_{11 \mathrm{a}} ; \mathrm{H}_{11 \mathrm{~b}} \\
\mathrm{H}_{10}, \mathrm{H}_{9} ; \mathrm{H}_{2}\end{array}$ & $\begin{array}{c}\mathrm{H}_{2} ; \mathrm{H}_{8} ; \mathrm{H}_{9}, \mathrm{H}_{10} ; \\
\mathrm{H}_{11 \mathrm{a}} ; \mathrm{H}_{11 \mathrm{~b}}\end{array}$ & $\mathrm{C}_{1}$ \\
\hline 2 & 57,8 & 3,08 & $1 \mathrm{H}$ & $\mathrm{d}$ & $\mathrm{J}_{2,1}=4,0$ & $\mathrm{H}_{1}$ & $\mathrm{H}_{8} ; \mathrm{H}_{11 \mathrm{a}} ; \mathrm{H}_{11 \mathrm{~b}}$ & $\mathrm{C}_{2}$ \\
\hline 3 & 190,1 & & & & & & $\mathrm{H}_{5} ; \mathrm{H}_{2}$ & $\mathrm{C}_{3}$ \\
\hline 4 & 157,2 & & & & & & $\mathrm{H}_{5} ; \mathrm{H}_{2}$ & $\mathrm{C}_{4}$ \\
\hline 5 & 128,7 & 6,46 & $1 \mathrm{H}$ & S & & & & $\mathrm{C}_{5}$ \\
\hline 6 & 194,4 & & & & & & $\mathrm{H}_{5} ; \mathrm{H}_{2}$ & $\mathrm{C}_{6}$ \\
\hline 7 & 85,3 & & & & & & $\begin{array}{c}\mathrm{H}_{5} ; \mathrm{H}_{1} ; \mathrm{H}_{2} ; \mathrm{H}_{8} \\
\mathrm{H}_{11 \mathrm{a}} ; \mathrm{H}_{11 \mathrm{~b}}\end{array}$ & $\mathrm{C}_{7}$ \\
\hline 8 & 53,1 & 3,34 & $1 \mathrm{H}$ & dtd & $\begin{array}{c}\mathrm{J}_{8,9}=3,0 ; \mathrm{J}_{8,11 \mathrm{a}}=1,5 ; \mathrm{J}_{8,11 \mathrm{~b}}= \\
1,5 ; \mathrm{J}_{8,10}=0,8\end{array}$ & $\begin{array}{c}\mathrm{H}_{11 \mathrm{a}} ; \mathrm{H}_{11 \mathrm{~b}} \\
\mathrm{H}_{10}, \mathrm{H}_{9}\end{array}$ & $\begin{array}{c}\mathrm{H}_{1} ; \mathrm{H}_{9} ; \mathrm{H}_{10} ; \mathrm{H}_{11 \mathrm{a}} ; \\
\mathrm{H}_{11 \mathrm{~b}}\end{array}$ & $\mathrm{C}_{8}$ \\
\hline 9 & 131,7 & 5,99 & $1 \mathrm{H}$ & $\mathrm{ddt}$ & $\begin{array}{c}\mathrm{J}_{9,10}=5,6 ; \mathrm{J}_{9,8}=3,0 ; \mathrm{J}_{9,1}=0,9 ; \\
\mathrm{J}_{9,11 \mathrm{a}}=0,9\end{array}$ & $\begin{array}{c}\mathrm{H}_{1} ; \mathrm{H}_{8} ; \mathrm{H}_{10} \\
\mathrm{H}_{11 \mathrm{a}}\end{array}$ & $\begin{array}{c}\mathrm{H}_{1} ; \mathrm{H}_{8} ; \mathrm{H}_{10} ; \mathrm{H}_{11 \mathrm{a}} ; \\
\mathrm{H}_{11 \mathrm{~b}}\end{array}$ & $\mathrm{C}_{9}$ \\
\hline 10 & 139,7 & 6,38 & $1 \mathrm{H}$ & $\mathrm{ddt}$ & $\begin{aligned} \mathrm{J}_{10,9}= & 5,6 ; \mathrm{J}_{10,1}=2,9 ; \mathrm{J}_{10,8}= \\
& 0,8 ; \mathrm{J}_{10,11 \mathrm{a}}=0,8\end{aligned}$ & $\begin{array}{c}\mathrm{H}_{1} ; \mathrm{H}_{8} ; \mathrm{H}_{9} \\
\mathrm{H}_{11 \mathrm{a}}\end{array}$ & $\begin{array}{c}\mathrm{H}_{2} ; \mathrm{H}_{8} ; \mathrm{H}_{9} ; \mathrm{H}_{11 \mathrm{a}} ; \\
\mathrm{H}_{11 \mathrm{~b}}\end{array}$ & $\mathrm{C}_{10}$ \\
\hline \multirow[t]{2}{*}{11} & 48,0 & $\left(\mathrm{H}_{11 \mathrm{a}}\right) 1,95$ & $1 \mathrm{H}$ & dtdd & $\begin{array}{c}\mathrm{J}_{11 \mathrm{a}, 11 \mathrm{~b}}=9,1 ; \mathrm{J}_{11 \mathrm{a}, 1}=1,5 ; \mathrm{J}_{11 \mathrm{a}, 8}= \\
1,5 ; \mathrm{J}_{11 \mathrm{a}, 9}=0,9 ; \mathrm{J}_{11 \mathrm{a}, 10}=0,8\end{array}$ & $\begin{array}{c}\mathrm{H}_{1} ; \mathrm{H}_{8} ; \mathrm{H}_{9} \\
\mathrm{H}_{10} ; \mathrm{H}_{11 \mathrm{~b}}\end{array}$ & $\begin{array}{l}\text { Acoplamentos } \\
\text { Encobertos }\end{array}$ & $\mathrm{C}_{11}$ \\
\hline & & $\left(\mathrm{H}_{11 \mathrm{~b}}\right) 1,76$ & $1 \mathrm{H}$ & $\mathrm{dt}$ & $\mathrm{J}_{11 \mathrm{~b} .11 \mathrm{a}}=9,1 ; \mathrm{J}_{11 \mathrm{~b}, 1}=1,5 ; \mathrm{J}_{11 \mathrm{a}, 8}=$ & $\mathrm{H}_{1} ; \mathrm{H}_{8} ; \mathrm{H}_{11 \mathrm{a}}$ & & $\mathrm{C}_{11}$ \\
\hline 12 & 167,5 & & & & & & $\mathrm{H}_{13} ; \mathrm{H}_{5}$ & \\
\hline 13 & 20,4 & 2,28 & $3 \mathrm{H}$ & S & & & & $\mathrm{C}_{13}$ \\
\hline 14 & 170,8 & & & & & & $\mathrm{H}_{15}$ & \\
\hline 15 & 20,4 & 2,10 & $3 \mathrm{H}$ & S & & & & $\mathrm{C}_{15}$ \\
\hline
\end{tabular}


Tabela 37: Experimentos de NOE-DIFF com o Composto 163.

\begin{tabular}{cc}
\hline Hidrogênios Irradiados & Hidrogênios com efeito NOE \\
\hline $\mathrm{H}_{1}$ & $\mathrm{H}_{2} ; \mathrm{H}_{10} ; \mathrm{H}_{11 \mathrm{a}} ; \mathrm{H}_{11 \mathrm{~b}}$ \\
$\mathrm{H}_{2}$ & $\mathrm{H}_{1} ; \mathrm{H}_{11 \mathrm{a}}$ \\
$\mathrm{H}_{8}$ & $\mathrm{H}_{9} ; \mathrm{H}_{11 \mathrm{a}} ; \mathrm{H}_{11 \mathrm{~b}}$ \\
$\mathrm{H}_{9}$ & $\mathrm{H}_{8} ; \mathrm{H}_{10}$ \\
$\mathrm{H}_{10}$ & $\mathrm{H}_{1} ; \mathrm{H}_{9}$ \\
$\mathrm{H}_{11 \mathrm{a}}$ & $\mathrm{H}_{1} ; \mathrm{H}_{2} ; \mathrm{H}_{8} ; \mathrm{H}_{11 \mathrm{~b}}$ \\
$\mathrm{H}_{11 \mathrm{~b}}$ & $\mathrm{H}_{1} ; \mathrm{H}_{8} ; \mathrm{H}_{9} ; \mathrm{H}_{10} ; \mathrm{H}_{11 \mathrm{a}}$ \\
$\mathrm{H}_{13}$ & $\mathrm{H}_{5}$ \\
\hline
\end{tabular}

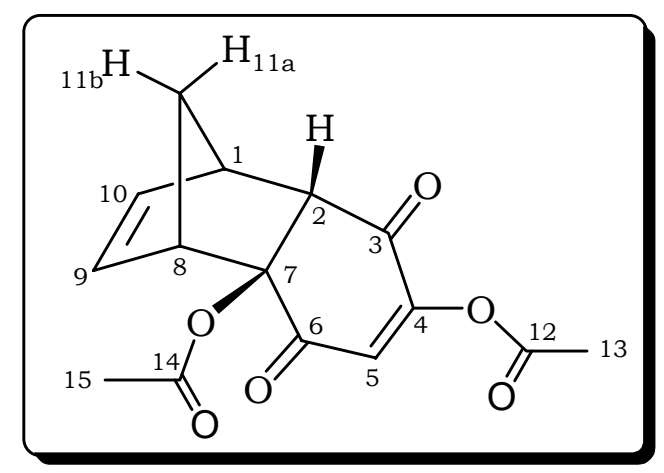




\section{Composto 164}

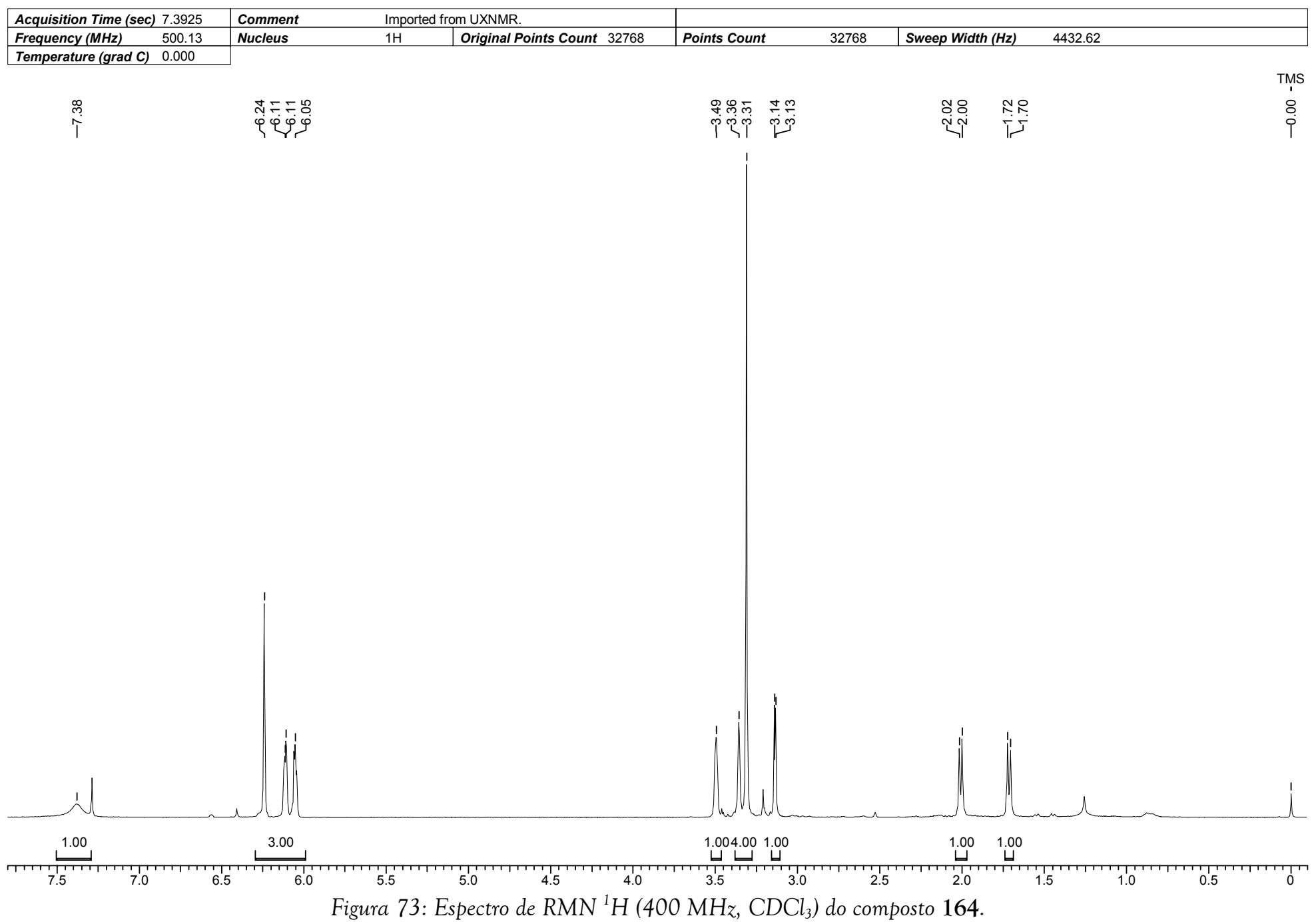

Figura 73: Espectro de $\mathrm{RMN}^{1} \mathrm{H}\left(400 \mathrm{MHz}, \mathrm{CDCl}_{3}\right)$ do composto 164 
Espectro de $R M N{ }^{13} \mathrm{C}\left\{{ }^{1} \mathrm{H}\right\}$

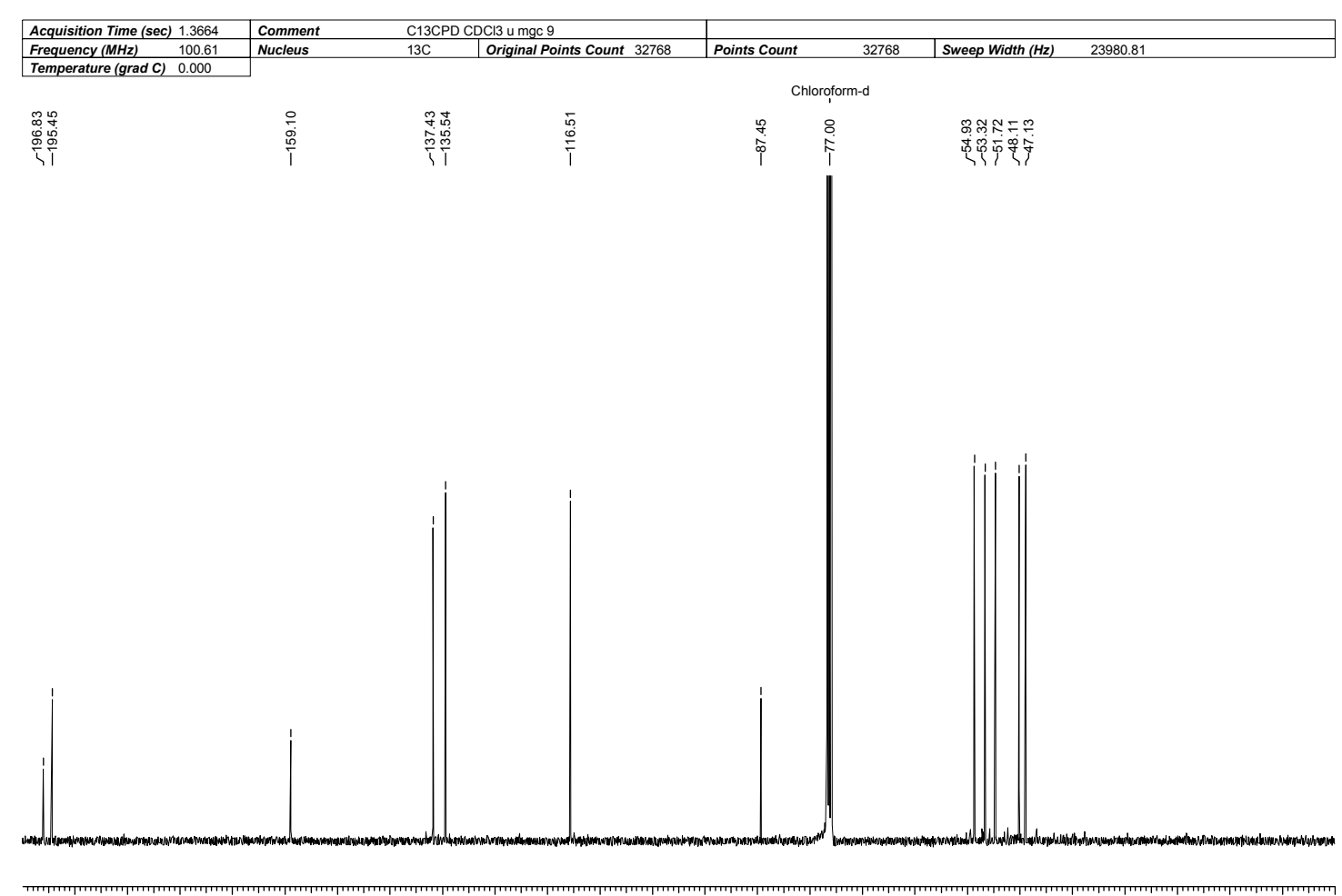

Espectro de $R M N^{13} \mathrm{C}(\mathrm{DEPT}-135){ }^{*}$

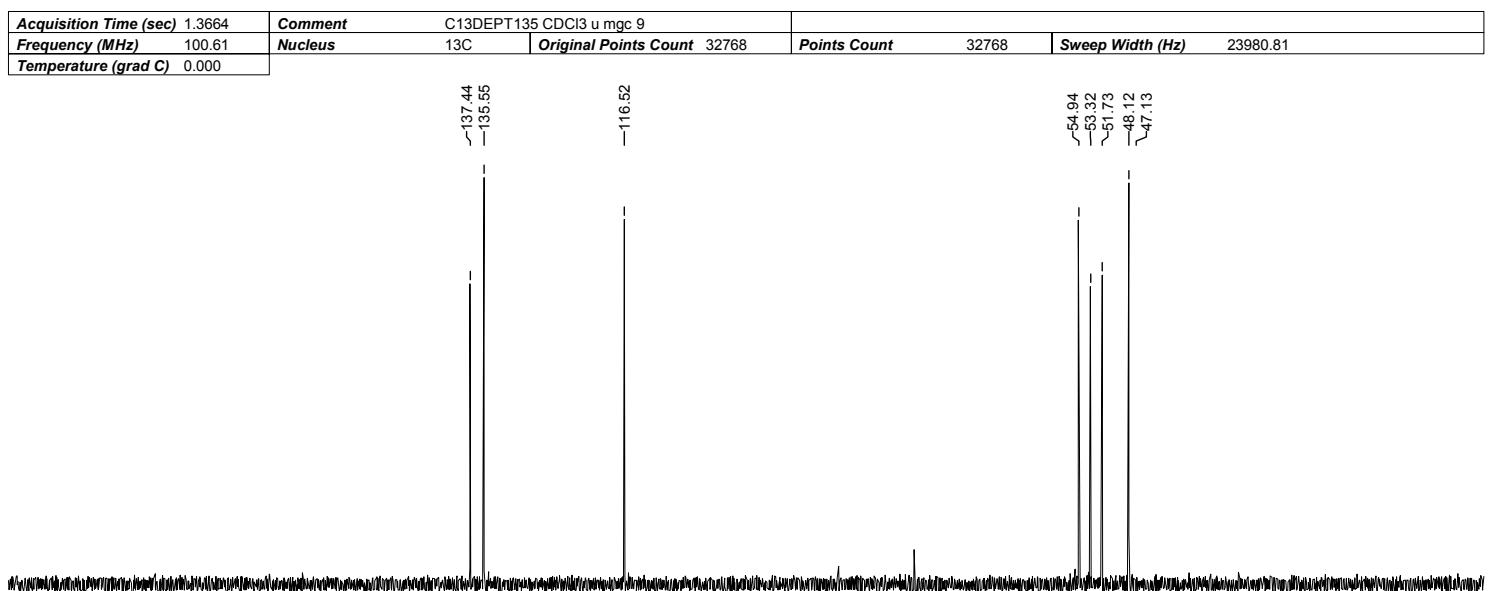

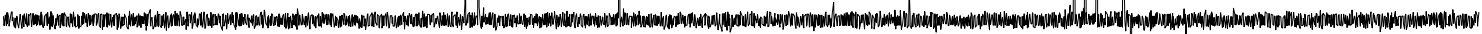

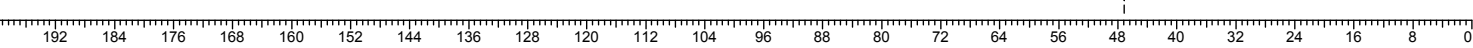

* Espectro de $\mathrm{RMN}{ }^{13} \mathrm{C}\left(100 \mathrm{MHz}, \mathrm{CDCl}_{3}\right)$ DEPT-135 do composto 164. $\uparrow\left(\mathrm{CH}, \mathrm{CH}_{3}\right), \downarrow$. $\left(\mathrm{CH}_{2}\right)$

Figura 74: Espectros de $\mathrm{RMN}^{13} \mathrm{C}\left(100 \mathrm{MHz}, \mathrm{CDCl}_{3}\right)$ do composto 164. 
Tabela 38: Dados Espectroscópicos do Composto 164

\begin{tabular}{|c|c|c|c|c|c|c|c|c|}
\hline $\mathrm{C}$ & $\delta \mathrm{C}(\mathrm{ppm})$ & $\delta \mathrm{H}(\mathrm{ppm})$ & $\begin{array}{l}\text { Integral } \\
\text { Relativa }\end{array}$ & Multiplicidade & $\begin{array}{c}\text { Constantes de Acoplamento } \\
(\mathrm{Hz})\end{array}$ & gCOSY & gHMBC & gHMQC \\
\hline 1 & 48,1 & 3,50 & $1 \mathrm{H}$ & ddddd & $\begin{array}{c}\mathrm{J}_{1,2}=4,2 ; \mathrm{J}_{1,10}=2,8 ; \mathrm{J}_{1,11 \mathrm{a}}=1,5 ; \\
\mathrm{J}_{1,11 \mathrm{~b}}=1,6 ; \mathrm{J}_{1,9}=0,8\end{array}$ & $\begin{array}{l}\mathrm{H}_{11 \mathrm{a}} ; \mathrm{H}_{11 \mathrm{~b}} \\
\mathrm{H}_{10}, \mathrm{H}_{9} ; \mathrm{H}_{2}\end{array}$ & $\begin{array}{c}\mathrm{H}_{2} ; \mathrm{H}_{8} ; \mathrm{H}_{9}, \mathrm{H}_{10} \\
\mathrm{H}_{11 \mathrm{a} ;} \mathrm{H}_{11 \mathrm{~b}}\end{array}$ & $\mathrm{C}_{1}$ \\
\hline 2 & 54,9 & 3,13 & $1 \mathrm{H}$ & $\mathrm{d}$ & $\mathrm{J}_{2,1}=4,2$ & $\mathrm{H}_{1}$ & $\mathrm{H}_{8} ; \mathrm{H}_{11 \mathrm{a}} ; \mathrm{H}_{11 \mathrm{~b}}$ & $\mathrm{C}_{2}$ \\
\hline 3 & 195,4 & & & & & & $\mathrm{H}_{5} ; \mathrm{H}_{2}$ & \\
\hline 4 & 159,1 & & & & & & $\mathrm{H}_{5} ; \mathrm{H}_{2}$ & \\
\hline 5 & 116,5 & 6,24 & $1 \mathrm{H}$ & $\mathrm{s}$ & & & & $\mathrm{C}_{5}$ \\
\hline 6 & 196,8 & & & & & & $\mathrm{H}_{5} ; \mathrm{H}_{2}$ & \\
\hline 7 & 87,4 & & & & & & $\begin{array}{c}\mathrm{H}_{5} ; \mathrm{H}_{2} ; \mathrm{H}_{8} ; \mathrm{H}_{11 \mathrm{~b}} ; \\
\mathrm{H}_{12}\end{array}$ & \\
\hline 8 & 51,7 & 3,35 & $1 \mathrm{H}$ & dddd & $\begin{array}{c}\mathrm{J}_{8,9}=3,1 ; \mathrm{J}_{8,11 \mathrm{a}}=1,5 ; \mathrm{J}_{8,11 \mathrm{~b}}=1,6 ; \\
\mathrm{J}_{8,10}=0,8\end{array}$ & $\begin{array}{c}\mathrm{H}_{11 \mathrm{a}} ; \mathrm{H}_{11 \mathrm{~b}} \\
\mathrm{H}_{10}, \mathrm{H}_{9}\end{array}$ & $\begin{array}{c}\mathrm{H}_{1} ; \mathrm{H}_{2} ; \mathrm{H}_{9} ; \mathrm{H}_{10} \\
\mathrm{H}_{11 \mathrm{a}} ; \mathrm{H}_{11 \mathrm{~b}}\end{array}$ & $\mathrm{C}_{8}$ \\
\hline 9 & 135,5 & 6,05 & $1 \mathrm{H}$ & dddd & $\begin{array}{c}\mathrm{J}_{9,10}=5,8 ; \mathrm{J}_{9,8}=3,1 ; \mathrm{J}_{9,1}=0,8 \\
\mathrm{~J}_{9,11 \mathrm{a}}=0,6\end{array}$ & $\begin{array}{c}\mathrm{H}_{1} ; \mathrm{H}_{8} ; \mathrm{H}_{10} \\
\mathrm{H}_{11 \mathrm{a}}\end{array}$ & $\begin{array}{c}\mathrm{H}_{1} ; \mathrm{H}_{8} ; \mathrm{H}_{10} ; \mathrm{H}_{11 \mathrm{a}} ; \\
\mathrm{H}_{11 \mathrm{~b}}\end{array}$ & $\mathrm{C}_{9}$ \\
\hline 10 & 137,4 & 6,11 & $1 \mathrm{H}$ & dddd & $\begin{array}{c}\mathrm{J}_{10,9}=5,8 ; \mathrm{J}_{10,1}=2,8 ; \mathrm{J}_{10,8}=0,8 \\
\mathrm{~J}_{10,11 \mathrm{a}}=0,6\end{array}$ & $\begin{array}{c}\mathrm{H}_{1} ; \mathrm{H}_{8} ; \mathrm{H}_{9} \\
\mathrm{H}_{11 \mathrm{a}}\end{array}$ & $\begin{array}{c}\mathrm{H}_{1} ; \mathrm{H}_{2} ; \mathrm{H}_{8} ; \mathrm{H}_{9} \\
\mathrm{H}_{11 \mathrm{a}} ; \mathrm{H}_{11 \mathrm{~b}}\end{array}$ & $\mathrm{C}_{10}$ \\
\hline 11 & 47,1 & $\left(\mathrm{H}_{11 \mathrm{a}}\right) 2,01$ & $1 \mathrm{H}$ & $\mathrm{dtt}$ & $\begin{array}{c}\mathrm{J}_{11 \mathrm{a}, 11 \mathrm{~b}}=9,0 ; \mathrm{J}_{11 \mathrm{a}, 1}=1,5 ; \mathrm{J}_{11 \mathrm{a}, 8}=1,5 ; \\
\mathrm{J}_{11 \mathrm{a}, 9}=0,6 ; \mathrm{J}_{11 \mathrm{a}, 10}=0,6\end{array}$ & $\begin{array}{c}\mathrm{H}_{1} ; \mathrm{H}_{8} ; \mathrm{H}_{9} \\
\mathrm{H}_{10} ; \mathrm{H}_{11 \mathrm{~b}}\end{array}$ & $\begin{array}{l}\text { Não aparece } \\
\text { acoplamentos }\end{array}$ & $\mathrm{C}_{11}$ \\
\hline \multirow{3}{*}{12} & \multirow{3}{*}{53,3} & $\left(\mathrm{H}_{11 \mathrm{~b}}\right) 1,72$ & $1 \mathrm{H}$ & $\mathrm{dt}$ & $\mathrm{J}_{11 \mathrm{~b} .11 \mathrm{a}}=9,0 ; \mathrm{J}_{11 \mathrm{~b}, 1}=1,6 ; \mathrm{J}_{11 \mathrm{a}, 8}=1,6$ & $\mathrm{H}_{1} ; \mathrm{H}_{8} ; \mathrm{H}_{11 \mathrm{a}}$ & & $\mathrm{C}_{11}$ \\
\hline & & 3,31 & $3 \mathrm{H}$ & s & & & & \multirow[t]{2}{*}{$\mathrm{C}_{12}$} \\
\hline & & $(\mathrm{OH}) 7,38$ & $1 \mathrm{H}$ & sl & & & & \\
\hline
\end{tabular}


Tabela 39: Experimentos de NOE-DIFF com o Composto 164.

\begin{tabular}{cc}
\hline Hidrogênios Irradiados & Hidrogênios com efeito NOE \\
\hline $\mathrm{H}_{2}$ & $\mathrm{H}_{1} ; \mathrm{H}_{11 \mathrm{a}} ; \mathrm{H}_{12}$ \\
$\mathrm{H}_{5}$ & $\mathrm{Não}$ apresenta \\
$\mathrm{H}_{12}$ & $\mathrm{H}_{2} ; \mathrm{H}_{11 \mathrm{a}}$ \\
$\mathrm{H}_{11 \mathrm{a}}$ & $\mathrm{H}_{1} ; \mathrm{H}_{2} ; \mathrm{H}_{8} ; \mathrm{H}_{11 \mathrm{~b}} ; \mathrm{H}_{12}$ \\
$\mathrm{H}_{11 \mathrm{~b}}$ & $\mathrm{H}_{1} ; \mathrm{H}_{8} ; \mathrm{H}_{9} ; \mathrm{H}_{10} ; \mathrm{H}_{11 \mathrm{a}}$ \\
\hline
\end{tabular}

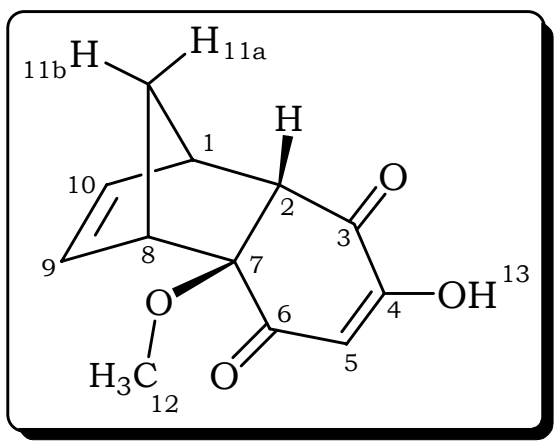




\section{Composto 165}

\begin{tabular}{|c|c|c|c|c|c|c|c|c|}
\hline \multicolumn{2}{|c|}{ Acquisition Time (sec) 3.9584} & \multirow{2}{*}{\begin{tabular}{|l|l|} 
Comment \\
Nucleus
\end{tabular}} & PROTON CDCl3 u mgc 14 & \multirow[b]{2}{*}{ Points Count } & \multirow[b]{2}{*}{32768} & \multirow[b]{2}{*}{ Sweep Width $(\mathrm{Hz})$} & \multirow[b]{2}{*}{8278.15} & \\
\hline Frequency $(\mathrm{MHz})$ & 400.13 & & Original Points Count 32768 & & & & & \\
\hline Temperature $(\operatorname{grad} C)$ & 0.000 & & & & & & & \\
\hline $\mathrm{OH}$ & & & & & & & & TMS \\
\hline$\stackrel{0}{\pi}$ & & 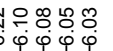 & & 庐过 & & 욤 & $\stackrel{\wedge}{\stackrel{\circ}{\leftarrow}}$ & 8 \\
\hline † & & 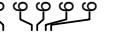 & & 19? & & דَّ & $\pi$ & $i$ \\
\hline
\end{tabular}
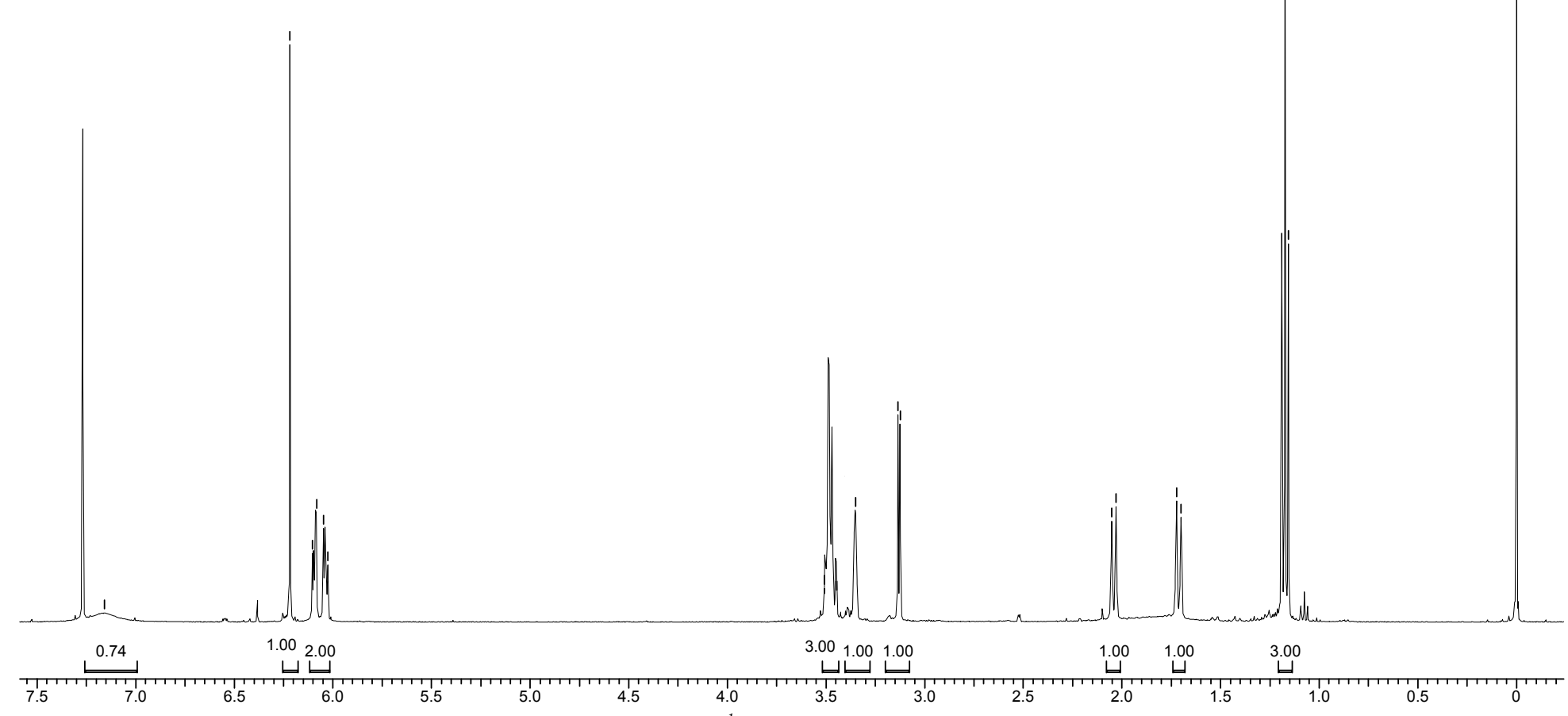

Figura 75: Espectro de $\mathrm{RMN}^{1} \mathrm{H}\left(400 \mathrm{MHz}, \mathrm{CDCl}_{3}\right)$ do composto 165. 
Espectro de $R M N{ }^{13} \mathrm{C}\left\{{ }^{1} \mathrm{H}\right\}$

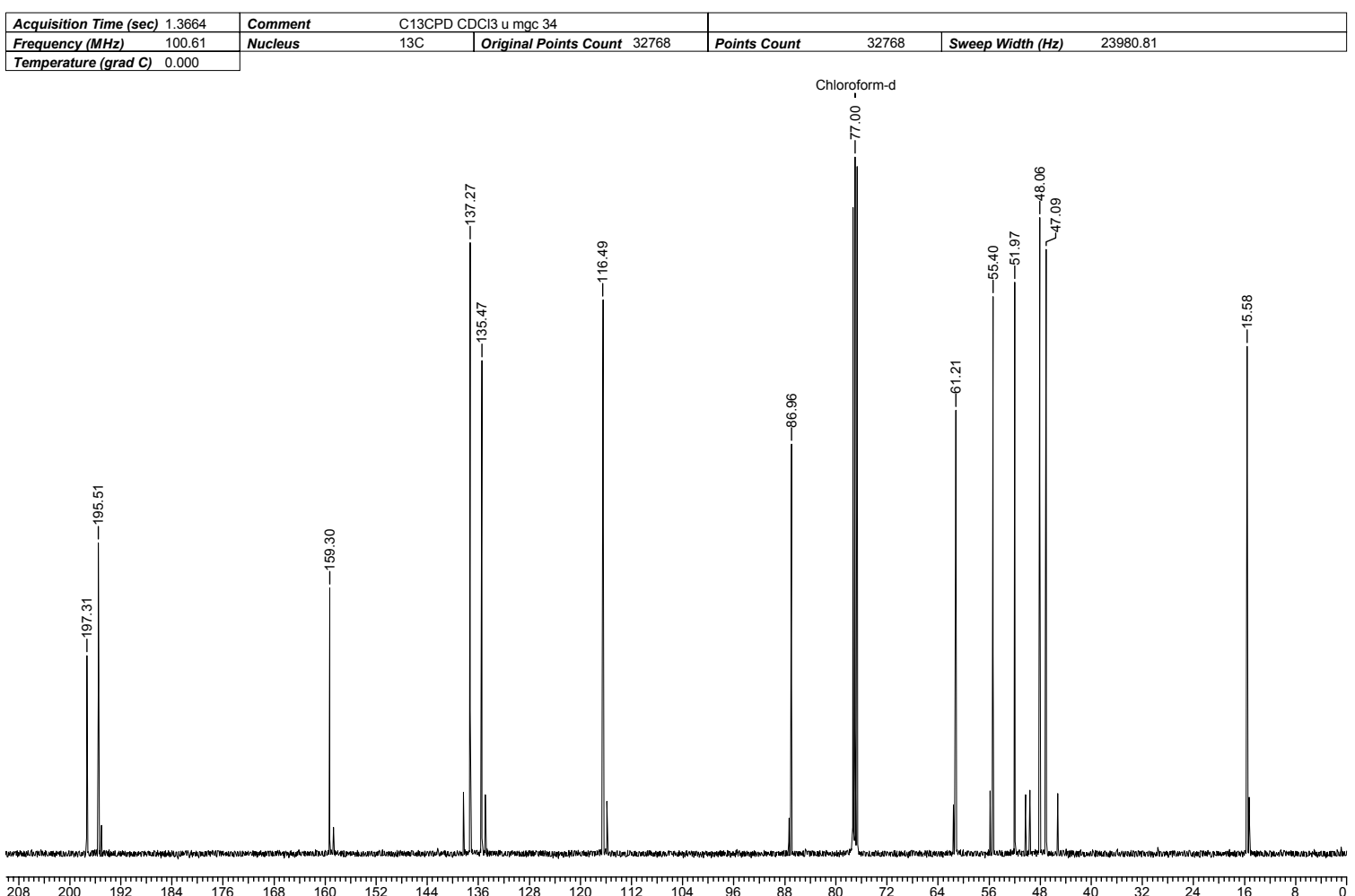

Espectro de RMN ${ }^{13} \mathrm{C}(\mathrm{DEPT}-135)$.

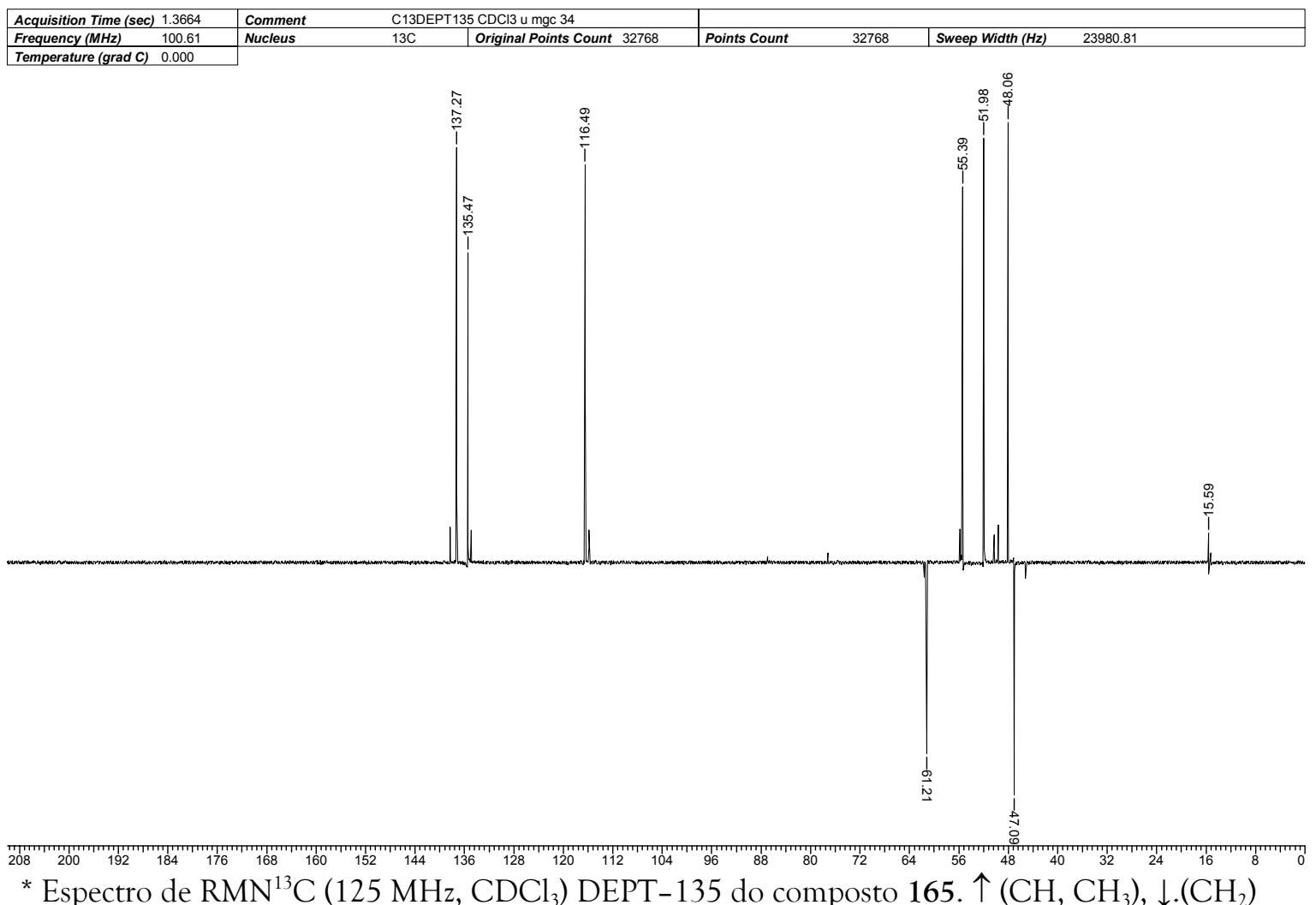

Figura 76: Espectros de $\mathrm{RMN}^{13} \mathrm{C}\left(100 \mathrm{MHz}, \mathrm{CDCl}_{3}\right)$ do composto 165 . 
Tabela 40: Dados Espectroscópicos do Composto 165.

\begin{tabular}{|c|c|c|c|c|c|}
\hline $\mathrm{C}$ & $\delta \mathrm{C}(\mathrm{ppm})$ & $\delta \mathrm{H}(\mathrm{ppm})$ & Integral relativa & Multiplicidade & Constantes de Acoplamento $(\mathrm{Hz})$ \\
\hline 1 & 48,1 & $3,43-3,52$ & $1 \mathrm{H}$ & $\mathrm{m}$ & \\
\hline 2 & 55,4 & 3,11 & $1 \mathrm{H}$ & $\mathrm{d}$ & $\mathrm{J}_{2,1}=4,1$ \\
\hline 3 & 195,5 & & & & \\
\hline 4 & 159,3 & & & & \\
\hline 5 & 116,5 & 6,22 & $1 \mathrm{H}$ & $\mathrm{s}$ & \\
\hline 6 & 197,3 & & & & \\
\hline 7 & 87,0 & & & & \\
\hline 8 & 52,0 & 3,35 & $1 \mathrm{H}$ & $\mathrm{m}$ & \\
\hline 9 & 135,5 & 6,04 & $1 \mathrm{H}$ & $\mathrm{dd}$ & $\mathrm{J}_{9,10}=5,6 ; \mathrm{J}_{9,8}=3,3$ \\
\hline 10 & 137,3 & 6,09 & $1 \mathrm{H}$ & $\mathrm{dd}$ & $\mathrm{J}_{10,9}=5,6 ; \mathrm{J}_{10,1}=2,7$ \\
\hline \multirow[t]{3}{*}{11} & 47,1 & $\left(\mathrm{H}_{11 \mathrm{a}}\right) 2,04$ & $1 \mathrm{H}$ & $\mathrm{dl}$ & $\mathrm{J}_{11 \mathrm{a}, 11 \mathrm{~b}}=8,8$ \\
\hline & & $\left(\mathrm{H}_{11 \mathrm{~b}}\right) 1,71$ & $1 \mathrm{H}$ & $\mathrm{dt}$ & $\mathrm{J}_{11 \mathrm{~b}, 11 \mathrm{a}}=8,8 ; \mathrm{J}_{11 \mathrm{~b}, 1}=1,5 ; \mathrm{J}_{11 \mathrm{~b}, 8}=1,5$ \\
\hline & & $(\mathrm{OH}) 7,16$ & $1 \mathrm{H}$ & sl & \\
\hline 13 & 61,2 & $3,43-3,52$ & $2 \mathrm{H}$ & $\mathrm{m}$ & \\
\hline 14 & 15,4 & 1,17 & $3 \mathrm{H}$ & $\mathrm{t}$ & $\mathrm{J}_{14,13}=7,10$ \\
\hline
\end{tabular}




\section{Composto 166}

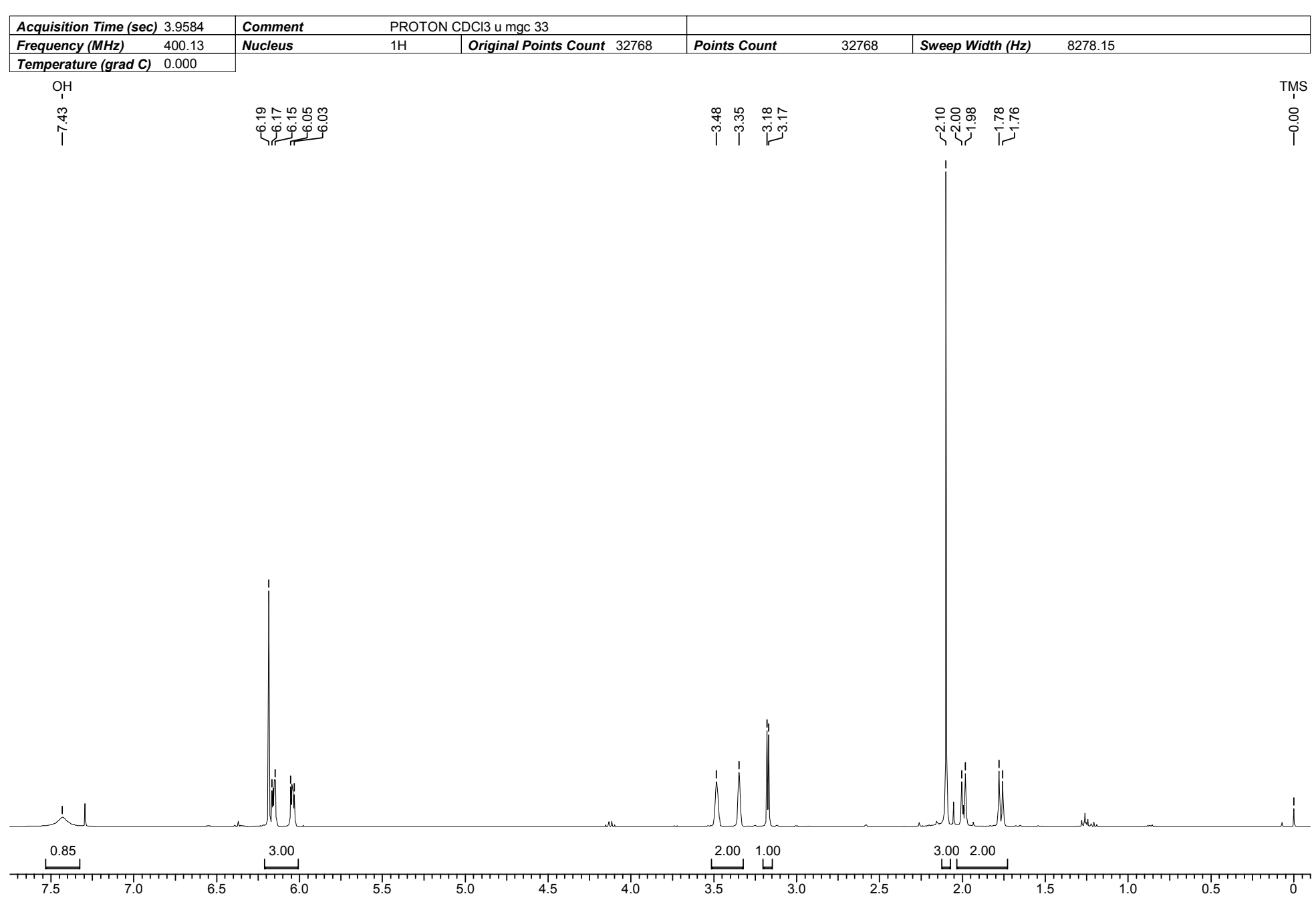

Figura 77: Espectro de $\mathrm{RMN}^{1} \mathrm{H}\left(400 \mathrm{MHz}, \mathrm{CDCl}_{3}\right)$ do composto 166. 
Espectro de $R M N{ }^{13} \mathrm{C}\left\{{ }^{1} \mathrm{H}\right\}$

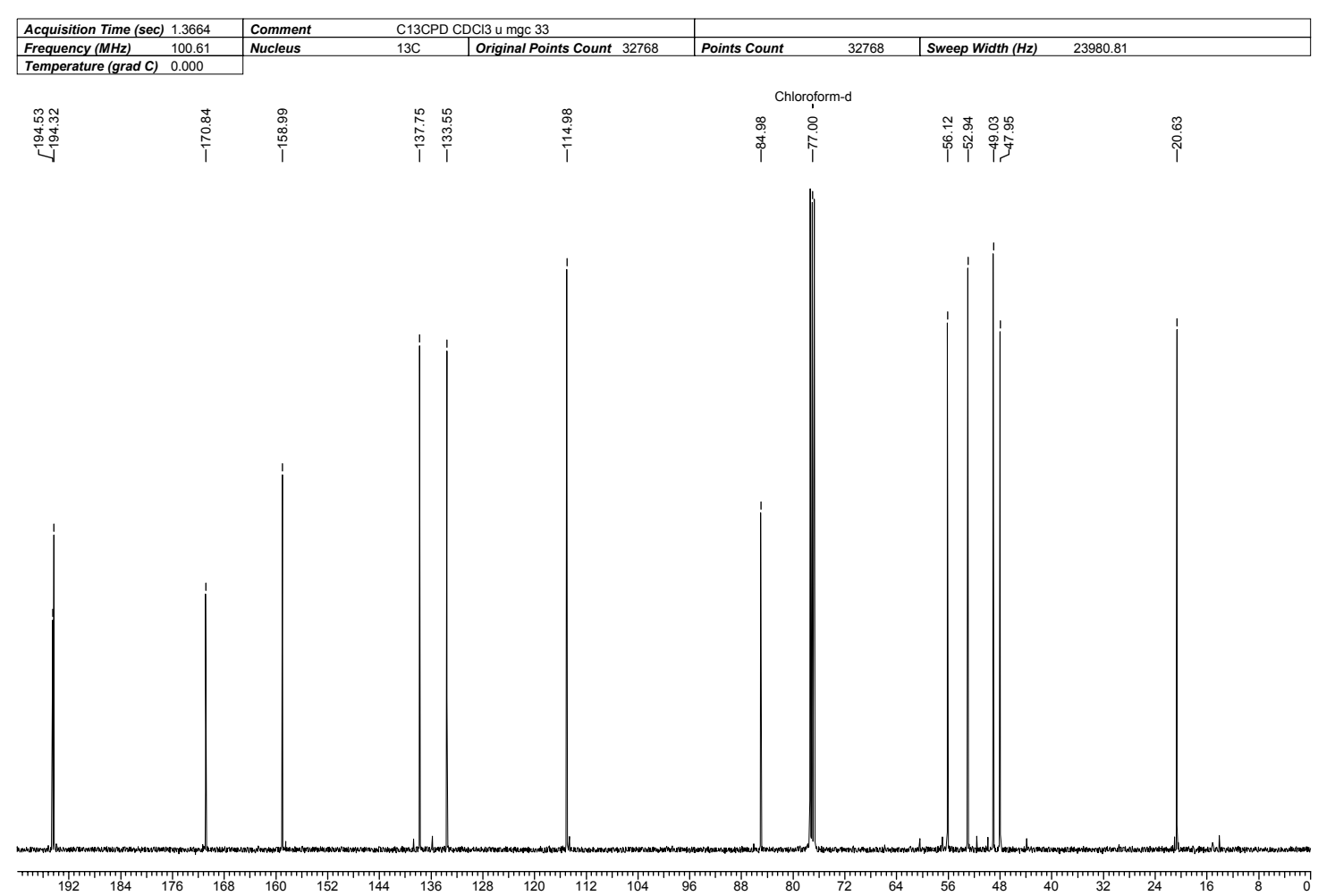

Espectro de RMN ${ }^{13} \mathrm{C}(\mathrm{DEPT}-135)$.

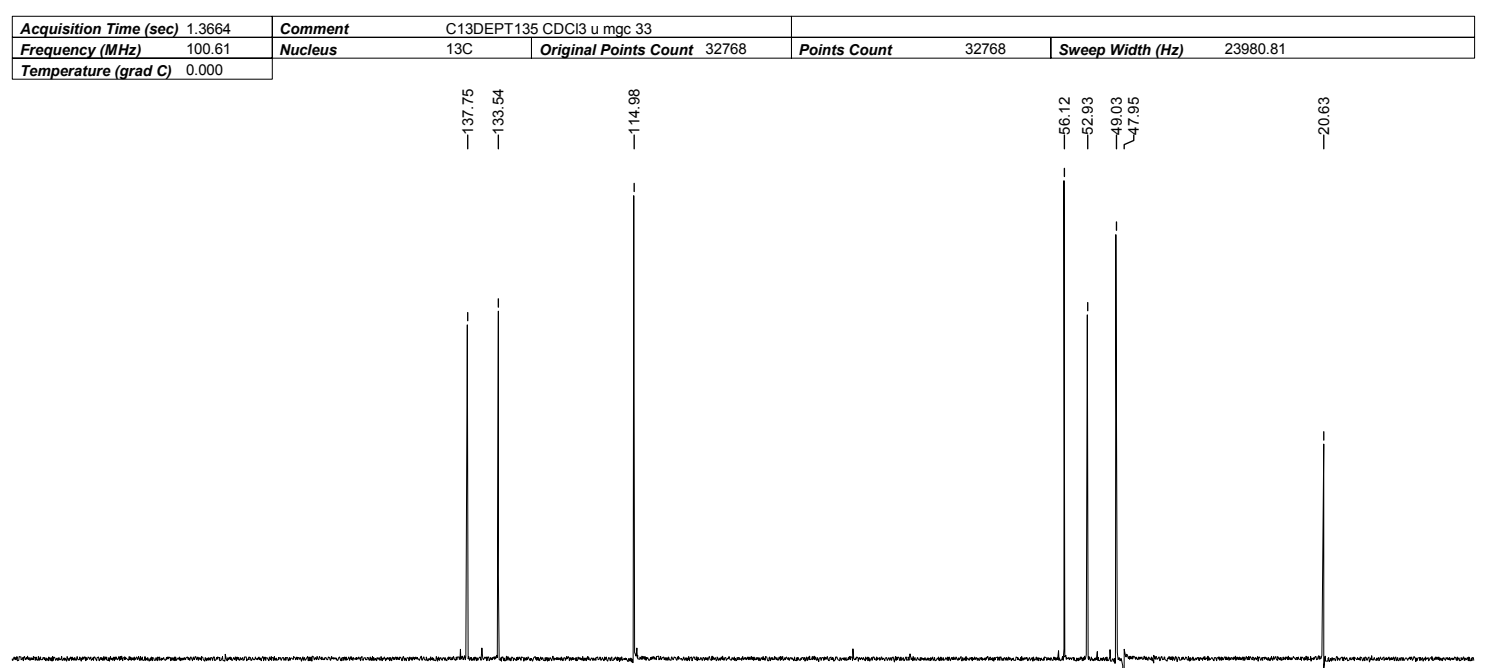

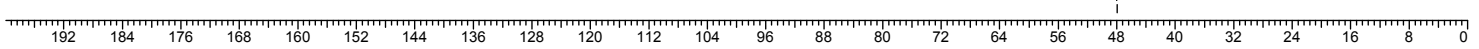

* Espectro de $\mathrm{RMN}{ }^{13} \mathrm{C}\left(125 \mathrm{MHz}, \mathrm{CDCl}_{3}\right)$ DEPT-135 do composto $166 . \uparrow\left(\mathrm{CH}, \mathrm{CH}_{3}\right), \downarrow \cdot\left(\mathrm{CH}_{2}\right)$

Figura 78: Espectros de $\mathrm{RMN}^{13} \mathrm{C}\left(100 \mathrm{MHz}, \mathrm{CDCl}_{3}\right)$ do composto 166 
Tabela 41: Dados Espectroscópicos do Composto 166.

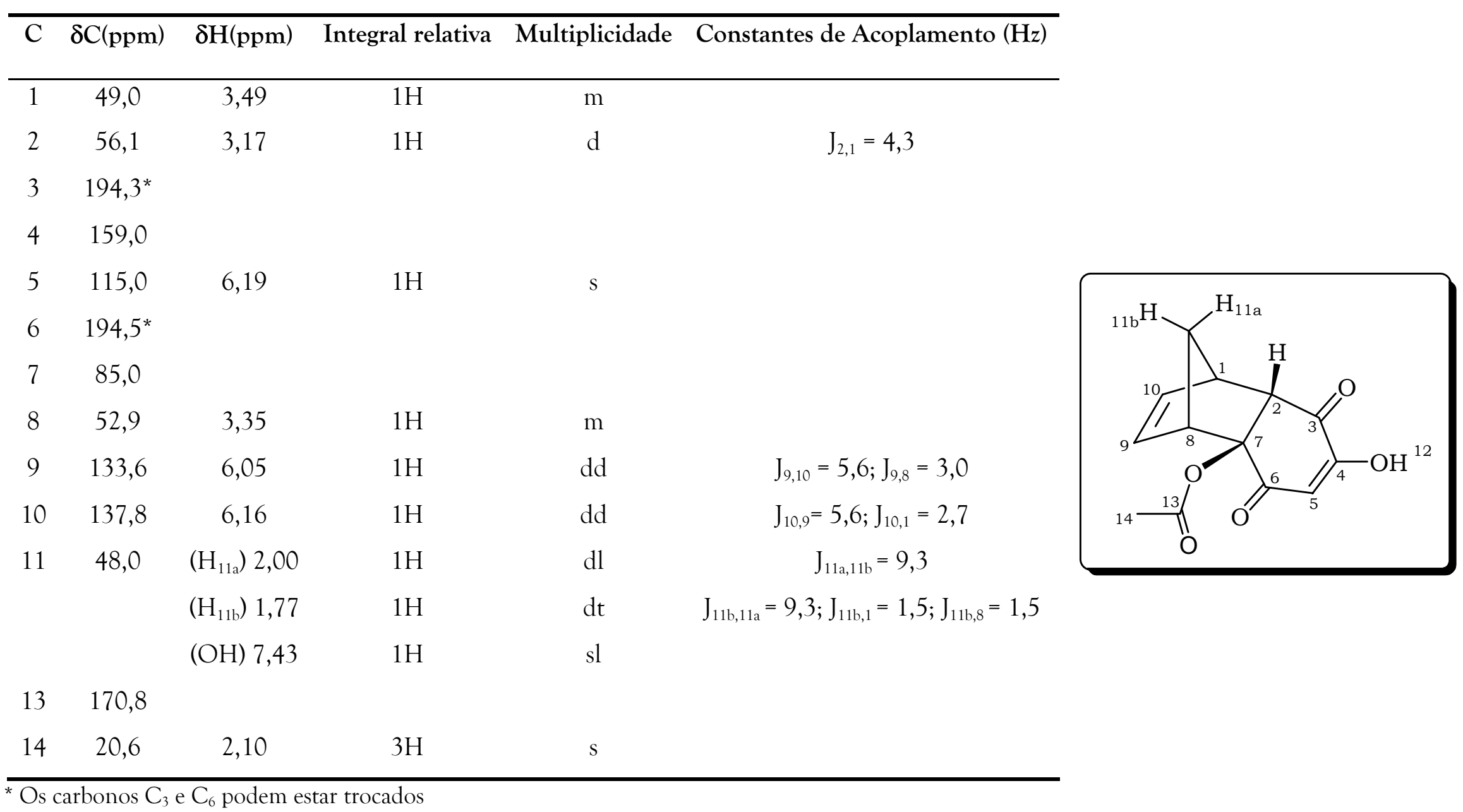




\section{Composto 139}

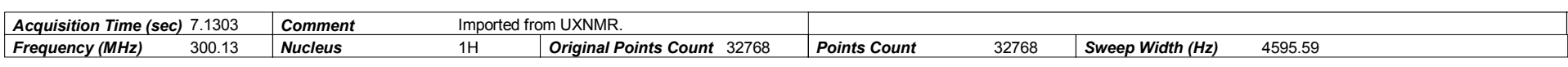

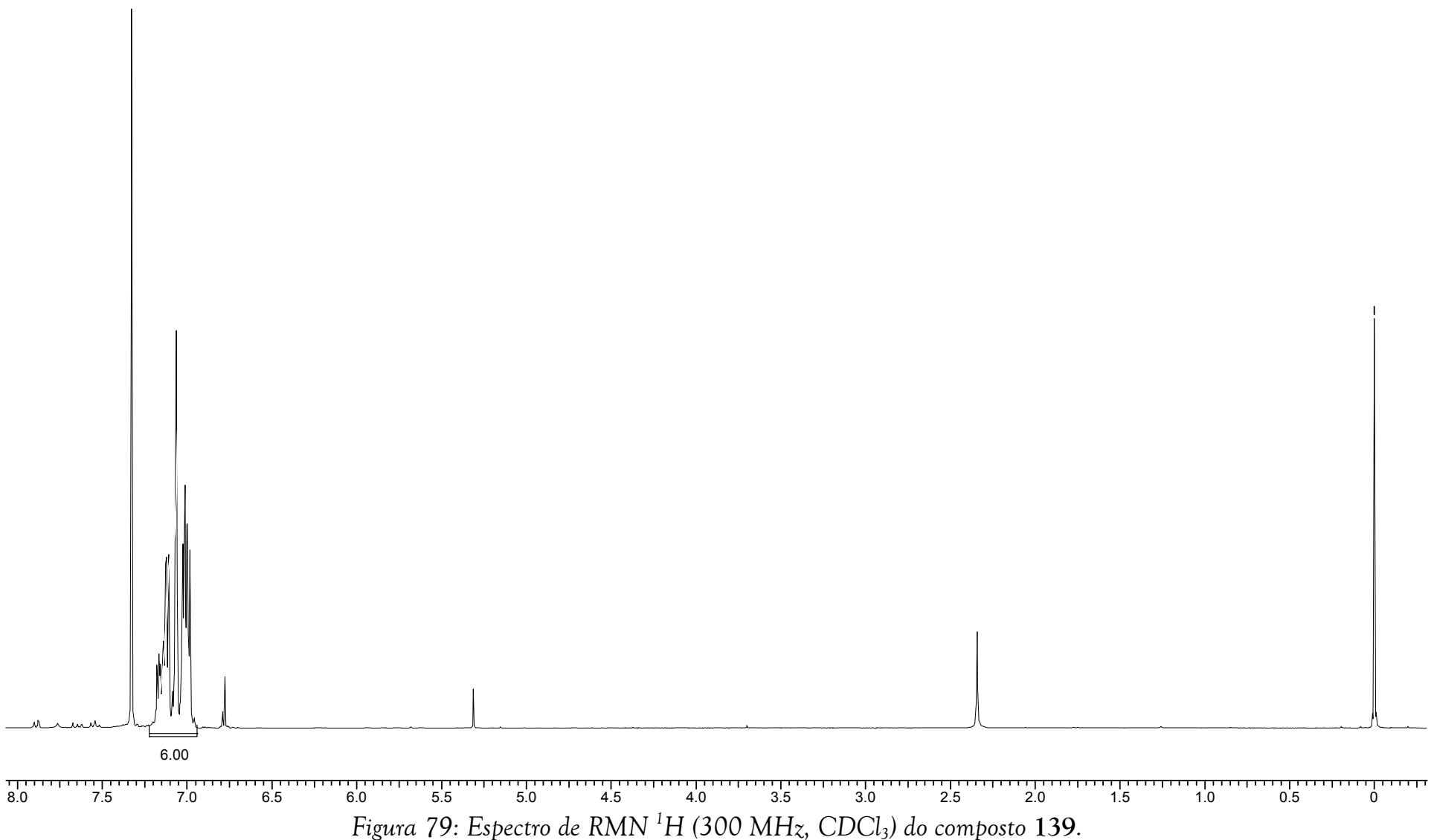


Espectro de $R M N{ }^{13} \mathrm{C}\left\{{ }^{1} \mathrm{H}\right\}$

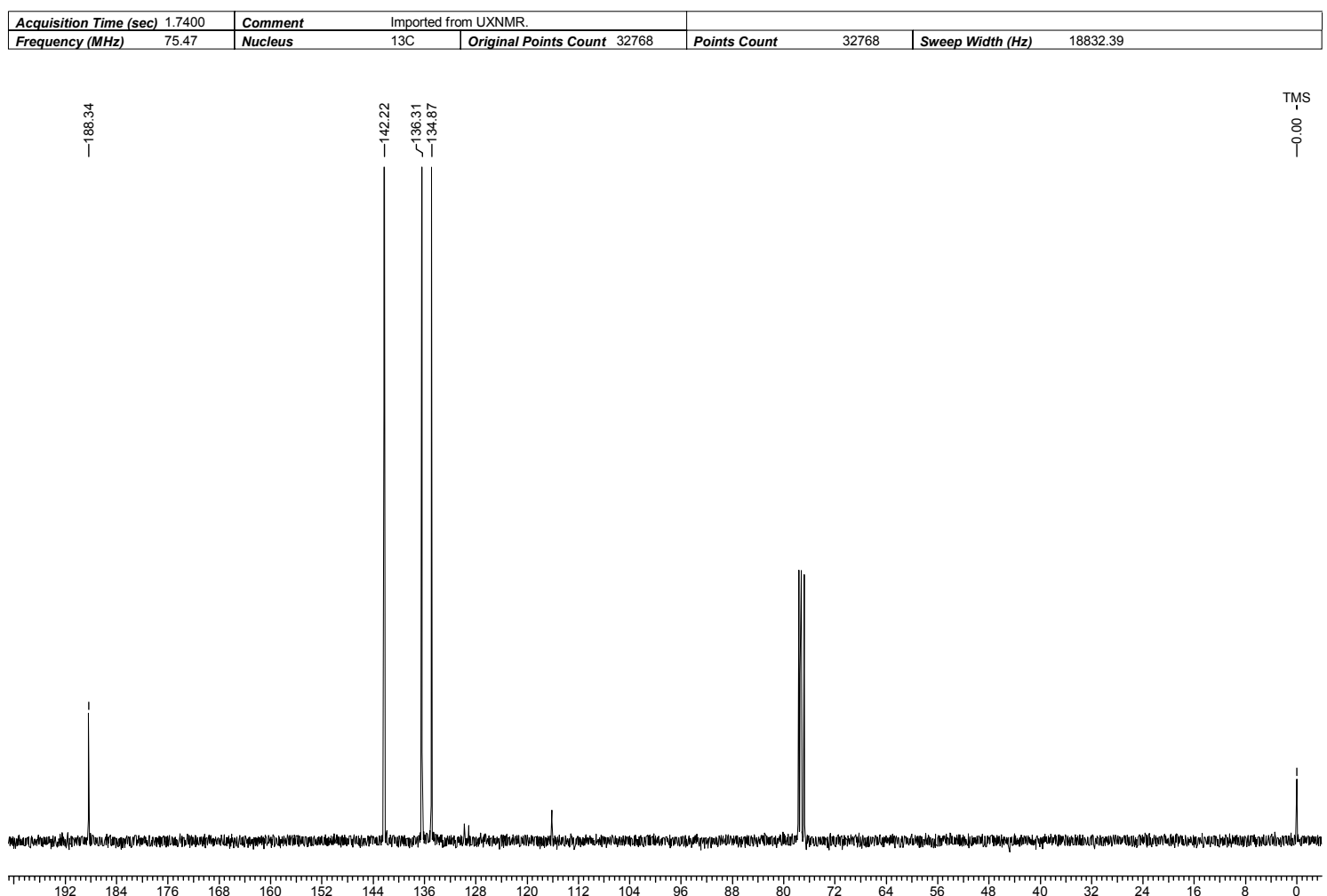

Espectro de RMN ${ }^{13} \mathrm{C}$ (DEPT 135). *

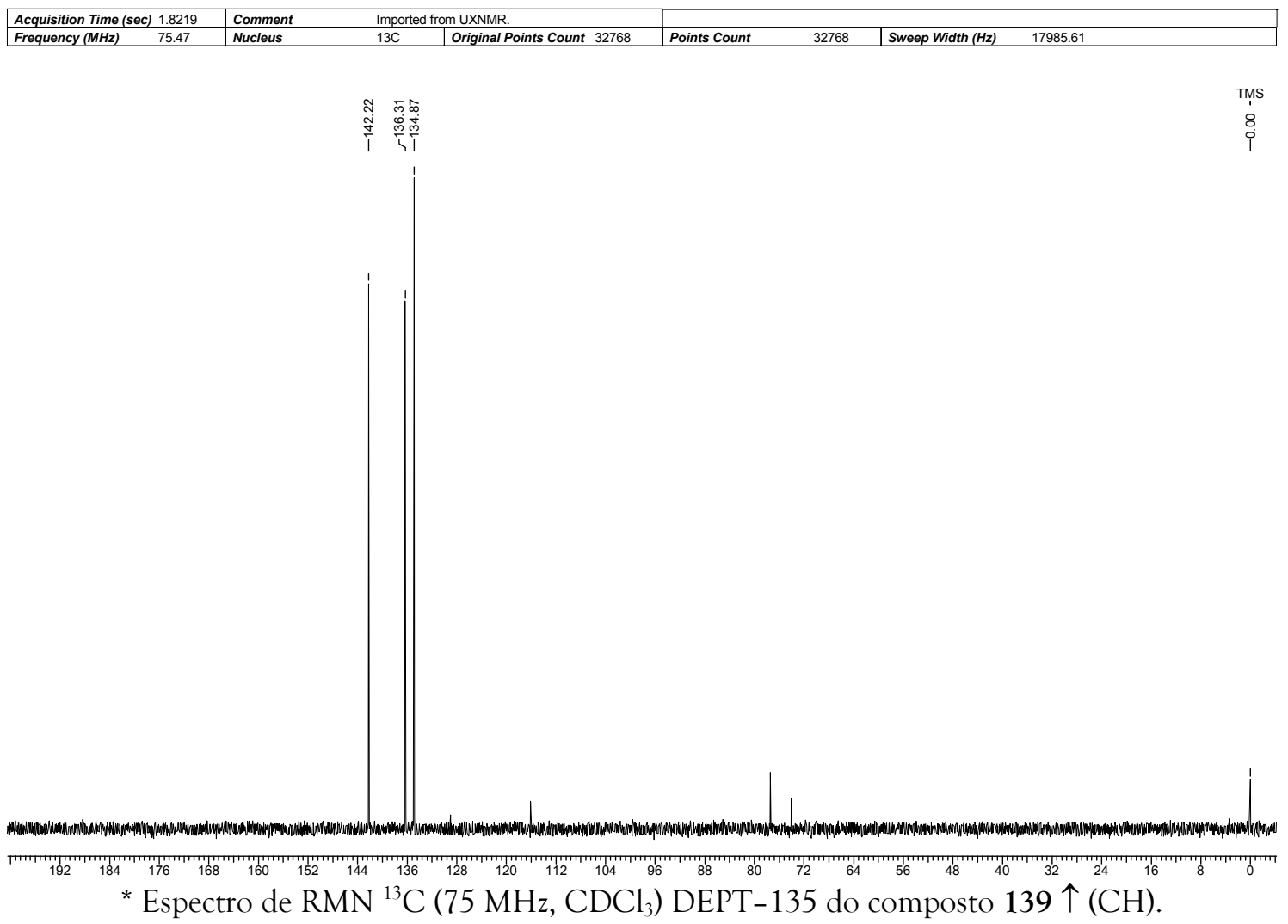

Figura 80: Espectros de RMN ${ }^{13} \mathrm{C}\left(75 \mathrm{MHz}, \mathrm{CDCl}_{3}\right)$ do composto 139. 
Tabela 42: Dados Espectroscópicos do Composto 139.

\begin{tabular}{ccccc}
\hline $\mathrm{C}$ & $\delta \mathrm{C}(\mathrm{ppm})$ & $\delta \mathrm{H}(\mathrm{ppm})$ & Integral Relativa & Multiplicidade \\
\hline 1 & 188,3 & & & \\
2 & 134,9 & $6,95-7,20$ & $2 \mathrm{H}$ & $\mathrm{m}$ \\
3 & 142,2 & $6,95-7,20$ & $2 \mathrm{H}$ & $\mathrm{m}$ \\
4 & 136,3 & $6,95-7,20$ & $2 \mathrm{H}$ & $\mathrm{m}$ \\
\hline
\end{tabular}

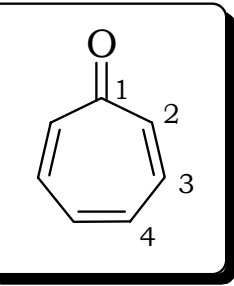




\section{Composto 140}

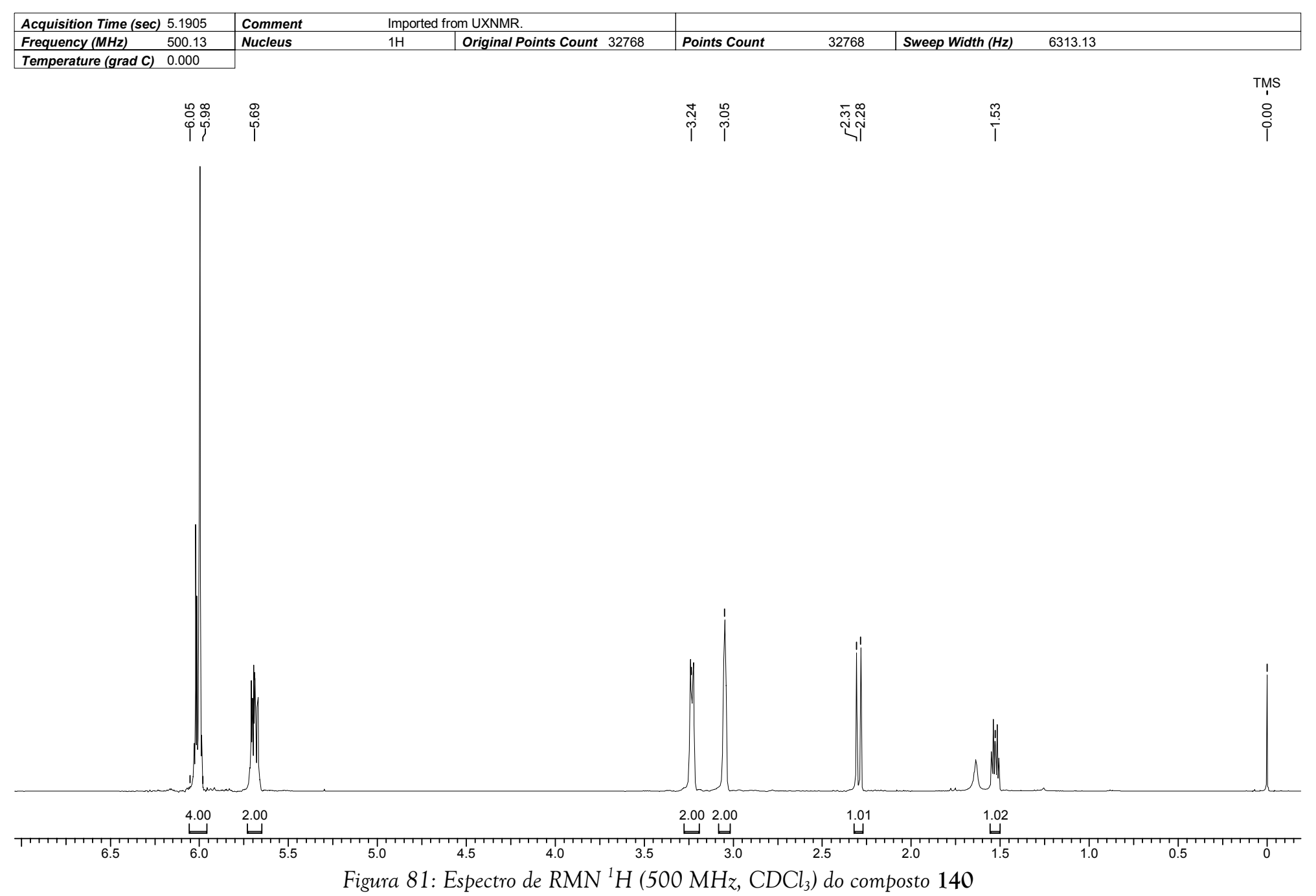

Figura 81: Espectro de $\mathrm{RMN}{ }^{1} \mathrm{H}\left(500 \mathrm{MHz}, \mathrm{CDCl}_{3}\right)$ do composto 140 
Espectro de $R M N{ }^{13} \mathrm{C}\left\{{ }^{1} \mathrm{H}\right\}$

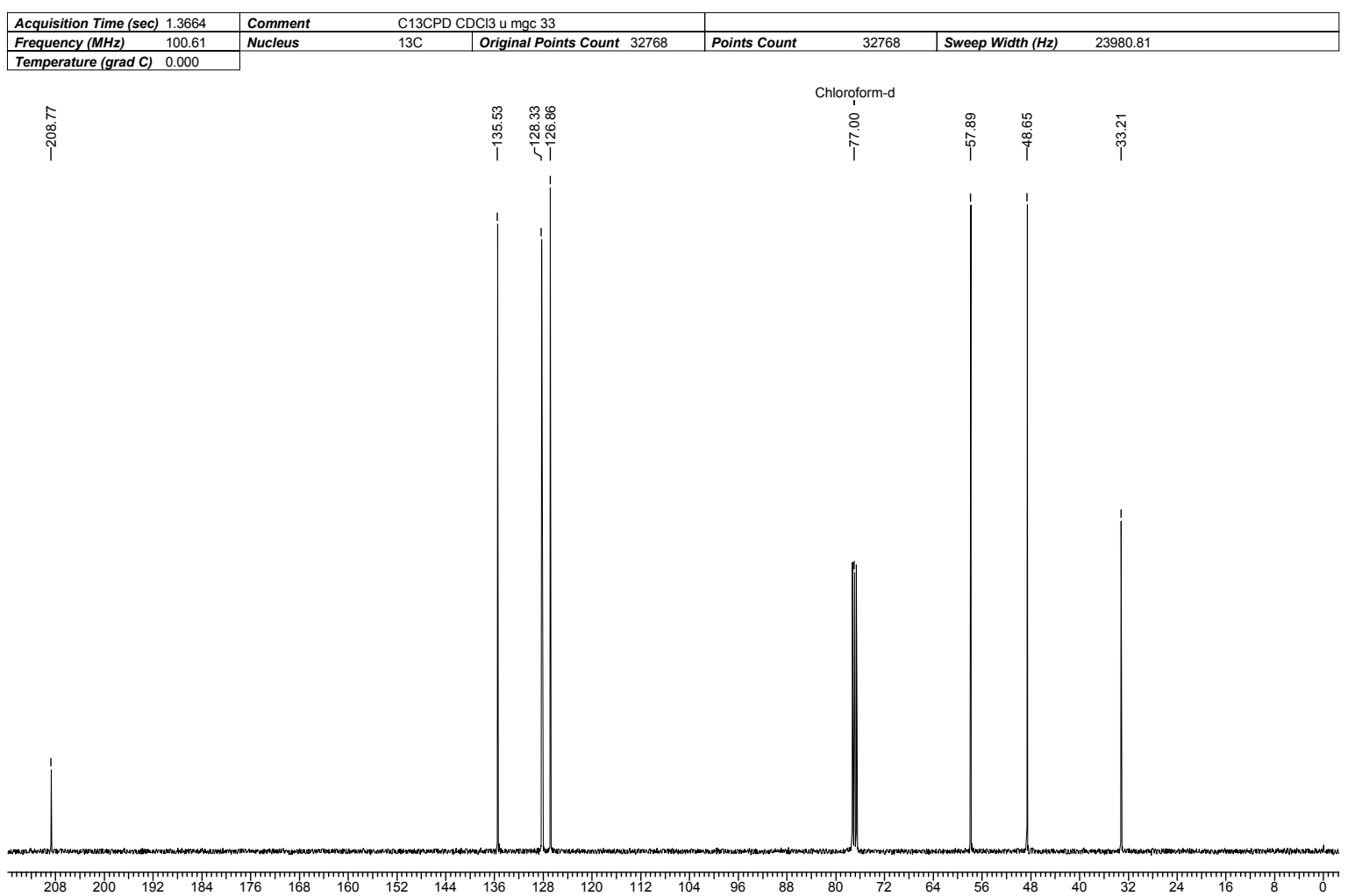

Espectro de RMN ${ }^{13} \mathrm{C}(\mathrm{DEPT}-135)$ *

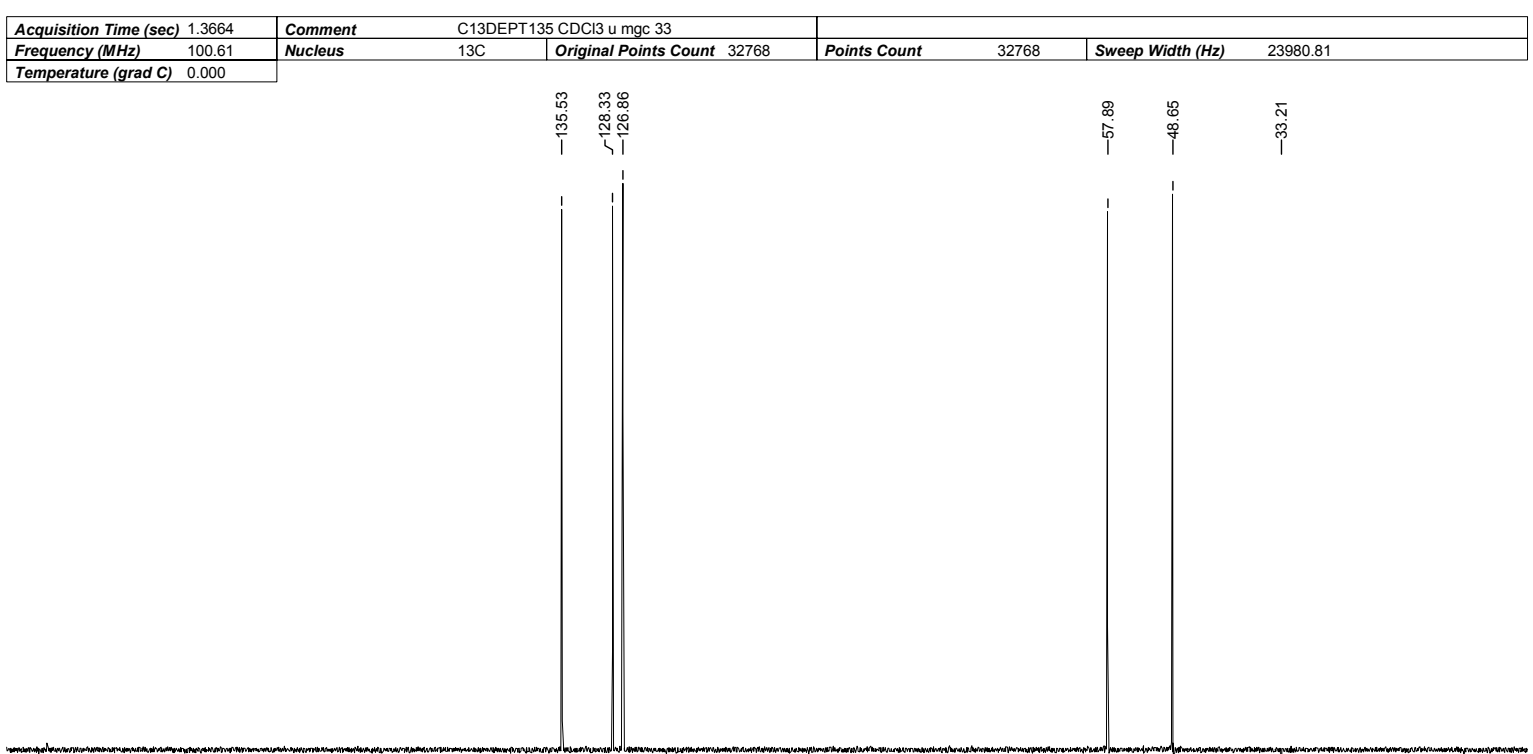

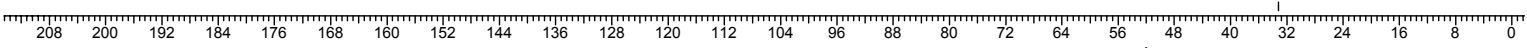

${ }^{*}$ Espectro de $\mathrm{RMN}{ }^{13} \mathrm{C}\left(100 \mathrm{MHz}, \mathrm{CDCl}_{3}\right)$ DEPT-135 do composto $140 . \uparrow\left(\mathrm{CH}, \mathrm{CH}_{3}\right), \downarrow \cdot\left(\mathrm{CH}_{2}\right)$

Figura 82: Espectros de $\mathrm{RMN}^{13} \mathrm{C}\left(100 \mathrm{MHz}, \mathrm{CDCl}_{3}\right)$ do composto 140. 
Tabela 43: Dados Espectroscópicos do Composto 140.

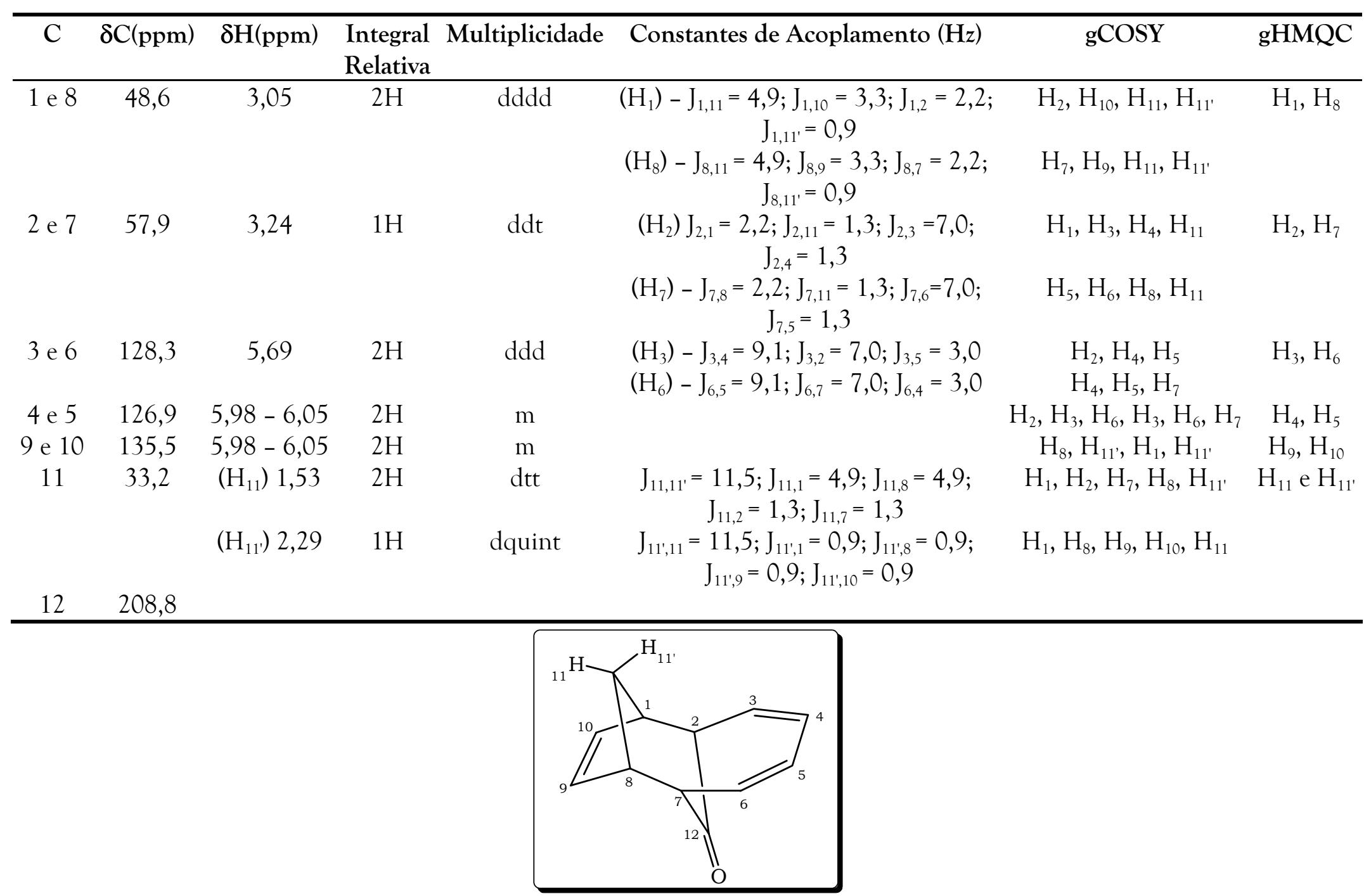




\section{Composto 141}

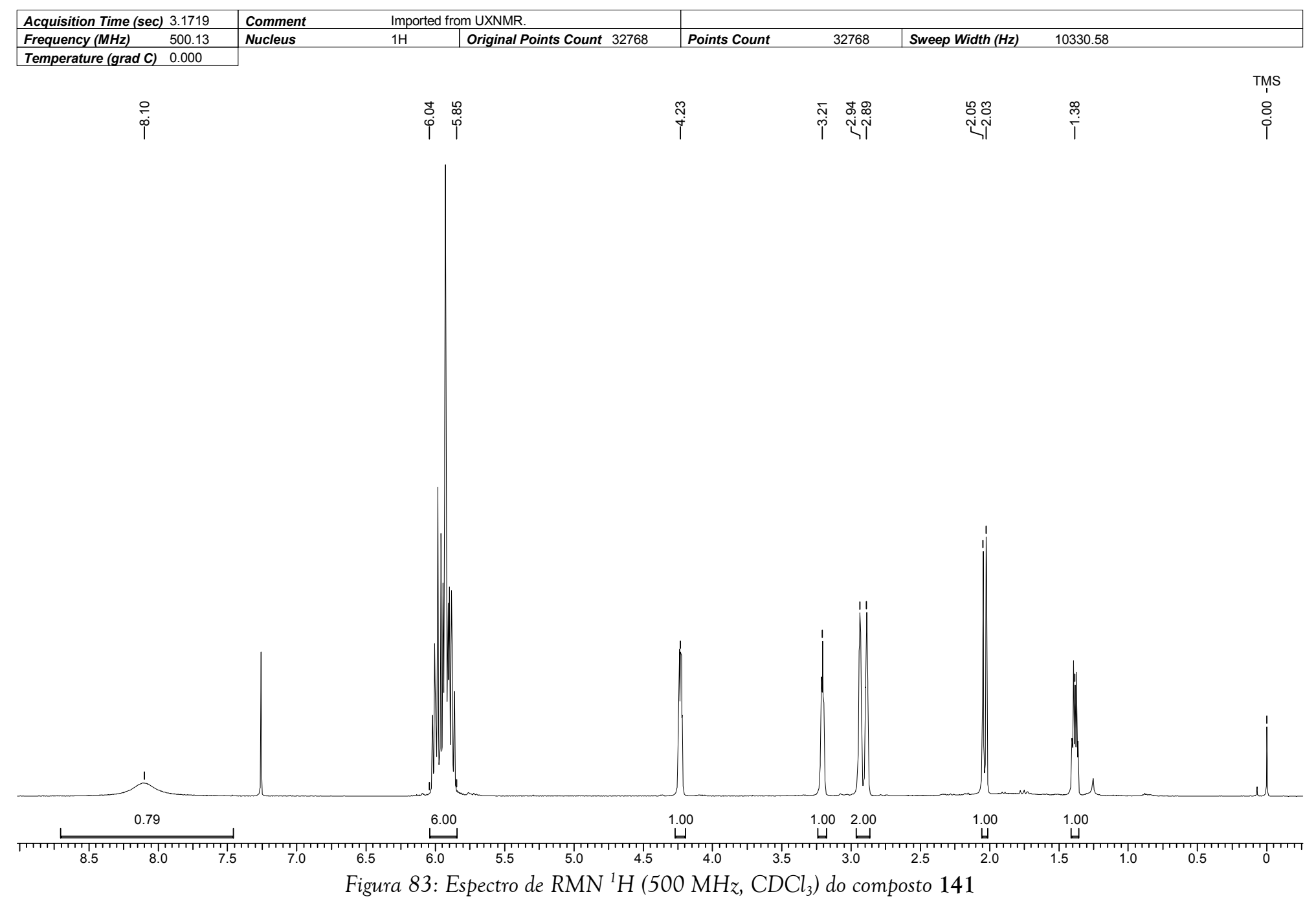


Espectro de $R M N{ }^{13} \mathrm{C}\left\{{ }^{1} \mathrm{H}\right\}$

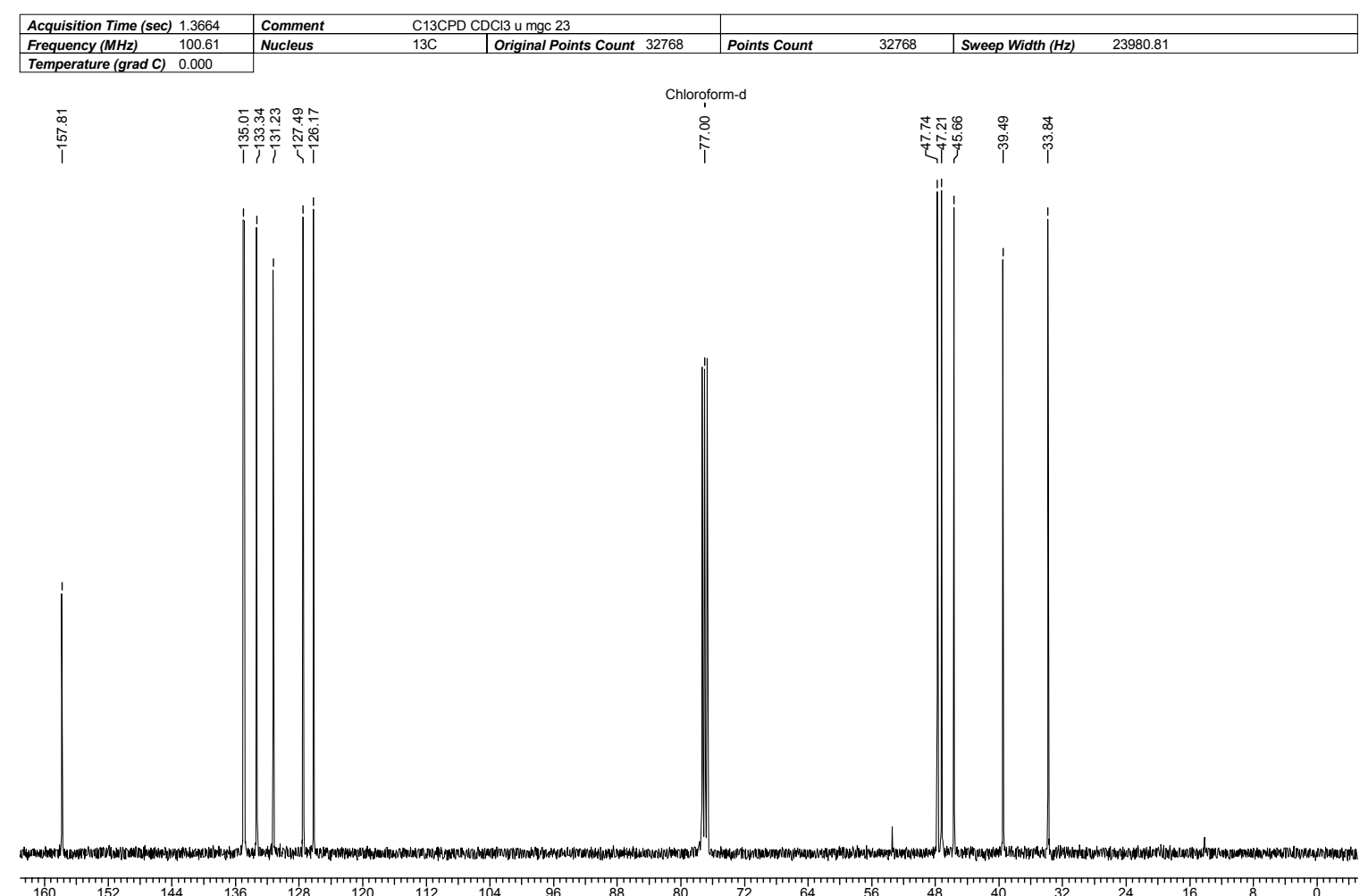

Espectro de RMN ${ }^{13} \mathrm{C}(\mathrm{DEPT}-135)$.

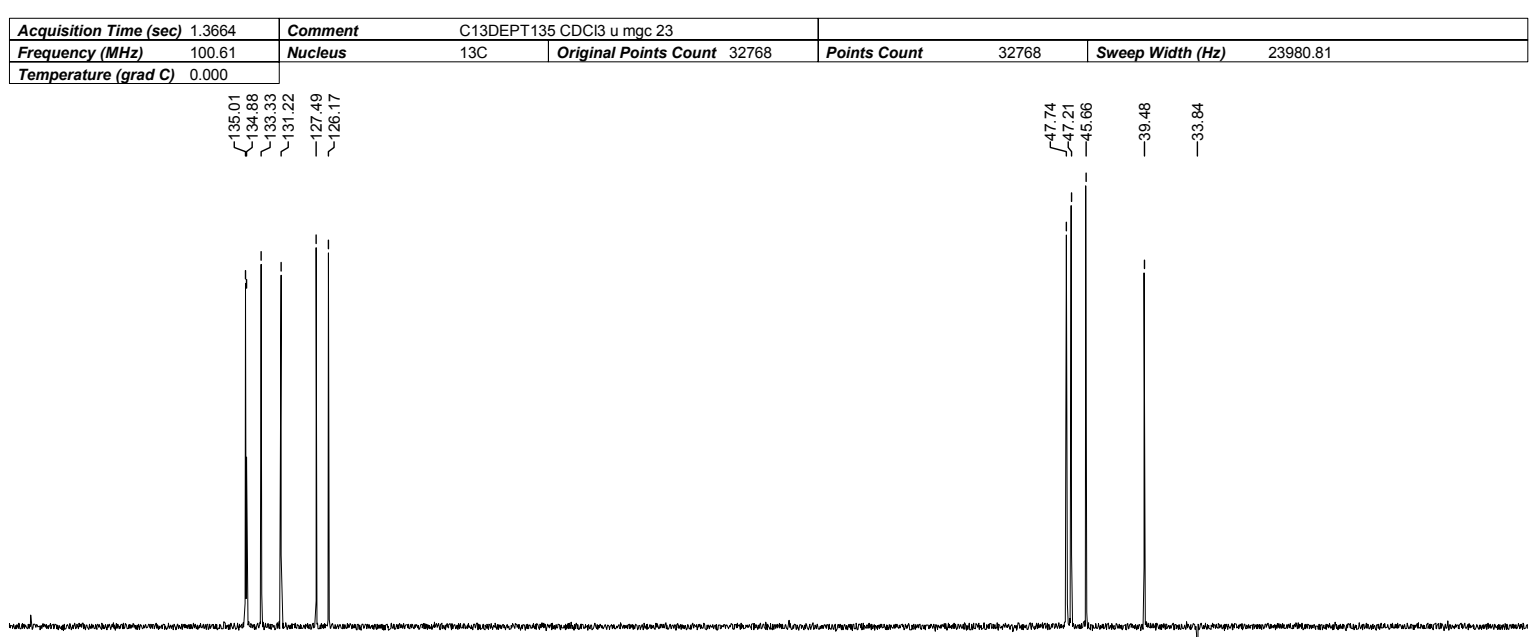

${ }_{15}$

${ }^{*}$ Espectro de $\mathrm{RMN}{ }^{13} \mathrm{C}\left(100 \mathrm{MHz}, \mathrm{CDCl}_{3}\right)$ DEPT-135 do composto $141 . \uparrow\left(\mathrm{CH}, \mathrm{CH}_{3}\right), \downarrow \cdot\left(\mathrm{CH}_{2}\right)$

Figura 84: Espectros de $\mathrm{RMN}^{13} \mathrm{C}\left(100 \mathrm{MHz}, \mathrm{CDCl}_{3}\right)$ do composto 141. 
Tabela 44: Dados Espectroscópicos do Composto 141.

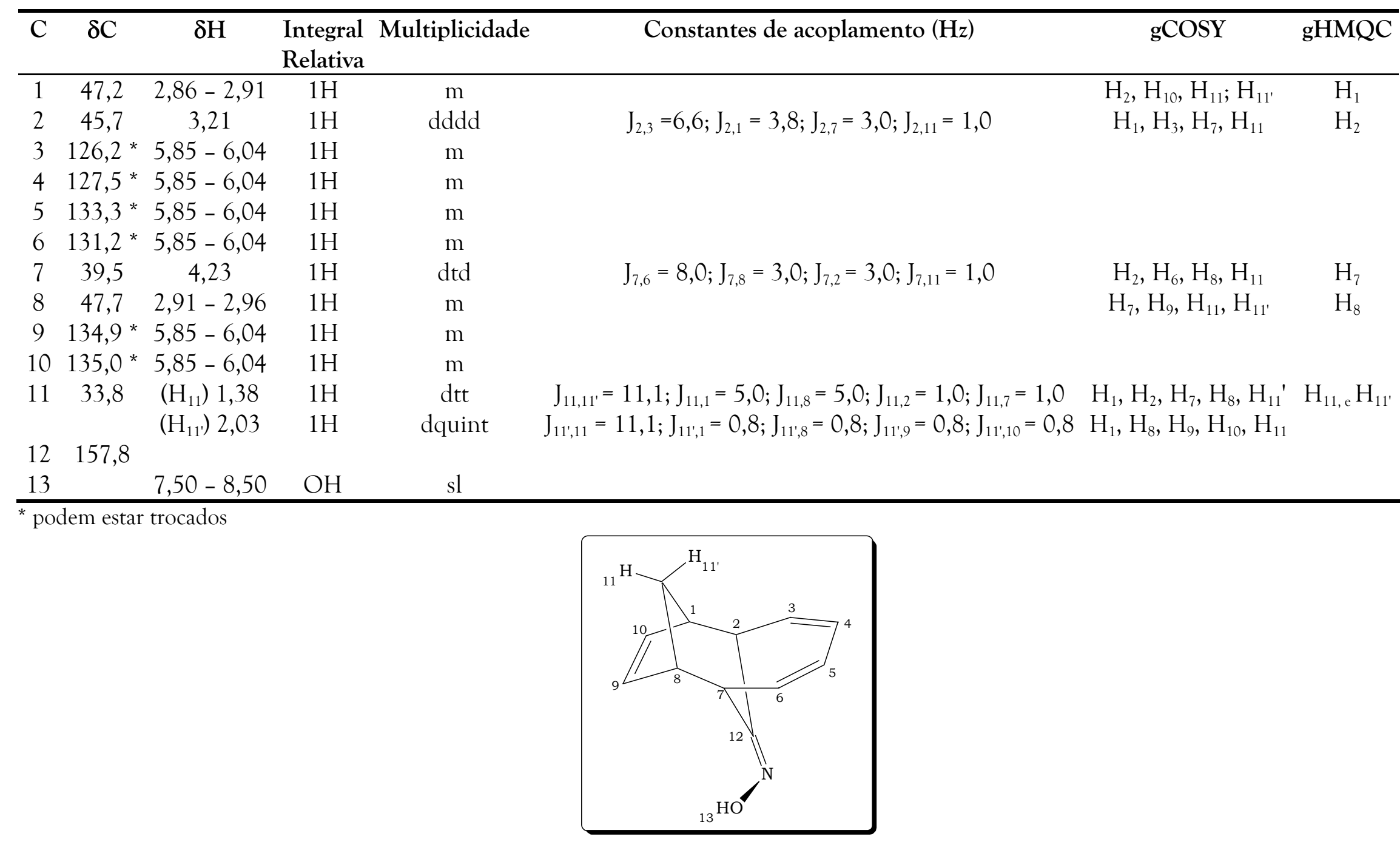




\section{Composto 142}

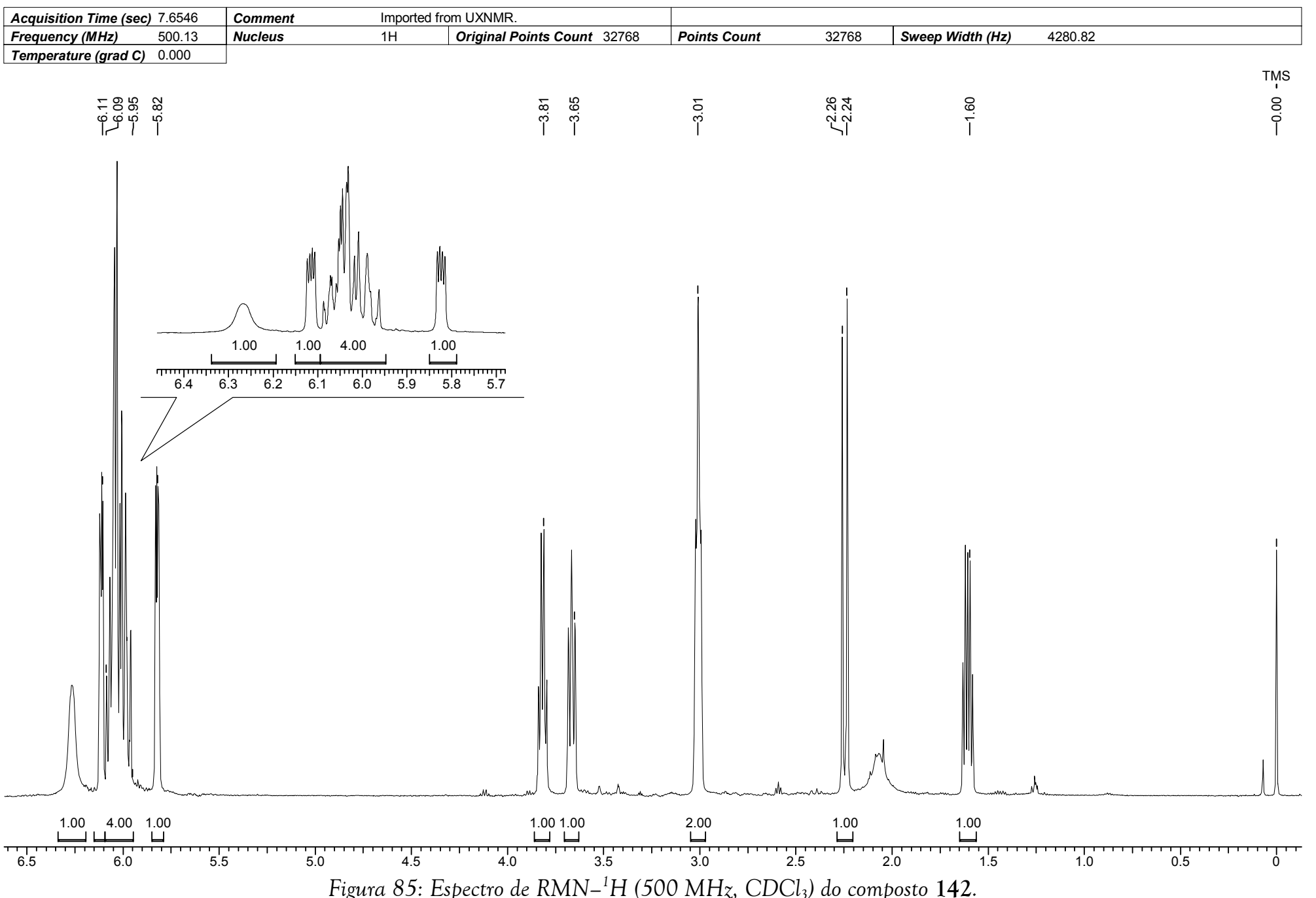


Espectro de $R M N{ }^{13} \mathrm{C}\left\{{ }^{1} \mathrm{H}\right\}$

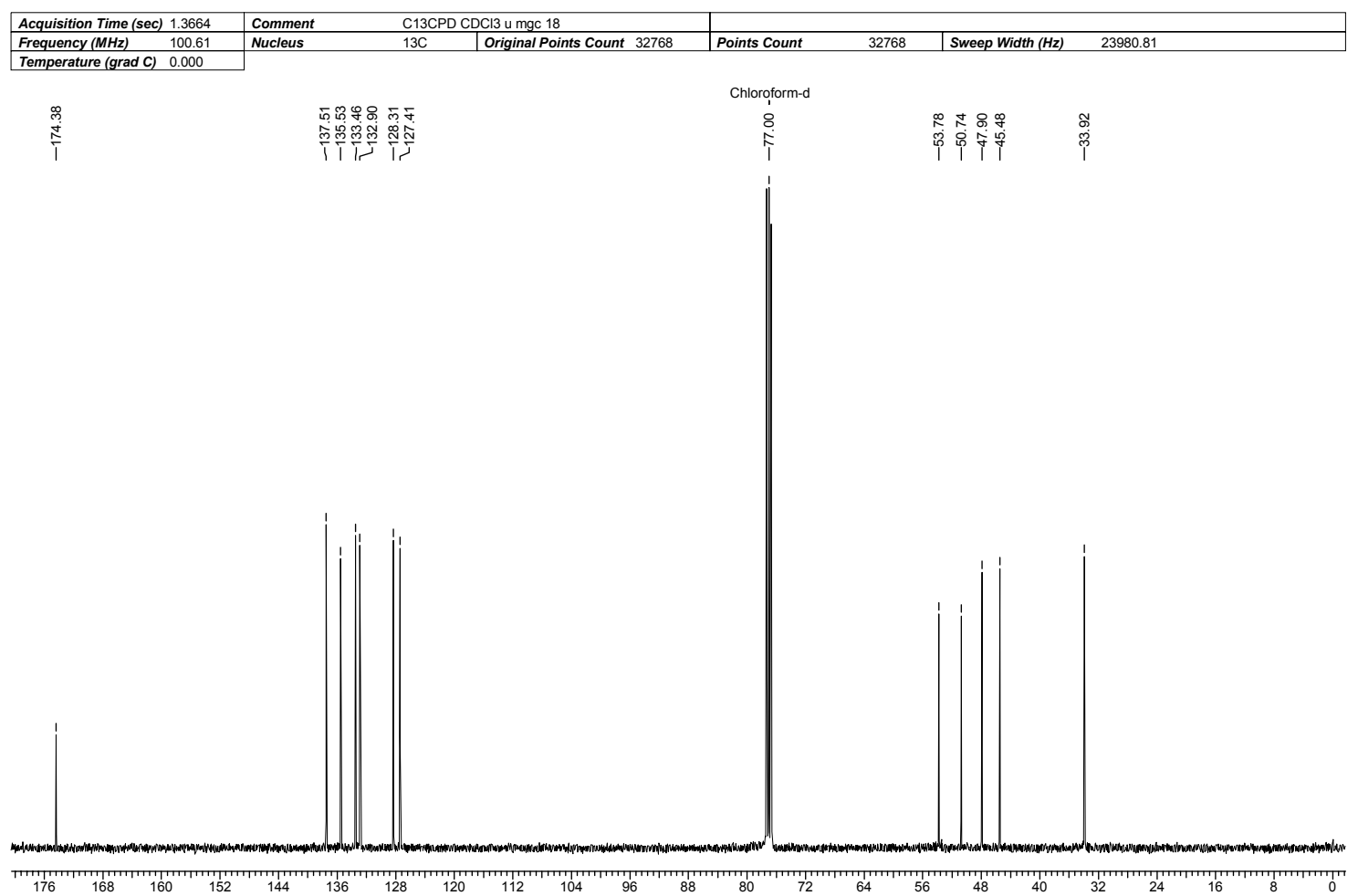

Espectro de RMN ${ }^{13} \mathrm{C}(\mathrm{DEPT}-135)$.

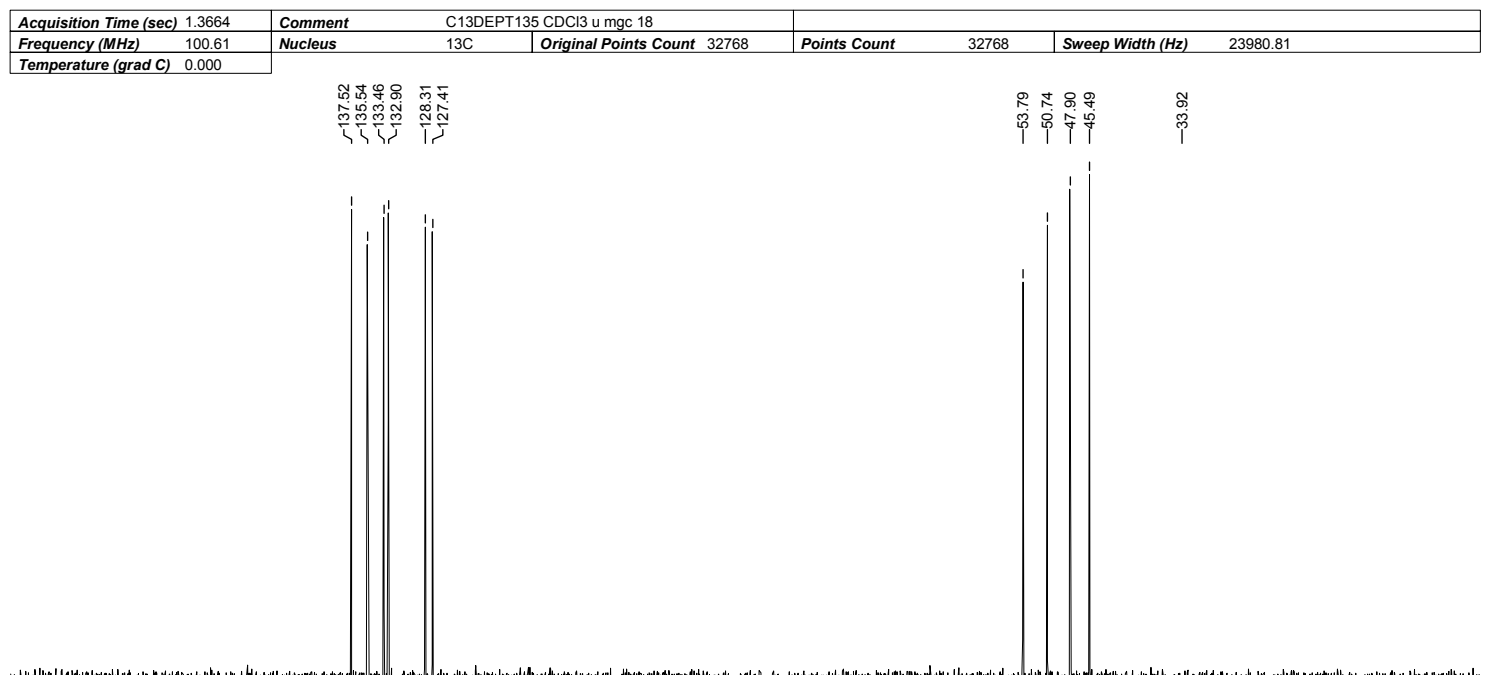

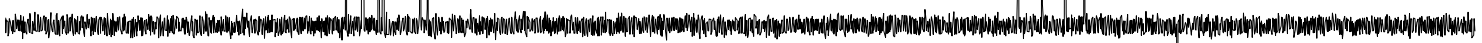

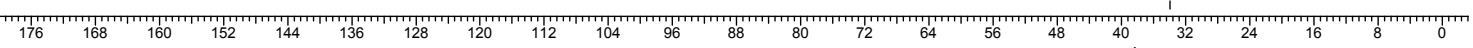

* Espectro de RMN ${ }^{13} \mathrm{C}\left(100 \mathrm{MHz}, \mathrm{CDCl}_{3}\right)$ DEPT-135 do composto $142 \uparrow\left(\mathrm{CH}, \mathrm{CH}_{3}\right), \downarrow$. $\left(\mathrm{CH}_{2}\right)$

Figura 86: Espectros de $\mathrm{RMN}^{13} \mathrm{C}\left(100 \mathrm{MHz}, \mathrm{CDCl}_{3}\right)$ do composto 142 
Tabela 45: Dados Espectroscópicos do Composto 142.

\begin{tabular}{|c|c|c|c|c|c|c|c|c|}
\hline $\mathrm{C}$ & $\delta \mathrm{C}(\mathrm{ppm})$ & $\delta \mathrm{H}(\mathrm{ppm})$ & $\begin{array}{l}\text { Integral } \\
\text { Relativa }\end{array}$ & Multiplicidade & Constantes de acoplamento $(\mathrm{Hz})$ & gCOSY & gHMBC & $\overline{\mathrm{gHMQC}}$ \\
\hline 1 & 47,9 & 2,99 & $1 \mathrm{H}$ & tdd & $\mathrm{J}_{1 / 2}=6,3 ; \mathrm{J}_{1 / 11}=6,3 ; \mathrm{J}_{1 / 10}=2,9 ; \mathrm{J}_{1 / 11^{\prime}}=1,5$ & $\mathrm{H}_{2}, \mathrm{H}_{8}, \mathrm{H}_{10}, \mathrm{H}_{11}, \mathrm{H}_{11}$ & $\mathrm{H}_{2}, \mathrm{H}_{8}, \mathrm{H}_{9}, \mathrm{H}_{10}, \mathrm{H}_{11}, \mathrm{H}_{11}$ & $\mathrm{H}_{1}$ \\
\hline 2 & 50,7 & 3,81 & $1 \mathrm{H}$ & $\mathrm{dt}$ & $\mathrm{J}_{2 / 3}=7,8 ; \mathrm{J}_{2 / 1}=6,3 ; \mathrm{J}_{2 / 13}=6,3$ & $\mathrm{H}_{1}, \mathrm{H}_{3}, \mathrm{H}_{11 *}, \mathrm{H}_{13}$ & $\mathrm{H}_{7}, \mathrm{H}_{11}, \mathrm{H}_{11}$ & $\mathrm{H}_{2}$ \\
\hline 3 & 127,4 & $5,95-6,09$ & $1 \mathrm{H}$ & $\mathrm{m}$ & & & $\mathrm{H}_{2}$ & \\
\hline 4 & 137,5 & $5,95-6,09$ & $1 \mathrm{H}$ & $\mathrm{m}$ & & & $\mathrm{H}_{2}$ & \\
\hline 5 & 133,5 & $5,95-6,09$ & $1 \mathrm{H}$ & $\mathrm{m}$ & & & $\mathrm{H}_{7}$ & \\
\hline 6 & 128,3 & $5,95-6,09$ & $1 \mathrm{H}$ & $\mathrm{m}$ & & & $\mathrm{H}_{7}$ & \\
\hline 7 & 53,8 & 3,64 & $1 \mathrm{H}$ & dddd & $\mathrm{J}_{7 / 6}=9,1 ; \mathrm{J}_{7 / 8}=6,3 ; \mathrm{J}_{7 / 11}=1,9 ; \mathrm{J}_{7 / 13}=1,0$ & $\mathrm{H}_{6}, \mathrm{H}_{8}, \mathrm{H}_{11}, \mathrm{H}_{13}$ & $\mathrm{H}_{2}, \mathrm{H}_{8}, \mathrm{H}_{9}, \mathrm{H}_{11}, \mathrm{H}_{11}$ & $\mathrm{H}_{7}$ \\
\hline 8 & 45,5 & 2,99 & $1 \mathrm{H}$ & $\operatorname{tdd}$ & $\mathrm{J}_{8 / 7}=6,3 ; \mathrm{J}_{8 / 11}=6,3 ; \mathrm{J}_{8 / 9}=2,9 ; \mathrm{J}_{8 / 11^{\prime}}=1,5$ & $\mathrm{H}_{7}, \mathrm{H}_{9}, \mathrm{H}_{11}, \mathrm{H}_{11}^{\prime}$ & $\mathrm{H}_{1}, \mathrm{H}_{7}, \mathrm{H}_{9}, \mathrm{H}_{10}, \mathrm{H}_{11}, \mathrm{H}_{11}$ & $\mathrm{H}_{8}$ \\
\hline 9 & 132,9 & 5,81 & $1 \mathrm{H}$ & ddd & $\mathrm{J}_{9 / 10}=5,9 ; \mathrm{J}_{9 / 8}=2,9 ; \mathrm{J}_{9 / 11^{\prime}}=0,7$ & $\mathrm{H}_{8}, \mathrm{H}_{10}, \mathrm{H}_{11}$ & $\mathrm{H}_{1}, \mathrm{H}_{8}, \mathrm{H}_{10}, \mathrm{H}_{11}$ & $\mathrm{H}_{9}$ \\
\hline 10 & 135,5 & 6,10 & $1 \mathrm{H}$ & ddd & $\mathrm{J}_{10 / 9}=5,9 ; \mathrm{J}_{10 / 1}=2,9 ; \mathrm{J}_{10 / 11^{1}}=0,7$ & $\mathrm{H}_{1}, \mathrm{H}_{9}, \mathrm{H}_{11}$ & $\mathrm{H}_{1}, \mathrm{H}_{8}, \mathrm{H}_{9}, \mathrm{H}_{11}$ & $\mathrm{H}_{10}$ \\
\hline \multirow[t]{2}{*}{11} & 33,9 & $\left(\mathrm{H}_{11}\right) 1,60$ & $1 \mathrm{H}$ & $\mathrm{dtd}$ & $\mathrm{J}_{11 / 11^{\prime}}=12,1 ; \mathrm{J}_{11 / 1}=6,3 ; \mathrm{J}_{11 / 8}=6,3 ; \mathrm{J}_{11 / 7}=1,9$ & $\mathrm{H}_{1}, \mathrm{H}_{2 *}, \mathrm{H}_{7}, \mathrm{H}_{11}$ & $\mathrm{H}_{1}, \mathrm{H}_{2}, \mathrm{H}_{7}, \mathrm{H}_{8}, \mathrm{H}_{9}, \mathrm{H}_{10}$ & $\mathrm{H}_{11} ; \mathrm{H}_{11}$ \\
\hline & & $\left(\mathrm{H}_{11}\right) 2,25$ & $1 \mathrm{H}$ & $\mathrm{dtt}$ & $\begin{array}{c}\mathrm{J}_{11^{\prime} / 11}=12,1 ; \mathrm{J}_{11^{\prime} / 1}=1,5 ; \mathrm{J}_{11^{\prime} / 8}=1,5 ; \\
\mathrm{J}_{11^{\prime} / 9}=0,7 ; \mathrm{J}_{11^{\prime} / 10}=0,7\end{array}$ & $\mathrm{H}_{1}, \mathrm{H}_{8}, \mathrm{H}_{9}, \mathrm{H}_{10}, \mathrm{H}_{11}$ & & \\
\hline \multirow[t]{2}{*}{12} & 174,4 & & & & & & & \\
\hline & & $\left(\mathrm{H}_{13}\right) 6,27$ & $\mathrm{NH}$ & sl & & & & \\
\hline
\end{tabular}

* acoplamentos que aparecem na análise ${ }^{1} \mathrm{H}-{ }^{1} \mathrm{H}$ gCOSY, mas não são medidos.

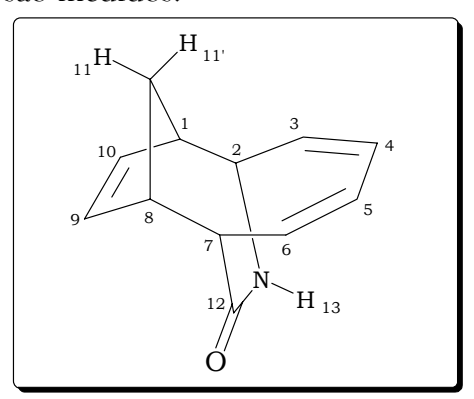




\section{Composto 170}

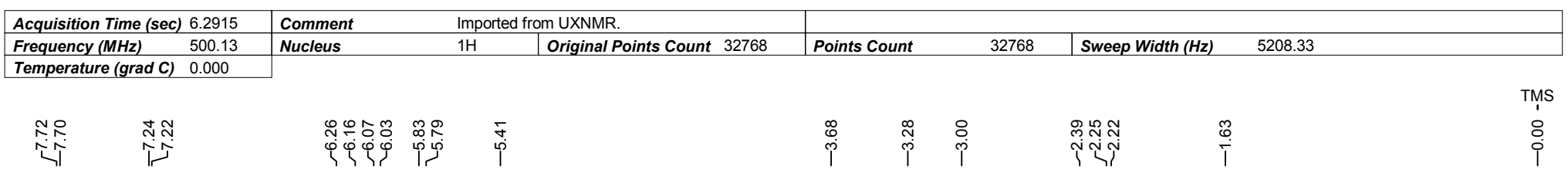

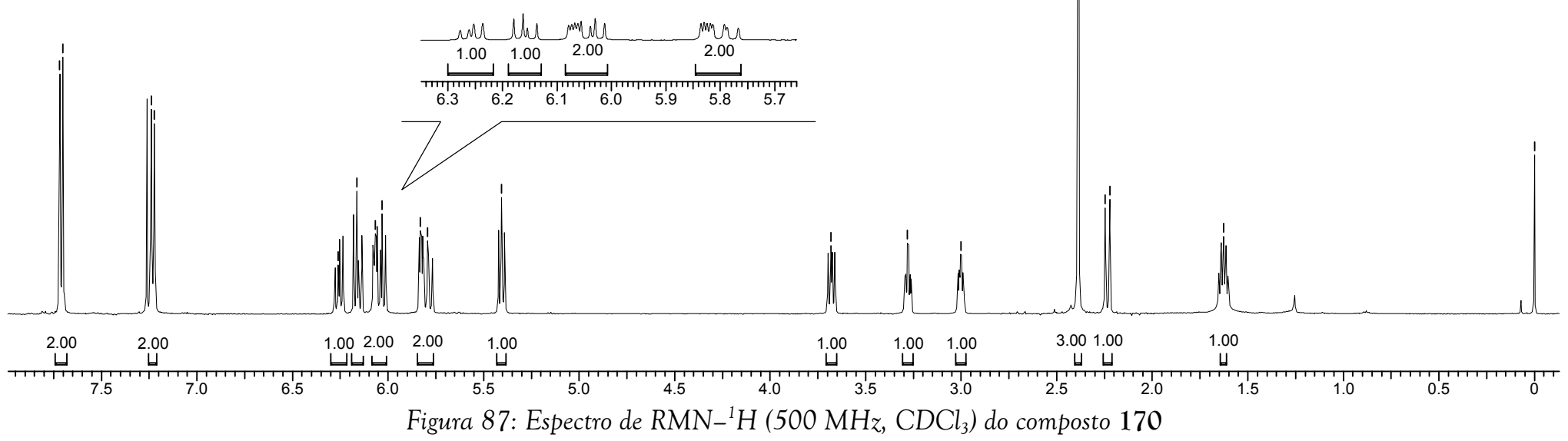


Espectro de $R M N{ }^{13} \mathrm{C}\left\{{ }^{1} \mathrm{H}\right\}$

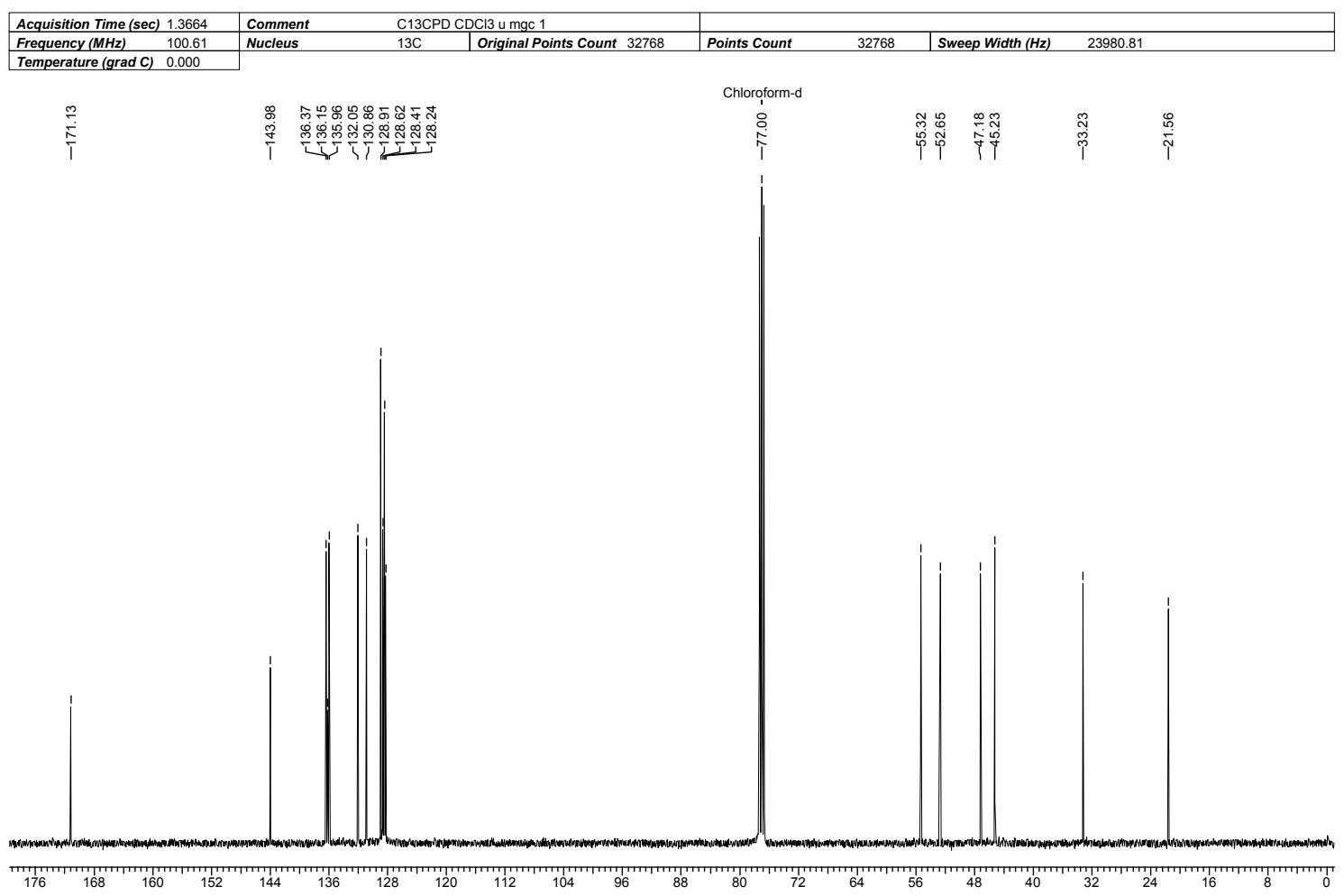

Espectro de RMN ${ }^{13} \mathrm{C}(\mathrm{DEPT}-135)$.

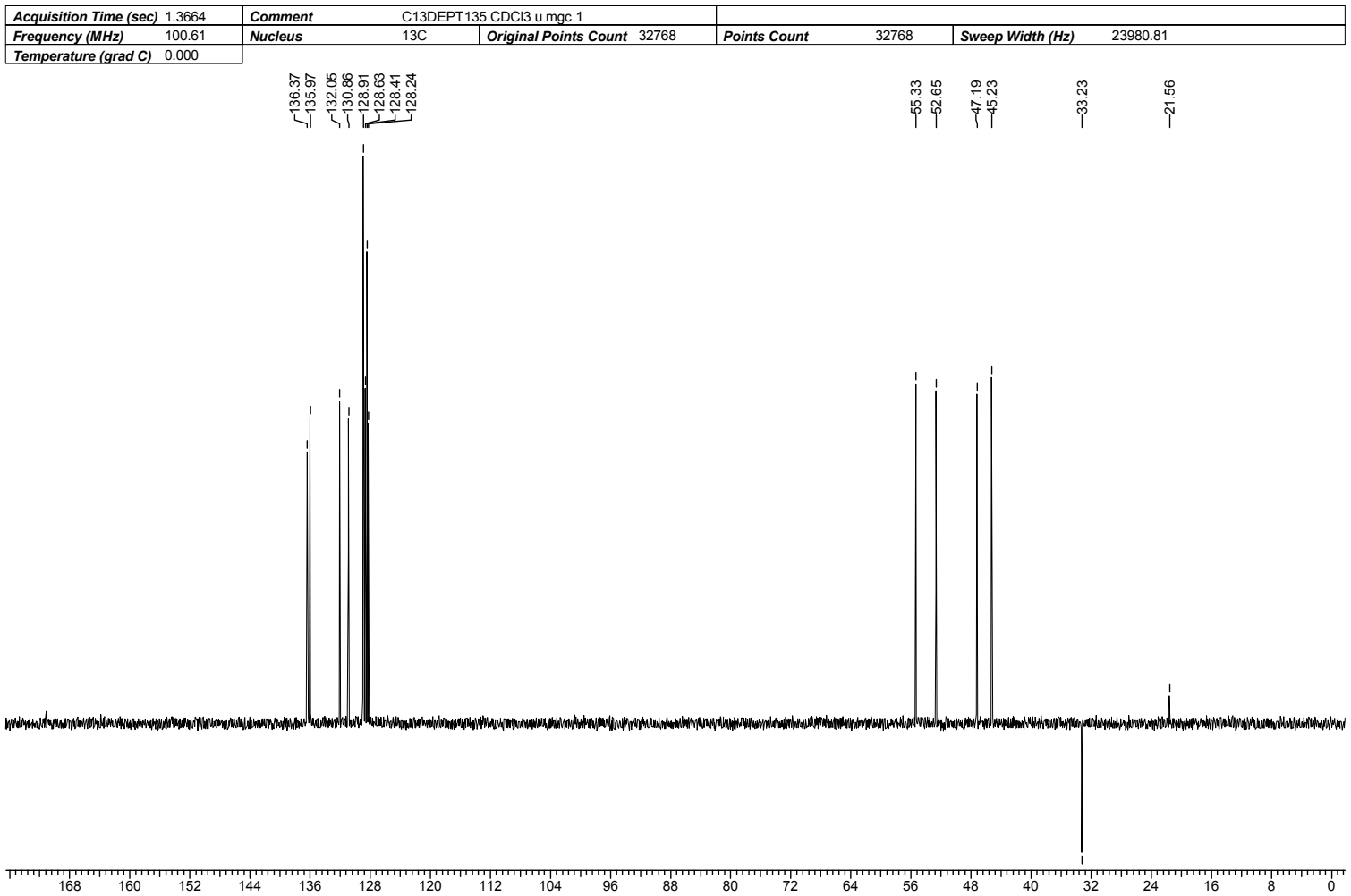

${ }^{*}$ Espectro de RMN ${ }^{13} \mathrm{C}\left(100 \mathrm{MHz}, \mathrm{CDCl}_{3}\right)$ DEPT-135 do composto $170 \uparrow\left(\mathrm{CH}, \mathrm{CH}_{3}\right)$,.$\left(\mathrm{CH}_{2}\right)$

Figura 88: Espectros de $\mathrm{RMN}^{13} \mathrm{C}\left(100 \mathrm{MHz}, \mathrm{CDCl}_{3}\right)$ do composto 170 
Tabela 46: Dados Espectroscópicos do Composto 170.

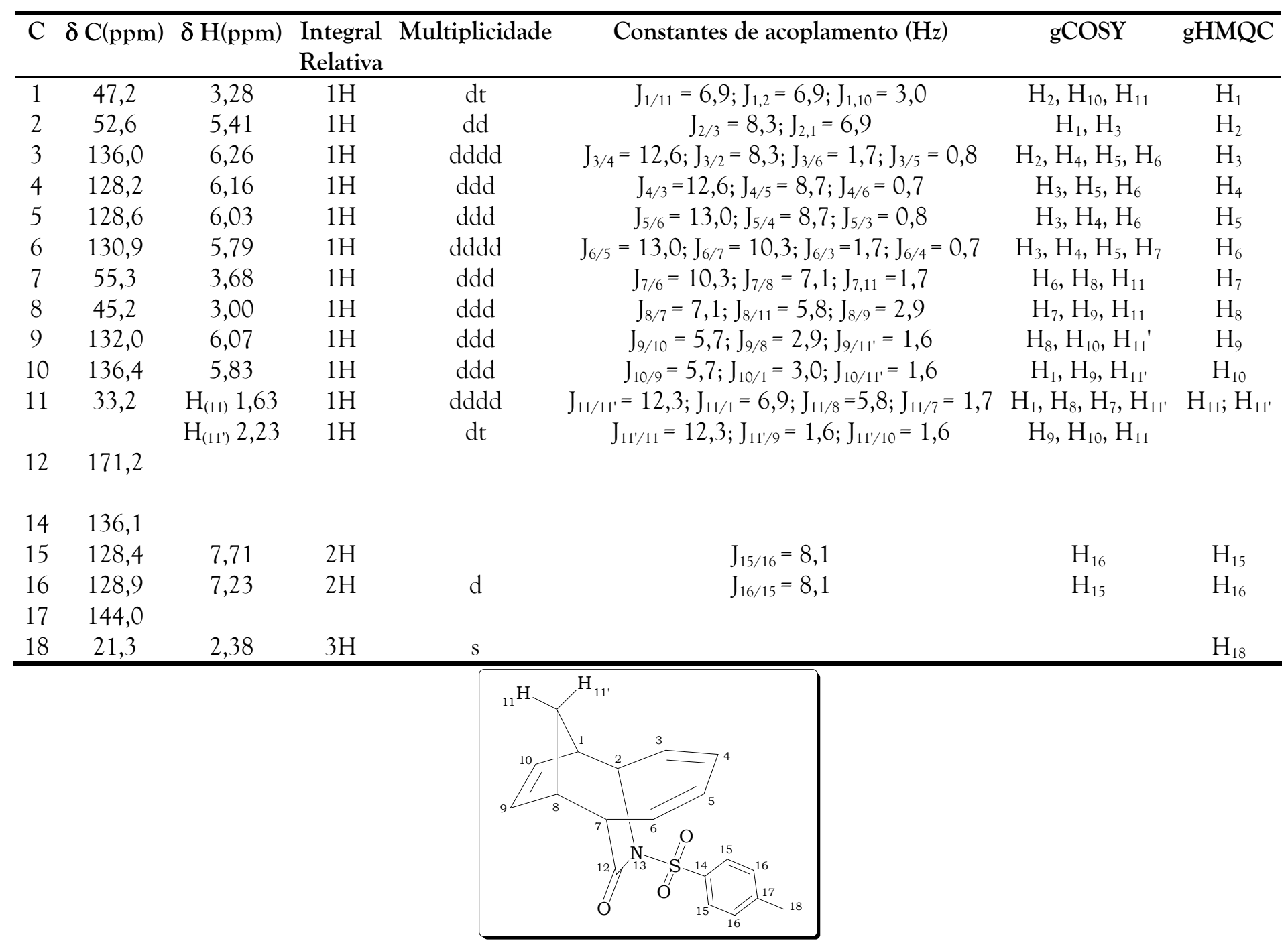




\section{Composto 171}

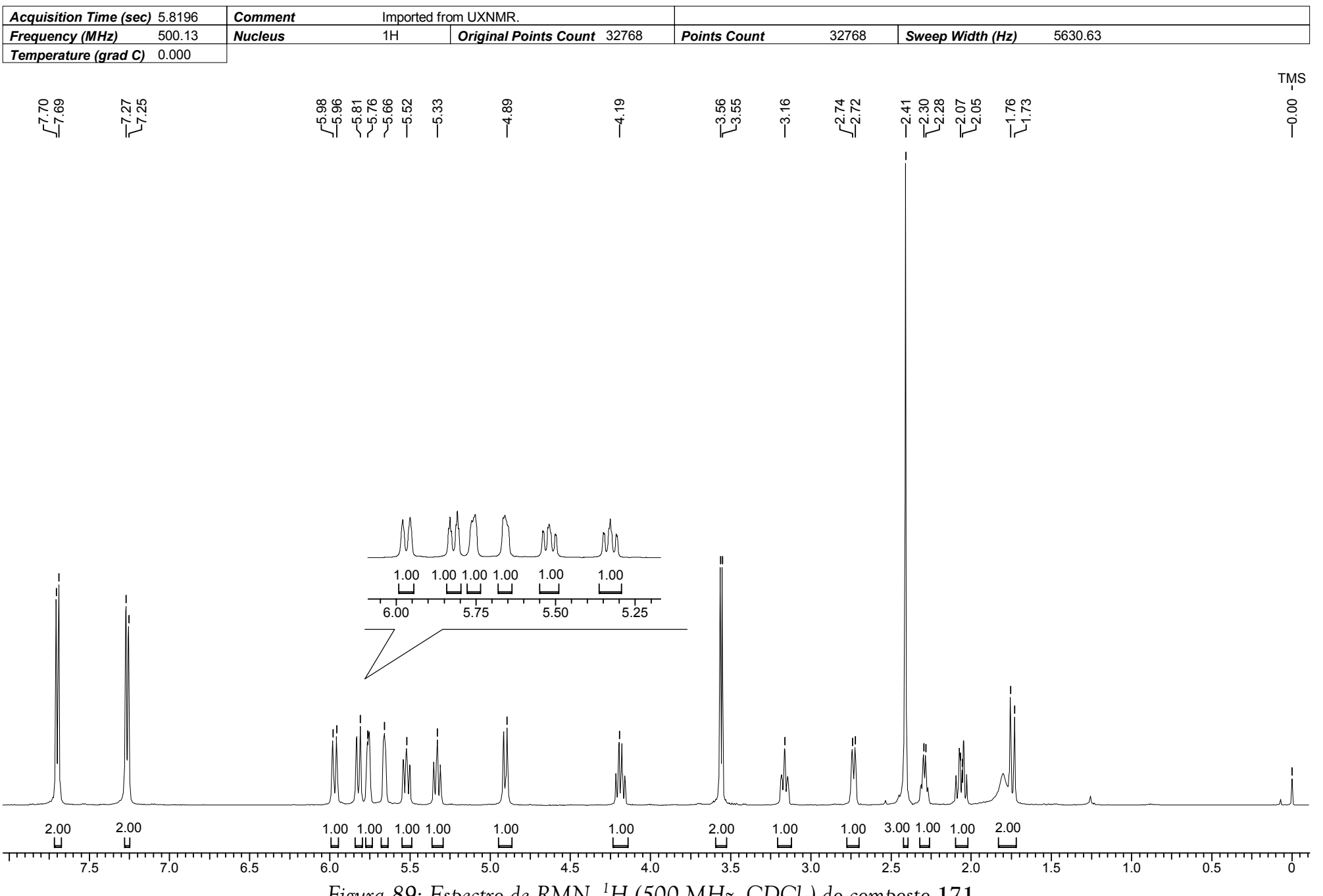

Figura 89: Espectro de $\mathrm{RMN}^{-1} \mathrm{H}\left(500 \mathrm{MHz}, \mathrm{CDCl}_{3}\right.$ ) do composto 171 . 
Espectro de $R M N{ }^{13} \mathrm{C}\left\{{ }^{1} \mathrm{H}\right\}$
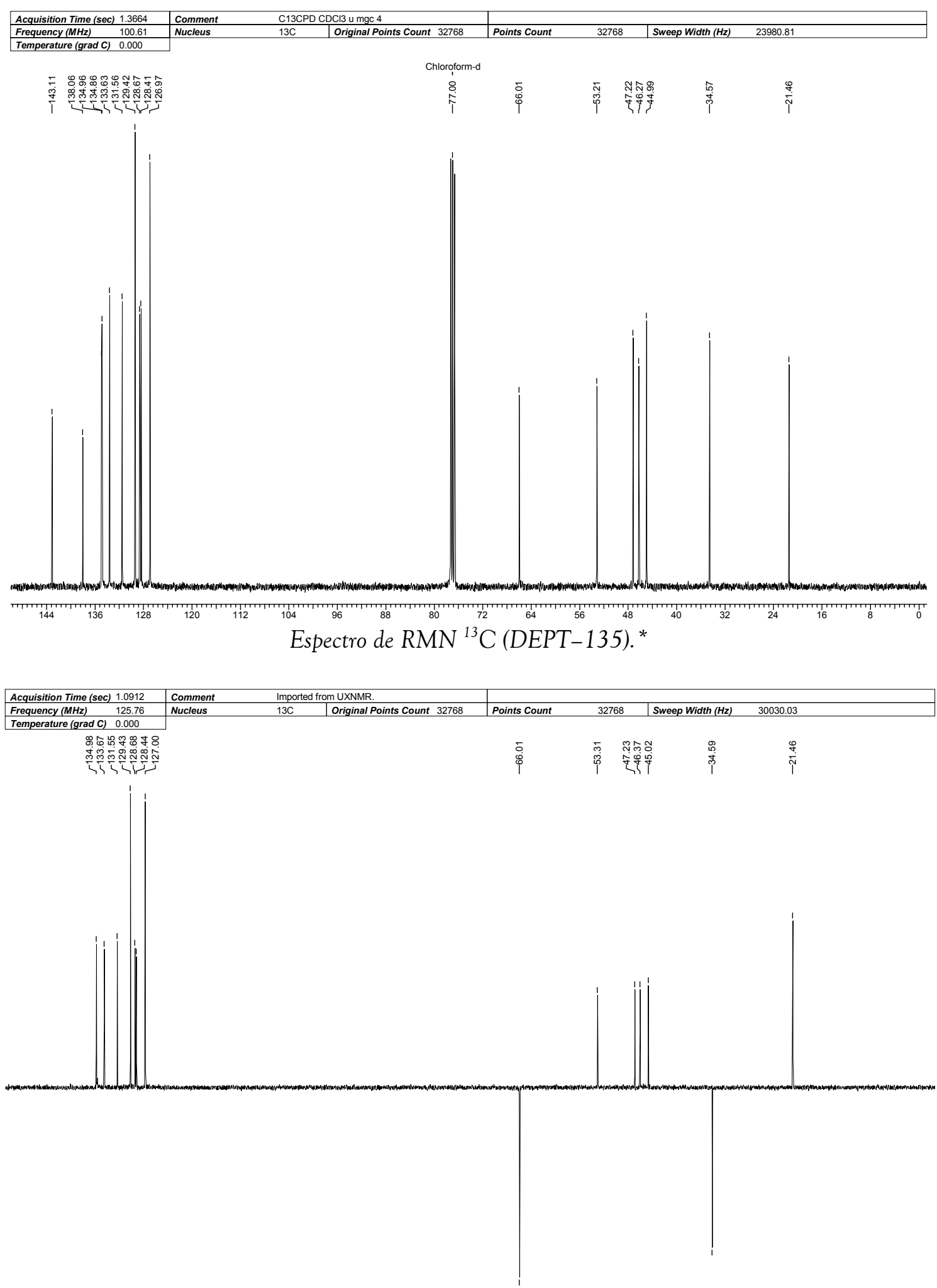

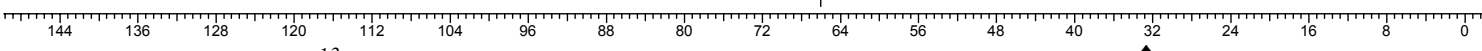

* Espectro de $\mathrm{RMN}{ }^{13} \mathrm{C}\left(125 \mathrm{MHz}, \mathrm{CDCl}_{3}\right)$ DEPT-135 do composto 171. $\uparrow\left(\mathrm{CH}, \mathrm{CH}_{3}\right), \downarrow \cdot\left(\mathrm{CH}_{2}\right)$

Figura 90: Espectros de $\mathrm{RMN}^{13} \mathrm{C}\left(100 / 125 \mathrm{MHz}, \mathrm{CDCl}_{3}\right)$ do composto 171. 
Tabela 47: Dados Espectroscópicos do Composto 171.

\begin{tabular}{|c|c|c|c|c|c|c|c|c|}
\hline $\mathrm{C}$ & $\delta \mathrm{C}(\mathrm{ppm})$ & $\delta \mathrm{H}(\mathrm{ppm})$ & $\begin{array}{l}\text { Integral } \\
\text { Relativa }\end{array}$ & Multiplicidade & Constantes de acoplamento $(\mathrm{Hz})$ & gHMBC & gCOSY & gHMQC \\
\hline 1 & 46,3 & 3,17 & $1 \mathrm{H}$ & tddd & $\mathrm{J}_{1 / 11}=9,5 ; \mathrm{J}_{1,2}=9,5 ; \mathrm{J}_{1,10}=3,0 ; \mathrm{J}_{1,9}=1,3 ; \mathrm{J}_{1,11^{\prime}}=0,8$ & $\mathrm{H}_{2}, \mathrm{H}_{3}, \mathrm{H}_{8}, \mathrm{H}_{9}, \mathrm{H}_{10}, \mathrm{H}_{11}, \mathrm{H}_{11}$ & $\mathrm{H}_{2}, \mathrm{H}_{9}, \mathrm{H}_{10}, \mathrm{H}_{11}, \mathrm{H}_{11}$ & $\mathrm{H}_{1}$ \\
\hline 2 & 53,2 & 4,19 & $1 \mathrm{H}$ & $\mathrm{td}$ & $\mathrm{J}_{2 / 1}=9,5 ; \mathrm{J}_{2,14}=9,5 ; \mathrm{J}_{2,3}=8,1$ & $\mathrm{H}_{1}, \mathrm{H}_{3}, \mathrm{H}_{4}, \mathrm{H}_{10}, \mathrm{H}_{11}, \mathrm{H}_{11}$ & $\mathrm{H}_{1}, \mathrm{H}_{3}, \mathrm{H}_{14}$ & $\mathrm{H}_{2}$ \\
\hline 3 & 134,9 & 5,53 & $1 \mathrm{H}$ & dddd & $\mathrm{J}_{3 / 4}=11,6 ; \mathrm{J}_{3 / 2}=8,1 ; \mathrm{J}_{3 / 5}=1,8 ; \mathrm{J}_{3 / 6}=0,8$ & $\mathrm{H}_{1}, \mathrm{H}_{2}, \mathrm{H}_{4}, \mathrm{H}_{5}$ & $\mathrm{H}_{2}, \mathrm{H}_{4}, \mathrm{H}_{5}, \mathrm{H}_{6}$ & $\mathrm{H}_{3}$ \\
\hline 4 & 128,4 & 5,81 & $1 \mathrm{H}$ & ddd & $\mathrm{J}_{4 / 3}=11,6 ; \mathrm{J}_{4 / 6}=2,0 ; \mathrm{J}_{4 / 5}=1,8$ & $\mathrm{H}_{2}, \mathrm{H}_{3}, \mathrm{H}_{5}, \mathrm{H}_{6}$ & $\mathrm{H}_{3}, \mathrm{H}_{5}, \mathrm{H}_{6}$ & $\mathrm{H}_{4}$ \\
\hline 5 & 128,7 & 5,97 & $1 \mathrm{H}$ & dddd & $J_{5 / 6}=11,3 ; J_{5 / 4}=2,0 ; J_{5 / 3}=1,8 ; J_{5 / 7}=0,9$ & $\mathrm{H}_{3}, \mathrm{H}_{4}, \mathrm{H}_{6}, \mathrm{H}_{7}$ & $\mathrm{H}_{3}, \mathrm{H}_{4}, \mathrm{H}_{6}, \mathrm{H}_{7}$ & $\mathrm{H}_{5}$ \\
\hline 6 & 135,0 & 5,32 & $1 \mathrm{H}$ & dddd & $\mathrm{J}_{6 / 5}=11,3 ; \mathrm{J}_{6 / 7}=8,8 ; \mathrm{J}_{6 / 4}=2,0 ; \mathrm{J}_{6 / 3}=0,8$ & $\mathrm{H}_{4}, \mathrm{H}_{5}, \mathrm{H}_{7}, \mathrm{H}_{12}$ & $\mathrm{H}_{3}, \mathrm{H}_{4}, \mathrm{H}_{5}, \mathrm{H}_{7}$ & $\mathrm{H}_{6}$ \\
\hline 7 & 47,2 & 2,29 & $1 \mathrm{H}$ & dtdd & $\mathrm{J}_{7 / 6}=8,8 ; \mathrm{J}_{7 / 12}=7,1 ; \mathrm{J}_{7 / 12^{\prime}}=7,1 ; \mathrm{J}_{7 / 8}=2,5 ; \mathrm{J}_{7,5}=0,9$ & $\mathrm{H}_{5}, \mathrm{H}_{6}, \mathrm{H}_{8}, \mathrm{H}_{9}, \mathrm{H}_{11}, \mathrm{H}_{11}, \mathrm{H}_{12}$ & $\mathrm{H}_{5}, \mathrm{H}_{6}, \mathrm{H}_{8}, \mathrm{H}_{12}$ & $\mathrm{H}_{7}$ \\
\hline 8 & 45,0 & 2,73 & $1 \mathrm{H}$ & dddd & $\mathrm{J}_{8 / 11}=9,5 ; \mathrm{J}_{8 / 9}=3,2 ; \mathrm{J}_{8 / 7}=2,5 ; \mathrm{J}_{8 / 10}=1,0$ & $\mathrm{H}_{1}, \mathrm{H}_{6}, \mathrm{H}_{7}, \mathrm{H}_{9}, \mathrm{H}_{10}, \mathrm{H}_{11}, \mathrm{H}_{11}, \mathrm{H}_{12}$ & $\mathrm{H}_{7}, \mathrm{H}_{9}, \mathrm{H}_{10}, \mathrm{H}_{11},\left(\mathrm{H}_{11}\right)$ & $\mathrm{H}_{8}$ \\
\hline 9 & 133,6 & 5,76 & $1 \mathrm{H}$ & ddd & $\mathrm{J}_{9 / 10}=5,5 ; \mathrm{J}_{9 / 8}=3,2 ; \mathrm{J}_{9 / 1}=1,3$ & $\mathrm{H}_{1}, \mathrm{H}_{7}, \mathrm{H}_{8}, \mathrm{H}_{10}, \mathrm{H}_{11}, \mathrm{H}_{11}$ & $\mathrm{H}_{1}, \mathrm{H}_{8}, \mathrm{H}_{10}, \mathrm{H}_{11}$ & $\mathrm{H}_{9}$ \\
\hline 10 & 131,6 & 5,66 & $1 \mathrm{H}$ & $\mathrm{ddt}$ & $\mathrm{J}_{10 / 9}=5,5 ; \mathrm{J}_{10 / 1}=3,0 ; \mathrm{J}_{10 / 8}=1,0 ; \mathrm{J}_{10 / 11}=1,0$ & $\mathrm{H}_{1}, \mathrm{H}_{2}, \mathrm{H}_{8}, \mathrm{H}_{9}, \mathrm{H}_{11}, \mathrm{H}_{11}$ & $\mathrm{H}_{1}, \mathrm{H}_{8}, \mathrm{H}_{9},\left(\mathrm{H}_{11}\right)$ & $\mathrm{H}_{10}$ \\
\hline 11 & 34,6 & $\mathrm{H}_{(11)} 2,06$ & $1 \mathrm{H}$ & $\mathrm{dt}$ & $\mathrm{J}_{11 / 11^{1}}=13,9 ; \mathrm{J}_{11 / 1}=9,5 ; \mathrm{J}_{11 / 8}=9,5$ & $\mathrm{H}_{1}, \mathrm{H}_{2}, \mathrm{H}_{7}, \mathrm{H}_{8}, \mathrm{H}_{9}, \mathrm{H}_{10}$ & $\mathrm{H}_{1}, \mathrm{H}_{8}, \mathrm{H}_{11}$ & $\mathrm{H}_{11} ; \mathrm{H}_{11^{\prime}}$ \\
\hline \multirow{4}{*}{12} & \multirow{4}{*}{66,0} & $\mathrm{H}_{\left(11^{\prime}\right)} 1,74$ & $1 \mathrm{H}$ & ddd & $\mathrm{J}_{11^{\prime} / 11}=13,9 ; \mathrm{J}_{11^{\prime} / 10}=1,0 ; \mathrm{J}_{11^{\prime} / 1}=0,8$ & \multirow{4}{*}{$\mathrm{H}_{6}, \mathrm{H}_{7}, \mathrm{H}_{8}$} & $\mathrm{H}_{1},\left(\mathrm{H}_{8}\right),\left(\mathrm{H}_{9}\right), \mathrm{H}_{10}, \mathrm{H}_{11}$ & \multirow{4}{*}{$\mathrm{H}_{12}$} \\
\hline & & 3,56 & $2 \mathrm{H}$ & $\mathrm{d}$ & $\mathrm{J}_{12 / 7}=7,1$ & & $\mathrm{H}_{7}$ & \\
\hline & & $\mathrm{H}_{(13)} 1,80$ & $\mathrm{OH}$ & sl & & & & \\
\hline & & $\mathrm{H}_{(14)} 4,89$ & $\mathrm{NH}$ & $\mathrm{d}$ & $\mathrm{J}_{14 / 2}=9,5$ & & $\mathrm{H}_{2}$ & \\
\hline 15 & 138,1 & & & & & $\mathrm{H}_{16}, \mathrm{H}_{17}$ & & \\
\hline 16 & 127,0 & 7,70 & $2 \mathrm{H}$ & $\mathrm{d}$ & $\mathrm{J}_{16 / 17}=8,3$ & $\mathrm{H}_{17}$ & $\mathrm{H}_{17}$ & $\mathrm{H}_{16}$ \\
\hline 17 & 129,4 & 7,26 & $2 \mathrm{H}$ & $\mathrm{d}$ & $\mathrm{J}_{17 / 16}=8,3$ & $\mathrm{H}_{16}, \mathrm{H}_{19}$ & $\mathrm{H}_{16}$ & $\mathrm{H}_{17}$ \\
\hline 18 & 143,1 & & & & & $\mathrm{H}_{16}, \mathrm{H}_{17}, \mathrm{H}_{19}$ & & \\
\hline 19 & 21,5 & 2,41 & $\mathrm{H}$ & s & & $\mathrm{H}_{17}$ & & $\mathrm{H}_{19}$ \\
\hline
\end{tabular}

em parênteses ( ) : "acoplamentos" que são observados no experimento de ${ }^{1} \mathrm{H}-{ }^{1} \mathrm{H}$ COSY, mas que não são vistos no experimento de $1 \mathrm{D}$ de ${ }^{1} \mathrm{H}$ nem no Jres. 
Tabela 48: Experimentos de NOE-DIFF com o Composto 171.

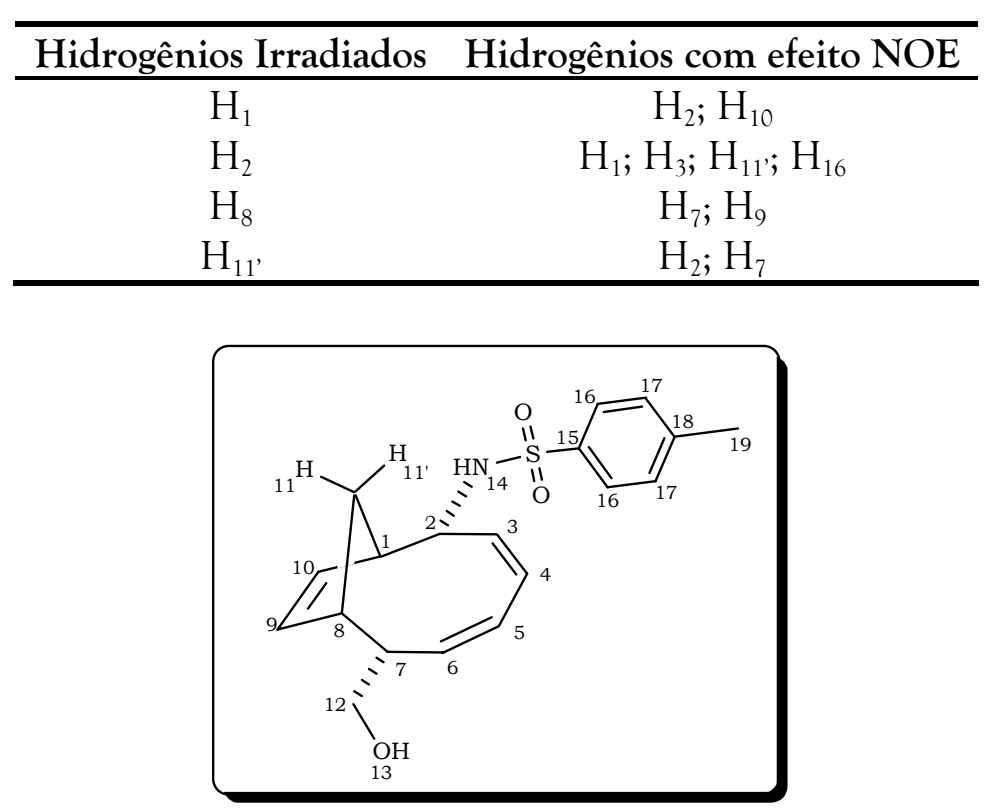




\section{Composto 172}

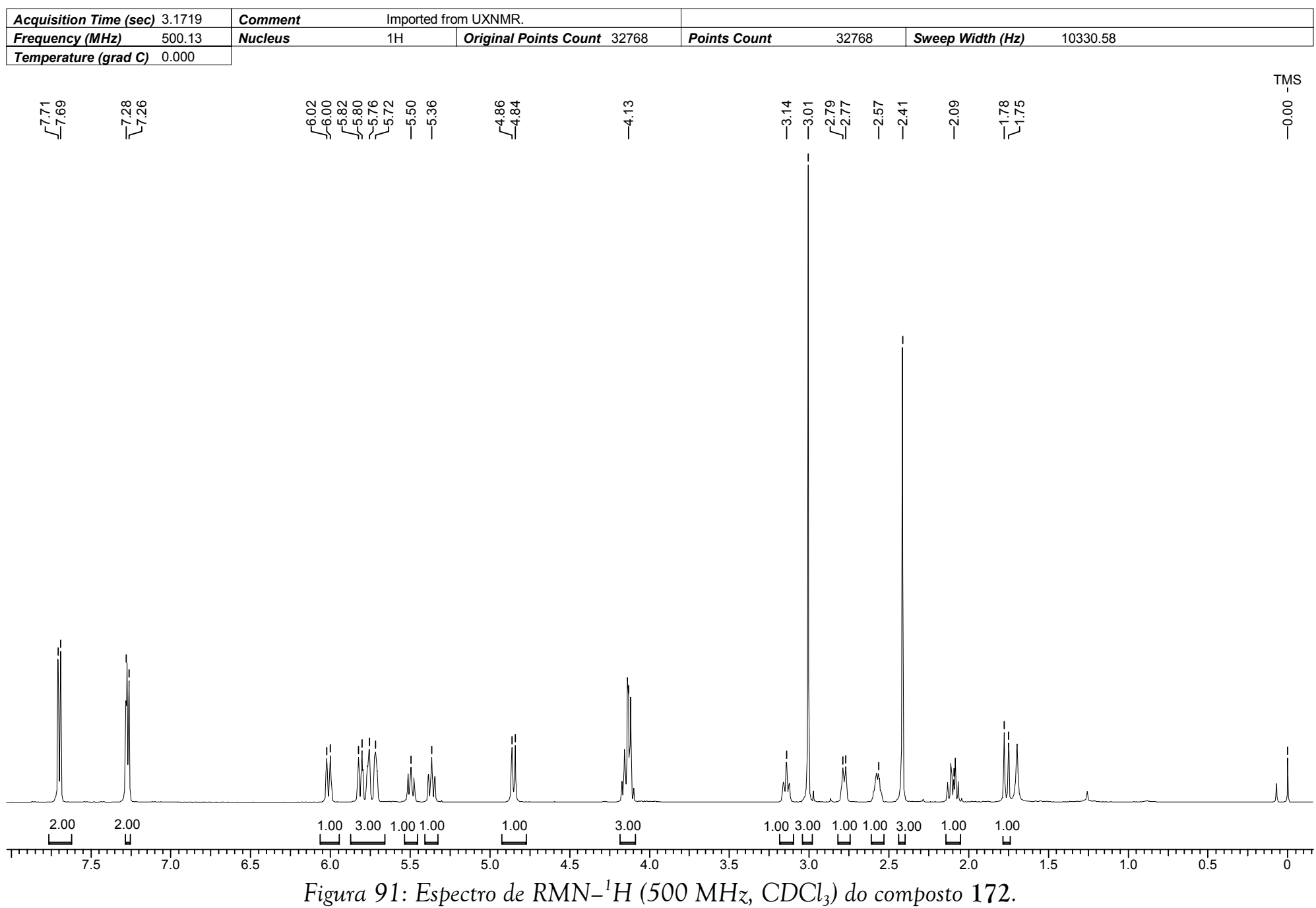


Espectro de $R M N{ }^{13} \mathrm{C}\left\{{ }^{1} \mathrm{H}\right\}$

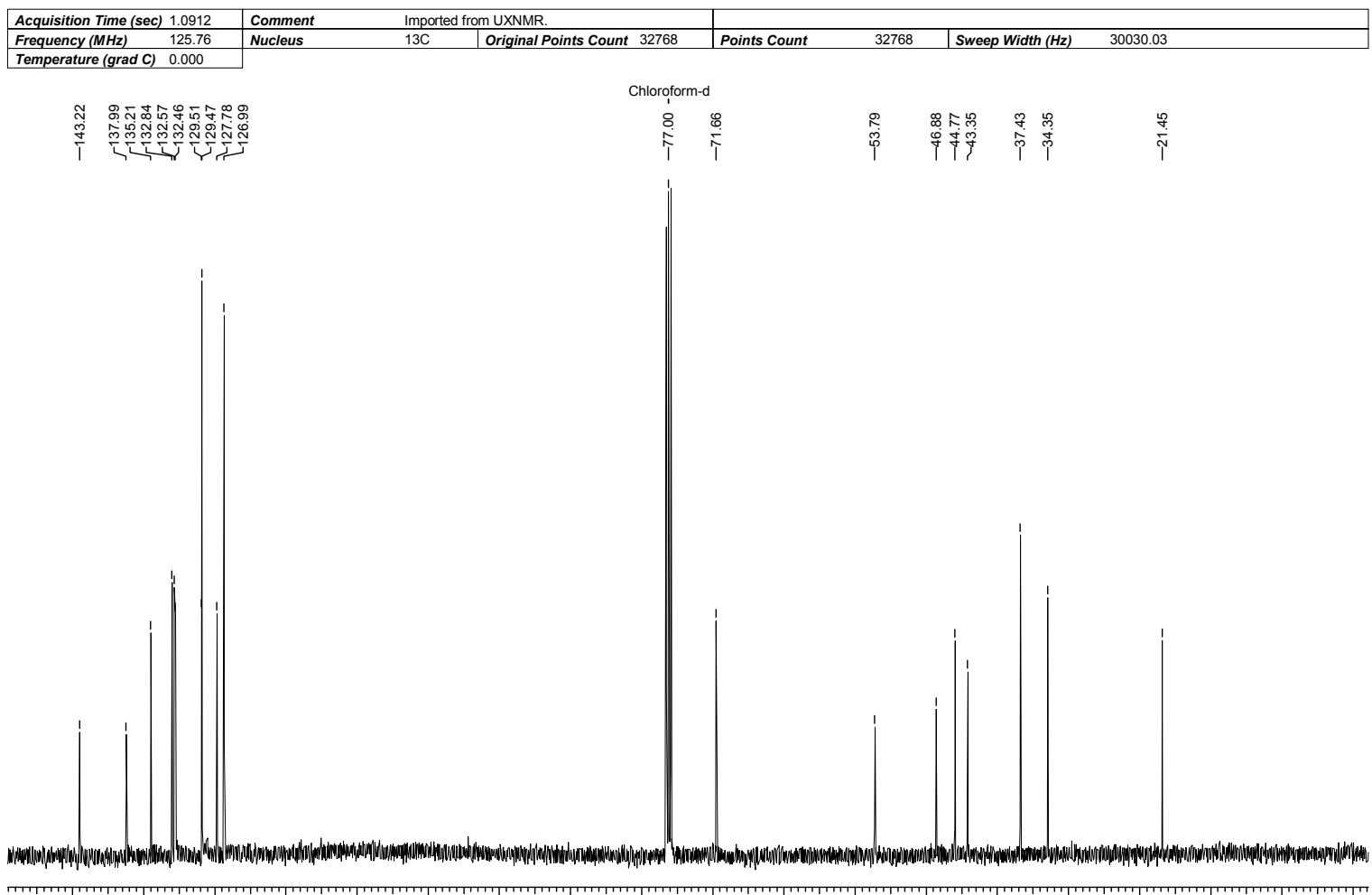

${ }_{144}$

Espectro de RMN ${ }^{13} \mathrm{C}(\mathrm{DEPT}-135)$.

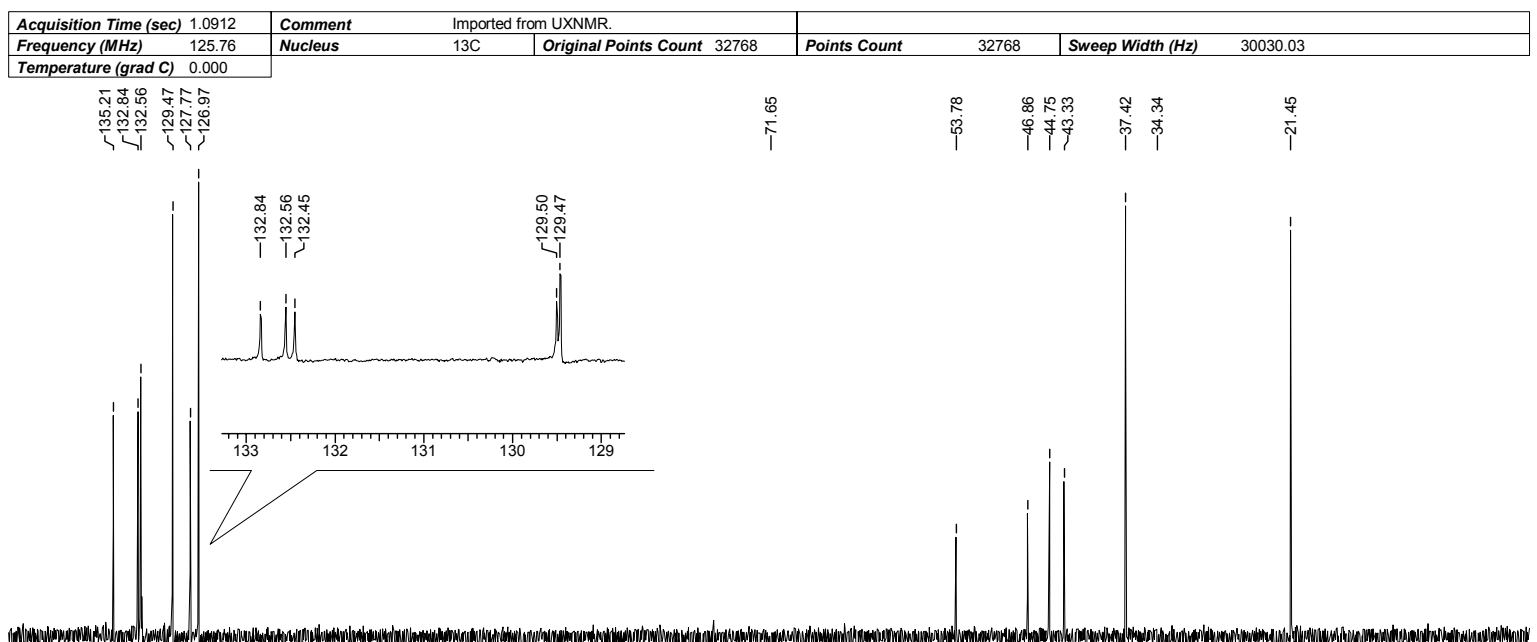

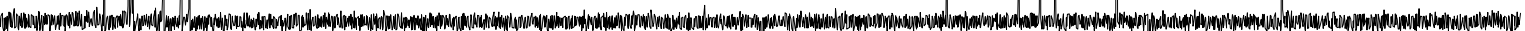

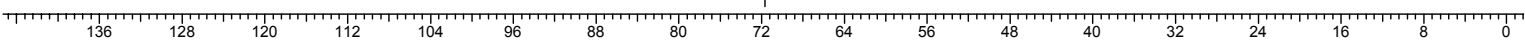

${ }^{*}$ Espectro de $\mathrm{RMN}{ }^{13} \mathrm{C}\left(125 \mathrm{MHz}, \mathrm{CDCl}_{3}\right) \mathrm{DEPT}-135$ do composto $172 . \uparrow\left(\mathrm{CH}, \mathrm{CH}_{3}\right), \downarrow \cdot\left(\mathrm{CH}_{2}\right)$

Figura 92: Espectros de $\mathrm{RMN}^{13} \mathrm{C}\left(125 \mathrm{MHz}, \mathrm{CDCl}_{3}\right)$ do composto 172. 
Tabela 49: Dados Espectroscópicos do Composto 172.

\begin{tabular}{|c|c|c|c|c|c|c|c|}
\hline $\mathrm{C}$ & $\delta \mathrm{C}(\mathrm{ppm})$ & $\delta \mathrm{H}(\mathrm{ppm})$ & $\begin{array}{l}\text { Integral } \\
\text { Relativa }\end{array}$ & Multiplicidade & Constantes de acoplamento $(\mathrm{Hz})$ & gCOSY & gHMQC \\
\hline 1 & 46,9 & 3,14 & $1 \mathrm{H}$ & dddt & $\mathrm{J}_{1 / 11}=9,6 ; \mathrm{J}_{1,2}=8,2 ; \mathrm{J}_{1,10}=2,8 ; \mathrm{J}_{1,9}=1,3 ; \mathrm{J}_{1,11^{\prime}}=1,3$ & $\mathrm{H}_{2}, \mathrm{H}_{9}, \mathrm{H}_{10}, \mathrm{H}_{11}, \mathrm{H}_{11}$ & $\mathrm{H}_{1}$ \\
\hline 2 & 53,8 & 4,15 & $1 \mathrm{H}$ & dt & $\mathrm{J}_{2 / 14}=10,1 ; \mathrm{J}_{2,1}=8,2 ; \mathrm{J}_{2,3}=8,2$ & $\mathrm{H}_{1}, \mathrm{H}_{3}, \mathrm{H}_{14}$ & $\mathrm{H}_{2}$ \\
\hline 3 & 135,2 & 5,50 & $1 \mathrm{H}$ & ddd & $J_{3 / 4}=11,6 ; J_{3 / 2}=8,2 ; J_{3 / 5}=2,1$ & $\mathrm{H}_{2}, \mathrm{H}_{4}, \mathrm{H}_{5}$ & $\mathrm{H}_{3}$ \\
\hline 4 & 127,8 & 5,81 & $1 \mathrm{H}$ & dt & $\mathrm{J}_{4 / 3}=11,6 ; \mathrm{J}_{4 / 6}=2,1 ; \mathrm{J}_{4 / 5}=2,1$ & $\mathrm{H}_{3}, \mathrm{H}_{5}, \mathrm{H}_{6}$ & $\mathrm{H}_{4}$ \\
\hline 5 & 129,5 & 6,01 & $1 \mathrm{H}$ & $\mathrm{dt}$ & $\mathrm{J}_{5 / 6}=11,4 ; \mathrm{J}_{5 / 4}=2,1 ; \mathrm{J}_{5 / 3}=2,1$ & $\mathrm{H}_{3}, \mathrm{H}_{4}, \mathrm{H}_{6}$ & $\mathrm{H}_{5}$ \\
\hline 6 & 132,6 & 5,36 & $1 \mathrm{H}$ & ddd & $\mathrm{J}_{6 / 5}=11,4 ; \mathrm{J}_{6 / 7}=8,9 ; \mathrm{J}_{6 / 4}=2,1$ & $\mathrm{H}_{4}, \mathrm{H}_{5}, \mathrm{H}_{7}$ & $\mathrm{H}_{6}$ \\
\hline 7 & 43,4 & 2,57 & $1 \mathrm{H}$ & dtd & $\mathrm{J}_{7 / 6}=8,9 ; \mathrm{J}_{7 / 12}=6,8 ; \mathrm{J}_{7 / 12^{\prime}}=6,8 ; \mathrm{J}_{7 / 8}=3,2$ & $\mathrm{H}_{5}, \mathrm{H}_{6}, \mathrm{H}_{8}, \mathrm{H}_{12}, \mathrm{H}_{12}$ & $\mathrm{H}_{7}$ \\
\hline 8 & 44,8 & 2,78 & $1 \mathrm{H}$ & dddt & $\mathrm{J}_{8 / 11}=9,6 ; \mathrm{J}_{8 / 7}=3,2 ; \mathrm{J}_{8 / 9}=2,8 ; \mathrm{J}_{8 / 10}=1,0 ; \mathrm{J}_{8 / 11^{\prime}}=1,0$ & $\mathrm{H}_{7}, \mathrm{H}_{9}, \mathrm{H}_{10}, \mathrm{H}_{11}, \mathrm{H}_{11}$ & $\mathrm{H}_{8}$ \\
\hline 9 & 132,8 & 5,76 & $1 \mathrm{H}$ & ddd & $\mathrm{J}_{9 / 10}=6,0 ; \mathrm{J}_{9 / 8}=2,8 ; \mathrm{J}_{9 / 1}=1,3$ & $\mathrm{H}_{1}, \mathrm{H}_{8}, \mathrm{H}_{10}$ & $\mathrm{H}_{9}$ \\
\hline 10 & 132,5 & 5,71 & $1 \mathrm{H}$ & dddd & $\mathrm{J}_{10 / 9}=6,0 ; \mathrm{J}_{10 / 1}=2,8 ; \mathrm{J}_{10 / 8}=1,0 ; \mathrm{J}_{10 / 11^{\prime}}=0,5$ & $\mathrm{H}_{1}, \mathrm{H}_{8}, \mathrm{H}_{9}, \mathrm{H}_{11^{\prime}}$ & $\mathrm{H}_{10}$ \\
\hline 11 & 34,3 & $\mathrm{H}_{(11)} 2,09$ & $1 \mathrm{H}$ & $\mathrm{dt}$ & $\mathrm{J}_{11 / 11^{\prime}}=13,9 ; \mathrm{J}_{11 / 1}=9,6 ; \mathrm{J}_{11 / 8}=9,6$ & $\mathrm{H}_{1}, \mathrm{H}_{8}, \mathrm{H}_{11^{\prime}}$ & $\mathrm{H}_{11}, \mathrm{H}_{11^{\prime}}$ \\
\hline & & $\mathrm{H}_{\left(11^{\prime}\right)} 1,76$ & $1 \mathrm{H}$ & dddd & $J_{11^{\prime} / 11}=13,9 ; J_{11^{\prime} / 1}=1,3 ; J_{11^{\prime} / 8}=1,0 ; J_{11^{\prime} / 10}=0,5$ & $\mathrm{H}_{1}, \mathrm{H}_{8}, \mathrm{H}_{10}, \mathrm{H}_{11}$ & \\
\hline 12 & 71,6 & $\mathrm{H}_{(12)} 4,11$ & $1 \mathrm{H}$ & $\mathrm{dd}$ & $J_{12 / 12^{\prime}}=9,3 ; J_{12 / 7}=6,8$ & $\mathrm{H}_{7}, \mathrm{H}_{12}$ & $\mathrm{H}_{12}, \mathrm{H}_{12}$ \\
\hline & & $\mathrm{H}_{\left(12^{\prime}\right)} 4,14$ & $1 \mathrm{H}$ & $\mathrm{dd}$ & $J_{12^{\prime} / 12}=9,3 ; J_{12 / 7}=6,8$ & $\mathrm{H}_{7}, \mathrm{H}_{12}$ & \\
\hline 13 & 37,4 & 3,01 & $3 \mathrm{H}$ & s & & & $\mathrm{H}_{13}$ \\
\hline & & $\mathrm{H}_{(14)} 4,84$ & $\mathrm{NH}$ & d & $\mathrm{J}_{14 / 2}=10,1$ & $\mathrm{H}_{2}$ & \\
\hline 15 & 138,0 & & & & & & \\
\hline 16 & 127,0 & 7,70 & $2 \mathrm{H}$ & d & $\mathrm{J}_{16 / 17}=8,3$ & $\mathrm{H}_{17}$ & $\mathrm{H}_{16}$ \\
\hline 17 & 129,5 & 7,27 & $2 \mathrm{H}$ & d & $J_{17 / 16}=8,3$ & $\mathrm{H}_{16}$ & $\mathrm{H}_{17}$ \\
\hline 18 & 143,2 & & & & & & \\
\hline 19 & 21,4 & 2,42 & $3 \mathrm{H}$ & s & & & $\mathrm{H}_{19}$ \\
\hline
\end{tabular}




\section{Composto 173}

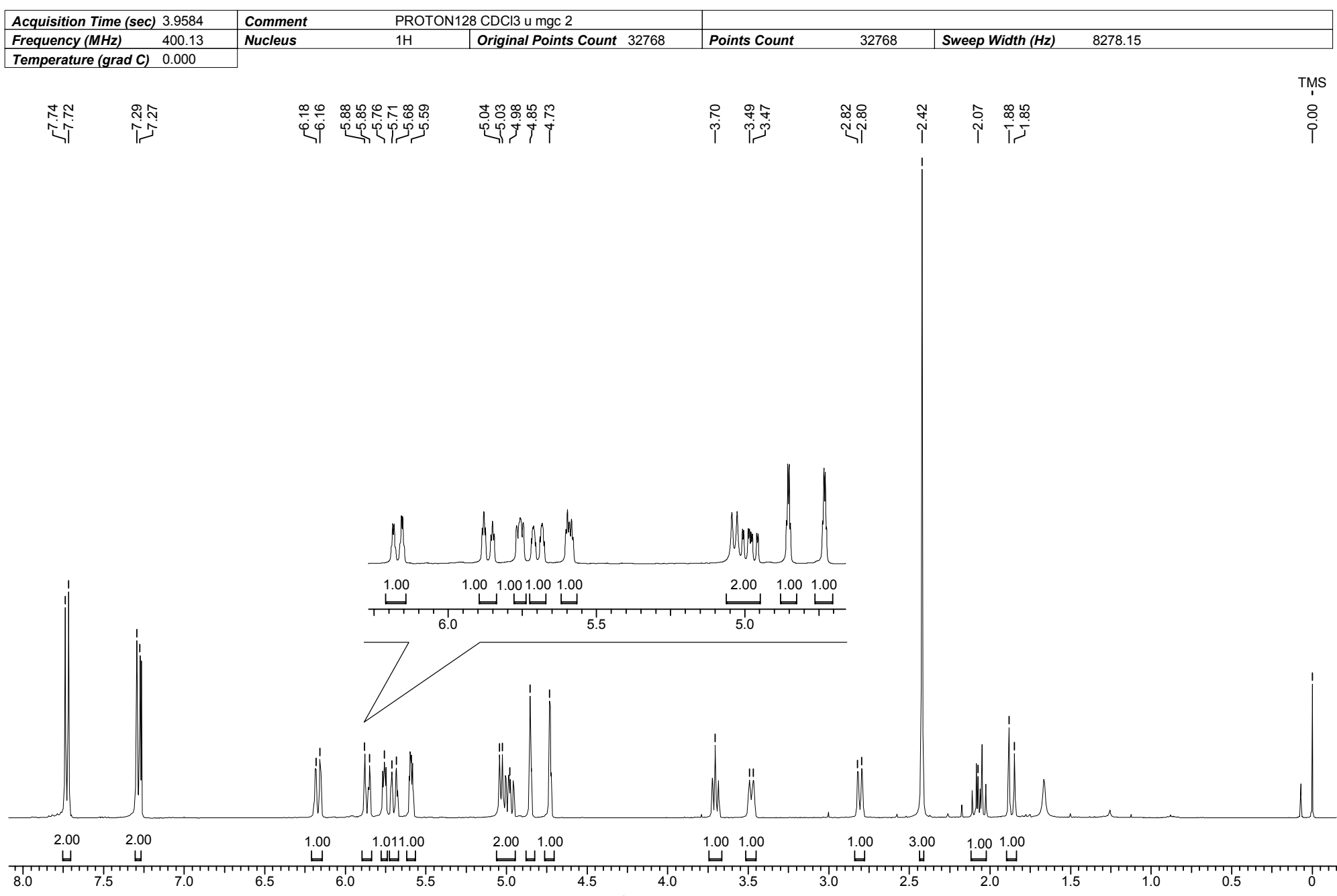

Figura 93: Espectro de $\mathrm{RMN}^{1}{ }^{1} \mathrm{H}\left(400 \mathrm{MHz}, \mathrm{CDCl}_{3}\right)$ do composto 173. 
Espectro de $R M N{ }^{13} \mathrm{C}\left\{{ }^{1} \mathrm{H}\right\}$

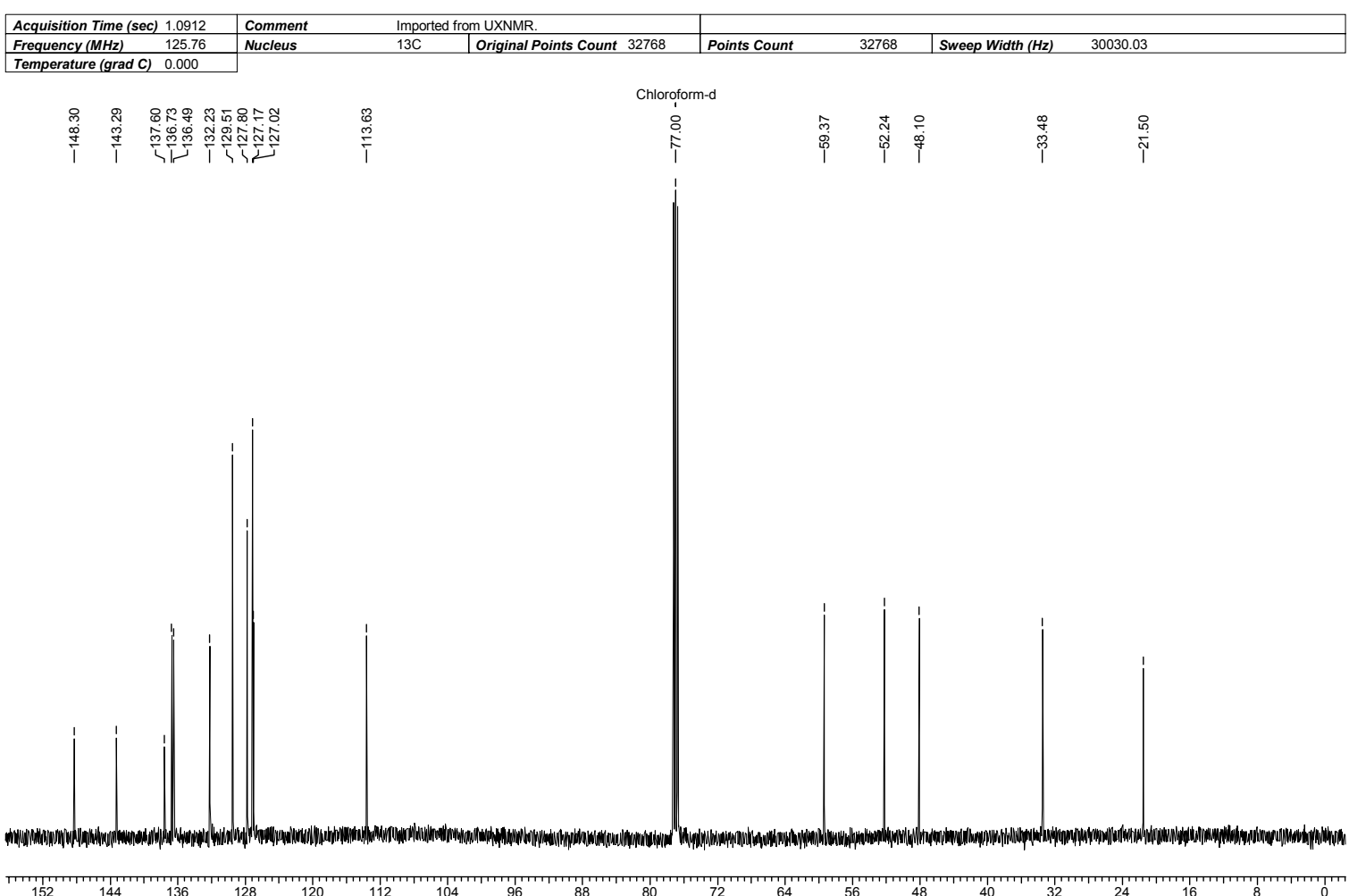

Espectro de RMN ${ }^{13} \mathrm{C}(\mathrm{DEPT}-135)$.

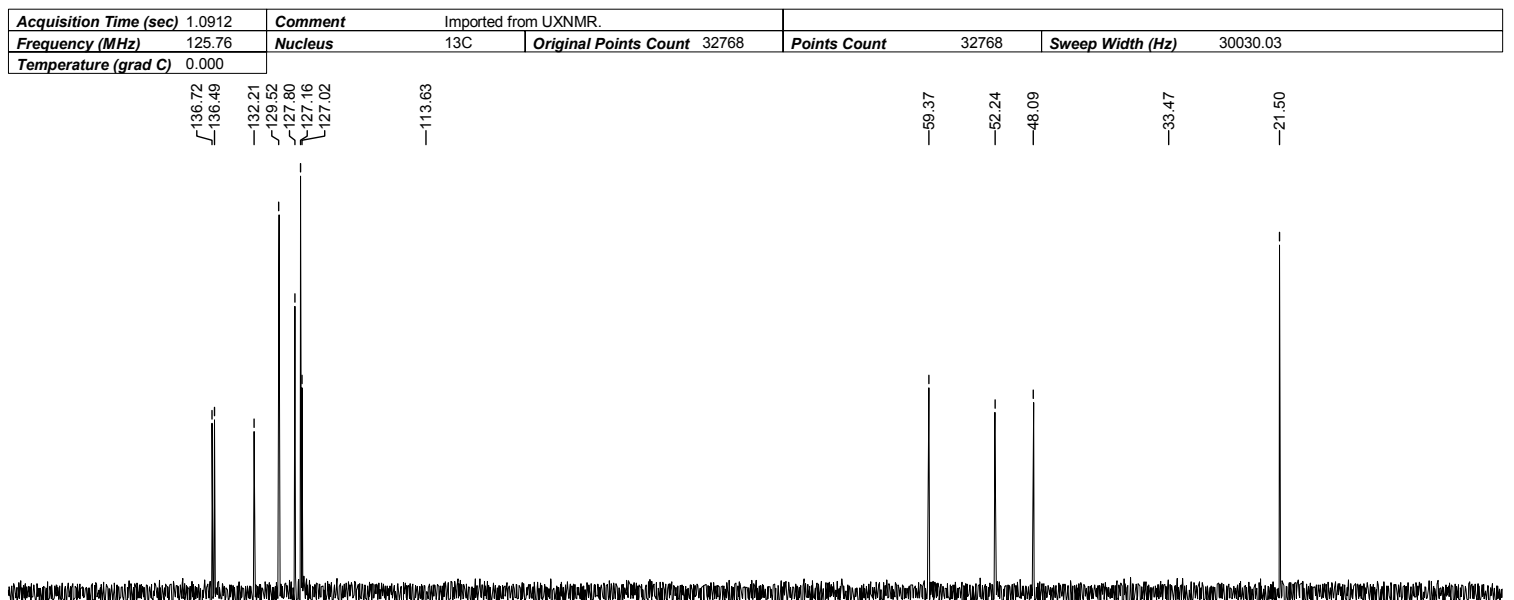

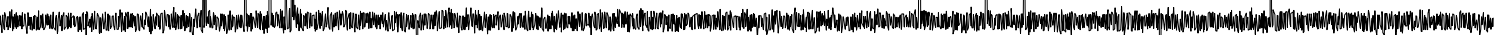

${ }_{152}$

${ }^{*}$ Espectro de $\mathrm{RMN}{ }^{13} \mathrm{C}\left(125 \mathrm{MHz}, \mathrm{CDCl}_{3}\right)$ DEPT-135 do composto $173 . \uparrow\left(\mathrm{CH}, \mathrm{CH}_{3}\right), \downarrow \cdot\left(\mathrm{CH}_{2}\right)$

Figura 94: Espectros de $\mathrm{RMN}^{13} \mathrm{C}\left(125 \mathrm{MHz}, \mathrm{CDCl}_{3}\right)$ do composto 173. 
Tabela 50: Dados Espectroscópicos do Composto 173.

\begin{tabular}{|c|c|c|c|c|c|c|c|c|}
\hline $\mathrm{C}$ & $\delta \mathrm{C}(\mathrm{ppm})$ & $\delta \mathrm{H}(\mathrm{ppm})$ & $\begin{array}{l}\text { Integral } \\
\text { Relativa }\end{array}$ & Multiplicidade & Constantes de acoplamento $(\mathrm{Hz})$ & gHMBC & $\mathrm{gCOSY}$ & gHMQC \\
\hline 1 & 52,2 & 2,81 & $1 \mathrm{H}$ & ddq & $\mathrm{J}_{1 / 11}=9,6 ; \mathrm{J}_{1 / 10}=2,0 ; \mathrm{J}_{1 / 2}=1,0 ; \mathrm{J}_{1 / 9}=1,0 ; \mathrm{J}_{1 / 11^{\prime}}=1,0$ & $\mathrm{H}_{2}, \mathrm{H}_{3}, \mathrm{H}_{8}, \mathrm{H}_{9}, \mathrm{H}_{10}, \mathrm{H}_{11}, \mathrm{H}_{11^{\prime}}$ & $\mathrm{H}_{2}, \mathrm{H}_{9}, \mathrm{H}_{10}, \mathrm{H}_{11}, \mathrm{H}_{11^{\prime}}$ & $\mathrm{H}_{1}$ \\
\hline 2 & 59,4 & 3,70 & $1 \mathrm{H}$ & $\mathrm{tt}$ & $\mathrm{J}_{2 / 14}=7,5 ; \mathrm{J}_{2 / 3}=7,5 ; \mathrm{J}_{2 / 1}=1,0 ; \mathrm{J}_{2 / 4}=1,0$ & $\mathrm{H}_{1}, \mathrm{H}_{3}, \mathrm{H}_{4}, \mathrm{H}_{10}, \mathrm{H}_{11}, \mathrm{H}_{11}$ & $\mathrm{H}_{1}, \mathrm{H}_{3}, \mathrm{H}_{4}, \mathrm{H}_{14}$ & $\mathrm{H}_{2}$ \\
\hline 3 & 132,2 & 4,98 & $1 \mathrm{H}$ & ddd & $\mathrm{J}_{3 / 4}=11,6 ; \mathrm{J}_{3 / 2}=7,5 ; \mathrm{J}_{3 / 5}=1,8$ & $\mathrm{H}_{1}, \mathrm{H}_{2}, \mathrm{H}_{4}, \mathrm{H}_{5}$ & $\mathrm{H}_{2}, \mathrm{H}_{4}, \mathrm{H}_{5}$ & $\mathrm{H}_{3}$ \\
\hline 4 & 127,8 & 5,70 & $1 \mathrm{H}$ & dddd & $\mathrm{J}_{4 / 3}=11,6 ; \mathrm{J}_{4 / 5}=2,5 ; \mathrm{J}_{4 / 6}=1,8 ; \mathrm{J}_{4 / 2}=1,0$ & $\mathrm{H}_{2}, \mathrm{H}_{3}, \mathrm{H}_{5}, \mathrm{H}_{6}$ & $\mathrm{H}_{2}, \mathrm{H}_{3}, \mathrm{H}_{5}, \mathrm{H}_{6}$ & $\mathrm{H}_{4}$ \\
\hline 5 & 127,0 & 5,86 & $1 \mathrm{H}$ & ddd & $\mathrm{J}_{5 / 6}=11,6 ; \mathrm{J}_{5 / 4}=2,5 ; \mathrm{J}_{5 / 3}=1,8$ & $\mathrm{H}_{3}, \mathrm{H}_{4}, \mathrm{H}_{6}$ & $\mathrm{H}_{3}, \mathrm{H}_{4}, \mathrm{H}_{6}$ & $\mathrm{H}_{5}$ \\
\hline 6 & 136,5 & 6,17 & $1 \mathrm{H}$ & $\mathrm{dq}$ & $\mathrm{J}_{6 / 5}=11,6 ; \mathrm{J}_{6 / 4}=\mathrm{J}_{6 / 12}=\mathrm{J}_{6 / 12^{\prime}}=1,8$ & $\mathrm{H}_{4}, \mathrm{H}_{5}, \mathrm{H}_{7}, \mathrm{H}_{12}, \mathrm{H}_{12}$ & $\left(\mathrm{H}_{3}\right), \mathrm{H}_{4}, \mathrm{H}_{5}, \mathrm{H}_{12}, \mathrm{H}_{12^{\prime}}$ & $\mathrm{H}_{6}$ \\
\hline 7 & 148,3 & & & & & $\mathrm{H}_{5}, \mathrm{H}_{6}, \mathrm{H}_{8}, \mathrm{H}_{9}, \mathrm{H}_{11}, \mathrm{H}_{11}, \mathrm{H}_{12}, \mathrm{H}_{12}$ & & \\
\hline 8 & 48,1 & 3,48 & $1 \mathrm{H}$ & dddtd & $\mathrm{J}_{8 / 11}=9,6 ; \mathrm{J}_{8 / 9}=3,0 ; \mathrm{J}_{8 / 10}=2,0 ; \mathrm{J}_{8 / 12}=\mathrm{J}_{8 / 12^{2}}=1,8 ; \mathrm{J}_{8 / 11^{\prime}}=1,0$ & $\mathrm{H}_{1}, \mathrm{H}_{6}, \mathrm{H}_{9}, \mathrm{H}_{10}, \mathrm{H}_{11}, \mathrm{H}_{11^{\prime}}, \mathrm{H}_{12}, \mathrm{H}_{12}$ & $\mathrm{H}_{9}, \mathrm{H}_{10}, \mathrm{H}_{11}, \mathrm{H}_{11}, \mathrm{H}_{12}, \mathrm{H}_{12}$ & $\mathrm{H}_{8}$ \\
\hline 9 & 136,7 & 5,76 & $1 \mathrm{H}$ & ddt & $\mathrm{J}_{9 / 10}=5,6 ; \mathrm{J}_{9 / 8}=3,0 ; \mathrm{J}_{9 / 1}=\mathrm{J}_{9 / 11^{\prime}}=1,0$ & $\mathrm{H}_{1}, \mathrm{H}_{8}, \mathrm{H}_{10}, \mathrm{H}_{11}, \mathrm{H}_{11}$ & $\mathrm{H}_{1}, \mathrm{H}_{8}, \mathrm{H}_{10}, \mathrm{H}_{11}$ & $\mathrm{H}_{9}$ \\
\hline 10 & 127,8 & 5,59 & & $\mathrm{dtd}$ & $J_{10 / 9}=5,6 ; J_{10 / 1}=2,0 ; J_{10 / 8}=2,0 ; J_{10 / 11^{\prime}}=1,0$ & $\mathrm{H}_{1}, \mathrm{H}_{2}, \mathrm{H}_{8}, \mathrm{H}_{9}, \mathrm{H}_{11}, \mathrm{H}_{11}$ & $\mathrm{H}_{1}, \mathrm{H}_{8}, \mathrm{H}_{9}, \mathrm{H}_{11^{\prime}}$ & $\mathrm{H}_{10}$ \\
\hline 11 & 33,5 & $\mathrm{H}_{(11)} 2,07$ & & $\mathrm{dt}$ & $J_{11 / 11^{\prime}}=13,9 ; J_{11 / 1}=9,6 ; J_{11 / 8}=9,6$ & $\mathrm{H}_{1}, \mathrm{H}_{2}, \mathrm{H}_{8}, \mathrm{H}_{9}, \mathrm{H}_{10}$ & $\mathrm{H}_{1}, \mathrm{H}_{8}, \mathrm{H}_{11^{\prime}}$ & $\mathrm{H}_{11}, \mathrm{H}_{11^{\prime}}$ \\
\hline \multirow{4}{*}{12} & \multirow{4}{*}{113,6} & & $1 \mathrm{H}$ & dquint & $\mathrm{J}_{11^{\prime} / 11}=13,9 ; \mathrm{J}_{11^{\prime} / 10}=\mathrm{J}_{11^{\prime} / 1}=\mathrm{J}_{11^{\prime} / 9}=\mathrm{J}_{11^{\prime} / 8}=1,0$ & \multirow{4}{*}{$\mathrm{H}_{6}, \mathrm{H}_{8}$} & $\mathrm{H}_{1}, \mathrm{H}_{8}, \mathrm{H}_{9}, \mathrm{H}_{10}, \mathrm{H}_{11}$ & \multirow{4}{*}{$\mathrm{H}_{12}, \mathrm{H}_{12^{\prime}}$} \\
\hline & & $\mathrm{H}_{\left(12^{\prime}\right)} 4,73$ & $1 \mathrm{H}$ & $\mathrm{q}$ & $\mathrm{J}_{12^{\prime} / 12}=\mathrm{J}_{12^{\prime} / 8}=\mathrm{J}_{12^{\prime} / 6}=1,8$ & & $\mathrm{H}_{6}, \mathrm{H}_{8}, \mathrm{H}_{12}$ & \\
\hline & & $\mathrm{H}_{(12)} 4,85$ & $1 \mathrm{H}$ & q & $\mathrm{J}_{12 / 12^{2}}=\mathrm{J}_{12 / 8}=\mathrm{J}_{12 / 6}=1,8$ & & $\mathrm{H}_{6}, \mathrm{H}_{8}, \mathrm{H}_{12^{\prime}}$ & \\
\hline & & $\mathrm{H}_{(14)} 5,03$ & $\mathrm{NH}$ & $\mathrm{d}$ & $\mathrm{J}_{14 / 2}=7,5$ & & $\mathrm{H}_{2}$ & \\
\hline 15 & 137,6 & & & & & $\mathrm{H}_{16}, \mathrm{H}_{17}$ & & \\
\hline 16 & 127,0 & 7,73 & $2 \mathrm{H}$ & $\mathrm{d}$ & $\mathrm{J}_{16 / 17}=8,4$ & $\mathrm{H}_{17}$ & $\mathrm{H}_{17}$ & $\mathrm{H}_{16}$ \\
\hline 17 & 129,5 & 7,28 & $2 \mathrm{H}$ & $\mathrm{d}$ & $\mathrm{J}_{17 / 16}=8,4$ & $\mathrm{H}_{16}$ & $\mathrm{H}_{16}$ & $\mathrm{H}_{17}$ \\
\hline 18 & 143,3 & & & & & $\mathrm{H}_{16}, \mathrm{H}_{17}, \mathrm{H}_{19}$ & & \\
\hline 19 & 21,5 & 2,42 & $3 \mathrm{H}$ & $\mathrm{s}$ & & $\mathrm{H}_{17}$ & & $\mathrm{H}_{19}$ \\
\hline
\end{tabular}

em parênteses ( ) : "acoplamentos" que são observados no experimento de ${ }^{1} \mathrm{H}-{ }^{1} \mathrm{H}$ COSY, mas que não são medidos no experimento $1 \mathrm{D}$ de ${ }^{1} \mathrm{H}$ nem no Jres. 
Tabela 51: Experimentos de NOE-DIFF com o Composto 173.

\begin{tabular}{cc}
\hline Hidrogênios Irradiados & Hidrogênios com efeito NOE \\
\hline $\mathrm{H}_{2}$ & $\mathrm{H}_{1} ; \mathrm{H}_{11}$ \\
$\mathrm{H}_{8}$ & $\mathrm{H}_{9} ; \mathrm{H}_{11} ; \mathrm{H}_{11} ; \mathrm{H}_{12}$ \\
$\mathrm{H}_{10}$ & $\mathrm{H}_{1}$ \\
$\mathrm{H}_{11}$ & $\mathrm{H}_{1} ; \mathrm{H}_{2} ; \mathrm{H}_{8}$ \\
\hline
\end{tabular}

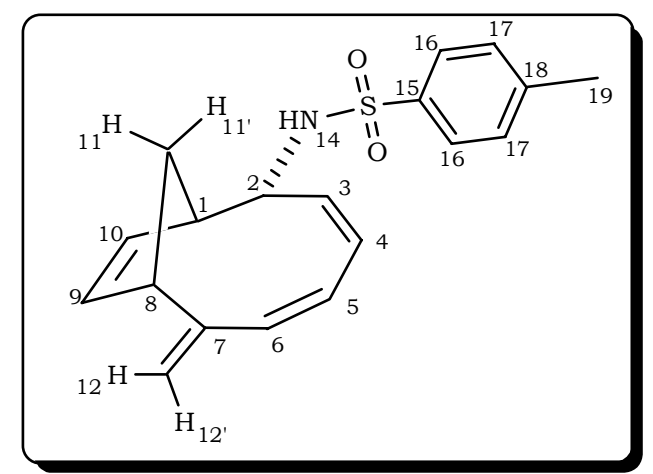




\section{Composto 174}

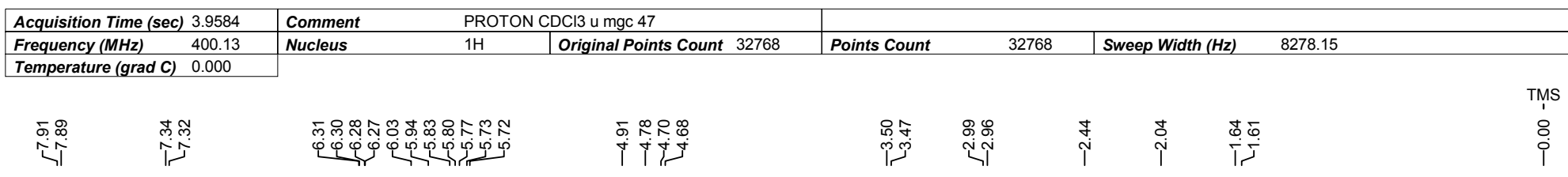
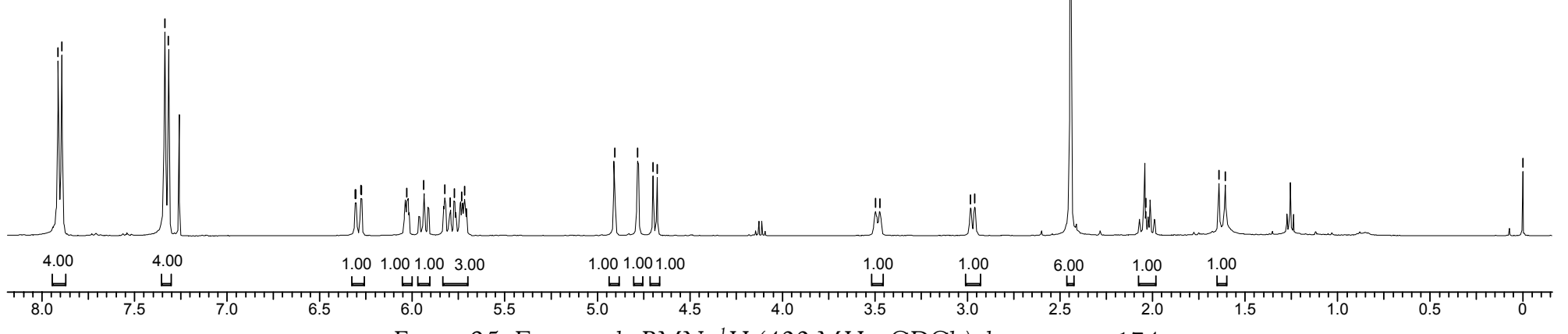

Figura 95: Espectro de $\mathrm{RMN}-{ }^{1} \mathrm{H}\left(400 \mathrm{MHz}, \mathrm{CDCl}_{3}\right)$ do composto 174 . 
Espectro de $R M N{ }^{13} \mathrm{C}\left\{{ }^{1} \mathrm{H}\right\}$

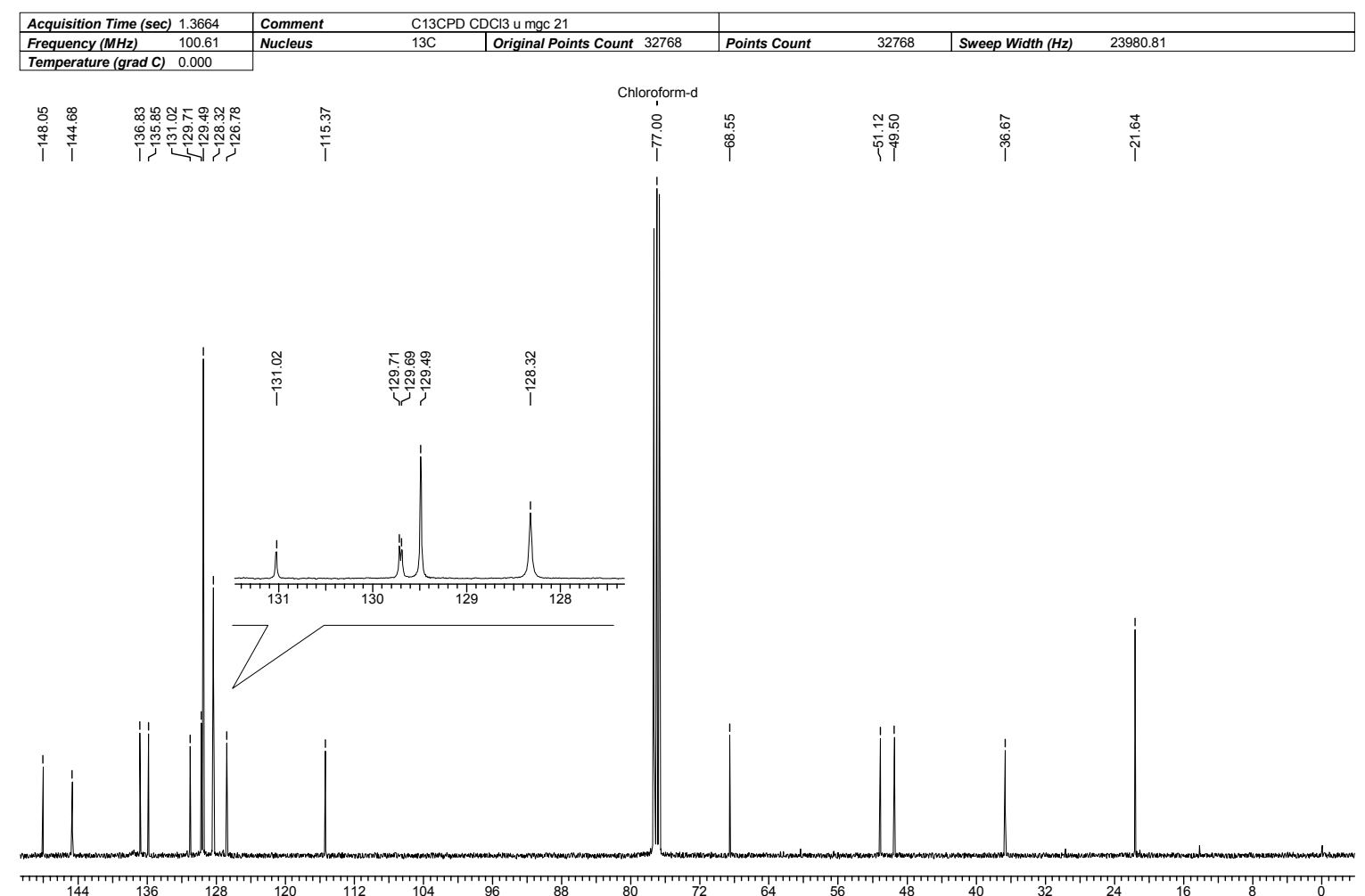

Espectro de RMN ${ }^{13} \mathrm{C}(\mathrm{DEPT}-135)$.

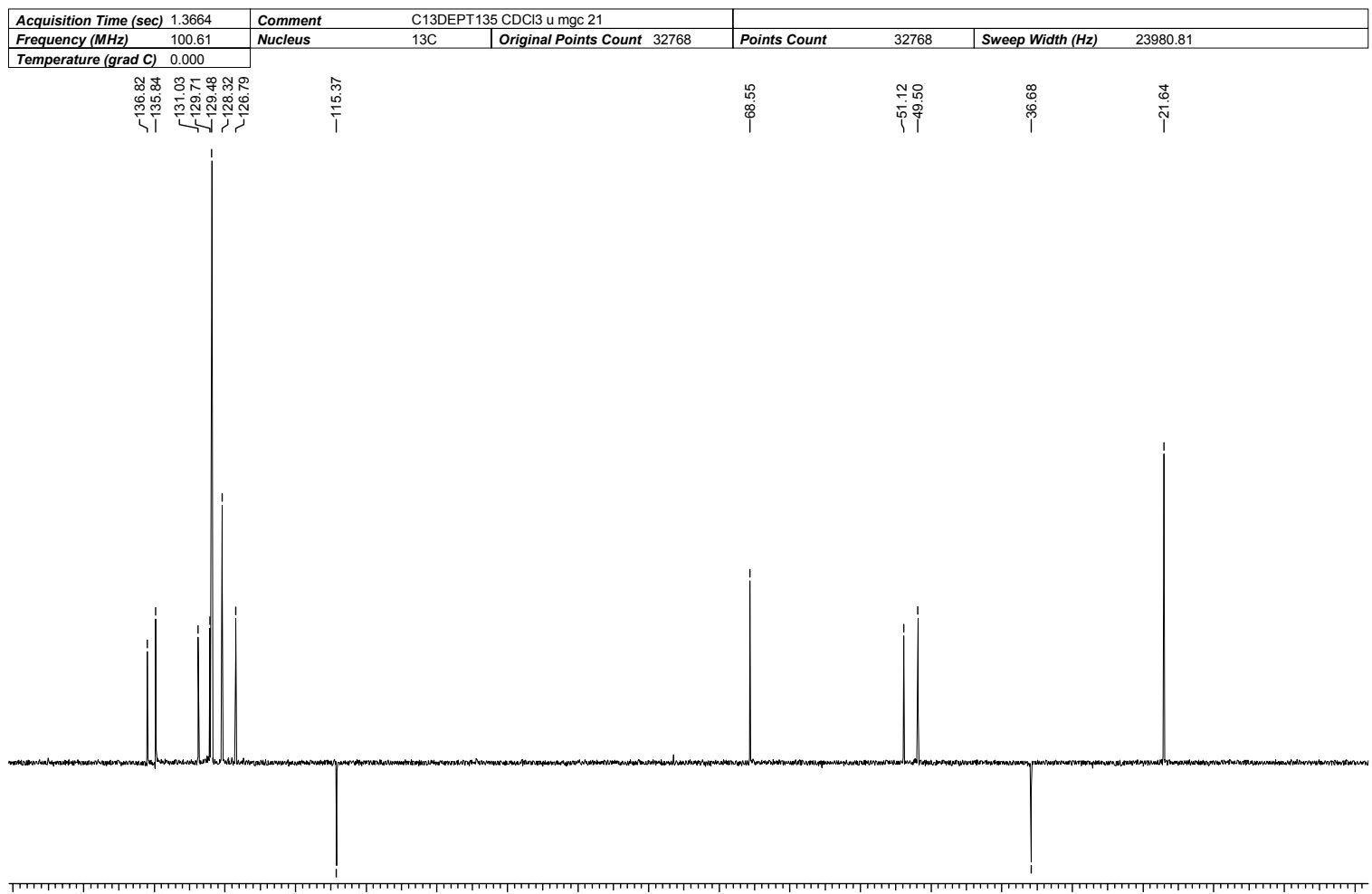

* Espectro de $\mathrm{RMN}^{13} \mathrm{C}\left(100 \mathrm{MHz}, \mathrm{CDCl}_{3}\right) \mathrm{DEPT}-135$ do composto $174 . \uparrow\left(\mathrm{CH}, \mathrm{CH}_{3}\right), \downarrow .\left(\mathrm{CH}_{2}\right)$

Figura 96: Espectros de RMN ${ }^{13} \mathrm{C}\left(100 \mathrm{MHz}, \mathrm{CDCl}_{3}\right)$ do composto 174. 
Tabela 52: Dados Espectroscópicos do Composto 174

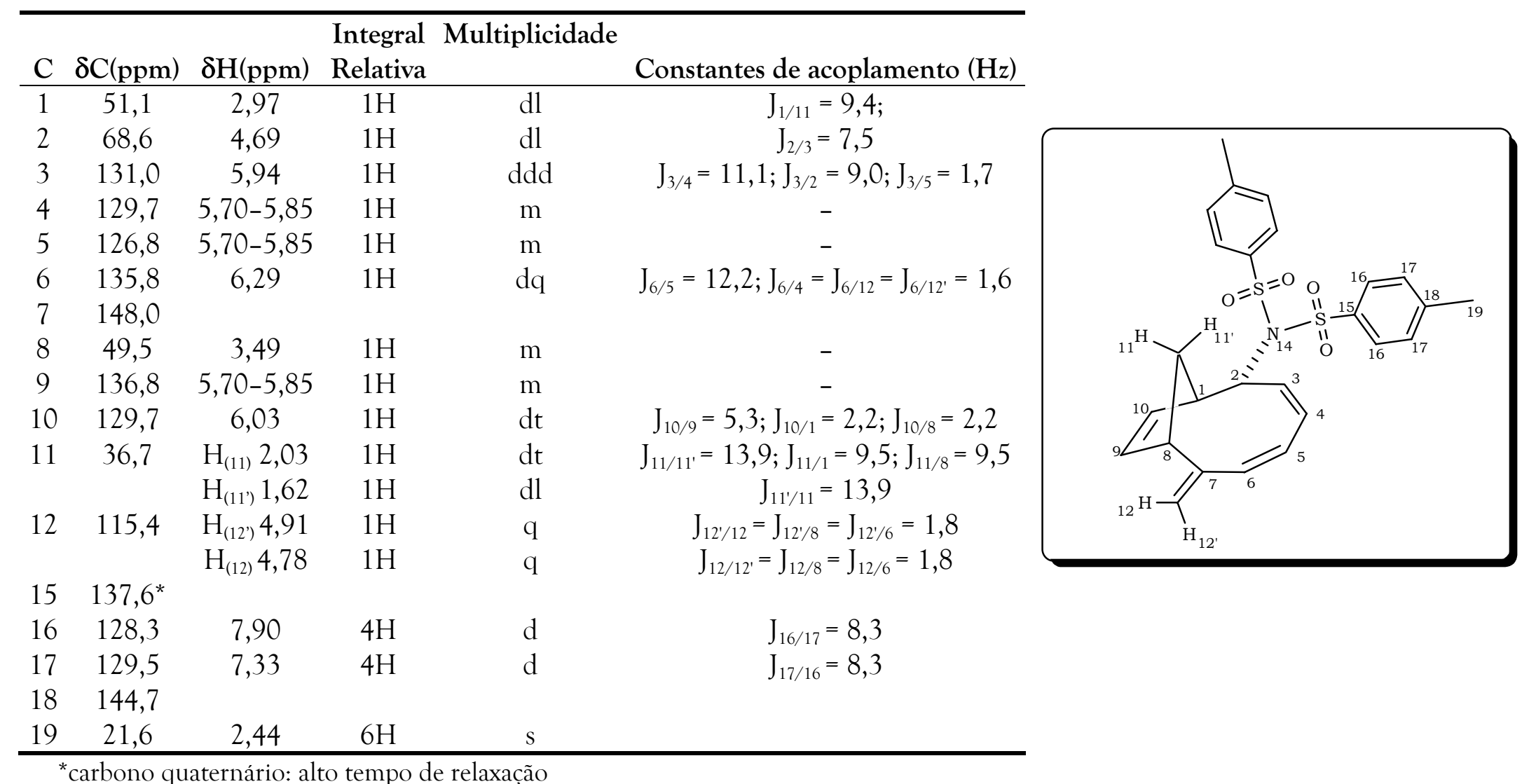

*carbono quaternário: alto tempo de relaxação 


\section{Composto 180}

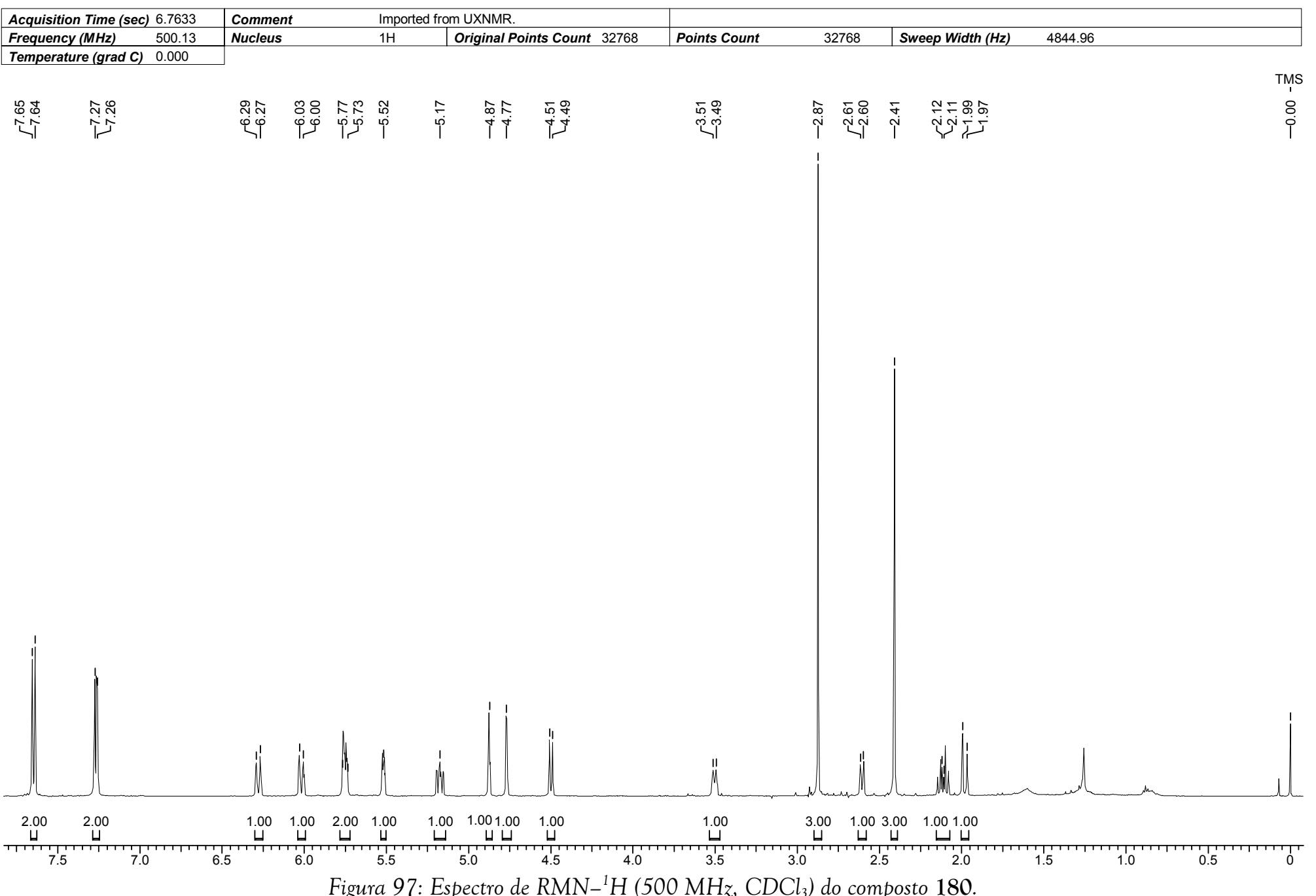

Figura 97: Espectro de $\mathrm{RMN}-{ }^{1} \mathrm{H}\left(500 \mathrm{MHz}, \mathrm{CDCl}_{3}\right)$ do composto 180. 
Espectro de $R M N{ }^{13} \mathrm{C}\left\{{ }^{1} \mathrm{H}\right\}$

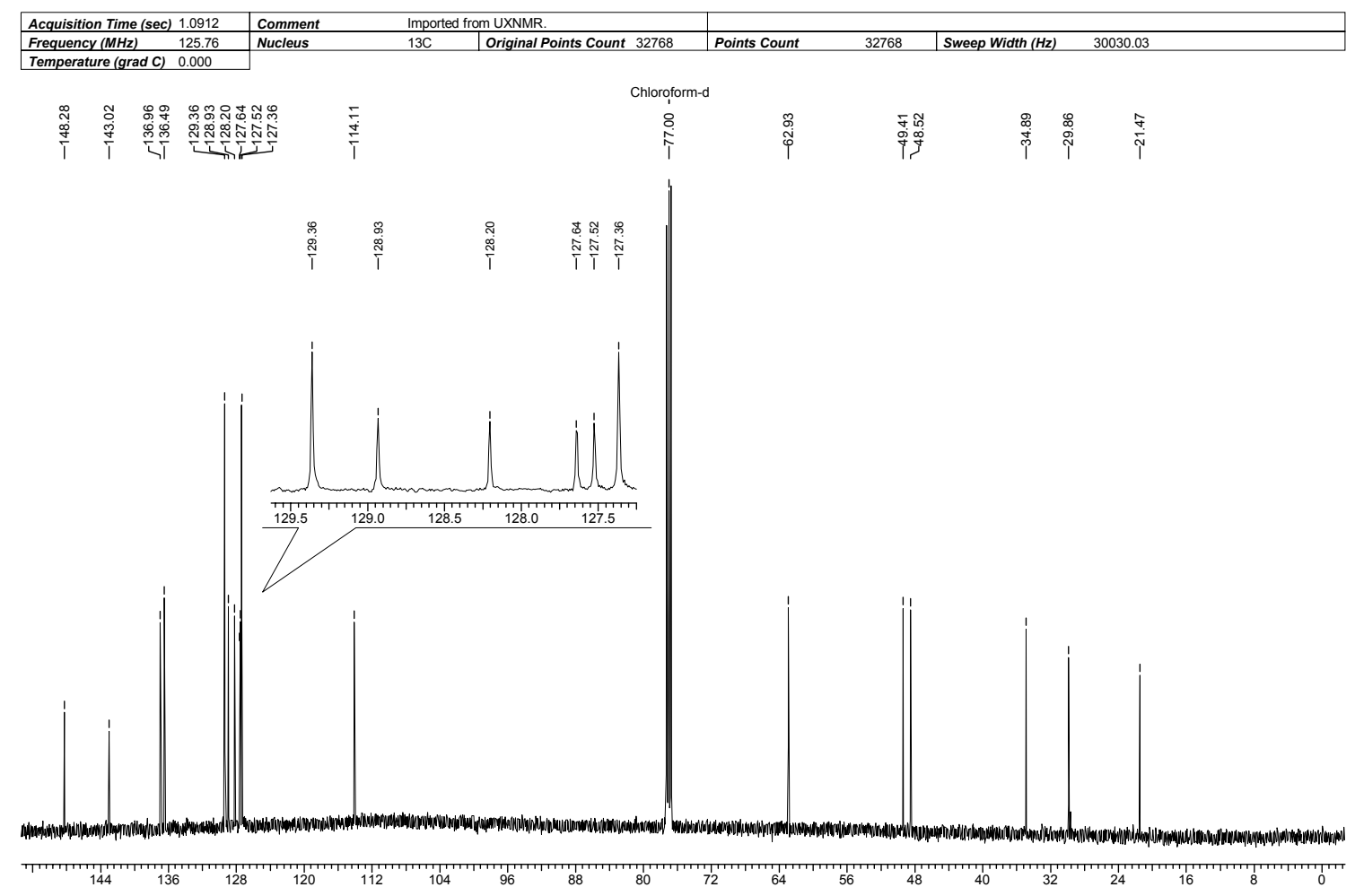

Espectro de RMN ${ }^{13} \mathrm{C}(\mathrm{DEPT}-135)$.

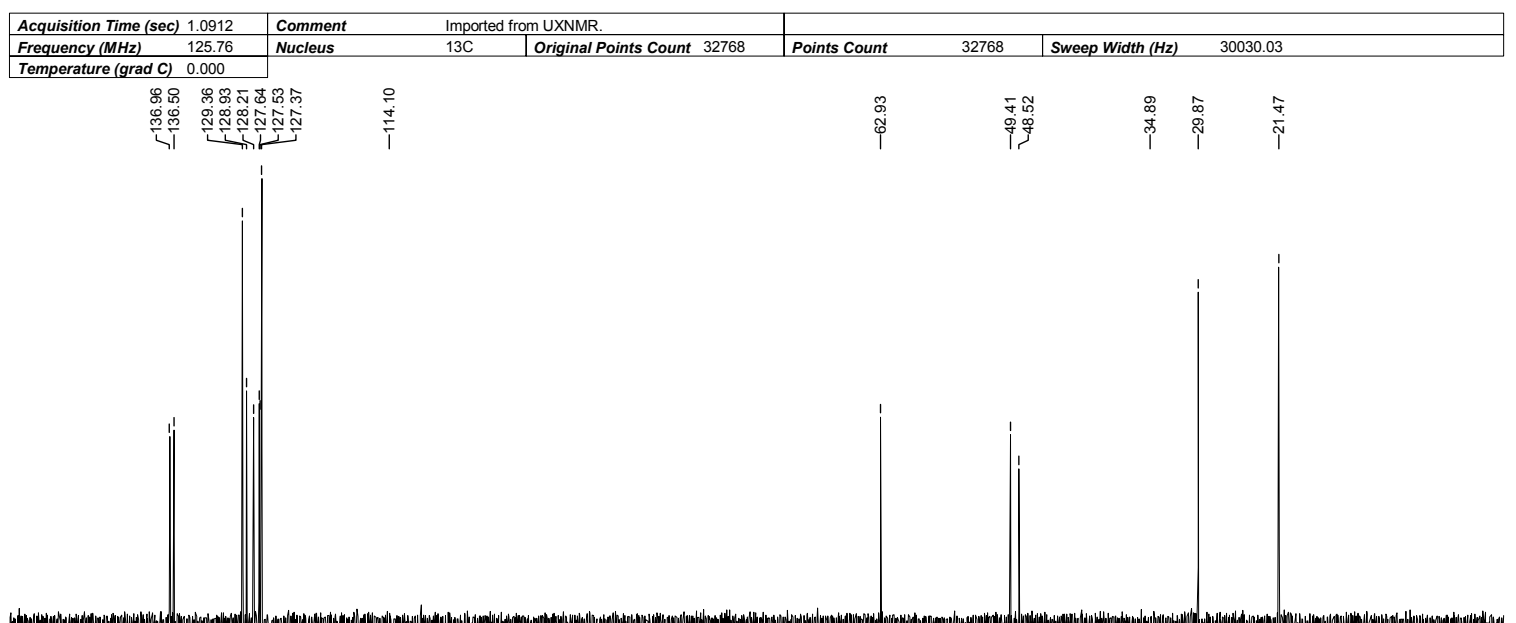

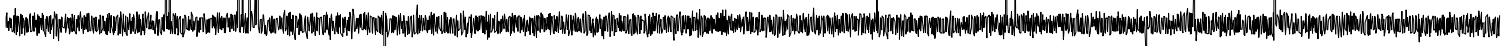

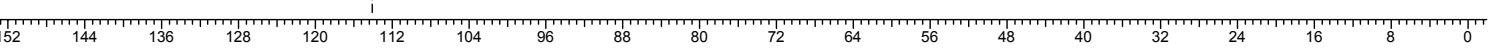

${ }^{*}$ Espectro de $\mathrm{RMN}{ }^{13} \mathrm{C}\left(125 \mathrm{MHz}, \mathrm{CDCl}_{3}\right)$ DEPT-135 do composto $180 . \uparrow\left(\mathrm{CH}, \mathrm{CH}_{3}\right), \downarrow \cdot\left(\mathrm{CH}_{2}\right)$

Figura 98: Espectros de $\mathrm{RMN}^{13} \mathrm{C}\left(125 \mathrm{MHz}, \mathrm{CDCl}_{3}\right)$ do composto 180 
Tabela 53: Dados Espectroscópicos do Composto 180.

\begin{tabular}{|c|c|c|c|c|c|c|c|}
\hline $\mathrm{C}$ & $\delta \mathrm{C}(\mathrm{ppm})$ & $\delta \mathrm{H}(\mathrm{ppm})$ & $\begin{array}{l}\text { Integral } \\
\text { Relativa }\end{array}$ & Multiplicidade & Constantes de acoplamento $(\mathrm{Hz})$ & gCOSY & gHMQC \\
\hline 1 & 49,4 & 2,60 & $1 \mathrm{H}$ & ddq & $\mathrm{J}_{1 / 11}=9,5 ; \mathrm{J}_{1 / 10}=2,2 ; \mathrm{J}_{1 / 2}=1,0 ; \mathrm{J}_{1 / 9}=1,0 ; \mathrm{J}_{1 / 11^{\prime}}=1,0$ & $\mathrm{H}_{2}, \mathrm{H}_{9}, \mathrm{H}_{10}, \mathrm{H}_{11}, \mathrm{H}_{11}$ & $\mathrm{H}_{1}$ \\
\hline 2 & 62,9 & 4,50 & $1 \mathrm{H}$ & $\mathrm{dt}$ & $\mathrm{J}_{2 / 3}=8,7 ; \mathrm{J}_{2 / 1}=1,0 ; \mathrm{J}_{2 / 4}=1,0$ & $\mathrm{H}_{1}, \mathrm{H}_{3}, \mathrm{H}_{4}$ & $\mathrm{H}_{2}$ \\
\hline 3 & 127,5 & 5,17 & $1 \mathrm{H}$ & ddd & $\mathrm{J}_{3 / 4}=11,4 ; \mathrm{J}_{3 / 2}=8,7 ; \mathrm{J}_{3 / 5}=1,8$ & $\mathrm{H}_{2}, \mathrm{H}_{4}, \mathrm{H}_{5}$ & $\mathrm{H}_{3}$ \\
\hline 4 & 128,2 & $5,73-5,77$ & $2 \mathrm{H}$ & $\mathrm{m}$ & - & $\mathrm{H}_{2}, \mathrm{H}_{3}, \mathrm{H}_{5}, \mathrm{H}_{6}$ & $\mathrm{H}_{4}$ \\
\hline 5 & 127,6 & 6,02 & $1 \mathrm{H}$ & ddd & $\mathrm{J}_{5 / 6}=11,9 ; \mathrm{J}_{5 / 4}=2,5 ; \mathrm{J}_{5 / 3}=1,8$ & $\mathrm{H}_{3}, \mathrm{H}_{4}, \mathrm{H}_{6}$ & $\mathrm{H}_{5}$ \\
\hline 6 & 136,5 & 6,28 & $1 \mathrm{H}$ & $\mathrm{dq}$ & $\mathrm{J}_{6 / 5}=11,9 ; \mathrm{J}_{6 / 4}=\mathrm{J}_{6 / 12}=\mathrm{J}_{6 / 12^{\prime}}=1,8$ & $\mathrm{H}_{4}, \mathrm{H}_{5}, \mathrm{H}_{12}, \mathrm{H}_{12}$ & $\mathrm{H}_{6}$ \\
\hline 7 & 148,3 & - & - & & - & - & - \\
\hline 8 & 48,5 & $3,48-3,52$ & $1 \mathrm{H}$ & $\mathrm{m}$ & - & $\mathrm{H}_{9}, \mathrm{H}_{10}, \mathrm{H}_{11}, \mathrm{H}_{11^{\prime}}, \mathrm{H}_{12}, \mathrm{H}_{12^{\prime}}$ & $\mathrm{H}_{8}$ \\
\hline 9 & 137,0 & $5,73-5,77$ & $2 \mathrm{H}$ & $\mathrm{m}$ & - & $\mathrm{H}_{1}, \mathrm{H}_{8}, \mathrm{H}_{10}$ & $\mathrm{H}_{9}$ \\
\hline 10 & 128,9 & 5,52 & $1 \mathrm{H}$ & ddd & $\mathrm{J}_{10 / 9}=5,6 ; \mathrm{J}_{10 / 1}=2,2 ; \mathrm{J}_{10 / 8}=1,5$ & $\mathrm{H}_{1}, \mathrm{H}_{8}, \mathrm{H}_{9}$ & $\mathrm{H}_{10}$ \\
\hline \multirow[t]{2}{*}{11} & 34,9 & $\mathrm{H}_{(11)} 2,11$ & $1 \mathrm{H}$ & $\mathrm{dt}$ & $\mathrm{J}_{11 / 11^{\prime}}=13,8 ; \mathrm{J}_{11 / 1}=9,5 ; \mathrm{J}_{11 / 8}=9,5$ & $\mathrm{H}_{1}, \mathrm{H}_{8}, \mathrm{H}_{11}$ & $\mathrm{H}_{11}, \mathrm{H}_{11}$ \\
\hline & & $\mathrm{H}_{\left(11^{\prime}\right)} 1,98$ & $1 \mathrm{H}$ & $\mathrm{dt}$ & $\mathrm{J}_{11^{\prime} / 11}=13,8 ; \mathrm{J}_{11^{\prime} / 1}=\mathrm{J}_{11^{\prime} / 8}=1,0$ & $\mathrm{H}_{1}, \mathrm{H}_{8}, \mathrm{H}_{11}$ & \\
\hline \multirow[t]{2}{*}{12} & 114,1 & $\mathrm{H}_{\left(12^{\prime}\right)} 4,77$ & $1 \mathrm{H}$ & q & $\mathrm{J}_{12 / 12^{\prime}}=\mathrm{J}_{12 / 8}=\mathrm{J}_{12 / 6}=1,8$ & $\mathrm{H}_{6}, \mathrm{H}_{8}, \mathrm{H}_{12}$ & $\mathrm{H}_{12}, \mathrm{H}_{12}$ \\
\hline & & $\mathrm{H}_{(12)} 4,87$ & $1 \mathrm{H}$ & q & $\mathrm{J}_{12^{\prime} / 12}=\mathrm{J}_{12^{\prime} / 8}=\mathrm{J}_{12^{\prime} / 6}=1,8$ & $\mathrm{H}_{6}, \mathrm{H}_{8}, \mathrm{H}_{12}$ & \\
\hline 14 & 29,9 & 2,87 & $3 \mathrm{H}$ & $\mathrm{s}$ & - & - & $\mathrm{H}_{14}$ \\
\hline 15 & 136,5 & - & - & & - & - & \\
\hline 16 & 127,4 & 7,65 & $2 \mathrm{H}$ & d & $\mathrm{J}_{16 / 17}=8,3$ & $\mathrm{H}_{17}$ & $\mathrm{H}_{16}$ \\
\hline 17 & 129,4 & 7,27 & $2 \mathrm{H}$ & d & $\mathrm{J}_{17 / 16}=8,3$ & $\mathrm{H}_{16}$ & $\mathrm{H}_{17}$ \\
\hline 18 & 143,0 & & & & - & & \\
\hline 19 & 21,5 & 2,41 & $3 \mathrm{H}$ & s & - & & $\mathrm{H}_{19}$ \\
\hline
\end{tabular}

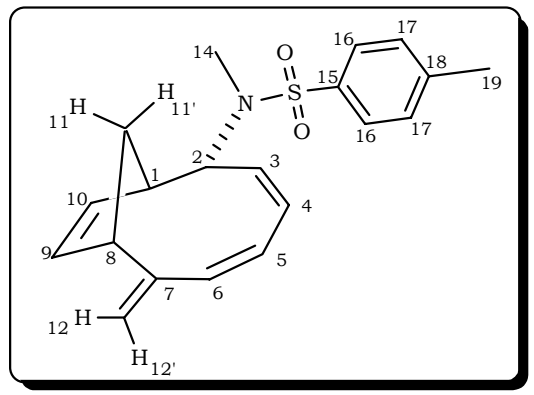




\section{Composto 183}

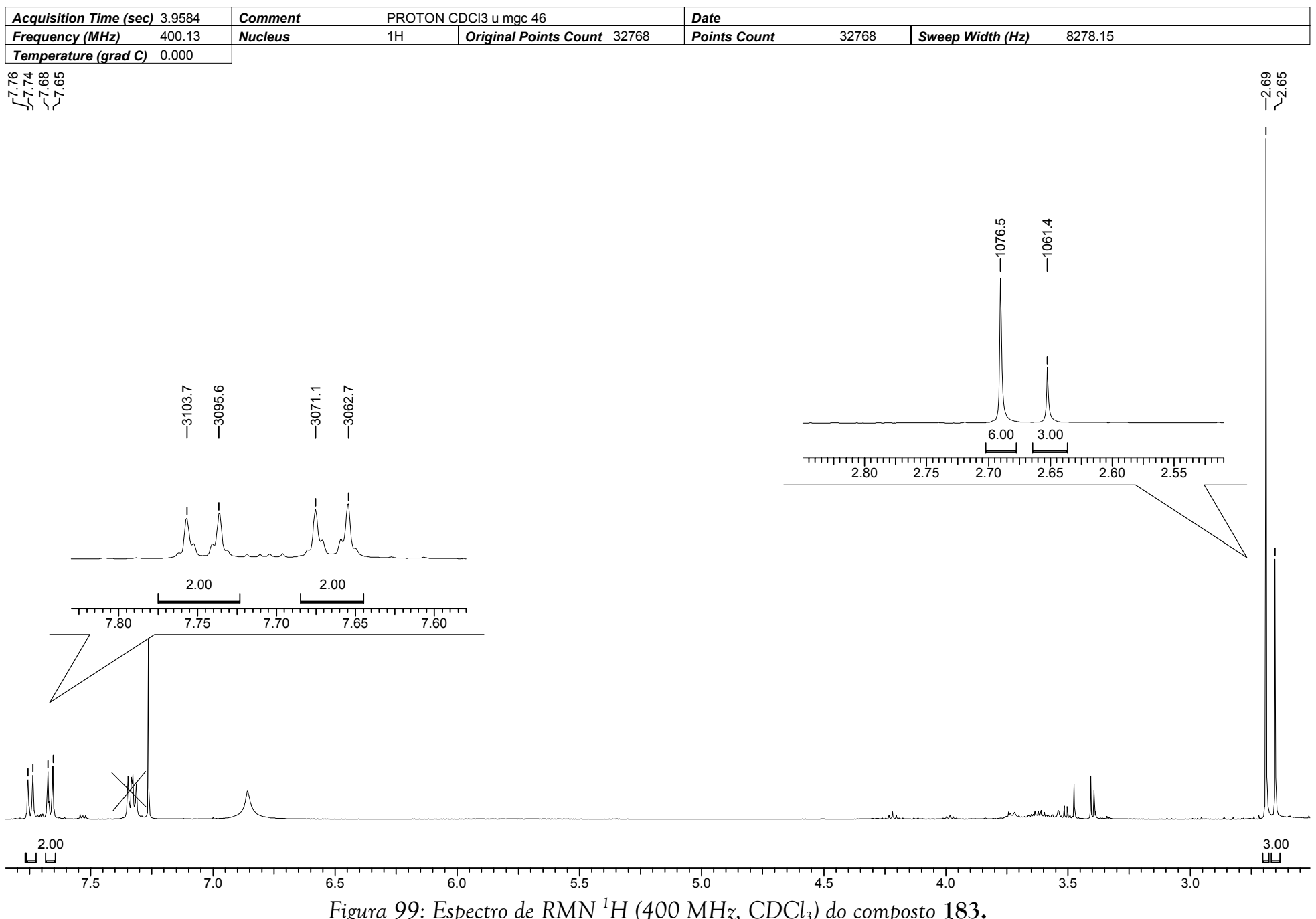




\section{Composto 281}

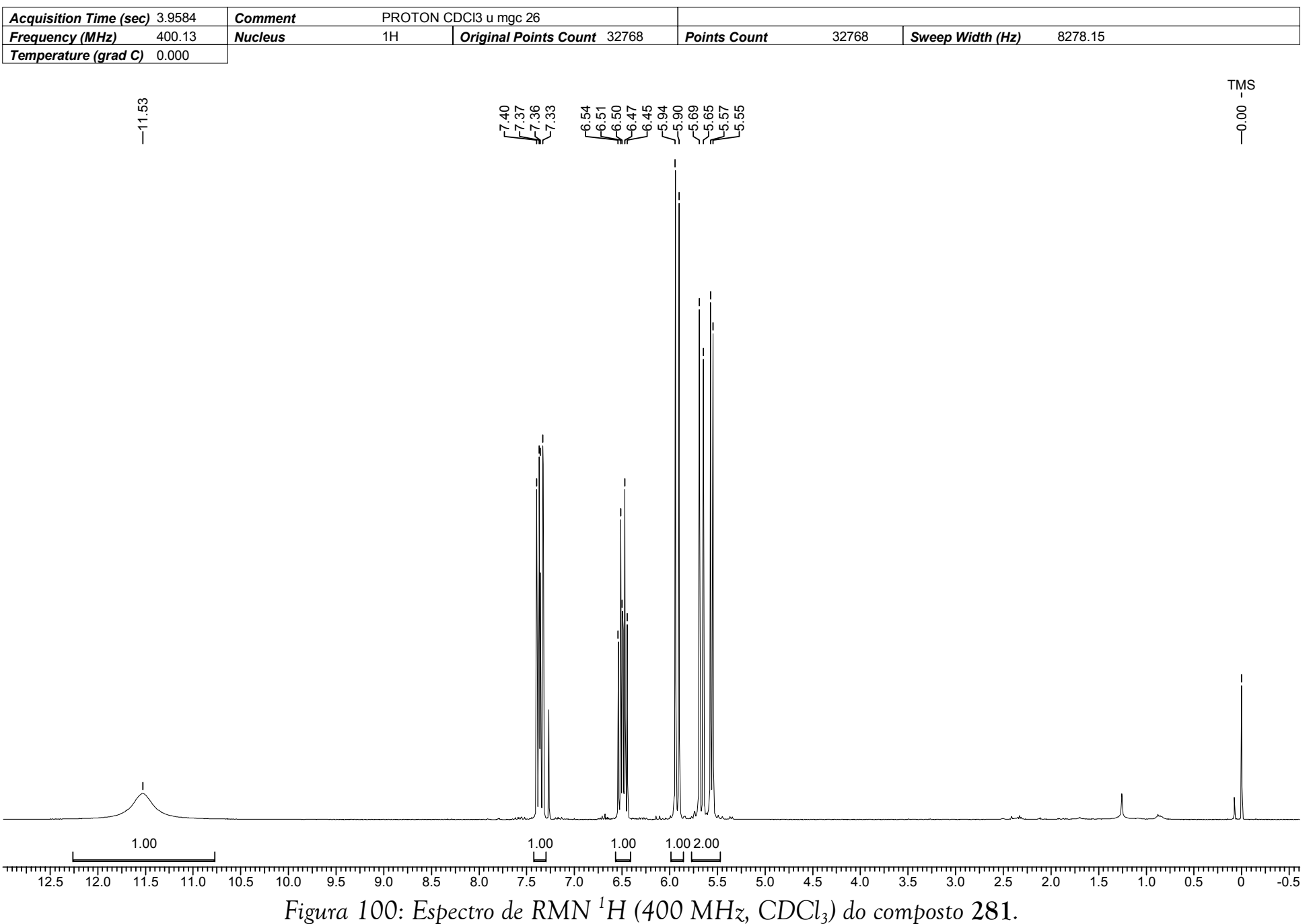

Figura 100: Espectro de $\mathrm{RMN}^{1} \mathrm{H}\left(400 \mathrm{MHz}, \mathrm{CDCl}_{3}\right)$ do composto 281 . 
Espectro de $R M N{ }^{13} \mathrm{C}\left\{{ }^{1} \mathrm{H}\right\}$

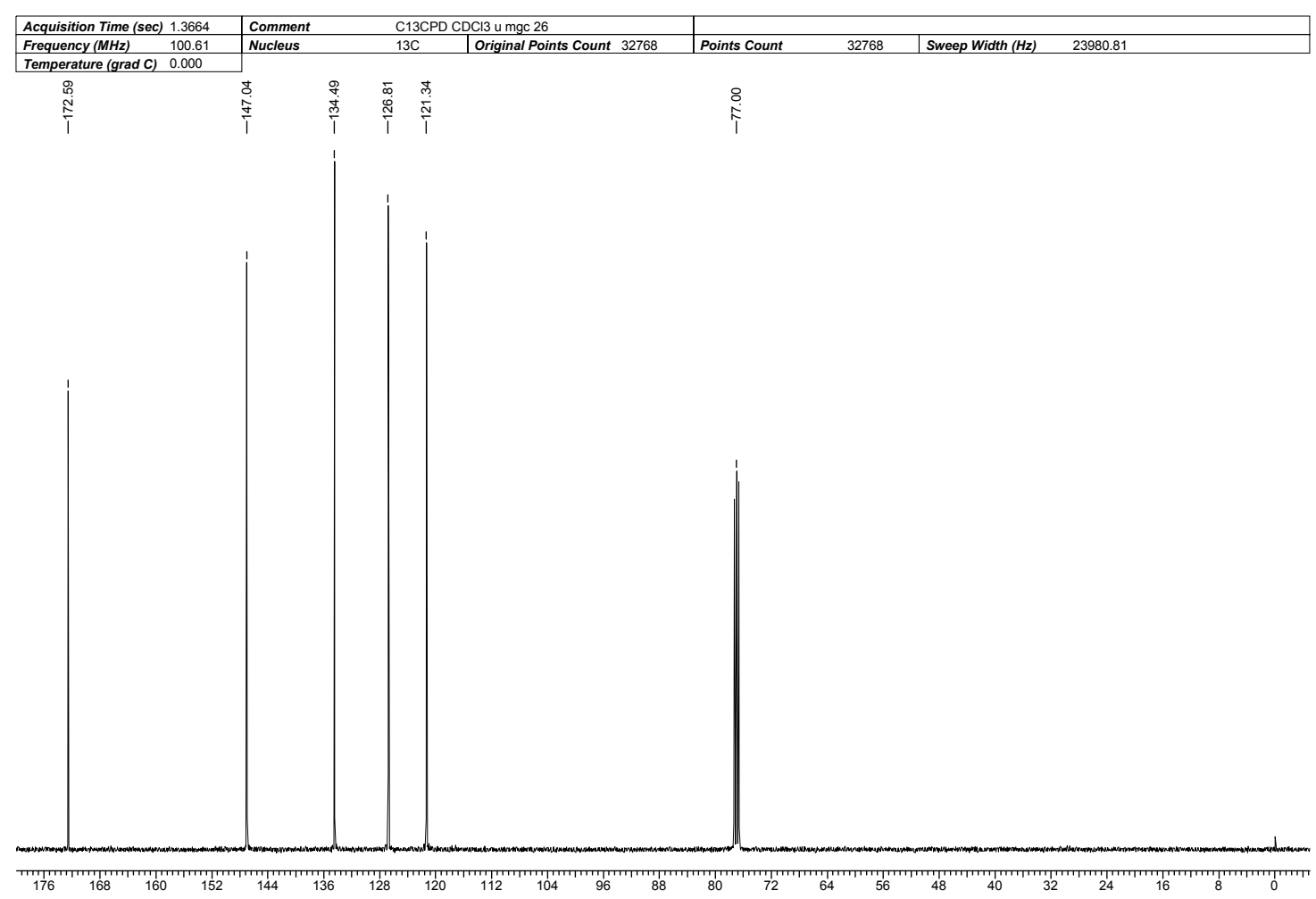

Espectro de RMN ${ }^{13} \mathrm{C}(\mathrm{DEPT}-135)$.

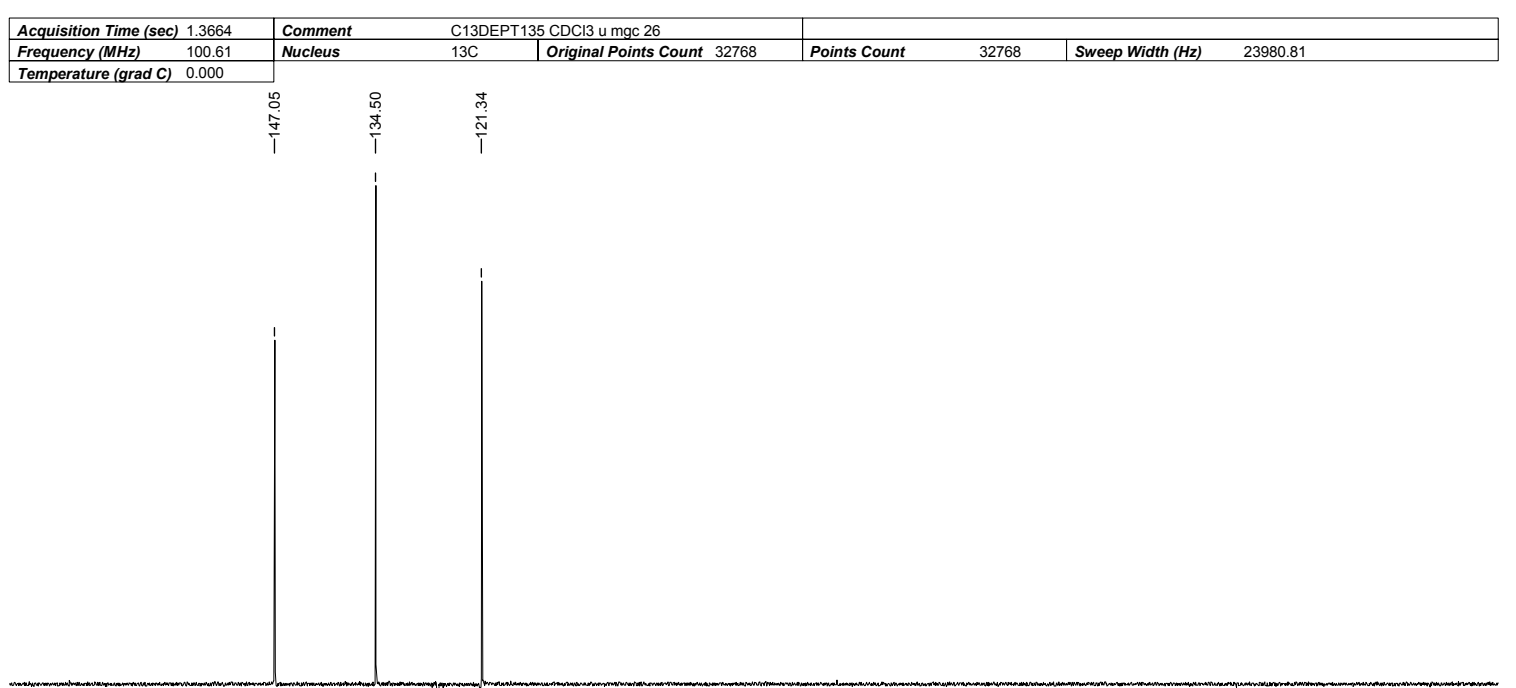

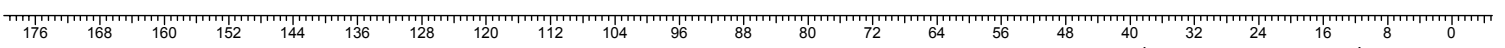

* Espectro de RMN ${ }^{13} \mathrm{C}\left(100 \mathrm{MHz}, \mathrm{CDCl}_{3}\right)$ DEPT-135 do composto $281 . \uparrow\left(\mathrm{CH}, \mathrm{CH}_{3}\right), \downarrow .\left(\mathrm{CH}_{2}\right)$

Figura 101: Espectros de $R M N{ }^{13} \mathrm{C}\left(100 \mathrm{MHz}, \mathrm{CDCl}_{3}\right)$ do composto 281. 
Tabela 54: Dados Espectroscópicos do Composto 281.

\begin{tabular}{|c|c|c|c|c|c|c|}
\hline $\mathrm{C}$ & $\delta \mathrm{C}(\mathrm{ppm})$ & $\delta \mathrm{H}(\mathrm{ppm})$ & $\begin{array}{l}\text { Integral } \\
\text { Relativa }\end{array}$ & Multiplicidade & Constante de Acoplamento $(\mathrm{Hz})$ & \\
\hline 1 & 172,6 & $10,90-12,40$ & $(\mathrm{OH})$ & $\mathrm{sl}$ & - & \\
\hline 2 & 121,3 & 5,92 & $1 \mathrm{H}$ & dtd & $\mathrm{J}_{2 / 3}=15,4 ; \mathrm{J}_{2 / 4}=0,8 ; \mathrm{J}_{2 / 5 \mathrm{a}}=0,8 ; \mathrm{J}_{2 / 5 \mathrm{~b}}=0,6$ & \\
\hline 3 & 147,0 & 7,36 & $1 \mathrm{H}$ & dddd & $\mathrm{J}_{3 / 2}=15,4 ; \mathrm{J}_{3 / 4}=10,8 ; \mathrm{J}_{3 / 5 \mathrm{a}}=0,8 ; \mathrm{J}_{3 / 5 \mathrm{~b}}=0,6$ & \\
\hline 4 & 134,5 & 6,49 & $1 \mathrm{H}$ & dddd & $\mathrm{J}_{4 /, 5 \mathrm{a}}=16,9 ; \mathrm{J}_{4 / 3}=10,8 ; \mathrm{J}_{4 /, 5 \mathrm{~b}}=10,0 ; \mathrm{J}_{4 / 2}=0,8$ & \\
\hline 5 & 126,8 & $\left(\mathrm{H}_{5 \mathrm{a}}\right) 5,67$ & $1 \mathrm{H}$ & ddt & $\mathrm{J}_{5 \mathrm{a} / 4}=16,9 ; \mathrm{J}_{5 \mathrm{a} / 5 \mathrm{~b}}=1,4 ; \mathrm{J}_{5 \mathrm{a} / 2}=0,8 ; \mathrm{J}_{5 \mathrm{a} / 3}=0,8$ & \\
\hline & & $\left(\mathrm{H}_{5 \mathrm{~b}}\right) 5,56$ & $1 \mathrm{H}$ & ddt & $\mathrm{J}_{5 \mathrm{~b} / 4}=10,0 ; \mathrm{J}_{5 \mathrm{a} / 5 \mathrm{~b}}=1,4 ; \mathrm{J}_{5 \mathrm{~b} / 2}=0,6 ; \mathrm{J}_{5 \mathrm{~b} / 3}=0,6$ & \\
\hline
\end{tabular}




\section{Composto 282}

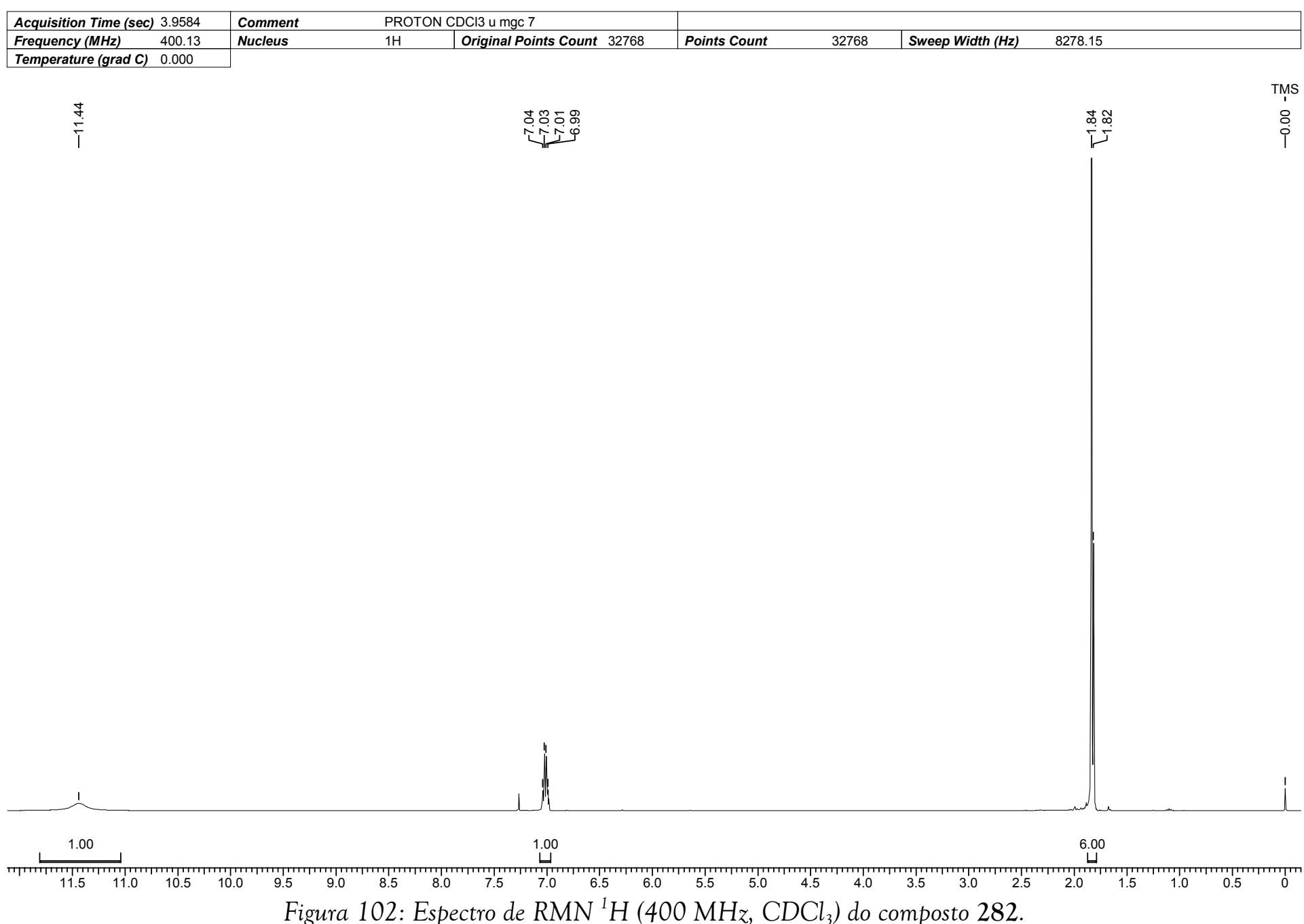

Figura 102: Espectro de $\mathrm{RMN}^{1} \mathrm{H}\left(400 \mathrm{MHz}, \mathrm{CDCl}_{3}\right)$ do composto 282 
Espectro de $R M N{ }^{13} \mathrm{C}\left\{{ }^{1} \mathrm{H}\right\}$

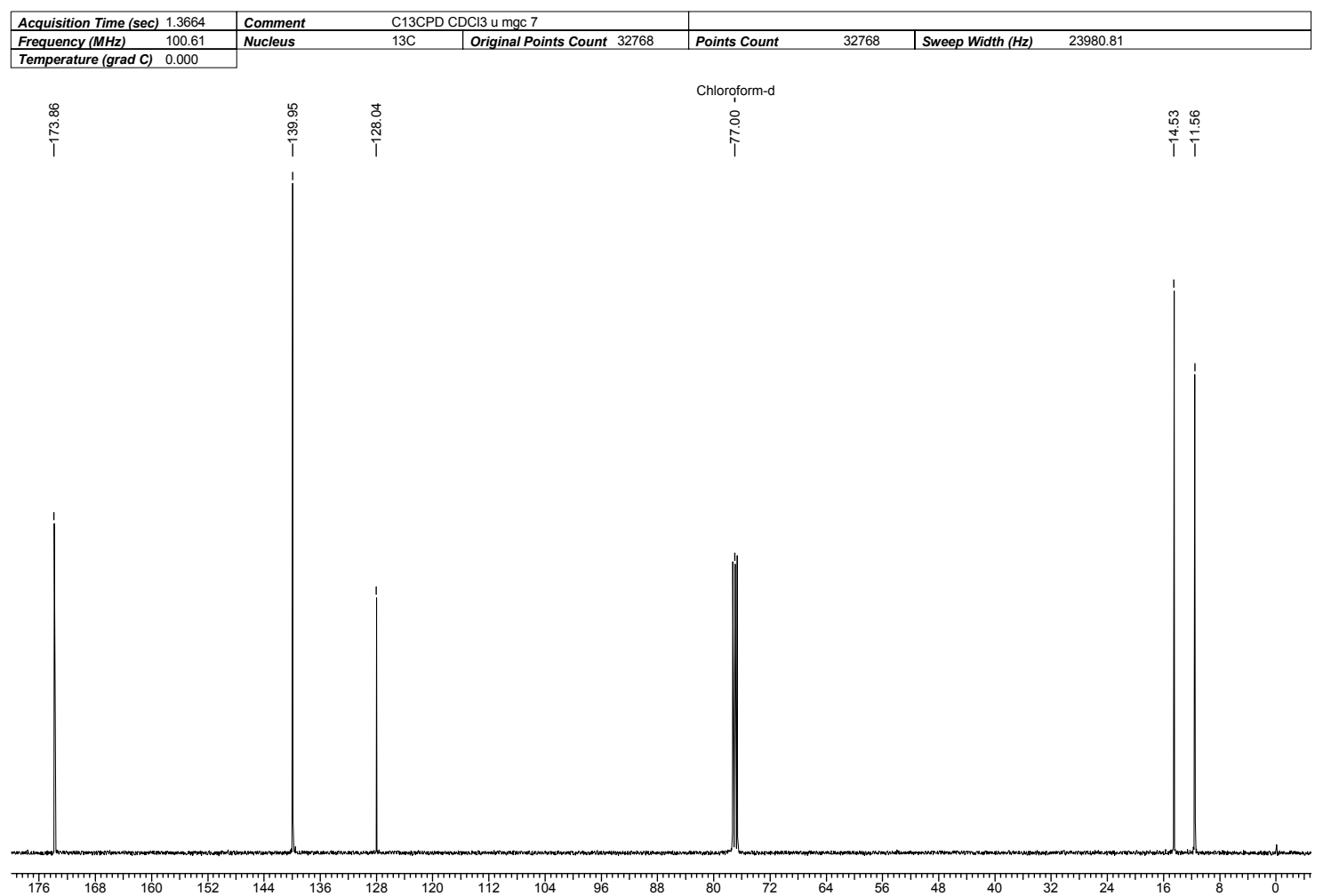

Espectro de RMN ${ }^{13} \mathrm{C}(\mathrm{DEPT}-135)$.

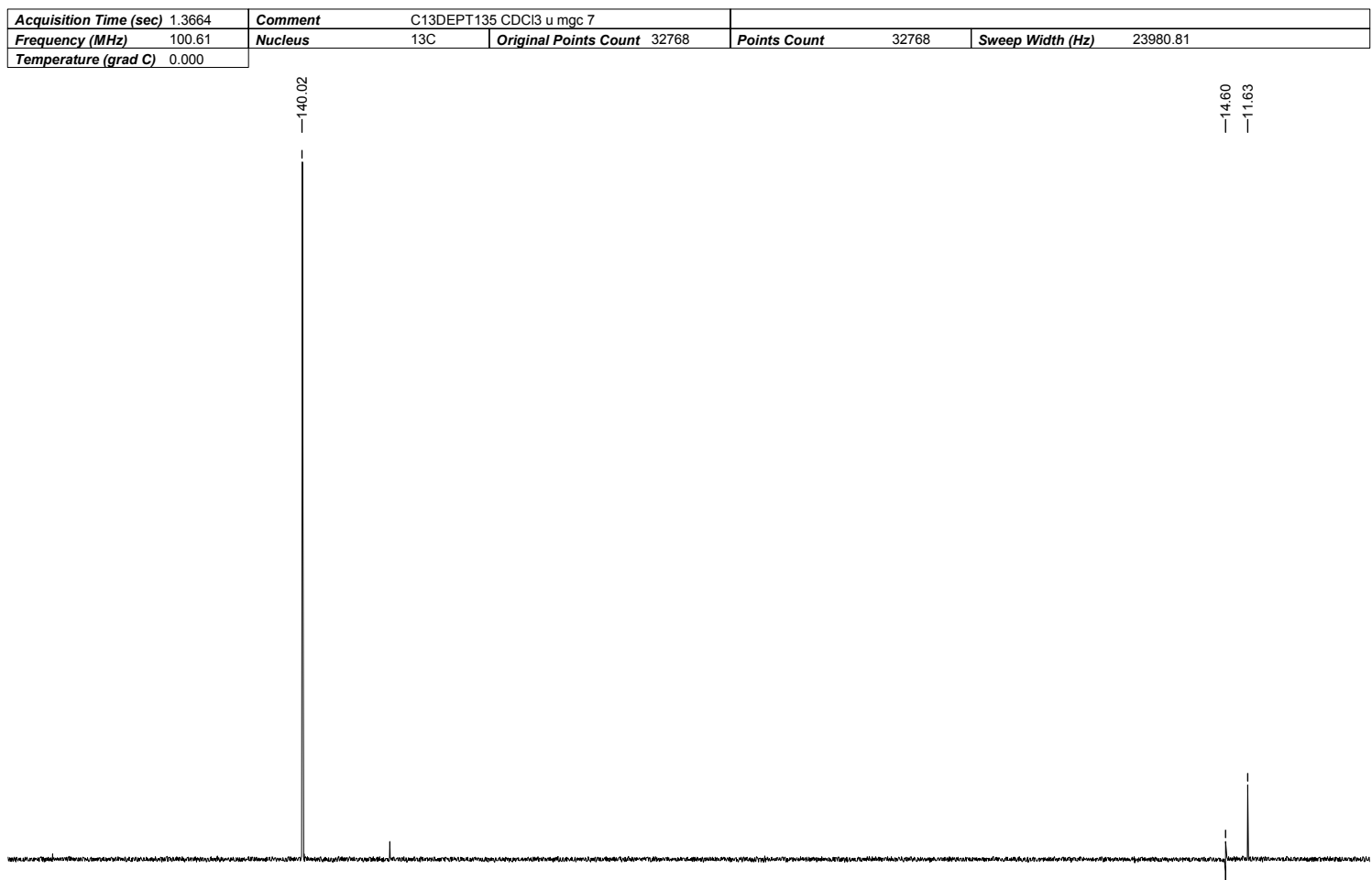

${ }_{176}$

* Espectro de RMN ${ }^{13} \mathrm{C}\left(100 \mathrm{MHz}, \mathrm{CDCl}_{3}\right)$ DEPT-135 do composto $282 \uparrow\left(\mathrm{CH}, \mathrm{CH}_{3}\right), \downarrow \cdot\left(\mathrm{CH}_{2}\right)$

Figura 103: Espectros de $\mathrm{RMN}^{13} \mathrm{C}\left(100 \mathrm{MHz}, \mathrm{CDCl}_{3}\right)$ do composto 282. 
Tabela 55: Dados Espectroscópicos do composto 282

\begin{tabular}{cccccc}
\hline $\mathrm{C}$ & $\delta \mathrm{C}(\mathrm{ppm})$ & $\delta \mathrm{H}(\mathrm{ppm})$ & $\begin{array}{c}\text { Integral } \\
\text { Relativa }\end{array}$ & Multiplicidade & Constante de Acoplamento $(\mathrm{Hz})$ \\
\hline 1 & 173,9 & $11,10-11,76$ & $\mathrm{OH}$ & $\mathrm{sl}$ & - \\
2 & 128,0 & - & - & - & - \\
3 & 140,0 & $6,97-7,07$ & $1 \mathrm{H}$ & $\mathrm{m}$ & - \\
4 & 11,6 & $1,81-1,87$ & $3 \mathrm{H}$ & $\mathrm{m}$ & - \\
5 & 14,5 & $1,81-1,87$ & $3 \mathrm{H}$ & $\mathrm{m}$ & - \\
\hline
\end{tabular}

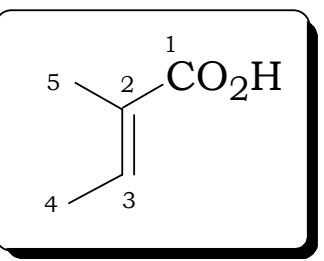




\section{Composto 296}

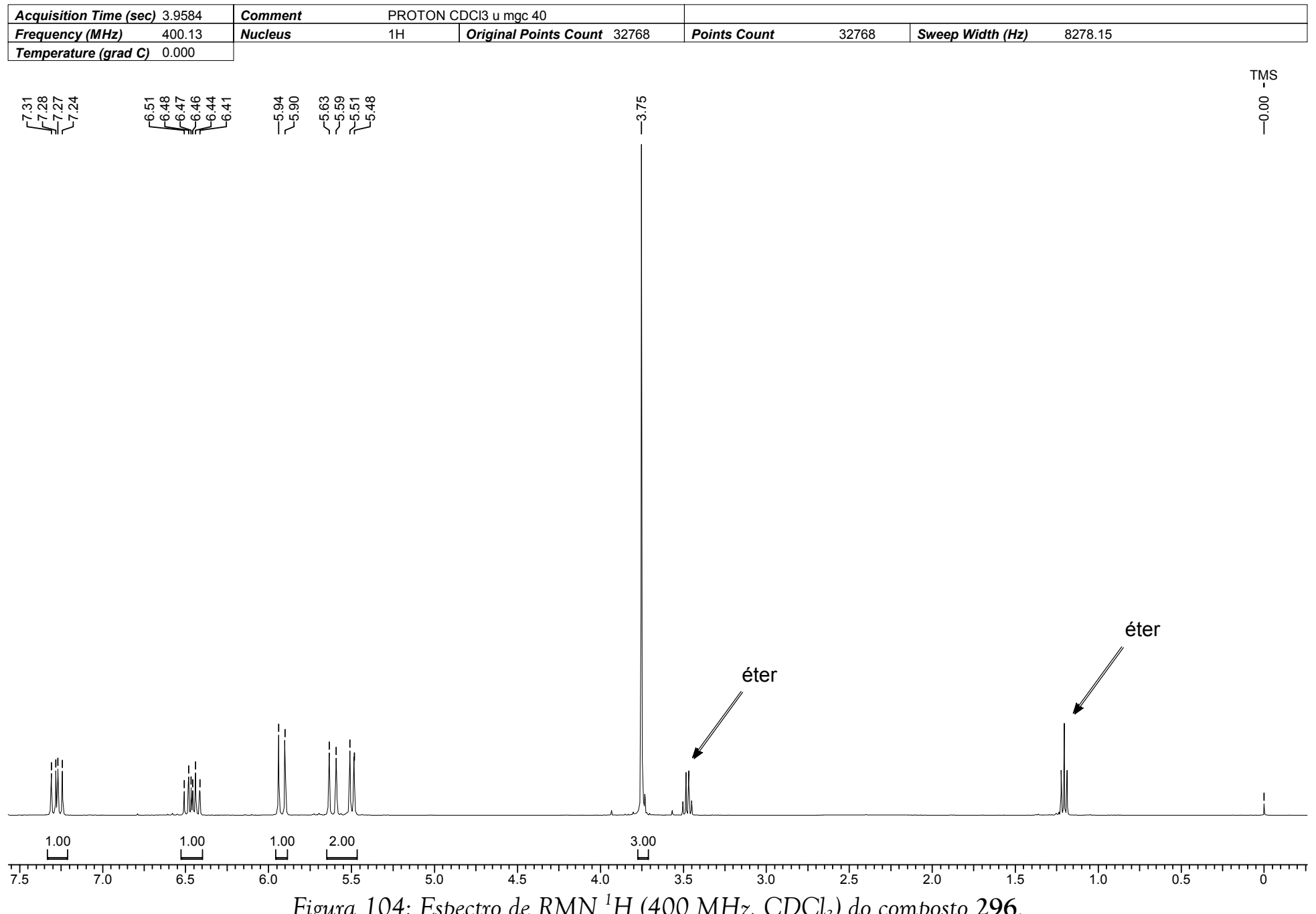

Figura 104: Espectro de $\mathrm{RMN}^{1} \mathrm{H}\left(400 \mathrm{MHz}, \mathrm{CDCl}_{3}\right)$ do composto 296. 
Espectro de $R M N{ }^{13} \mathrm{C}\left\{{ }^{1} \mathrm{H}\right\}$

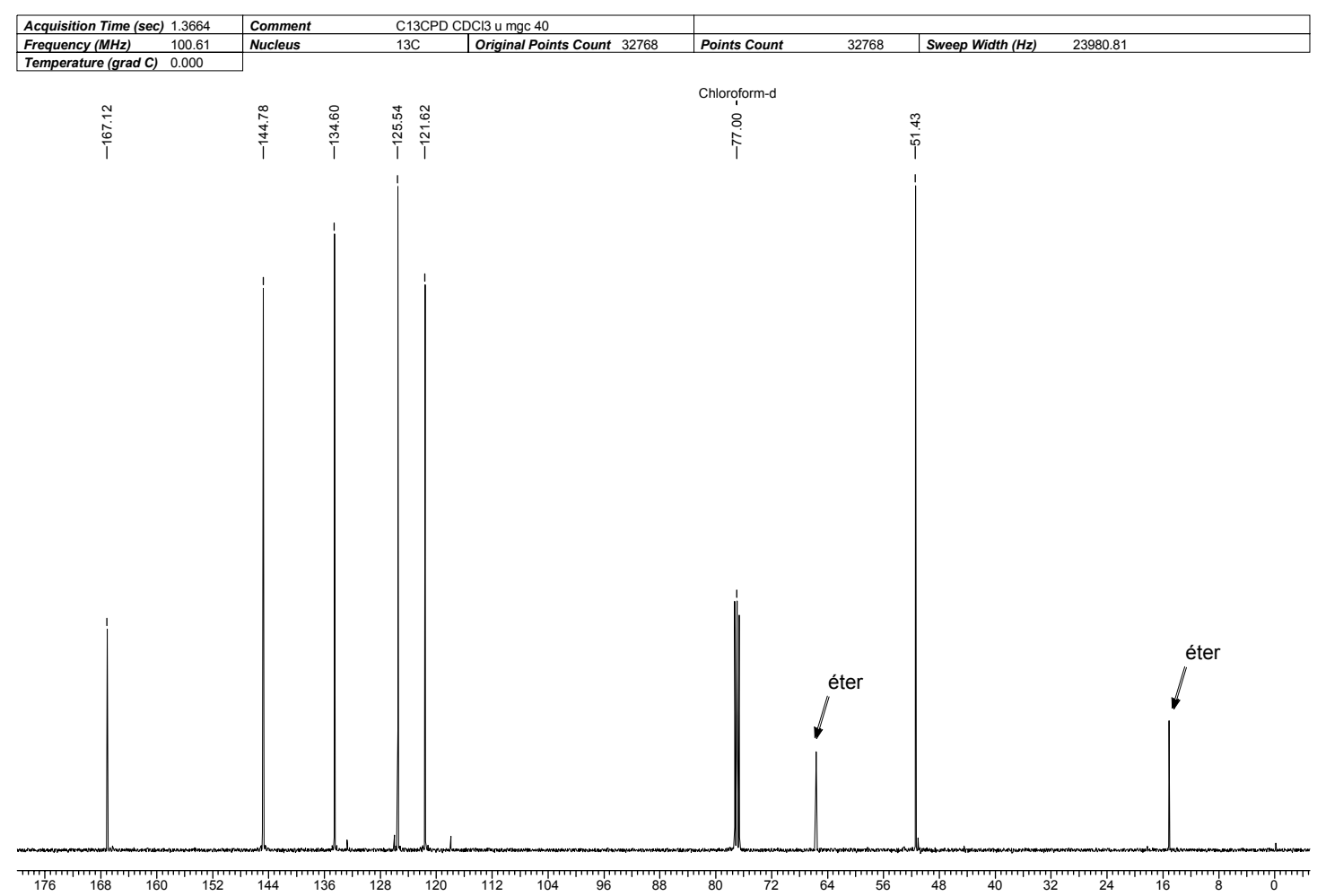

Espectro de RMN ${ }^{13} \mathrm{C}(\mathrm{DEPT}-135) .{ }^{*}$

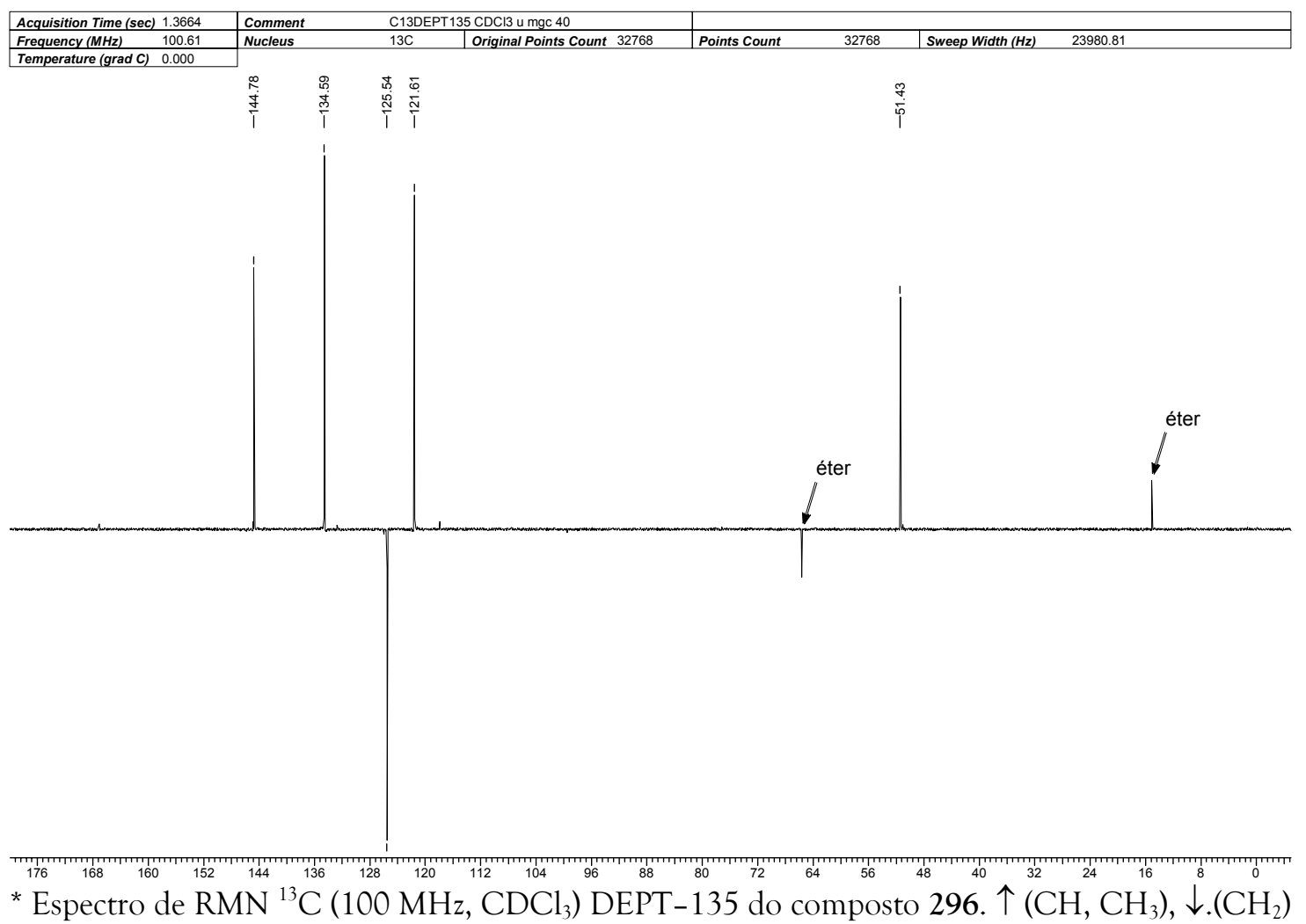

${ }^{*}$ Espectro de $\mathrm{RMN}{ }^{13} \mathrm{C}\left(100 \mathrm{MHz}, \mathrm{CDCl}_{3}\right) \mathrm{DEPT}-135$ do composto $296 . \uparrow\left(\mathrm{CH}, \mathrm{CH}_{3}\right), \downarrow \cdot\left(\mathrm{CH}_{2}\right)$

Figura 105: Espectros de $R M N{ }^{13} \mathrm{C}\left(100 \mathrm{MHz}, \mathrm{CDCl}_{3}\right)$ do composto 296. 
Tabela 56: Dados Espectroscópicos do Composto 296.

\begin{tabular}{cccccc}
\hline $\mathrm{C}$ & $\delta \mathrm{C}(\mathrm{ppm})$ & $\delta \mathrm{H}(\mathrm{ppm})$ & Integral Relativa & Multiplicidade & Constante de Acoplamento $(\mathrm{Hz})$ \\
\hline 1 & 167,1 & - & - & - & \\
2 & 121,6 & 5,92 & $1 \mathrm{H}$ & $\mathrm{ddt}$ & $\mathrm{J}_{2 / 3}=15,4 ; \mathrm{J}_{2 / 5 \mathrm{a}}=0,8 ; \mathrm{J}_{2 / 5 \mathrm{~b}}=0,7 ; \mathrm{J}_{2 / 4}=0,7$ \\
3 & 144,8 & 7,27 & $1 \mathrm{H}$ & $\mathrm{ddt}$ & $\mathrm{J}_{3 / 2}=15,4 ; \mathrm{J}_{3 / 4}=11,0 ; \mathrm{J}_{3 / 5 \mathrm{a}}=0,8 ; \mathrm{J}_{3 / 5 \mathrm{~b}}=0,8$ \\
4 & 134,6 & 6,46 & $1 \mathrm{H}$ & $\mathrm{dddd}$ & $\mathrm{J}_{4 / 5 \mathrm{a}}=17,0 ; \mathrm{J}_{4 / 3}=11,0 ; \mathrm{J}_{4 / 5 \mathrm{~b}}=10,0 ; \mathrm{J}_{4 / 2}=0,7$ \\
5 & 125,5 & $\left(\mathrm{H}_{5 \mathrm{a}}\right) 5,62$ & $1 \mathrm{H}$ & $\mathrm{ddt}$ & $\mathrm{J}_{5 \mathrm{a} / 4}=17,0 ; \mathrm{J}_{5 \mathrm{a} / 5 \mathrm{~b}}=1,5 ; \mathrm{J}_{5 \mathrm{a} / 2}=0,8 ; \mathrm{J}_{5 \mathrm{a} / 3}=0,8$ \\
& & $\left(\mathrm{H}_{5 \mathrm{~b}}\right) 5,50$ & $1 \mathrm{H}$ & $\mathrm{dddd}$ & $\mathrm{J}_{5 \mathrm{~b} / 4}=10,0 ; \mathrm{J}_{5 \mathrm{a} / 5 \mathrm{~b}}=1,5 ; \mathrm{J}_{5 \mathrm{~b} / 3}=0,8 ; \mathrm{J}_{5 \mathrm{~b} / 2}=0,7$ \\
6 & 51,4 & 3,75 & $3 \mathrm{H}$ & $\mathrm{s}$ & - \\
\hline
\end{tabular}

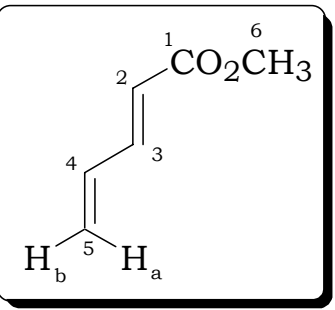




\section{Composto 283}

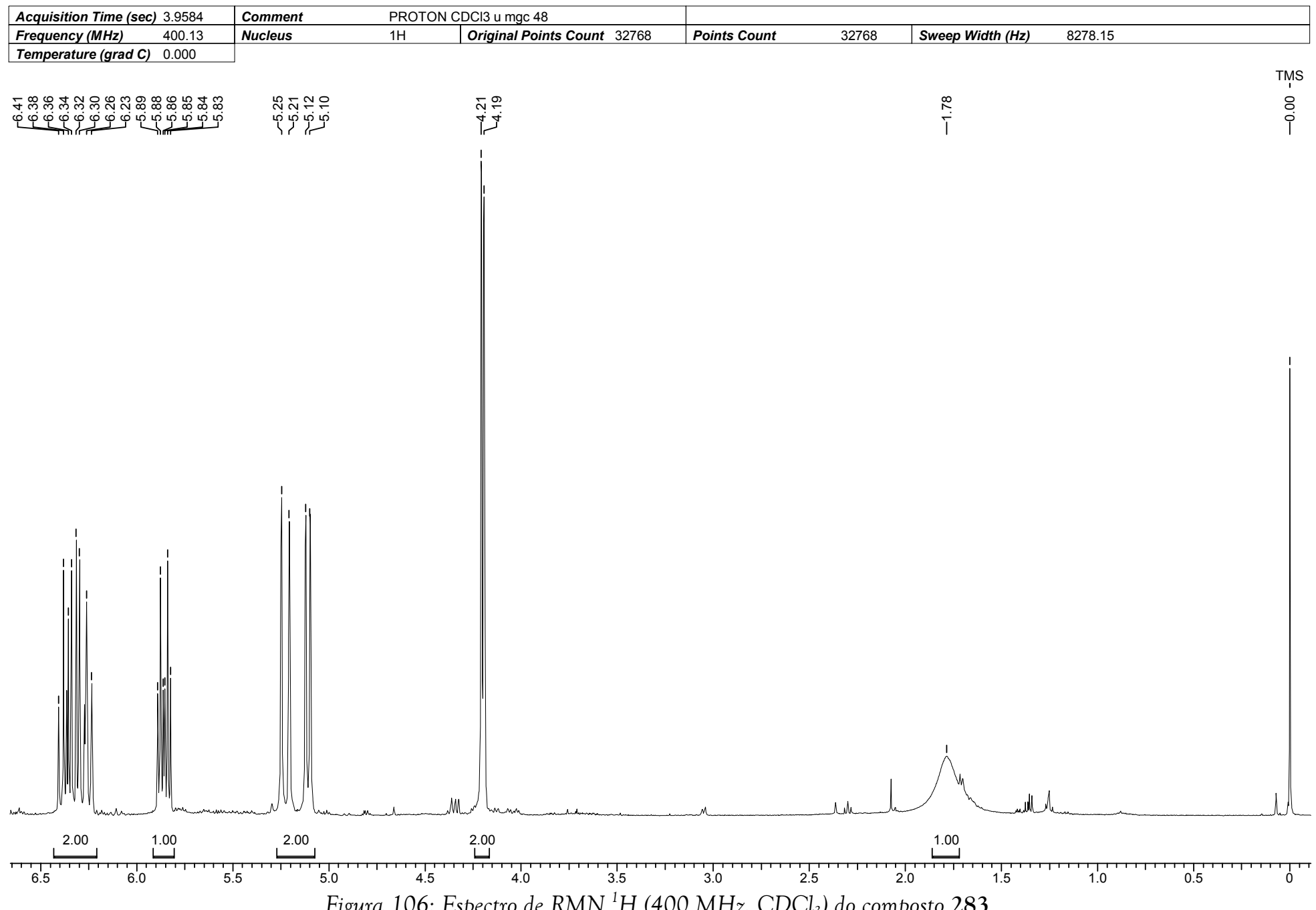

Figura 106: Espectro de RMN ${ }^{1} \mathrm{H}\left(400 \mathrm{MHz}, \mathrm{CDCl}_{3}\right)$ do composto 283. 
Espectro de $R M N{ }^{13} \mathrm{C}\left\{{ }^{1} \mathrm{H}\right\}$

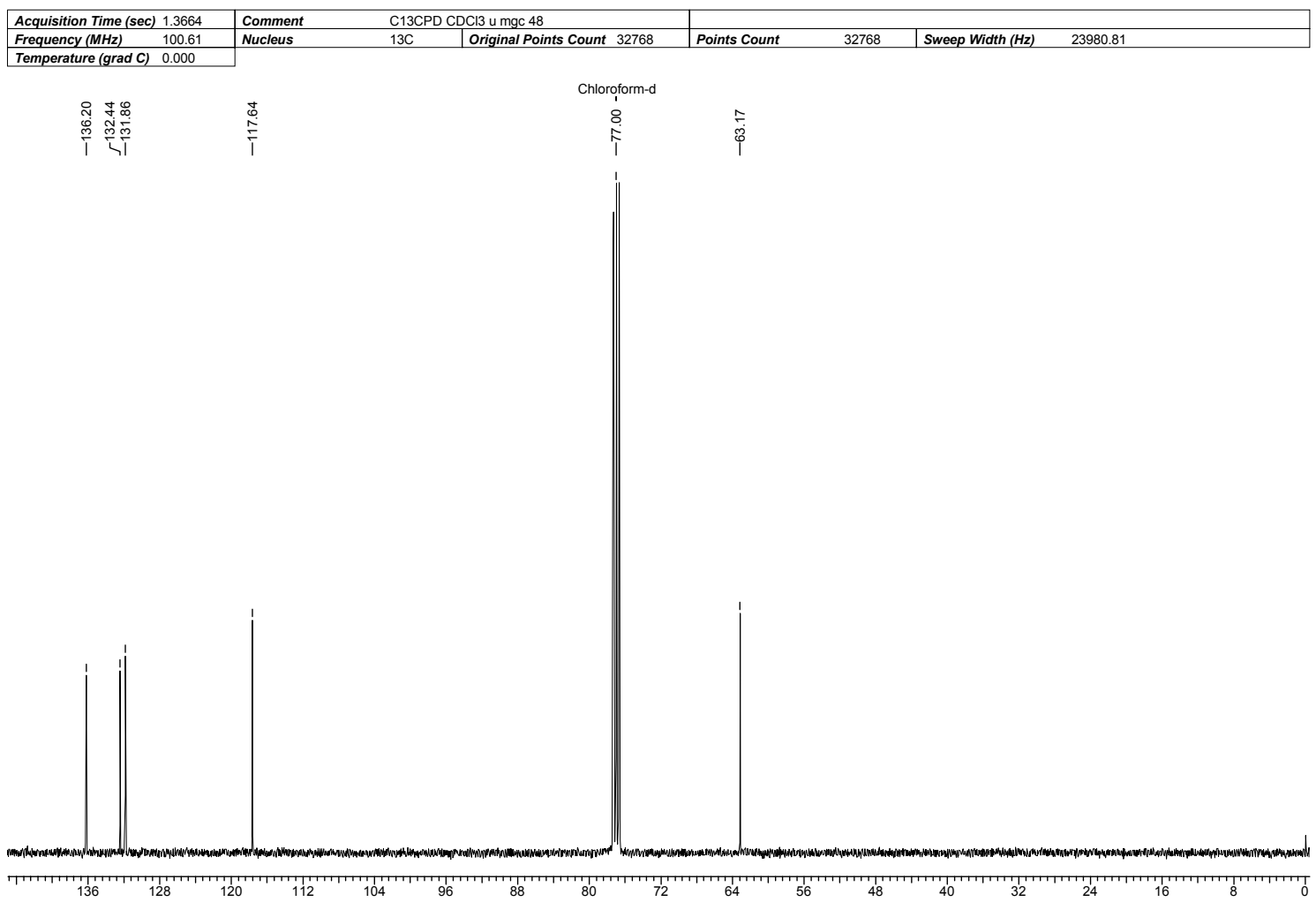

Espectro de RMN ${ }^{13} \mathrm{C}(\mathrm{DEPT}-135) .{ }^{*}$

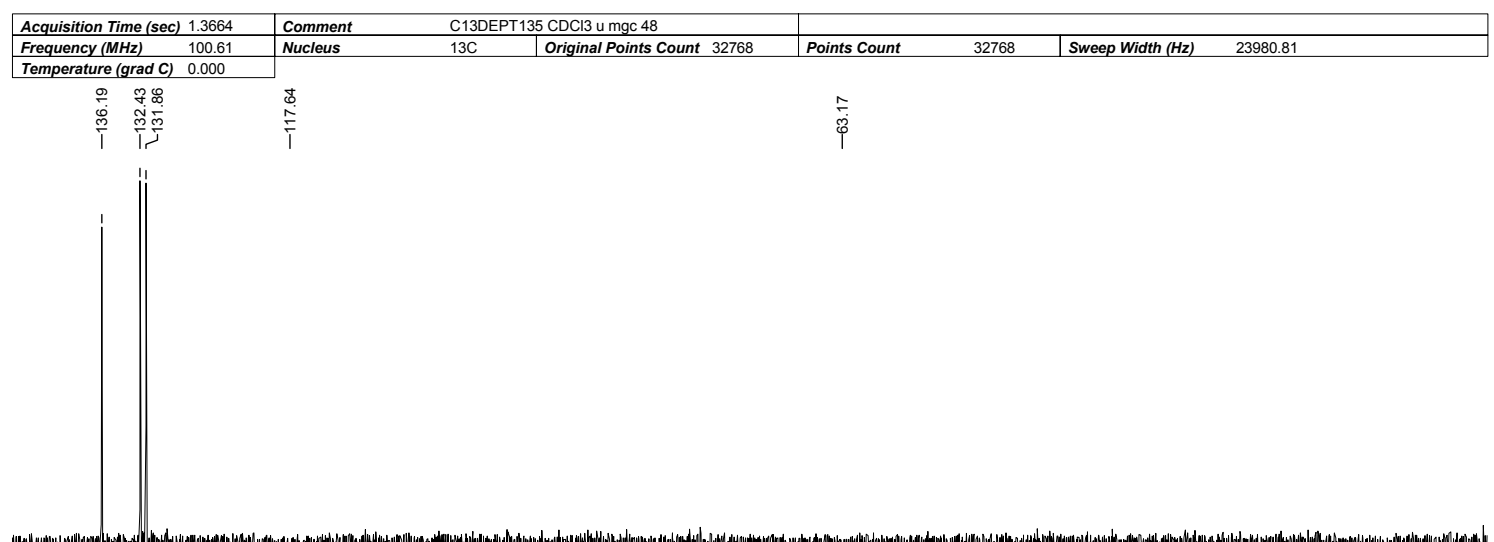

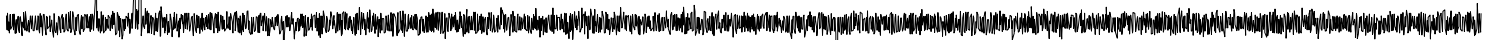

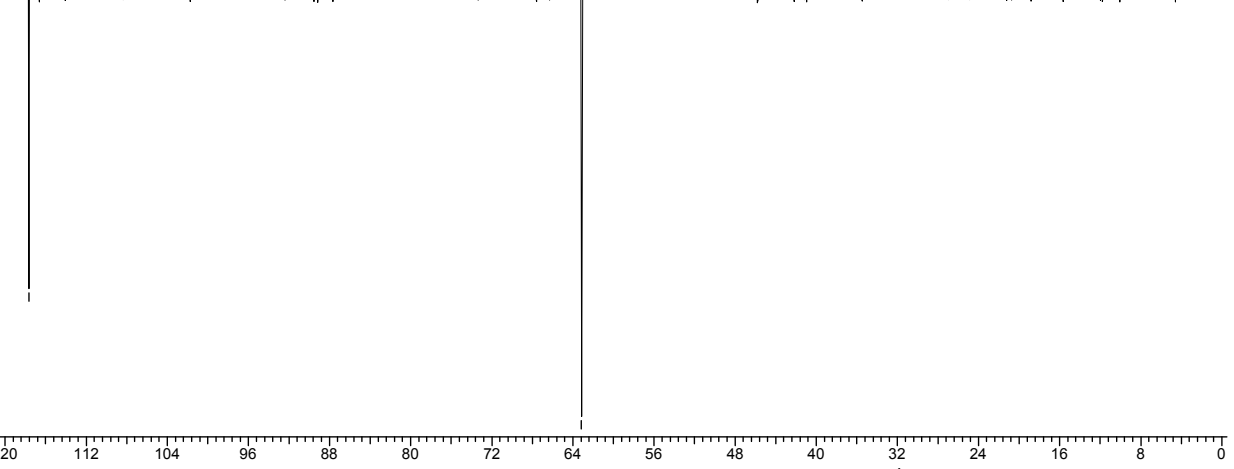

Figura 107: Espectros de RMN ${ }^{13} \mathrm{C}\left(100 \mathrm{MHz}, \mathrm{CDCl}_{3}\right)$ do composto 283. 
Tabela 57: Dados Espectroscópicos do Composto 283

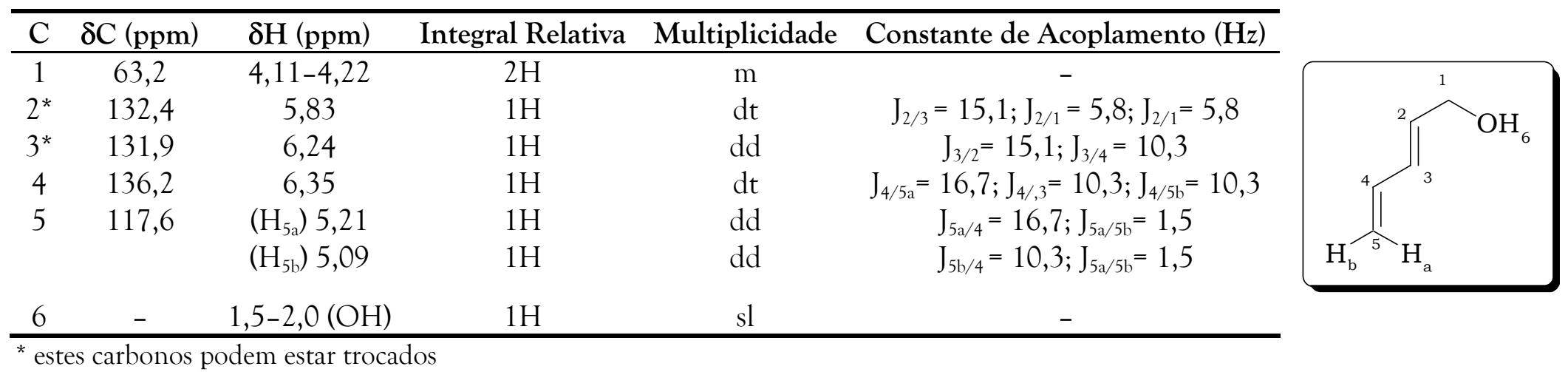




\section{Composto 285}

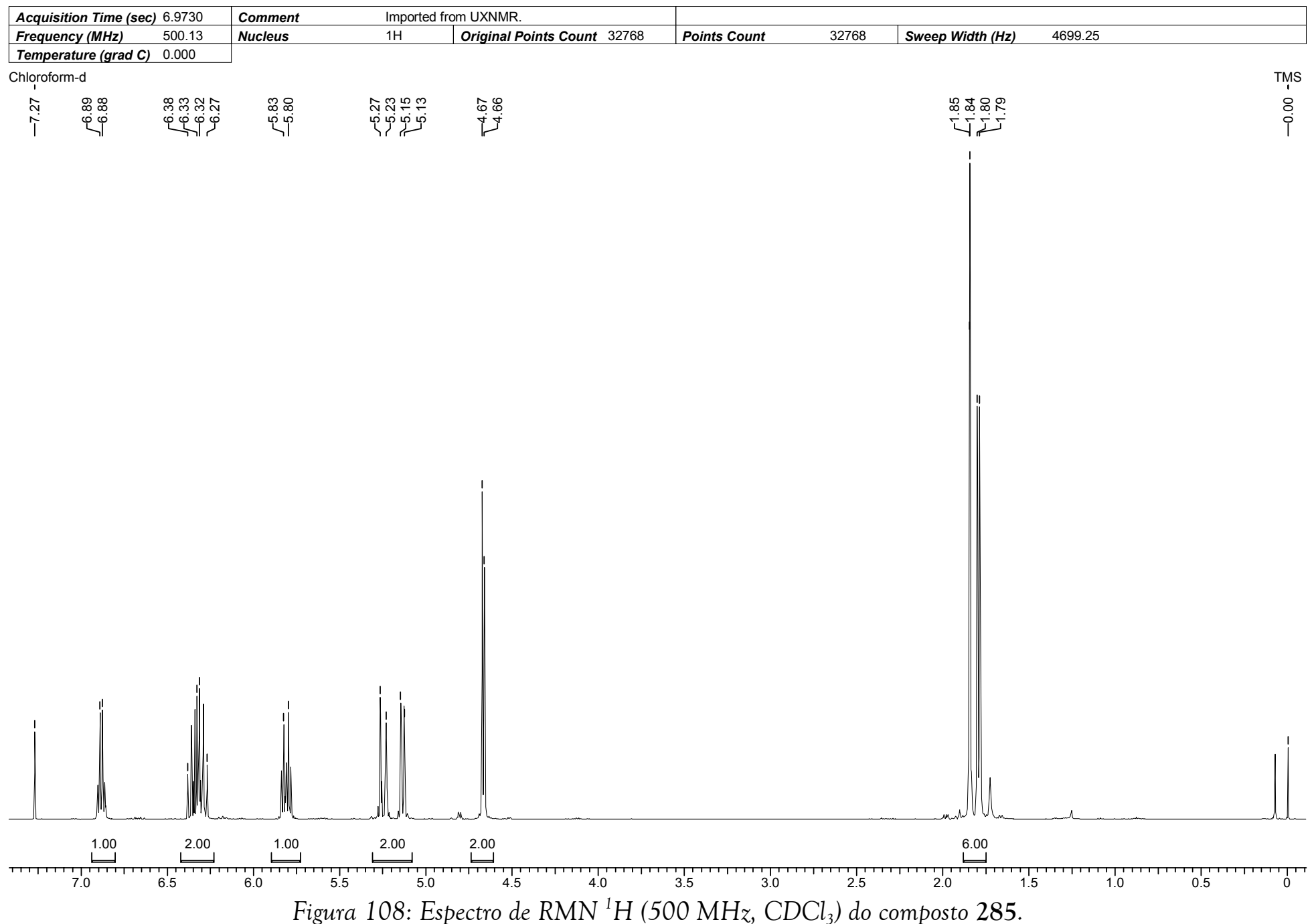

Figura 108: Espectro de $\mathrm{RMN}^{1} \mathrm{H}\left(500 \mathrm{MHz}, \mathrm{CDCl}_{3}\right)$ do composto 285. 
Espectro de $R M N{ }^{13} \mathrm{C}\left\{{ }^{1} \mathrm{H}\right\}$

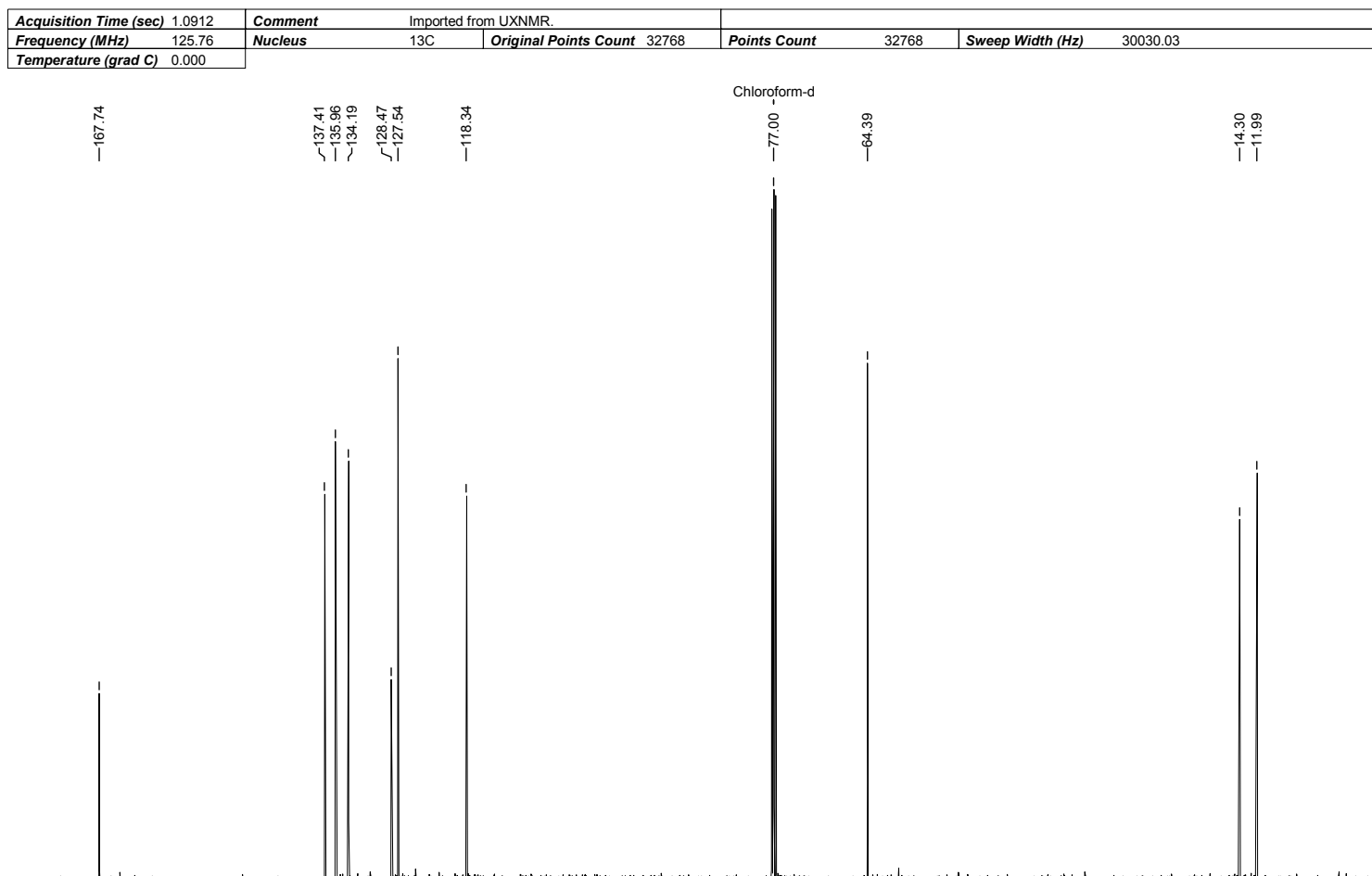

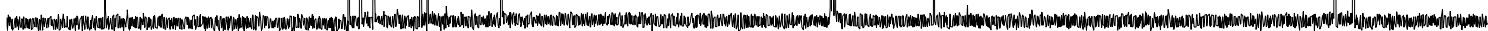

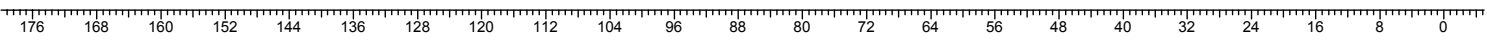

Espectro de $\mathrm{RMN}^{13} \mathrm{C}(\mathrm{DEPT}-135)$.

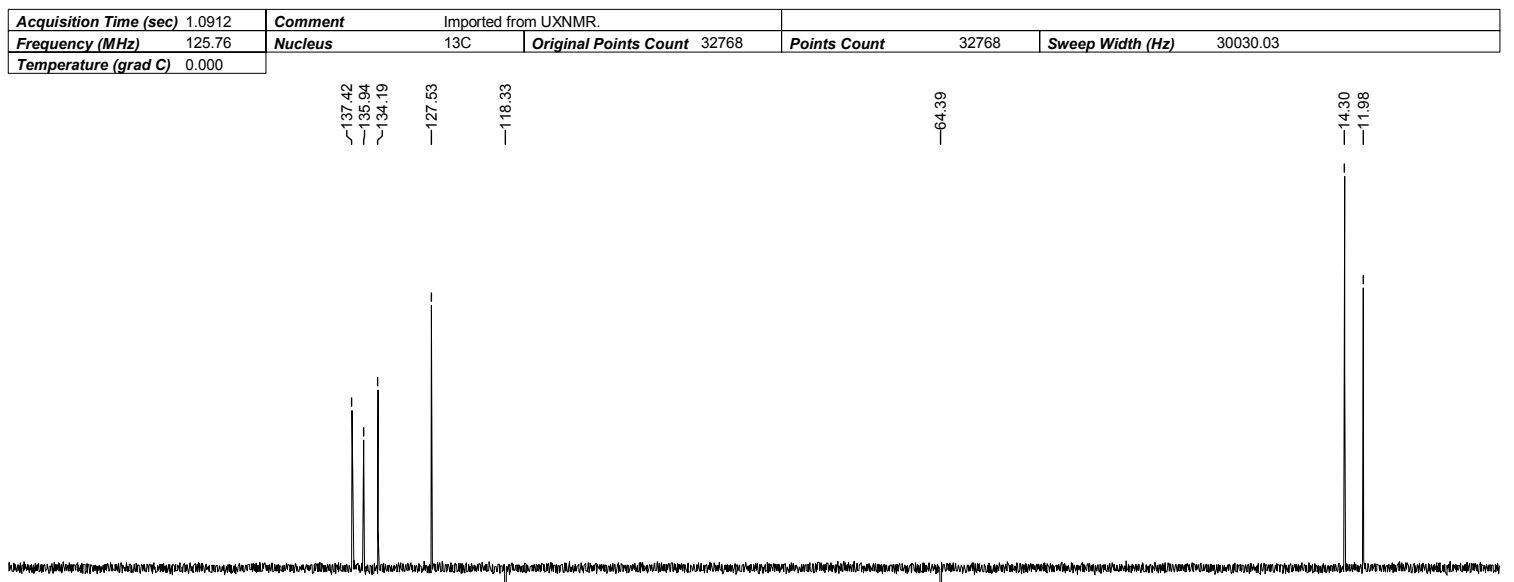

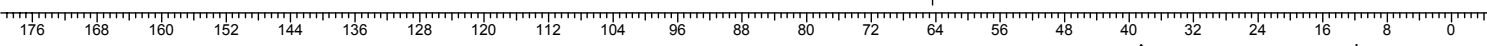

* Espectro de $\mathrm{RMN}{ }^{13} \mathrm{C}\left(125 \mathrm{MHz}, \mathrm{CDCl}_{3}\right)$ DEPT-135 do composto 285. $\uparrow\left(\mathrm{CH}, \mathrm{CH}_{3}\right), \downarrow\left(\mathrm{CH}_{2}\right)$

Figura 109: Espectros de $\mathrm{RMN}^{13} \mathrm{C}\left(125 \mathrm{MHz}, \mathrm{CDCl}_{3}\right)$ do composto 285 
Tabela 58: Dados Espectroscópicos do Composto 285.

\begin{tabular}{|c|c|c|c|c|c|c|c|c|}
\hline $\mathrm{C}$ & $\delta \mathrm{C}(\mathrm{ppm})$ & $\delta \mathrm{H}(\mathrm{ppm})$ & $\begin{array}{l}\text { Integral } \\
\text { Relativa }\end{array}$ & Multiplicidade & Constantes de Acoplamento $(\mathrm{Hz})$ & gCOSY & gHMBC & gHMQC \\
\hline 1 & 64,4 & $4,65-4,69$ & $2 \mathrm{H}$ & $\mathrm{m}$ & - & $\mathrm{H}_{2} ; \mathrm{H}_{3}$ & $\mathrm{H}_{2 ;} \mathrm{H}_{3}$ & $\mathrm{H}_{1}$ \\
\hline 2 & 127,5 & 5,81 & $1 \mathrm{H}$ & $\mathrm{dt}$ & $\mathrm{J}_{2,3}=14,6 ; \mathrm{J}_{2,1}=6,2 ; \mathrm{J}_{2,1}=6,2$ & $\mathrm{H}_{1 ;} \mathrm{H}_{3 ;}$ & $\mathrm{H}_{1 ;} \mathrm{H}_{3} ; \mathrm{H}_{4}$ & $\mathrm{H}_{2}$ \\
\hline 3 & 134,2 & 6,30 & $1 \mathrm{H}$ & ddt & $J_{3,2}=14,6 ; J_{3,4}=10,5 ; J_{3,1}=1,3 ; J_{3,1}=1,3$ & $\mathrm{H}_{2 ;} \mathrm{H}_{4 ;} \mathrm{H}_{1}$ & $\mathrm{H}_{1} ; \mathrm{H}_{4 ;} \mathrm{H}_{5 \mathrm{a}} ; \mathrm{H}_{5 \mathrm{~b}}$ & $\mathrm{H}_{3}$ \\
\hline 4 & 136,0 & 6,35 & $1 \mathrm{H}$ & $\mathrm{dt}$ & $\mathrm{J}_{4,5 \mathrm{a}}=16,4 ; \mathrm{J}_{4,5 \mathrm{~b}}=10,5 ; \mathrm{J}_{4,3}=10,5$ & $\mathrm{H}_{3 ;} \mathrm{H}_{5 \mathrm{a} ;} \mathrm{H}_{5 \mathrm{~b}}$ & $\mathrm{H}_{2} ; \mathrm{H}_{3 ;} \mathrm{H}_{5 \mathrm{a}}$ & $\mathrm{H}_{4}$ \\
\hline \multirow[t]{2}{*}{5} & 118,3 & $\left(\mathrm{H}_{5 \mathrm{a}}\right) 5,25$ & $1 \mathrm{H}$ & $\mathrm{d}$ & $\mathrm{J}_{5 \mathrm{a}, 4}=16,4$ & $\mathrm{H}_{4}$ & $\mathrm{H}_{3 ;} \mathrm{H}_{4}$ & $\mathrm{H}_{5 \mathrm{a} / \mathrm{b}}$ \\
\hline & & $\left(\mathrm{H}_{5 \mathrm{~b}}\right) 5,14$ & $1 \mathrm{H}$ & d & $J_{5 b, 4}=10,5$ & $\mathrm{H}_{4}$ & - & - \\
\hline 6 & 167,7 & - & - & - & - & - & $\mathrm{H}_{1} ; \mathrm{H}_{8} ; \mathrm{H}_{10}$ & - \\
\hline 7 & 128,5 & - & - & - & - & - & $\mathrm{H}_{8} ; \mathrm{H}_{9 ;} \mathrm{H}_{10}$ & - \\
\hline 8 & 137,4 & 6,89 & $1 \mathrm{H}$ & qq & $\mathrm{J}_{8,9}=7,0 ; \mathrm{J}_{8,10}=1,4$ & $\mathrm{H}_{9} ; \mathrm{H}_{10}$ & $\mathrm{H}_{9} ; \mathrm{H}_{10}$ & $\mathrm{H}_{8}$ \\
\hline 9 & 14,3 & 1,80 & $3 \mathrm{H}$ & $\mathrm{dq}$ & $\mathrm{J}_{9,8}=7,0 ; \mathrm{J}_{9,10}=1,2$ & $\mathrm{H}_{8} ; \mathrm{H}_{10}$ & $\mathrm{H}_{8}$ & $\mathrm{H}_{9}$ \\
\hline 10 & 12,0 & 1,85 & $3 \mathrm{H}$ & $\mathrm{dq}$ & $\mathrm{J}_{10,8}=1,4 ; \mathrm{J}_{10,9}=1,2$ & $\mathrm{H}_{8} ; \mathrm{H}_{9}$ & $\mathrm{H}_{8}$ & $\mathrm{H}_{10}$ \\
\hline
\end{tabular}

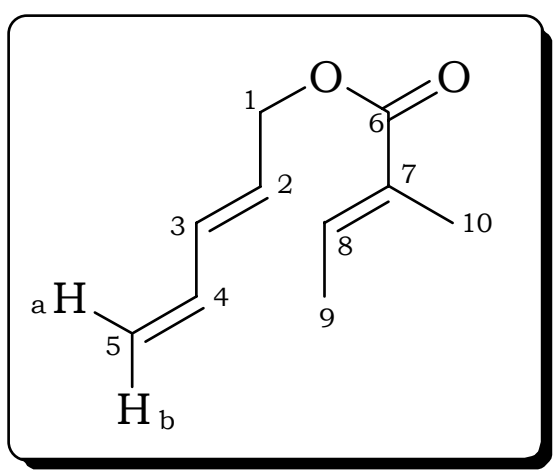




\section{Composto 298}

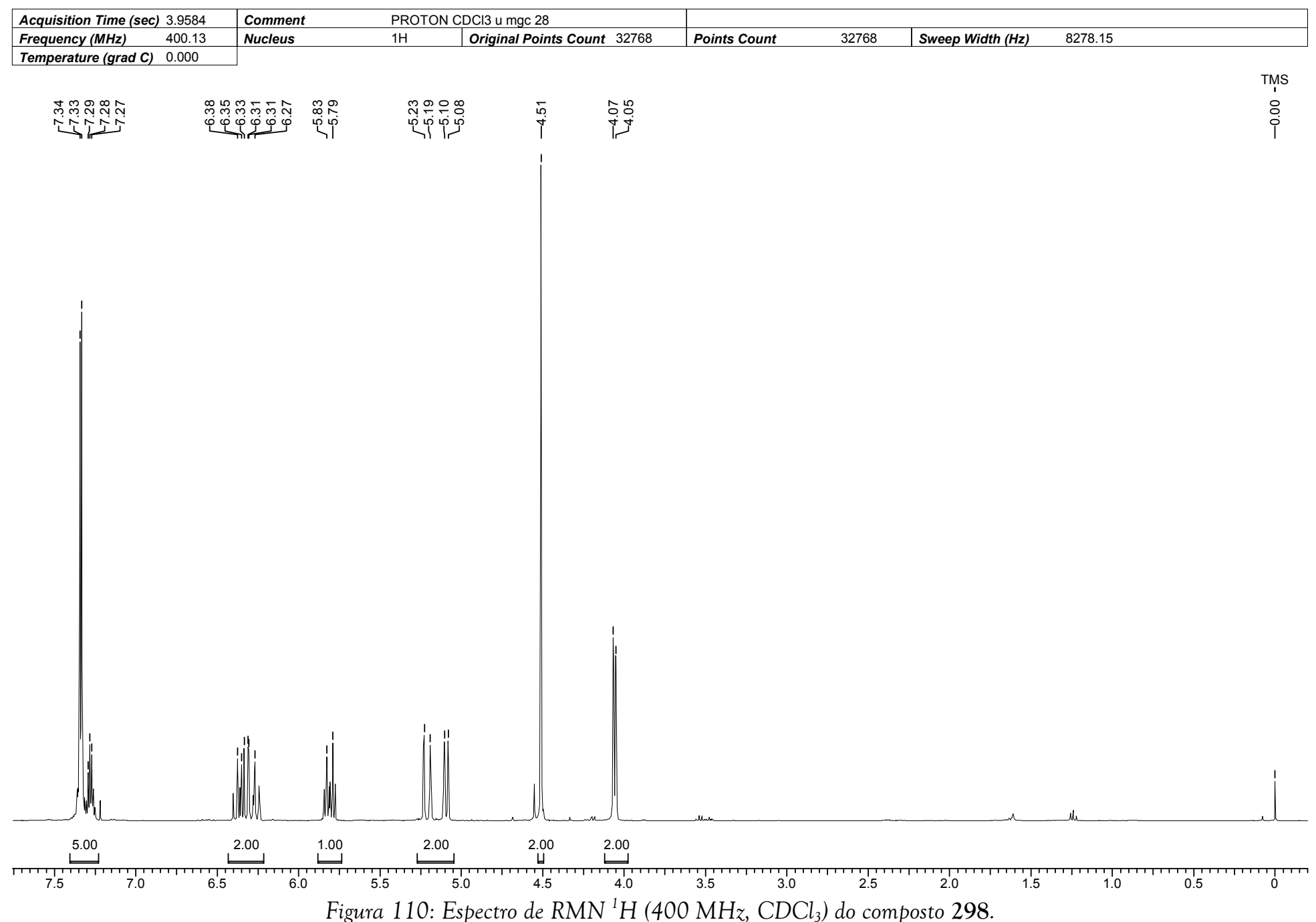


Espectro de RMN ${ }^{13} \mathrm{C}\left\{{ }^{1} \mathrm{H}\right\}$

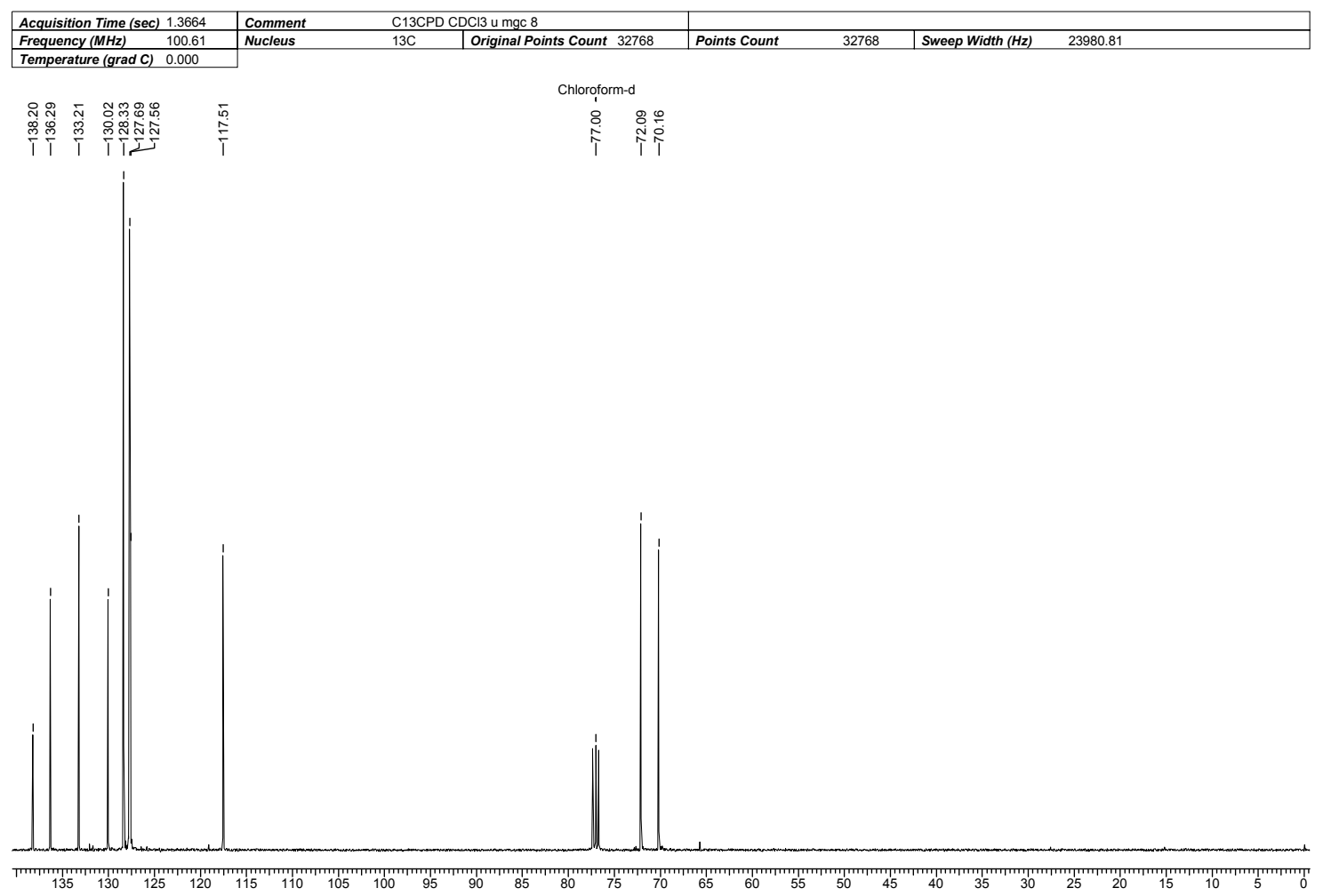

Espectro de RMN ${ }^{13} \mathrm{C}(\mathrm{DEPT}-135)$.

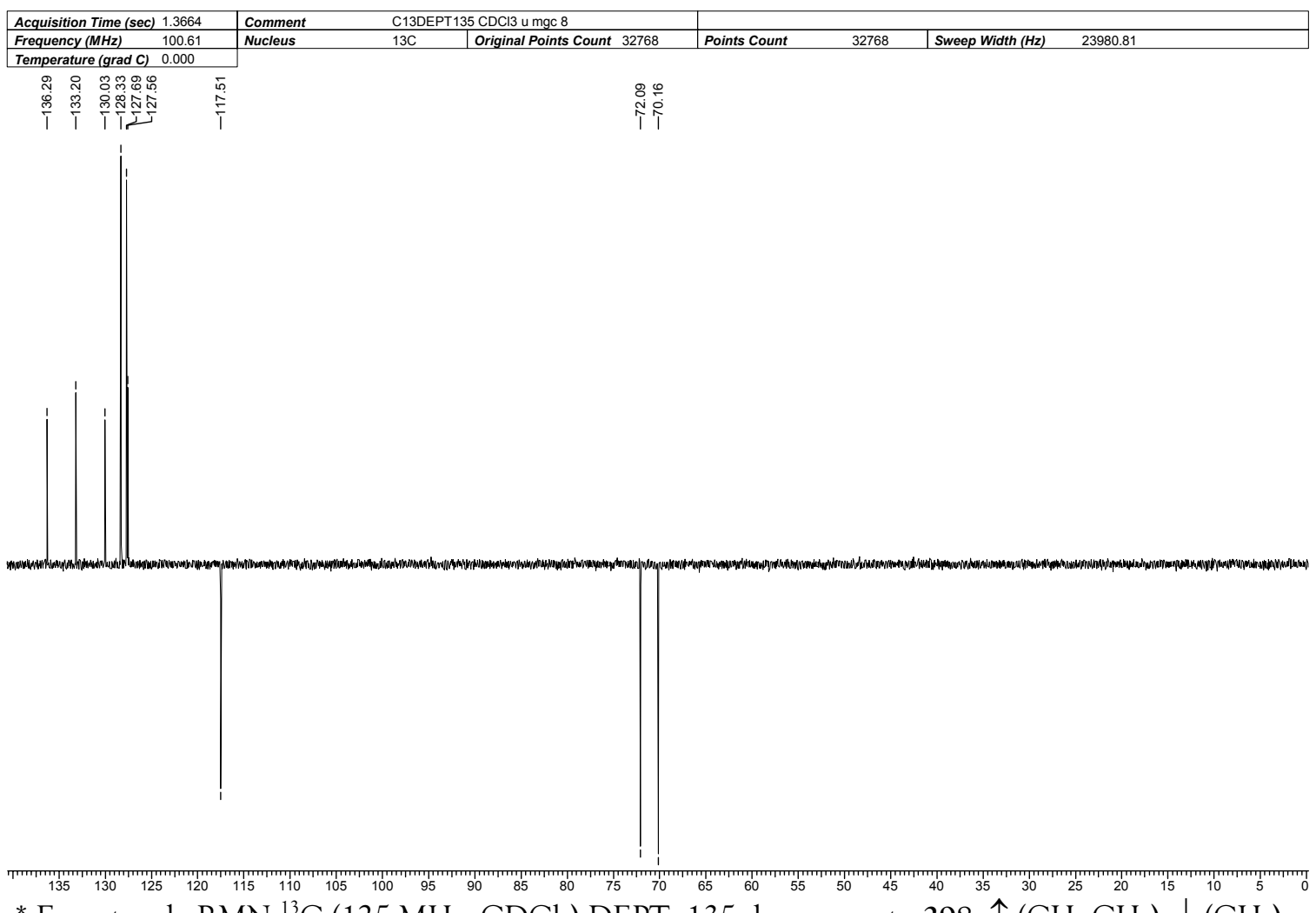

* Espectro de RMN ${ }^{13} \mathrm{C}\left(125 \mathrm{MHz}, \mathrm{CDCl}_{3}\right)$ DEPT-135 do composto 298. $\uparrow\left(\mathrm{CH}, \mathrm{CH}_{3}\right), \downarrow$. $\left(\mathrm{CH}_{2}\right)$

Figura 111: Espectros de $\mathrm{RMN}^{13} \mathrm{C}\left(100 \mathrm{MHz}, \mathrm{CDCl}_{3}\right)$ do composto 298. 
Tabela 59: Dados Espectroscópicos do composto 298.

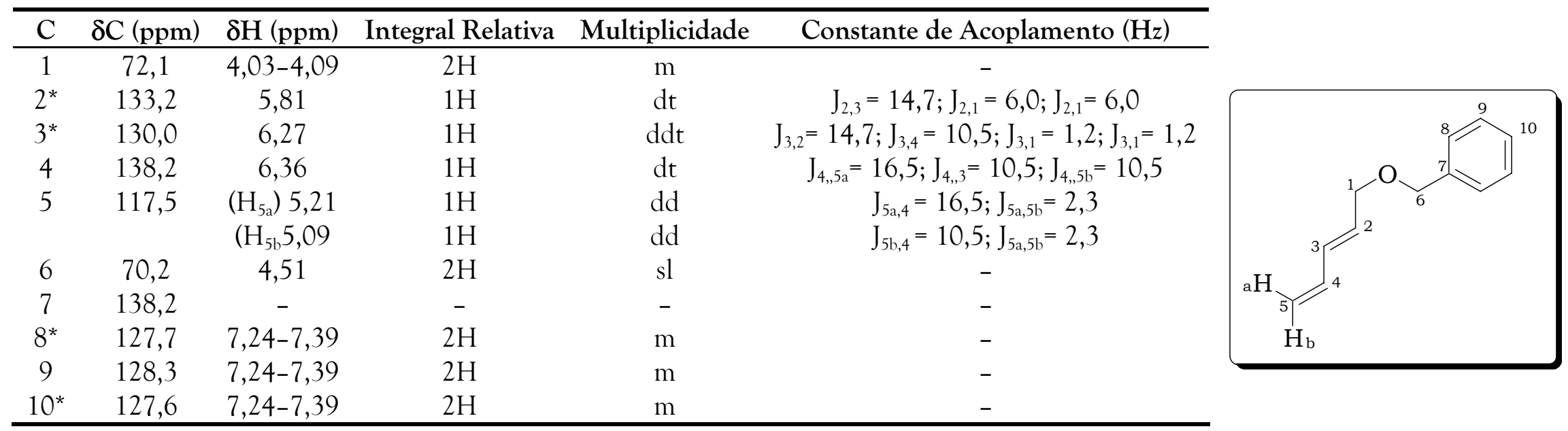

* podem estar trocados 


\section{Composto 300}

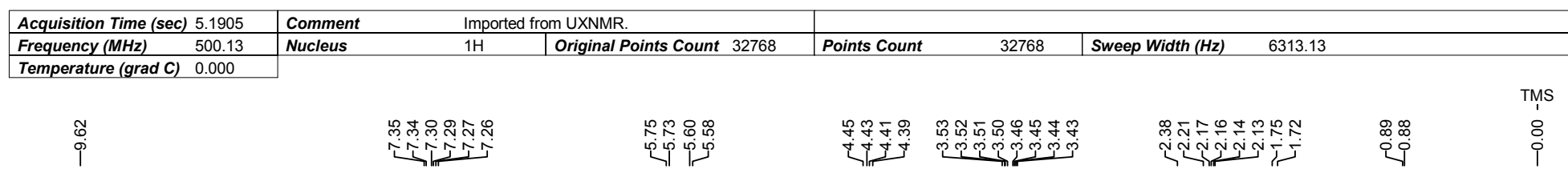

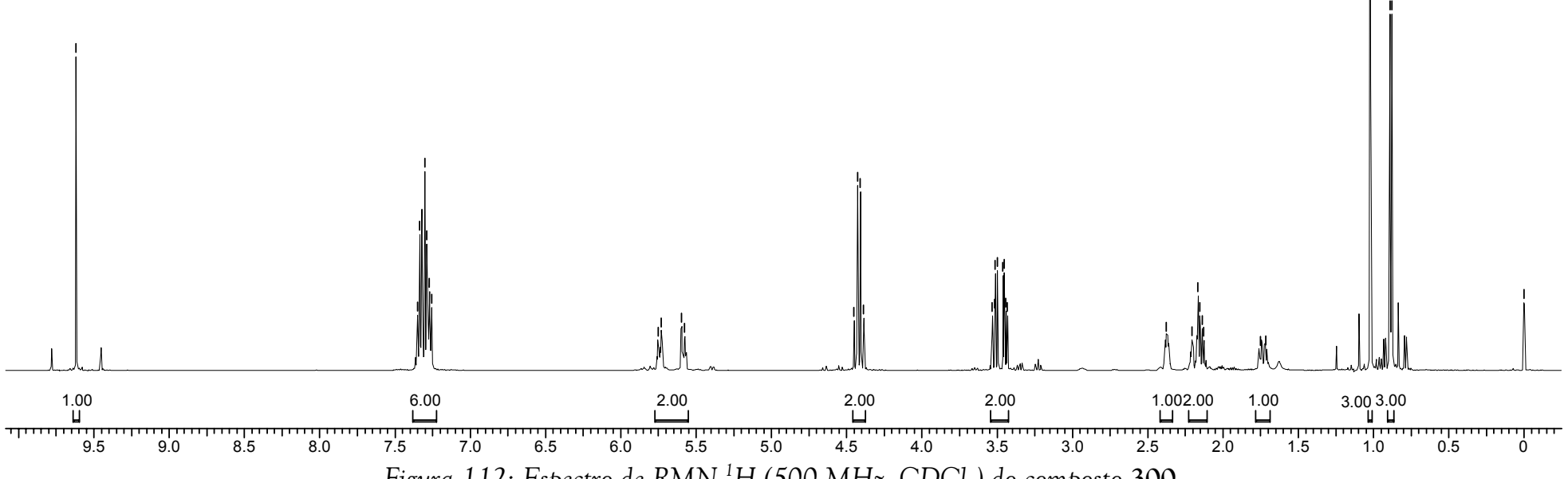

Figura 112: Espectro de $\mathrm{RMN}^{1} \mathrm{H}\left(500 \mathrm{MHz}, \mathrm{CDCl}_{3}\right)$ do composto 300. 
Espectro de $R M N{ }^{13} \mathrm{C}\left\{{ }^{1} \mathrm{H}\right\}$

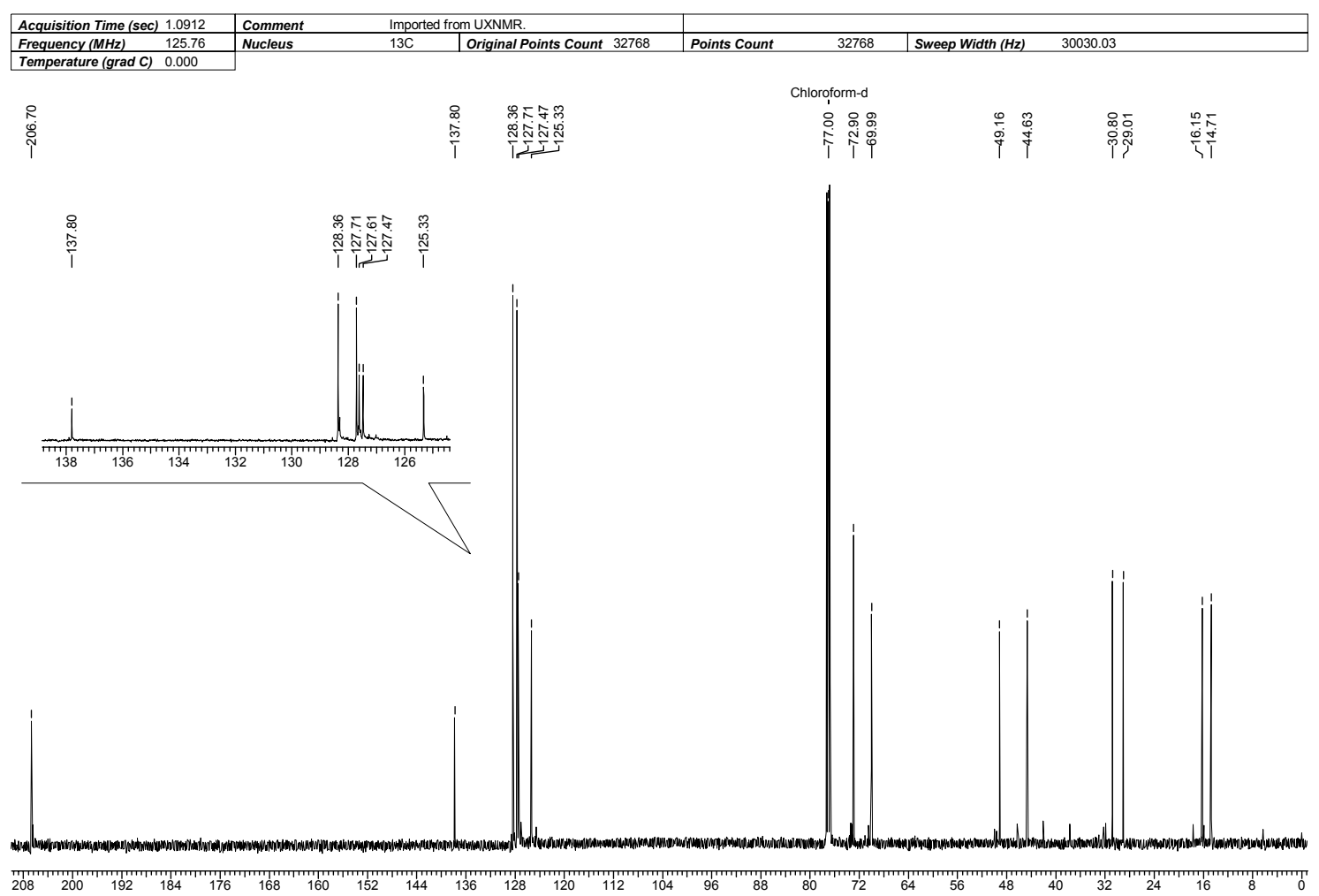

Espectro de RMN ${ }^{13} \mathrm{C}(\mathrm{DEPT}-135)$.

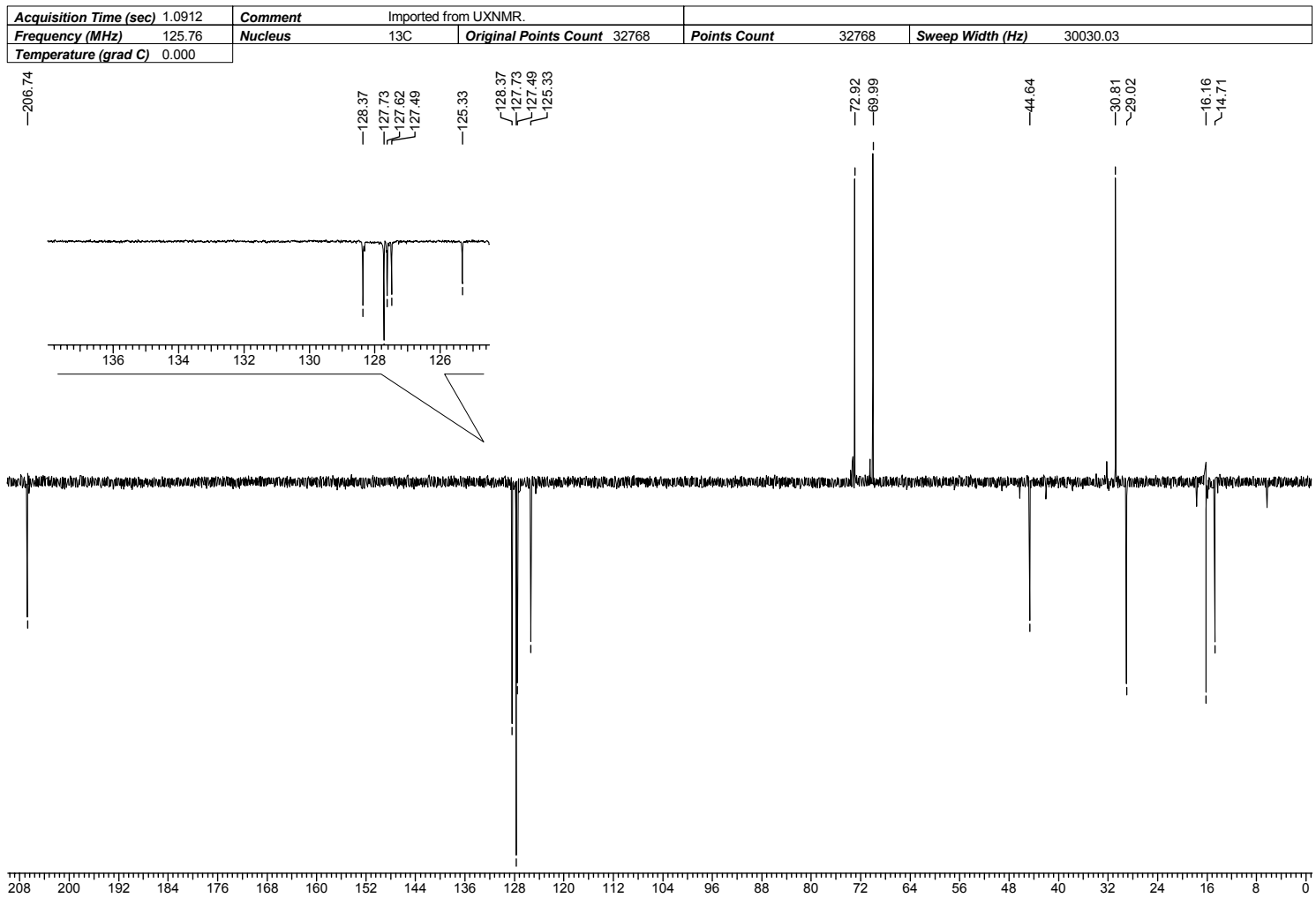

${ }^{*}$ Espectro de RMN ${ }^{13} \mathrm{C}\left(125 \mathrm{MHz}, \mathrm{CDCl}_{3}\right)$ DEPT-135 do composto 300. $\downarrow\left(\mathrm{CH}, \mathrm{CH}_{3}\right) \uparrow\left(\mathrm{CH}_{2}\right)$

Figura 113: Espectros de $\mathrm{RMN}^{13} \mathrm{C}\left(125 \mathrm{MHz}, \mathrm{CDCl}_{3}\right)$ do composto 300. 
Tabela 60: Dados Espectroscópicos do Composto 300.

\begin{tabular}{|c|c|c|c|c|c|c|c|c|}
\hline $\mathrm{C}$ & $\delta \mathrm{C}(\mathrm{ppm})$ & $\delta \mathrm{H}(\mathrm{ppm})$ & $\begin{array}{l}\text { Integral } \\
\text { Relativa }\end{array}$ & Multiplicidade & $\begin{array}{c}\text { Constantes de } \\
\text { Acoplamento }(\mathrm{Hz})\end{array}$ & gCOSY & gHMBC & gHMQC \\
\hline 1 & 206,7 & 9,62 & $1 \mathrm{H}$ & $\mathrm{s}$ & - & - & $\mathrm{H}_{3} ; \mathrm{H}_{14}$ & $\mathrm{H}_{1}$ \\
\hline 2 & 49,2 & - & - & - & - & - & $\mathrm{H}_{1} ; \mathrm{H}_{3} ; \mathrm{H}_{4 \mathrm{a}} ; \mathrm{H}_{4 \mathrm{~b}} ; \mathrm{H}_{6} ; \mathrm{H}_{8 \mathrm{a}} ; \mathrm{H}_{8 \mathrm{~b}} ; \mathrm{H}_{14} ; \mathrm{H}_{15}$ & - \\
\hline 3 & 29,0 & $2,10-2,17$ & $1 \mathrm{H}$ & $\mathrm{m}$ & - & $\mathrm{H}_{4 \mathrm{a}} ; \mathrm{H}_{4 \mathrm{~b}} ; \mathrm{H}_{7} ; \mathrm{H}_{15}$ & $\mathrm{H}_{4 \mathrm{a}} ; \mathrm{H}_{4 \mathrm{~b}} ; \mathrm{H}_{5} ; \mathrm{H}_{14} ; \mathrm{H}_{15}$ & $\mathrm{H}_{3}$ \\
\hline \multirow[t]{2}{*}{4} & 30,8 & $\left(\mathrm{H}_{4 \mathrm{a}}\right) 1,68-1,78$ & $1 \mathrm{H}$ & $\mathrm{m}$ & - & $\mathrm{H}_{3} ; \mathrm{H}_{4 \mathrm{~b}} ; \mathrm{H}_{5} ; \mathrm{H}_{6} ; \mathrm{H}_{15}$ & $\mathrm{H}_{3} ; \mathrm{H}_{5} ; \mathrm{H}_{6} ; \mathrm{H}_{15}$ & $\mathrm{H}_{4 \mathrm{a}, \mathrm{b}}$ \\
\hline & & $\left(\mathrm{H}_{4 \mathrm{~b}}\right) 2,14-2,24$ & $1 \mathrm{H}$ & $\mathrm{m}$ & - & $\mathrm{H}_{3} ; \mathrm{H}_{4 \mathrm{a}} ; \mathrm{H}_{5} ; \mathrm{H}_{6}$ & - & - \\
\hline 5 & 127,5 & $5,72-5,76$ & $1 \mathrm{H}$ & $\mathrm{m}$ & - & $\mathrm{H}_{3} ; \mathrm{H}_{4 \mathrm{a}} ; \mathrm{H}_{4 \mathrm{~b}} ; \mathrm{H}_{6} ; \mathrm{H}_{7}$ & $\mathrm{H}_{3} ; \mathrm{H}_{4 \mathrm{a}} ; \mathrm{H}_{4 \mathrm{~b}} ; \mathrm{H}_{6} ; \mathrm{H}_{7}$ & $\mathrm{H}_{5}$ \\
\hline 6 & 125,3 & $5,56-5,61$ & $1 \mathrm{H}$ & $\mathrm{m}$ & - & $\mathrm{H}_{4 \mathrm{a}} ; \mathrm{H}_{4 \mathrm{~b}} ; \mathrm{H}_{5} ; \mathrm{H}_{7}$ & $\mathrm{H}_{4 \mathrm{a}} ; \mathrm{H}_{4 \mathrm{~b}} ; \mathrm{H}_{5} ; \mathrm{H}_{7} ; \mathrm{H}_{8 \mathrm{a}} ; \mathrm{H}_{8 \mathrm{~b}}$ & $\mathrm{H}_{6}$ \\
\hline 7 & 44,6 & $2,35-2,40$ & $1 \mathrm{H}$ & $\mathrm{m}$ & - & $\mathrm{H}_{3} ; \mathrm{H}_{5} ; \mathrm{H}_{6} ; \mathrm{H}_{8 \mathrm{a}} ; \mathrm{H}_{8 \mathrm{~b}}$ & $\mathrm{H}_{3} ; \mathrm{H}_{5} ; \mathrm{H}_{6} ; \mathrm{H}_{8 \mathrm{a}} ; \mathrm{H}_{8 \mathrm{~b}} ; \mathrm{H}_{14}$ & $\mathrm{H}_{7}$ \\
\hline \multirow[t]{2}{*}{8} & 70,0 & $\left(\mathrm{H}_{8 \mathrm{a}}\right) 3,45$ & $1 \mathrm{H}$ & $\mathrm{dd}$ & $\mathrm{J}_{8 \mathrm{a}, 8 \mathrm{~b}}=9,9 ; \mathrm{J}_{8 \mathrm{a}, 7}=4,1$ & $\mathrm{H}_{7} ; \mathrm{H}_{8 \mathrm{~b}}$ & $\mathrm{H}_{6} ; \mathrm{H}_{7} ; \mathrm{H}_{9}$ & $\mathrm{H}_{8 \mathrm{a}, \mathrm{b}}$ \\
\hline & & $\left(\mathrm{H}_{8 \mathrm{~b}}\right) 3,52$ & $1 \mathrm{H}$ & $\mathrm{dd}$ & $\mathrm{J}_{8 \mathrm{~b}, 8 \mathrm{a}}=9,9 ; \mathrm{J}_{8 \mathrm{~b}, 7}=7,5$ & $\mathrm{H}_{7} ; \mathrm{H}_{8 \mathrm{a}}$ & - & - \\
\hline \multirow[t]{2}{*}{9} & 72,9 & $\left(\mathrm{H}_{9 \mathrm{a}}\right) 4,40$ & $1 \mathrm{H}$ & $\mathrm{d}$ & $\mathrm{J}_{9 \mathrm{a}, 9 \mathrm{~b}}=11,8$ & $\mathrm{H}_{9 b}$ & $\mathrm{H}_{11} ; \mathrm{H}_{8}$ & $\mathrm{H}_{9 \mathrm{a}, \mathrm{b}}$ \\
\hline & & $\left(\mathrm{H}_{9 \mathrm{~b}}\right) 4,44$ & $1 \mathrm{H}$ & $\mathrm{d}$ & $\mathrm{J}_{9 \mathrm{~b}, 9_{\mathrm{a}}}=11,8$ & $\mathrm{H}_{9 \mathrm{a}}$ & - & - \\
\hline 10 & 137,8 & - & - & - & - & - & $\mathrm{H}_{9 ;} \mathrm{H}_{11} ; \mathrm{H}_{12}$ & - \\
\hline 11 & 127,7 & $7,20-7,38$ & $2 \mathrm{H}$ & $\mathrm{m}$ & - & - & $\mathrm{H}_{9}$ & $\mathrm{H}_{11}$ \\
\hline 12 & 128,4 & $7,20-7,38$ & $2 \mathrm{H}$ & $\mathrm{m}$ & - & - & - & $\mathrm{H}_{12}$ \\
\hline 13 & 127,6 & $7,20-7,38$ & $1 \mathrm{H}$ & $\mathrm{m}$ & - & - & - & $\mathrm{H}_{13}$ \\
\hline 14 & 14,7 & 1,02 & $3 \mathrm{H}$ & s & - & - & $\mathrm{H}_{1} ; \mathrm{H}_{3}$ & $\mathrm{H}_{14}$ \\
\hline 15 & 16,2 & 0,89 & $3 \mathrm{H}$ & $\mathrm{dl}$ & $\mathrm{J}_{15,3}=6,6$ & $\mathrm{H}_{3} ; \mathrm{H}_{4 \mathrm{a}}$ & $\mathrm{H}_{3} ; \mathrm{H}_{4 \mathrm{a}} ; \mathrm{H}_{4 \mathrm{~b}}$ & $\mathrm{H}_{15}$ \\
\hline
\end{tabular}


Tabela 61: Experimentos de NOE-DIFF com o Composto 300.

\begin{tabular}{cc}
\hline Hidrogênios Irradiados & Hidrogênios com efeito NOE \\
\hline $\mathrm{H}_{1}$ & $\mathrm{H}_{3} ; \mathrm{H}_{5} ; \mathrm{H}_{6} ; \mathrm{H}_{8} ; \mathrm{H}_{9} ; \mathrm{H}_{5} ;$ aromáticos \\
$\mathrm{H}_{4 \mathrm{a}}$ & $\mathrm{H}_{1} ; \mathrm{H}_{5} ; \mathrm{H}_{7} ; \mathrm{H}_{8}$ \\
$\mathrm{H}_{5}$ & $\mathrm{H}_{3} ; \mathrm{H}_{44} ; \mathrm{H}_{4 \mathrm{~b}} ; \mathrm{H}_{6}$ \\
$\mathrm{H}_{6}$ & $\mathrm{H}_{1} ; \mathrm{H}_{5} ; \mathrm{H}_{7} ; \mathrm{H}_{8}$ \\
$\mathrm{H}_{7}$ & $\mathrm{H}_{4 \mathrm{a}} ; \mathrm{H}_{6} ; \mathrm{H}_{8} ; \mathrm{H}_{14} ; \mathrm{H}_{15} ;$ aromáticos \\
$\mathrm{H}_{8}$ & $\mathrm{H}_{1} ; \mathrm{H}_{3} ; \mathrm{H}_{5} ; \mathrm{H}_{6} ; \mathrm{H}_{7} ; \mathrm{H}_{9} ;$ aromáticos \\
$\mathrm{H}_{14}$ & $\mathrm{H}_{1} ; \mathrm{H}_{44} ; \mathrm{H}_{7} ; \mathrm{H}_{15}$ \\
$\mathrm{H}_{15}$ & $\mathrm{H}_{3} ; \mathrm{H}_{4 \mathrm{a}} ; \mathrm{H}_{7} ; \mathrm{H}_{14}$ \\
\hline
\end{tabular}

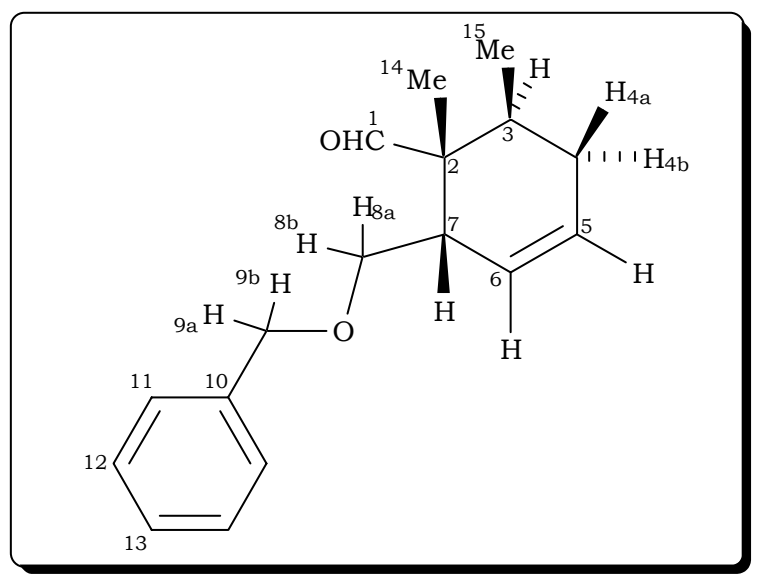




\section{Composto 301}

\begin{tabular}{|c|c|c|c|c|c|c|c|c|c|}
\hline \multirow{2}{*}{$\begin{array}{l}\text { Acquisition Time (sec) } \\
\text { Frequency }(\mathrm{MHz})\end{array}$} & \multirow{2}{*}{$\begin{array}{l}3.9584 \\
400.13\end{array}$} & \multirow{2}{*}{\begin{tabular}{|l|} 
Comment \\
Nucleus \\
\end{tabular}} & \multicolumn{2}{|l|}{ PROTON CDCl3 u mgc 16} & \multirow[b]{2}{*}{ Points Count } & \multirow{2}{*}{32768} & \multirow{3}{*}{ Sweep Width (Hz) } & \multirow[b]{2}{*}{8278.15} & \\
\hline & & & Original Points Count & 32768 & & & & & \\
\hline Temperature (grad C) 0 & 0.000 & & & & & & & & TMS \\
\hline 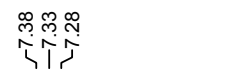 & & 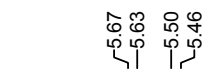 & 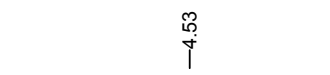 & 总蒫芯 & 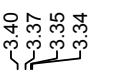 & & ' & ن & i \\
\hline
\end{tabular}

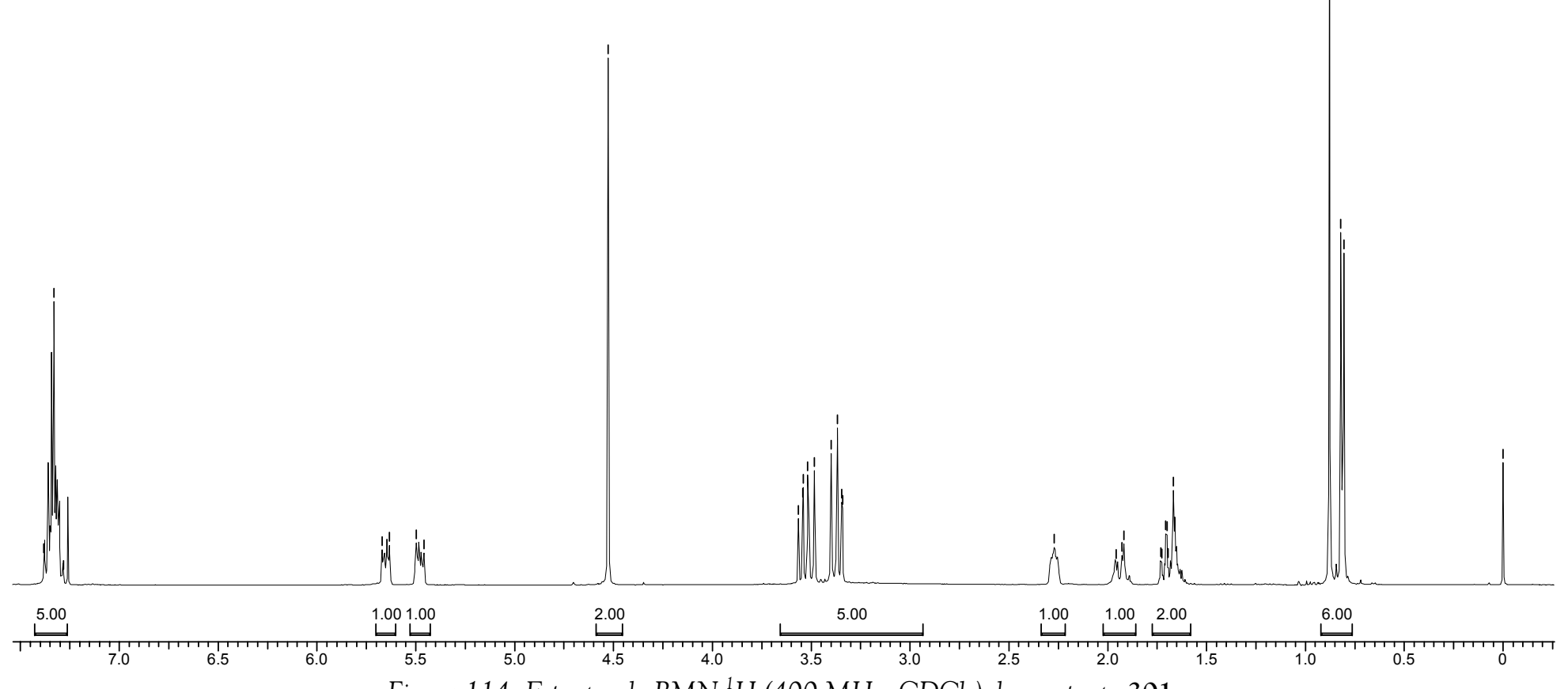

Figura 114: Espectro de $\mathrm{RMN}^{1} \mathrm{H}\left(400 \mathrm{MHz}, \mathrm{CDCl}_{3}\right)$ do composto 301. 
Espectro de $R M N{ }^{13} \mathrm{C}\left\{{ }^{1} \mathrm{H}\right\}$

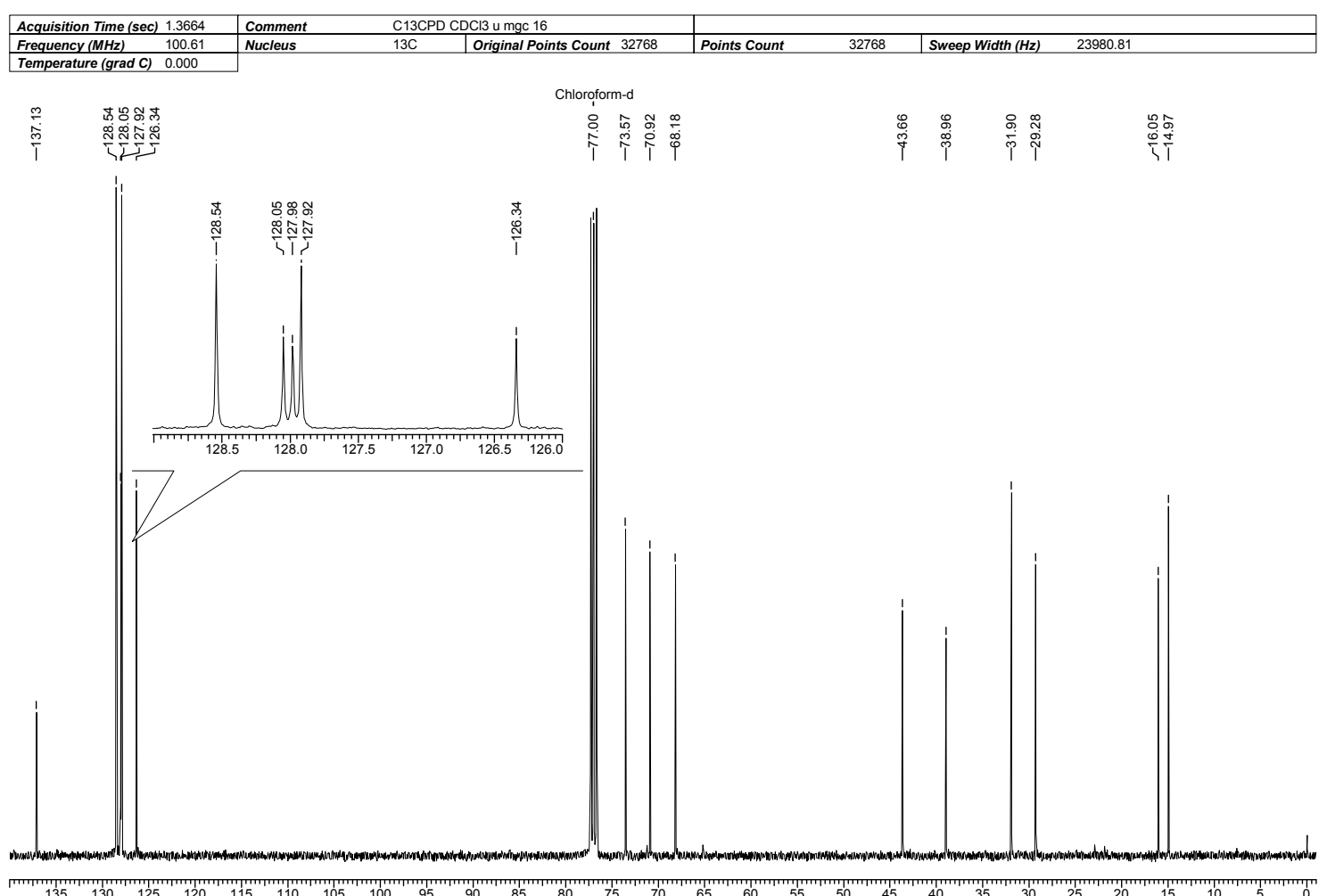

Espectro de RMN ${ }^{13} \mathrm{C}(\mathrm{DEPT}-135)$.

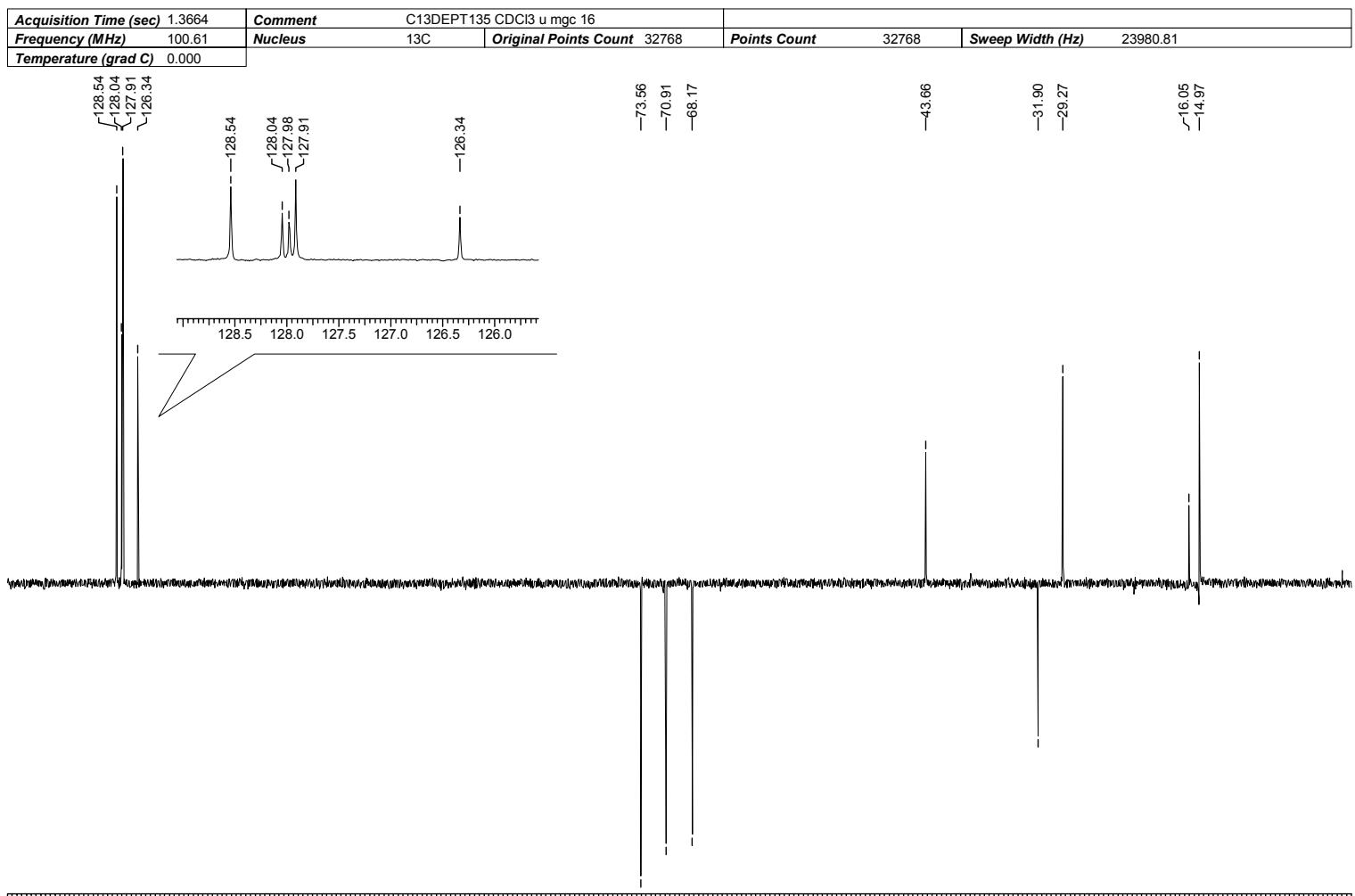

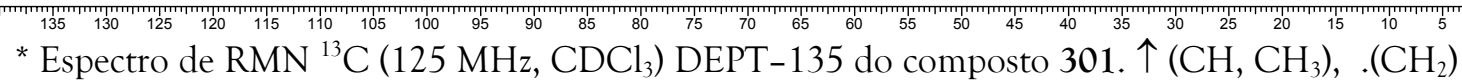

Figura 115: Espectros de $\mathrm{RMN}^{13} \mathrm{C}\left(100 \mathrm{MHz}, \mathrm{CDCl}_{3}\right)$ do composto 301 . 
Tabela 62: Dados Espectroscópicos do Composto 301.

\begin{tabular}{|c|c|c|c|c|c|c|c|c|}
\hline $\mathrm{C}$ & $\delta \mathrm{C}(\mathrm{ppm})$ & $\delta \mathrm{H}(\mathrm{ppm})$ & $\begin{array}{l}\text { Integral } \\
\text { Relativa }\end{array}$ & Multiplicidade & $\begin{array}{c}\text { Constantes de } \\
\text { Acoplamento }(\mathrm{Hz})\end{array}$ & $\mathrm{gCOSY}$ & gHMBC & gHMQC \\
\hline \multirow[t]{2}{*}{1} & 68,2 & $\left(\mathrm{H}_{1 \mathrm{a}}\right) 3,38$ & $1 \mathrm{H}$ & $\mathrm{d}$ & $\mathrm{J}_{\mathrm{a} a, 1 \mathrm{~b}}=11,9$ & $\mathrm{H}_{1 \mathrm{~b}}$ & $\mathrm{H}_{3} ; \mathrm{H}_{14}$ & $\mathrm{H}_{\mathrm{la}, \mathrm{b}}$ \\
\hline & & $\mathrm{H}\left({ }_{1 b}\right) 3,50$ & & $\mathrm{~d}$ & $\mathrm{~J}_{1 \mathrm{~b}, 1 \mathrm{a}}=11,9$ & $\mathrm{H}_{1 \mathrm{a}}$ & - & - \\
\hline 2 & 39,0 & - & - & - & - & - & $\begin{array}{c}\mathrm{H}_{1 \mathrm{a}} ; \mathrm{H}_{1 \mathrm{~b}} ; \mathrm{H}_{3} ; \mathrm{H}_{4 \mathrm{a}} ; \mathrm{H}_{4 \mathrm{~b}} \\
\mathrm{H}_{6} ; \mathrm{H}_{7} ; \mathrm{H}_{8 \mathrm{a}} ; \mathrm{H}_{8 \mathrm{~b}} ; \mathrm{H}_{14} ; \mathrm{H}_{15}\end{array}$ & $\mathrm{H}_{2}$ \\
\hline 3 & 29,3 & $1,60-1,69$ & $1 \mathrm{H}$ & $\mathrm{m}$ & - & $\mathrm{H}_{4 \mathrm{a}} ; \mathrm{H}_{4 \mathrm{~b}} ; \mathrm{H}_{15}$ & $\mathrm{H}_{4 \mathrm{a}} ; \mathrm{H}_{4 \mathrm{~b}} ; \mathrm{H}_{5} ; \mathrm{H}_{7} ; \mathrm{H}_{14} ; \mathrm{H}_{15}$ & $\mathrm{H}_{3}$ \\
\hline \multirow[t]{2}{*}{4} & 31,9 & $\left(\mathrm{H}_{4 \mathrm{a}}\right) 1,64-1,74$ & $1 \mathrm{H}$ & $\mathrm{m}$ & - & $\mathrm{H}_{3} ; \mathrm{H}_{4 \mathrm{~b}} ; \mathrm{H}_{5} ; \mathrm{H}_{6}$ & $\mathrm{H}_{3} ; \mathrm{H}_{5} ; \mathrm{H}_{6} ; \mathrm{H}_{15}$ & $\mathrm{H}_{4 a, b}-$ \\
\hline & & $\left(\mathrm{H}_{4 \mathrm{~b}}\right) 1,94$ & $1 \mathrm{H}$ & dddd & $\begin{array}{c}\mathrm{J}_{4 \mathrm{~b}, 4 \mathrm{a}}=13,0 ; \mathrm{J}_{4 \mathrm{~b}, 5}=4,8 ; \mathrm{J}_{4 \mathrm{~b}, 3}=2,3 ; \mathrm{J}_{4 \mathrm{~b}, 6}= \\
1,0\end{array}$ & $\mathrm{H}_{3} ; \mathrm{H}_{4 \mathrm{a}} ; \mathrm{H}_{5} ; \mathrm{H}_{6}$ & - & - \\
\hline 5 & 128,0 & 5,65 & $1 \mathrm{H}$ & $\mathrm{ddt}$ & $\mathrm{J}_{5,6}=10,0 ; \mathrm{J}_{5,4 \mathrm{~b}}=4,8 ; \mathrm{J}_{5,4 \mathrm{a}}=1,7 ; \mathrm{J}_{5,7}=1,7$ & $\mathrm{H}_{4 \mathrm{a}} ; \mathrm{H}_{4 \mathrm{~b}} ; \mathrm{H}_{6} ; \mathrm{H}_{7}$ & $\mathrm{H}_{3} ; \mathrm{H}_{4 \mathrm{a}} ; \mathrm{H}_{4 \mathrm{~b}} ; \mathrm{H}_{6} ; \mathrm{H}_{7}$ & $\mathrm{H}_{5}$ \\
\hline 6 & 126,4 & 5,481 & $1 \mathrm{H}$ & $\mathrm{ddt}$ & $\mathrm{J}_{6,5}=10,0 ; \mathrm{J}_{6,7}=5,2 ; \mathrm{J}_{6,4 \mathrm{~b}}=1,0 ; \mathrm{J}_{6,4 \mathrm{a}}=1,0$ & $\mathrm{H}_{4 \mathrm{a}} ; \mathrm{H}_{4 \mathrm{~b}} ; \mathrm{H}_{5} ; \mathrm{H}_{7}$ & $\mathrm{H}_{4 \mathrm{a}} ; \mathrm{H}_{4 \mathrm{~b}} ; \mathrm{H}_{5} ; \mathrm{H}_{7} ; \mathrm{H}_{8 \mathrm{a}} ; \mathrm{H}_{8 \mathrm{~b}}$ & $\mathrm{H}_{6}$ \\
\hline 7 & 43,7 & 2,27 & $1 \mathrm{H}$ & dddd & $\mathrm{J}_{7,8 \mathrm{~b}}=8,8 ; \mathrm{J}_{7,6}=5,2 ; \mathrm{J}_{7,8 \mathrm{a}}=2,4 ; \mathrm{J}_{7,5}=1,7$ & $\mathrm{H}_{5} ; \mathrm{H}_{6} ; \mathrm{H}_{8 \mathrm{a}} ; \mathrm{H}_{8 \mathrm{~b}}$ & $\begin{array}{c}\mathrm{H}_{1 \mathrm{a}} ; \mathrm{H}_{1 \mathrm{~b}} ; \mathrm{H}_{3} ; \mathrm{H}_{5} ; \mathrm{H}_{6} ; \mathrm{H}_{8 \mathrm{a}} ; \\
\mathrm{H}_{8 \mathrm{~b}} ; \mathrm{H}_{14}\end{array}$ & $\mathrm{H}_{7}$ \\
\hline \multirow[t]{2}{*}{8} & 71,0 & $\left(\mathrm{H}_{8 \mathrm{a}}\right) 3,36$ & $1 \mathrm{H}$ & dd & $\mathrm{J}_{8 \mathrm{a}, 8 \mathrm{~b}}=10,1 ; \mathrm{J}_{8 \mathrm{a}, 7}=2,4$ & $\mathrm{H}_{7} ; \mathrm{H}_{8 \mathrm{~b}}$ & $\mathrm{H}_{6} ; \mathrm{H}_{7} ; \mathrm{H}_{9}$ & $\mathrm{H}_{8 \mathrm{a}, \mathrm{b}}$ \\
\hline & & $\left(\mathrm{H}_{8 \mathrm{~b}}\right) 3,55$ & $1 \mathrm{H}$ & $\mathrm{dd}$ & $\mathrm{J}_{8 \mathrm{~b}, 8 \mathrm{a}}=10,1 ; \mathrm{J}_{8 \mathrm{~b}, 7}=8,8$ & $\mathrm{H}_{7} ; \mathrm{H}_{8 \mathrm{a}}$ & - & - \\
\hline 9 & 73,6 & 4,53 & $2 \mathrm{H}$ & sl & - & - & $\mathrm{H}_{11} ; \mathrm{H}_{8 \mathrm{a}} ; \mathrm{H}_{8 \mathrm{~b}}$ & $\mathrm{H}_{9 \mathrm{a}, \mathrm{b}}$ \\
\hline 10 & 137,2 & - & - & - & - & - & $\mathrm{H}_{9} ; \mathrm{H}_{11} ; \mathrm{H}_{12}$ & - \\
\hline 11 & 127,9 & $7,27-7,40$ & $2 \mathrm{H}$ & $\mathrm{m}$ & - & - & - & $\mathrm{H}_{11}$ \\
\hline 12 & 128,5 & $7,27-7,40$ & $2 \mathrm{H}$ & $\mathrm{m}$ & - & - & - & $\mathrm{H}_{12}$ \\
\hline 13 & 128,0 & $7,27-7,40$ & $1 \mathrm{H}$ & $\mathrm{m}$ & - & - & - & $\mathrm{H}_{13}$ \\
\hline 14 & 15,0 & 0,88 & $3 \mathrm{H}$ & s & - & - & $\mathrm{H}_{1 \mathrm{a}} ; \mathrm{H}_{1 \mathrm{~b}} ; \mathrm{H}_{3} ; \mathrm{H}_{7}$ & $\mathrm{H}_{14}$ \\
\hline 15 & 16,1 & 0,81 & $3 \mathrm{H}$ & $\mathrm{dl}$ & $\mathrm{J}_{15,3}=6,6$ & $\mathrm{H}_{3} ; \mathrm{H}_{4 \mathrm{a}}$ & $\mathrm{H}_{3} ; \mathrm{H}_{4 \mathrm{a}} ; \mathrm{H}_{4 \mathrm{~b}}$ & $\mathrm{H}_{15}$ \\
\hline
\end{tabular}




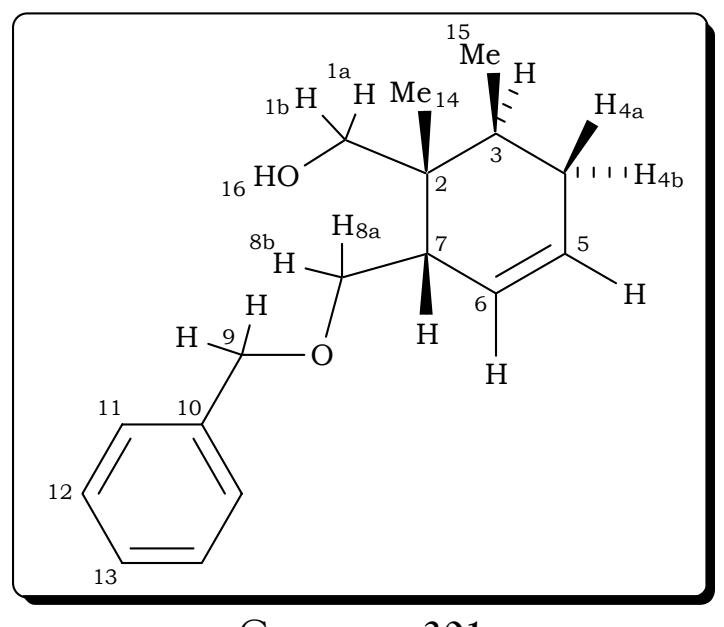

Composto 301 


\section{Composto 223}

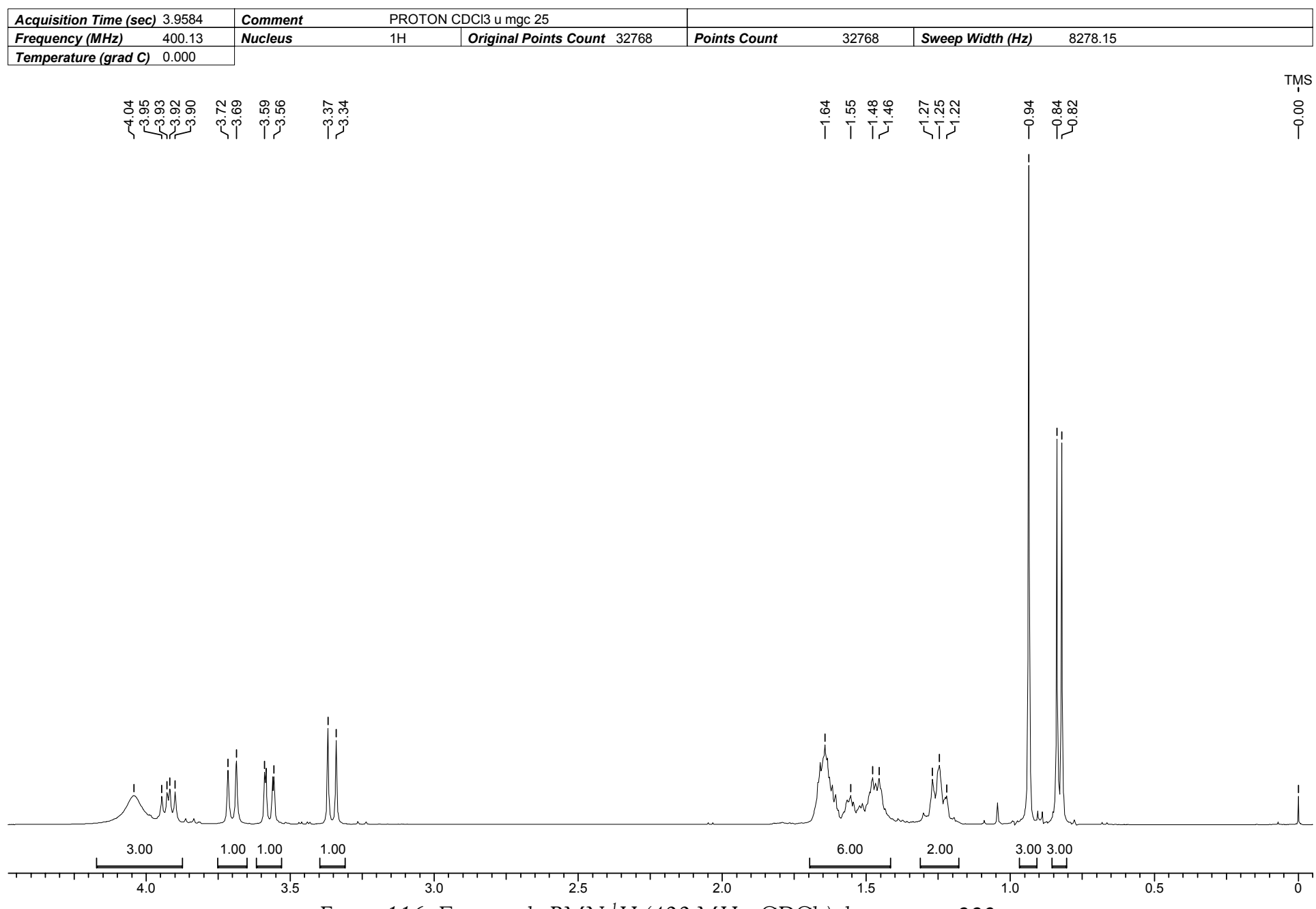

Figura 116: Espectro de $\mathrm{RMN}{ }^{1} \mathrm{H}\left(400 \mathrm{MHz}, \mathrm{CDCl}_{3}\right)$ do composto 223. 
Espectro de $R M N{ }^{13} \mathrm{C}\left\{{ }^{1} \mathrm{H}\right\}$

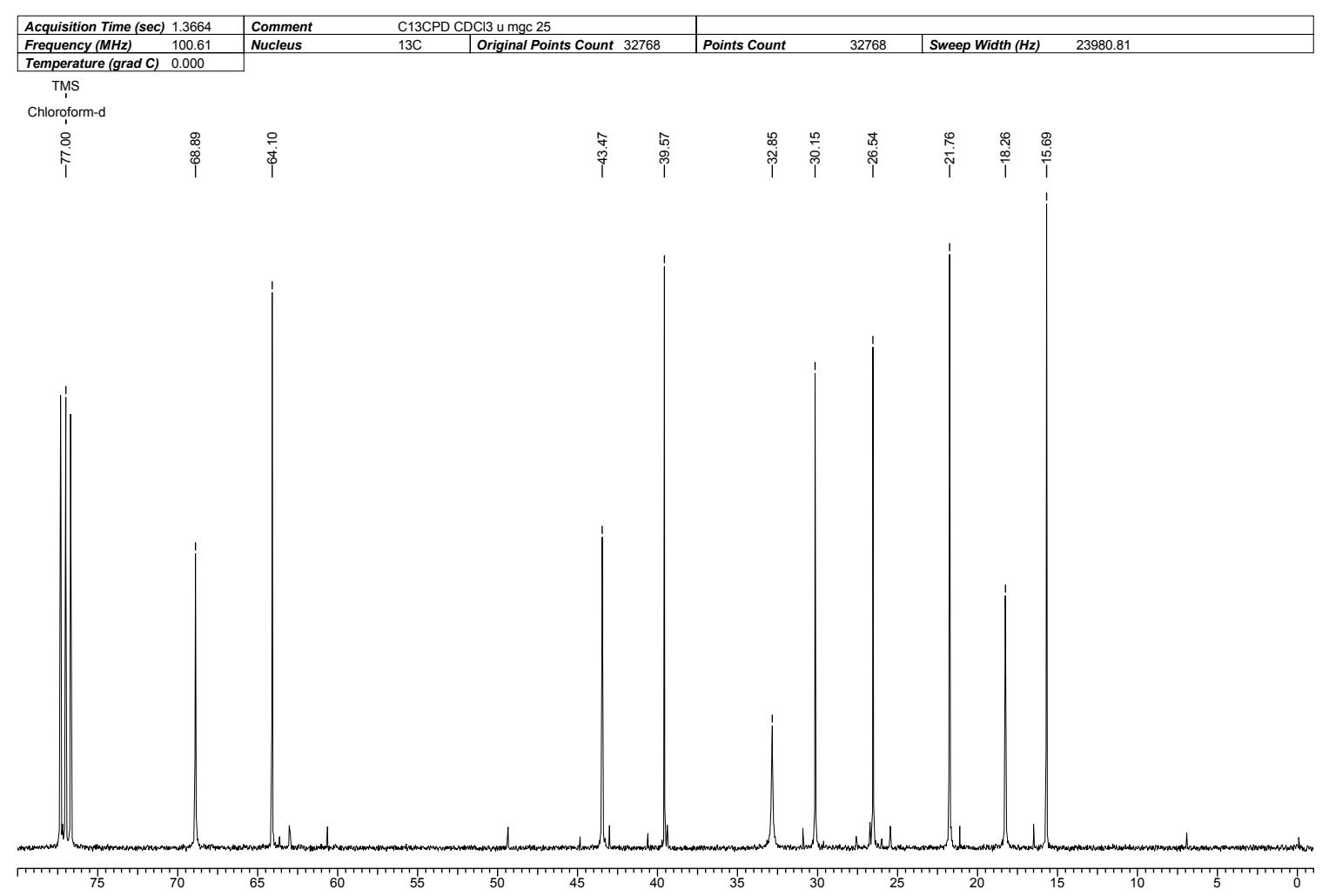

Espectro de RMN ${ }^{13} \mathrm{C}(\mathrm{DEPT}-135)$.

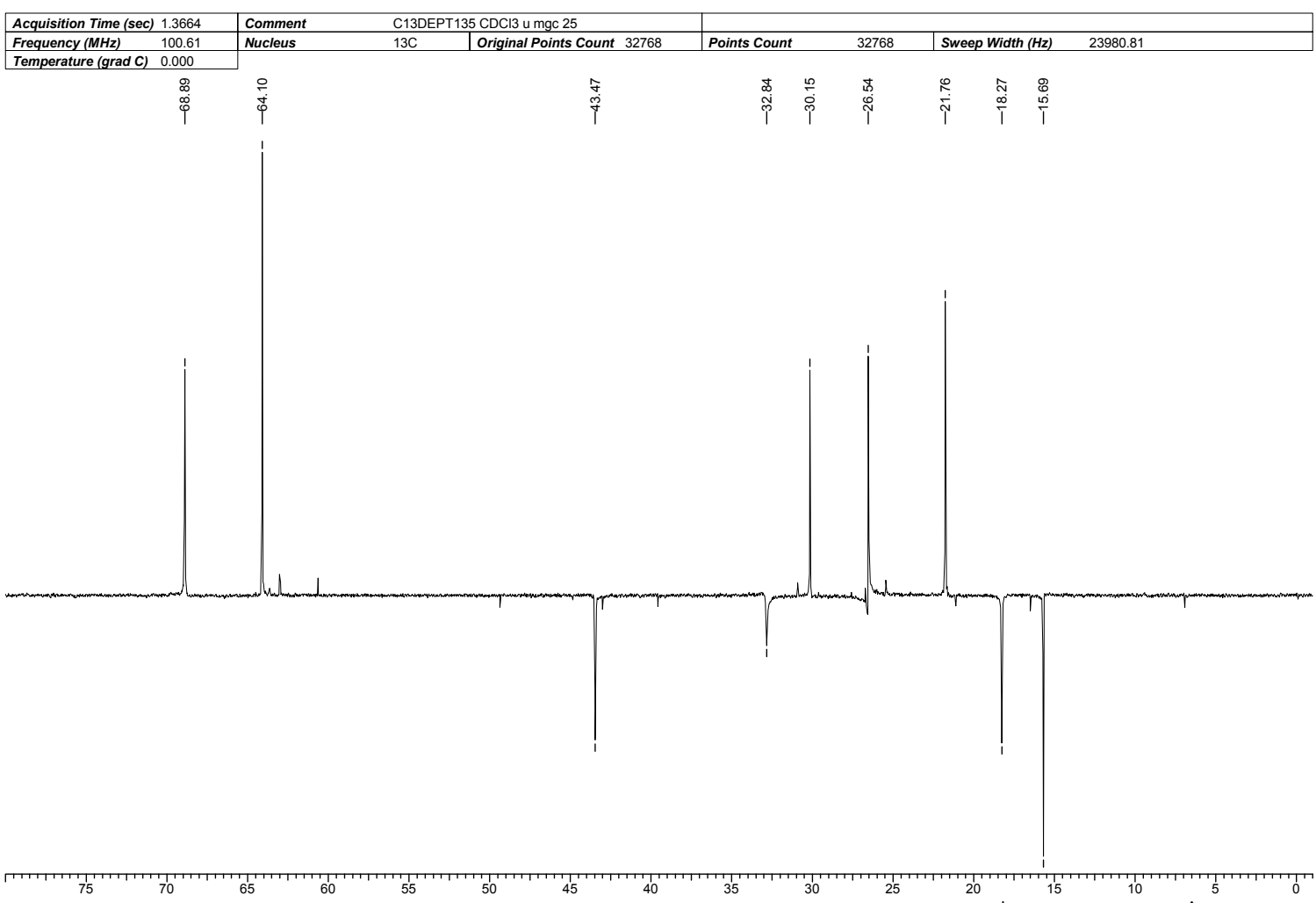

* Espectro de RMN ${ }^{13} \mathrm{C}\left(125 \mathrm{MHz}, \mathrm{CDCl}_{3}\right)$ DEPT-135 do composto $223 . \downarrow\left(\mathrm{CH}, \mathrm{CH}_{3}\right), . \uparrow\left(\mathrm{CH}_{2}\right)$

Figura 17: Espectros de $\mathrm{RMN}^{13} \mathrm{C}\left(100 \mathrm{MHz}, \mathrm{CDCl}_{3}\right)$ do composto 223. 
Tabela 63: Dados Espectroscópicos do Composto 223.

\begin{tabular}{cccccc}
\hline $\mathrm{C}$ & $\boldsymbol{\delta C}(\mathbf{p p m})$ & $\delta \mathrm{H}(\mathbf{p p m})$ & Integral Relativa & Multiplicidade & Constantes de Acoplamento $(\mathrm{Hz})$ \\
\hline 1 & 68,9 & $\left(\mathrm{H}_{1 \mathrm{a}}\right) 3,36$ & $1 \mathrm{H}$ & $\mathrm{d}$ & $\mathrm{J}_{1 \mathrm{a} / 1 \mathrm{~b}}=11,6$ \\
& - & $\mathrm{H}\left({ }_{1 \mathrm{~b}}\right) 3,70$ & $1 \mathrm{H}$ & $\mathrm{d}$ & $\mathrm{J}_{1 \mathrm{~b} / 1 \mathrm{a}}=11,6$ \\
2 & 39,6 & - & - & - & - \\
3 & 32,8 & $1,20-1,70$ & $1 \mathrm{H}$ & $\mathrm{m}$ & - \\
4 & 30,2 & $\left(\mathrm{H}_{4 \mathrm{a}}\right) 1,20-1,70$ & $2 \mathrm{H}$ & $\mathrm{m}$ & - \\
5 & 21,8 & $\left(\mathrm{H}_{5 \mathrm{a}}\right) 1,20-1,70$ & $2 \mathrm{H}$ & $\mathrm{m}$ & - \\
6 & 26,5 & $\left(\mathrm{H}_{6 \mathrm{a}}\right) 1,20-1,70$ & $2 \mathrm{H}$ & $\mathrm{m}$ & - \\
7 & 43,5 & $1,20-1,70$ & $1 \mathrm{H}$ & $\mathrm{m}$ & $\mathrm{J}_{8 \mathrm{a} / 8 \mathrm{~b}}=11,1 ; \mathrm{J}_{8 \mathrm{a} / 7}=2,0$ \\
8 & 64,1 & $\left(\mathrm{H}_{8 \mathrm{a}}\right) 3,57$ & $1 \mathrm{H}$ & $\mathrm{dd}$ & $\mathrm{J}_{8 \mathrm{~b} / 8 \mathrm{a}}=11,1 ; \mathrm{J}_{8 \mathrm{~b} / 7}=7,3$ \\
& - & $\left(\mathrm{H}_{8 \mathrm{~b}}\right) 3,93$ & $1 \mathrm{H}$ & $\mathrm{dd}$ & - \\
9 & 18,3 & 0,94 & $3 \mathrm{H}$ & $\mathrm{s}$ & $\mathrm{J}_{15 / 3}=6,8$ \\
10 & 15,7 & 0,83 & $3 \mathrm{H}$ & $\mathrm{d}$ & - \\
11 & - & $3,97-4,14$ & $1 \mathrm{H}$ & $\mathrm{sl}$ & - \\
12 & - & $3,97-4,14$ & $1 \mathrm{H}$ & $\mathrm{sl}$ & - \\
\hline
\end{tabular}

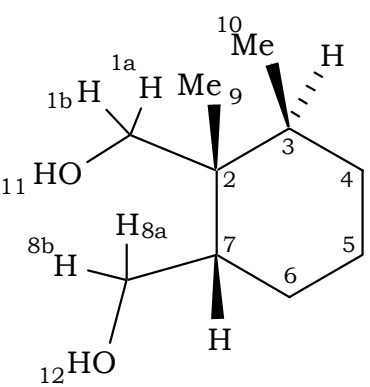




\section{Composto 224}

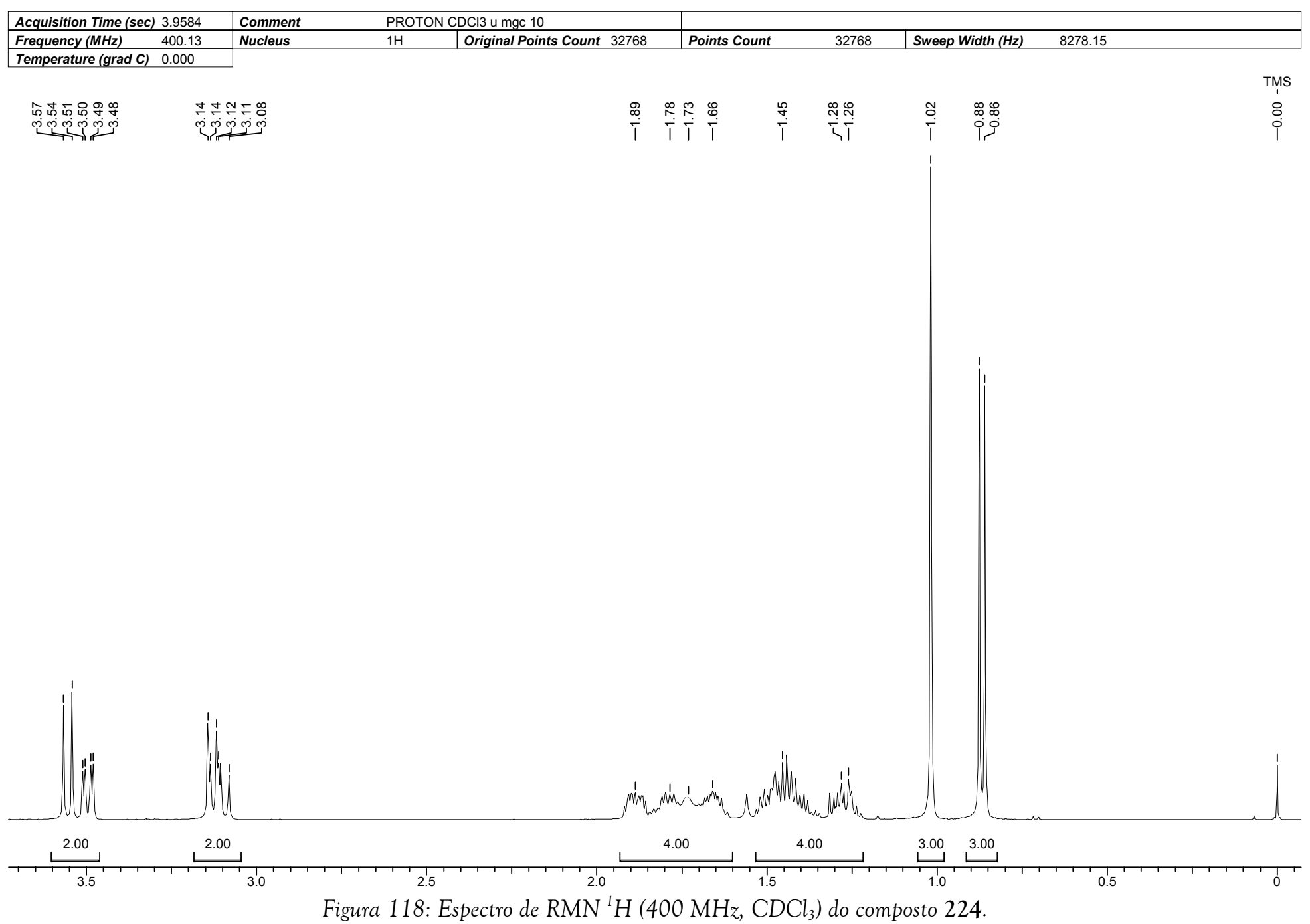


Espectro de $R M N{ }^{13} \mathrm{C}\left\{{ }^{1} \mathrm{H}\right\}$

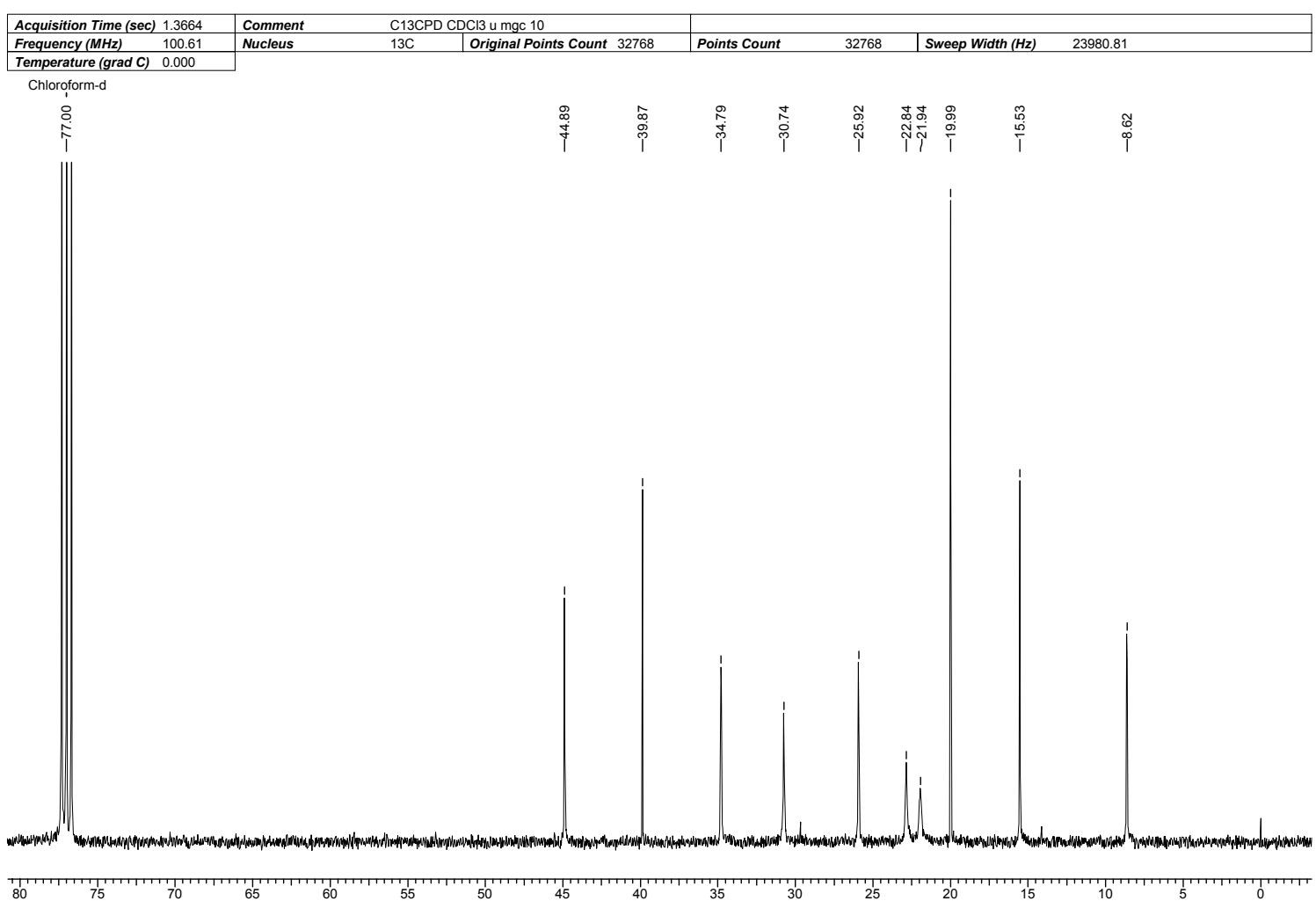

Espectro de RMN ${ }^{13} \mathrm{C}(\mathrm{DEPT}-135)$.

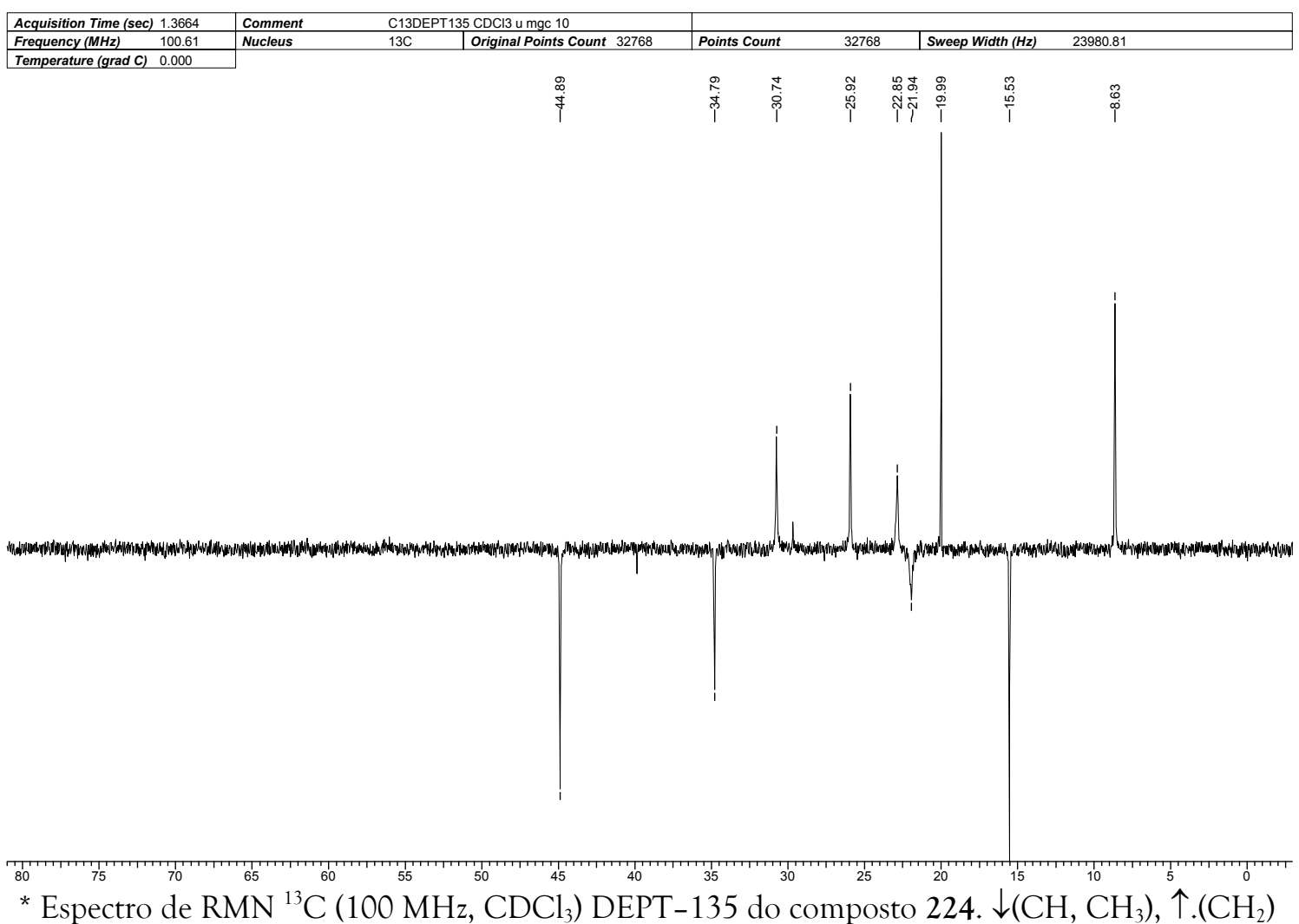

* Espectro de RMN ${ }^{13} \mathrm{C}\left(100 \mathrm{MHz}, \mathrm{CDCl}_{3}\right)$ DEPT-135 do composto $224 . \downarrow\left(\mathrm{CH}, \mathrm{CH}_{3}\right)$, $\uparrow .\left(\mathrm{CH}_{2}\right)$

Figura 119: Espectros de $R M N{ }^{13} \mathrm{C}\left(100 \mathrm{MHz}, \mathrm{CDCl}_{3}\right)$ do composto 224. 
Tabela 64: Dados Espectroscópicos do Composto 224.

\begin{tabular}{|c|c|c|c|c|c|}
\hline $\mathrm{C}$ & $\delta \mathrm{C}(\mathrm{ppm})$ & $\delta \mathrm{H}(\mathrm{ppm})$ & $\begin{array}{l}\text { Integral } \\
\text { Relativa }\end{array}$ & Multiplicidade & Constante de Acoplamento $(\mathrm{Hz})$ \\
\hline 1 & 22,8 & $\begin{array}{l}\left(\mathrm{H}_{1 \mathrm{a}}\right) 3,13 \\
\left(\mathrm{H}_{1 \mathrm{~b}}\right) 3,56\end{array}$ & $\begin{array}{l}1 \mathrm{H} \\
1 \mathrm{H}\end{array}$ & $\begin{array}{l}\mathrm{d} \\
\mathrm{d}\end{array}$ & $\begin{array}{l}\mathrm{J}_{1 \mathrm{a} / 1 \mathrm{~b}}=9,4 \\
\mathrm{~J}_{1 \mathrm{~b} / 1 \mathrm{a}}=9,4\end{array}$ \\
\hline 2 & 39,9 & - & - & & - \\
\hline 3 & 34,8 & $1,22-1,94$ & $1 \mathrm{H}$ & $\mathrm{m}$ & - \\
\hline 4 & 30,7 & $1,22-1,94$ & $2 \mathrm{H}$ & $\mathrm{m}$ & - \\
\hline 5 & 20,0 & $1,22-1,94$ & $2 \mathrm{H}$ & $\mathrm{m}$ & - \\
\hline 6 & 25,9 & $1,22-1,94$ & $2 \mathrm{H}$ & $\mathrm{m}$ & - \\
\hline 7 & 44,9 & $1,22-1,94$ & $1 \mathrm{H}$ & $\mathrm{m}$ & - \\
\hline 8 & 8,6 & $\begin{array}{l}\left(\mathrm{H}_{8 \mathrm{a}}\right) 3,11 \\
\left(\mathrm{H}_{8 \mathrm{~b}}\right) 3,49\end{array}$ & $\begin{array}{l}1 \mathrm{H} \\
1 \mathrm{H}\end{array}$ & $\begin{array}{l}\mathrm{dd} \\
\mathrm{dd}\end{array}$ & $\begin{array}{c}\mathrm{J}_{8 \mathrm{a} / 8 \mathrm{~b}}=12,1, \mathrm{~J}_{8 \mathrm{a} / 7}=9,4 \\
\mathrm{~J}_{8 \mathrm{~b} / 8 \mathrm{a}}=9,4, \mathrm{~J}_{8 \mathrm{~b} / 7}=3,0\end{array}$ \\
\hline 9 & 21,9 & 1,02 & $3 \mathrm{H}$ & s & - \\
\hline 10 & 15,5 & 0,87 & $3 \mathrm{H}$ & d & $\mathrm{J}_{10 / 3}=6,9$ \\
\hline
\end{tabular}

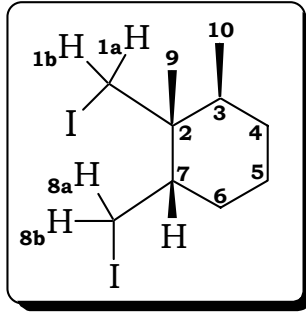




\section{Composto 303}

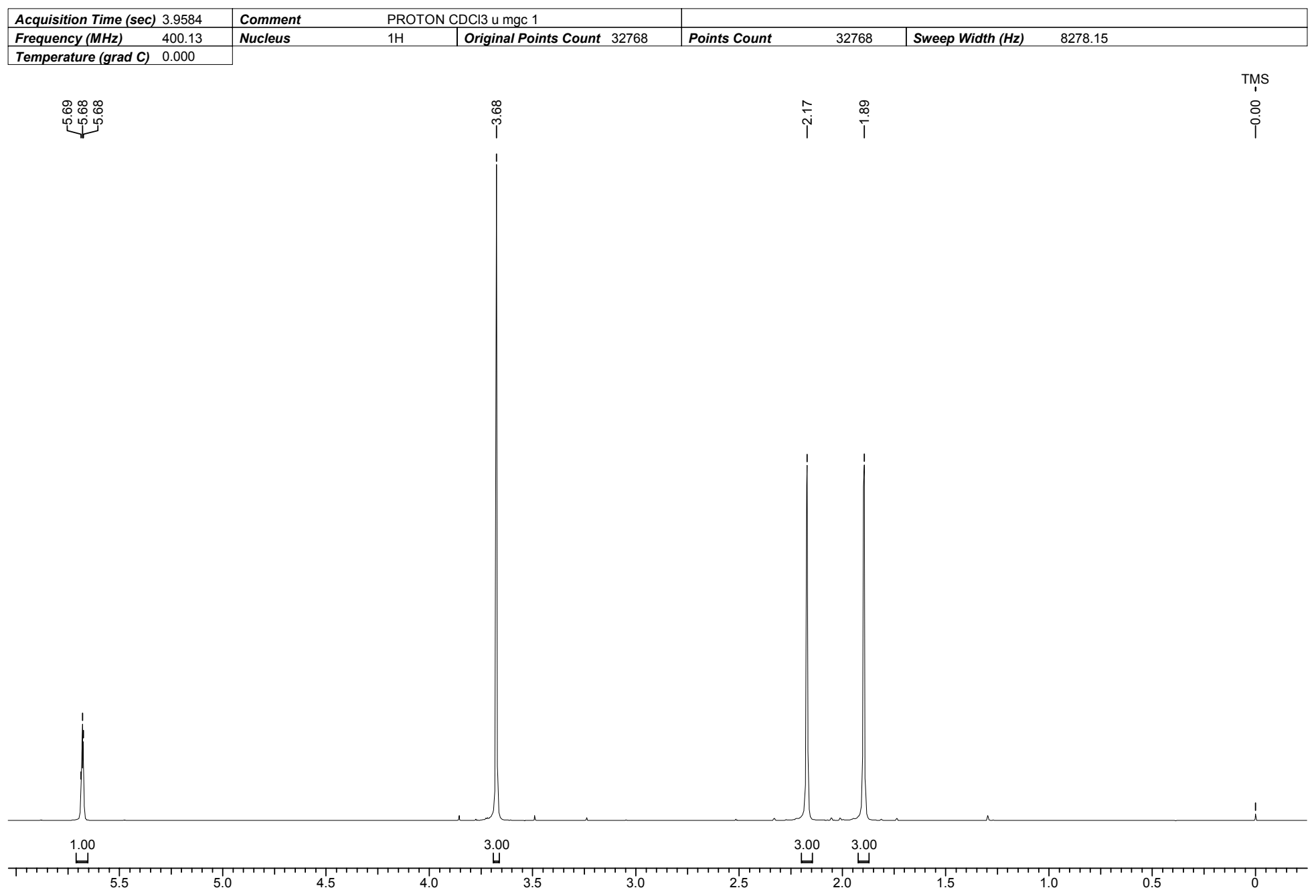

Figura 120: Espectro de $\mathrm{RMN}^{1} \mathrm{H}\left(400 \mathrm{MHz}, \mathrm{CDCl}_{3}\right)$ do composto 303. 
Tabela 65: Dados Espectroscópicos do Composto 303.

\begin{tabular}{cccc}
\hline$\delta \mathrm{H}(\mathrm{ppm})$ & $\begin{array}{c}\text { Integral } \\
\text { Relativa }\end{array}$ & Multiplicidade & \multicolumn{2}{c}{ Constante de Acoplamento $(\mathrm{Hz})$} \\
\hline$\left(\mathrm{H}_{1}\right) 3,67$ & $3 \mathrm{H}$ & $\mathrm{s}$ & \\
$\left(\mathrm{H}_{3}\right) 5,68$ & $1 \mathrm{H}$ & $\mathrm{qq}$ & $\mathrm{J}_{3 / 5 \mathrm{a}}=\mathrm{J}_{3 / 5 \mathrm{~b}}=\mathrm{J}_{3 / 5 \mathrm{c}}=1,5 ; \mathrm{J}_{3 / 6 \mathrm{a}}=\mathrm{J}_{3 / 6 \mathrm{~b}}=\mathrm{J}_{3 / 6 \mathrm{c}}=1,3$ \\
$\left(\mathrm{H}_{5}\right) 1,89$ & $3 \mathrm{H}$ & $\mathrm{d}$ & $\mathrm{J}_{5 / 3}=1,5$ \\
$\left(\mathrm{H}_{6}\right) 2,17$ & $3 \mathrm{H}$ & $\mathrm{d}$ & $\mathrm{J}_{6 / 3}=1,3$ \\
\hline
\end{tabular}

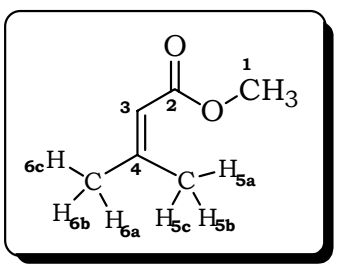




\section{Compostos 286a ou $286 b$}

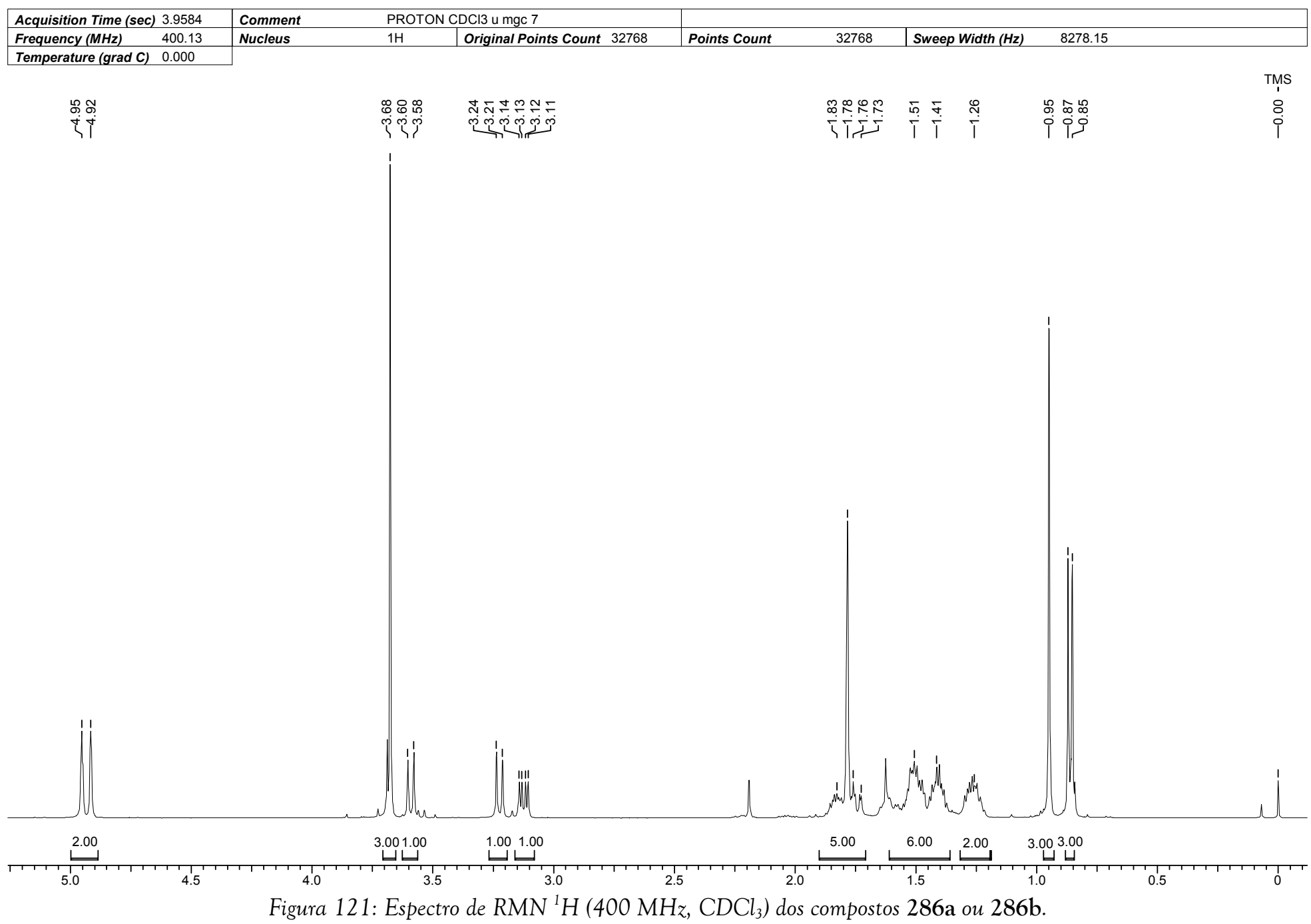


Espectro de $R M N{ }^{13} \mathrm{C}\left\{{ }^{1} \mathrm{H}\right\}$

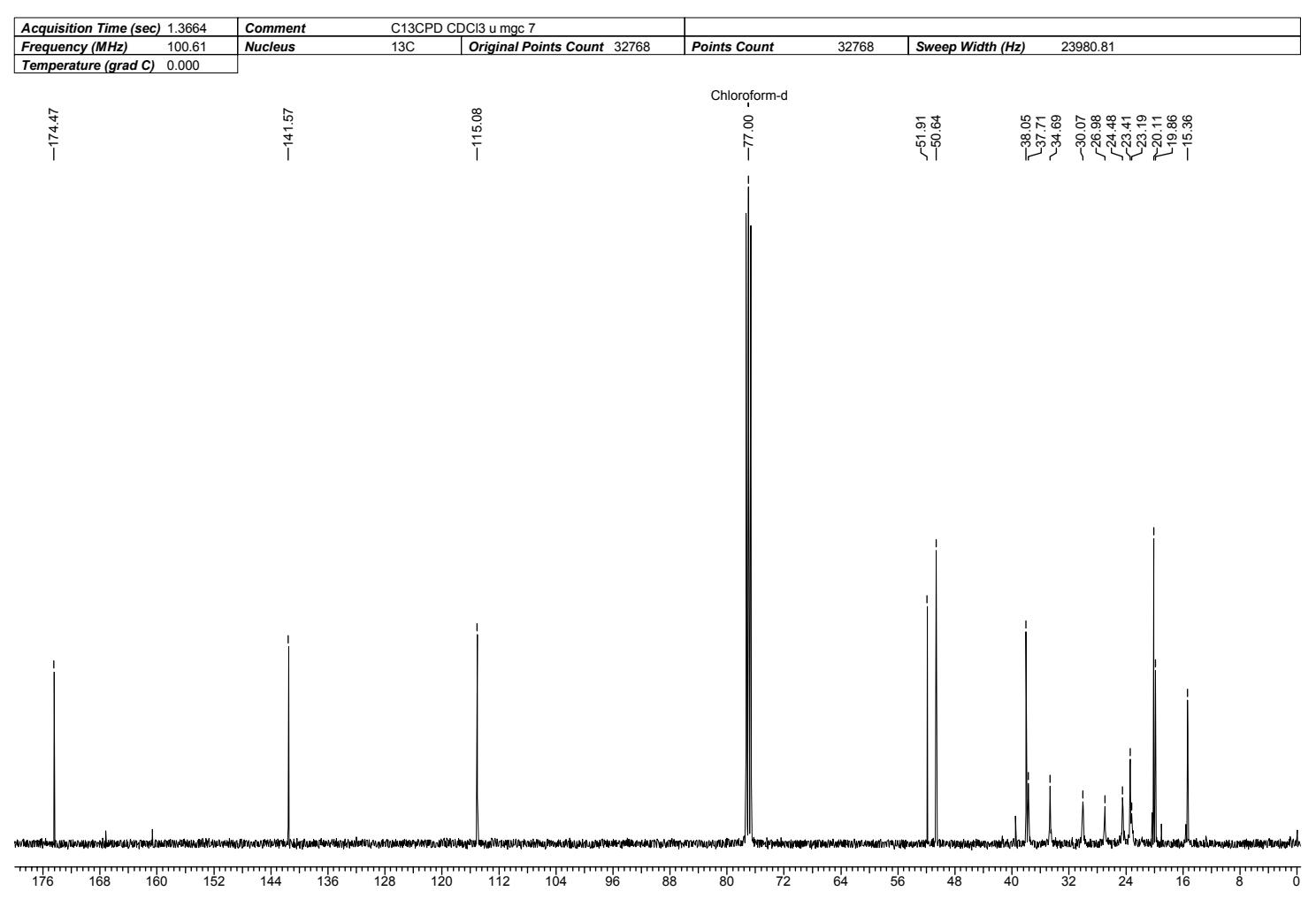

Espectro de RMN ${ }^{13} \mathrm{C}(\mathrm{DEPT}-135)$.

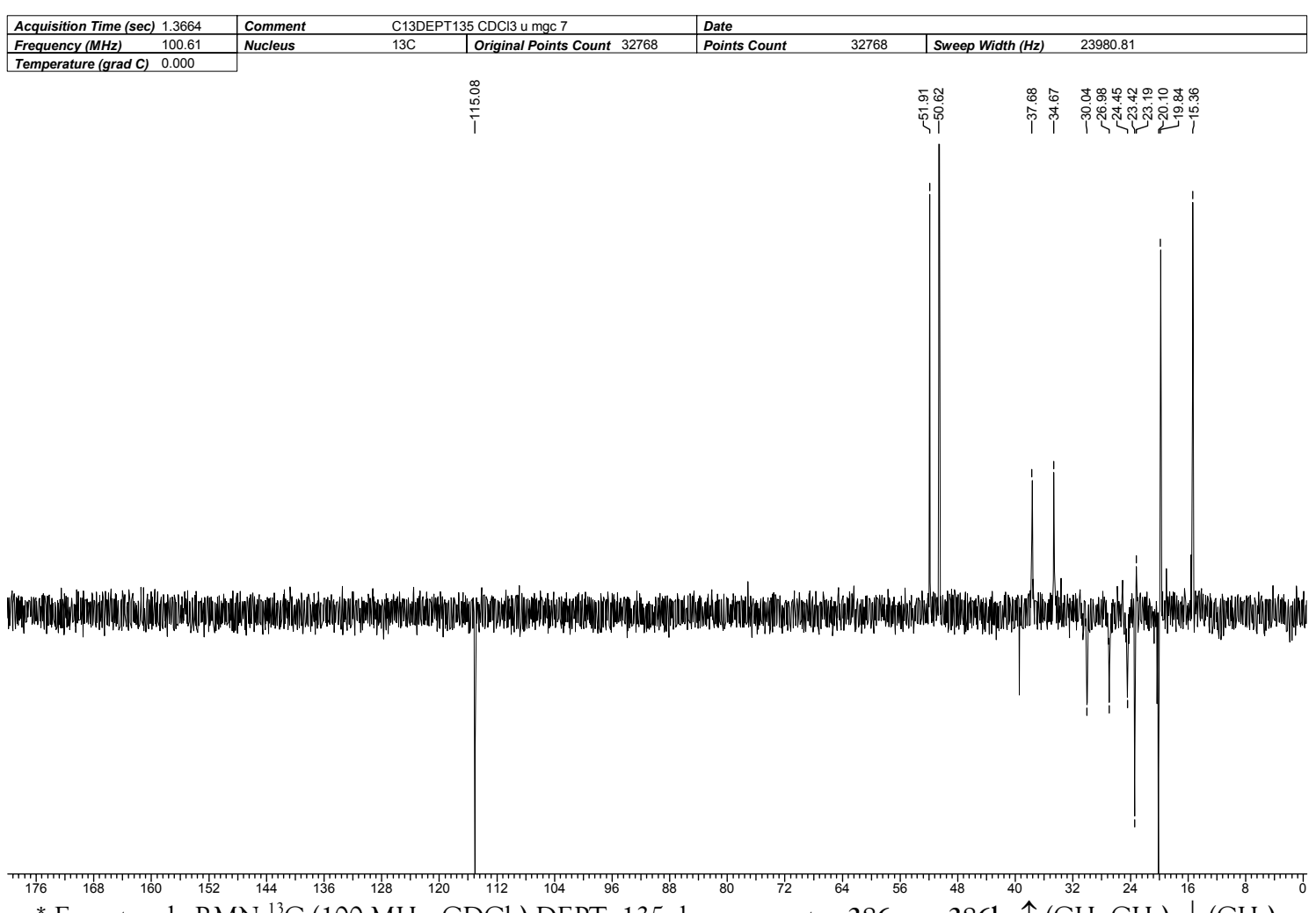

${ }^{*}$ Espectro de $\mathrm{RMN}^{13} \mathrm{C}\left(100 \mathrm{MHz}, \mathrm{CDCl}_{3}\right)$ DEPT- 135 dos compostos $286 \mathrm{a}$ ou $286 \mathrm{~b} . \uparrow\left(\mathrm{CH},{ }^{24} \mathrm{CH}_{3}\right), \downarrow \cdot\left(\mathrm{CH}_{2}\right)$

Figura 122: Espectros de $\mathrm{RMN}^{13} \mathrm{C}\left(100 \mathrm{MHz}, \mathrm{CDCl}_{3}\right)$ dos compostos 286a ou $286 \mathrm{~b}$. 
Tabela 66: Dados Espectroscópicos dos Compostos 286a ou 286b.

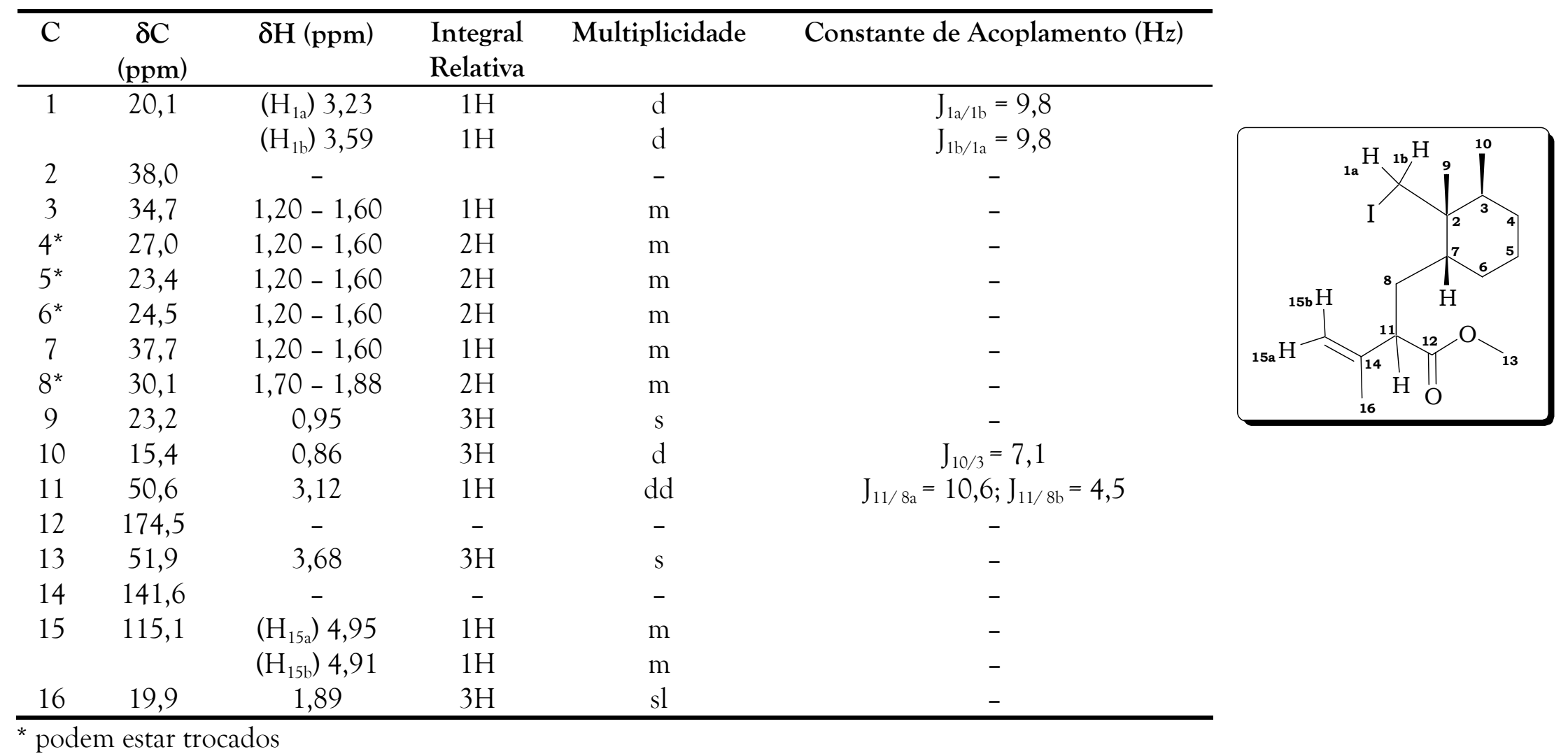




\section{Compostos 286a ou $286 b$}

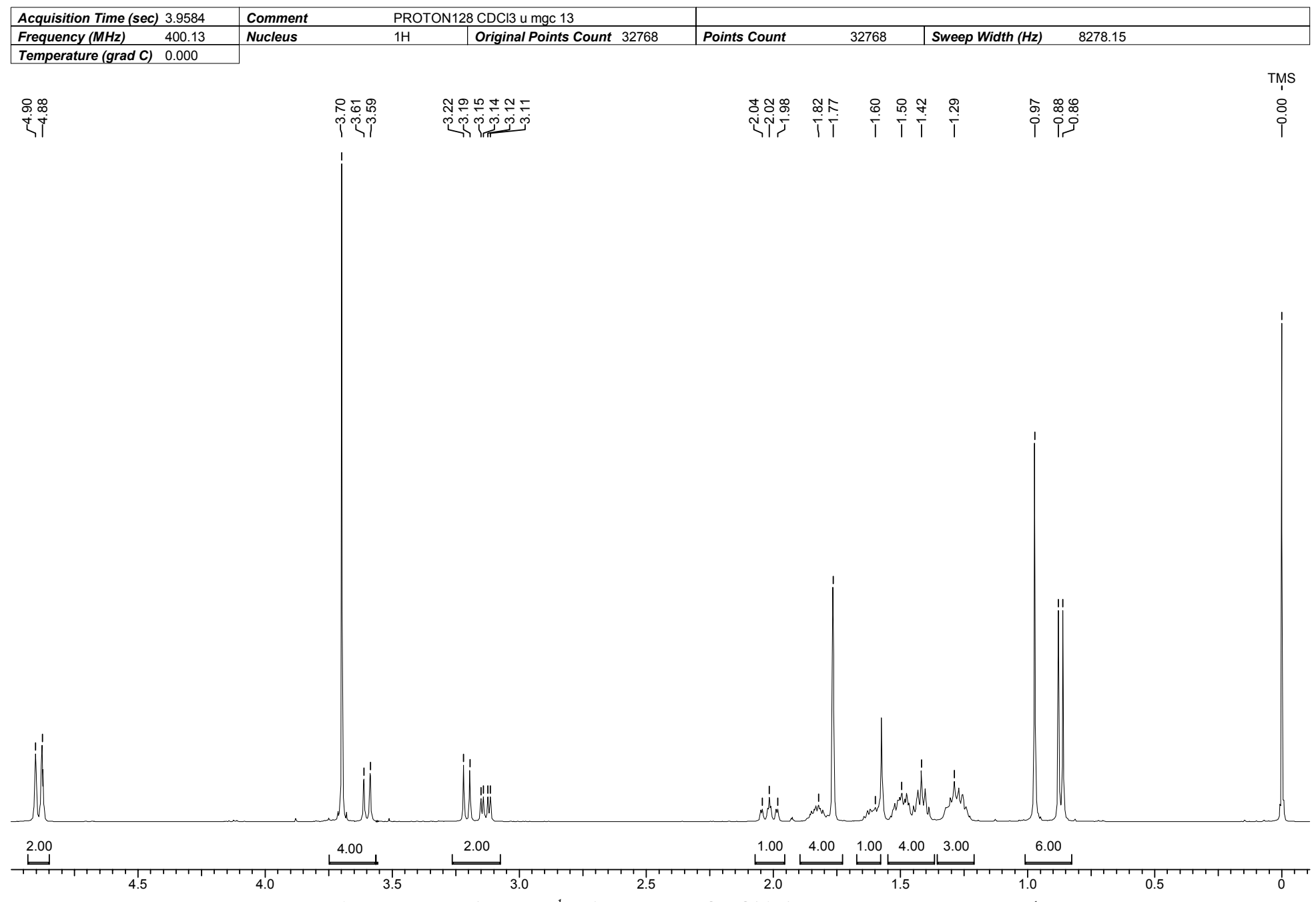

Figura 123: Espectro de $\mathrm{RMN}^{1} \mathrm{H}\left(400 \mathrm{MHz}, \mathrm{CDCl}_{3}\right)$ dos compostos 286a ou $286 \mathbf{b}$. 
Espectro de $R M N{ }^{13} \mathrm{C}\left\{{ }^{1} \mathrm{H}\right\}$

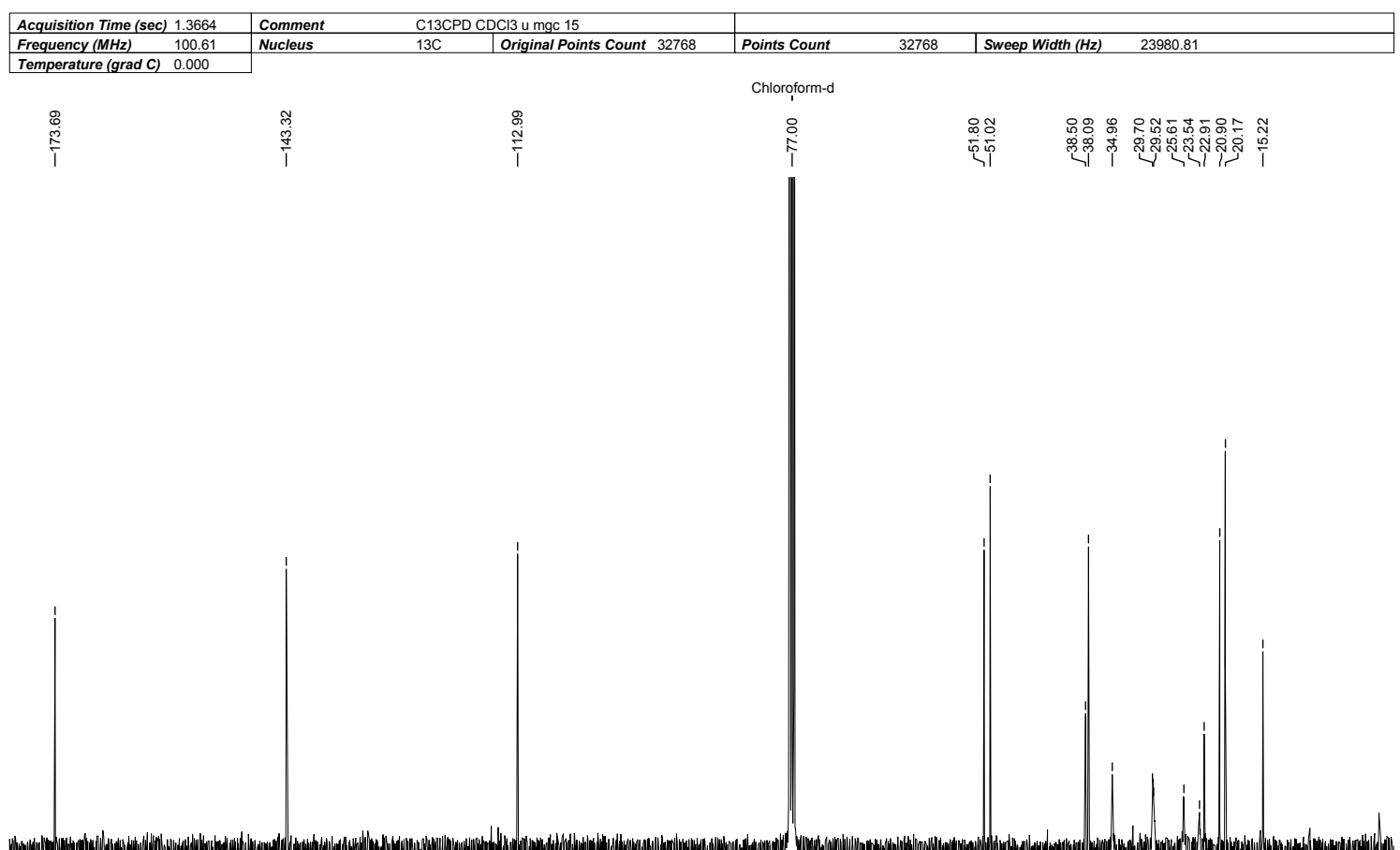

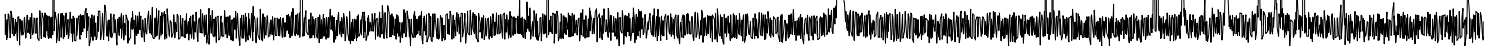

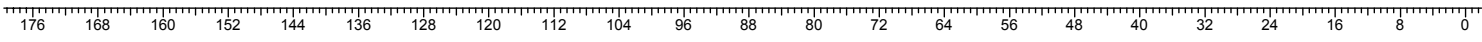

Espectro de RMN ${ }^{13} \mathrm{C}(\mathrm{DEPT}-135)$.

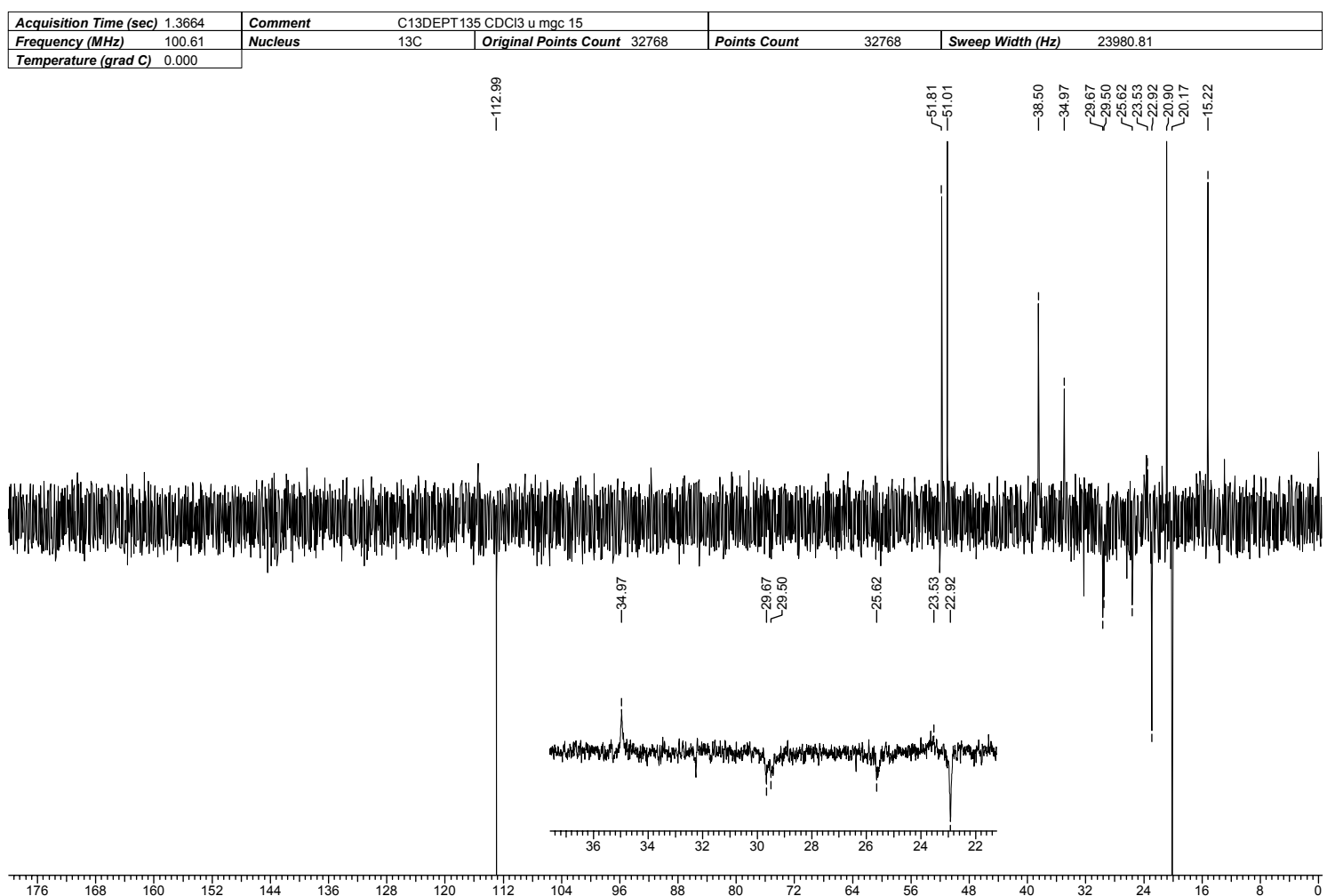

* Espectro de $\mathrm{RMN}{ }^{13} \mathrm{C}\left(100 \mathrm{MHz}, \mathrm{CDCl}_{3}\right)$ DEPT-135 dos compostos 286a ou 286b $\left.\uparrow\left(\mathrm{CH}, \mathrm{CH}_{3}\right), \downarrow \mathrm{CH}_{2}\right)$

Figura 124: Espectros de $\mathrm{RMN}^{13} \mathrm{C}\left(100 \mathrm{MHz}, \mathrm{CDCl}_{3}\right)$ dos compostos 286a ou $286 \mathrm{~b}$. 
Tabela 67: Dados Espectroscópicos do Composto 286a ou 286b.

\begin{tabular}{|c|c|c|c|c|c|c|}
\hline $\mathrm{C}$ & $\delta \mathrm{C}(\mathrm{ppm})$ & $\delta \mathrm{H}(\mathrm{ppm})$ & $\begin{array}{l}\text { Integral } \\
\text { Relativa }\end{array}$ & Multiplicidade & Constante de Acoplamento $(\mathrm{Hz})$ & \\
\hline 1 & 20,2 & $\left(\mathrm{H}_{1 \mathrm{a}}\right) 3,21$ & $1 \mathrm{H}$ & $\mathrm{d}$ & $\mathrm{J}_{1 \mathrm{a} / 1 \mathrm{~b}}=9,8$ & \\
\hline & & $\left(\mathrm{H}_{1 \mathrm{~b}}\right) 3,60$ & $1 \mathrm{H}$ & d & $\mathrm{J}_{1 \mathrm{~b} / 1 \mathrm{a}}=9,8$ & \\
\hline 2 & 38,1 & - & & - & - & 1 \\
\hline 3 & 35,0 & $1,20-1,65$ & $1 \mathrm{H}$ & $\mathrm{m}$ & - & $\mathrm{I}^{\prime}$ \\
\hline $4^{*}$ & 29,5 & $1,20-1,65$ & $2 \mathrm{H}$ & $\mathrm{m}$ & - & \\
\hline $5^{*}$ & 22,9 & $1,20-1,65$ & $2 \mathrm{H}$ & $\mathrm{m}$ & - & \\
\hline $6^{*}$ & 25,6 & $1,20-1,65$ & $2 \mathrm{H}$ & $\mathrm{m}$ & - & | \\
\hline 7 & 37,7 & $1,20-1,65$ & $1 \mathrm{H}$ & $\mathrm{m}$ & - & ${ }_{15 a} \mathrm{H}$ \\
\hline $8^{*}$ & 29,7 & $\left(\mathrm{H}_{8 \mathrm{a}}\right) 1,78-1,88$ & $1 \mathrm{H}$ & $\mathrm{m}$ & - & $\left.\right|_{16} \mathrm{H} \stackrel{\mathrm{O}}{\mathrm{O}}$ \\
\hline & & $\left(\mathrm{H}_{8 \mathrm{~b}}\right) 2,02$ & $1 \mathrm{H}$ & ddd & $\mathrm{J}_{8 \mathrm{~b} / 8 \mathrm{a}}=13,4 ; \mathrm{J}_{8 \mathrm{~b} / 11}=10,8 ; \mathrm{J}_{8 \mathrm{~b} / 7}=2,5$ & 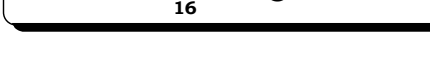 \\
\hline 9 & 23,6 & 0,97 & $3 \mathrm{H}$ & s & - & \\
\hline 10 & 15,2 & 0,87 & $3 \mathrm{H}$ & d & $\mathrm{J}_{10 / 3}=7,1$ & \\
\hline 11 & 51,0 & 3,13 & $1 \mathrm{H}$ & $\mathrm{dd}$ & $\mathrm{J}_{11 / 8 \mathrm{a}}=10,8 ; \mathrm{J}_{11 / 8 \mathrm{~b}}=3,8$ & \\
\hline 12 & 173,7 & - & - & - & - & \\
\hline 13 & 51,8 & 3,70 & $3 \mathrm{H}$ & $\mathrm{s}$ & - & \\
\hline 14 & 143,3 & - & - & - & - & \\
\hline \multirow[t]{2}{*}{15} & 113,0 & $\left(\mathrm{H}_{15 \mathrm{a}}\right) 4,90$ & $1 \mathrm{H}$ & $\mathrm{m}$ & - & \\
\hline & & $\left(\mathrm{H}_{15 \mathrm{~b}}\right) 4,88$ & $1 \mathrm{H}$ & $\mathrm{m}$ & - & \\
\hline 16 & 20,9 & 1,76 & $3 \mathrm{H}$ & sl & - & \\
\hline
\end{tabular}




\section{Compostos $287+288$}

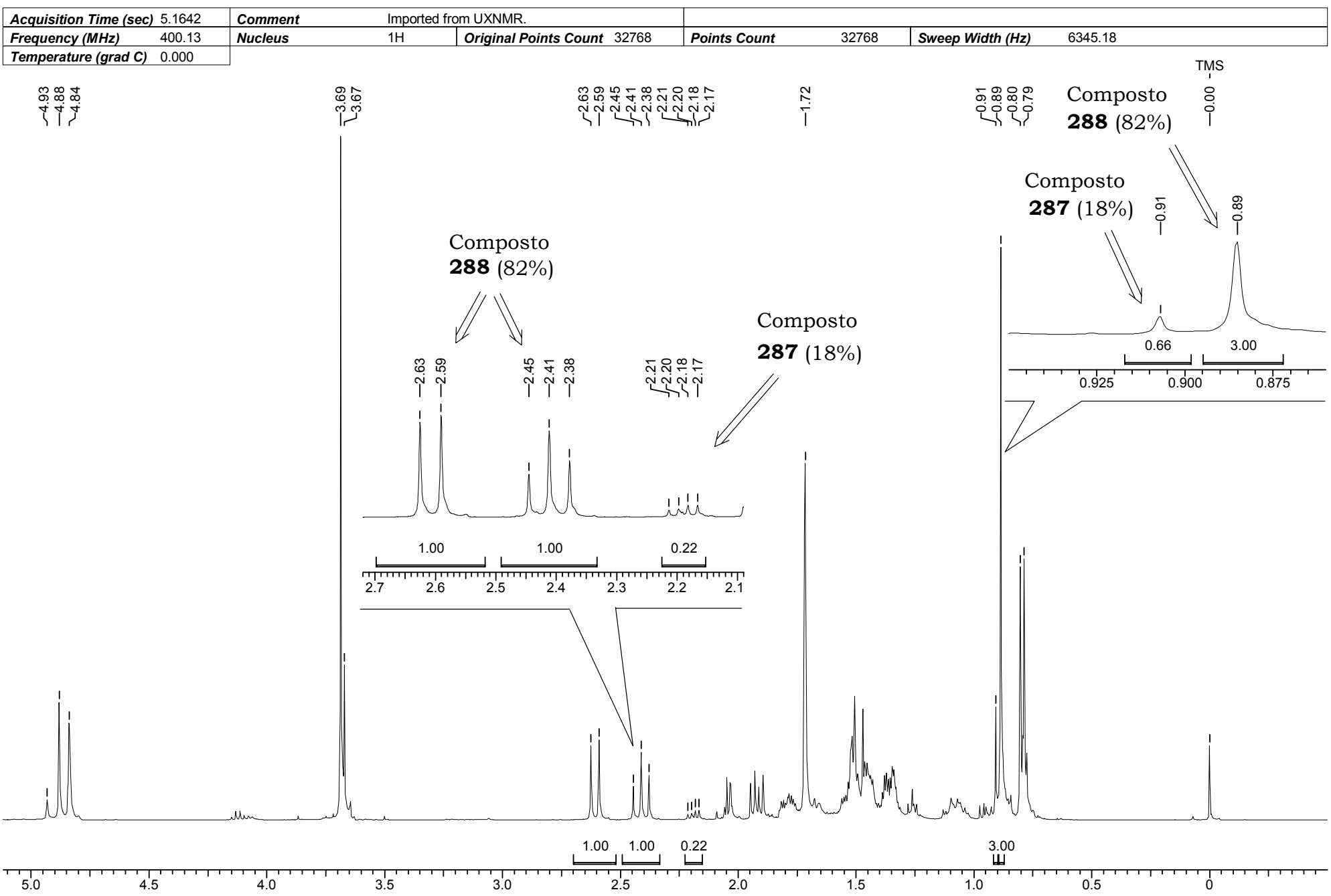

Figura 125: Espectro de $\mathrm{RMN}^{1} \mathrm{H}\left(400 \mathrm{MHz}, \mathrm{CDCl}_{3}\right)$ dos compostos $287+288$. 


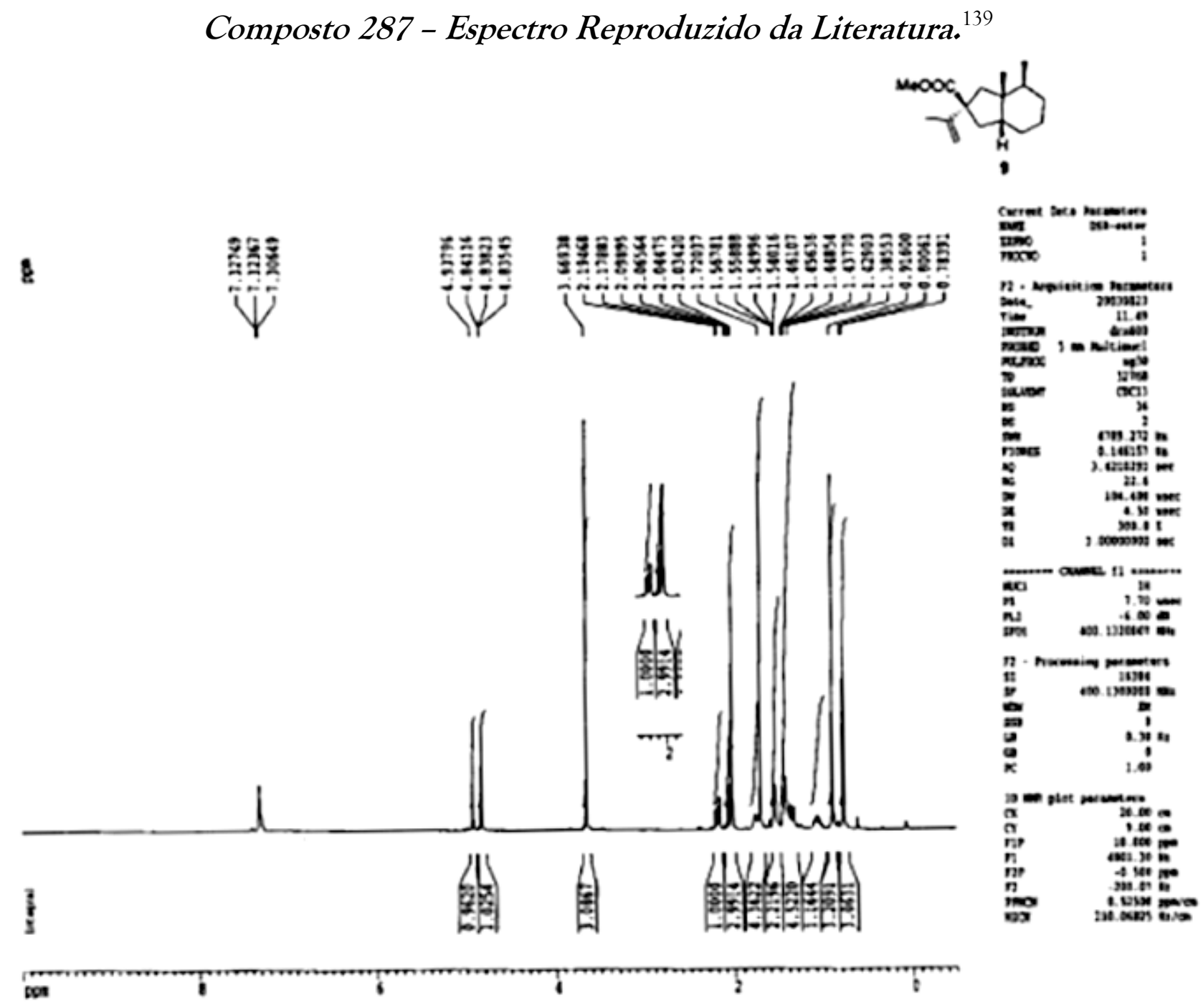

Figura 126: Espectro de $\mathrm{RMN}^{1} \mathrm{H}\left(400 \mathrm{MHz}, \mathrm{CDCl}_{3}\right)$ do composto 287 Reproduzido da Literatura. 


\section{Composto 304}

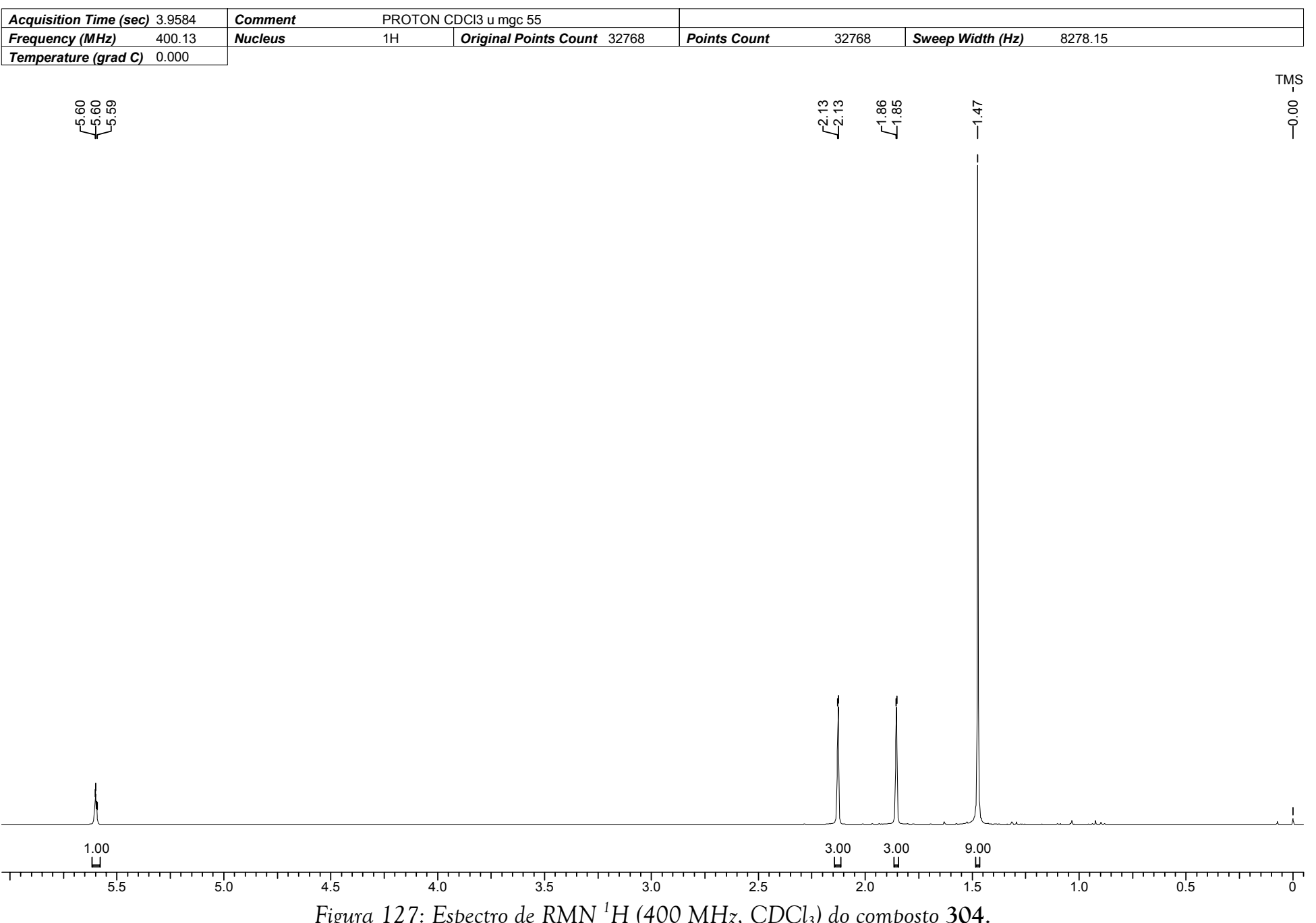


Tabela 68: Dados espectroscópicos do composto 304.

\begin{tabular}{cccc}
\hline$\delta \mathrm{H}(\mathrm{ppm})$ & $\begin{array}{c}\text { Integral } \\
\text { Relativa }\end{array}$ & Multiplicidade & Constante de Acoplamento $(\mathrm{Hz})$ \\
\hline$\left(\mathrm{H}_{1}\right) 1,47$ & $9 \mathrm{H}$ & $\mathrm{s}$ & - \\
$\left(\mathrm{H}_{4}\right) 5,60$ & $1 \mathrm{H}$ & sept & $\mathrm{J}_{3 / 6 \mathrm{a}}=\mathrm{J}_{3 / 6 \mathrm{~b}}=\mathrm{J}_{3 / 6 \mathrm{c}}=\mathrm{J}_{3 / 7 \mathrm{a}}=\mathrm{J}_{3 / 7 \mathrm{~b}}=\mathrm{J}_{3 / 7 \mathrm{c}}=1,3$ \\
$\left(\mathrm{H}_{6}\right) 1,85$ & $3 \mathrm{H}$ & $\mathrm{d}$ & $\mathrm{J}_{6 / 4}=1,3$ \\
$\left(\mathrm{H}_{7}\right) 2,12$ & $3 \mathrm{H}$ & $\mathrm{d}$ & $\mathrm{J}_{7 / 4}=1,3$ \\
\hline
\end{tabular}

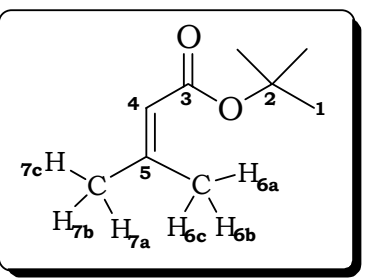




\section{Compostos 305a+305b}

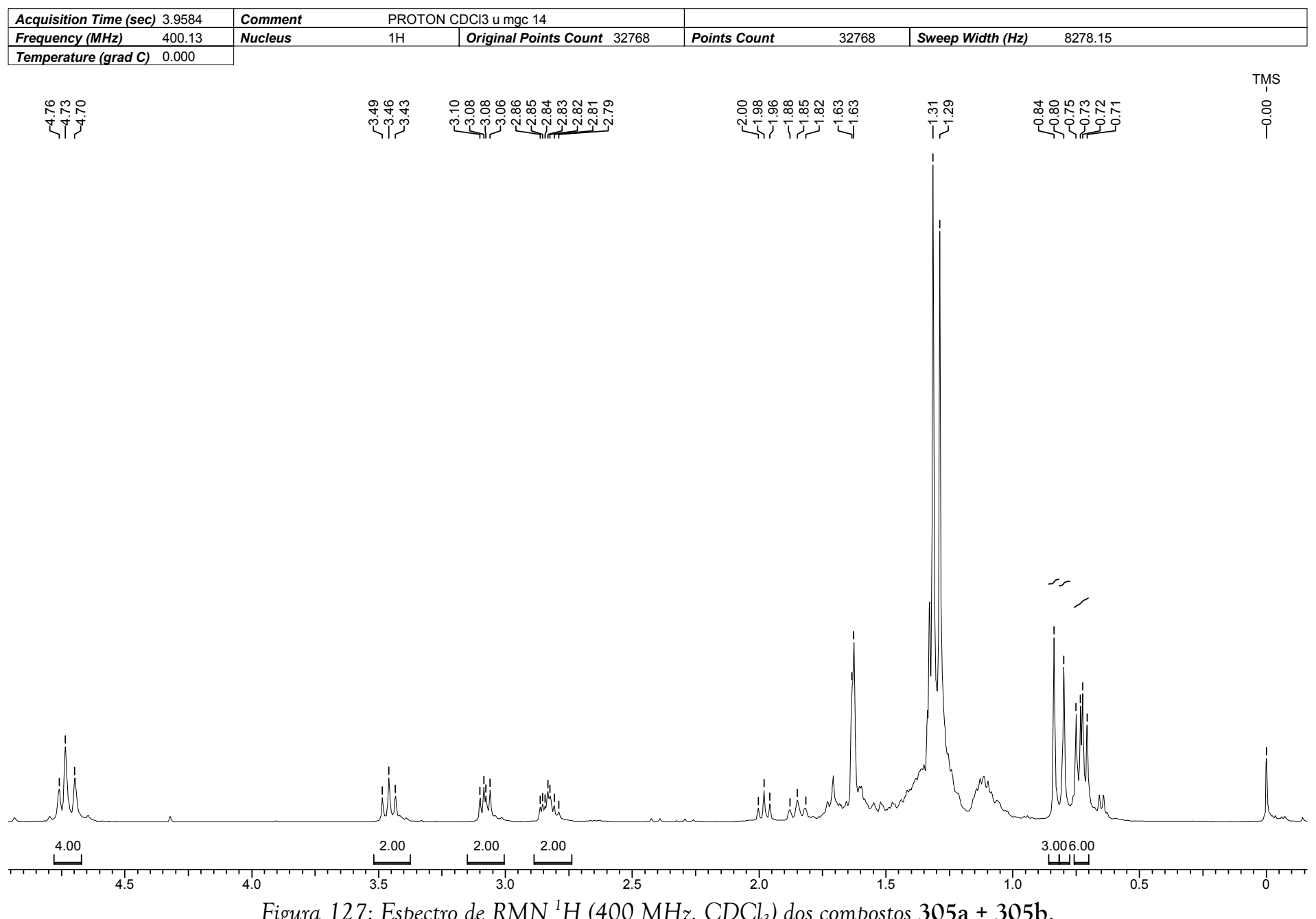

Figura 127: Espectro de $\mathrm{RMN}^{1} \mathrm{H}\left(400 \mathrm{MHz}, \mathrm{CDCl}_{3}\right)$ dos compostos 305a + 305b 


\section{Compostos $306+307$}

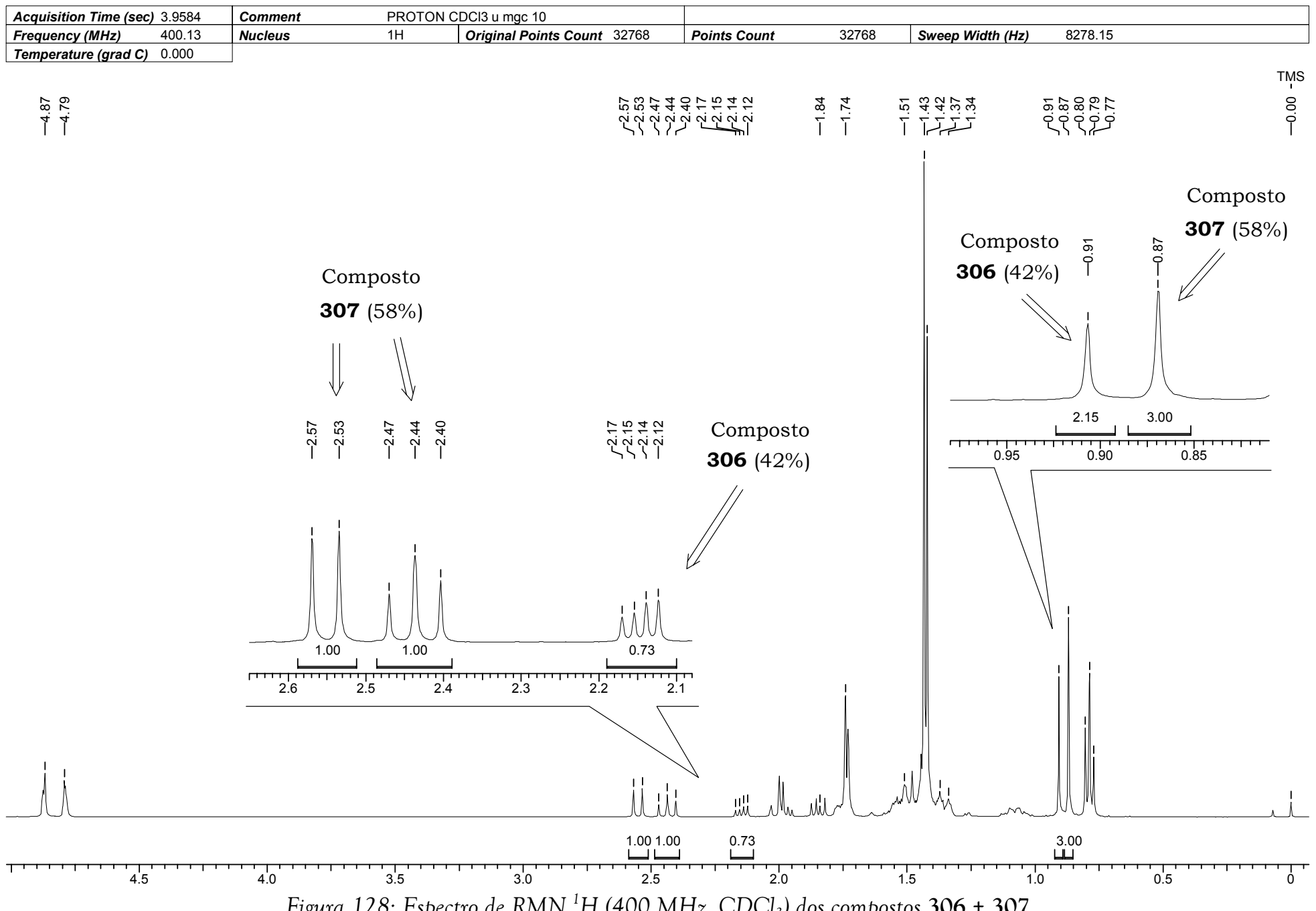

Figura 128: Espectro de $\mathrm{RMN}{ }^{1} \mathrm{H}\left(400 \mathrm{MHz}, \mathrm{CDCl}_{3}\right)$ dos compostos $306+307$ 


\section{Compostos $306+307$}

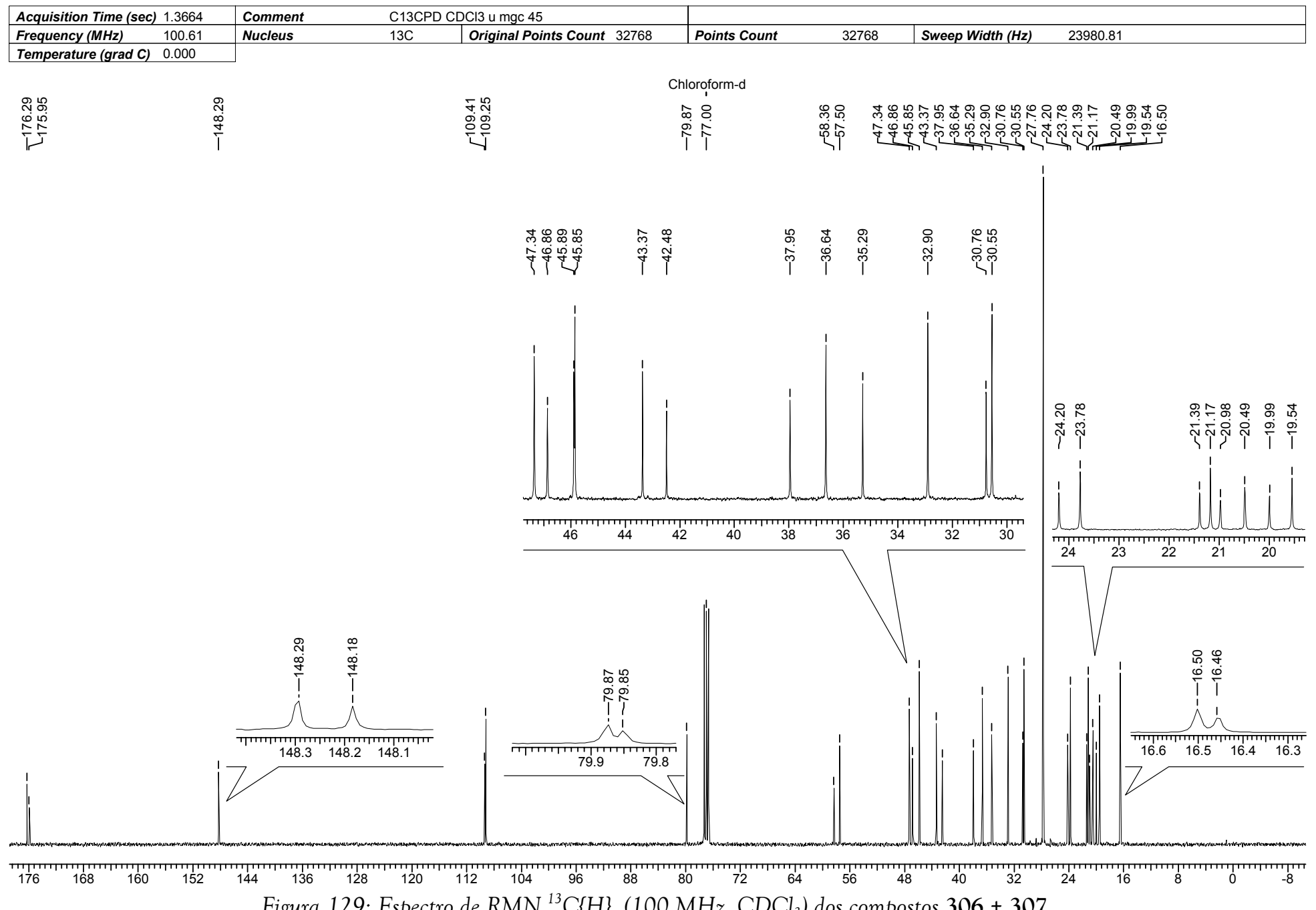

Figura 129: Espectro de $\mathrm{RMN}^{13} \mathrm{C}\{\mathrm{H}\}\left(100 \mathrm{MHz}, \mathrm{CDCl}_{3}\right)$ dos compostos $306+307$ 


\section{Compostos $308+309$}

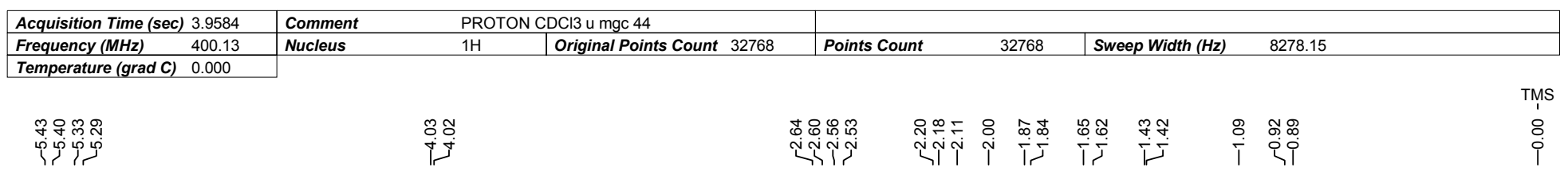

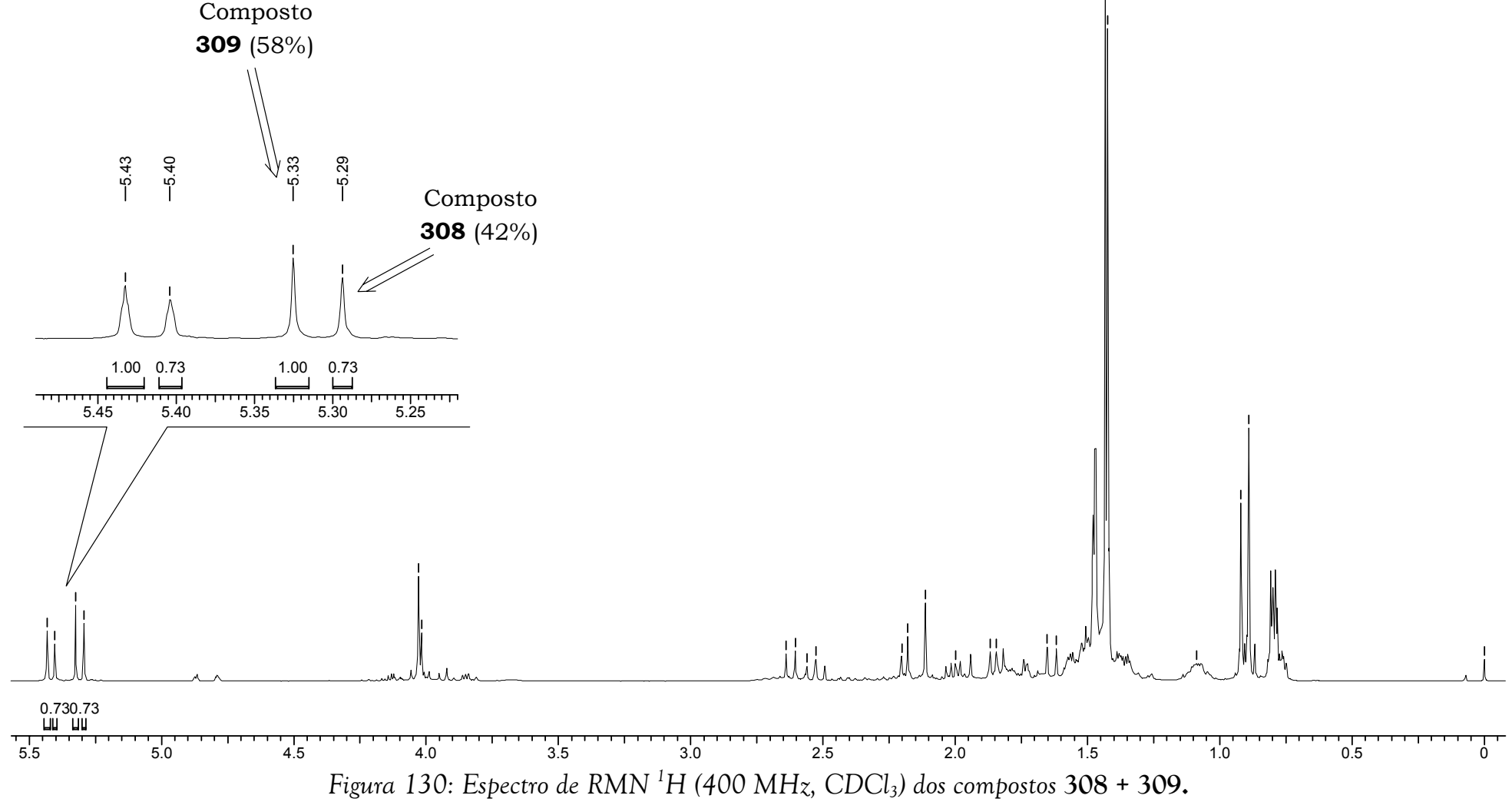




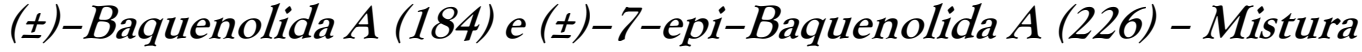

\begin{tabular}{|c|c|c|c|c|c|c|c|c|c|}
\hline \multicolumn{2}{|c|}{ Acquisition Time (sec) 3.9584} & \multirow{2}{*}{$\begin{array}{l}\text { Comment } \\
\text { Nucleus } \\
\end{array}$} & \multicolumn{2}{|c|}{ PROTON128 CDCl3 u mgc 31} & \multirow[b]{2}{*}{ Points Count } & \multirow[b]{2}{*}{32768} & \multirow[b]{2}{*}{ Sweep Width ( $\mathrm{Hz}$ ) } & \multirow[b]{2}{*}{8278.15} & \\
\hline Frequency $(\mathrm{MHz})$ & 400.13 & & $1 \mathrm{H}$ & Original Points Count 32768 & & & & & \\
\hline Temperature (grad C) & 0.000 & & & & & & & & TMS \\
\hline 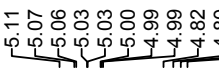 & & & & & 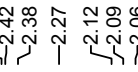 & | & 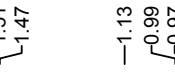 & نَn & 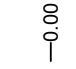 \\
\hline
\end{tabular}

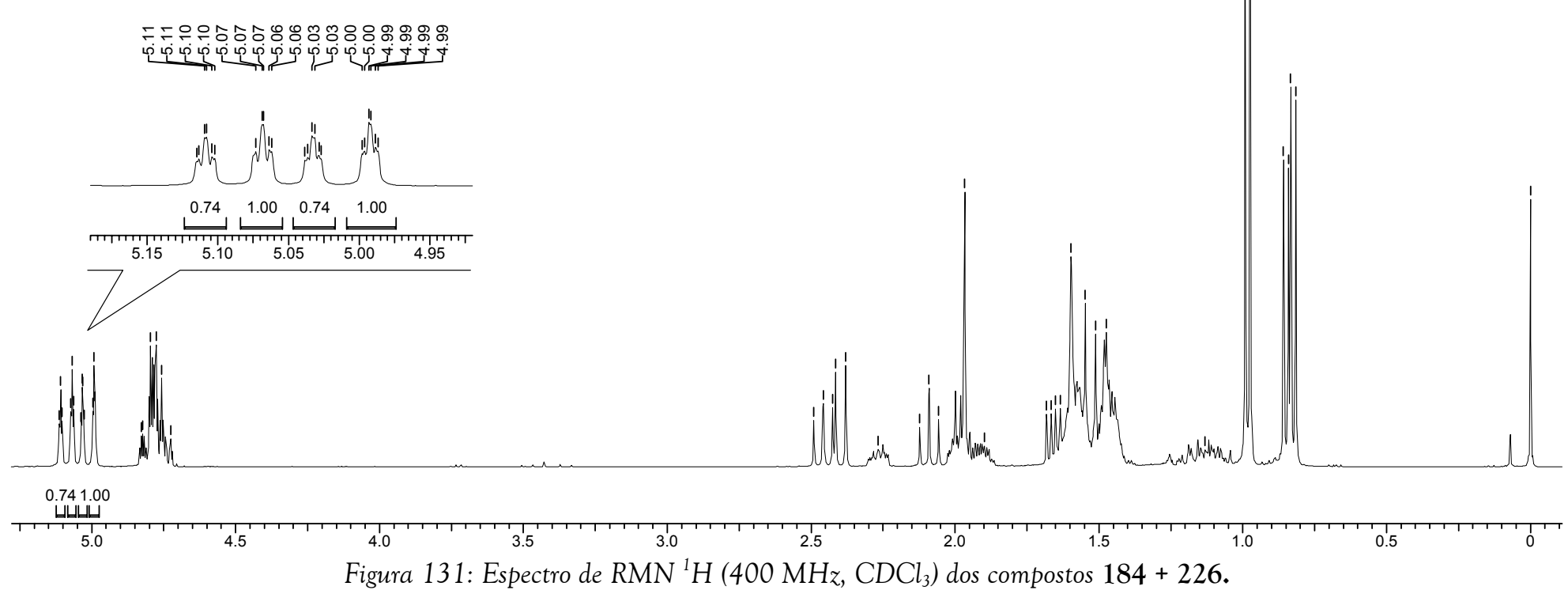




\section{(士)-Baquenolida A (184)}

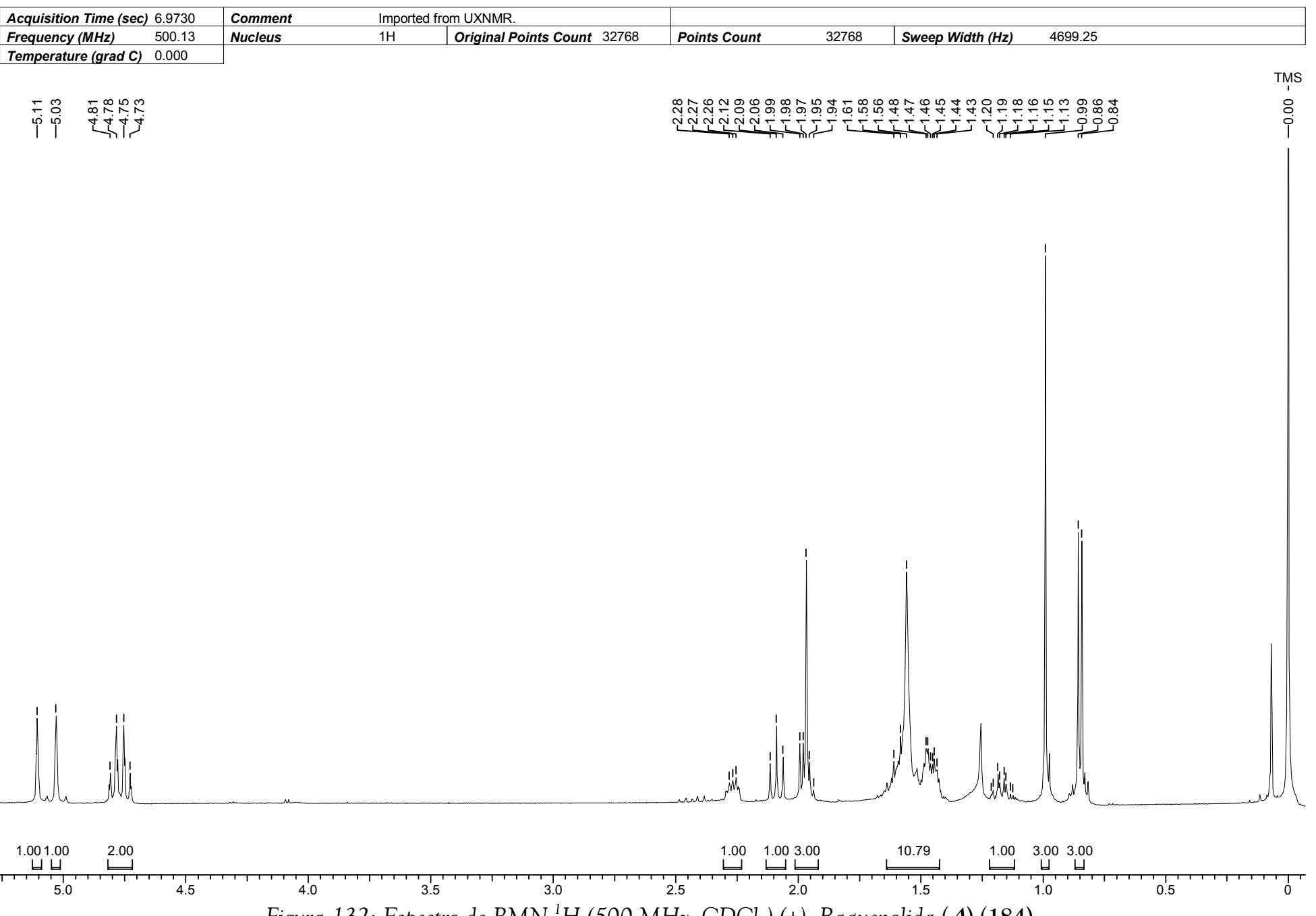

Figura 132: Espectro de $\mathrm{RMN}^{1} \mathrm{H}\left(500 \mathrm{MHz}, \mathrm{CDCl}_{3}\right)( \pm)$-Baquenolida $(A)(184)$. 


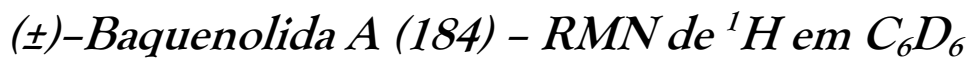

\begin{tabular}{|c|c|c|c|c|c|c|c|c|c|}
\hline Acquisition Time (sec) & 6.0817 & Comment & Imported from UXNMR. & & & & & & \\
\hline Frequency $(\mathrm{MHz})$ & 500.13 & Nucleus & Original Points Count 32768 & Points Count & 32768 & Sweep Width (Hz) & 5387.93 & & \\
\hline Temperature (grad C) & 0.000 & & & & & & & & \\
\hline$\stackrel{5}{+}$ & & & & $\stackrel{\text { J }}{\text { i }}$ & & 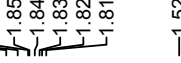 & 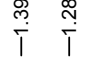 & 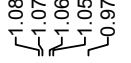 & în \\
\hline
\end{tabular}

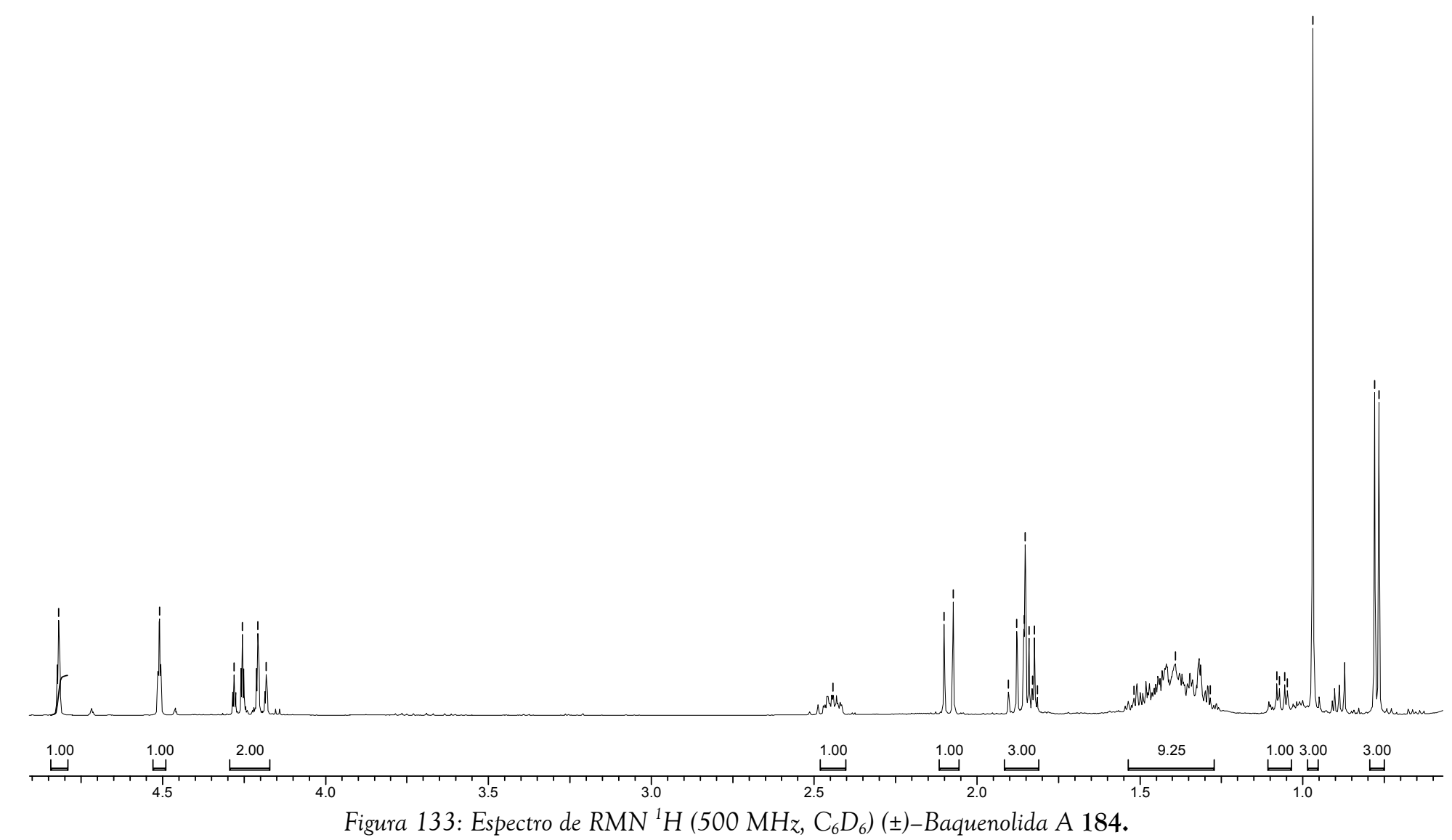


Espectro de $R M N{ }^{13} \mathrm{C}\left\{{ }^{1} \mathrm{H}\right\}$

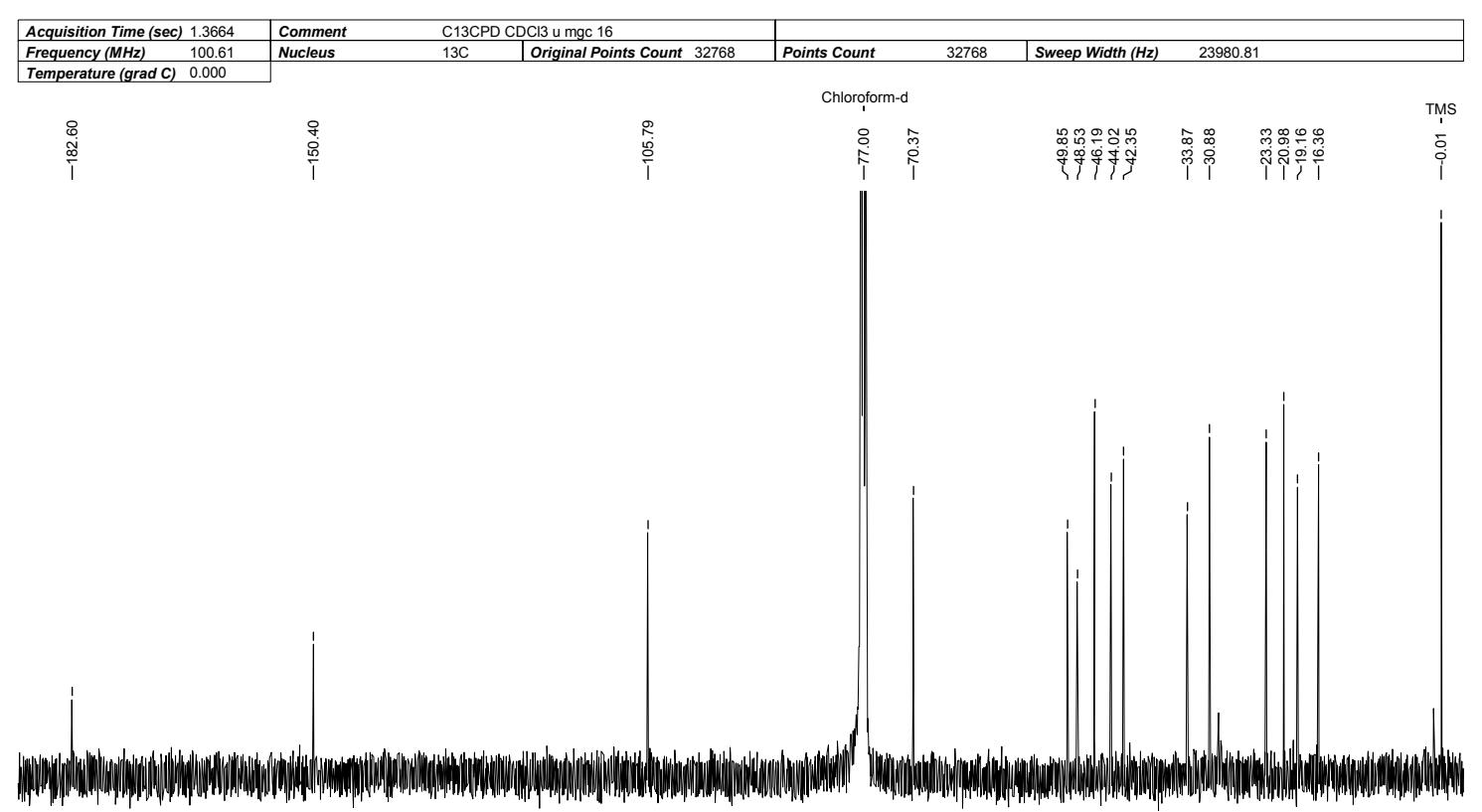

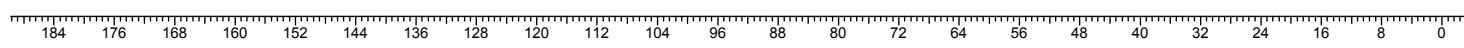

Espectro de RMN ${ }^{13} \mathrm{C}(\mathrm{DEPT}-135)$.

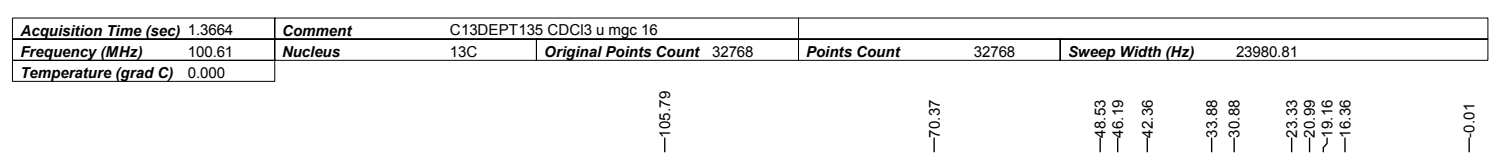

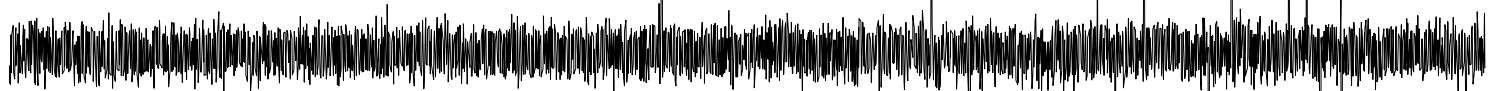

${ }_{184}^{m}$

* Espectro de RMN ${ }^{13} \mathrm{C}\left(100 \mathrm{MHz}, \mathrm{CDCl}_{3}\right)$ DEPT-135 da ( \pm )-baquenolida A (184) ( $\left.\downarrow\left(\mathrm{CH}, \mathrm{CH}_{3}\right), \uparrow \mathrm{CH}_{2}\right)$

Figura 134: Espectros de $\mathrm{RMN}^{13} \mathrm{C}\left(100 \mathrm{MHz}, \mathrm{CDCl}_{3}\right)$ da ( \pm )-Baquenolida $\mathrm{A}(184)$. 
Tabela 69: Dados Espectroscópicos da (土)-Baquenolida A (184) - Análise em $\mathrm{CDCl}_{3}$.

\begin{tabular}{|c|c|c|c|c|c|}
\hline $\mathrm{C}$ & $\delta \mathrm{C}(\mathrm{ppm})$ & $\delta \mathrm{H}(\mathrm{ppm})$ & Integral Relativa & Multiplicidade & Constante de Acoplamento $(\mathrm{Hz})$ \\
\hline $1^{*}$ & 23,3 & $\left(\mathrm{H}_{1 \mathrm{a}} / \mathrm{H}_{1 \mathrm{~b}}\right) 1,10-1,22 / 1,40-1,68$ & $2 \mathrm{H}$ & $\mathrm{m}$ & \\
\hline $2^{*}$ & 21,0 & $1,10-1,22 / 1,40-1,68$ & $2 \mathrm{H}$ & $\mathrm{m}$ & \\
\hline $3^{*}$ & 30,9 & $1,10-1,22 / 1,40-1,68$ & $2 \mathrm{H}$ & $\mathrm{m}$ & \\
\hline 4 & 33,9 & $1,10-1,22 / 1,40-1,68$ & $1 \mathrm{H}$ & $\mathrm{m}$ & \\
\hline 5 & 44,0 & & - & - & - \\
\hline \multirow[t]{2}{*}{6} & 48,5 & ${ }^{*} \mathrm{H}_{(6 \mathrm{a})} 1,98$ & $1 \mathrm{H}$ & $\mathrm{d}$ & $\mathrm{J}_{6 \mathrm{a} / 6 \mathrm{~b}}=14,2$ \\
\hline & - & ${ }^{*} \mathrm{H}_{(6 \mathrm{~b})} 1,95$ & $1 \mathrm{H}$ & d & $\mathrm{J}_{6 \mathrm{~b} / 6 \mathrm{a}}=14,2$ \\
\hline 7 & 49,9 & - & - & - & - \\
\hline 8 & 182,6 & - & - & - & - \\
\hline \multirow[t]{2}{*}{9} & 42,4 & $\mathrm{H}_{\left(9_{\mathrm{a}}\right)} 1,98$ & $1 \mathrm{H}$ & $\mathrm{dd}$ & $\mathrm{J}_{9 \mathrm{a} / 9 \mathrm{~b}}=13,3 ; \mathrm{J}_{9 \mathrm{a} / 10}=7,0$ \\
\hline & - & $\mathrm{H}_{(9 \mathrm{~b})} 2,09$ & $1 \mathrm{H}$ & $\mathrm{dd}$ & $\mathrm{J}_{9 \mathrm{~b} / 10}=13,3 ; \mathrm{J}_{9 \mathrm{~b} / 9 \mathrm{a}}=12,9$ \\
\hline 10 & 46,2 & 2,27 & $1 \mathrm{H}$ & dddd & $\mathrm{J}_{10 / 9 \mathrm{~b}}=13,3 ; \mathrm{J}_{10 / 9 \mathrm{a}}=7,0 ; \mathrm{J}_{10 / 1 \mathrm{a}}=4,9 ; \mathrm{J}_{10 / 1 \mathrm{~b}}=2,3$ \\
\hline 11 & 150,4 & - & - & - & - \\
\hline \multirow[t]{2}{*}{12} & 70,4 & $*\left(\mathrm{H}_{12 \mathrm{a}}\right) 4,80$ & $1 \mathrm{H}$ & ddd & $J_{12 \mathrm{a} / 12 \mathrm{~b}}=12,8 ; J_{12 \mathrm{a} / 13 \mathrm{~b}}=2,3 ; J_{12 \mathrm{a} / 13 \mathrm{a}}=2,1$ \\
\hline & - & $*\left(\mathrm{H}_{12 \mathrm{~b}}\right) 4,74$ & $1 \mathrm{H}$ & ddd & $J_{12 b / 12 s}=12,8 ; J_{12 b / 13 b}=2,3 ; J_{12 b / 13 a}=2,1$ \\
\hline \multirow[t]{2}{*}{13} & 105,8 & $\left(\mathrm{H}_{13 \mathrm{a}}\right) 5,03$ & $1 \mathrm{H}$ & $\mathrm{t}$ & $\mathrm{J}_{13 \mathrm{a} / 12 \mathrm{a}}=\mathrm{J}_{13 \mathrm{a} / 12 \mathrm{~b}}=2,1$ \\
\hline & - & $\left(\mathrm{H}_{13 \mathrm{~b}}\right) 5,11$ & $1 \mathrm{H}$ & $\mathrm{t}$ & $\mathrm{J}_{13 \mathrm{~b} / 12 \mathrm{a}}=\mathrm{J}_{13 \mathrm{~b} / 12 \mathrm{~b}}=2,3$ \\
\hline $14^{*}$ & 16,4 & 0,99 & $3 \mathrm{H}$ & $\mathrm{s}$ & - \\
\hline $15^{*}$ & 19,2 & 0,85 & $3 \mathrm{H}$ & $\mathrm{d}$ & $\mathrm{J}_{15 / 4}=6,8$ \\
\hline
\end{tabular}

* podem estar trocados

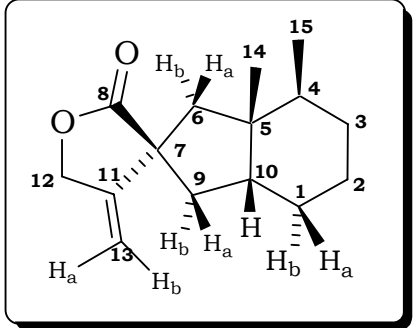


(士)-Baquenolida A (184) - Amostra Sintética. ${ }^{138}$

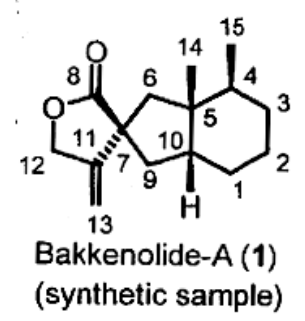

(synthetic sample)

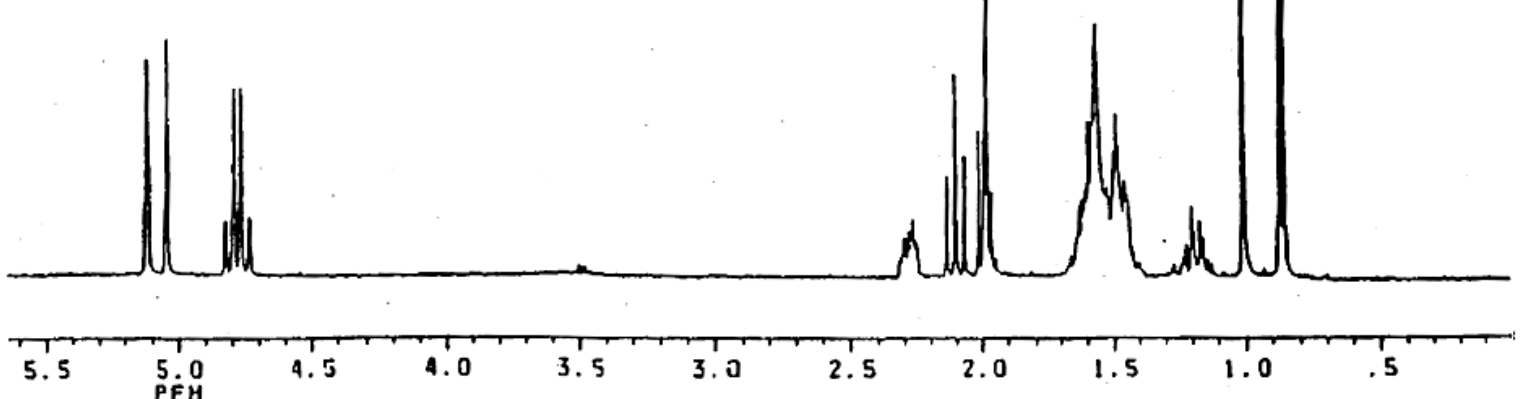

Figura 135: Espectro de $\mathrm{RMN}^{1} \mathrm{H}\left(400 \mathrm{MHz}, \mathrm{CDCl}_{3}\right)$ - Amostra Sintética da Baquenolida A (184) 
Baquenolida A (184) - Amostra Autêntica. ${ }^{138}$

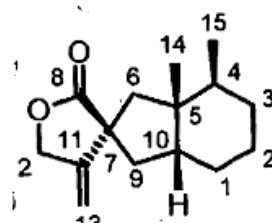

akkenolide-A (1)

(authentic sample

from Dr. J. Harmatha)

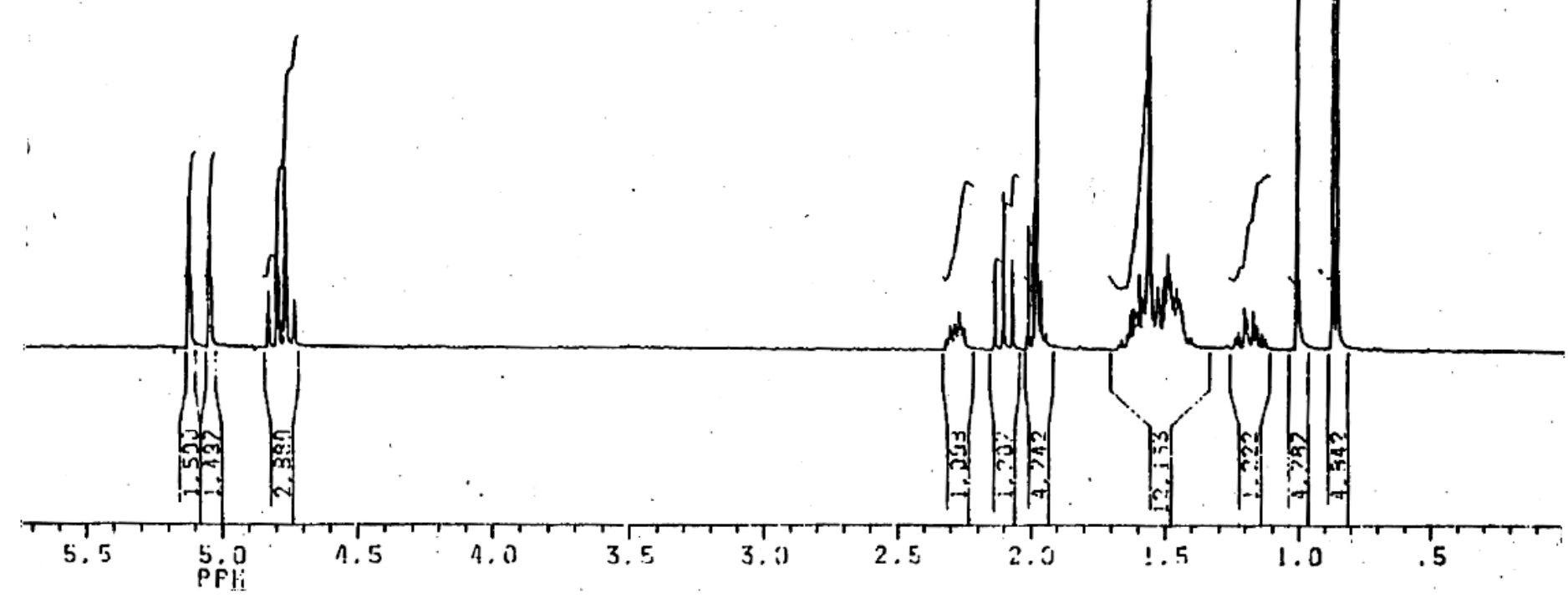

Figura 136: Espectro de $\mathrm{RMN}^{1} \mathrm{H}\left(\mathrm{CDCl}_{3}\right)$ - Amostra Autêntica da Baquenolida A (184) 
Baquenolida A (184) - Amostra Autêntica ${ }^{138}$

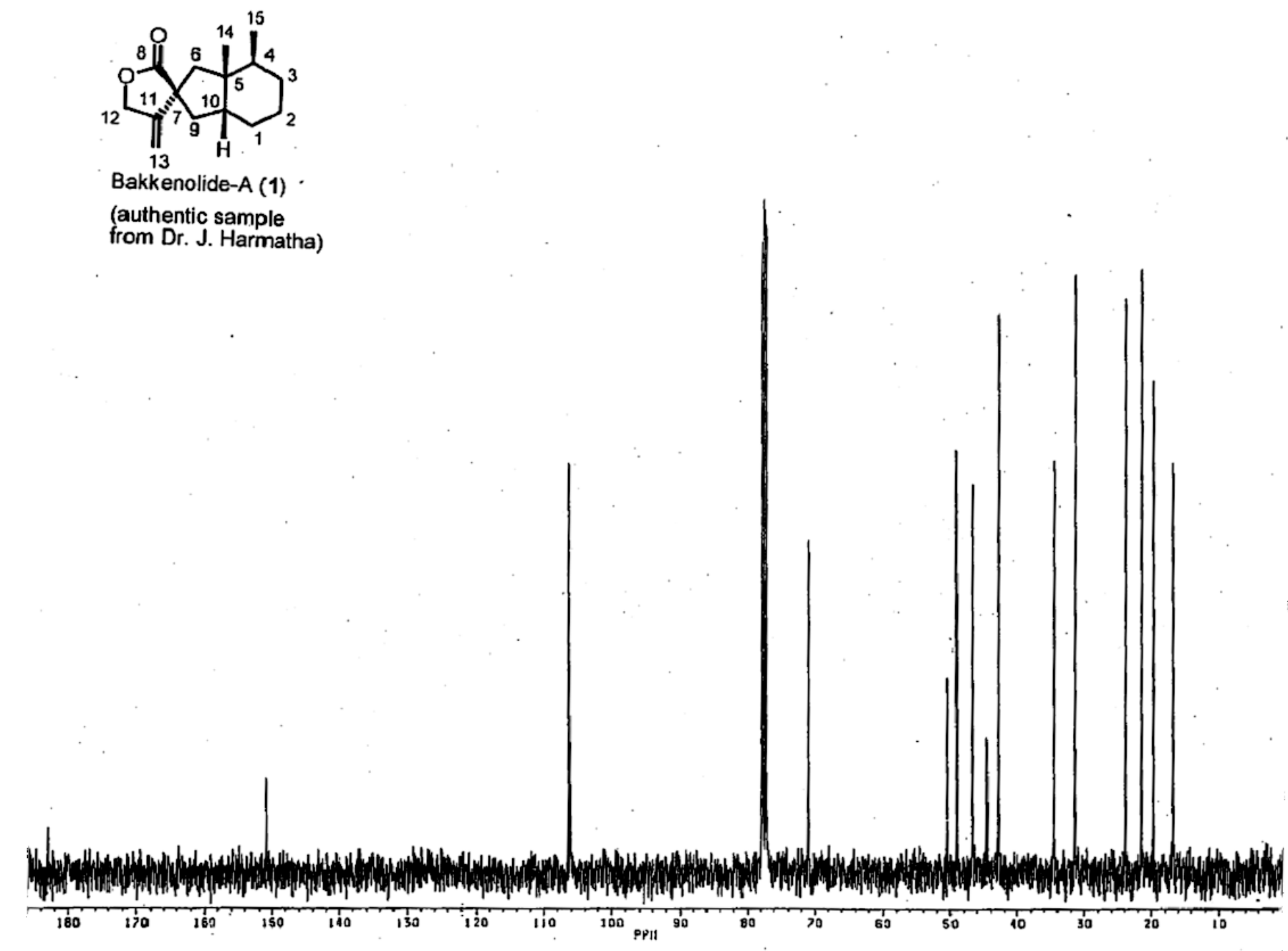

Figura 137: Espectro de $\mathrm{RMN}^{13} \mathrm{C}\left(100 \mathrm{MHz}, \mathrm{CDCl}_{3}\right)$ - Amostra Autêntica da Baquenolida A (184) 
( \pm )-7-epi-Baquenolida A (226)

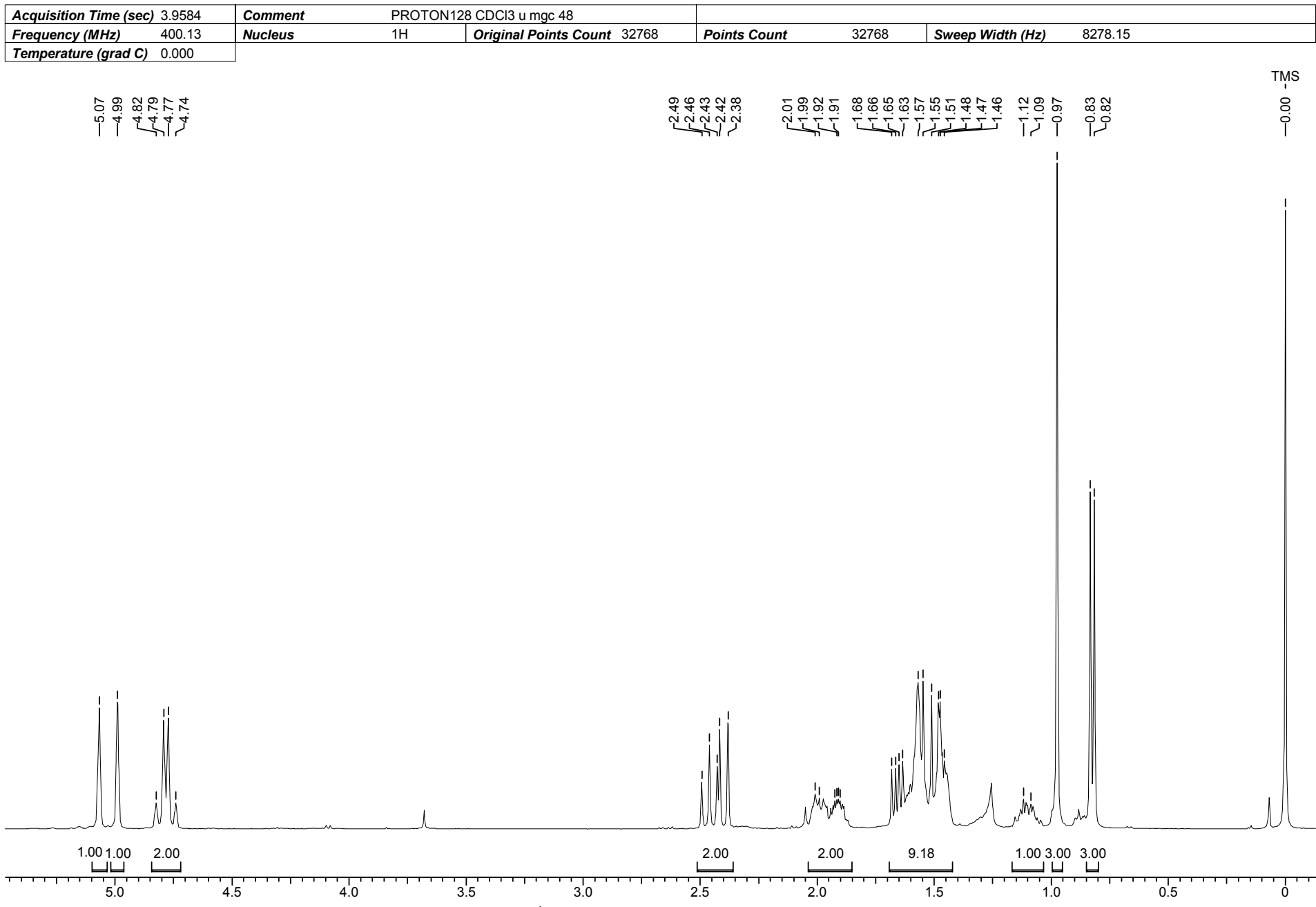

Figura 138: Espectro de $\mathrm{RMN}^{1} \mathrm{H}\left(400 \mathrm{MHz}, \mathrm{CDCl}_{3}\right)( \pm)$-7-epi-baquenolida $\boldsymbol{A}$ (226). 
Espectro de $R M N{ }^{13} \mathrm{C}\left\{{ }^{1} \mathrm{H}\right\}$

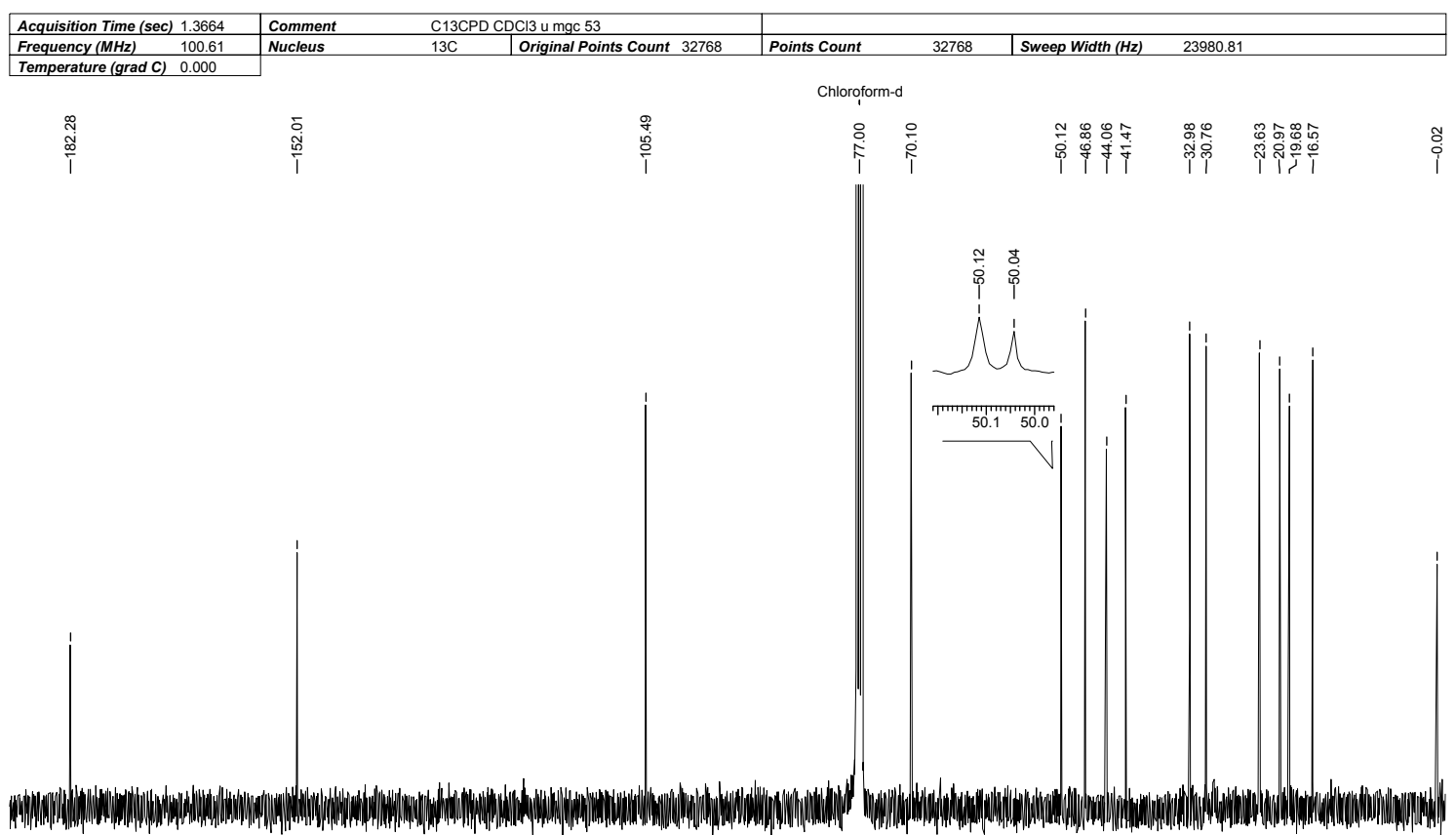

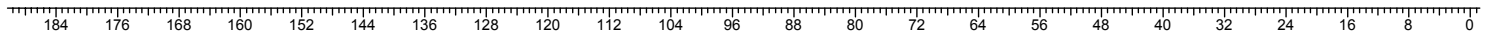

Espectro de RMN ${ }^{13} \mathrm{C}(\mathrm{DEPT}-135)$.

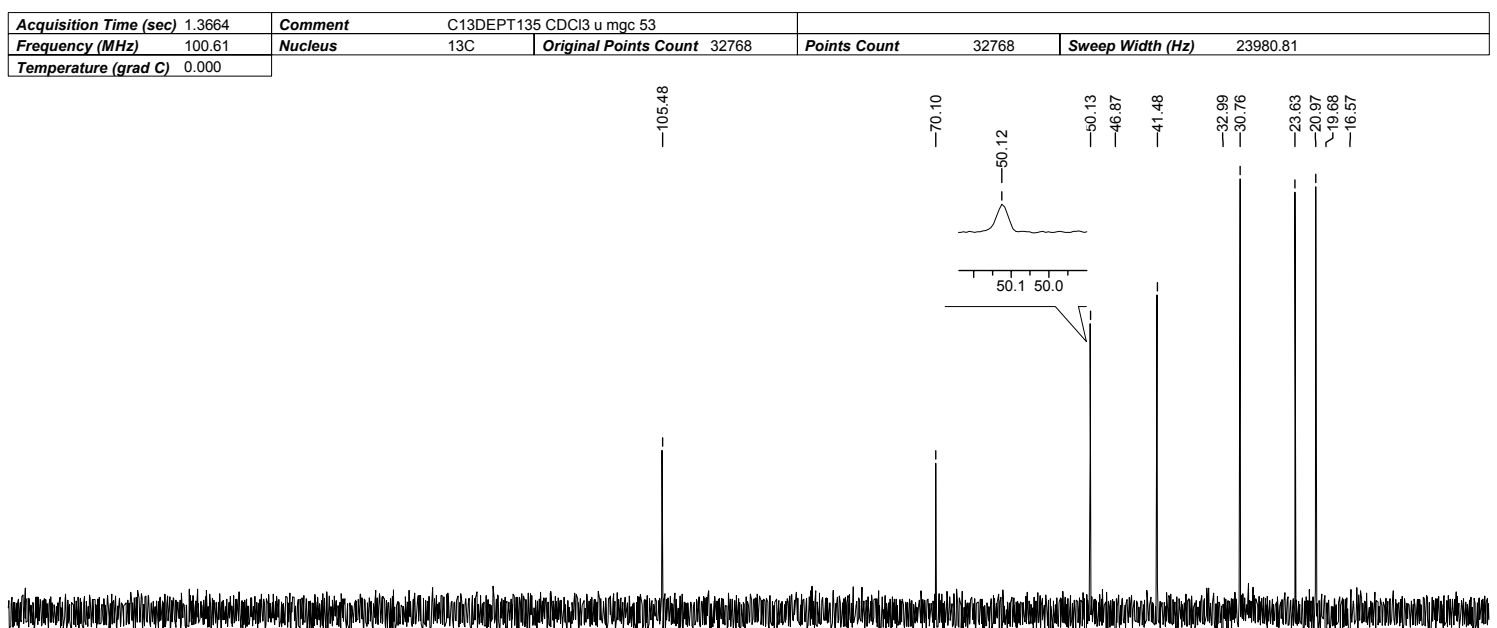

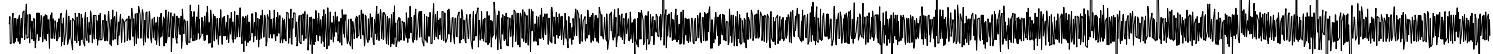

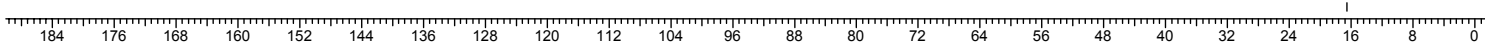

* Espectro de RMN ${ }^{13} \mathrm{C}\left(100 \mathrm{MHz}, \mathrm{CDCl}_{3}\right)$ DEPT-135 da $( \pm)-7$-epi-baquenolida A (226) $\left(\downarrow\left(\mathrm{CH}_{1} \mathrm{CH}_{3}\right), \uparrow \mathrm{CH}_{2}\right)$

Figura 139: Espectros de $\mathrm{RMN}^{13} \mathrm{C}\left(100 \mathrm{MHz}, \mathrm{CDCl}_{3}\right)$ da ( \pm )-7-epi-baquenolida $\mathrm{A}$ (226). 
Tabela 70: Dados Espectroscópicos da (土)-7-epi-Baquenolida A (226) - Análise em $\mathrm{CDCl}_{3}$.

\begin{tabular}{|c|c|c|c|c|c|}
\hline $\mathrm{C}$ & $\delta \mathrm{C}(\mathrm{ppm})$ & $\delta \mathrm{H}(\mathrm{ppm})$ & Integral Relativa & Multiplicidade & Constante de Acoplamento $(\mathrm{Hz})$ \\
\hline $1^{*}$ & 23,6 & $1,02-1,18 / 1,42-1,65$ & $2 \mathrm{H}$ & $\mathrm{m}$ & \\
\hline $2^{*}$ & 21,0 & $1,02-1,18 / 1,42-1,65$ & $2 \mathrm{H}$ & $\mathrm{m}$ & \\
\hline $3^{*}$ & 30,8 & $1,02-1,18 / 1,42-1,65$ & $2 \mathrm{H}$ & $\mathrm{m}$ & \\
\hline 4 & 33,0 & 1,91 & $1 \mathrm{H}$ & dqd & $\mathrm{J}_{4 / 3 \mathrm{a}}=12,5 ; \mathrm{J}_{4 / 15 \mathrm{a}}=\mathrm{J}_{4 / 15 \mathrm{~b}}=\mathrm{J}_{4 / 15 \mathrm{c}}=6,7 ; \mathrm{J}_{4 / 3 \mathrm{~b}}=3,0$ \\
\hline 5 & 44,1 & & - & - & - \\
\hline \multirow[t]{2}{*}{6} & 50,1 & ${ }^{*} \mathrm{H}_{(6 \mathrm{a})} 1,52$ & $1 \mathrm{H}$ & $\mathrm{d}$ & $\mathrm{J}_{6 \mathrm{a} / 6 \mathrm{~b}}=14,1$ \\
\hline & - & ${ }^{*} \mathrm{H}_{(6 \mathrm{~b})} 2,40$ & $1 \mathrm{H}$ & $\mathrm{d}$ & $\mathrm{J}_{6 \mathrm{~b} / 6 \mathrm{a}}=14,1$ \\
\hline 7 & 50,0 & - & - & - & - \\
\hline 8 & 182,3 & - & - & - & - \\
\hline \multirow[t]{2}{*}{9} & 41,5 & $\mathrm{H}_{(9 \mathrm{a})} 1,66$ & $1 \mathrm{H}$ & dd & $\mathrm{J}_{9 \mathrm{a} / 9 \mathrm{~b}}=12,5 ; \mathrm{J}_{9 \mathrm{a} / 10}=6,6$ \\
\hline & - & $\mathrm{H}_{(9 \mathrm{~b})} 2,46$ & $1 \mathrm{H}$ & dd & $\mathrm{J}_{9 \mathrm{~b} / 10}=13,7 ; \mathrm{J}_{9 \mathrm{~b} / 9 \mathrm{a}}=12,5$ \\
\hline 10 & 46,9 & $1,95-2,03$ & $1 \mathrm{H}$ & $\mathrm{m}$ & - \\
\hline 11 & 152,0 & - & - & - & - \\
\hline \multirow[t]{2}{*}{12} & 70,1 & $*\left(\mathrm{H}_{12 \mathrm{a}}\right) 4,81$ & $1 \mathrm{H}$ & ddd & $J_{12 \mathrm{a} / 12 \mathrm{~b}}=12,9 ; J_{12 \mathrm{a} / 13 \mathrm{~b}}=2,2 ; J_{12 \mathrm{a} / 13 \mathrm{a}}=1,8$ \\
\hline & - & $*\left(\mathrm{H}_{12 \mathrm{~b}}\right) 4,76$ & $1 \mathrm{H}$ & ddd & $\mathrm{J}_{12 \mathrm{~b} / 12 \mathrm{~s}}=12,9 ; \mathrm{J}_{12 \mathrm{~b} / 13 \mathrm{~b}}=2,2 ; \mathrm{J}_{12 \mathrm{~b} / 13 \mathrm{a}}=1,8$ \\
\hline \multirow[t]{2}{*}{13} & 105,5 & $\left(\mathrm{H}_{13 \mathrm{a}}\right) 5,07$ & $1 \mathrm{H}$ & $\mathrm{t}$ & $\mathrm{J}_{13 \mathrm{a} / 12 \mathrm{a}}=\mathrm{J}_{13 \mathrm{a} / 12 \mathrm{~b}}=2,2$ \\
\hline & - & $\left(\mathrm{H}_{13 \mathrm{~b}}\right) 4,99$ & $1 \mathrm{H}$ & $\mathrm{t}$ & $\mathrm{J}_{13 \mathrm{~b} / 12 \mathrm{a}}=\mathrm{J}_{13 \mathrm{~b} / 12 \mathrm{~b}}=1,8$ \\
\hline $14^{*}$ & 16,6 & 0,97 & $3 \mathrm{H}$ & s & - \\
\hline $15^{*}$ & 19,7 & 0,82 & $3 \mathrm{H}$ & $\mathrm{d}$ & $\mathrm{J}_{15 / 4}=6,7$ \\
\hline \multicolumn{6}{|c|}{ * podem estar trocados } \\
\hline & & & $\mathrm{H}_{\mathrm{b}}$ & $\mathrm{I}_{\mathrm{a}} \mathrm{H}$ & \\
\hline
\end{tabular}




\section{(士)-7-epi-Baquenolida A (226) - Amostra Sintética. ${ }^{138}$}
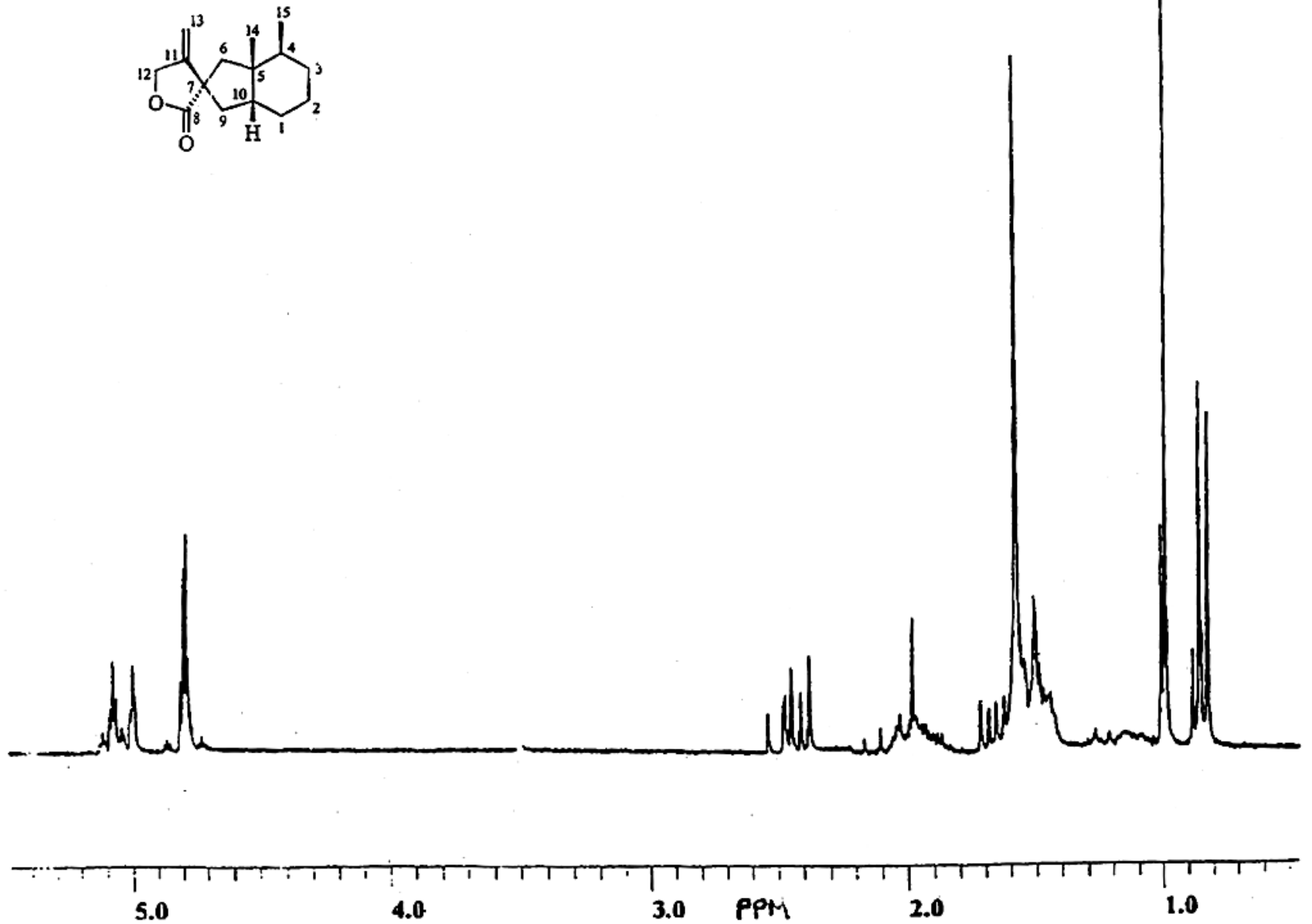

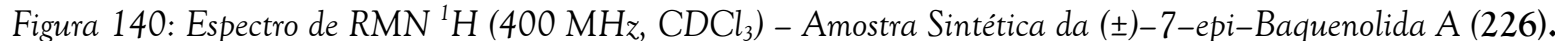




\section{Compostos $306+307$ - Reação Mantida Apenas a $-78^{\circ} \mathrm{C}$}

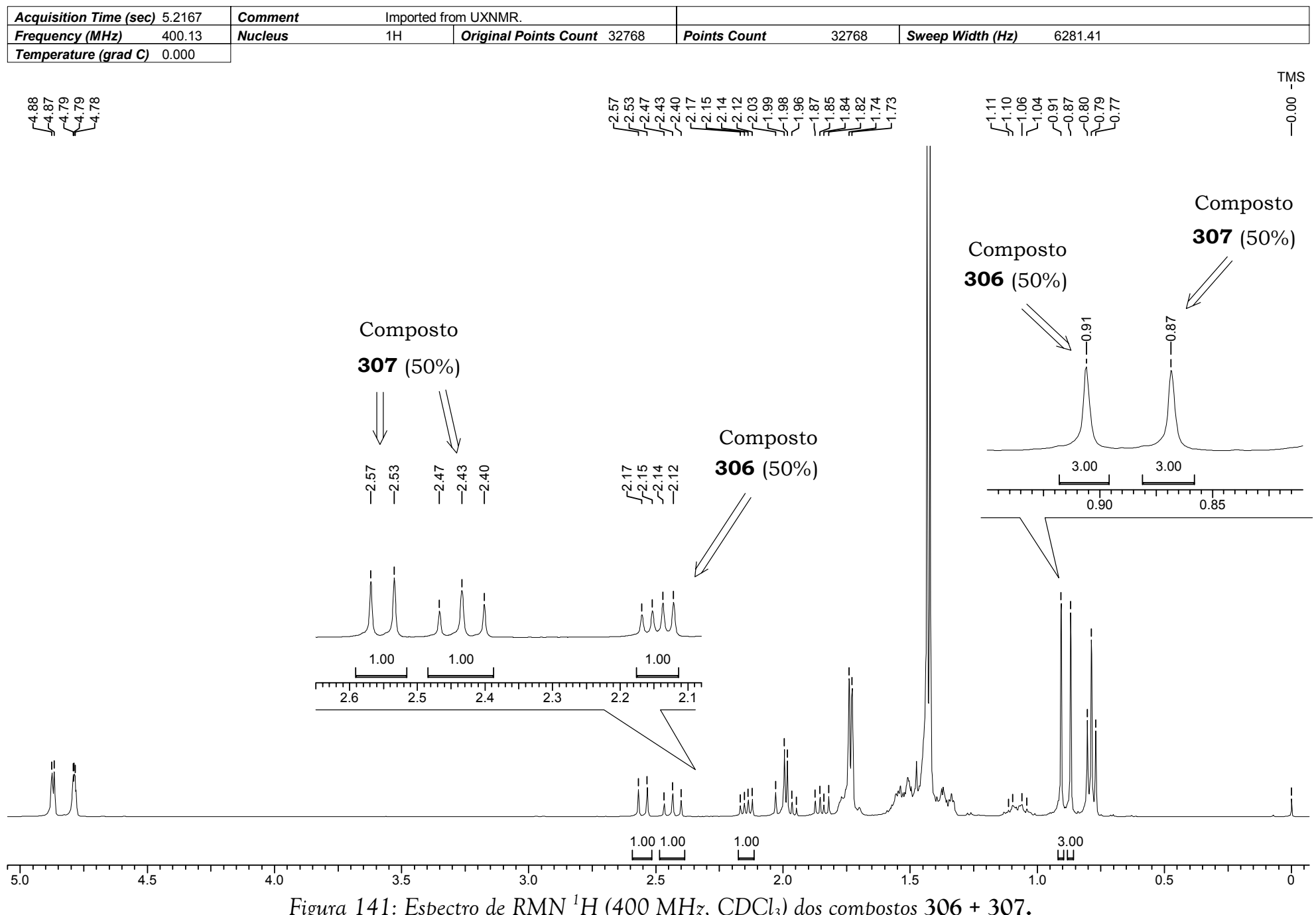




\section{Referências Bibliográficas}




\section{9 - Referências Bibliográficas}

1 - Fernandes, A. C.; Herold, B.; Maia, H.; Rauter, A. P.; Rodrigues, J. A. Guia IUPAC para a Nomenclatura de Compostos Orgânicos, Ed. Liedel, Lisboa, 2002.

2 - a) Garrat, P. J. Aromaticity, John Wiley \& Sons, New York, 1986. b) Badger, G. M. Aromatic Character and Aromaticity, Cambridge University Press, London, 1969. c) Neus, J.; Aromatizität: Geschichte und Mathematische Analyse eines Fundamentalen Chemischen Begriffs, HYLE - Publications, Germany, 2002.

3 - Vogel, E.; Roth, H. D. Angew. Chem. 1964, 76, 145.

4 - a) Vogel, E.; Boell, W. A. Angew. Chem. 1964, 76, 784. b) Effenberger, F.; Klenk, H.

Chem. Ber. 1976, 109, 769. c) Haddon, R. C. Tetrahedron 1972, 28, 3613. d) Haddon, R. C. Tetrahedron 1972, 28, 3635.

5 - a) Vogel, E.; Biskup, M.; Pretzer, W.; Boell, W. A. Angew. Chem. 1964, 76, 785. b) Vogel, E.; Pretzer, W.; Böll, W. A. Tetrahedron Lett. 1965, 40, 3613. c) Vogel, E.; Klug, W.; Breuer, A. Org. Synth. 1976, 55, 86. d) Vogel, E.; Klug, W.; Breuer, A. Org. Synth. Coll. 1988, 6, 862 .

6 - a) Grunewald, G. L.; Warner, A. M.; Hays, S. J. J. Med. Chem. 1972, 15, 747. b) Nelson, P. H. Bartsch, G. A.;; Untch, K. G.; Frield, J. H. J. Med. Chem. 1975, 18, 583.

c) Barrett, D. G.; Gellman, S. H. J. Am. Chem. Soc. 1993, 115, 9343. d) McQuade, D.

T.; Barret, D. G.; Desper, J. M.; Hayashi, R. K.; Gellman, S. H. J. Am. Chem. Soc. 1995, 117, 4862 .

7 - a) Masamune, S. Brooks, D. W. Tetrahedron Lett. 1977, 37, 3239. b) Massamune, S.;

Brooks, Morio, Kazuhiko, Sobczack, R. L. J. Am. Chem. Soc. 1976, 98, 8277.

8 - a) Allinger, N. L.; Sprague, J. T. J. Am. Chem. Soc. 1973, 95, 3893. b) Gavezzotti, A.; Simonetta, M. Helv. Chim. Acta 1976. 59, 2984.

9 - Espinosa-Müller, A.; Meezes, F. C. J. Chem. Phys.1978, 69, 367.

10 - Grunewald, G. L.; Uwaydah, I. M.; Christoffersen, R. E.; Spangler, D. Tetrahedron Lett. 1975, 11, 933.

11 - (a) Farnell, L.; Radom, L. J. Am. Chem. Soc. 1982, 104, 7650. (b) Catti, C.; Barzaghi, M.; Simonetta, M. J. Am. Chem. Soc. 1985, 107, 878. (c) Simonetta, M.; Barzaghi, M.; Gatti, C. J. Molec. Struct. THEOCHEM 1986, 138, 39. (d) Bock, C. W.; George, P.; Gluster, J. P. J. Molec. Struct. THEOCHEM 1991, 234, 227. (e) George, P.; Clusker, J. P.; Bock, C. W. J. Molec. Struct. THEOCHEM 1991, 235, 193. (f) Sironi, M.; Raimondi, M.; Copper, D. L.; Gerratt, J. J. Molec. Struct. THEOCHEM 1995, 338, 257.

12 - ver Chem. Rev. 2001, 101(5). a) Krygowski, T. M.; Cyrañski, M. K.; Czarnocki, Z.; Häfelinger, G.; Katritzky, A. R. Tetrahedron 2000, 56, 1783. b) Krygowski, T. M.; 
Cyrañski, M. K. Chem. Rev. 2001, 101, 1385. c) De Proft, F.; Geerlings, P. Chem. Rev. 2001, 101, 1451. d) Cyrañski, M. K.; Krygowski, T. M; Katritzky, A. R.; Schleyer, P. R. J. Org. Chem. 2002, 67, 1333. e) Krygowski, T. M; Cyrañski, M. K. Phys. Chem. Chem. Phys. 2004, 6, 249.

13 - Kekulé, A. Bull. Chim. Fr. 1865, 3, 98.

14 - Erlenmeyer, E. Liebigs Ann. Chem. 1866, 137, 327.

15 - Pascal, P. Lille. Ann. Chim. Phys. 1910, 19, 5. b) Pascal, P. Compt. Rend 1910, 150, 1054. c) Pascal, P. Revue Generale des Sciences Pures et Apppliquess 1923, 34, 388.

16 - a) Craig, D. P. Non Benzenoid Aromatic Coumpounds, ed. D. Insburg, Interscience, New York, 1959. b) Ingold, C. K. Structure and Mechanism in Organic Chemistry, Ithaca, Cornell University Press, New York, 1953.

17 -Schleyer, P. R.; Jiao, H. Pure Appl. Chem. 1996, 68, 209.

18 - a) Hückel, E. Z. Phys 1931, 70, 204. b) Hückel, E. Z. Phys 1932, 72, 310. c) Hückel, E. Z. Phys 1932, 76, 628. d) Hückel, E. Z. Elektrochem. 1937, 9, 752.

19 - Pauling, L.; Sherman, J. J. Chem. Phys. 1933, 1, 606.

20 - Kistiakowski, B.; Ruhoffm, J. R.; Smith, H. A.; Vaughan, W. E. J. Am. Chem. Soc. 1936, 58, 1657.

21 - Julg, A.; François, Ph. Theor. Chim. Acta 1967, 7, 249.

22 - a) Bird, C. Tetrahedron 1987, 43, 4725. b) Bird, C. Tetrahedron 1997, 53, 13111.

23 - a) Kruszewski, Krygowski, T. M. Tetrahedron Lett. 1972, 3839. b) Krygowski, T. M. J. Chem. Compt. Sci. 1993, 33, 70. c) Krygowski, T. M.; Cyrañski, M. K. Tetrahedron 1996, 52, 1713.

24 - Carpenter, J. E.; Weinhold, F. J. Mol. Struct. 1988, 169, 41.

25 - a) Glendening, E. D.; Weinhold, F. J. Comput. Chem. 1998, 19, 593. b) Glendening,

E. D.; Weinhold, F. J. Comput. Chem. 1998, 19, 610.

26 - Haddon, R. C.; Fukunaga, T Tetrahedron Lett. 1980, 21, 1191.

27 - a) Ponomarev, D. A.; Takhistov, V. V. J. Chem. Ed. 1997, 74, 201. b) George, P.; Glusker, J. P.; Charles, C. W. J. Molec. Struct. THEOCHEM 1991, 235, 193. c) Wiberg, K. B.; Ochterski, J. W. J. Comp. Chem.1997, 18, 108.

28 - Weinhold, F.; Landis, C. "Valence and Bonding" A Natural Bond Orbital DonorAcceptor Perspective, Cambridge University Press, United Kingdom, 2005.

29 -.MOLEKEL 4.1, P. Plükiger, H. P. Lüthi, S. Portmann, J. Weber, Swiss Center for Scientific Computing, Manno (Switzerland), 2000-2001.

30 - Hoffman, R. E. J. Magn. Reson. 2006, 178, 237.

31 - Schleyer, P. R.; Maeker, C.; Dransfeld, A.; Haijun, J.; Hommes, N. J. R. E. J. Am. Chem. Soc. 1996, 118, 6317

32 - Dauben, H. J.; Wilson, J. D.; Laity, J. L. J. Am. Chem. Soc. 1968, 90, 811. 
33 - Schleyer, P. R.; Manoharan, M.; Wang, Z. X.; Kiran, B.; Jiao, H.; Puchta, R.; Eikema Hommes, N. J. R. Org. Lett. 2001, 3, 2465.

34 - Geerlings, P.; De Proft, F.; Langenaeker, W. Chem. Rev. 2003, 103, 1793.

35 - Carey, F.; Sudberg, R. J. Advanced Organic Chemistry, Part B, 4 ${ }^{\text {th }}$ ed., Kluwer Academic/Plenum Publishers, New York, 2001.

36 - a) Sauer, J. Angew. Chem. Int.. Ed. 1966, 5, 211. b) Sauer, J. Angew. Chem. Int. Ed. 1967, 6, 16. c) Nicolaou, K. C.; Snyder, S. A.; Montagnon, T.; Vassilikogiannakis, G. Angew. Chem. Int. Ed. 2002, 41, 1668. d) Corey, E. J. Angew. Chem. Int. Ed. 2002, 41, 1650. e) Fringuelli, F.; Taticchi, A. The Diels-Alder Reaction: Selected Practical Methods, Jonh Wiley \& Sons, New York, 2002. f) Takao, K.; Munakata, R.; Tadano, K. Chem Rev. 2005, 105, 4779. g) Brocksom, T. J.; Nakamura, J.; Ferreira, M. L.; Brocksom, U. J. Braz. Chem. Soc. 2001, 12, 597. h) W. Carruthers Cycloaddition Reactions in Organic Synthesis, vol.8, Pergamon Press, Oxford, 1990.

37 - Diels, O.; Alder, K. Liebigs Ann. Chem. 1928, 460, 98.

38 - Berson, J. A. Tetrahedron 1992, 48, 3.

39 - Stork, G.; Van Tamelen, E. E. Friedman, L. J.; Burgstahler, A. W. J. Am. Chem Soc. 1951, 73, 4501.

40 - a) Alder, K.; Stein, G.; von Budedenbrock, F.; Eckardt, W.; Frercks, W.; Schneider,

S. Justus Liebgs Ann. Chem. 1934, 514, 1. b) Alder, K.; Stein, G.; Liebmann, M.; Rolland, E. Justus Liebgs Ann. Chem. 1934, 514, 197. c) Alder, K.; Stein, G.; Rolland, E.; Schulze, G. Justus Liebgs Ann. Chem. 1934, 514, 211.

41 - a) Gates, M.; Tschudi, G.; J. Am. Chem. Soc. 1952, 74, 1109. b) Gates, M.; Tschudi, G.; J. Am. Chem. Soc. 1956, 78, 1380. c) Gates, M. J. Am. Chem. Soc. 1950, 72, 228.

42 - Woodward, R. B.; Sonddheimer, D.; Taub, D.; Heusler, K.; McLamore, W. M. J. Am. Chem. Soc. 1952, 74, 4223.

43 - Sauer, J.; Sustmann, R. Angew. Chem. Int. Ed. 1980, 19, 779.

44 - a) Sauer, J.; Sustmann, R. Angew. Chem. Int. Ed. 1980, 19, 779. b) Ginsburg, D. Tetrahedron 1983, 39, 2095.

45 - a) Woodward, R. B.; Hoffmann, R. The Conservation of Orbital Symmetry, Verlag Chemie, Weinheim, 1970. b) Fukui, K.; Yonezawa, T.; Nagata, C. Bull. Chem Soc. Jpn 1954, 27(7), 423. c) Fukui, K.; Yonezawa, T.; Shingu, H. J. Chem. Phys. 1952, 20, 722.

46 -Fleming, I. Frontier Orbitals and Organic Chemical Reactions, Jonh Wiley \& Sons, New York, 1998.

47 - Carruters, W Some Modern Methods of Organic Synthesis, Cambridge University Press, United Kingdom, 1971.

48 - Domingo, L. R.; Aurell, M. J.; Contreras, R. J. Org. Chem. 2003, 68, 3884. 
49 - a) Gordillo, R; Houk, K. N. J. Am. Chem. Soc. 2006, 128, 3543. b) Pieniazek, S. N.;. Houk, K. N. Angew. Chem. Int. Ed. 2006, 45, 1442. c) Afarinkia, K, Bearpark, M. J.; Ndibwami, A. J. Org. Chem. 2003, 68, 7158. e referências citadas. Para uma melhor consulta sobre o assunto buscar por: Diels-Alder "Transition State" na web of science.

50 - Cayzer, T. N.; Paddon-Row, M. M.; Moran, D.; Payne, A. D.; Sherburn, M. S.; Turner, P. J. Org. Chem 2005, 70, 5561.

51 - Yates, P.; Eaton, P. J. Am. Chem. Soc. 1960, 82, 4436.

52 - Silva Filho, L. C.. Lacerda Jr., V.; Constantino, M. G.; da Silva, G. V. J.; Invernise, P. R. Beilstein. J. Org. Chem. 2005, 1, 14.

53 - Fringuelli, A. E. C.; Guo, M.; Minuti, L.; Taticchi, A.; wenkert, E. J. Org. Chem. $1988,53,4325$.

54 - Lacerda Jr., V.; Oliveira, K. T.; da Silva Filho, L. C.; Constantino, M. G.; Galembeck, S. E.; Resumos do XII Simpósio Brasileiro de Química Teórica-SBQT, P-298, Caxambu, Brasil, 2003.

55 - Inukai, T.; Kojima, T J. Org. Chem 1966, 31, 1121.

56 - a) Corey, E. J. Angew. Chem. Int. Ed. 2002, 41, 1650. b) Dias, L. C. J. Braz. Chem.Soc. 1997, 8, 289.

57 - a) Diedrich, M. K.; Klarner, F. G. J. Am. Chem. Soc. 1998, 120, 6212. b) Kiselev V. D.; Kashaeva, E. A.; Konovalov, A. Tetrahedron 1999, 55, 1153.

58 - Dauben, W. G.; Baker W. R. Tetrahedron Lett. 1982, 23, 2611.

59 - Aben, R. W. M.; Minuti, L.; Scheeren, H. W.; Tatichi, A. Tetrahedron Lett. 1991, 32, 6445.

60 - Dineen, T. A.; Roush, W. R. Org. Lett. 2004, 6, 2043.

61 - Nicolaou, K. C.; Vassilikogiannakis, G.; Mägerlein, W.; Kranich, R. Angew. Chem. Int. Ed. 2001, 40, 2482.

62 - Jacobi, P. A.; Blum, C. A.; DeSimone, Udodong, U. E. S. Tetrahedron Lett. 1989, 30, 7173.

63 -Lee, T. W.; Corey, E. J. J. Am. Chem. Soc. 2001, 123, 1872.

64 - a) Vichinewski, W.; Takahashi, A. M.; Nasi, A. M. T.Gonçalves, D. C. R. G.; Dias, D. A.; Lopes, J. N. C.; Goedken, V. L.; Gutiérrez, A. B.; Hers, W. Phytochemistry 1989, 28, 1441. b) Raffauf, R. F.; Huang, P. C.; Le Quesne, P. W.; Levery, S. B.; Brennan, T. F. J. Am. Chem. Soc. 1975, 97, 6884. c) Minnaard, A. J.; Wijnberg, J. B. P. A.; de Groot, A. Tetrahedron 1999, 55, 2146.

65 - a) Paquete, L. A.; Bailey, S. J. Org. Chem. 1995, 60, 7849. b) Paquete, L. A.; Montgomery, F. J.; Wang, T. Z. J. Org. Chem. 1995, 60, 7857. c) Paquete, L. A.; Zeng, Q.; Tsui, H. C.; Johnston, J. N. J. Org. Chem. 1998, 63, 8491. d) Paquete, L. A.; Hofferberth, J. E. J. Org. Chem. 2002, 68, 2266. 
66 - a) Marchand, A. P.; Allen, R. W. J. Org. Chem. 1974, 39, 1596. b) Wassermann, A. J. Chem. Soc. 1935, 1511. c) Oda, M.; Kawase, T.; Okada, T.; Enomoto, T. Org. Synth. Coll. IX, 186. d) Stroermer, M.J.; Butler, D. N.; Warrener, R. N.; Weerasuria, K. D. V.; Fairlie, D. P. Chem Europ. J. 2003, 9, 2068.

67 - a) Marchand, A. P.; LaRoe,W. D.; Sharma, G. V. M.; Suri, S. C.; Reddy, D. S. J. Org. Chem. 1986, 51, 1622. b) Gemal, A. L.; Luche, J. L. J. Am. Chem. Soc. 1981, 103, 5454.

68 - Constantino, M. G.; Matias, L. G. O.; da Silva, G. V. J.; Heleno, V. C. G. Synth. Commun. 1997, 27, 4285.

69 - Gemal, A. L.; luche, J. L. J. Am. Chem. Soc. 1981, 103, 5454.

70 - Beatriz, A.; Estudos Sobre a Sintese de Heliangolidos pela Reação de Diels-Alder Tese de Doutoramento, Departamento de Química da FFCLRP/USP 2001 (disponível na página http://artemis.ffclrp.usp.br/estudant.htm)

71 - Ziegler, F. E.; Kleir, S. I.; Pati, U. K.; Wang, T. F. J. Am. Chem. Soc. 1985, 107,2730.

72 - Florent, J. C.; Ughetto-Monfrin, J.; Monneret, C. J. Org. Chem. 1987, 52, 1051.

73 - PCMODEL 7.0, Serena Software, P.O.Box 3076, Bloomington, IN474-23076.

74 - Constantino, M. G.; Beatriz, A.; da Silva, G. V. J. Tetrahedron Lett. 2000, 41, 7001.

75 - Jung, M. E,; Lyster, M. A. J. Am. Chem. Soc. 1977, 99, 968.

76 - Marchand, A. P.; Reddy, G. M. Synthesis 1991, 198.

77 - Wharton, P. S.; Spessard, G. O. J. Org. Chem. 1972, 37, 548.

78 - Khajuria, R. K.; Jain, S. M.; Dhar, K. L. Indian J. Chem. 1996, 35B, 860.

79 - Bartrop, J. A.; Burstall, M. L. J. Chem. Soc. 1959, 2183.

80 - Landini, D.; Rolla, F. J. Org. Chem. 1982, 47, 154.

81 - Gómez-Vidal, J. A.; Forrester, M. T.; Silverman, R. B. Org. Lett. 2001, 3, 2477.

82 - Itô, S B.; Fujise, Y.; Okuda, T.; Inoue, Y. Bull. Chem. Soc. Jpn. 1966, 39, 1351.

83 - Radlick, P. J. Org. Chem. 1964, 29, 960.

84 -Corey, E.J.; Melvin, L.S.; Haslanger, M.F. Tetrahedron Lett. 1975, 36, 3117.

85 - Laxmisha, M. S.; Subba Rao, S. R. Tetrahedron Lett. 2000, 41, 3759.

86 - Grieco, P. A.; Flynn, D.L.; Zelle, R. E. J. Am. Chem. Soc. 1984, 106, 6414.

87 - Adams, R.; Thal, T. Sintesis Orgánicas, Ed Gilman, H.; Blatt, A. H., 1950, 1, 261.

88 - a) Smith, M. B. Organic Synthesis, McGraw-Hill Int. Ed., Singapure, 1994. b) Micóvic, V. M.; Mihailovic, M. LJ. J. Org. Chem. 1953, 18, 1190. c) Moffet, R.B. Org. Synth. Coll. IV, 354.

89 - a) Amonoo-Neizer, E. H.; Shaw, R. A.; Skovlin, D. O.; Smith, B. C. J. Chem. Soc. 1965, 2997. b) Griffith, D. A.; Heathcock, H. C. Tetrahedron Lett. 1995, 36, 2381.

90 - Vandewale, M.; Eycken, J. V.; Oppolzer, W.; Vullioud, C. Tetrahedron 1986, 42, 4035. 
91 - a) Constantino, M. G.; Oliveira, K. T.; Beatriz, A.; da Silva, G. V. J. Tetrahedron Lett. 2003, 44, 2641. b) Constantino, M. G.; Oliveira, K. T.; Beatriz, A.; da Silva, G. V. J. Magn. Reson. Chem. 2003, 41, 726.

92 - Wolff, S.; Huecas, M. E.; Agosta, W. C. J. Org. Chem. 1982, 47, 4358.

93 - a) Baumgarten, R.J; Curtis, V.A. "Deaminations” em "The Chemistry of Amines, Nitroso and Nitro Compounds, Supplement F”, Patai, S; Ed. Interscience, Chisester, In print, Cap.22, 931. b) Curtis, V. A.; Knutson, F. J.; Baumgarten, R. J. Tetrahedron Lett. 1981, 22, 199. c) DeCristopher, P.J.; Adamek, J. P.; Lyon, D. G.; Galante, J.J.; Haffner, R.H.; Boggio, R. J.; Baumgarten, R. J. J. Am. Chem. Soc. 1969, 91, 2384. d) DeCristopher, P.J.; Adamek, J. P.; Lyon, D. G.; Klein, S. A.; Baumgarten, R. J. J. Org. Chem.1974, 39, 3525.

94 - Adams, R.; Blatt, A.H.; Boekelheide, V.; Curtn, D.Y.; Niemann, C. Org. React.1983, 11,315 .

95 - a) Norcross, G.; Openshaw, H. T..J. Chem. Soc. 1949, S59. b) Battersby, R.A.; Binks, R. J. Chem. Soc. 1955, 2888.

96 - Arnold, R.T.; Richardson, P.N. J. Am. Chem. Soc. 1954, 3649.

97 - Palmgren, A.; Larsson, A. L. E.; Bäckvall, J. E.; Helquist, P. J. Org. Chem. 1999, 64, 836.

98 - Curphey, T. J.; Eschenmoser, A.; Keese, R.; Daniel, A. Org. Synth. Coll. I 1988, 1096. 99 - Caramori, G.; Oliveira, K. T.; Galembeck, S. E.; Bultinck, P.; Constantino M. G.

Chem. Eur. J. 2006, artigo submetido.

100 - a) Gaussian 98 (Revision A.7), M. J. Frisch, G. W. Trucks, H. B. Schlegel, G. E. Scuseria, M. A. Robb, J. R. Cheeseman, V. G. Zakrzewski, J. A. Montgomery, R. E. Stratmann, J. C. Burant, S. Dapprich, J. M. Millam, A. D. Daniels, K. N. Kudin, M. C. Strain, O. Farkas, J. Tomasi, V. Barone, M. Cossi, R. Cammi, B. Mennucci, C. Pomelli, C. Adamo, S. Clifford, J. Ochterski, G. A. Petersson, P. Y. Ayala, Q. Cui, K. Morokuma, D. K. Malick, A. D. Rabuck, K. Raghavachari, J. B. Foresman, J. Cioslowski, J. V. Ortiz, B. B. Stefanov, G. Liu, A. Liashenko, P. Piskorz, I. Komaromi, R. Gomperts, R. L. Martin, D. J. Fox, , T. Keith, M. A. Al-Laham, C. Y. Peng, A. Nanayakkara, C. Gonzalez, M. Challacombe, P. M. W. Gill, B. G. Johnson, W. Chen, M. W. Wong, J. L. Andres, M. Head-Gordon, E. S. Replogle, and J. A. Pople, Gaussian, Inc., Pittsburgh, PA, 1998.

b) Gaussian 03, Revision C.02, M.J. Frisch, G.W. Trucks, H.B. Schlegel, G.E. Scuseria, M.A. Robb, J.R. Cheeseman, J.A. Montgomery, Jr., T. Vreven, K.N. Kudin, J.C. Burant, J.M. Millam, S.S. Iyengar, J. Tomasi, V. Barone, B. Mennucci, M. Cossi, G. Scalmani, N. Rega, G.A. Petersson, H. Nakatsuji, M. Hada, M. Ehara, K. Toyota, R. Fukuda, J. Hasegawa, M. Ishida, T. Nakajima, Y. Honda, O. Kitao, H. Nakai, M. 
Klene, X. Li, J.E. Knox, H.P. Hratchian, J.B. Cross, V. Bakken, C. Adamo, J. Jaramillo, R. Gomperts, R.E. Stratmann, O. Yazyev, A.J. Austin, R. Cammi, C. Pomelli, J.W. Ochterski, P.Y. Ayala, K. Morokuma, G.A. Voth, P. Salvador, J.J. Dannenberg, V.G. Zakrzewski, S. Dapprich, A.D. Daniels, M.C. Strain, O. Farkas, D.K. Malick, A.D. Rabuck, K. Raghavachari, J.B. Foresman, J.V. Ortiz, Q. Cui, A.G. Baboul, S. Clifford, J. Cioslowski, B.B. Stefanov, G. Liu, A. Liashenko, P. Piskorz, I. Komaromi, R.L. Martin, D.J. Fox, T. Keith, M.A. Al-Laham, C.Y. Peng, A. Nanayakkara, M. Challacombe, P.M.W. Gill, B. Johnson, W. Chen, M.W. Wong, C. Gonzalez, and J.A. Pople, Gaussian, Inc., Wallingford CT, 2004.

101 - Gaussview 3.0, Gaussian, Inc., Cornegie Office Park-Building 6 Pittsburg PA 15106 USA.

102 - a) George, P.; Glusker, J. P.; Charles, C. W. J. Molec. Struct. THEOCHEM, 1991, 235, 193. b) Eis, M. J. v.; Wolf, W. H.; Bickelhaupt, F.; Boese, R. J. Chem. Soc., Perkin Trans. 2, 2000, 793.

103 - NBO 5.0: Glendening, E. D.; Badenhoop, J. K.; Reed, A. E.; Carpenter,J. E.; Bohmann, J. A.; Morales, C. M.; Weinhold, F., Theoretical Chemistry Institute, University of Wisconsin, Madison, WI, 2001.

104 - NBOView 1.0, NBO Orbital Graphics, Wendt, M.; Weinhold, F.; Department of Chemistry, University of Wisconsin, Madison, WI 53706, 2001.

105 - a) Silva Jr., L. F. Synthesis 2001, 5, 671. b) Novotný, L.; Kotva, K.; Toman, J.; Herout, V. Phytochemistry 1972, 11, 2795.

106 - a) Abe, N.; Onoda, R.; Shirahata, K.; Kato, T.; Woods, M. C.; Kitahara, Y. Tetrahedron Lett. 1968, 369. b) Naya, K.; Takagi, I.; Hayashi, M.; Nakamura, S.; Kobayashi, M.; Katsumura, S. Chem. Ind. 1968, 318. c) Abe, N.; Onoda, R. Tetrahedron Lett. 1968, 369. d) Naya, K.; Hayashi, M.;Takagi, I.; Nakamura, S.; Kobayashi, M. Bull. Chem. Soc. Jpn. 1972, 45, 3673.

107 - a) Rüngeler, P.; Castro, V.; Mora, G.; Gören, N.; Vichnewski, W.; Pahl, H. L.; Merfort, I.; Schmidt, T. J. Bioorg. Med. Chem. 1999, 7, 2343. e referências citadas: b) Kupchan, S. M.; Fessler, D. C.; Eakin, M. A.; Giacobbe, T. J. Science 1970, 168, 376. c) Schmidt, T. J. Bioorg. Med. Chem. 1997, 5, 645.

108 - Jamieson, G. R.; Reid, E. H.; Turner, B. P.; Jamieson, A. T. Phytochemistry 1976, 15, 1713.

109 - Nawrot, J. Harmatha, J. Novotny, L. Biochem. Syst. Ecol. 1984, 12, 99.

110 - a) Kitahara, Y.; Abe, N; Kato, T.; Shirahata, K. Nippon Kagaku Zasshi 1969, 30, 221.

b) Naya, K.; Takagi, I.; Kawaguchi, Y.; Asada, Y.; Hirose, Y.; Shinida, N. Tetrahedron 1968, 24, 5871.citados em Naya, K.; Hayashi, M.;Takagi, I.; Nakamura, S.; Kobayashi, M. Bull. Chem. Soc. Jpn. 1972, 45, 3673. 
111 - Porter, J.; Spurgeon, S. L. Biosynthesis of Isoprenoid Compounds vol 1, John Wiley \& Sons, New York, 1981.

112 - a) Naya, K.; Yoshimura, F.; Takagi, I. Bull. Chem. Soc. Jpn. 1971, 44, 3165. b)

Shirahata, K.; Kato, T.; Kitahara, Y.; Abe, N. Tetrahedron 1969, 25, 3179. c)

Shirahata, K.; Kato, T.; Kitahara, Y.; Abe, N. Tetrahedron 1969, 25, 4671.

113 - Hayashi, K.; Nakamura, H.; Mitsuhashi, H. Phytochemistry 1973, 12, 2931.

114 - Ishizaki, Y.; Tanahashi, Y.; Moriyama, Y.; Takahashi, T.; Koyama, H. Phytochemistry 1974, 13, 674 .

115 - Saritas, Y.; von Reuß, S. H.; König, W. A. Phytochemistry 2002, 59, 795.

116 - Harmatha, J.; Samek, Z.; Synáckova, M.; Novotný, L.; Herout, V.; Sorm, F. Collect. Czech. Chem. Commun. 1976, 41, 2047.

117 - Jakupovic, J.; Grenz, M.; Bohlmann, F. Planta Med. 1989, 55, 571.

118 - Solberg, Y. J. Hattori Bot. Lab. 1986, 60, 391.

119 - Hayashi, K. Phytochemistry 1989, 28, 3373.

120 - Marco, J. A.; Sanz, J. F.; García-Sarríon, A.; Rustaiyan, A. Phytochemistry 1991, 30, 2325.

121 - Aclinou, P.; Benkouider, A.; Massiot, G.; Le, Men-Olivier L. Phytochemistry 1991, 30, 2083.

122 - Chen, H.; Jia, Z.; Yang, L. Phytochemistry 1992, 31, 2146.

123 - Chen, H.M.; Cai, M.S.; Jia, Z.J. Phytochemistry 1997, 45, 1441.

124 - Abe, N.; Onoda, R.; Shirahata, K.; Kato, T.; Woods, M. C.; Kitahara, Y.; Ro, K.; Kurihara, T. Tetrahedron Lett. 1968, 1993.

125 - Wu, T. S.; Kao, M. S.; Wu, P. L.; Lin, F. W.; Shi, L. S.; Liou, M. J.; Li, C. Y. Chem. Pharm. Bull. 1999, 47, 375.

126 - Wu, T.S.; Kao, M.S.; Wu, P.L.; Lin, F.W.; Shi, L.S.; Teng, C.M. Phytochemistry 1999, 52, 901.

127 - Shirahata, K.; Abe, N.; Kato, T.; Kitahara, Y. Bull. Chem. Soc. Jpn. 1968, 41, 1732.

128 - Naya, K.; Kawai, M.; Naito, M.; Kasai, T. Chem. Lett. 1972, 241.

129 - Hayashi, K.; Nakamura, H.; Mitsuhashi, H. Chem. Pharm. Bull. 1973, 21, 2806.

130 - a) Evans, D. A.; Sims, C. L. Tetrahedron Lett. 1973, 4691. b) Evans, D. A.; Sims, C. L.; Andrews, G. C. J. Am. Chem. Soc. 1977, 99, 5453.

131 - Campbell, S. F.; Constantino, M. G.; Brocksom, T. J.; Petragnani, N. Synth. Commun. 1975, 5, 353.

132 - a) Petragnani, N.; Brocksom, T. J.; Ferraz, H. M. C.; Constantino, M. G. Synthesis 1977, 112. b) Petragnani, N.; Brocksom, T. J.; Ferraz, H. M. C.; Constantino, M. G. Quim. Nova 1978, 1, 8.

133 - Brocksom. T. J.; Constantino, M. G.; Ferraz, H. M. C. Synth. Commun. 1977, 7,483.

134 - Greene, A. E.; Deprés, J. P. J. Am. Chem. Soc. 1979, 101, 4003. 
135 - Greene, A. E.; Deprés, J. P.; Coelho, F.; Brocksom, T. J. J. Org. Chem. 1985, 50, 3943.

136 - a) Brocksom, T. J.; Constantino, M. G. An. Acad. Brasil. Ciênc. 1982, 54, 655. b) Brocksom, T. J.; Constantino, M. G. J. Org. Chem. 1985, 47, 3450.

137 - Back, T, G.; Payne, J. E. Org. Lett. 1999, 1, 663.

138 - Back, T, G.; Nava-Salgado, V. O.; Payne, J. E. J. Org. Chem. 2001, 66, 4361.

139 - Reddy, S. Org. Lett. 2004, 6, 3345.

140 - da Silva, G. V. J. Sintese Total da ( \pm -_Baquenolida A, Tese de Doutoramento, Instituto de Química, USP, 1984.

141 - Srikrishna, A.; Reddy, T. J. Tetrahedron 1998, 54, 11517.

142 - Nakamura, J. Reações de Diels-Alder Intramolecular na Sintese de Bacanos. Reações de Diels-Alder Multicomponente na Sintese de Sistemas Decalinicos, Tese de Doutoramento, Departamento de Química do Centro de Ciências Exatas de São Carlos, UFSCAR, 2003.

143 - a) Constantino, M. G.; Lacerda Jr., V. ; Silva Filho, L. C.; Silva, G. V. J. Lett. Org. Chem 2004, 1, 369. b) Constantino, M. G.; Lacerda Jr., V.; Silva, G. V. J. J. Heterocyclic Chem. 2003, 40, 369. c) Constantino, M. G.; Lacerda Jr., V.; Silva, G. V. J. Molecules 2002, 7, 456. d) Constantino, M. G.; Lacerda Jr., V.; Aragão, V. Molecules 2001, 6, 770.

144 - Wikipedia, The Free Encyclopedia, http://en.wikipedia.org/wiki/Diels-Alder_reaction, http://en.wikipedia.org/wiki/Diels-Alder_reaction\#endnote_Constantino2002.

145 - Muskat, I. E.; Becker, B. C.; Lowenstein, J. S. J. Am. Chem. Soc. 1930, 52, 326.

146 - Buckles, R.; Mock, G. J. Org. Chem. 1950, 15, 680.

147 - Peck, R.L. Chem. Abst. 1960, 54, 6719h

148 - Oida, S.; Ohki, E. Chem. Pharm. Bull. 1969, 17, 1996.

149 - White, J. D.; Sheldon, B. G. J. Org. Chem. 1981, 46, 2273.

150 - Engelbert C. Org. React.1984, 32, 15.

151 - Reddy, D. S.; Kozmin, S. A. J. Org. Chem. 2004, 69, 4860.

152 - Du, X.; Chu, H. V.; Kwon, O. Org. Lett. 2003, 5, 1923.

153 - Greene, T. W.; Wuts, P. G. M. Protective Groups in Organic Synthesis, 2 ed., John Wiley \& Sons Inc., New York, 1991.

154 - Brockson, T. J.; Coelho, F.; Deprés, J. P.; Greene, A. E.; de Lima, M. E. F.; Hamelin, O.; Hartmann, B.; Kanazawa, A. M.; Wang, Y. J. Am. Chem. Soc. 2002, 124, 15313.

155 - Amsberry, K. L.; Borchardt, R. T. J. Org. Chem. 1990, 55, 5867.

156 - a) Rathke, M. W.; Sullivan, D. L. Tetrahedron Lett. 1972, 4249. b) Herrmann, J. L.;

Kieczkowsky, G. R.; Schlessinger, R. H. Tetrahedron Lett. 1973, 2433. 
157 - Cunha, S.; Lião, L. M.; Bonfim, R. R.; Bastos, R. M.; Monteiro, A. P. M.; Alencar, K. S. Quim. Nova 2003, 26, 425.

158 - a) Jensen, F. Introduction to Computational Chemistry, Jonh Wiley \& Sons, Chichester, 1999. b) Smith, W. B. Introduction to Theoretical Organic Chemistry and Molecular Modeling, VCH Publishers, New York, 1996.

159 - Para a realização deste trabalho dispúnhamos de 2 PCs sendo um deles Pentium IV 3,4 GHz com $4 \mathrm{GHz}$ de memória e outro Pentium IV 3,2 GHz com $2 \mathrm{GHz}$ de memória, ambos operando com sistema operacional LINUX.

160 - Heleno, V. C. G. Estudos de Transformações Químicas em Produtos Naturais Polifuncionalizados, Dissertação de Mestrado, Departamento de Química da FFCLRP, USP, 1999.

161 - Perrin, D. D.; Armarego, W. L. F.; Perrin, D. R. Purification of Laboratory Chemicals, $2^{a}$ edição, Pergamon Press Ltd, Oxford, 1980.

162 -SpecViewer "Free Software” versão 5.0, http://www.acdlabs.com/ 